\title{
The Potential Impacts of OTEC Intakes on Aquatic Organisms at an OTEC Site under Development on
}

\section{Kauai, HI}

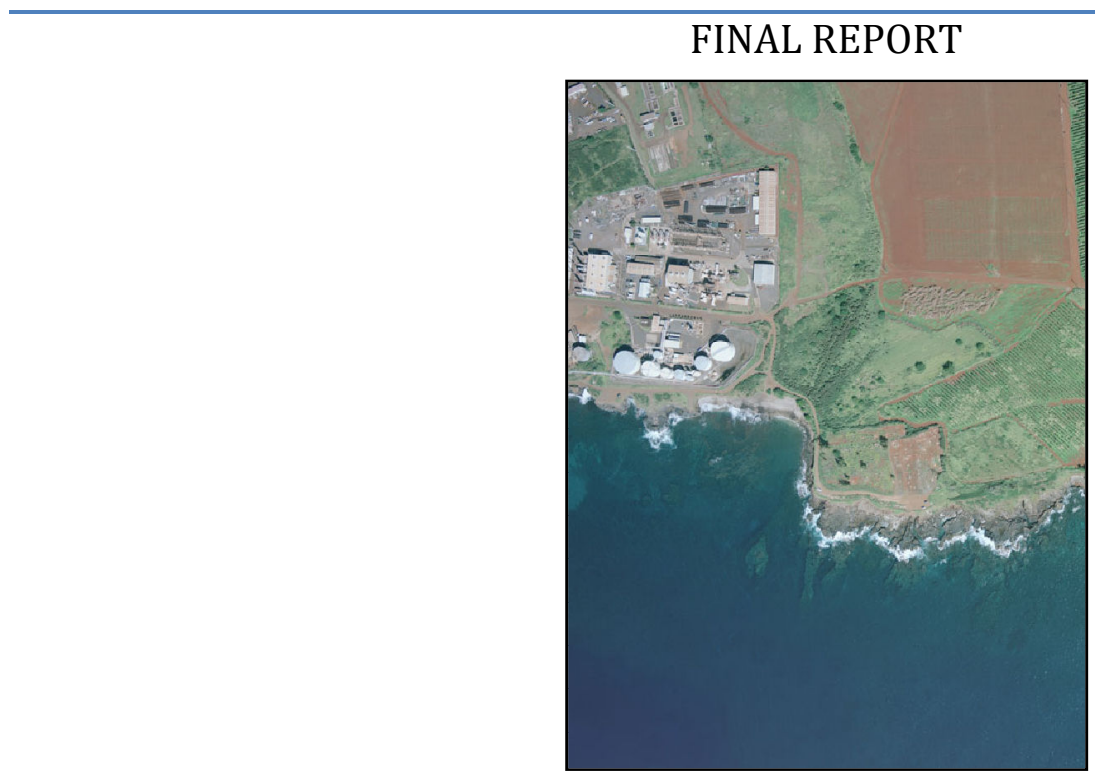

Submitted to:

\section{U.S. Department of Energy}

Golden Field Office

Award Number: DE-EE0002653

Submitted by:

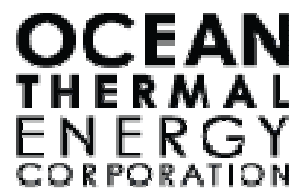

10432 Balls Ford Road

Suite 300/Office 322

Manassas, VA 20109
ALDEN Research Laboratory, Inc. 30 Shrewsbury Street Holden, MA 01520

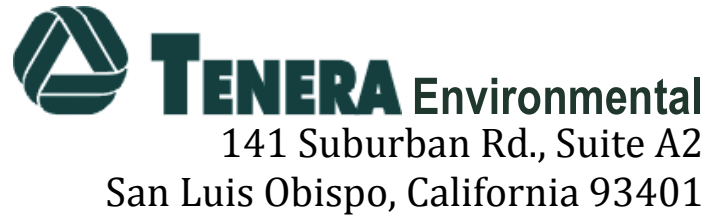




\section{TABLE OF CONTENTS}

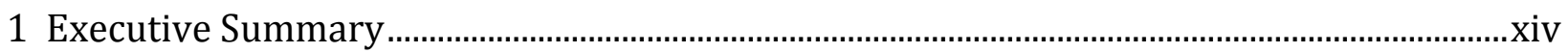

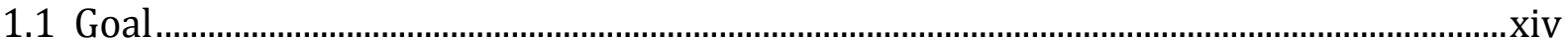

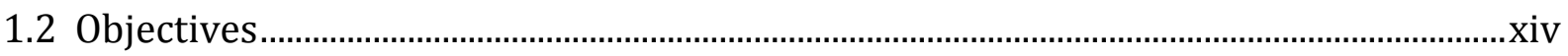

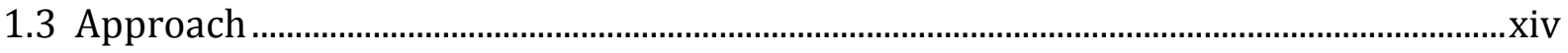

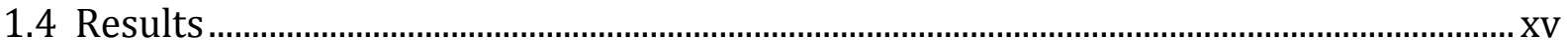

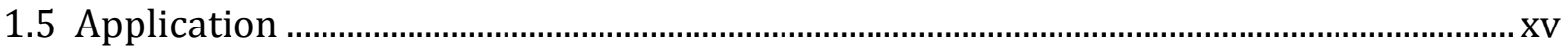

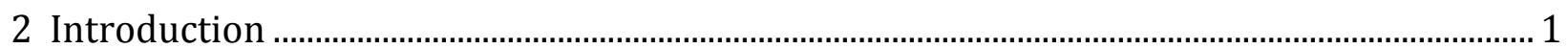

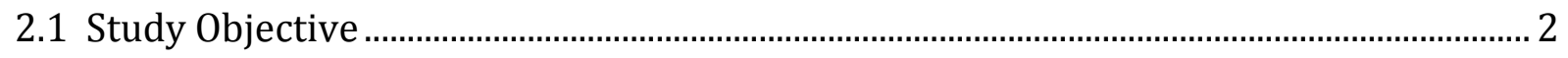

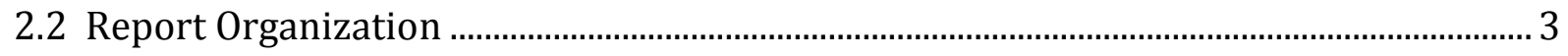

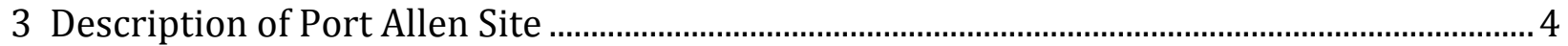

3.1 Proposed OTEC Facility Features ……............................................................................ 4

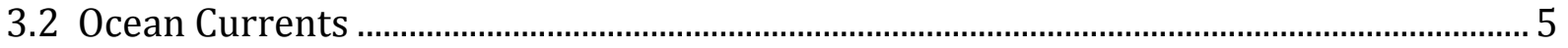

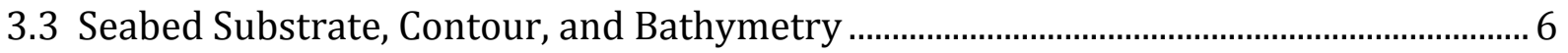

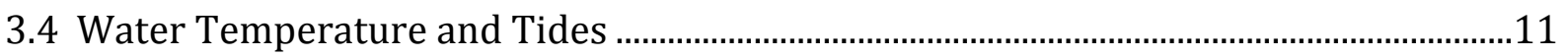

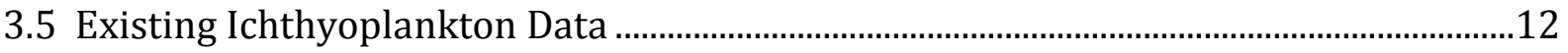

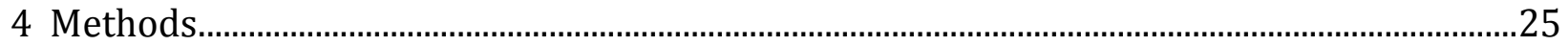

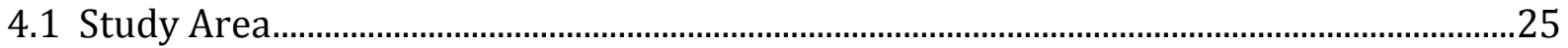

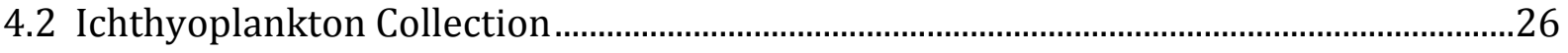

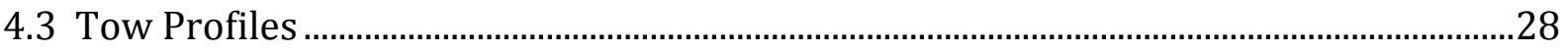

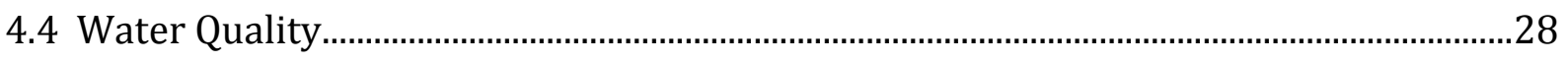

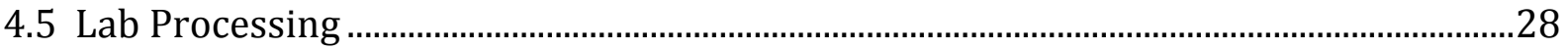

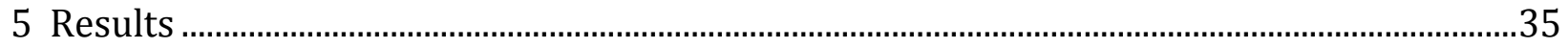

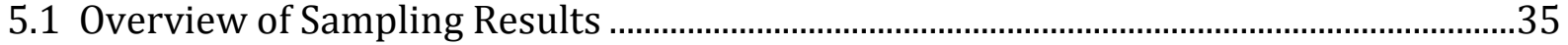

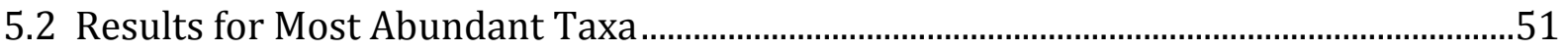

5.2.1 Infantfishes and Gobies (Schindleria spp. and Gobiidae) .........................................51

5.2.2 Blennies and Hawaiian triplefin (Salariinae, Blenniinae and Enneapterygius

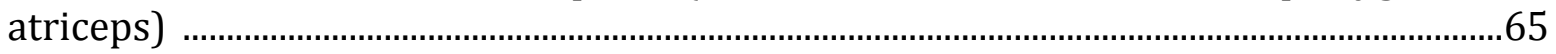

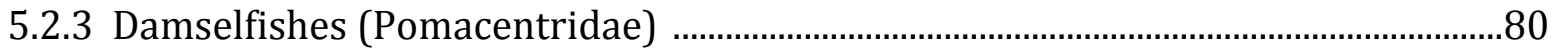

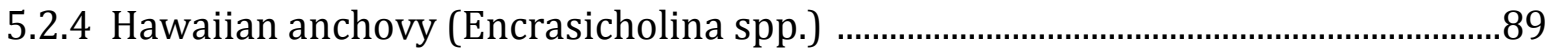

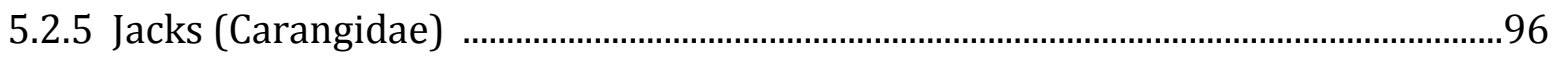

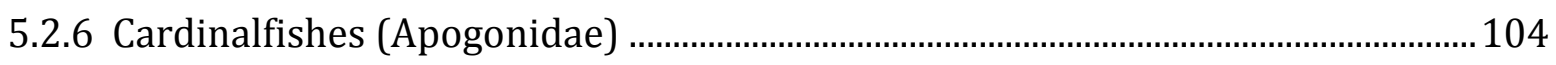

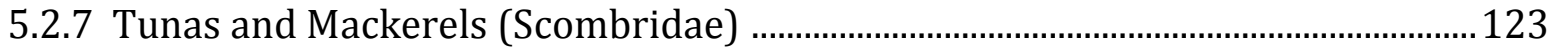

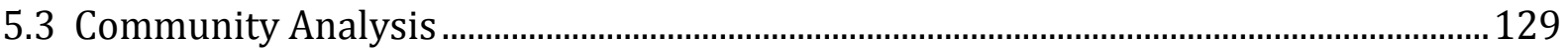

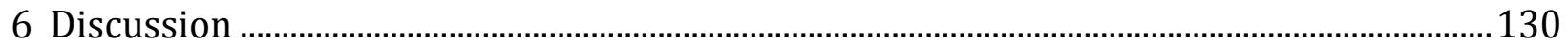




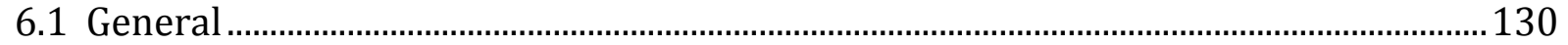

6.2 Ichthyoplankton Taxa ............................................................................................ 132

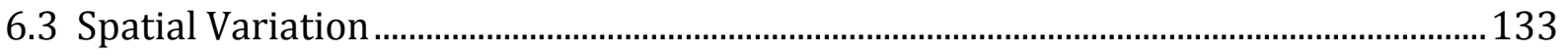

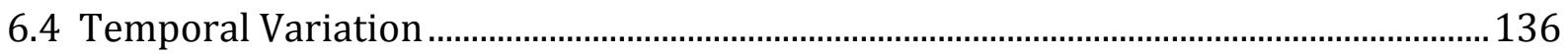

6.5 Implications for OTEC Warm Water Intakes...............................................................138

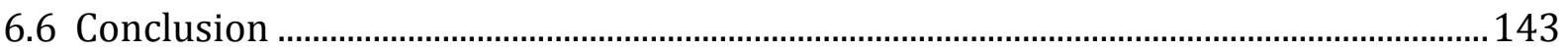

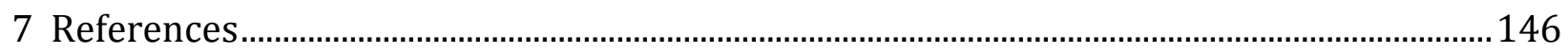

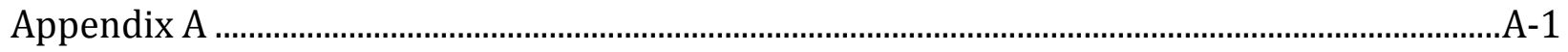

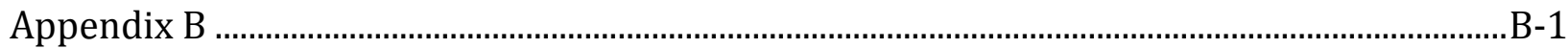

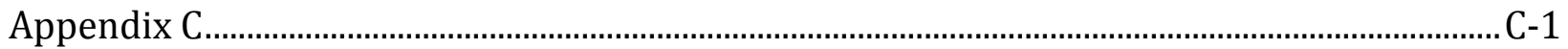




\section{TABLE OF FIGURES}

Figure 2-1. Illustration of impingement and entrainment of fish at an intake screen. Top right shows a juvenile fish impinged on a traveling water screen in a laboratory study and bottom right shows a fish larva collected in an entrainment sample of a field study. 1

Figure 3-1. Location of proposed Port Allen OTEC facility, Port Allen, Kauai (Images from Google Earth).

Figure 3-2. Proposed OTEC facility location (with approximate locations of appurtenant structures) (Image from Google Earth)...........................................................................................

Figure 3-3. Longterm mean ocean currents near Port Allen (Image from Firing and Brainard 2006).

Figure 3-4. Seabed zones in the sampling area offshore of Port Allen. Red box demarcates approximate sampling area (Image from Shallow-Water Benthic Habitats of the Main Hawaiian Islands - 2007, available at: http://ccma.nos.noaa.gov/products/biogeography/hawaii_cd_07/maps/maps_kauai.aspx).

Figure 3-5. Geomorphological structure in the sampling area offshore of Port Allen. Red box demarcates approximate sampling area (Image from Shallow-Water Benthic Habitats of the Main Hawaiian Islands - 2007, available at:

http://ccma.nos.noaa.gov/products/biogeography/hawaii_cd_07/maps/maps_kauai.aspx).

Figure 3-6. Biological cover in the sampling area offshore of Port Allen. Red box demarcates approximate sampling area (Image from Shallow-Water Benthic Habitats of the Main Hawaiian Islands - 2007, available at:

http://ccma.nos.noaa.gov/products/biogeography/hawaii_cd_07/maps/maps_kauai.aspx).

Figure 3-7. Bathymetry and depth contours (in meters) for area offshore of Port Allen, Kauai. Red box in inset demarcates approximate sampling area (Image from Chart 200-002 of Multibeam Bathymetry Data Synthesis [SOEST 2011]).

Figure 3-8. Beach profile for Salt Pond Beach Park located approximately 1.5 miles (2.4 $\mathrm{km}$ ) from the Port Allen sampling area (http://www.soest.hawaii.edu/coasts/data/kauai/beachprofile.html).

Figure 3-9. Weekly average water temperature during the weeks in which surveys were conducted..

Figure 3-10. Weekly average tidal heights during the weeks in which surveys were conducted..

Figure 3-11. Aerial image of Hawaiian Electric Company's Honolulu Generating Station 
intake structure (Images from Bing Maps and MapQuest).....

13

Figure 3-12. Aerial image of Hawaiian Electric Company's Kahe Generating Station intake structure (Images from Bing Maps and MapQuest).

Figure 3-13. Sampling locations (red arrows) in Kaneohe Bay during the study conducted by Watson and Leis (1974) (Images from Bing Maps and MapQuest).

Figure 3-14. Sampling locations off of Kahe Point during the study conducted by Leis (1982). Plankton sampling stations were $0.1,0.3,0.6$, and 1.9 miles $(0.2,0.5,1.0$, and 3.0 $\mathrm{km}$ ) from shore (Images from Leis (1982) and MapQuest).

Figure 3-15. Map of the sampling locations used by Boehlert and Mundy (1996). Sampling locations are designated for leeward (L) and windward (W) side and number by nautical miles offshore.

Figure 3-16. Inshore sampling locations on Kauai. Red box shows locations in Hanapepe Harbor at Port Allen where the current study was conducted (Image from Miller et al. 1979).

Figure 3-17. Location of ichthyoplankton tows approximately 8.1 miles (13 km) offshore of Oahu (red line) during the study conducted by Clarke (1991). Images from Google Earth and MapQuest

Figure 4-1. Ichthyoplankton sampling stations offshore of Port Allen.

Figure 4-2. Equipment used for collecting ichthyoplankton samples during this study. Clockwise from top: bongo net assembly being retrieved after a deployment, bongo nets (9.8 ft [3 m] long), cod end filtering bucket (0.01 in [335 $\mu \mathrm{m}]$ mesh), bongo net assembly collecting a sample (flowmeters are visible in the bongo mouth rings).

Figure 4-3. Illustration of the measurement locations for notochord length and head depth (height) and width of a preflexion stage larval fish. Larval fish is a jacksmelt from Moser 1996.

Figure 4-4. Explanation of dispersion statistics for length frequency histograms. 33

Figure 5-1. Average concentrations (plus one standard error) of fish eggs at the three sampling stations off Port Allen, Kauai from April-December 2012.

Figure 5-2. Average concentrations (plus one standard error) of fish eggs during day (gray bars) and night (black bars) sampling at the three stations off Port Allen, Kauai from AprilDecember 2012.

Figure 5-3. Average concentrations (plus one standard error) of fish larvae for all taxa combined at the three sampling stations off Port Allen, Kauai from April-December 2012.

Figure 5-4. Average concentrations (plus one standard error) of fish larvae for all taxa 
combined during day (gray bars) and night (black bars) sampling at the three stations off Port Allen, Kauai from April-December 2012.

Figure 5-5. Average concentrations (plus one standard error) of fish eggs at two depth strata at Station 3 off Port Allen, Kauai from April-December 2012. Numbers at tops of bars are mean values.

Figure 5-6. Average concentrations (plus one standard error) of fish larvae for all taxa combined at two depth strata at Station 3 off Port Allen, Kauai from April-December 2012. Numbers at tops of bars are mean values. 50

Figure 5-7. Hawaiian shrimp goby (photo by J.P. Hoover) ........................................................... 51

Figure 5-8. Schindleria spp. larvae collected during this study.................................................. 53

Figure 5-9. Average concentrations (plus one standard error) of Schindleria spp. larvae at the three sampling stations off Port Allen, Kauai from April-December 2012 ...................... 54

Figure 5-10. Average concentrations (plus one standard error) of Schindleria spp. larvae during day (gray bars) and night (black bars) sampling at the three stations off Port Allen, Kauai from April-December 2012.

Figure 5-11. Average concentrations (plus one standard error) of Schindleria spp. larvae at two depth strata at Station 3 off Port Allen, Kauai from April-December 2012. Numbers at tops of bars are mean values.

Figure 5-12. Length frequency of Schindleria spp. larvae measured from the samples........ 58

Figure 5-13. Larval length versus head capsule measurements of Schindleria spp. larvae. These measurements are for larvae measured during this study and others conducted in Hawaii.

Figure 5-14. Gobiidae larvae collected during this study.

Figure 5-15. Average concentrations (plus one standard error) of Gobiidae larvae at the three sampling stations off Port Allen, Kauai from April-December 2012.

Figure 5-16. Average concentrations (plus one standard error) of Gobiidae larvae during day (gray bars) and night (black bars) sampling at the three stations off Port Allen, Kauai from April-December 2012.

Figure 5-17. Average concentrations (plus one standard error) of Gobiidae larvae at two depth strata at Station 3 off Port Allen, Kauai from April-December 2012. Numbers at tops of bars are mean values.

Figure 5-18. Length frequency of Gobiidae larvae measured from the samples.

Figure 5-19. Larval length versus head capsule measurements of Gobiidae larvae. These measurements are for larvae measured during this study and others conducted in Hawaii. 
Figure 5-20. Salariinae larvae collected during this study.

Figure 5-21. Average concentrations (plus one standard error) of Salariinae larvae at the three sampling stations off Port Allen, Kauai from April-December 2012.

Figure 5-22. Average concentrations (plus one standard error) of Salariinae larvae during day (gray bars) and night (black bars) sampling at the three stations off Port Allen, Kauai from April-December 2012.

Figure 5-23. Average concentrations (plus one standard error) of Salariinae larvae at two depth strata at Station 3 off Port Allen, Kauai from April-December 2012. Numbers at tops of bars are mean values. 72

Figure 5-24. Length frequency of Salariinae larvae measured during this study. 73

Figure 5-25. Larval length versus head capsule measurements of Salariinae and blenny larvae combined. These measurements are for larvae measured during this study and others conducted in Hawaii.

Figure 5-26. Hawaiian triplefin (Enneapterygius atriceps) larvae collected during this study

Figure 5-27. Average concentrations (plus one standard error) of Enneapterygius atriceps larvae at the three sampling stations off Port Allen, Kauai from April-December 2012...... 76 Figure 5-28. Average concentrations (plus one standard error) of Enneapterygius atriceps larvae during day (gray bars) and night (black bars) sampling at the three stations off Port Allen, Kauai from April-December 2012.

Figure 5-29. Average concentrations (plus one standard error) of Enneapterygius atriceps larvae at two depth strata at Station 3 off Port Allen, Kauai from April-December 2012. Numbers at tops of bars are mean values.

Figure 5-30. Length frequency of Enneapterygius atriceps larvae measured during this study.

Figure 5-31. Larval length versus head capsule measurements of Enneapterygius atriceps larvae. These measurements are for larvae measured during this study and others conducted in Hawaii. 79

Figure 5-32. 'alo'ilo'i - Hawaiian dascyllus (Photo by J.E. Randall) .......................................... 80

Figure 5-33. mamo - Hawaiian sergant (Photo by J.P. Hoover)

Figure 5-34. Pomacentridae larvae (top two images) and juvenile (bottom) collected during this study.

Figure 5-35. Average concentrations (plus one standard error) of Pomacentridae larvae at the three sampling stations off Port Allen, Kauai from April-December 2012. 85 
Figure 5-36. Average concentrations (plus one standard error) of Pomacentridae larvae during day (gray bars) and night (black bars) sampling at the three stations off Port Allen, Kauai from April-December 2012.

Figure 5-37. Average concentrations (plus one standard error) of Pomacentridae larvae at two depth strata at Station 3 off Port Allen, Kauai from April-December 2012. Numbers at tops of bars are mean values.

Figure 5-38. Length frequency of Pomacentridae larvae measured during this study......... 88 Figure 5-39. Larval length versus head capsule measurements of Pomacentridae larvae. These measurements are for larvae measured during this study and others conducted in Hawaii. 88

Figure 5-40. Hawaiian anchovy (Encrasicholina spp.) larva collected during this study...... 91

Figure 5-41. Average concentrations (plus one standard error) of Encrasicholina spp. larvae at the three sampling stations off Port Allen, Kauai from April-December 2012....... 92 Figure 5-42. Average concentrations (plus one standard error) of Encrasicholina spp. larvae during day (gray bars) and night (black bars) sampling at the three stations off Port Allen, Kauai from April-December 2012.

Figure 5-43. Average concentrations (plus one standard error) of Encrasicholina spp. larvae at two depth strata at Station 3 off Port Allen, Kauai from April-December 2012. Numbers at tops of bars are mean values.

Figure 5-44. Length frequency of Encrasicholina spp. larvae measured during this study. 95 Figure 5-45. Larval length versus head capsule measurements of Encrasicholina spp. larvae. These measurements are for larvae measured during this study and others conducted in Hawaii. 95

Figure 5-46. 'ōmilu - bluefin trevally (Photo by J.E. Randall).......................................................... 96

Figure 5-47. āmuka - yellowtail scad (Photo by J.P. Hoover)...................................................... 97

Figure 5-48. Carangidae larvae collected during this study......................................................... 98

Figure 5-49. Average concentrations (plus one standard error) of Carangidae larvae at the three sampling stations off Port Allen, Kauai from April-December 2012. 100

Figure 5-50. Average concentrations (plus one standard error) of Carangidae larvae during day (gray bars) and night (black bars) sampling at the three stations off Port Allen, Kauai from April-December 2012.

Figure 5-51. Average concentrations (plus one standard error) of Carangidae larvae at two depth strata at Station 3 off Port Allen, Kauai from April-December 2012. Numbers at tops of bars are mean values. 
Figure 5-52. Length frequency of Carangidae larvae measured during this study. 103

Figure 5-53. Larval length versus head capsule measurements of Carangidae larvae. These measurements are for larvae measured during this study and others conducted in Hawaii.

Figure 5-54. Apogonidae larvae collected during this study. 106

Figure 5-55. Average concentrations (plus one standard error) of all Apogonidae larvae combined at the three sampling stations off Port Allen, Kauai from April-December 2012.

Figure 5-56. Average concentrations (plus one standard error) of all Apogonidae larvae combined during day (gray bars) and night (black bars) sampling at the three stations off Port Allen, Kauai from April-December 2012.

Figure 5-57. Average concentrations (plus one standard error) of Apogonidae larvae at two depth strata at Station 3 off Port Allen, Kauai from April-December 2012. Numbers at tops of bars are mean values.

Figure 5-58. Length frequency of Apogonidae larvae measured during this study.

Figure 5-59. Larval length versus head capsule measurements of all Apogonidae larvae. This includes larvae identified as Apogonidae, Apogon spp., and Pristiapogon spp. These measurements are for larvae measured during this study and others conducted in Hawaii.

Figure 5-60. Apogon spp. larva collected during this study.

Figure 5-61. Average concentrations (plus one standard error) of Apogon spp. larvae at the three sampling stations off Port Allen, Kauai from April-December 2012.

Figure 5-62. Average concentrations (plus one standard error) of Apogon spp. larvae during day (gray bars) and night (black bars) sampling at the three stations off Port Allen, Kauai from April-December 2012.

Figure 5-63. Average concentrations (plus one standard error) of Apogon spp. larvae at two depth strata at Station 3 off Port Allen, Kauai from April-December 2012. Numbers at tops of bars are mean values.

Figure 5-64. Length frequency of Apogon spp. larvae measured during this study.

Figure 5-65. Pristiapogon spp. larvae collected during this study.

Figure 5-66. Average concentrations (plus one standard error) of Pristiapogon spp. larvae at the three sampling stations off Port Allen, Kauai from April-December 2012.

Figure 5-67. Average concentrations (plus one standard error) of Pristiapogon spp. larvae during day (gray bars) and night (black bars) sampling at the three stations off Port Allen, Kauai from April-December 2012. 
Figure 5-68. Average concentrations (plus one standard error) of Pristiapogon spp. larvae at two depth strata at Station 3 off Port Allen, Kauai from April-December 2012. Numbers at tops of bars are mean values.

Figure 5-69. Length frequency of Pristiapogon spp. larvae measured during this study...121

Figure 5-70. Scombridae larvae collected during this study. 123

Figure 5-71. Average concentrations (plus one standard error) of Scombridae larvae at the three sampling stations off Port Allen, Kauai from April-December 2012.

Figure 5-72. Average concentrations (plus one standard error) of Scombridae larvae during day (gray bars) and night (black bars) sampling at the three stations off Port Allen, Kauai from April-December 2012.

Figure 5-73. Average concentrations (plus one standard error) of Scombridae larvae at two depth strata at Station 3 off Port Allen, Kauai from April-December 2012. Numbers at tops of bars are mean values.

Figure 5-74. Length frequency of Scombridae larvae measured during this study.

Figure 5-75. Multivariate analysis of average concentrations of larvae for each of the nine surveys (numbers above symbols) for the oblique tows through the water column at Stations 1 (red circle), 2 (green triangle), and 3 (blue square) using non-metric multidimensional scaling. 


\section{TABLE OF TABLES}

Table 3-1. Most abundant taxa of fish larvae collected at HGS. The average concentrations are calculated from the annual averages calculated for the period from April 2006-April 2012. Only taxa comprising up to $95 \%$ of total abundance are shown.

Table 3-2. Most abundant taxa of fish larvae collected at KGS. The average concentrations are calculated from the annual averages calculated for the period from April 2006-April 2012. Only taxa comprising up to $95 \%$ of total abundance are shown.

Table 3-3. Most abundant taxa of fish larvae collected. These taxa accounted for $88 \%$ of all larvae collected.

Table 3-4. Density of larvae collected offshore and inshore at Hanapepe Harbor during winter and summer (Miller et al. 1979).

Table 3-5. Ranks by number of specimens captured, numbers captured, and cumulative percentages of total nearshore fish larvae for the 20 most abundant families (left columns) and the 20 most abundant lower taxa (right columns) taken in samples from oceanic waters near Oahu, Hawaii, 1977-78 (from Clarke 1991)............................................................. 23

Table 3-6. Top ten species in Kauai as reported by the commercial fishing industry (data provided by the Hawaii Division of Aquatic Resources, 01/21/2011).................................... 24

Table 4-1. Sampling matrix for ichthyoplankton sampling program....................................... 28

Table 4-2. List of larval fish taxa measured to notochord lengths and head capsule dimensions.

Table 5-1. Sample dates and number of samples collected during ichthyoplankton surveys off Port Allen, Kauai. Station 3 Upper represents the samples collected from the upper water column at Station 3.

Table 5-2. Summary of adjusted numbers and concentrations of fish eggs and larvae from ichthyoplankton surveys off Port Allen, Kauai from April-December 2012 ........................... 38

Table 5-3. Summary of adjusted concentrations of fish eggs and larvae from oblique tows of the entire water column at Stations 1, 2, and 3 off Port Allen, Kauai from April-December 2012.

Table 5-4. Results of ANOVA of data on fish eggs from oblique tows of the entire water column at Stations 1, 2, and 3 during day and night sampling cycles across nine surveys off Port Allen, Kauai from April-December 2012. Tests significant at probability level of 95\% are in bold.

Table 5-5. Results of ANOVA of data on fish larvae for all taxa combined from oblique tows of the entire water column at Stations 1,2, and 3 during day and night sampling cycles across nine surveys off Port Allen, Kauai from April-December 2012.Tests significant at 
probability level of $95 \%$ are in bold.

Table 5-6. Results of ANOVA of data on Schindleria spp. larvae from oblique tows of the entire water column at Stations 1,2, and 3 during day and night sampling cycles across nine surveys off Port Allen, Kauai from April-December 2012. Tests significant at probability level of $95 \%$ are in bold.

Table 5-7. Results of ANOVA of data on Gobiidae larvae from oblique tows of the entire water column at Stations 1, 2, and 3 during day and night sampling cycles across nine surveys off Port Allen, Kauai from April-December 2012. Tests significant at probability level of $95 \%$ are in bold.

Table 5-8. Results of ANOVA of data on Salariinae larvae from oblique tows of the entire water column at Stations 1, 2, and 3 during day and night sampling cycles across nine surveys off Port Allen, Kauai from April-December 2012. Tests significant at probability level of $95 \%$ are in bold.

Table 5-9. Results of ANOVA of data on Enneapterygius atriceps larvae from oblique tows of the entire water column at Stations 1,2, and 3 during day and night sampling cycles across nine surveys off Port Allen, Kauai from April-December 2012. Tests significant at probability level of $95 \%$ are in bold.

Table 5-10. Numbers of ripe ovarian eggs in relation to fish length for Hawaiian sergeant (Stevenson 1963).

Table 5-11. Damselfish larval durations (Wellington and Victor 1989).

Table 5-12. Estimated growth rates of larval and juvenile Hawaiian dascyllus (from Booth 1995).

Table 5-13. Results of ANOVA of data on Pomacentridae larvae from oblique tows of the entire water column at Stations 1,2, and 3 during day and night sampling cycles across nine surveys off Port Allen, Kauai from April-December 2012. Tests significant at probability level of $95 \%$ are in bold.

Table 5-14. Results of ANOVA of data on Carangidae larvae from oblique tows of the entire water column at Stations 1, 2, and 3 during day and night sampling cycles across nine surveys off Port Allen, Kauai from April-December 2012. Tests significant at probability level of $95 \%$ are in bold.

Table 5-15. Results of ANOVA of data on Apogonidae larvae from oblique tows of the entire water column at Stations 1, 2, and 3 during day and night sampling cycles across nine surveys off Port Allen, Kauai from April-December 2012. Tests significant at probability level of $95 \%$ are in bold.

Table 5-16. Results of ANOVA of data on Apogon spp. larvae from oblique tows of the entire water column at Stations 1, 2, and 3 during day and night sampling cycles across nine 
surveys off Port Allen, Kauai from April-December 2012. Tests significant at probability level of $95 \%$ are in bold.

Table 5-17. Results of ANOVA of data on Pristiapogon spp. larvae from oblique tows of the entire water column at Stations 1, 2, and 3 during day and night sampling cycles across nine surveys off Port Allen, Kauai from April-December 2012. Tests significant at probability level of $95 \%$ are in bold.

Table 5-18. Results of ANOVA of data on Scombridae larvae from oblique tows of the entire water column at Stations 1, 2, and 3 during day and night sampling cycles across nine surveys off Port Allen, Kauai from April-December 2012. Tests significant at probability level of $95 \%$ are in bold.

Table 6-1. Mean notochord length and largest head capsule dimension of the dominant taxa collected. 


\section{Executive Summary}

Ocean thermal energy conversion (OTEC) is a marine renewable energy technology with the potential to contribute significantly to the baseload power needs of tropical island communities and remote U.S. military installations. As with other renewable energy technologies, however, there are potential challenges to its commercialization: technological, financial, social, and environmental. Given the large volumes of seawater required to drive the electricity-producing cycle, there is potential for the intakes to negatively impact the marine resources of the source waterbody through the impingement and entrainment of marine organisms.

\subsection{Goal}

The goal of this project was to identify feasible warm water intake designs for a land-based OTEC facility proposed for development in Port Allen, Kauai and to characterize the populations of ichthyoplankton near the proposed warm water intake location that could be at risk of entrainment.

\subsection{Objectives}

The specific objectives of this project were to:

- Complete a site-specific assessment of available and feasible warm water intake technologies to determine the best intake designs for minimizing impacts to aquatic organisms at the proposed land-based OTEC site in Port Allen, Kauai.

- Complete a field sampling program to collect biological data to characterize the baseline populations of ichthyoplankton near the sites being considered for the warm water intake at the proposed land-based OTEC site in Port Allen, Kauai.

\subsection{Approach}

The objectives of this project were completed through comprehensive engineering analyses and field data collection. Relative to the assessment of warm water intakes, conceptual designs were developed for various onshore and offshore intake configurations and with various intake technologies. The initial intake designs were narrowed down to those with the greatest potential to meet environmental and financial objectives. The selected intake designs were further refined in a later phase to identify those that are economically feasible to construct.

Relative to the field data collection, ichthyoplankton samples were collected with plankton nets from an area offshore of Port Allen where a warm water intake would likely be sited. Samples were collected in a manner that would aid in determining whether there were any 
variations in density associated with distance from shore, depth, diel period, or season.

\subsection{Results}

Three conceptual warm water intake designs were initially developed that would address concerns over impingement and entrainment of marine organisms. These designs were conservative in that they included fine mesh screen/slot sizes $(2 \mathrm{~mm})$. The estimated costs for the three intake designs (modified traveling water screens with an onshore intake, modified traveling water screens with and offshore velocity cap intake, and offshore cylindrical wedgewire screens) were $\$ 123,000,000, \$ 198,000,000$, and $\$ 210,000,000$, respectively. Since these designs are prohibitively expensive, modified designed were prepared using alternative construction techniques and screen mesh/slot sizes. The refined designs utilized $9.5-\mathrm{mm}$ screen mesh/slot sizes. The estimated costs for the three modified intake designs (modified traveling water screens with an onshore intake, modified traveling water screens with and offshore velocity cap intake, and offshore cylindrical wedgewire screens) were $\$ 50,000,000, \$ 55,000,000$, and $\$ 55,000,000$, respectively.

The estimated numbers from the 204 samples totaled 297,638 unidentified fish eggs and 49,969 fish larvae from a minimum of 101 taxa. The average concentration of fish larvae from the sampling done during all the surveys at all of the stations was 2,111 larvae per $1,000 \mathrm{~m}^{3}$. The assemblage was diverse, with 11 taxa comprising the top $90 \%$ of specimens collected, which included larvae that could not be identified into a taxonomic category. The most abundant taxa were infantfishes (Schindleria spp.), blennies (Salariinae), gobies (Gobiidae), damselfishes (Pomacentridae), Hawaiian triplefin (Enneapterygius atriceps), lanternfishes (Myctophidae), and Hawaiian anchovy or nehu (Encrasicholina spp.). The most abundant larvae were generally from fishes with adults that inhabit shallow nearshore distributions, but larvae from deepwater fishes such as the Myctophidae were also abundant.

Larval concentrations were highest in the station closest to shore and lowest at the station farthest from shore. Egg concentrations did not vary significantly with distance from shore. Peak concentrations for eggs and larvae occurred in April/May and July/August/September, respectively. There was no significant difference detected in the concentrations of eggs or larvae in the two depth strata sampled at the most offshore sampling station. Statistical analysis indicated that there was greater variation among the monthly sampling surveys (temporal variation) than among the sampling stations within each survey (spatial variation).

\subsection{Application}

The results of this project can be applied to further assess the feasibility of a land-based 
OTEC facility in Port Allen, Kauai. Warm water intake designs were developed that may meet economic criteria for developers, though whether they meet environmental performance goals is yet to be determined until OTEC intake regulations are further developed. The field sampling offshore of Port Allen provides basic biological information about tropical ichthyoplankton, an area of biology for which data are very sparse. The data collected as part of this project can also be used in later phases of assessment to refine screening mesh sizes (using relationships between length and head capsule dimensions) and to assess potential entrainment impacts of the warm water intake (using demographic or conditional mortality models). 


\section{Introduction}

In the fledgling marine and hydrokinetic (MHK) renewable energy industry, the U.S. Department of Energy (DOE) has taken a leadership role by providing funding to support projects that advance both specific project deployment efforts and the advancement of the MHK industry as a whole. Ocean thermal energy conversion (OTEC) is an MHK technology with the potential to provide baseload power to tropical island communities and remote U.S. military installations. As with other renewable energy technologies, however, there are potential challenges to its commercialization: technological, financial, social, and environmental. Given the large volumes of seawater required to drive the electricityproducing cycle, there is potential for the intakes to negatively impact the marine resources of the source waterbody.

Implicit in the responsible development of the OTEC industry, is the careful evaluation of the intake technologies available for the withdrawal of the warm and cold water required to drive the electricity-producing cycle. Of the two intakes, the warm water intake has the greater potential to impact marine life since it will be drawing water from a more biologically-productive area of the ocean. The most significant potential impacts to marine organisms at warm water OTEC intakes can be broadly categorized into impingement and entrainment (Figure 2-1). Each represents an interaction between the organisms in the source waterbody (ocean) and the intake screening technology and each is dependent on organism and screen mesh size.

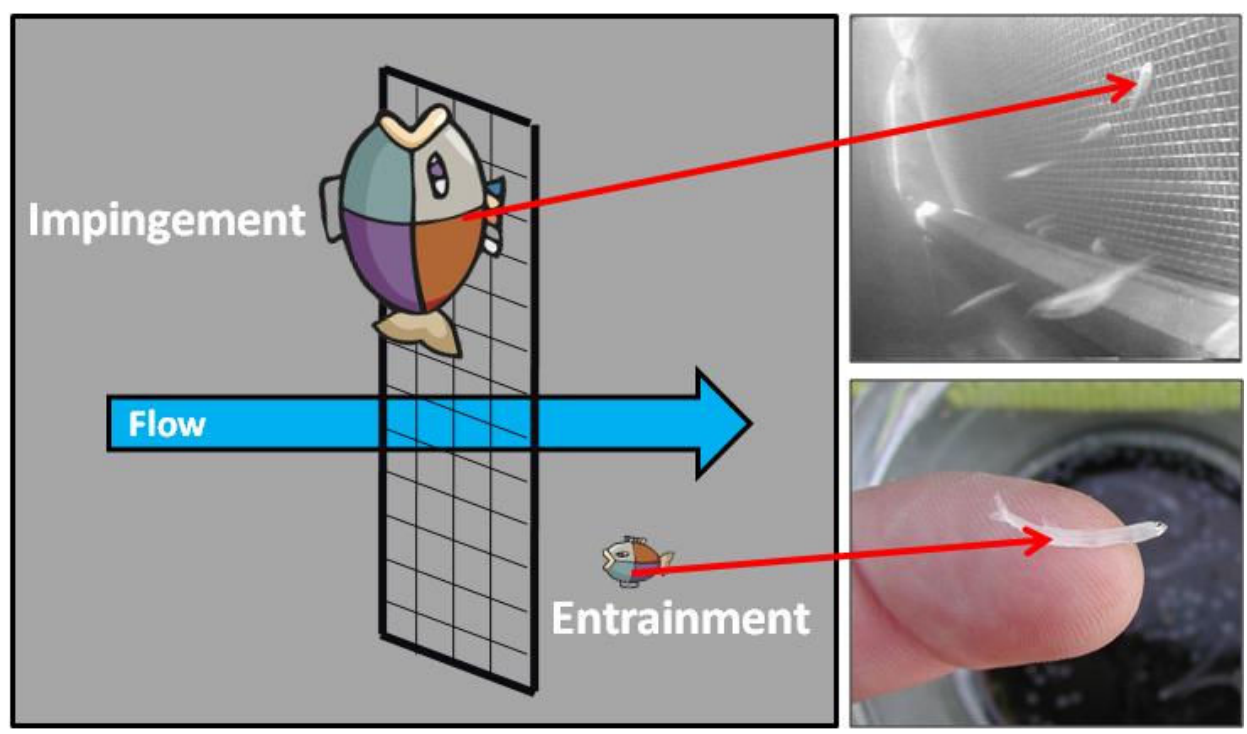

Figure 2-1. Illustration of impingement and entrainment of fish at an intake screen. Top right shows a juvenile fish impinged on a traveling water screen in a laboratory study and bottom right shows a fish larva collected in an entrainment sample of a field study. 
Impingement is the entrapment of larger organisms against the screen mesh by the flow of the withdrawn water (Figure 2-1). The magnitude of impingement losses for any species from intake operation is a function of the involvement of the species with the intake (number or proportion impinged) and the subsequent mortality of those organisms (referred to as impingement mortality). Entrainment is the passage of smaller organisms through the screening mesh (Figure 2-1). The magnitude of entrainment losses for any species from intake operation is a function of the involvement of the species with the intake (number or proportion entrained) and the subsequent mortality of those organisms as they pass through the process equipment (referred to as entrainment mortality).

Entrainable-sized organisms are typically characterized by those with limited to no swimming ability; impingeable-sized organisms are typically characterized by larger individuals with greater swimming abilities. As such, entrainable-sized organisms are often the target of intake impact analyses when water is being drawn from a marine waterbody where early life stages of marine organisms are likely to be present. Due to the susceptibility of entrainable-sized organisms, they are also often a principal focus of permit requirements for seawater intakes (e.g., Clean Water Act Section 316(b)) in the U.S. For these reasons, characterizing the baseline populations of entrainable-sized ichthyoplankton near an intake is an important first step in developing a facility such as an OTEC plant that proposes to draw large volumes of seawater for its operation.

\subsection{Study Objective}

Given the potential for intake-related impacts, it is critical that the warm water intake technology selected is designed to minimize environmental risks. By comprehensively assessing the feasibility and performance of all of the intake technologies available, OTEC developers can more confidently select the one with the greatest potential for a given site. Furthermore, conducting baseline biological sampling at the proposed intake location is important for making initial assessments of the potential impacts to marine life that a warm water OTEC intake may present. The project described in this report was designed to meet both of these objectives by:

- Completing a site-specific assessment of available and feasible warm water intake technologies to determine the best intake designs for minimizing impacts to aquatic organisms at a proposed shore-based OTEC site in Port Allen, Kauai.

- Completing a field sampling program at a proposed shore-based OTEC site in Port Allen, Kauai to collect biological data to characterize the baseline populations of ichthyoplankton near the sites being considered for the warm water intake.

A previous Interim Report (OCEES and Alden 2011, included as Appendix C) was issued in 
July 2011 and summarizes the results of the warm water intake assessment. This Final Report summarizes the results of the biological field sampling program that was conducted in Port Allen, Kauai.

\subsection{Report Organization}

This Final Report has been prepared as a stand-alone document. It describes the ninemonth field sampling program that was conducted near the potential location of the warm water intake for the proposed shore-based OTEC facility in Port Allen, Kauai. Taken in concert with the warm water intake assessment described in the Interim Report (OCEES and Alden 2011, Appendix C), the field work described in this report constitutes the other critical component required to determine the environmental feasibility of a shore-based OTEC facility in Port Allen. In addition, the results of this study will be important in the warm water intake design process. Trends in spatial and temporal variations in fish abundances can be used to more effectively locate and operate the warm water intake. For this reason, although the Interim Report and Final Report have been issued separately, they should be considered collectively in assessing the environmental feasibility of a shorebased OTEC facility in Port Allen.

To the extent that the goal of the original DOE Funding Opportunity Announcement was to promote the development of OTEC as a viable marine renewable energy technology, additional work was completed in regards to the warm water intake design. The objective of this additional work was to evaluate additional warm water intake designs that would be considered more economically-feasible than those issued in the Interim Report (OCEES and Alden 2011, Appendix C). The intent was to evaluate alternative designs that could reduce the costs of the warm water intake (while maintaining minimum environmental performance criteria) in an effort to make OTEC development more economically-feasible at this site. The results of these additional warm water intake design efforts are summarized in Appendix B of this report. 


\section{Description of Port Allen Site}

\subsection{Proposed OTEC Facility Features}

The proposed shore-based Port Allen OTEC facility is to be situated near Port Allen, on the south side of the island of Kauai, in Hawaii (Figure 3-1). The facility intake and discharge are to be located in the Pacific Ocean just southeast of Hanapepe Bay. The facility is to consist of one or more warm water intake structures, one or more cold water intake structures, and one or more return structures (Figure 3-2).

The facility is to have a nominal rated capacity of 20 megawatts (MW) using a thermodynamic process to exploit the difference in temperature between surface water and deep sea water to produce electricity. The full-scale warm water intake would withdraw approximately 1,473 million gallons per day (MGD) [64.5 cubic meters per second $\left.\left(\mathrm{m}^{3} / \mathrm{sec}\right)\right]$ from a depth of $33 \mathrm{ft}(10 \mathrm{~m})$. The full-scale cold water intake would withdraw approximately 1,008 MGD (44.2 $\left.\mathrm{m}^{3} / \mathrm{sec}\right)$ from a depth of 3,281 ft (1000 m).

Discerning the potential impact of the warm water intake was the objective of the biological sampling efforts described in this report; no biological sampling was conducted relative to the deeper cold water intake.

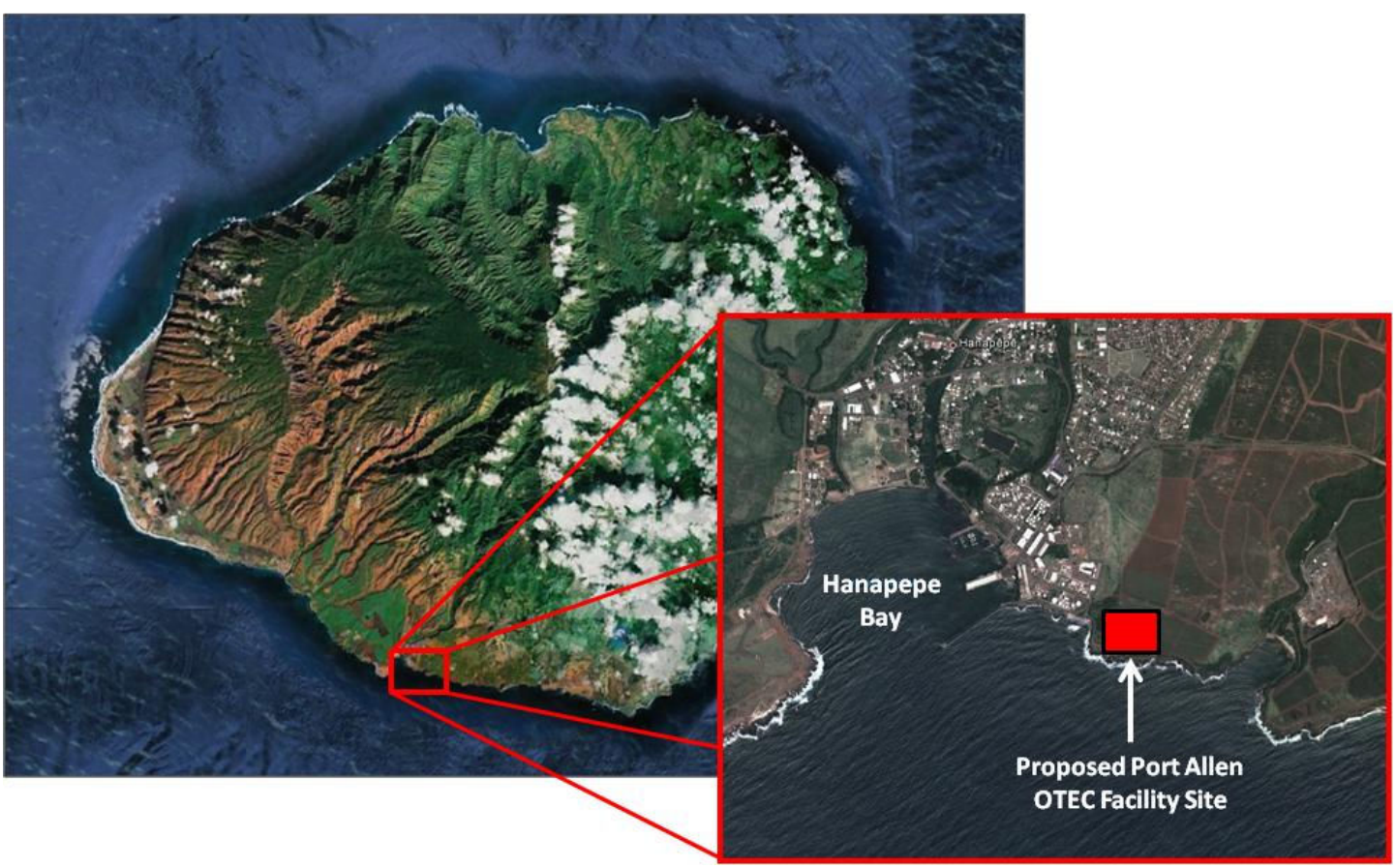

Figure 3-1. Location of proposed Port Allen OTEC facility, Port Allen, Kauai (Images from Google Earth). 


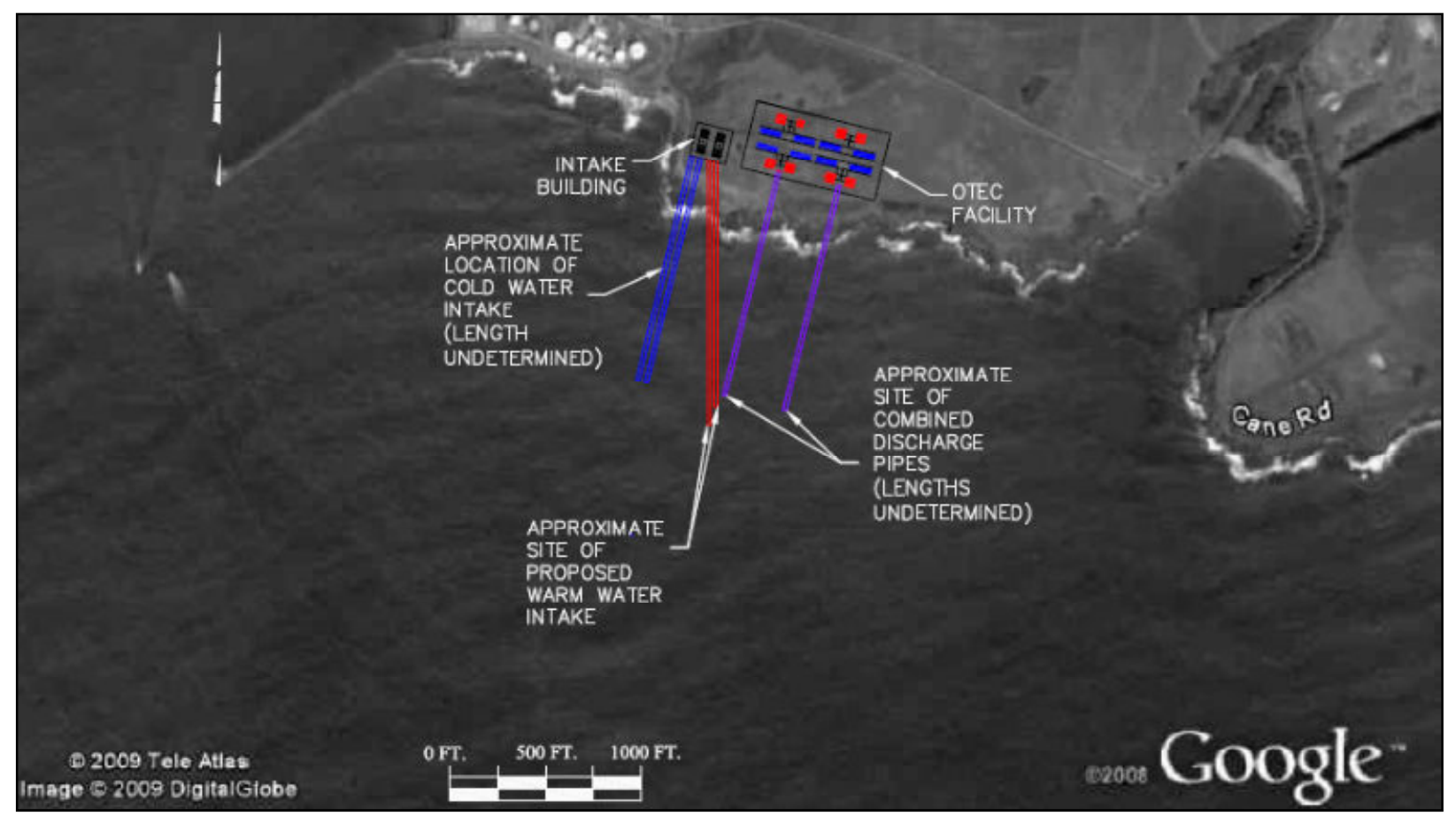

Figure 3-2. Proposed OTEC facility location (with approximate locations of appurtenant structures) (Image from Google Earth).

\subsection{Ocean Currents}

No high resolution ocean current data are readily available for the nearshore area of the south coast of Kauai where this field sampling program was conducted. However, gross nearshore ocean current data available from Firing and Brainard (2006) indicate that the predominant ocean currents parallel the Port Allen coastline from the northwest to the southeast (Figure 3-3). Predominant ocean currents change to a westward direction as distance from shore increases, reaching a mean of $0.15 \mathrm{~m} / \mathrm{sec}(0.5 \mathrm{ft} / \mathrm{sec})$ south of Kauai and Niihau. However, the U.S. Coast Pilot indicates that the direction of the prevailing currents off of Puolo Point just west of Port Allen is west (NOS 2013). 


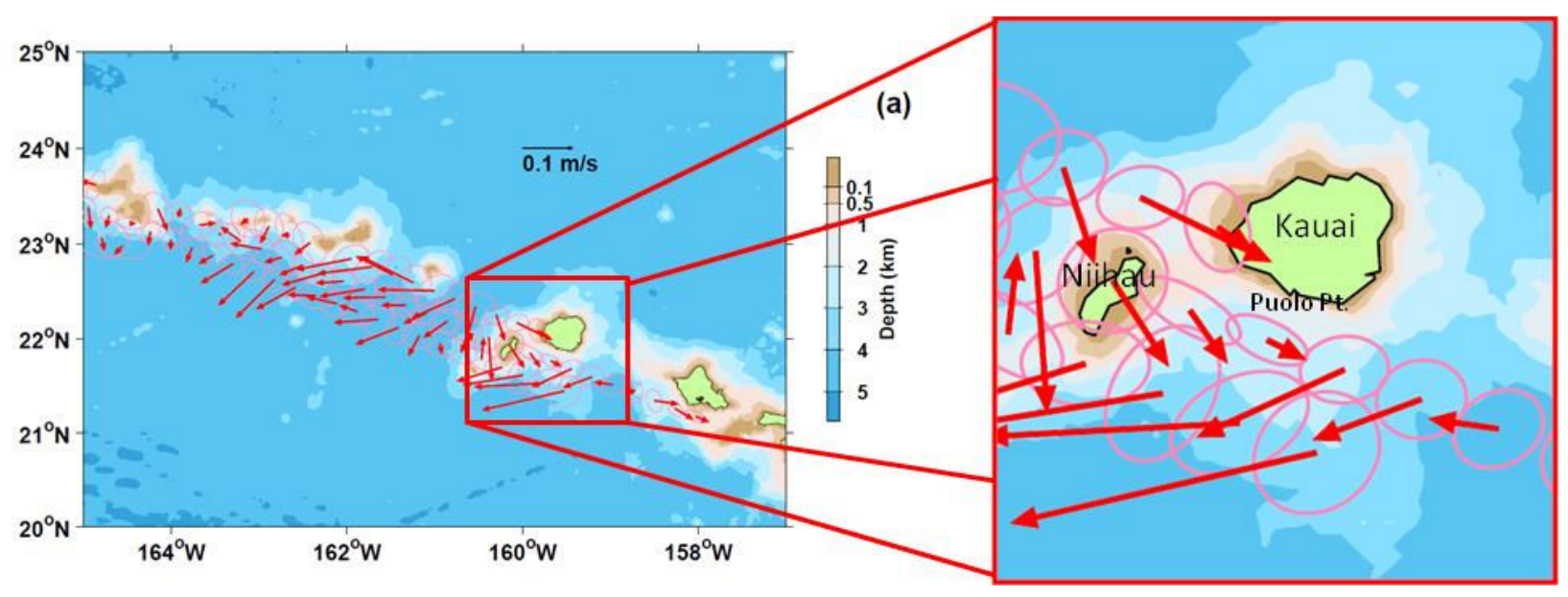

Figure 3-3. Longterm mean ocean currents near Port Allen (Image from Firing and Brainard 2006).

\subsection{Seabed Substrate, Contour, and Bathymetry}

The area offshore of Port Allen is classified as a bank/shelf by the National Ocean Service (NOS) Biogeography Branch. It is characterized by a flattened platform between the shoreline and the deeper ocean waters. In this area, the seabed is comprised of pavement, pavement with sand channels, and sand (Figure 3-5). Pavement is described by the NOS Biogeography Branch as "Flat, low relief, solid carbonate rock that is often covered by a thin sand veneer. The pavement's surface often has sparse coverage of macroalgae, hard coral, zoanthids, and other sessile invertebrates that does not obscure the underlying surface". The biological cover is classified as patchy turf algae (50-90\% cover) (Figure 3-6). Patchy turf algae is described by the NOS Biogeography Branch as "Discontinuous macroalgae with breaks in coverage that are too diffuse or irregular, or result in isolated patches of macroalgae that are too small (smaller than the MMU) to be mapped as continuous macroalgae."

The seabed in the area offshore of Port Allen is characterized by a gentle slope as it approaches the escarpment where depth increases rapidly with distance from shore (Figure 3-7). Note that the sampling area was limited to the bank/shelf and did not extend to the escarpment or beyond. Figure 3-8 depicts the seabed profile for a nearby beach approximately 1.5 miles $(2.4 \mathrm{~km})$ from the sampling area. 


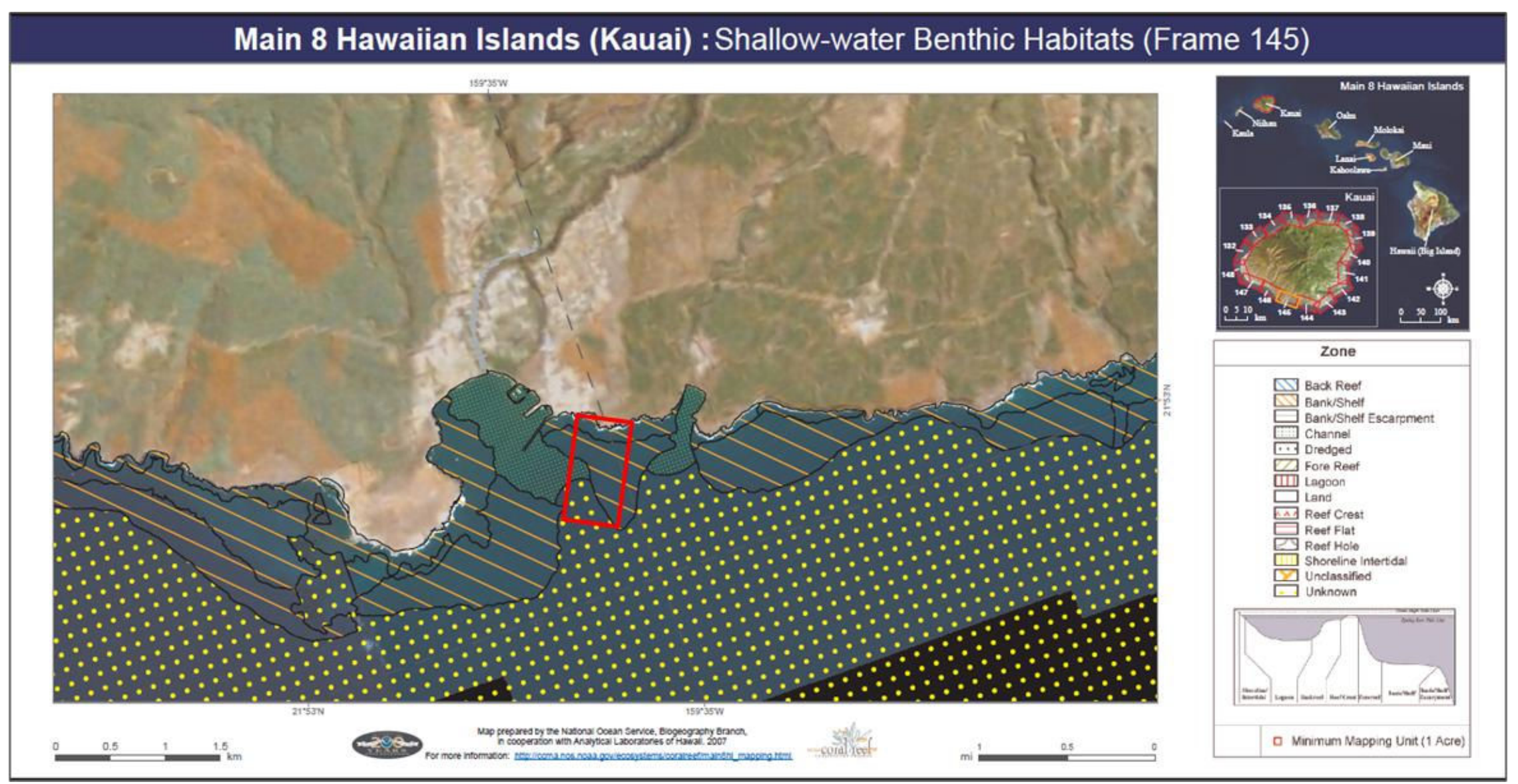

Figure 3-4. Seabed zones in the sampling area offshore of Port Allen. Red box demarcates approximate sampling area (Image from Shallow-Water Benthic Habitats of the Main Hawaiian Islands - 2007, available at: http://ccma.nos.noaa.gov/products/biogeography/hawaii_cd_07/maps/maps_kauai.aspx). 


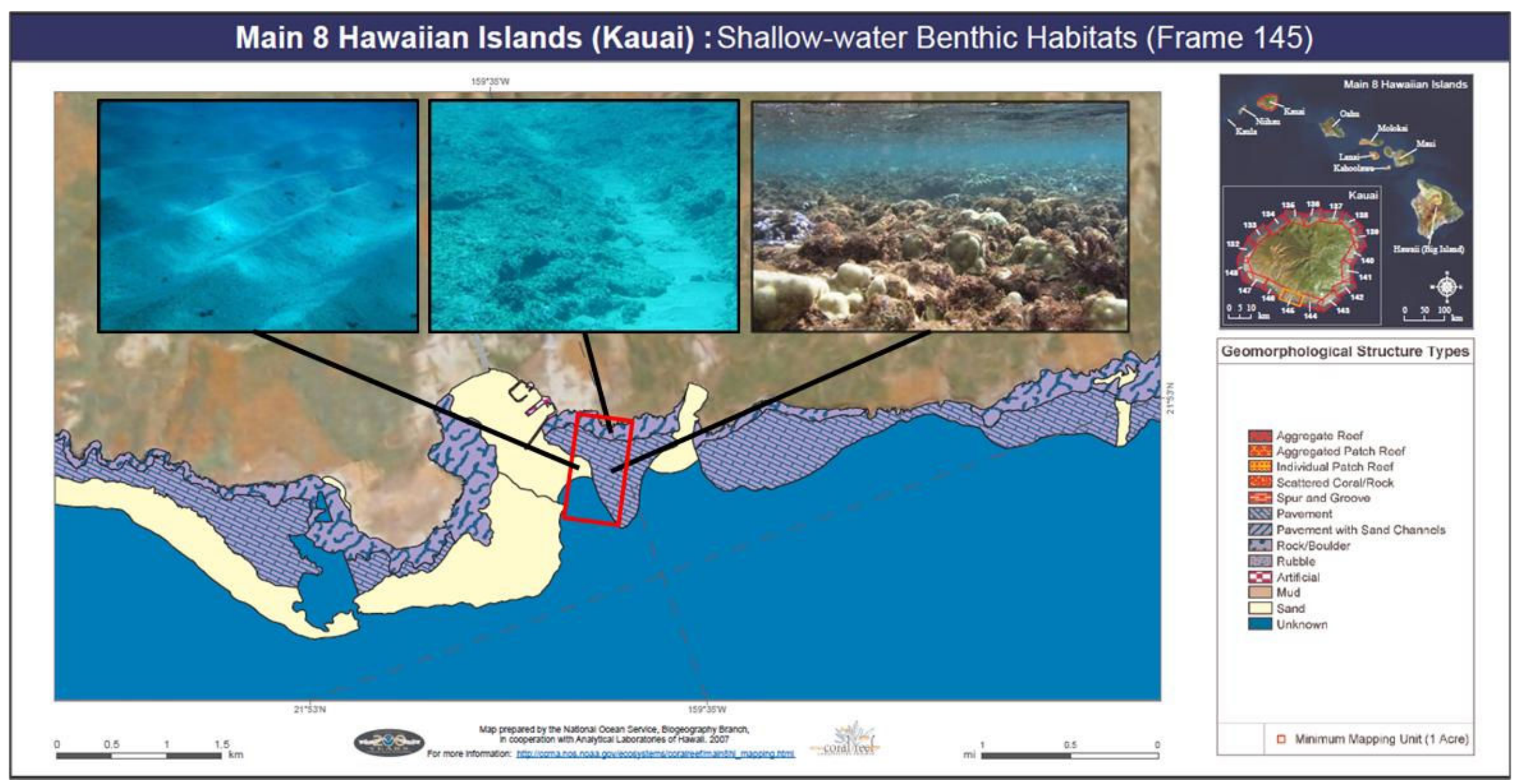

Figure 3-5. Geomorphological structure in the sampling area offshore of Port Allen. Red box demarcates approximate sampling area (Image from Shallow-Water Benthic Habitats of the Main Hawaiian Islands - 2007, available at: http://ccma.nos.noaa.gov/products/biogeography/hawaii_cd_07/maps/maps_kauai.aspx). 


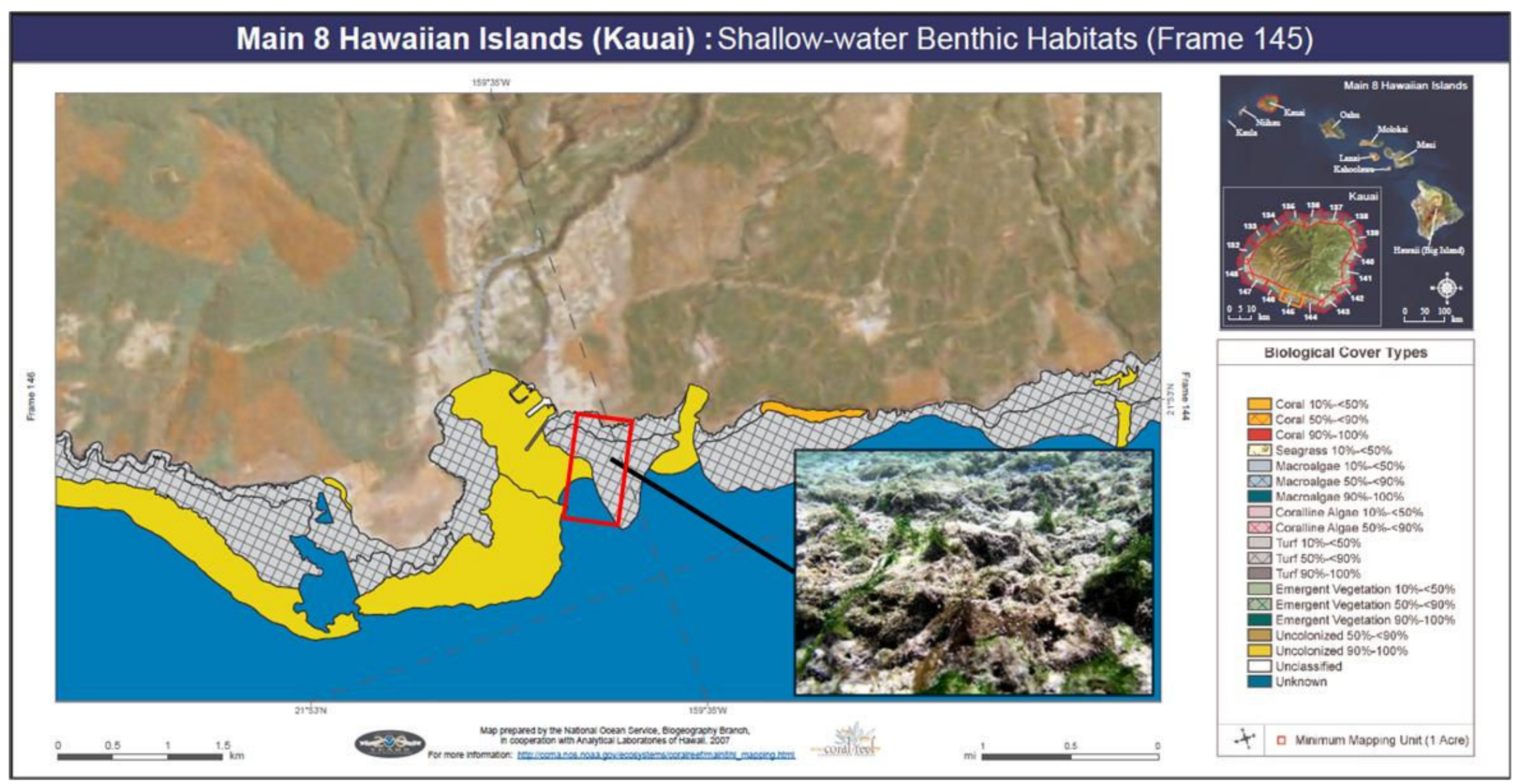

Figure 3-6. Biological cover in the sampling area offshore of Port Allen. Red box demarcates approximate sampling area (Image from Shallow-Water Benthic Habitats of the Main Hawaiian Islands - 2007, available at: http://ccma.nos.noaa.gov/products/biogeography/hawaii_cd_07/maps/maps_kauai.aspx). 


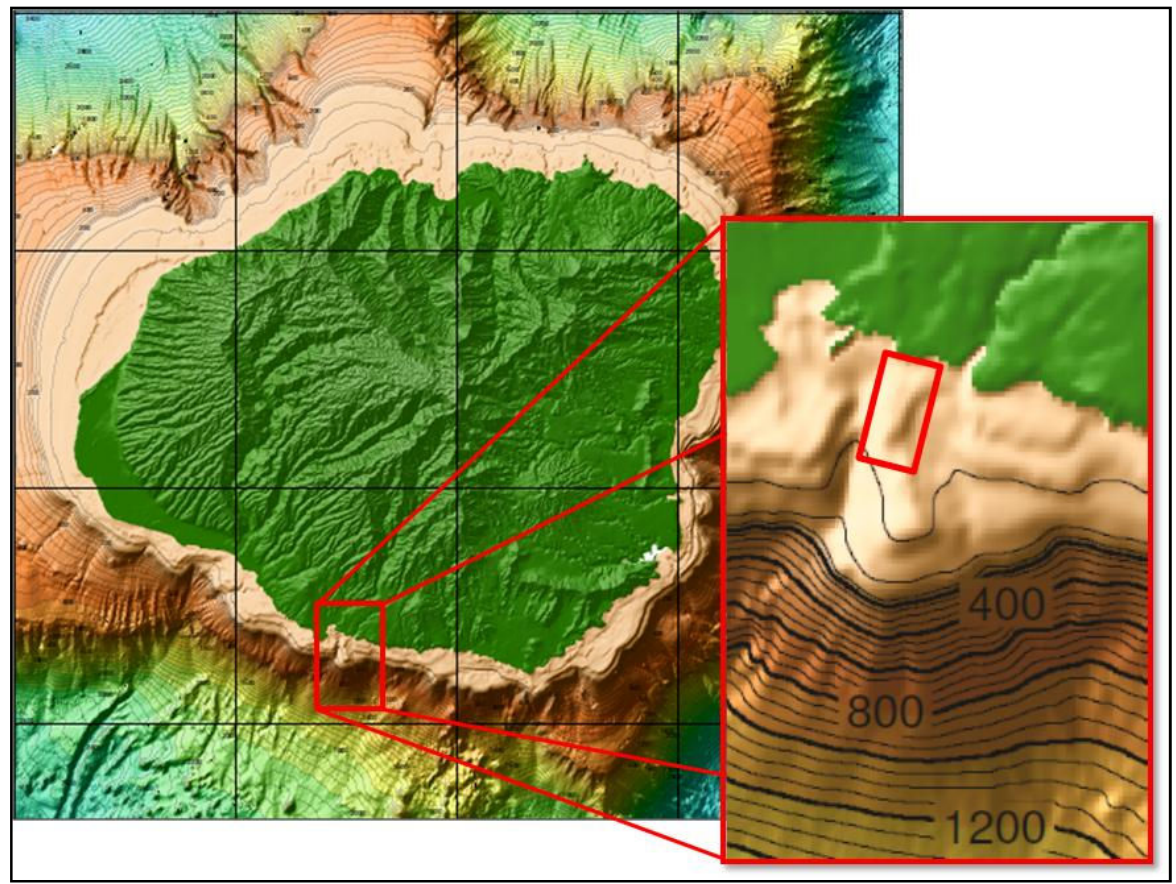

Figure 3-7. Bathymetry and depth contours (in meters) for area offshore of Port Allen, Kauai. Red box in inset demarcates approximate sampling area (Image from Chart 200002 of Multibeam Bathymetry Data Synthesis [SOEST 2011]).

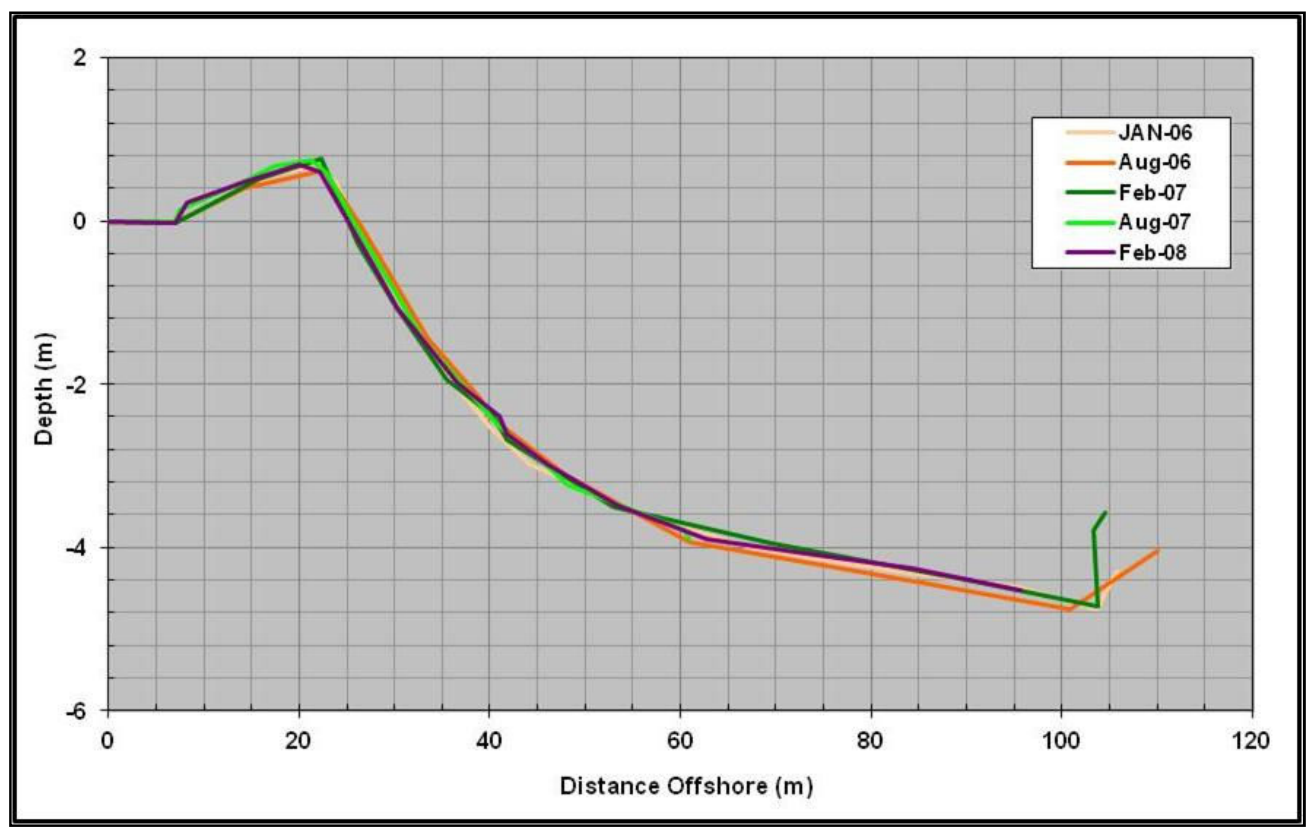

Figure 3-8. Beach profile for Salt Pond Beach Park located approximately 1.5 miles (2.4 km) from the Port Allen sampling area (http://www.soest.hawaii.edu/coasts/data/kauai/beachprofile.html). 


\subsection{Water Temperature and Tides}

The NOAA tide and current station in Hanapepe Bay in Port Allen (No. 1611347) was discontinued in 1997. The next closest NOAA station (No. 1611400) is in Nawiliwili Harbor on the east side of Kauai near Lihue. Figure 3-9 presents weekly average water temperatures during the weeks in which surveys were conducted. Water temperature varied relatively little over the duration of the study $\left(25.9\right.$ to $27.6^{\circ} \mathrm{C}\left[78.6\right.$ to $\left.\left.81.6^{\circ} \mathrm{F}\right]\right)$. Figure 3-10 presents weekly average tidal heights during the weeks in which surveys were conducted. Tidal ranges were relatively small over the duration of the study $(-0.03$ to 0.67 $\mathrm{m}$ [-0.1 to $2.2 \mathrm{ft}])$. The mean range is reported to be $1.2 \mathrm{ft}(0.37 \mathrm{~m})$.

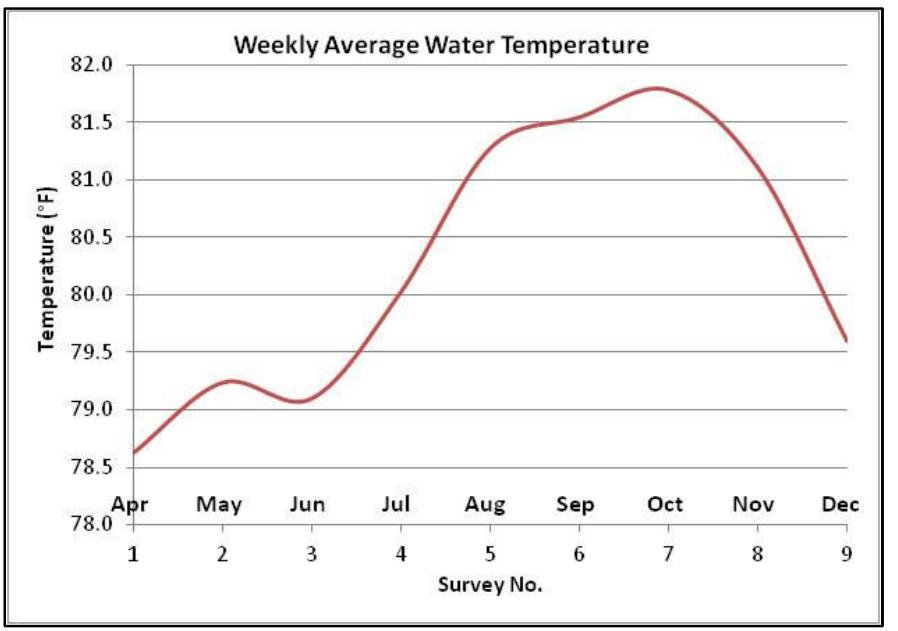

Figure 3-9. Weekly average water temperature during the weeks in which surveys were conducted.

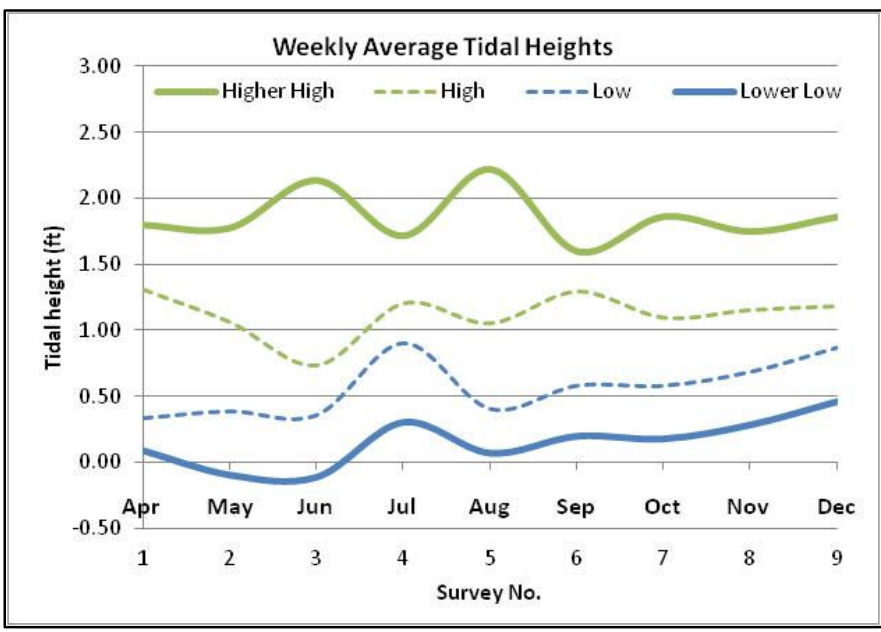

Figure 3-10. Weekly average tidal heights during the weeks in which surveys were conducted. 


\subsection{Existing Ichthyoplankton Data}

There is relatively little known about the species of ichthyoplankton occurring in the nearshore environment of the Hawaiian Islands and essentially nothing known about the nearshore ichthyoplankton near Port Allen, Kauai. The following section provides a description of the existing information on ichthyoplankton available for the Hawaiian Islands. Some of the data presented below are more applicable to the Port Allen site than others due to the similarity of the sampling locations and study design; however, some of the data (e.g., data collected far offshore in deeper waters) are likely to be less representative of the species and abundances expected at the Port Allen site.

\subsubsection{Hawaiian Electric Company's Impingement and Entrainment Monitoring}

Annual impingement and entrainment monitoring studies were conducted at the cooling water intake structures (CWISs) at the Hawaiian Electric Company's Honolulu Generating Station (HGS) (Figure 3-11) and Kahe Generating Stations (KGS) (Figure 3-12) from April 2006 to April 2011 (HECO 2011a, b). A 2.0-ft (61-cm) diameter, 335- $\mu \mathrm{m}$ mesh plankton net was deployed at both sites. At HGS, the net was pulled back and forth between two locations directly upstream of the intake structure at depths from 6.6 to $10 \mathrm{ft}$ ( 2 to $3 \mathrm{~m}$ ). At KGS, the net was suspended in the water flow in the Units 1-4 and Units 5-6 forebays. The targeted sample volumes were $100 \mathrm{~m}^{3}$ and $50 \mathrm{~m}^{3}$ at HGS and KGS, respectively. Samples were collected once every six hours over 24-hr periods, totaling four samples per 24-hr period. After collection, samples were rinsed gently into the nets' cod ends and preserved in a $5-10 \%$ formalin-seawater solution. Samples were sorted to the lowest possible taxon, enumerated, and measured in the laboratory. The most abundantly collected taxa for HGS and KGS are presented in Table 3-1 and Table 3-2, respectively. 


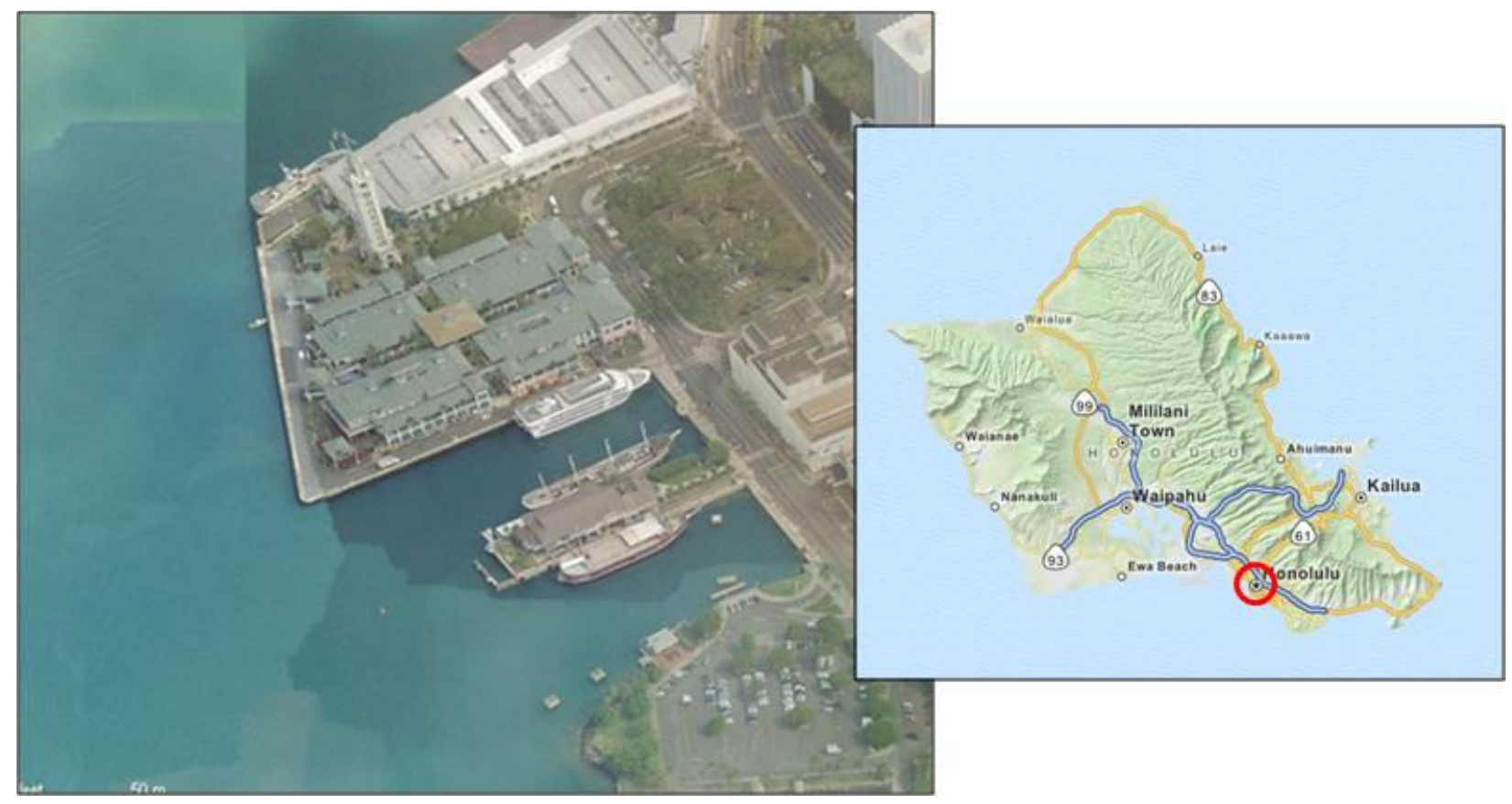

Figure 3-11. Aerial image of Hawaiian Electric Company's Honolulu Generating Station intake structure (Images from Bing Maps and MapQuest).

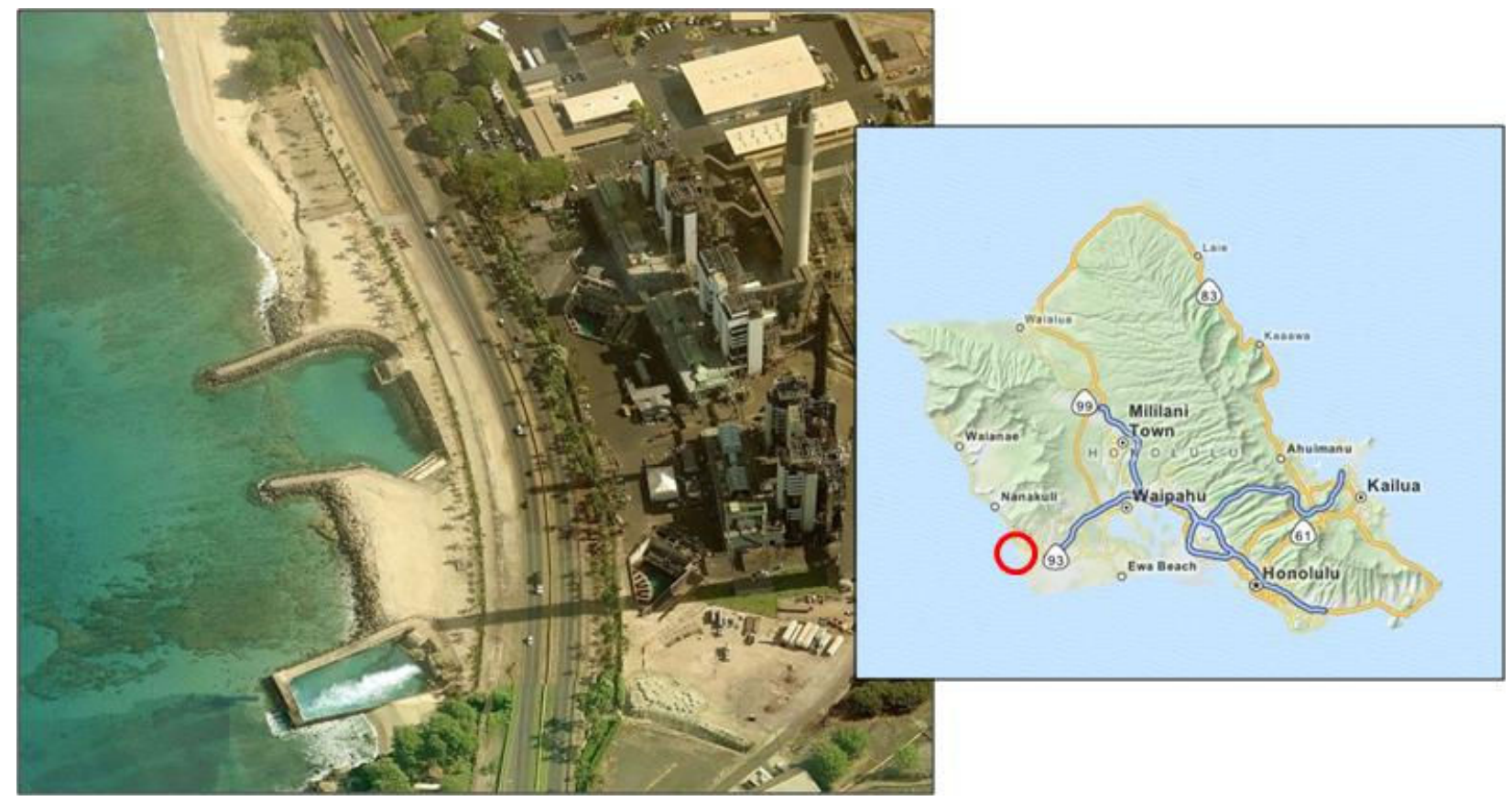

Figure 3-12. Aerial image of Hawaiian Electric Company's Kahe Generating Station intake structure (Images from Bing Maps and MapQuest). 
Table 3-1. Most abundant taxa of fish larvae collected at HGS. The average concentrations are calculated from the annual averages calculated for the period from April 2006-April 2012. Only taxa comprising up to 95\% of total abundance are shown.

\begin{tabular}{llcrc}
\hline Taxa & Common Name & $\begin{array}{c}\text { Estimated } \\
\text { Concentration } \\
\text { (\# per 1,000 } \mathbf{~ m}^{\mathbf{3}} \text { ) }\end{array}$ & $\begin{array}{r}\text { Percent } \\
\text { of Total }\end{array}$ & $\begin{array}{c}\text { Cumulative } \\
\text { Percent }\end{array}$ \\
\hline Pomacentridae & damselfishes & 427.36 & 36.4 & 36.4 \\
Encrasicholina spp. & anchovies & 196.11 & 16.7 & 53.1 \\
Gobiidae & gobies & 114.76 & 9.8 & 62.8 \\
Apogonidae/Gobioidei & cardinalfishes/gobies & 83.28 & 7.1 & 69.9 \\
Schindleria spp. & infantfishes & 60.70 & 5.2 & 75.1 \\
Gobioidei & gobies & 48.81 & 4.2 & 79.2 \\
larval/post-larval fish & larval fishes & 43.09 & 3.7 & 82.9 \\
Carangidae & jacks & 29.25 & 2.5 & 85.4 \\
Foa brachygramma & bay cardinalfish & 20.72 & 1.8 & 87.2 \\
Myctophidae & lanternfishes & 21.39 & 1.8 & 89.0 \\
Apogonidae & cardinalfishes & 17.90 & 1.5 & 90.5 \\
Perciformes & Perciformes fishes & 14.83 & 1.3 & 91.8 \\
Blenniidae & blennies & 14.76 & 1.3 & 93.0 \\
Salariinae & blennies & 15.02 & 1.3 & 94.3 \\
Gnathanodon speciosus & golden trevally & 10.95 & 0.9 & 95.2 \\
all others & & 55.94 & 4.8 & 100.0 \\
\hline Total & & $\mathbf{1 , 1 7 4 . 8 6}$ & $\mathbf{1 0 0 . 0}$
\end{tabular}

Table 3-2. Most abundant taxa of fish larvae collected at KGS. The average concentrations are calculated from the annual averages calculated for the period from April 2006-April 2012. Only taxa comprising up to $95 \%$ of total abundance are shown.

\begin{tabular}{llcrc}
\hline Taxa & Common Name & $\begin{array}{c}\text { Estimated } \\
\text { Concentration } \\
\text { (\# per 1,000 } \mathbf{~ m}^{\mathbf{3}} \text { ) }\end{array}$ & $\begin{array}{r}\text { Percent } \\
\text { of Total }\end{array}$ & $\begin{array}{c}\text { Cumulative } \\
\text { Percent }\end{array}$ \\
\hline Pomacentridae & damselfishes & 254.10 & 42.6 & 42.6 \\
Gobiidae & gobies & 60.26 & 10.1 & 52.7 \\
Schindleria spp. & infantfishes & 41.59 & 7.0 & 59.7 \\
Enneapterygius atriceps & Hawaiian triplefin & 41.39 & 6.9 & 66.6 \\
Salariinae & blennies & 36.31 & 6.1 & 72.7 \\
larval/post-larval fish & larval fishes & 27.83 & 4.7 & 77.4 \\
Apogonidae & cardinalfishes & 30.94 & 5.2 & 82.6 \\
Apogonidae/Gobioidei & cardinalfishes/gobies & 28.57 & 4.8 & 87.4 \\
Myctophidae & lanternfishes & 18.53 & 3.1 & 90.5 \\
Pristiapogon spp. & cardinalfishes & 13.10 & 2.2 & 92.7 \\
Perciformes & Perciformes fishes & 8.63 & 1.4 & 94.1 \\
Cyclothone spp. & bristlemouths & 9.27 & 1.6 & 95.7 \\
all others & & 25.7 & 4.3 & 100.0 \\
\hline Total & & $\mathbf{5 9 6 . 2 2}$ & $\mathbf{1 0 0 . 0}$
\end{tabular}

The intake at KGS and, to a lesser degree, the intake at HGS are similar to a shoreline intake that could be built at Port Allen. Therefore, the species present in the HECO entrainment monitoring samples are likely to be similar to those that would be present in the nearshore 
water of Port Allen, Kauai.

\subsubsection{Ichthyoplankton of Kaneohe Bay, Hawaii (Watson and Leis 1974)}

This year-long study was designed to assess the fish egg resources of Kaneohe Bay to inform aquaculture efforts at the Hawaii Institute of Marine Biology. In particular, the program was initiated to: 1) determine the species composition of ichthyoplankton in the bay; 2) determine the diel changes in their abundance; 3) determine seasonal patterns in ichthyoplankton distribution; and 4) determine if there is a relationship between seasonal distributions of egg abundance and environmental factors. Additional goals related to spawning patterns and potential for different species to be used for aquaculture are not summarized herein.

Bi-weekly surface plankton tows were collected over a 13-month period. Samples were collected in the morning, afternoon, and night at two locations: Sampan Channel and the middle part of south Kaneohe Bay (Figure 3-13). The Sampan Channel location was selected because it was thought to be a major source of ichthyoplankton into Kaneohe Bay and representative of the clean-water environments of the bay. The other location (shown farther south in Figure 3-13) was selected as representative of the pollution-stressed, less actively-circulating portion of the bay. Together, these two sampling locations were thought to contain the common egg and larval species of the bay. The locations from which samples were collected are representative of the type of locations where warm water is likely to be withdrawn by an OTEC facility in Port Allen.

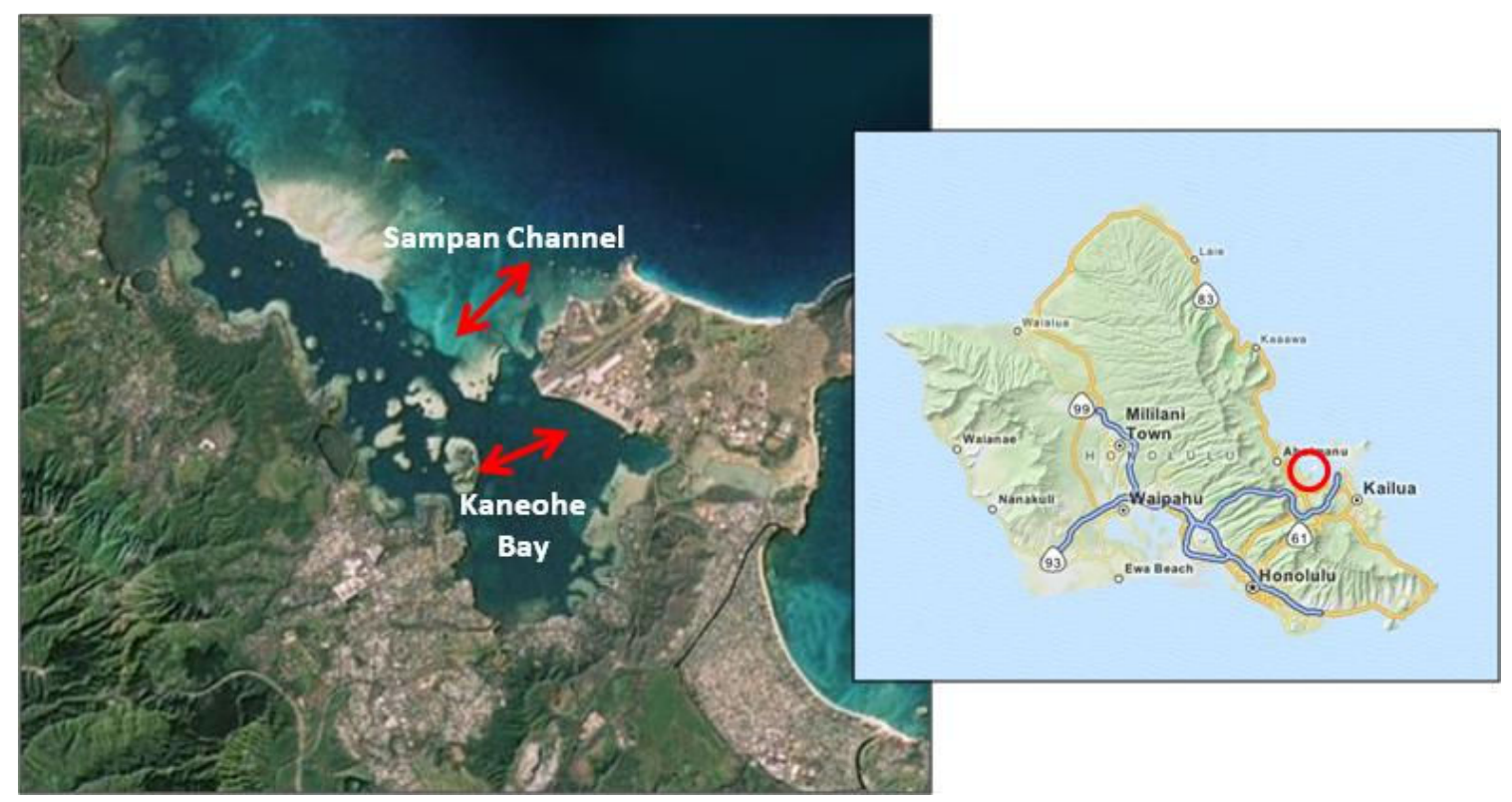

Figure 3-13. Sampling locations (red arrows) in Kaneohe Bay during the study conducted by Watson and Leis (1974) (Images from Bing Maps and MapQuest). 
No attempts were made to look at vertical stratification of ichthyoplankton. The Sampan Channel location was shallow $(\sim 4 \mathrm{~m})$ and well mixed vertically, so sampling at multiple depths was unnecessary. At the second sampling location, previous studies had shown only weak stratification (Bathen 1968; as cited in Watson and Leis 1974) and deeper samples yielded no additional species (Miller 1972; as cited in Watson and Leis 1974). Other research indicated slightly greater density of Hawaiian anchovy (nehu) eggs at the surface but no difference in densities of nehu larvae (Tester 1951; as cited in Watson and Leis 1974).

Each sampling series consisted of several net tows. At each sampling station, two replicate tows were made in opposite directions at morning, afternoon, and night. A total of 29 series were made between 25 March 1971 and 20 April 1972, roughly every two weeks. Samples were taken as close as possible to mid-tide. Tows were made with a $1-\mathrm{m}(100-\mathrm{cm})$ plankton net equipped with $505-\mu \mathrm{m}$ mesh. The top of the net was set 2 in $(5 \mathrm{~cm})$ above the surface.

In South Kaneohe Bay, 20 species of eggs were collected. The most abundant eggs collected, in order of decreasing abundance, were members of the family Carangidae (Atule mate and Gnathanodon speciosus), Engraulidae (Stolephorus (Encrasicholina) purpureus), and Dussumieriidae (Etrumeus micropus). These four fish species accounted for $78.2 \%$ of the eggs collected in the bay. The most abundant larvae collected were Engraulidae (Encrasicholina purpureus), Gobiidae, Apogonidae (Foa brachygrammus and others), Pomacentridae (Abudefdufspp. and Pomacentrus jenkensi), and Carangidae (Atule mate). These five taxa accounted for $78.6 \%$ of the total larvae collected.

In Sampan Channel, 39 egg species were collected (20 exclusively at only this station and not at the other sampling location). The "Omaka Complex" (comprised of omaka, Thalassoma spp., Labridae, and Acanthuridea) accounted for 79.9\% of the eggs collected. Other common eggs included Gnathanodon speciosus, Tetraodontiformes, Synodotidae, Crystallodytes cookei, and Encrasicholina purpureus. The most abundant larvae collected were Gobiidae, Schindleridae (Schindleria pietschmanni), Apogonidae (Foa brachygrammus and others), Eleotridae (Asterropteryx semipunctata), and Engraulidae (Encrasicholina purpureus).

Most fish species spawned year-round, although some species showed some seasonal variation, with reef species demonstrating spawning peaks during March to May and September to October. Atule mate and Gnathanodon speciosus had peaks in spring, summer, and fall. Larval species encountered in large numbers were pelagic bay species which spawn pelagic eggs or reef species that spawn demersal eggs. In some cases there were statistically significant relationships between egg abundance, surface water temperature, and day length. For species that spawn offshore, there was some correlation 
between egg abundance and rising tides.

\subsubsection{Nearshore Distributional Gradients of Larval Fish (15 Taxa) and Planktonic Crustaceans (6 Taxa) in Hawaii (Leis 1982)}

Zooplankton was sampled off the west coast of Oahu, Hawaii in May and July 1975. Samples were collected at four locations located $0.1,0.3,0.6$, and 1.9 miles $(0.2,0.5,1.0$, and $3.0 \mathrm{~km}$ ) offshore (Figure 3-14). Inshore, the bottom was primarily coral (live and dead) and sand. Offshore, the bottom was primarily sand. Depths greater than 1,640 ft (500 m) occurred within 3.1 miles ( $5 \mathrm{~km}$ ) of shore. Samples were collected using obliquely towed nets behind a vessel traveling at about $3.3 \mathrm{ft} / \mathrm{sec}(1 \mathrm{~m} / \mathrm{sec})$. Nets were $2.3 \mathrm{of} 3.3 \mathrm{ft}$ (70 or $100 \mathrm{~cm})$ in diameter with $505-\mu \mathrm{m}$ mesh. Nets towed in water greater than $33 \mathrm{ft}(10 \mathrm{~m})$ were fished at the bottom of the isothermal layer. In shallower water, nets were towed as close to the sea bottom as possible.

In the laboratory, fish larvae were sorted under magnification and identified to the lowest taxon possible. The most abundant taxa, in order of decreasing abundance, are presented in Table 3-3. These taxa accounted for $88 \%$ of the fish larvae collected.

The inshore sampling locations correlate well with the stations sampled in Port Allen as part of this study. Therefore, the species present in the Leis (1982) sampling are likely to be similar to those that would be present in the nearshore water of Port Allen, Kauai.

Table 3-3. Most abundant taxa of fish larvae collected. These taxa accounted for $88 \%$ of all larvae collected.

\begin{tabular}{l}
\hline Taxon \\
\hline Tripterygion atriceps \\
Schindleria pietschmanni \\
Unidentified No. 166 \\
Cyclothone spp. \\
Exallias brevis \\
Ceratoscopelus warming \\
Unidentified No. 8 \\
Thunnus albacores \\
Eviota epiphanies \\
Bolinichthys sp.(p?) \\
Abudefduf abdominalis \\
Diaphus spp. \\
Lampadena (urophuos?) \\
Auxis sp. (p?) \\
Schindleria praematurus \\
\hline
\end{tabular}




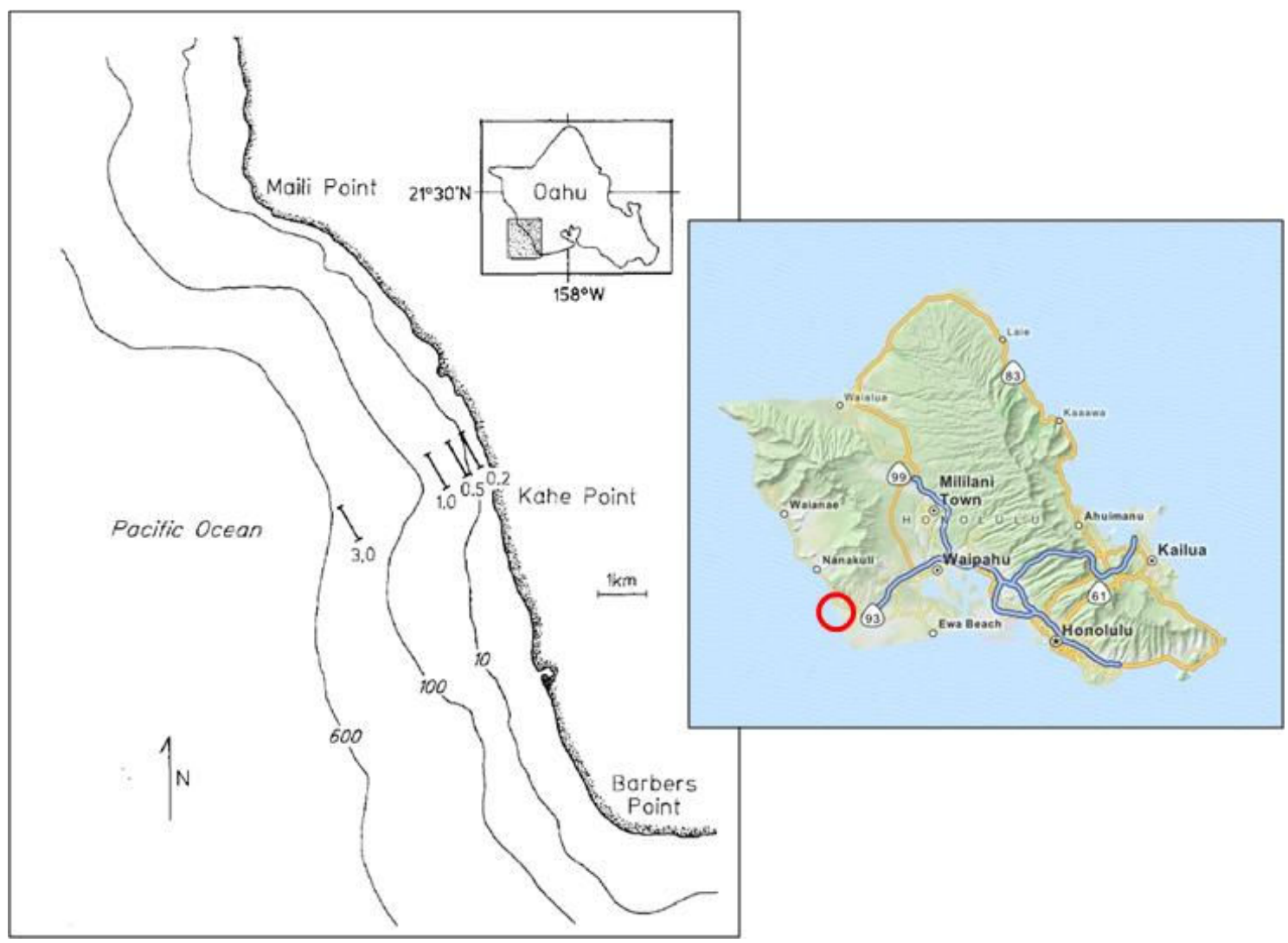

Figure 3-14. Sampling locations off of Kahe Point during the study conducted by Leis (1982). Plankton sampling stations were $0.1,0.3,0.6$, and 1.9 miles $(0.2,0.5,1.0$, and 3.0 km) from shore (Images from Leis (1982) and MapQuest).

\subsubsection{Ichthyoplankton Vertical Distributions Near Oahu, Hawaii, 1985-1986: Data Report (Boehlert and Mundy 1996)}

Boehlert and Mundy (1996) conducted ichthyoplankton sampling in 1985-1986, in part, to respond to concerns about whether the intake or return from a proposed OTEC plant at Kahe Point on Oahu would overlap with areas of high ichthyoplankton abundance.

Four seasonal cruises were taken in the waters off of Oahu, HI in 1985-1986: September 1985, December 1985, April 1986, and June 1986. One transect located on the leeward side had three sampling locations at $1.2,5.8$, and 17.3 miles $(1.8,9.3$, and $27.8 \mathrm{~km})$ offshore. A second transect located on the windward side had three sampling locations at 2.3, 5.8, and $17.3(3.7,9.3$, and $27.8 \mathrm{~km}$ ) offshore (Figure 3-15). Both nearshore locations were chosen to have bottom depths of approximately $328 \mathrm{ft}(100 \mathrm{~m})$. Discrete-depth samples were taken in eight depth strata between 0 and $263 \mathrm{ft}(0$ and $80 \mathrm{~m})$ at the two nearshore stations and nine depth strata between 0 and $656 \mathrm{ft}(0$ and $200 \mathrm{~m})$ at the four offshore stations. Samples were collected both day and night. Subsurface samples were taken with a 10.8-ft2 
(1-m2) multiple opening-closing net and at the sea surface with a 5.3-ft2 (0.49-m2) Manta net which ability to take samples to a depth of $2.3 \mathrm{ft}(0.7 \mathrm{~m})$.

Over 155,000 larvae were collected during the study representing 375 taxa. The dominant taxa were Gobiidae (46.8\%), Myctophidae (21.3\%), Gonostomatidae (8.0\%), Phosichthyidae (5.0\%), Schindleriidae (4.0\%), Carangidae (1.8\%), Scombridae (1.4\%), Paralepididae (0.8\%), Blenniidae (0.7\%), and Synodontidae (0.6\%). An additional 8.35\% were unidentified.

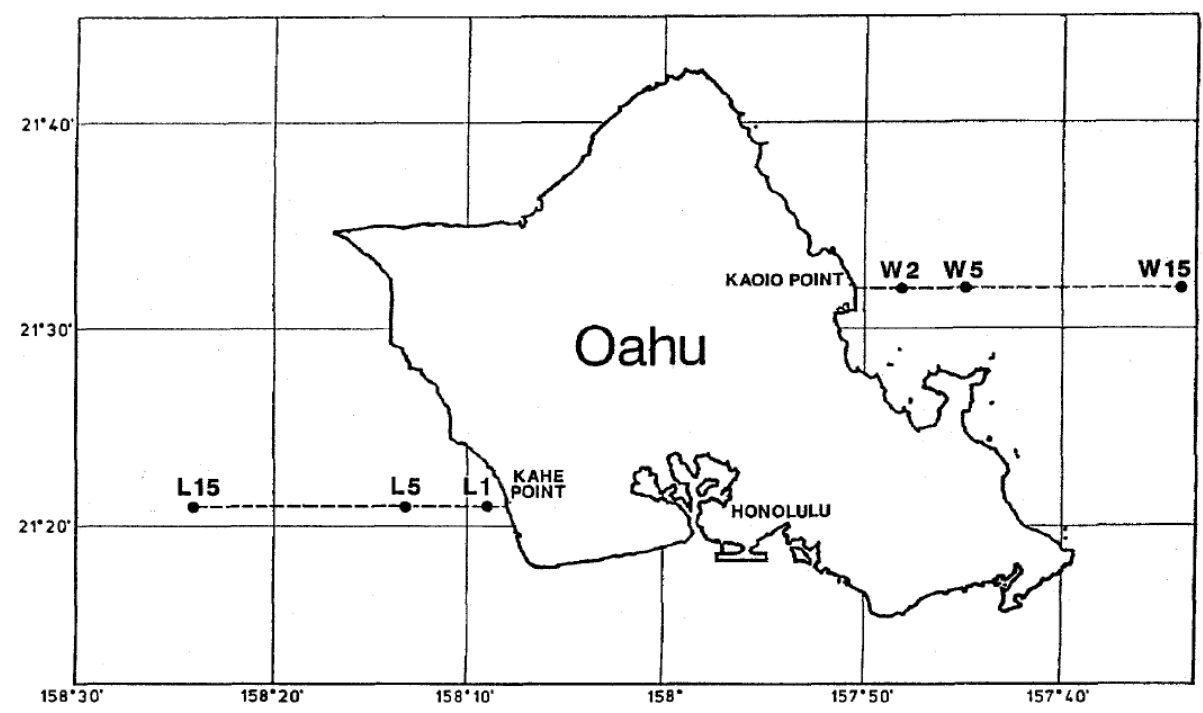

Figure 3-15. Map of the sampling locations used by Boehlert and Mundy (1996). Sampling locations are designated for leeward $(\mathrm{L})$ and windward $(\mathrm{W})$ side and number by nautical miles offshore.

\subsubsection{An Atlas of Common Nearshore Marine Fish Larvae of the Hawaiian Islands (Miller et al. 1979)}

Ichthyoplankton collections used to develop this atlas were collected primarily by the Hawaii Institute of Marine Biology between 1970 and 1974. These data were collected primarily to determine the importance of different nearshore habitats as nursery grounds for marine fishes and the impact of shoreline development on larval fish. Miller et al. (1979) used these data to develop descriptions of roughly $75 \%$ of the larval fish encountered during sampling and the resulting atlas can be used to identify larval fishes.

Samples were taken using a 3.3-ft (1-m) diameter net equipped with 500- $\mu \mathrm{m}$ mesh. Nets were towed at about $3.3 \mathrm{ft} / \mathrm{sec}(1 \mathrm{~m} / \mathrm{sec})$ with the top rim of the net protruding 2 in $(5 \mathrm{~cm})$ above the surface. Tows averaged 10 minutes and filtered an average of $21,189 \mathrm{ft}^{3}\left(600 \mathrm{~m}^{3}\right)$ of water. The majority of larvae collected were 0.1 to 0.3 in (3 to $8 \mathrm{~mm}$ ) SL. 
Surveys were conducted in nearshore environments throughout the Hawaiian Islands. Surveys of Kauai, Oahu, and Maui were conducted during daylight hours so it was not possible to determine any diel variation in abundances. In addition, samples were collected only in winter and summer, so information on seasonal variations is incomplete. Two locations were sampled within Hanapepe Harbor (Figure 3-16): inshore 23 to $36 \mathrm{ft}$ (7 to $11 \mathrm{~m}$ ) deep and offshore 95 to $183 \mathrm{ft}$ ( 29 to $56 \mathrm{~m}$ ) deep. Concentrations of organisms by taxon and season are presented in Table 3-4.

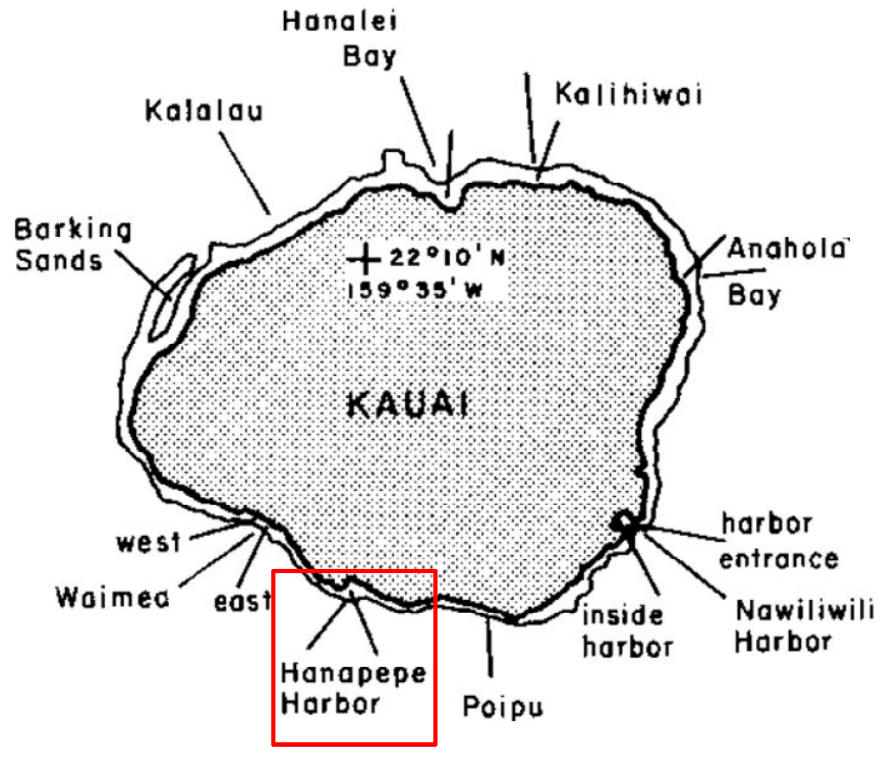

Figure 3-16. Inshore sampling locations on Kauai. Red box shows locations in Hanapepe Harbor at Port Allen where the current study was conducted (Image from Miller et al. 1979). 
Table 3-4. Density of larvae collected offshore and inshore at Hanapepe Harbor during winter and summer (Miller et al. 1979).

\begin{tabular}{|c|c|c|c|c|}
\hline \multirow[b]{2}{*}{ Taxon } & \multicolumn{2}{|c|}{ Winter } & \multicolumn{2}{|c|}{ Summer } \\
\hline & $\begin{array}{c}\text { Offshore } \\
\text { (larvae/ 1,000 } \\
\mathbf{m}^{3} \text { ) }\end{array}$ & $\begin{array}{c}\text { Inshore } \\
\text { (larvae/ 1,000 } \\
\left.\mathbf{m}^{3}\right)\end{array}$ & $\begin{array}{c}\text { Offshore } \\
\text { (larvae/ 1,000 } \\
\mathbf{m}^{3} \text { ) }\end{array}$ & $\begin{array}{c}\text { Inshore } \\
\text { (larvae/ 1,000 } \\
\left.\mathbf{m}^{3}\right)\end{array}$ \\
\hline Cyclothone spp. & -- & 0.8 & 5.7 & 3.0 \\
\hline Vinciguerria nimbaria & -- & 2.0 & 0.7 & 0.8 \\
\hline Ceratoscopelus warmingii & 3.7 & 2.0 & 13.7 & 4.3 \\
\hline Diaphus spp. & 1.9 & 2.0 & -- & -- \\
\hline Hygophum proximum & -- & -- & -- & -- \\
\hline Lampadena spp. & -- & -- & -- & -- \\
\hline Cypselurus spp. & -- & -- & 0.7 & -- \\
\hline Kyphosus spp. & -- & -- & 0.4 & -- \\
\hline Mullidae & -- & -- & 55.0 & 3.0 \\
\hline Foa brachygramma & -- & -- & -- & 2.3 \\
\hline Seriola spp. & -- & -- & 5.0 & -- \\
\hline Coryphaena hippurus & -- & -- & 0.7 & 0.8 \\
\hline Abudefduf abdominalis & -- & -- & 0.8 & 0.8 \\
\hline Eupomacentrus fasciolatus & -- & -- & -- & -- \\
\hline Gempylidae & 1.9 & -- & 0.7 & -- \\
\hline Auxis spp. & -- & -- & 2.8 & -- \\
\hline Thunnus albacares & -- & -- & -- & -- \\
\hline Gobiidae & 2.9 & 0.8 & -- & 4.4 \\
\hline Psilogobius mainlandi & 1.9 & 0.8 & -- & -- \\
\hline Tripterygion atriceps & -- & 1.8 & 0.7 & 1.6 \\
\hline Enchelyurus brunneolus & 1.0 & -- & -- & -- \\
\hline Exallias brevis & -- & -- & 4.2 & 5.1 \\
\hline Schindleriidae & -- & -- & -- & 19.4 \\
\hline Tetraodontidae & -- & -- & 1.5 & 0.7 \\
\hline Ranzania laevis & 0.9 & -- & -- & -- \\
\hline Melanocetus johnsoni & 1.0 & -- & 0.7 & 0.7 \\
\hline Total fish & 32.0 & 15.0 & 133.0 & 63.0 \\
\hline No. of Species & 14.0 & 12.0 & 43.0 & 30.0 \\
\hline
\end{tabular}




\subsubsection{Larvae of Nearshore Fishes in Oceanic Waters near Oahu, Hawaii (Clarke 1991)}

Ichthyoplankton tows were taken parallel to the shore about 8.1 miles $(13 \mathrm{~km})$ off the west coast of Oahu, Hawaii (Figure 3-17). Water depths in this area are 1.2 miles (2 km) or greater.

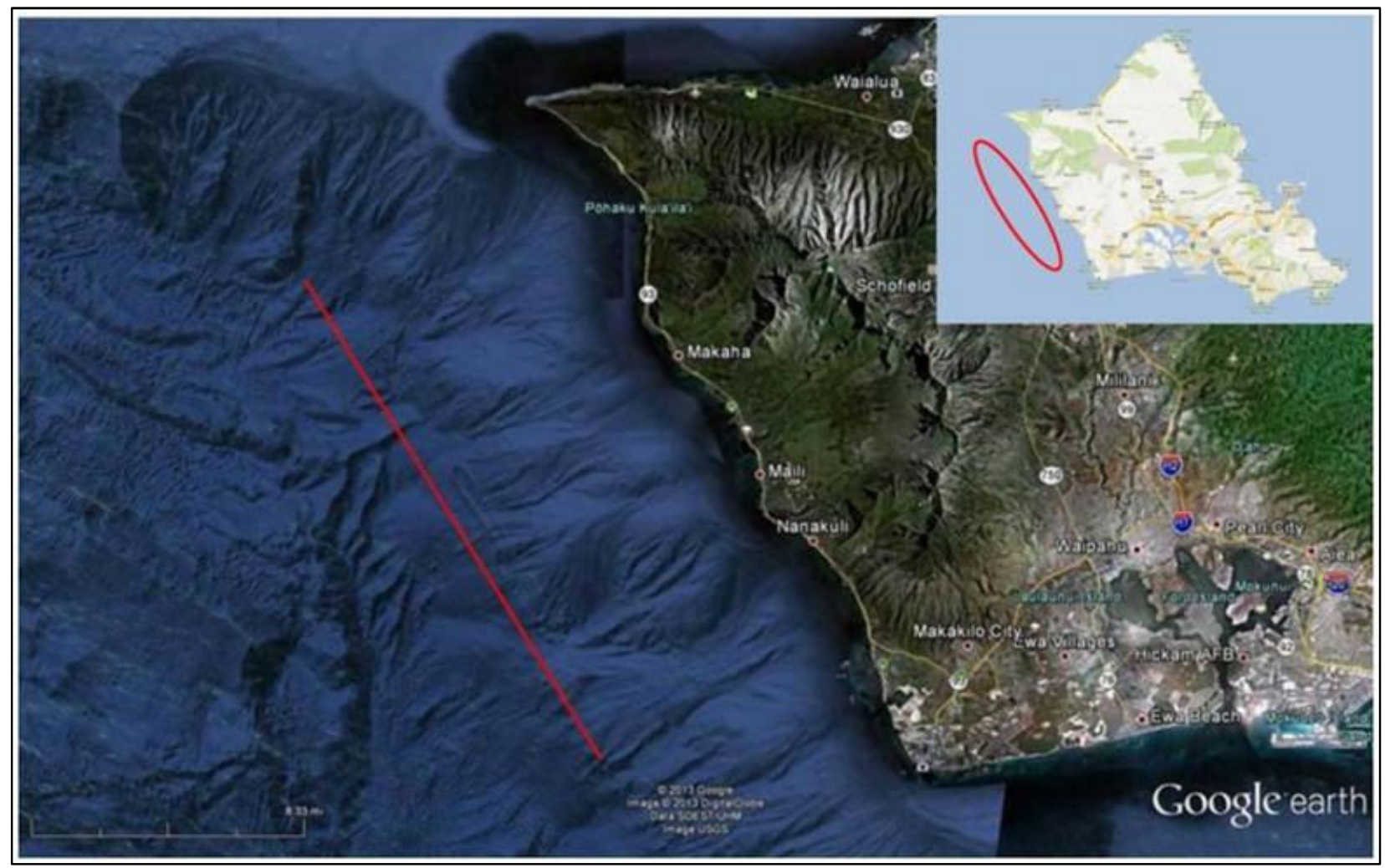

Figure 3-17. Location of ichthyoplankton tows approximately 8.1 miles $(13 \mathrm{~km})$ offshore of Oahu (red line) during the study conducted by Clarke (1991). Images from Google Earth and MapQuest.

Samples were collected between August 1977 and October 1978. Most samples were collected within 1-2 days of the new moon in each lunar month. Samples were collected at night using three net types:

- $\quad$ 9.8-ft (3-m) Isaacs-Kidd midwater trawl with a 0.24-in $(6-\mathrm{mm})$ mesh body towed at $6.6 \mathrm{ft} / \mathrm{sec}(2 \mathrm{~m} / \mathrm{sec})$ between the surface and a mean maximum depth of $1,066 \mathrm{ft}(325 \mathrm{~m})$;

- Bongo net frame with 4.1-ft $(1.25-\mathrm{m})$ diameter nets with 0.01-in (2.5-mm) mesh towed at $5.7 \mathrm{ft} / \mathrm{sec}(1.75 \mathrm{~m} / \mathrm{sec})$ between the surface and a mean depth of $997 \mathrm{ft}$ (304 m); and

- Bongo net frame with 2.3-ft $(0.7-\mathrm{m})$ diameter nets with either 0.013- or 0.007in $(0.333-$ or $0.183-\mathrm{mm})$ mesh towed at $3.3 \mathrm{ft} \sec (1 \mathrm{~m} / \mathrm{sec})$ between the surface 
and a mean depth of $735 \mathrm{ft}(224 \mathrm{~m})$.

A total of 5,192 larvae was identified, with an additional 74 tentatively identified to 53 families of fishes. Twenty families dominated the catch. These families accounted for greater than $90 \%$ of the total catch, with Labridae accounting for almost $25 \%$ of the total (Table 3-5).

Table 3-5. Ranks by number of specimens captured, numbers captured, and cumulative percentages of total nearshore fish larvae for the $\mathbf{2 0}$ most abundant families (left columns) and the 20 most abundant lower taxa (right columns) taken in samples from oceanic waters near Oahu, Hawaii, 1977-78 (from Clarke 1991).

\begin{tabular}{|c|c|c|c|c|c|c|c|}
\hline \multicolumn{4}{|c|}{ Families } & \multicolumn{4}{|c|}{ Lower Taxa } \\
\hline & & & Cumulative & & & & Cumulative \\
\hline Rank & & No. & Percent & Rank & & No. & Percent \\
\hline 1 & Labridae & 1,222 & 23.6 & 1 & Parapercis & 521 & 10.0 \\
\hline 2 & Parapercidae & 521 & 33.6 & 2 & Labrid S & 483 & 19.3 \\
\hline 3 & Serranidae & 400 & 41.3 & 3 & Luzonichthys earlei & 260 & 24.4 \\
\hline 4 & Gobiidae & 334 & 47.7 & 4 & Synodus & 169 & 27.6 \\
\hline 5 & Carangidae & 332 & 54.1 & 5 & Labrid 3 & 149 & 30.5 \\
\hline 6 & Acanthuridae & 251 & 58.9 & 6 & Labrid T & 115 & 32.7 \\
\hline 7 & Mullidae & 212 & 63.0 & 7 & Centropyge L3 & 102 & 34.7 \\
\hline 8 & Synodontidae & 203 & 66.9 & 8 & Symphysanodon & 100 & 36.6 \\
\hline 9 & Scorpaenidae & 177 & 70.3 & 9 & Naso & 99 & 38.5 \\
\hline 10 & Pomacanthidae & 157 & 73.3 & 10 & Labrid N & 96 & 40.4 \\
\hline 11 & Callionymidae & 148 & 76.2 & 11 & Eleotris sandvicensis & 90 & 42.1 \\
\hline 12 & Microdesmidae & 113 & 78.4 & 12 & Goby A & 90 & 43.8 \\
\hline 13 & Sysphysanodon & 100 & 80.3 & 13 & Ptereleotis heteroptera & 80 & 45.3 \\
\hline 14 & Eleotridae & 90 & 82.1 & 14 & Labrid G & 80 & 46.9 \\
\hline 15 & Apogonidae & 86 & 83.7 & 15 & Labrid B & 77 & 48.4 \\
\hline 16 & Scaridae & 81 & 85.3 & 16 & Serranid A & 70 & 49.7 \\
\hline 17 & Pomacentridae & 76 & 86.8 & 17 & Callionymid A & 70 & 49.7 \\
\hline 18 & Blennidae & 74 & 88.2 & 18 & Goby B & 55 & 52.2 \\
\hline 19 & Lutjanidae & 73 & 89.6 & 19 & Ctenochaetus & 53 & 53.2 \\
\hline 20 & Schindleriidae & 52 & 90.6 & 20 & Acanthurus & 51 & 54.2 \\
\hline
\end{tabular}

\subsubsection{Larval fishes and zooplankton in a cyclonic eddy in Hawaiian waters (Lobel and Robinson 1998)}

Lobel and Robinson (1998) collected plankton samples from near the surface to a depth of $16.4 \mathrm{ft}(5 \mathrm{~m})$ in an area near, and within, a cool-water eddy and also over the reef and nearshore deep water during night collections off the Kona coast of the island of Hawaii in 1982. The highest concentrations (87 individuals per $1,000 \mathrm{~m}^{3}$ ) were found in samples collected over the reef from March through August 1982. Individuals of 20 different families of fish categorized as being coastal or nearshore fishes were collected during this study in the eddy. 


\subsubsection{Commercial landings record for Kauai}

Commercial landings records were supplied by the Hawaii Division of Aquatic Resources (pers comm.. 01/21/2011) for the island of Kauai for the 2008 calendar year (Table 3-6). These data are useful for determining the island-specific value of each species to the commercial fishing industry.

Table 3-6. Top ten species in Kauai as reported by the commercial fishing industry (data provided by the Hawaii Division of Aquatic Resources, 01/21/2011).

\begin{tabular}{|c|c|c|c|c|c|c|}
\hline \multicolumn{2}{|c|}{$\begin{array}{l}\text { Kauai landings by area } \\
\text { fished }\end{array}$} & \multicolumn{2}{|c|}{ Kauai port landings } & \multicolumn{3}{|c|}{$\begin{array}{c}\text { Top } 10 \text { species reported by fish } \\
\text { dealers }\end{array}$} \\
\hline Species & $\begin{array}{c}\text { Lbs. } \\
\text { caught }\end{array}$ & Species & $\begin{array}{c}\text { Lbs. } \\
\text { caught }\end{array}$ & Species & $\begin{array}{c}\text { Lbs. } \\
\text { bought }\end{array}$ & $\begin{array}{l}\text { Value } \\
\text { (US\$) }\end{array}$ \\
\hline Yellowfin tuna & 225,377 & Yellowfin tuna & 223,349 & Yellowfin tuna & 129,284 & $\$ 418,376$ \\
\hline Akule & 166,786 & Ono & 87,027 & Ono & 61,766 & $\$ 230,118$ \\
\hline Ono & 78,165 & Mahi mahi & 50,267 & Uku & 27,224 & $\$ 104,521$ \\
\hline Mahi mahi & 49,392 & $\mathrm{Aku}$ & 48,803 & Mahi mahi & 27,023 & $\$ 92,116$ \\
\hline Aku & 49,093 & Blue marlin & 41,127 & Akule & 13,181 & $\$ 37,842$ \\
\hline Blue marlin & 41,120 & Uku & 33,679 & Blue marlin & 24,706 & $\$ 33,645$ \\
\hline Hahalalu & 24,651 & Akule & 27,440 & Onaga & 1,419 & $\$ 8,766$ \\
\hline Uku & 21,291 & Bigeye tuna & 13,714 & Menpachi & 2,161 & $\$ 7,425$ \\
\hline Bigeye tuna & 13,662 & Menpachi & 7,144 & $\mathrm{Aku}$ & 3,892 & $\$ 7,311$ \\
\hline Menpachi & 7,144 & Onaga & 5,294 & Bigeye tuna & 1,893 & $\$ 6,904$ \\
\hline
\end{tabular}




\section{Methods}

\subsection{Study Area}

Ichthyoplankton samples were collected from the area offshore of Port Allen, just east of Kauai Island Utility Cooperative's Port Allen Generating Station. Samples were collected from three separate sampling areas (stations) running along a transect extending from the shore to approximately $1 \mathrm{~km}$ offshore: the sampling station closest to shore was Station 1 , the middle sampling station was Station 2, and the offshore sampling station was Station 3 (Figure 4-1). The stations were arranged to cover discrete depth ranges to provide data on how ichthyoplankton abundance varied with distance from shore and with depth. Station 1 covered depths between 4.6 and $10.7 \mathrm{~m}$ (15 and $35 \mathrm{ft}$ ), Station 2 between 10.7 and $15.2 \mathrm{~m}$ (35 and $50 \mathrm{ft}$ ), and Station 3 between 15.2 and $30.5 \mathrm{~m} \mathrm{(50} \mathrm{and} 100 \mathrm{ft}$ ). Note in Figure 4-1 that although the location and orientation of the stations was optimized to capture the greatest area possible, the periphery of each station included some depths outside of the range for that station; those locations were excluded from sampling.

Each station was approximately $320 \mathrm{~m}(980 \mathrm{ft})$ by $250 \mathrm{~m}(820 \mathrm{ft})$ making the overall area from which samples were collected approximately $950 \mathrm{~m}(3,117 \mathrm{ft})$ by $250 \mathrm{~m}(820 \mathrm{ft})$. Each station was subdivided into a 20-m (65.6-ft) square grid. Sampling locations were randomly selected from the grid prior to each sampling survey.

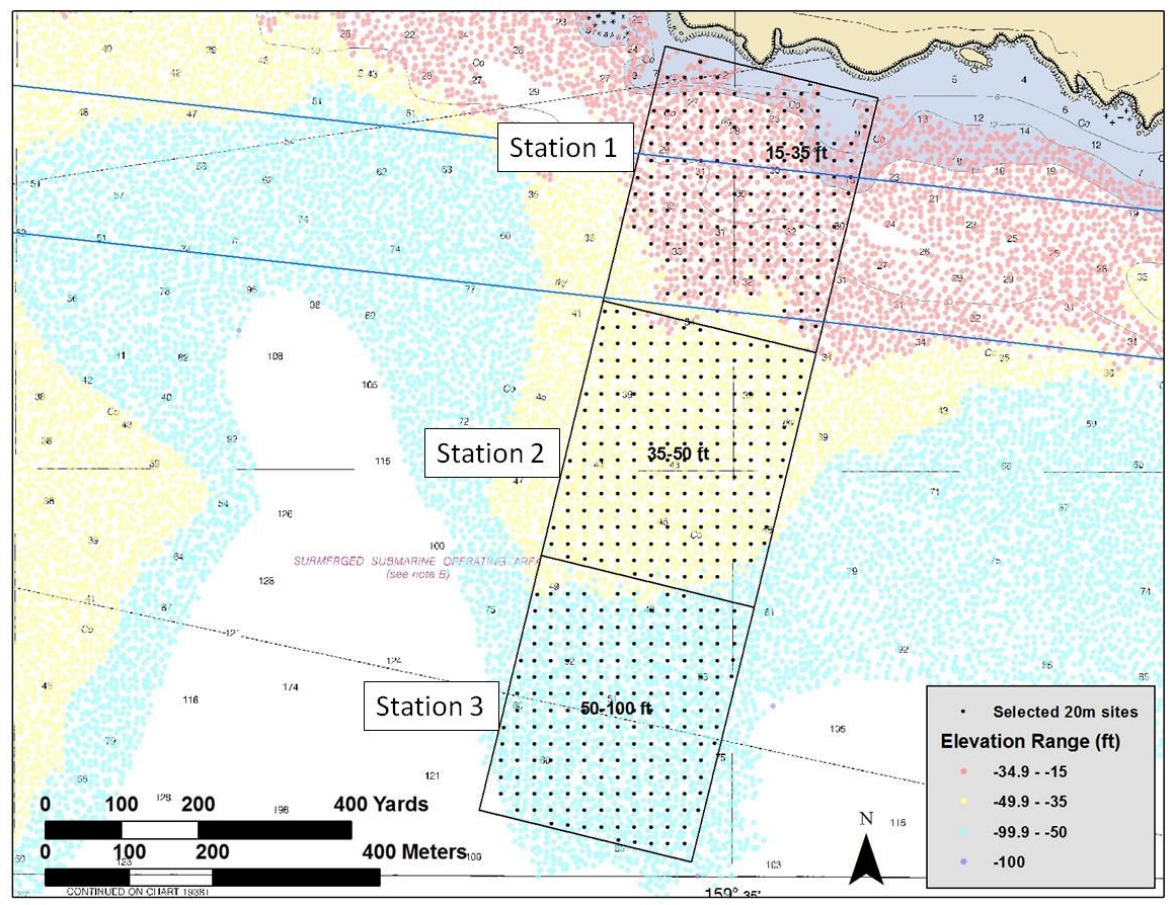

Figure 4-1. Ichthyoplankton sampling stations offshore of Port Allen. 


\subsection{Ichthyoplankton Collection}

Ichthyoplankton samples were collected from a small research vessel with a towed bongo net (Sea-Gear Model Model 9765). The bongo net was comprised of two conjoined mouth rings (61-cm [24-inch] diameter each), each supporting a 3-m (9.8-ft) long conical plankton net of 335- $\mu \mathrm{m}$ mesh. A Sea-Gear mechanical flowmeter (Model MF315) was mounted in each of the net mouths to record the flow sampled by each net. The cod end was capped with a quick-release filtering bucket with 335- $\mu$ m mesh. Figure 4-2 depicts the equipment used for collecting ichthyoplankton samples during this study.

The bongo net was towed obliquely, with the aid of a capstan winch, through the water column from within approximately $3 \mathrm{~m}(10 \mathrm{ft})$ of the sea bed to the surface. The net was fished up and down through the water column at approximately 0.5 to $0.6 \mathrm{~m} / \mathrm{sec}$ (1.5 to 2.0 $\mathrm{ft} / \mathrm{sec})$ until the target sample volume of $100 \mathrm{~m}^{3}\left(3,531 \mathrm{ft}^{3}\right)$ was collected. At the completion of a tow, the bongo net frame was secured to the vessel gunwale and the contents of the nets rinsed from the outside with filtered seawater. Rinsed samples from the two nets were decanted from the cod end filtering buckets, consolidated through a 335$\mu \mathrm{m}$ screen, combined into a single sample jar, and preserved in $5 \%$ buffered formalin seawater.

Each monthly sampling survey was conducted over a 24-hour period which was divided into two 12-hour sampling cycles - day and night. Samples were collected from the full depth (i.e., bottom to surface) at Stations 1 and 2; however, at Station 3, samples were collected from two depths (bottom to surface and mid-depth to surface) to determine whether any vertical stratification of ichthyoplankton could be detected. Three replicate samples were collected from each station and the two depths at Station 3 for a total of 12 samples per cycle and 24 samples per monthly survey (Table 4-1). 


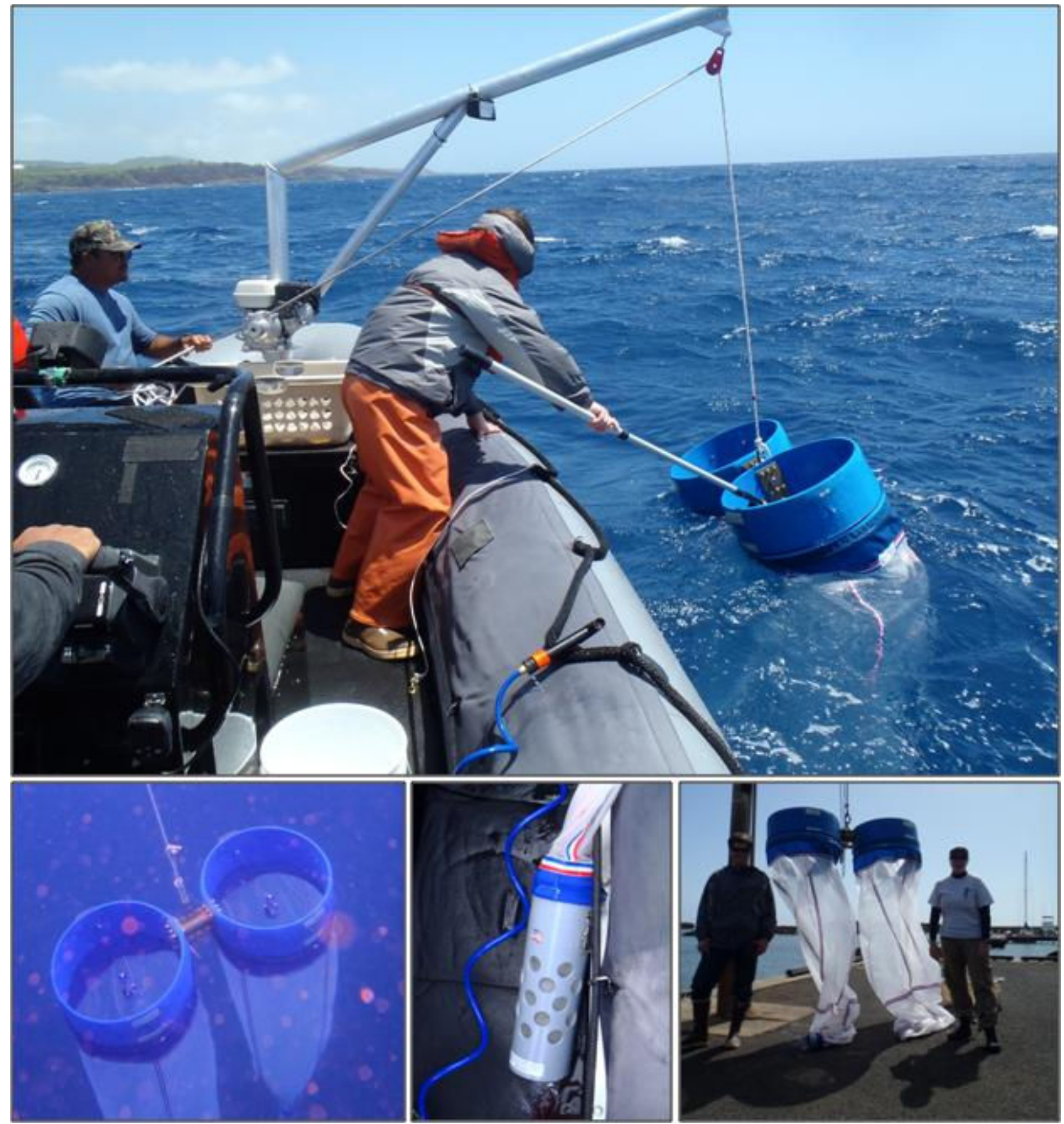

Figure 4-2. Equipment used for collecting ichthyoplankton samples during this study. Clockwise from top: bongo net assembly being retrieved after a deployment, bongo nets (9.8 ft [3 m] long), cod end filtering bucket (0.01 in [335 $\mu \mathrm{m}]$ mesh), bongo net assembly collecting a sample (flowmeters are visible in the bongo mouth rings). 
Table 4-1. Sampling matrix for ichthyoplankton sampling program.

\begin{tabular}{lcccc} 
Sampling station & Diel periods & Depths & Replicates & Total samples \\
\hline \#1 - onshore & 2 & 1 & 3 & 6 \\
\#2 - middle & 2 & 1 & 3 & 6 \\
\#3 - offshore & 2 & 2 & 3 & 12 \\
\hline Samples per month & & & 24 \\
Months of study program & & 9 \\
Total number samples targeted for study program & & 216 \\
\hline
\end{tabular}

\subsection{Tow Profiles}

An Onset HOBO U20 Water Level Data Logger was attached to net frame and logged depth (pressure) as the net was fished through the water column. Depth data were logged at onesecond intervals to provide high resolution depth profiles for each tow.

\subsection{Water Quality}

Water quality parameters were measured once per sampling cycle at Stations 1 and 2 at mid-depth. Water quality parameters at Station 3 were measured once per sampling cycle at the mid-point of each of the two depths sampled (i.e., full-depth and mid-depth). The parameters measured included water temperature, salinity, dissolved oxygen, and $\mathrm{pH}$.

\subsection{Lab Processing}

\subsubsection{Sample Sorting}

Samples were initially preserved in the field in 5\% buffered formalin seawater solution. After the samples were shipped to the Tenera Environmental laboratory in San Luis Obispo, California, and after a minimum time of 72 hours after initial preservation in formalin, the samples were transferred into a preservative solution of 70 to 80 percent ethanol. The samples were examined under a dissecting microscope and all fish eggs and larvae were removed and placed in labeled vials. When there was a large amount of collected plankton in a sample, the sample was split prior to processing. In cases where samples contained a large quantity of fish eggs, an aliquot (sub-sample) was taken from the processed portion of the sample and only this sub-sample was processed for eggs. All larvae in the original, or split, samples were enumerated and identified to the lowest practical taxon.

A Quality Assurance/Quality Control (QA/QC) program was applied to the laboratory processing of the samples. The first 10 samples completed by an individual were reexamined by a designated quality control (QC) technician. A technician was allowed to 
miss one target organism if the total number of target organisms in the sample was less than 20. For samples with 20 or more target organisms, the technician was required to maintain a removal efficiency of at least $90 \%$. After a technician had completed 10 consecutive samples with equal to or greater than $90 \%$ efficiency, they had one of their next 10 samples randomly selected for QA/QC validation ('1 sample in 10' QC program). If the technician failed to achieve an efficiency level of at least $90 \%$, then their next 10 samples were re-examined by the QA/QC technician until they met the required level of efficiency. If the technician maintained the required level of efficiency, then random QA/QC checks resumed at the level of ' 1 sample in 10'.

\subsubsection{Taxonomic Identification}

Individual larval fishes were identified to the lowest taxonomic classification possible (e.g., genus and species are lower levels of classification than order or family). The lack of complete larval descriptions for the various stages of many of the Hawaiian larval fishes and most of their eggs made visual identification to lower taxonomic levels problematic. In Section 0 there is a description of the more abundant larvae that were collected in this study and a description of why these were only identified to the taxonomic level of family.

A QA/QC program was also conducted for the taxonomists identifying the samples. After a taxonomist had identified the fish larvae from 10 samples, one sample was randomly chosen and the larvae were re-identified and counted by a second taxonomist. The taxonomic results were compared between the two taxonomists by comparing the number of identification and count agreements between the two taxonomists, and then a percent taxonomic disagreement (PTD) index was calculated. The error rate was quantified as the proportion of individual specimens in the sample identified or counted differently by the two taxonomists. The PTD goal was $\leq 10 \%$. If the PTD goal of $10 \%$ was exceeded, taxonomist interaction was used to determine problem areas, identify consistent disagreements, and define corrective actions. If the first taxonomist maintained a PTD of $\leq 10 \%$ then they continued to have one of each of their next ten samples checked by a second taxonomist. If they fell below this level, then the next ten consecutive samples they had identified were checked for accuracy by a second taxonomist until ten consecutive samples were identified with a PTD value of $\leq 10 \%$. Identifications were verified with taxonomic voucher collections maintained by Tenera Environmental.

\subsubsection{Morphometric Measurement}

Approximately 100 fish larvae from 10 taxa were measured from a randomly selected subset of the collected samples (Table 4-2). The body length (standard [notochord] length [NL]) was measured on each specimen to the nearest $0.1 \mathrm{~mm}$ using a digital camera mounted on a dissecting microscope interfaced with ImagePro® digital imaging analysis software. The system was recalibrated whenever necessary to adjust the microscope magnification to accommodate larvae of different sizes. Head capsule dimensions (head 
width and depth - Figure 4-3) were also measured for taxa where these data were not available from ichthyoplankton studies at three locations on the island of Oahu, also in Hawaii.

Table 4-2. List of larval fish taxa measured to notochord lengths and head capsule dimensions.

\begin{tabular}{ll}
\hline Taxa & Common name \\
\hline Apogonidae & cardinalfishes \\
Apogon spp. & cardinalfishes \\
Pristiapogon spp. & cardinalfishes \\
Carangidae & jacks and trevalleys \\
Enneapterygius atriceps & Hawaiian triplefin \\
Gobiidae & gobies \\
Pomacentridae & damselfishes \\
Salariinae & blennies \\
Schindleria spp. & infant fishes \\
Scombridae & tunas and mackerels \\
\hline
\end{tabular}

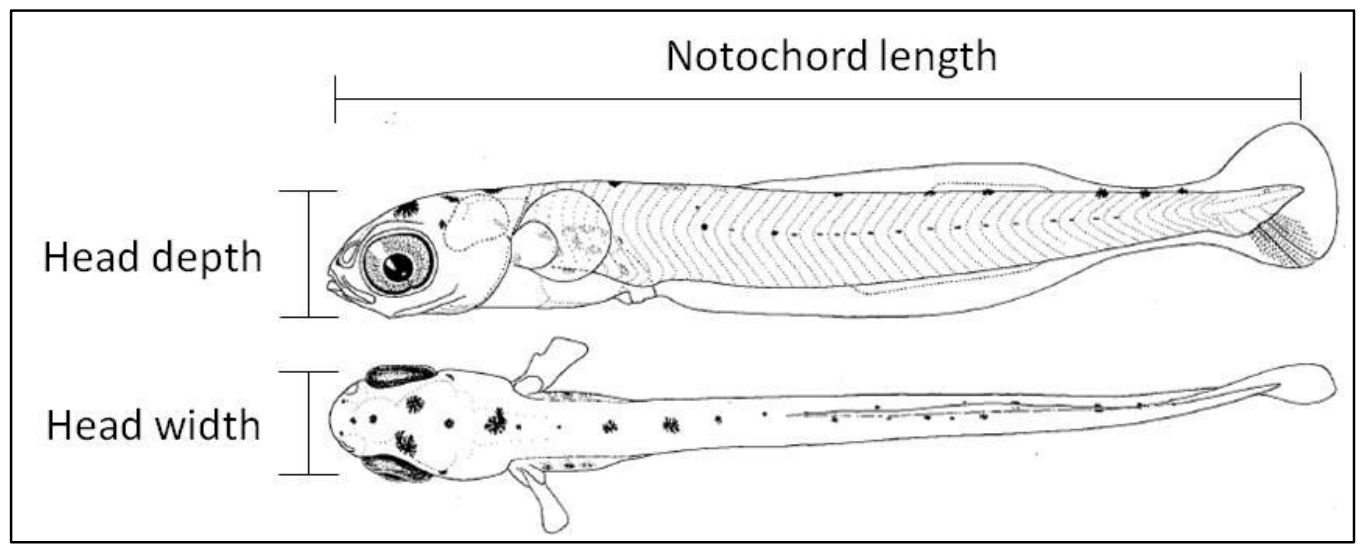

Figure 4-3. Illustration of the measurement locations for notochord length and head depth (height) and width of a preflexion stage larval fish. Larval fish is a jacksmelt from Moser 1996.

\subsection{Data Analysis}

The sample volumes and numbers of eggs and larvae per sample, adjusted as necessary for any sample splits, were combined to calculate the concentration (number per $\mathrm{m}^{3}$ ) per sample. Sample concentrations were calculated for all fish eggs and larvae combined as well as for individual taxa of fish larvae. The concentration of larvae per sample provided the fundamental data for all of the data summaries provided in this report. The data were combined into estimates of the average concentration per cycle, station, or survey by treating the three samples collected from each station during the day and night sampling cycles as individual strata in a stratified sampling design with six strata being sampled 
during each survey - two cycles at three stations. These estimates were used in the various data summaries and presentations provided in this report. Only one sample was collected during the night sampling cycle during Survey 9 in December and that sample was not included in any of the data summaries or analyses. As a result, only the samples from the day sampling cycle in December were analyzed.

Differences among stations and day-night sampling cycles were evaluated using analysis of variance (ANOVA) using the SAS software Proc Mixed procedure to accommodate the combination of random and fixed effects in the ANOVA models (SAS Institute 2008). The analysis was done for the most abundant taxa of fish larvae, as well as total larvae from all of the taxa and the total concentrations of fish eggs in the samples. The ANOVA assumes that the variances among all the treatment groups are homogeneous and the data are normally distributed. These assumptions were evaluated by testing the original data as well as data transformed using $\log (x+$ constant $), \sqrt{ }(x+$ constant $), \sqrt{ } \sqrt{(x+\text { constant }) \text {, where } x}$ was the original concentration from a sample. The transformations of values of zero required that a constant be added. The value of the constant used can potentially bias the analysis of the data (Schroeter et al. 1993); therefore, assumption tests were run with constants of $1.0,0.5,0.1$ and 0.01 . The Levene test was used to examine the assumption of homogeniety of variances (Milliken and Johnson 1984). The best combination of transformation and constant was chosen based on the results of the Levene test and examination of quantile plots of the residuals. Due to the robustness of ANOVA to violations of assumptions, especially with the large samples sizes in this study, a probability level of 90 percent or $\alpha=0.10$ was used in the Levene test. If the Levene test was significant, the option for using Satterthwaite's adjusted degrees of freedom was specified in the SAS Proc Mixed procedure (Milliken and Johnson 1984). Data were not analyzed if the Levene test was significant and the quantile plot indicated large departures from normality. This occurred for several taxa that were collected in high abundances from only one or two surveys.

The ANOVA resulted in tests of the two main effects, station and day-night cycles, as well as the interaction of the two effects using a probability level of 95 percent or $\alpha=0.05$ to determine significance. When the interaction was significant due to differing effects between day-night cycles among the three stations, the individual levels for each station and sampling cycle were examined and results presented for comparisons between the same sample cycle at the stations being compared, or between sample cycles at the same station. The surveys were treated as a random factor or block with the two main effects replicated within each block. All of the interaction effects and a posteriori tests of differences among stations were analyzed using the PDIFF option in the SAS Proc Mixed procedure.

The additional samples collected during each cycle at Station 3 from the upper portion of 
the water column could also be considered as separate sample strata but the data from these samples were collected to adjust the concentration from the samples that were collected from the entire water column using the normal oblique tow. A second tow at the same location was used to provide an estimate of fish larval and egg concentrations in the upper water column. The depths of the two tows were collected from the Hobo pressure depth logger attached to the net frame during the sampling. The maximum depth recorded during the tow was used in the calculations. Pairs of tows where the difference between the maximum depths of the paired tows was less than $3 \mathrm{~m}(9.8 \mathrm{ft})$ were not included in the analysis. There were also three sampling cycles where the depth recorder malfunctioned, which were excluded from this analysis. Also, only one sample was collected during the night sampling cycle during the Survey 9 in December and that sample was not included since a matching sample from the upper water column was not collected. The analysis resulted in 45 pairs of samples that were adjusted as follows to obtain estimates of larval concentrations in the deeper depth strata:

Concentration $_{\text {Deep }}=\left[\right.$ Concentration $_{\text {Total }}-\left(\right.$ Concentration $\left.\left._{U p p e r} * p_{S}\right)\right] /\left(1-p_{S}\right)$,

where $p_{S}=$ proportion of the depth of the tow through the upper water column (Concentration Upper) to the depth of the tow through the entire water column (Concentration Total). The depths of the tows through the entire water column ranged from 3-13 m (9.8 to $42.7 \mathrm{ft}$ ) below the tows through the upper water column.

The data from the upper strata collected during the sampling, and the calculated concentrations for the deep strata were analyzed using procedures similar to the approach for the data at the three stations described previously in this section, including the use of multiple transformations and constants. The data were analyzed using ANOVA with the SAS software Proc Mixed procedure (SAS Institute 2008) with the data from the two depth strata blocked by survey and cycle. This is equivalent to a paired t-test of the difference between the two depths for each set of sample replicates.

The data from the length measurement of the larvae from the most abundant taxa were output as boxplots using SAS Graph (SAS Institute 2008). An explanation of the legend accompanying the histograms is shown in Figure 4-4, and may be referred to for interpreting the length frequency dispersion statistics for selected taxa that are presented in Section 4 - Results. The tick marks below the histogram represent the individual measurements.

The body length and head capsule data collected from the larvae from this study and from other sampling in Hawaii were used to calculate allometric regressions where head capsule is a power function of notochord length (NL). 

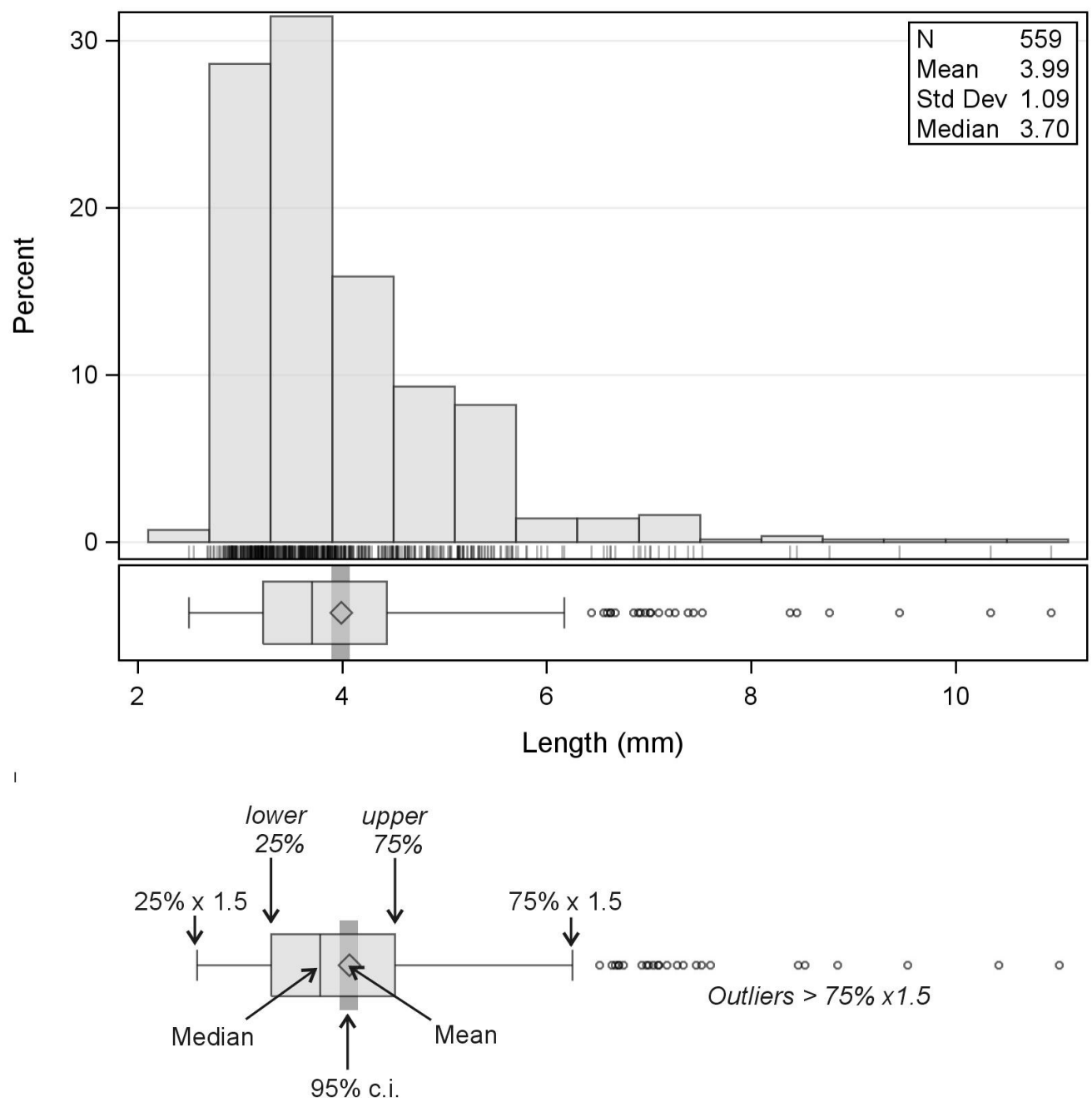

Figure 4-4. Explanation of dispersion statistics for length frequency histograms. 
Multivariate statistical methods are useful for characterizing community structure and dynamics and examining spatial and temporal patterns of variation that may be indicative of disturbances or ecological interactions (Gray et al. 1990; Agard et al. 1993; Olsgard and Gray 1995). Multivariate analysis was used in this report to summarize and contrast community changes at the three station locations over the nine surveys. The average concentrations from the day and night tows at each station for all nine surveys were used in the analysis with a total of 95 separate taxa groups. A common approach in multivariate community analysis that is not focused on examining diversity is to remove the rare species from the analysis as they generally add minimal information to the analysis, may unduly bias the results, and are not likely to be indicative of normal community composition (Clarke and Warwick 2001). For this analysis taxa that occurred in fewer than four of the 27 combinations of surveys and stations were not included in the analysis. The larval concentrations among the 57 taxa groups analyzed ranged from 0.004 to 3.04 larvae per $\mathrm{m}^{3}$. To account for the almost three orders of magnitude range of values among the data, the data were transformed as $\log (x+1)$ to reduce the effects of species with very large concentrations. The data for Survey 9 in December only included the day time sampling cycle. All multivariate analyses were conducted using PRIMER Version 6.1 (Clarke and Gorley 2006).

The multivariate technique of non-metric multidimensional scaling (MDS) was used to examine patterns of variation at the three stations over the nine surveys. The transformed average larval concentrations were used to construct a Bray-Curtis distance matrix among all of the samples in a data set. MDS constructs an optimal configuration of samples based on the conditions imposed by a ranking of the dissimilarities among the samples. 


\section{Results}

\subsection{Overview of Sampling Results}

Sampling for ichthyoplankton off Port Allen was conducted approximately monthly from April 2012 through December 2012. During the nine surveys, a total of 205 samples were collected (Table 5-1). All of the planned samples were collected the three stations during both the day and night sampling cycles, except during Survey 9 in December when only a single sample was collected during the night survey before the sampling was aborted due to severe weather and sea conditions. All of the 205 samples were processed in the laboratory (sorting and identification), but the one sample from the night sampling cycle in December was not included in the analyses.

Table 5-1. Sample dates and number of samples collected during ichthyoplankton surveys off Port Allen, Kauai. Station 3 Upper represents the samples collected from the upper water column at Station 3 .

\begin{tabular}{lcccccc}
\hline & & \multicolumn{5}{c}{ Station } \\
\cline { 3 - 6 } Survey & $\begin{array}{c}\text { Survey } \\
\text { Date }\end{array}$ & $\mathbf{1}$ & $\mathbf{2}$ & $\mathbf{3}$ & $\mathbf{3}$ & \\
\hline KAOBC01 & Upper & Total \\
KAOBC02 & $4 / 1 / 2012$ & 6 & 6 & 6 & 6 & 24 \\
KAOBC03 & $5 / 2 / 2012$ & 6 & 6 & 6 & 6 & 24 \\
KAOBC04 & $6 / 6 / 2012$ & 6 & 6 & 6 & 6 & 24 \\
KAOBC05 & $7 / 11 / 2012$ & 6 & 6 & 6 & 6 & 24 \\
KAOBC06 & $8 / 1 / 2012$ & 6 & 6 & 6 & 6 & 24 \\
KAOBC07 & $9 / 5 / 2012$ & 6 & 6 & 6 & 6 & 24 \\
KAOBC08 & $10 / 3 / 2012$ & 6 & 6 & 6 & 6 & 24 \\
KAOBC09 & $11 / 7 / 2012$ & 6 & 6 & 6 & 6 & 24 \\
Total Collected & $12 / 4 / 2012$ & 3 & 3 & 4 & 3 & 13 \\
Total Analyzed & & 51 & 51 & 52 & 51 & 205 \\
\hline
\end{tabular}

The estimated numbers from the 204 samples totaled 297,638 unidentified fish eggs and 49,969 fish larvae from a minimum of 101 taxa (Table 5-2). The average concentration of fish larvae from the sampling done during all the surveys at all of the stations, including the midwater tows at Station 3 was 2,111 larvae per 1,000 $\mathrm{m}^{3}$. The assemblage was diverse, with 11 taxa comprising the top $90 \%$ of specimens collected, which included larvae that could not be identified into a taxonomic category. The most abundant taxa were infantfishes (Schindleria spp.), blennies (Salariinae), gobies (Gobiidae), damselfishes (Pomacentridae), Hawaiian triplefin (Enneapterygius atriceps), lanternfishes (Myctophidae), and Hawaiian anchovy or nehu (Encrasicholina spp.). The most abundant larvae were generally from fishes with adults that inhabit shallow nearshore distributions, but larvae from deepwater fishes such as the Myctophidae were also abundant. 
The overall average concentration of larvae from the samples collected using the oblique tows through the entire water column was highest at Station 1 which was closest to shore (Table 5-3). While the difference in overall concentration between Stations 1 and 2 was small, the lowest average concentration occurred at Station 3. The average concentration at Station 3 may be affected by collecting across a greater range of depths relative to Stations 1 and 2 which may have had more uniform concentrations of larvae through the entire water column. Although the average concentration was lowest at Station 3, the number of unique taxa of larval fish collected at that station (81) was slightly higher than the number at the other two stations (73 and 66) , which may also reflect the greater depth strata and habitats sampled at that station. Infantfish (Schindleria spp.) larvae were the most abundant taxon at all three stations. Consistent with the nearshore distribution of adults, blennies (Salariinae) including Hawaiian triplefin (Enneapterygius atriceps), were more abundant at Station 1 which was closest to shore. Also consistent with the distributions of adults in deeper water, lanternfishes (Myctophidae including Lampadena spp.), headlightfishes (Diaphus spp.), and highseas lampfish (Triphoturus nigrescens) were all more abundant further from shore at Station 3. Pelagic fishes including jacks (Carangidae), and the mackerels and tunas (Scombridae) were also more abundant at Stations 2 and 3 than at Station 1. The comparison among stations for the Hawaiian anchovy or nehu (Encrasicholina spp.) did not follow the expected pattern based on the distribution of adult nehu which likely occur in highest abundance inside Hanapepe Bay. As a result, nehu would be expected to occur in highest abundance at Station 1.

The estimated average concentration of fish eggs from the samples was approximately the same at all three stations (Table 5-3). The fish eggs were not identified, but likely included eggs from fishes with both deepwater and nearshore distributions, although many shallow nearshore fishes such as gobies, blennies, and damselfishes lay eggs in nests and therefore, do not have planktonic eggs that would have been collected during the sampling. Fish eggs were collected in highest abundance during April and May and were collected in lowest abundance during the June and December surveys (Figure 5-1). The low abundances in December was likely due to the absence of any samples at night from that survey, as fish eggs were generally collected in higher abundances during the night sampling periods during all of the other surveys, except for April (Figure 5-2). The statistical analysis of the data at the three stations and between day-night sampling cycles required that the data for fish eggs be transformed using $\log (x+0.1)$. The ANOVA of the data on fish eggs detected a significant difference between day and night sampling cycles $(\mathrm{p}<0.05)$ due to the higher abundances collected at night, while no difference was detected among the three stations ( $p>0.05)$ (Table 5-4).

The pattern of abundance of fish larvae from all taxa combined was similar at all three stations with the highest abundances from the samples collected during the July, August, and September surveys and the lowest during the December survey (Figure 5-3). 
Abundances were also generally higher from samples collected during the night sampling period, although the difference was less pronounced from the samples collected at Station 3 where the difference between day and night was not significant (Figure 5-4). To satisfy the assumption of the ANOVA, the larval data was transformed using $\log (\mathrm{x}+0.1)$. The ANOVA for fish larvae from all taxa combined detected a significant interaction between the factors for station and sampling cycle $(\mathrm{p}<0.05)$ requiring that the individual comparisons among these treatment combinations be examined (Table 5-5). The comparisons among the individual treatment combinations detected significant differences between the day and night sampling cycles at Station 1 due to the higher abundances at night and between stations 1 and 3 during the night sampling cycle when abundances were higher at Station 1.

The concentrations from the plankton tows of the upper portion of the water column at Station 3 were used to adjust the concentrations collected from the plankton tows through the entire water column at this station to calculate estimates of fish egg and larval concentrations in the depth strata below the depth of the midwater tow. The analysis of the data from the two depth strata required transformation of the data for fish eggs using $\log (\mathrm{x}+0.5)$, and for total fish larvae using $\sqrt{ } \sqrt{(x+1.0)}$. The ANOVA did not detect a significant difference between depth strata for fish eggs $(\mathrm{p}=0.157)$ or total fish larvae $(\mathrm{p}=0.806)$. The absence of any statistically significant patterns between depths and across surveys are reflected in the results for fish eggs (Figure 5-5) and fish larvae for all taxa combined (Figure 5-6).

All raw data by survey are provided in Appendix A. 
Table 5-2. Summary of adjusted numbers and concentrations of fish eggs and larvae from ichthyoplankton surveys off Port Allen, Kauai from April-December 2012.

\begin{tabular}{|c|c|c|c|c|c|}
\hline Taxon & Common Name & $\begin{array}{l}\text { Total } \\
\text { Count }\end{array}$ & $\begin{array}{c}\text { Average } \\
\text { Concentration } \\
\text { per } 1,000 \mathbf{~ m}^{3}\end{array}$ & $\begin{array}{l}\text { Percent } \\
\text { of Total }\end{array}$ & $\begin{array}{c}\text { Cumulative } \\
\text { Percent }\end{array}$ \\
\hline unidentified fish eggs & fish eggs & 297,638 & $11,927.91$ & $100.0 \%$ & $100.0 \%$ \\
\hline \multicolumn{6}{|l|}{ Fish Larvae } \\
\hline Schindleria spp. & infantfishes & 12,754 & 539.64 & $25.6 \%$ & $25.6 \%$ \\
\hline Salariinae & blennies & 7,969 & 335.16 & $15.9 \%$ & $41.4 \%$ \\
\hline Gobiidae & gobies & 5,758 & 242.85 & $11.5 \%$ & $52.9 \%$ \\
\hline Pomacentridae & damselfishes & 5,301 & 221.60 & $10.5 \%$ & $63.4 \%$ \\
\hline Enneapterygius atriceps & Hawaiian triplefin & 4,148 & 180.46 & $8.5 \%$ & $72.0 \%$ \\
\hline Myctophidae & lanternfishes & 2,400 & 102.35 & $4.8 \%$ & $76.8 \%$ \\
\hline Encrasicholina spp. & anchovies & 2,251 & 95.72 & $4.5 \%$ & $81.4 \%$ \\
\hline larval/post-larval fish & larval fishes & 1,702 & 69.85 & $3.3 \%$ & $84.7 \%$ \\
\hline Cyclothone spp. & bristlemouths & 1,160 & 47.64 & $2.3 \%$ & $86.9 \%$ \\
\hline Carangidae & jacks & 805 & 33.68 & $1.6 \%$ & $88.5 \%$ \\
\hline Pristiapogon spp. & cardinalfishes & 747 & 31.09 & $1.5 \%$ & $90.0 \%$ \\
\hline Apogon spp. & cardinalfishes & 474 & 19.96 & $0.9 \%$ & $90.9 \%$ \\
\hline Diaphus spp. & headlightfishes & 473 & 19.74 & $0.9 \%$ & $91.9 \%$ \\
\hline Triphoturus nigrescens & highseas lampfish & 347 & 14.23 & $0.7 \%$ & $92.5 \%$ \\
\hline Vinciguerria spp. & lightfishes & 244 & 13.19 & $0.6 \%$ & $93.2 \%$ \\
\hline Lampadena spp. & lanternfishes & 286 & 12.03 & $0.6 \%$ & $93.7 \%$ \\
\hline Perciformes & $\begin{array}{l}\text { Perciformes fishes } \\
\text { delicate round }\end{array}$ & 284 & 11.73 & $0.6 \%$ & $94.3 \%$ \\
\hline Spratelloides delicatulus & herring & 239 & 10.23 & $0.5 \%$ & $94.8 \%$ \\
\hline Scombridae & mackerels and tunas & 231 & 9.57 & $0.5 \%$ & $95.2 \%$ \\
\hline Apogonidae & cardinalfishes & 161 & 6.59 & $0.3 \%$ & $95.6 \%$ \\
\hline Decapterus spp. & scad & 160 & 6.55 & $0.3 \%$ & $95.9 \%$ \\
\hline Priolepis spp. & gobies & 153 & 6.46 & $0.3 \%$ & $96.2 \%$ \\
\hline $\begin{array}{l}\text { Labridae } \\
\text { Lophiiformes/ }\end{array}$ & wrasses & 130 & 5.46 & $0.3 \%$ & $96.4 \%$ \\
\hline Tetraodontiformes & anglerfishes/puffers & 130 & 5.36 & $0.3 \%$ & $96.7 \%$ \\
\hline Hygophum proximum & lanternfish & 124 & 4.63 & $0.2 \%$ & $96.9 \%$ \\
\hline Balistidae & $\begin{array}{l}\text { triggerfishes } \\
\text { transparent }\end{array}$ & 111 & 4.57 & $0.2 \%$ & $97.1 \%$ \\
\hline Pseudamiops diaphanes & cardinalfish & 100 & 4.30 & $0.2 \%$ & $97.3 \%$ \\
\hline Cirrhitidae & hawkfishes & 92 & 3.87 & $0.2 \%$ & $97.5 \%$ \\
\hline Scorpaenidae & scorpion fishes & 83 & 3.87 & $0.2 \%$ & $97.7 \%$ \\
\hline Cubiceps spp. & cigarfishes & 93 & 3.85 & $0.2 \%$ & $97.9 \%$ \\
\hline Bathygobius spp. & frillfin gobies & 73 & 3.05 & $0.1 \%$ & $98.0 \%$ \\
\hline Gempylidae & snake mackerels & 60 & 2.38 & $0.1 \%$ & $98.1 \%$ \\
\hline Symbolophorus spp. & lanternfishes & 49 & 2.28 & $0.1 \%$ & $98.2 \%$ \\
\hline Microdesmidae & dartfishes & 47 & 2.04 & $0.1 \%$ & $98.3 \%$ \\
\hline
\end{tabular}


Table 5-2 (cont). Summary of adjusted numbers and concentrations of fish eggs and larvae from ichthyoplankton surveys off Port Allen, Kauai from April-December 2012.

\begin{tabular}{|c|c|c|c|c|c|}
\hline Taxon & Common Name & $\begin{array}{l}\text { Total } \\
\text { Count } \\
\end{array}$ & $\begin{array}{c}\text { Average } \\
\text { Concentration } \\
\text { per } 1,000 \mathbf{~ m}^{3}\end{array}$ & $\begin{array}{l}\text { Percent } \\
\text { of Total }\end{array}$ & $\begin{array}{c}\text { Cumulative } \\
\text { Percent }\end{array}$ \\
\hline Callionymidae & dragonets & 48 & 1.91 & $0.1 \%$ & $98.4 \%$ \\
\hline Apogonidae/Gobiidae & cardinalfishes/gobies & 45 & 1.84 & $0.1 \%$ & $98.5 \%$ \\
\hline Synodontidae & lizardfishes & 40 & 1.70 & $0.1 \%$ & $98.6 \%$ \\
\hline Plagiotremus spp. & fangblennies & 37 & 1.61 & $0.1 \%$ & $98.7 \%$ \\
\hline Blenniidae & blennies & 36 & 1.59 & $0.1 \%$ & $98.7 \%$ \\
\hline Sphyraena spp. & barracudas & 36 & 1.48 & $0.1 \%$ & $98.8 \%$ \\
\hline Pomacanthidae & angelfishes & 33 & 1.44 & $0.1 \%$ & $98.9 \%$ \\
\hline Eviota spp. & gobies & 35 & 1.43 & $0.1 \%$ & $98.9 \%$ \\
\hline Clupeidae & herrings & 32 & 1.37 & $0.1 \%$ & $99.0 \%$ \\
\hline Diplophos spp. & lightfishes & 31 & 1.30 & $0.1 \%$ & $99.1 \%$ \\
\hline Labridae/Scaridae & $\begin{array}{l}\text { wrasses/parrotfishes } \\
\text { Hawaiian surf }\end{array}$ & 31 & 1.25 & $0.1 \%$ & $99.1 \%$ \\
\hline Iso hawaiiensis & sardine & 28 & 1.04 & $<0.1 \%$ & $99.2 \%$ \\
\hline Stomiiformes & stomioids & 22 & 1.02 & $<0.1 \%$ & $99.2 \%$ \\
\hline Coryphaena spp. & $\begin{array}{l}\text { dolphinfish } \\
\text { deepwater }\end{array}$ & 25 & 1.00 & $<0.1 \%$ & $99.3 \%$ \\
\hline Epigonus spp. & cardinalfishes & 23 & 0.98 & $<0.1 \%$ & $99.3 \%$ \\
\hline Syngnathidae & pipefishes & 23 & 0.97 & $<0.1 \%$ & $99.4 \%$ \\
\hline Paralepididae & barracudinas & 18 & 0.94 & $<0.1 \%$ & $99.4 \%$ \\
\hline Exocoetidae & flyingfishes & 21 & 0.84 & $<0.1 \%$ & $99.5 \%$ \\
\hline Melamphaes spp. & bigscales & 13 & 0.79 & $<0.1 \%$ & $99.5 \%$ \\
\hline Selar crumenophthalmus & bigeye scad & 20 & 0.78 & $<0.1 \%$ & $99.5 \%$ \\
\hline Lampanyctus nobilis & lanternfish & 18 & 0.76 & $<0.1 \%$ & $99.6 \%$ \\
\hline Chaetodontidae & butterflyfishes & 17 & 0.75 & $<0.1 \%$ & $99.6 \%$ \\
\hline Ammodytidae & sand lances & 12 & 0.60 & $<0.1 \%$ & $99.6 \%$ \\
\hline Mullidae & goatfishes & 13 & 0.56 & $<0.1 \%$ & $99.7 \%$ \\
\hline Priacanthidae & bigeyes & 11 & 0.48 & $<0.1 \%$ & $99.7 \%$ \\
\hline Hygophum reinhardtii & slender lanternfish & 9 & 0.46 & $<0.1 \%$ & $99.7 \%$ \\
\hline Gonostomatidae & bristlemouths & 11 & 0.40 & $<0.1 \%$ & $99.7 \%$ \\
\hline Scaridae & parrotfishes & 9 & 0.40 & $<0.1 \%$ & $99.7 \%$ \\
\hline Howellidae & pelagic basslets & 10 & 0.36 & $<0.1 \%$ & $99.8 \%$ \\
\hline Bothidae & $\begin{array}{l}\text { lefteye flounders } \\
\text { squirrelfishes and }\end{array}$ & 9 & 0.35 & $<0.1 \%$ & $99.8 \%$ \\
\hline Holocentridae & $\begin{array}{l}\text { soldierfishes } \\
\text { albacores, mackerels, }\end{array}$ & 8 & 0.35 & $<0.1 \%$ & $99.8 \%$ \\
\hline Scombroidei & and tunas & 8 & 0.34 & $<0.1 \%$ & $99.8 \%$ \\
\hline Atherinomorus insularum & Hawaiian silverside & 8 & 0.32 & $<0.1 \%$ & $99.8 \%$ \\
\hline Creediidae & burrowers & 7 & 0.30 & $<0.1 \%$ & $99.8 \%$ \\
\hline Phosichthyidae & lightfishes & 7 & 0.27 & $<0.1 \%$ & $99.8 \%$ \\
\hline
\end{tabular}


Table 5-2 (cont). Summary of adjusted numbers and concentrations of fish eggs and larvae from ichthyoplankton surveys off Port Allen, Kauai from April-December 2012.

\begin{tabular}{|c|c|c|c|c|c|}
\hline Taxon & Common Name & $\begin{array}{l}\text { Total } \\
\text { Count }\end{array}$ & $\begin{array}{c}\text { Average } \\
\text { Concentration } \\
\text { per } 1,000 \mathrm{~m}^{3}\end{array}$ & $\begin{array}{l}\text { Percent } \\
\text { of Total }\end{array}$ & $\begin{array}{c}\text { Cumulative } \\
\text { Percent }\end{array}$ \\
\hline $\begin{array}{l}\text { Scombrolabrax } \\
\text { heterolepis }\end{array}$ & black mackerel & 6 & 0.25 & $<0.1 \%$ & $99.9 \%$ \\
\hline Acanthuridae & surgeonfishes & 6 & 0.24 & $<0.1 \%$ & $99.9 \%$ \\
\hline Nomeidae & driftfishes & 5 & 0.23 & $<0.1 \%$ & $99.9 \%$ \\
\hline $\begin{array}{l}\text { Bramidae } \\
\text { Asterropteryx }\end{array}$ & pomfrets & 6 & 0.23 & $<0.1 \%$ & $99.9 \%$ \\
\hline semipunctata & halfspotted goby & 4 & 0.17 & $<0.1 \%$ & $99.9 \%$ \\
\hline Elopomorpha & leptocephalus larvae & 4 & 0.17 & $<0.1 \%$ & $99.9 \%$ \\
\hline Ipnopidae & tripod fishes & 4 & 0.17 & $<0.1 \%$ & $99.9 \%$ \\
\hline Sudis atrox & fierce pike smelt & 2 & 0.16 & $<0.1 \%$ & $99.9 \%$ \\
\hline Percoidei & $\begin{array}{l}\text { Percoidei fishes } \\
\text { scaleless black }\end{array}$ & 3 & 0.13 & $<0.1 \%$ & $99.9 \%$ \\
\hline Melanostomiinae & dragonfishes & 3 & 0.13 & $<0.1 \%$ & $99.9 \%$ \\
\hline Notosudidae & waryfishes & 3 & 0.12 & $<0.1 \%$ & $99.9 \%$ \\
\hline Ranzania laevis & slender mola & 3 & 0.12 & $<0.1 \%$ & $99.9 \%$ \\
\hline Bregmaceros spp. & codlets & 2 & 0.09 & $<0.1 \%$ & $>99.9 \%$ \\
\hline Pleuronectoidei & flatfishes & 2 & 0.09 & $<0.1 \%$ & $>99.9 \%$ \\
\hline Kyphosidae & sea chubs & 2 & 0.08 & $<0.1 \%$ & $>99.9 \%$ \\
\hline Hipросатрus spp. & seahorses & 2 & 0.08 & $<0.1 \%$ & $>99.9 \%$ \\
\hline Malacosteinae & loosejaws & 2 & 0.08 & $<0.1 \%$ & $>99.9 \%$ \\
\hline Gigantura indica & telescope fish & 2 & 0.08 & $<0.1 \%$ & $>99.9 \%$ \\
\hline Anthiinae & $\begin{array}{l}\text { sea basses } \\
\text { double spotted }\end{array}$ & 2 & 0.07 & $<0.1 \%$ & $>99.9 \%$ \\
\hline Scomberoides lysan & $\begin{array}{l}\text { queenfish } \\
\text { scaleless }\end{array}$ & 1 & 0.05 & $<0.1 \%$ & $>99.9 \%$ \\
\hline Eustomias spp. & dragonfishes & 1 & 0.05 & $<0.1 \%$ & $>99.9 \%$ \\
\hline Anguilliformes & eels & 1 & 0.05 & $<0.1 \%$ & $>99.9 \%$ \\
\hline Ostraciidae & trunkfishes & 1 & 0.05 & $<0.1 \%$ & $>99.9 \%$ \\
\hline Evermannellidae & sabertooth fishes & 1 & 0.05 & $<0.1 \%$ & $>99.9 \%$ \\
\hline Foa brachygramma & bay cardinalfish & 1 & 0.04 & $<0.1 \%$ & $>99.9 \%$ \\
\hline Ahliesaurus brevis & waryfish & 1 & 0.04 & $<0.1 \%$ & $>99.9 \%$ \\
\hline Gadiformes & grenadiers & 1 & 0.04 & $<0.1 \%$ & $>99.9 \%$ \\
\hline Astronesthes spp. & snaggletooths & 1 & 0.04 & $<0.1 \%$ & $>99.9 \%$ \\
\hline Hemiramphidae & $\begin{array}{l}\text { halfbeaks } \\
\text { pipefishes and }\end{array}$ & 1 & 0.04 & $<0.1 \%$ & $>99.9 \%$ \\
\hline Syngnathiformes & seahorses & 1 & 0.03 & $<0.1 \%$ & $>99.9 \%$ \\
\hline Triglidae & searobins & 1 & 0.03 & $<0.1 \%$ & $>99.9 \%$ \\
\hline Champsodon fimbriatus & toothfish & 1 & 0.03 & $<0.1 \%$ & $>99.9 \%$ \\
\hline Caristiidae & manefishes & 1 & 0.03 & $<0.1 \%$ & $100.0 \%$ \\
\hline Total fish larvae & & 49,969 & 2,111 & & \\
\hline
\end{tabular}


Table 5-3. Summary of adjusted concentrations of fish eggs and larvae from oblique tows of the entire water column at Stations 1, 2, and 3 off Port Allen, Kauai from AprilDecember 2012.

\begin{tabular}{|c|c|c|c|c|}
\hline \multirow[b]{2}{*}{ Taxon } & \multirow[b]{2}{*}{ Common Name } & \multicolumn{3}{|c|}{ Concentration $\left(\# / \mathbf{1}, 000 \mathrm{~m}^{3}\right)$} \\
\hline & & Station 1 & Station 2 & Station 3 \\
\hline fish eggs & fish eggs & $12,602.3$ & $11,494.8$ & $11,361.7$ \\
\hline \multicolumn{5}{|l|}{ Fish Larvae } \\
\hline Schindleria spp. & infantfishes & 576.8 & 689.3 & 502.6 \\
\hline Salariinae & blennies & 515.5 & 356.0 & 227.6 \\
\hline Gobiidae & gobies & 199.8 & 340.7 & 223.7 \\
\hline Pomacentridae & damselfishes & 214.2 & 275.3 & 190.7 \\
\hline Enneapterygius atriceps & Hawaiian triplefin & 561.6 & 76.5 & 52.1 \\
\hline Myctophidae & lanternfishes & 84.1 & 81.3 & 123.8 \\
\hline Encrasicholina spp. & anchovies & 26.9 & 89.9 & 124.1 \\
\hline larval/post-larval fish & larval fishes & 48.4 & 79.3 & 71.1 \\
\hline Cyclothone spp. & bristlemouths & 31.4 & 43.1 & 49.7 \\
\hline Carangidae & jacks & 11.5 & 54.5 & 33.6 \\
\hline Pristiapogon spp. & cardinalfishes & 34.6 & 39.0 & 28.2 \\
\hline Apogon spp. & cardinalfishes & 37.4 & 19.7 & 12.2 \\
\hline Diaphus spp. & headlightfishes & 11.1 & 19.7 & 22.7 \\
\hline Triphoturus nigrescens & highseas lampfish & 8.5 & 15.4 & 17.5 \\
\hline Vinciguerria spp. & lightfishes & 11.7 & 11.3 & 10.2 \\
\hline Lampadena spp. & lanternfishes & 4.0 & 11.5 & 17.0 \\
\hline Perciformes & Perciformes fishes & 10.8 & 9.4 & 15.3 \\
\hline Spratelloides delicatulus & delicate round herring & 21.8 & 7.8 & 5.3 \\
\hline Scombridae & mackerels and tunas & 4.8 & 12.3 & 8.9 \\
\hline Apogonidae & cardinalfishes & 5.0 & 3.1 & 5.2 \\
\hline Decapterus spp. & scad & 2.7 & 4.9 & 9.5 \\
\hline Priolepis spp. & gobies & 12.2 & 6.6 & 4.1 \\
\hline Labridae & wrasses & 2.9 & 5.3 & 9.9 \\
\hline Lophiiformes/Tetraodontiformes & anglerfishes/puffers & 4.0 & 5.3 & 6.8 \\
\hline Hygophum proximum & lanternfish & 5.2 & 4.7 & 5.6 \\
\hline Balistidae & triggerfishes & 1.0 & 2.7 & 6.4 \\
\hline Pseudamiops diaphanes & transparent cardinalfish & 7.2 & 7.0 & 1.5 \\
\hline Cirrhitidae & hawkfishes & 1.9 & 2.0 & 4.7 \\
\hline Scorpaenidae & scorpion fishes & 2.6 & 2.7 & 4.6 \\
\hline Cubiceps spp. & cigarfishes & 3.5 & 3.5 & 4.1 \\
\hline Bathygobius spp. & frillfin gobies & 1.9 & 1.2 & 6.1 \\
\hline Gempylidae & snake mackerels & 1.3 & 2.0 & 2.2 \\
\hline Symbolophorus spp. & lanternfishes & 1.9 & 0.5 & 2.8 \\
\hline
\end{tabular}


Table 5-3 (cont). Summary of adjusted concentrations of fish eggs and larvae from oblique tows of the entire water column at Stations 1, 2, and 3 off Port Allen, Kauai from AprilDecember 2012.

\begin{tabular}{|c|c|c|c|c|}
\hline \multirow[b]{2}{*}{ Taxon } & \multirow[b]{2}{*}{ Common Name } & \multicolumn{3}{|c|}{ Concentration $\left(\# / \mathbf{1}, 000 \mathrm{~m}^{3}\right)$} \\
\hline & & Station 1 & Station 2 & Station 3 \\
\hline Microdesmidae & dartfishes & 1.3 & 2.5 & 2.6 \\
\hline Callionymidae & dragonets & - & 3.6 & 1.2 \\
\hline Apogonidae/Gobiidae & cardinalfishes/gobies & 0.2 & 2.7 & 3.0 \\
\hline Synodontidae & lizardfishes & 1.8 & 2.4 & 0.9 \\
\hline Plagiotremus spp. & fangblennies & 0.9 & 2.3 & 1.1 \\
\hline Blenniidae & blennies & 1.6 & 1.6 & 2.8 \\
\hline Sphyraena spp. & barracudas & - & 0.2 & 4.1 \\
\hline Pomacanthidae & angelfishes & 0.7 & - & 2.0 \\
\hline Eviota spp. & gobies & - & 0.9 & 3.3 \\
\hline Clupeidae & herrings & 2.5 & 1.2 & 0.5 \\
\hline Diplophos spp. & lightfishes & 0.2 & 1.6 & 2.1 \\
\hline Labridae/Scaridae & wrasses/parrotfishes & 0.9 & 0.6 & 2.9 \\
\hline Iso hawaiiensis & Hawaiian surf sardine & 0.2 & 3.7 & - \\
\hline Stomiiformes & stomioids & 0.6 & 0.5 & 1.7 \\
\hline Coryphaena spp. & dolphinfish & 0.3 & 0.8 & 1.4 \\
\hline Epigonus spp. & deepwater cardinalfishes & 0.0 & 1.2 & 1.3 \\
\hline Syngnathidae & pipefishes & 1.5 & 1.1 & 0.7 \\
\hline Paralepididae & barracudinas & 1.4 & 0.8 & 1.0 \\
\hline Exocoetidae & flyingfishes & - & - & 3.2 \\
\hline Melamphaes spp. & bigscales & 0.7 & 0.7 & 1.8 \\
\hline Selar crumenophthalmus & bigeye scad & - & - & 2.4 \\
\hline Lampanyctus nobilis & lanternfish & 0.4 & 0.7 & 0.9 \\
\hline Chaetodontidae & butterflyfishes & 0.4 & - & 0.7 \\
\hline Ammodytidae & sand lances & 0.7 & 0.7 & 0.3 \\
\hline Mullidae & goatfishes & 0.6 & - & 1.1 \\
\hline Priacanthidae & bigeyes & - & 1.8 & 0.2 \\
\hline Hygophum reinhardtii & slender lanternfish & 0.5 & - & 0.6 \\
\hline Gonostomatidae & bristlemouths & 0.1 & 0.7 & 0.4 \\
\hline Scaridae & parrotfishes & - & - & 1.6 \\
\hline Howellidae & pelagic basslets & 0.6 & - & 0.5 \\
\hline Bothidae & lefteye flounders & 0.3 & 0.5 & 0.6 \\
\hline Holocentridae & $\begin{array}{l}\text { squirrelfishes and soldierfishes } \\
\text { albacores, mackerels, and }\end{array}$ & 0.2 & - & 0.2 \\
\hline Scombroidei & tunas & - & - & 0.6 \\
\hline Atherinomorus insularum & Hawaiian silverside & - & 0.8 & 0.5 \\
\hline Creediidae & burrowers & 0.2 & 0.7 & - \\
\hline Phosichthyidae & lightfishes & 0.2 & 0.8 & 0.1 \\
\hline
\end{tabular}


Table 5-3 (cont). Summary of adjusted concentrations of fish eggs and larvae from oblique tows of the entire water column at Stations 1, 2, and 3 off Port Allen, Kauai from AprilDecember 2012.

\begin{tabular}{|c|c|c|c|c|}
\hline \multirow[b]{2}{*}{ Taxon } & \multirow[b]{2}{*}{ Common Name } & \multicolumn{3}{|c|}{ Concentration $\left(\# / \mathbf{1}, 000 \mathrm{~m}^{3}\right)$} \\
\hline & & Station 1 & Station 2 & Station 3 \\
\hline Scombrolabrax heterolepis & black mackerel & 0.4 & 0.2 & 0.5 \\
\hline Acanthuridae & surgeonfishes & - & - & 0.3 \\
\hline Nomeidae & driftfishes & 0.9 & - & - \\
\hline Bramidae & pomfrets & 0.1 & - & 0.5 \\
\hline Asterropteryx semipunctata & halfspotted goby & 0.3 & 0.2 & 0.2 \\
\hline Elopomorpha & leptocephalus larvae & 0.1 & - & 0.6 \\
\hline Ipnopidae & tripod fishes & - & 0.3 & 0.3 \\
\hline Sudis atrox & fierce pike smelt & - & - & 0.6 \\
\hline Percoidei & Percoidei fishes & 0.2 & 0.4 & - \\
\hline Melanostomiinae & scaleless black dragonfishes & 0.2 & 0.2 & - \\
\hline Notosudidae & waryfishes & 0.2 & - & - \\
\hline Ranzania laevis & slender mola & 0.1 & 0.3 & - \\
\hline Bregmaceros spp. & codlets & 0.4 & - & - \\
\hline Pleuronectoidei & flatfishes & - & - & 0.3 \\
\hline Kyphosidae & sea chubs & - & 0.2 & 0.2 \\
\hline Hippocampus spp. & seahorses & 0.3 & - & - \\
\hline Malacosteinae & loosejaws & - & - & 0.1 \\
\hline Gigantura indica & telescope fish & - & - & 0.1 \\
\hline Anthiinae & sea basses & - & - & 0.3 \\
\hline Scomberoides lysan & double spotted queenfish & - & - & - \\
\hline Eustomias spp. & scaleless dragonfishes & - & - & - \\
\hline Anguilliformes & eels & - & - & 0.2 \\
\hline Ostraciidae & trunkfishes & - & - & - \\
\hline Evermannellidae & sabertooth fishes & - & - & - \\
\hline Foa brachygramma & bay cardinalfish & 0.2 & - & - \\
\hline Ahliesaurus brevis & waryfish & - & 0.2 & - \\
\hline Gadiformes & grenadiers & - & - & - \\
\hline Astronesthes spp. & snaggletooths & - & - & 0.2 \\
\hline Hemiramphidae & halfbeaks & - & - & - \\
\hline Syngnathiformes & pipefishes and seahorses & - & - & 0.1 \\
\hline Triglidae & searobins & 0.1 & - & - \\
\hline Caristiidae & manefishes & 0.1 & - & - \\
\hline \multirow[t]{3}{*}{ Champsodon fimbriatus } & toothfish & 0.1 & - & - \\
\hline & Total larvae only & $2,490.8$ & $2,320.3$ & $1,862.4$ \\
\hline & Number of taxa & 73 & 66 & 81 \\
\hline
\end{tabular}




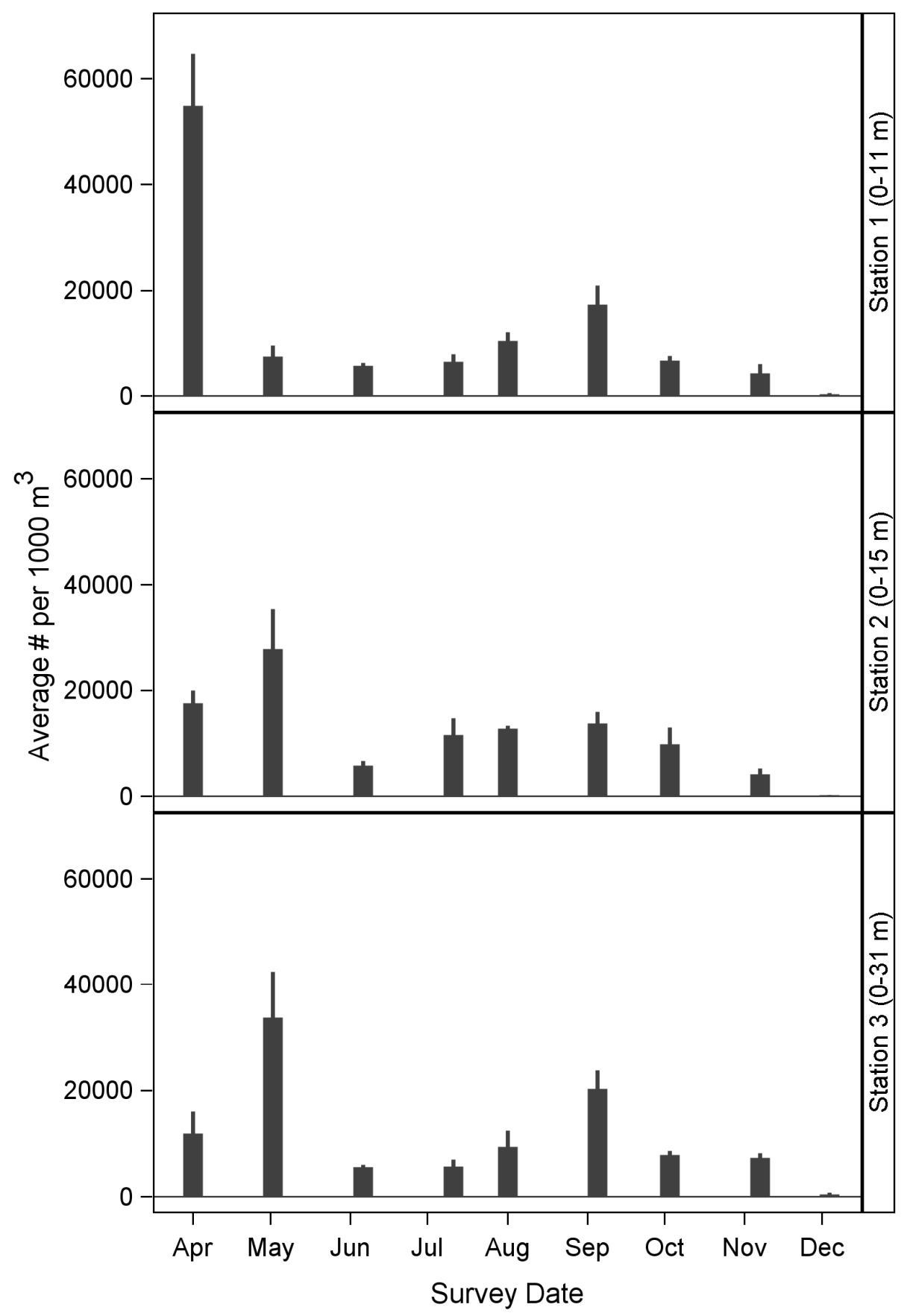

Figure 5-1. Average concentrations (plus one standard error) of fish eggs at the three sampling stations off Port Allen, Kauai from AprilDecember 2012. 


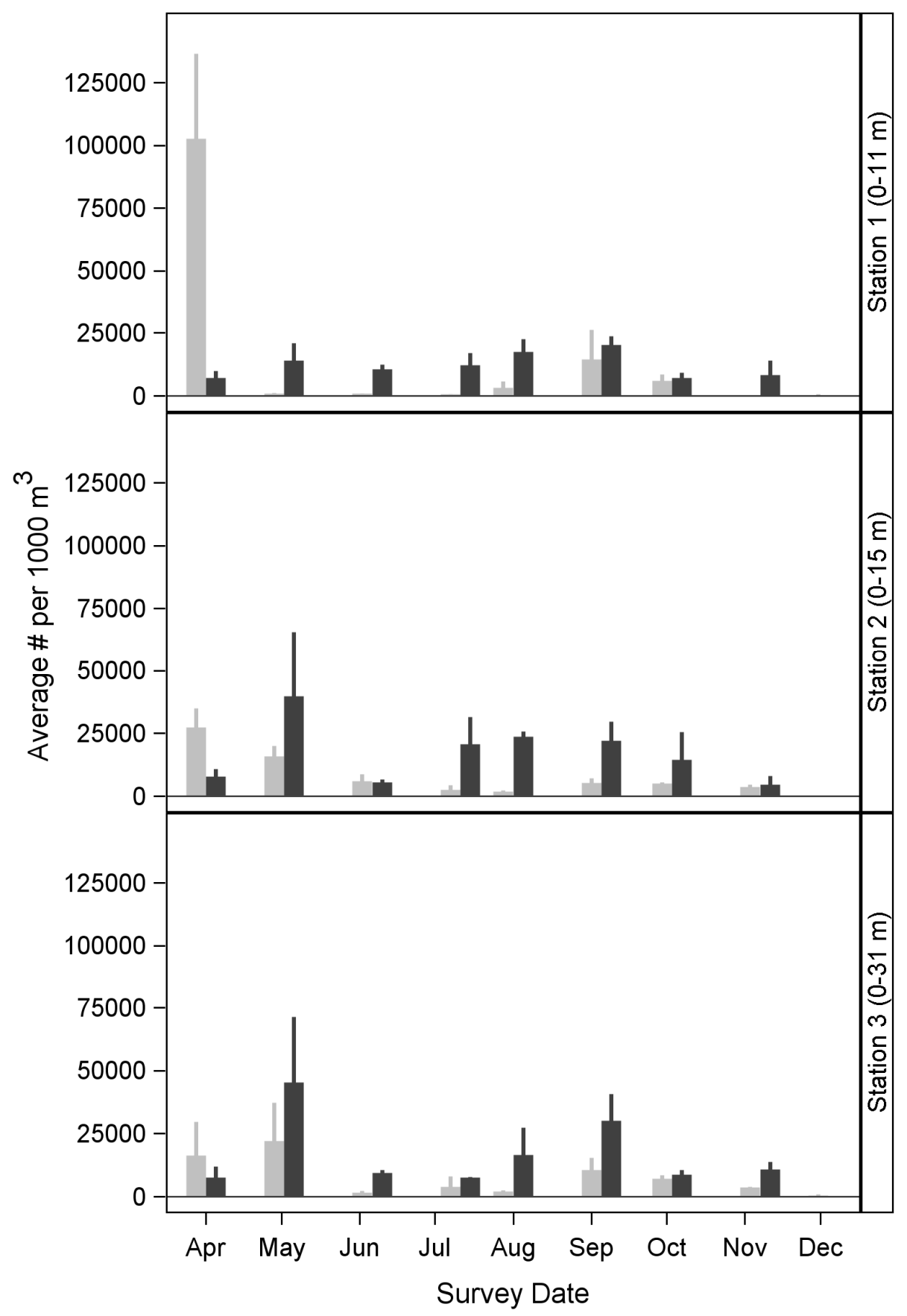

Figure 5-2. Average concentrations (plus one standard error) of fish eggs during day (gray bars) and night (black bars) sampling at the three stations off Port Allen, Kauai from April-December 2012. 


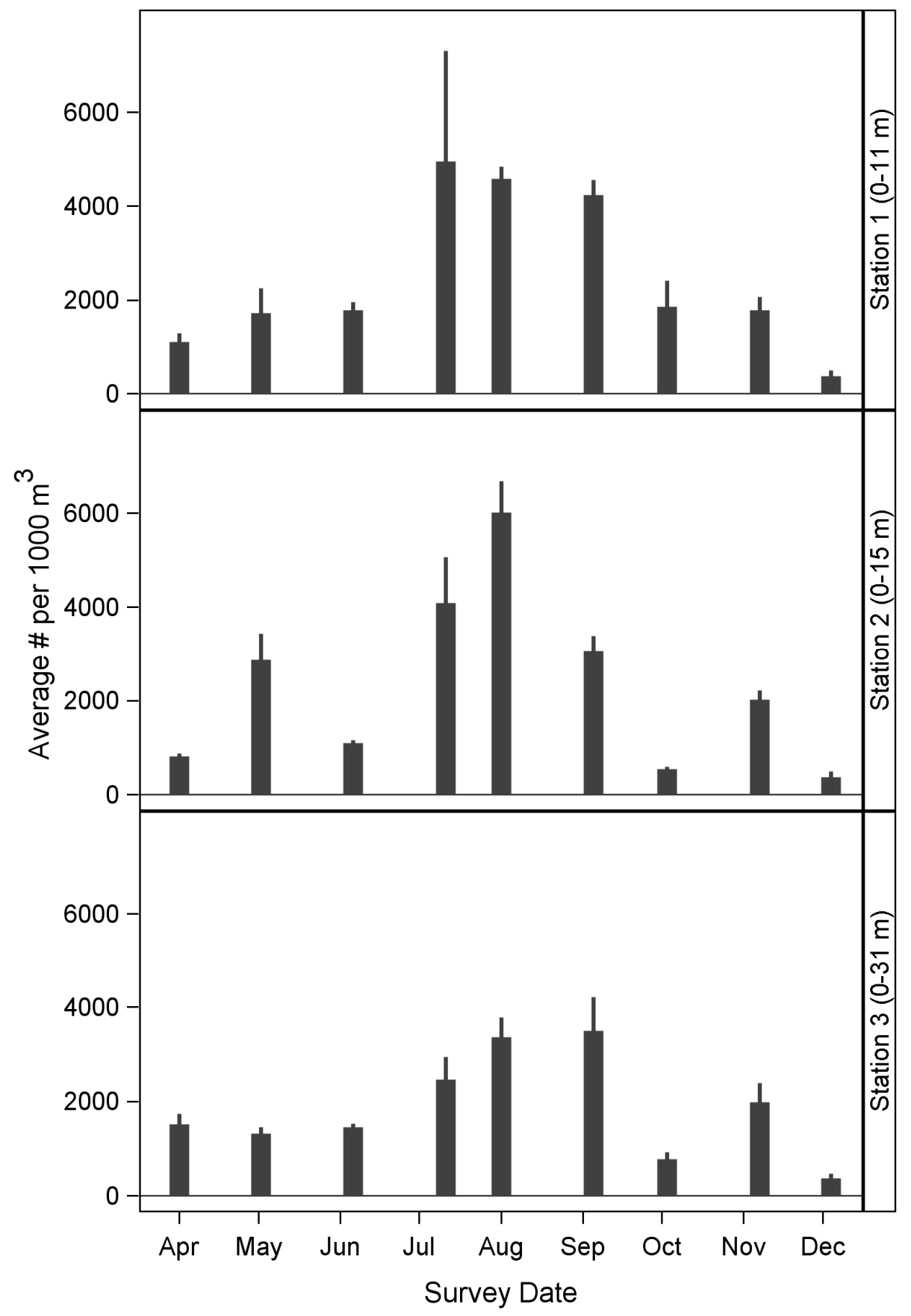

Figure 5-3. Average concentrations (plus one standard error) of fish larvae for all taxa combined at the three sampling stations off Port Allen, Kauai from April-December 2012. 


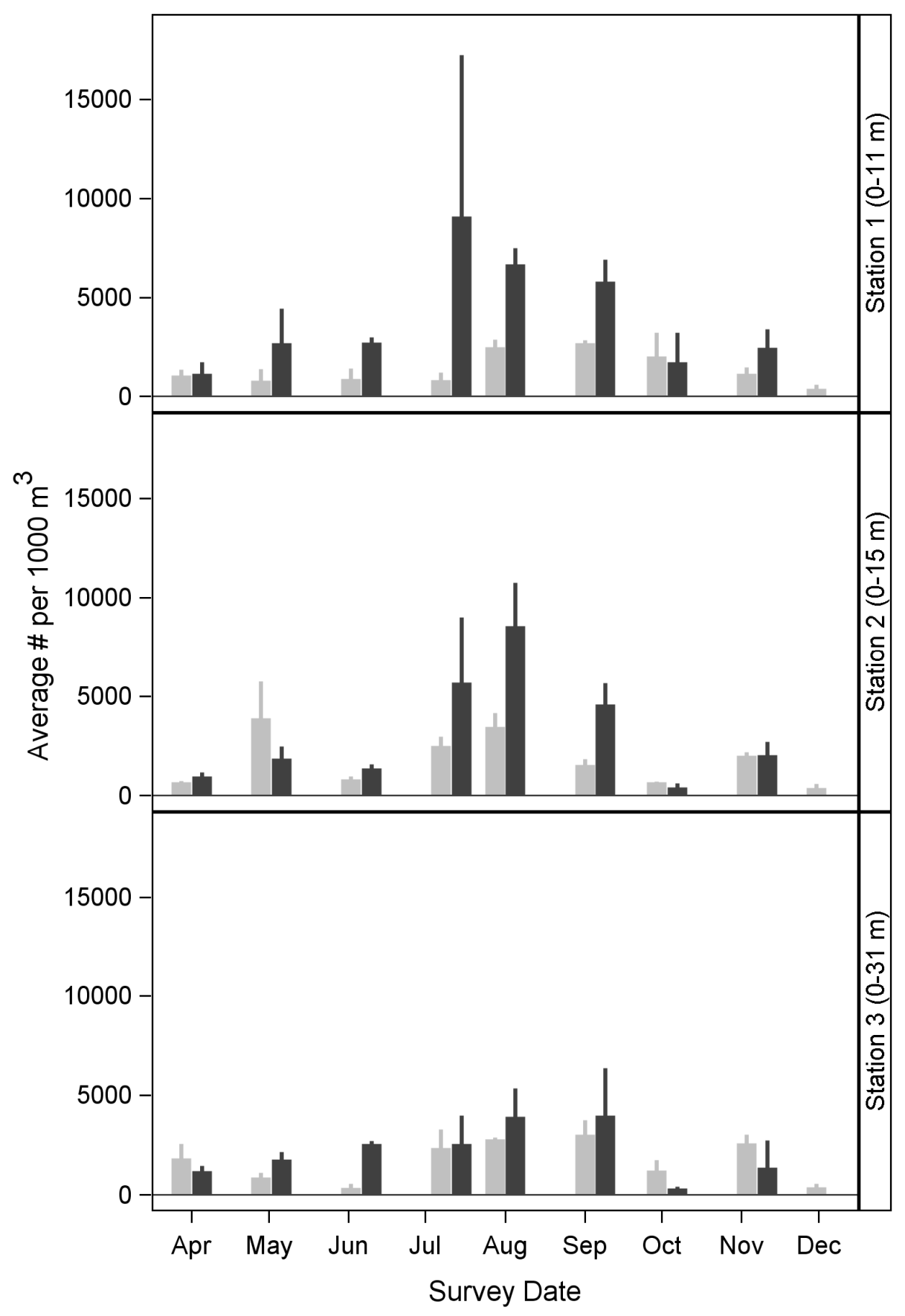

Figure 5-4. Average concentrations (plus one standard error) of fish larvae for all taxa combined during day (gray bars) and night (black bars) sampling at the three stations off Port Allen, Kauai from AprilDecember 2012. 
Table 5-4. Results of ANOVA of data on fish eggs from oblique tows of the entire water column at Stations 1, 2, and 3 during day and night sampling cycles across nine surveys off Port Allen, Kauai from April-December 2012. Tests significant at probability level of $95 \%$ are in bold.

\begin{tabular}{lcccc}
\hline Effect & $\begin{array}{c}\text { Numerator } \\
\text { degrees of } \\
\text { freedom }\end{array}$ & $\begin{array}{c}\text { Denominator } \\
\text { degrees of } \\
\text { freedom }\end{array}$ & F-Value & Probability \\
\hline Station & 2 & 139 & 2.64 & 0.0746 \\
Sampling Cycle & 1 & 140 & 47.68 & $<.0001$ \\
Interaction - Cycle*Station & 2 & 139 & 0.76 & 0.4699 \\
\hline
\end{tabular}

Table 5-5. Results of ANOVA of data on fish larvae for all taxa combined from oblique tows of the entire water column at Stations 1, 2, and 3 during day and night sampling cycles across nine surveys off Port Allen, Kauai from April-December 2012.Tests significant at probability level of $95 \%$ are in bold.

\begin{tabular}{lcrrc}
\hline Effect & $\begin{array}{c}\text { Numerator } \\
\text { degrees of } \\
\text { freedom }\end{array}$ & $\begin{array}{c}\text { Denominator } \\
\text { degrees of } \\
\text { freedom }\end{array}$ & F-Value & Probability \\
\hline Station & 2 & 139 & 1.17 & 0.3149 \\
Sampling Cycle & 1 & 140 & 19.76 & $<.0001$ \\
Interaction - Cycle*Station & 2 & 139 & 5.71 & $\mathbf{0 . 0 0 4 1}$ \\
\hline & & & \\
Comparison of Treatment Levels for Interaction & & T-Value & Probability \\
\hline Station 1-D vs. Station 2-D & 139 & -1.42 & 0.1575 \\
Station 1-D vs. Station 3-D & 139 & -1.30 & 0.1961 \\
Station 2-D vs. Station 3-D & 139 & 0.12 & 0.9030 \\
Station 1-D vs. Station 1-N & 139 & -5.25 & $<.0001$ \\
Station 2-D vs. Station 2-N & 139 & -1.91 & 0.0584 \\
Station 3-D vs. Station 3-N & 139 & -0.67 & 0.5019 \\
Station 1-N vs. Station 2-N & 139 & 1.94 & 0.0545 \\
Station 1-N vs. Station 3-N & 139 & 3.27 & $\mathbf{0 . 0 0 1 4}$ \\
Station 2-N vs. Station 3-N & 139 & 1.33 & 0.1869 \\
\hline
\end{tabular}




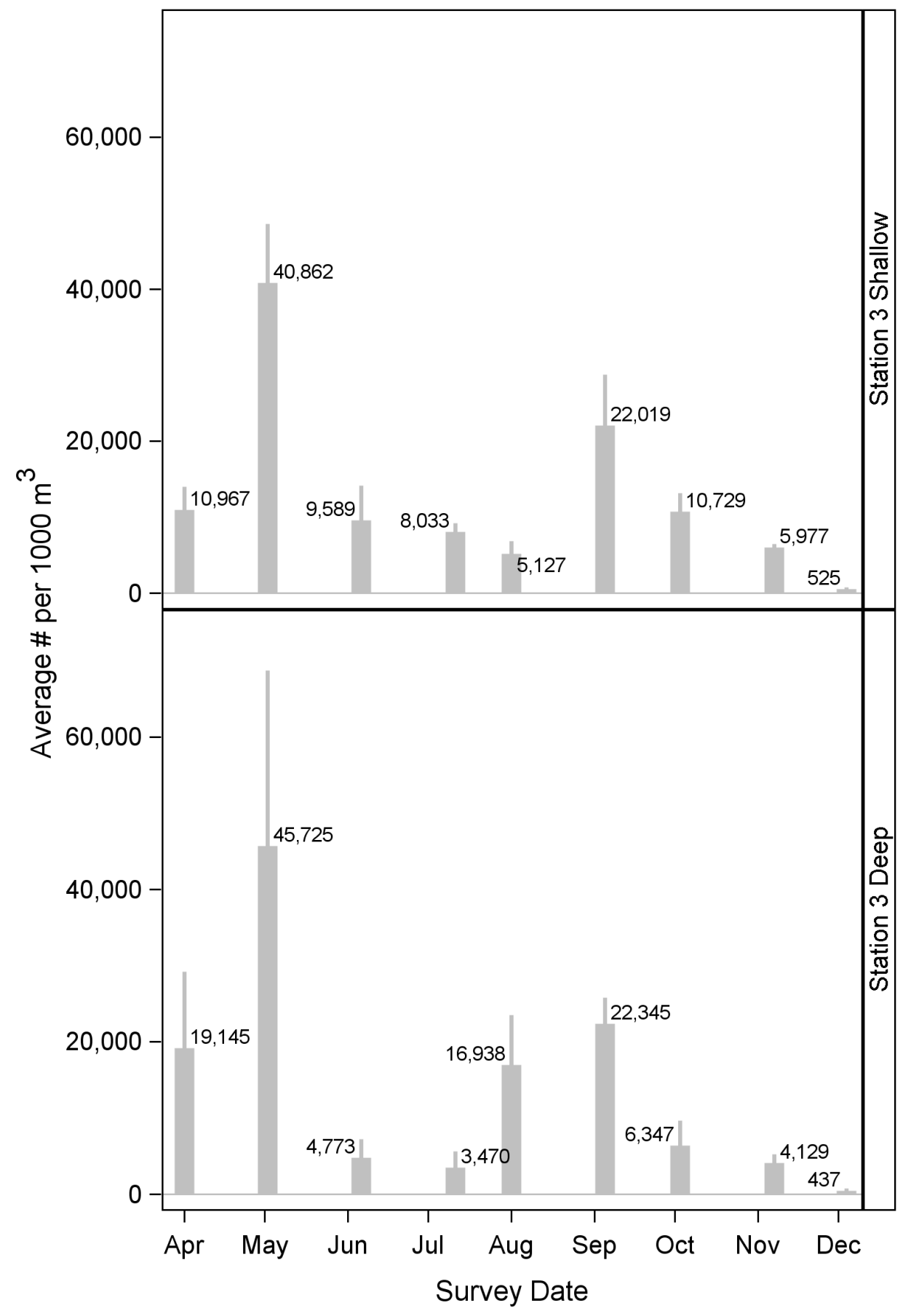

Figure 5-5. Average concentrations (plus one standard error) of fish eggs at two depth strata at Station 3 off Port Allen, Kauai from AprilDecember 2012. Numbers at tops of bars are mean values. 


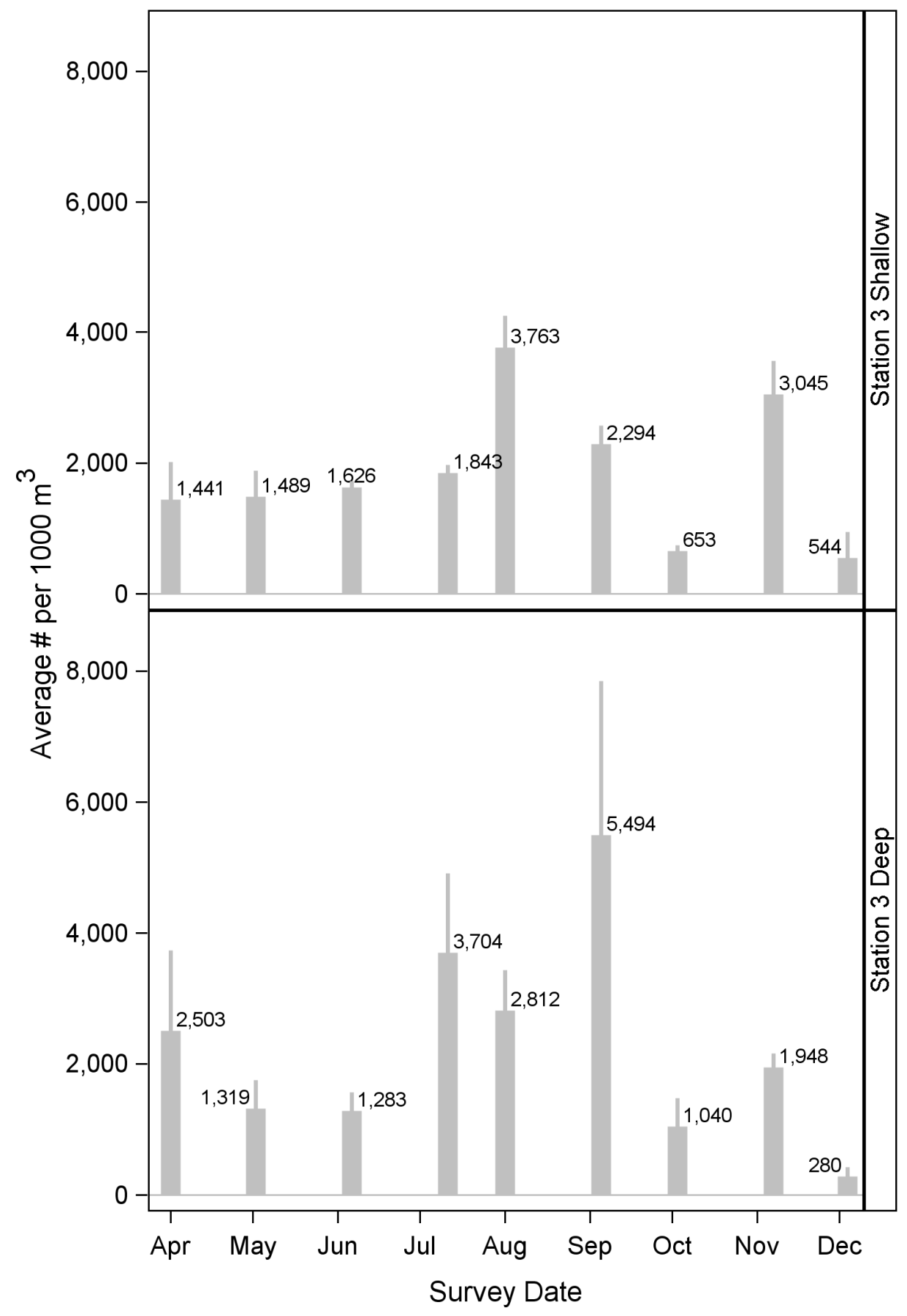

Figure 5-6. Average concentrations (plus one standard error) of fish larvae for all taxa combined at two depth strata at Station 3 off Port Allen, Kauai from April-December 2012. Numbers at tops of bars are mean values. 


\subsection{Results for Most Abundant Taxa}

The following sections present detailed results for the most abundant fishes collected during the study. More detailed analyses were not done for fishes with larvae that were likely transported into the nearshore sampling area from deeper water. These would include lanternfishes (Myctophidae), bristlemouths (Cyclothone spp.), headlight fishes (Diaphus spp.), and lampfishes such as Triphoturus nigrescens. The adults of these fishes do not occur in the nearshore area and would not be affected by larval losses due to entrainment as the larvae would be unlikely to migrate back into the natal habitat of the adults.

\subsubsection{Infantfishes and Gobies (Schindleria spp. and Gobiidae)}

Gobies are small, demersal fishes that are found worldwide in shallow tropical and subtropical environments (Figure 5-7). The family Gobiidae contains approximately 1,950 species in 210 genera (Nelson 2006) and is the largest family of fishes in the marine

environment. There are 34 marine species and four freshwater species of gobies known from the Hawaiian Islands (Randall 2007).

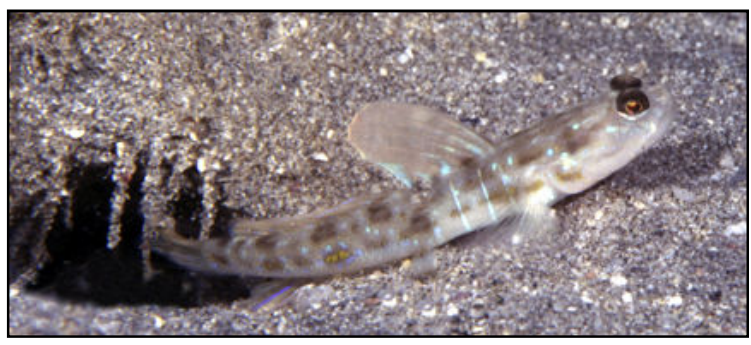

Figure 5-7. Hawaiian shrimp goby (photo by J.P. Hoover).

Schindleria spp., or infantfishes, are members of the family Schindleriidae which is part of the suborder Gobioidei and related to the gobies. It has a distinctive morphology and could therefore be separated from other gobioids in the samples from this study. They are gonochorists, or non sex changers, since the females lack precursor testicular structures found in most sex changing gobies (Thacker 1993). It is one of the smallest fishes in the world and is neotenic, meaning that it is sexually mature in a larva-like form. Two species of Schindleria are known from Hawaii. Schindleria are neritic (nearshore) fishes that are likely the most abundant fish in Hawaiian waters (Gosline and Brock 1960). Due to their abundance, fast population turnover, and high productivity, they may be a very important part of the energy budget for a reef (Whittle 2003). They are typically associated with surface waters and are attracted to lights. They are a tropical family but are not found in the Atlantic or the Caribbean.

\section{Life History and Ecology}

Members of the goby family share a variety of distinguishing characteristics. Their body shape is elongate and can be either somewhat compressed or depressed (Moser 1996). Most members of the family lack both a lateral line and swim bladder (Moyle and Cech 1988). Gobies generally have two dorsal fins, the first consisting of 2-8 flexible spines and 
the second containing a spine and several segmented rays. Their caudal fin is rounded and their pelvic fins are typically joined to form a cup-like disc (Moser 1996). The eyes of most gobies are relatively large and are a dominant feature of their blunt heads. Goby species are extremely variable in coloration. They range from the drab, cryptically colored species that inhabit mudflats to the striking, brightly colored species of tropical and subtropical reefs (Moser 1996).

One of the most important characteristics of the goby family is their small size. Due to their size and evolved tolerances for a variety of environmental conditions, gobies have been able to colonize habitats that are inaccessible to most other fishes. These include cracks and crevices in coral reefs, invertebrate burrows, mudflats, mangrove swamps, freshwater streams on oceanic islands, and inland seas and estuaries (Moyle and Cech 1988). Other examples of these adaptations include three species in the genus Bryaninops found in Hawaiian waters that are adapted for living commensally on the slender fronds of gorgonian sea whips, and the Hawaiian shrimp goby Psilogobius mainlandi which lives in burrows symbiotically with the snapping shrimp Alpheus rapax.

\section{Reproduction and Growth}

Nearly all gobies lay demersal eggs in a patch, or "nest", which is guarded by the male parent. Eggs are sometimes deposited in burrows or tubes that are inhabited by gobies and that have been constructed by benthic macroinvertebrates such as commensal shrimps. Randall (2007) notes that some gobies have been shown to be protogynous hermaphrodites, beginning life as females and later developing into functional males. Schindleria has been found to mature exceptionally rapidly, attaining reproductive size in as few as 23 days after hatching. Whittle (2003) determined a growth rate of $0.72 \mathrm{~mm}$ per day to a maximum of $17.3 \mathrm{~mm}$ total length for Schindleria.

Larval durations are relatively short for most gobies and this restricted dispersal capability may explain the reduced number of species that occur in the Hawaiian archipelago.

\subsubsection{Sampling Results}

In many instances, larvae in this study could not be reliably identified to the level of species and were therefore combined into the family designation, Gobiidae. A few individuals could be identified to either the species or genus level. These included Asterropteryx semipunctatus, Bathygobius spp., Eviota spp. and Priolepis spp. The analyses for gobies was done on the combined abundances of all these taxa. 


\subsection{Infantfishes (Schindleria spp.)}

The larva collected in highest abundance (25.6\% of the total larvae collected) was the infantfish (Schindleria spp.) (Figure 5-8) with an average concentration from all the samples of about 540 larvae per $1,000 \mathrm{~m}^{3}$ (Table 5-2). It was collected during every survey but was most abundant during the July and August surveys (Figure 5-9). There were more of these larvae collected during the night sampling than during the day (Figure 5-10). An ANOVA for this taxa, after transformation $(\log [\mathrm{x}+0.01])$, detected a significant interaction between the factors for station and sampling cycle $(p<0.05)$ requiring that the individual comparisons among these treatment combinations be examined (Table 5-6). The comparisons among the individual treatment combinations detected significant differences

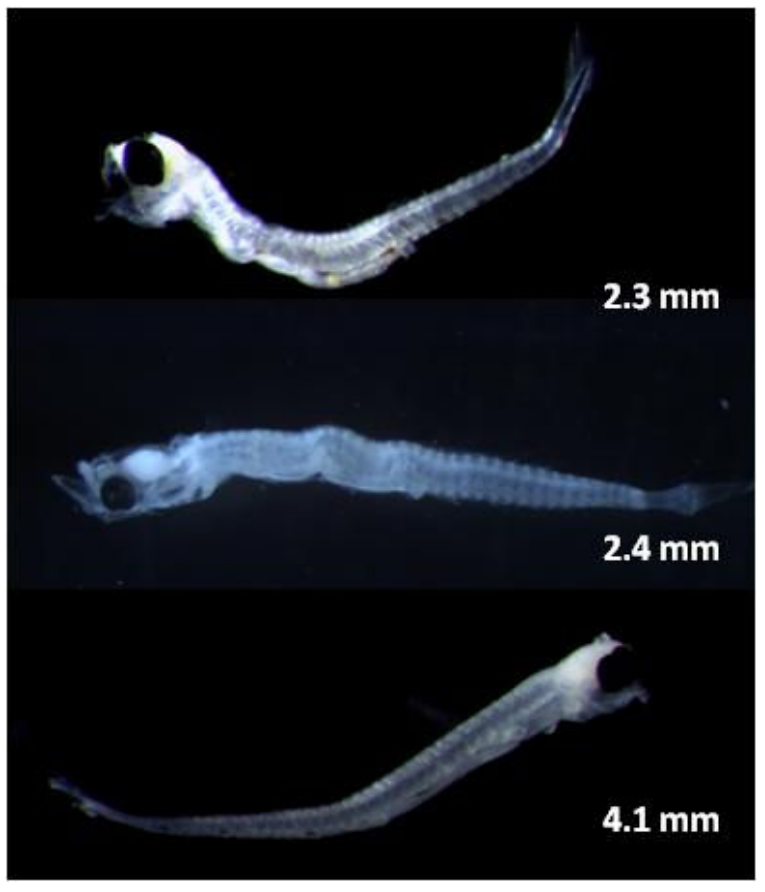

Figure 5-8. Schindleria spp. larvae collected during this study. between the daylight sampling cycles at Stations 1 and 2 and also between Stations 1 and 3 with Station 1 abundances being lower in both instances. The comparisons also detected significant differences between the day and night sampling cycles at all three stations with the night sampling cycle having higher abundances than the day cycle.

The calculated values for the deeper depth strata at Station 3, indicated that this taxa was generally more abundant in the deeper portion of the water column (Figure 5-11), but the ANOVA of the abundances at the two depths after $\log$ transformation $(\log [\mathrm{x}+0.5])$ did not detect a significant difference between depth strata $(\mathrm{p}=0.325)$.

The notochord length of the Schindleria larvae measured from the study ranged from about 2.5 to $19 \mathrm{~mm}$ (Figure 5-12). The mean length was $9.7 \mathrm{~mm}$ while the median length was $10.4 \mathrm{~mm}$. The relationships between notochord length and head capsule measurements for Schindleria larvae are presented in Figure 5-13. Generally the head height and width for this size larvae were similar as shown in the two regression lines for the measured lengths. 


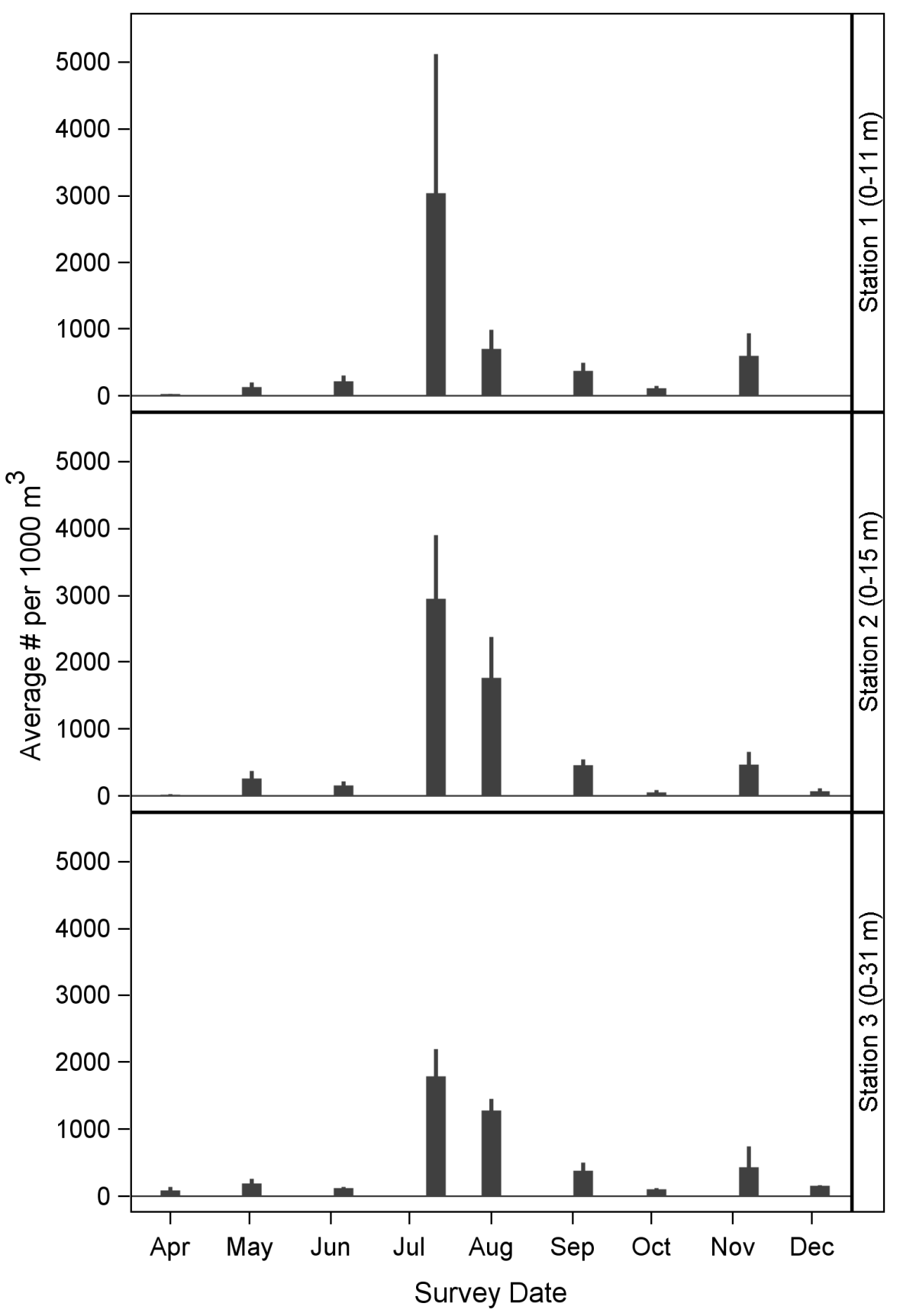

Figure 5-9. Average concentrations (plus one standard error) of Schindleria spp. larvae at the three sampling stations off Port Allen, Kauai from April-December 2012. 


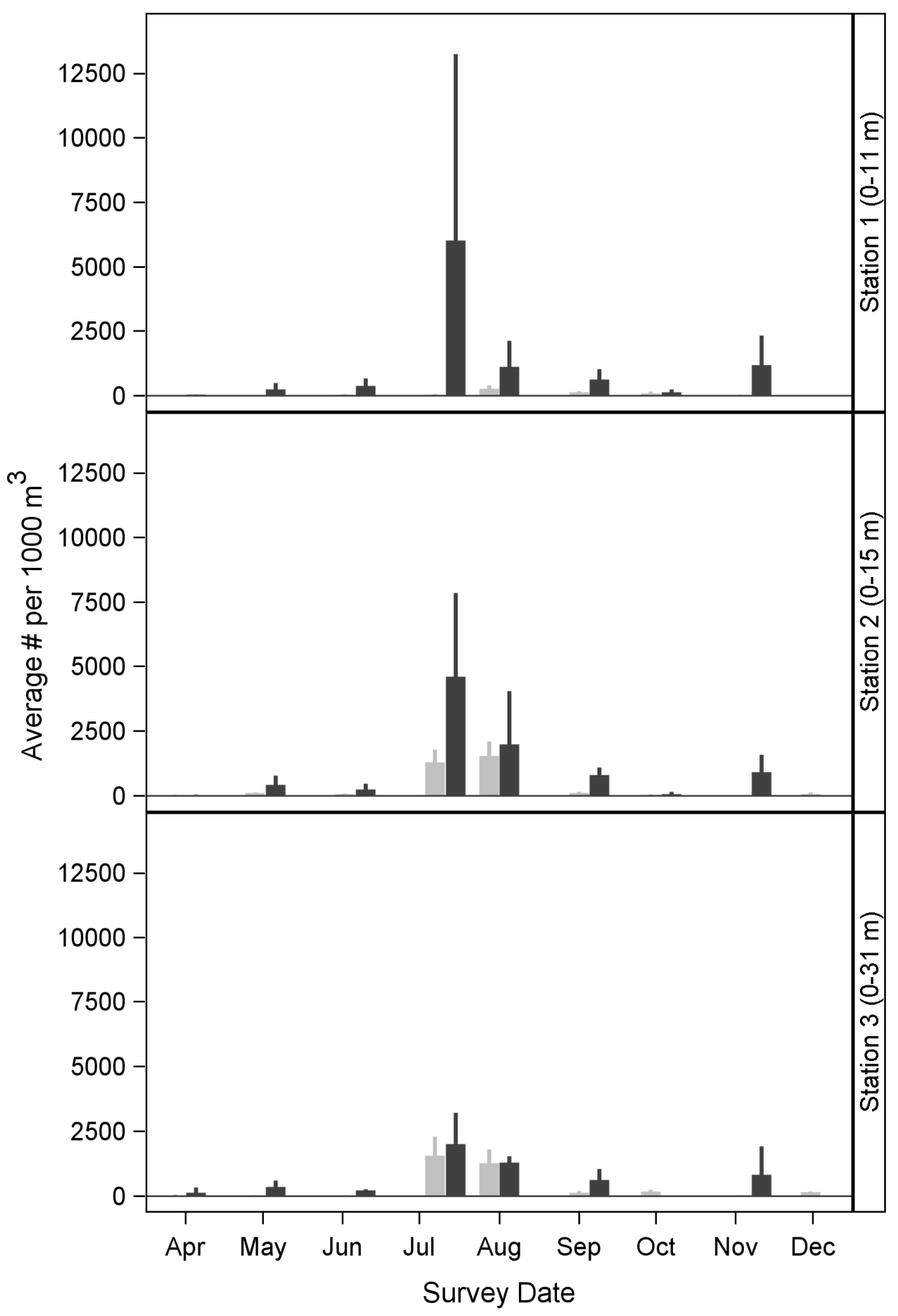

Figure 5-10. Average concentrations (plus one standard error) of Schindleria spp. larvae during day (gray bars) and night (black bars) sampling at the three stations off Port Allen, Kauai from AprilDecember 2012. 
Table 5-6. Results of ANOVA of data on Schindleria spp. larvae from oblique tows of the entire water column at Stations 1, 2, and 3 during day and night sampling cycles across nine surveys off Port Allen, Kauai from April-December 2012. Tests significant at probability level of $95 \%$ are in bold.

\begin{tabular}{lcccc}
\hline Effect & $\begin{array}{c}\text { Numerator } \\
\text { degrees of } \\
\text { freedom }\end{array}$ & $\begin{array}{c}\text { Denominator } \\
\text { degrees of } \\
\text { freedom }\end{array}$ & F-Value & Probability \\
\hline Station & 2 & 139 & 2.52 & 0.0838 \\
Sampling Cycle & 1 & 140 & 60.93 & $<.0001$ \\
Interaction - Cycle*Station & 2 & 139 & 5.84 & $\mathbf{0 . 0 0 3 7}$ \\
\hline & & & \\
Comparison of Treatment Levels for Interaction & & T-Value & Probability \\
\hline Station 1-D vs. Station 2-D & 139 & -3.47 & $\mathbf{0 . 0 0 0 7}$ \\
Station 1-D vs. Station 3-D & 139 & -3.67 & $\mathbf{0 . 0 0 0 3}$ \\
Station 2-D vs. Station 3-D & 139 & -0.20 & 0.8411 \\
Station 1-D vs. Station 1-N & 140 & -7.35 & $<.0001$ \\
Station 2-D vs. Station 2-N & 140 & -3.36 & $\mathbf{0 . 0 0 1 0}$ \\
Station 3-D vs. Station 3-N & 140 & -3.05 & $\mathbf{0 . 0 0 2 7}$ \\
Station 1-N vs. Station 2-N & 139 & 0.64 & 0.5239 \\
Station 1-N vs. Station 3-N & 139 & 0.75 & 0.4565 \\
Station 2-N vs. Station 3-N & 139 & 0.11 & 0.9143 \\
\hline
\end{tabular}




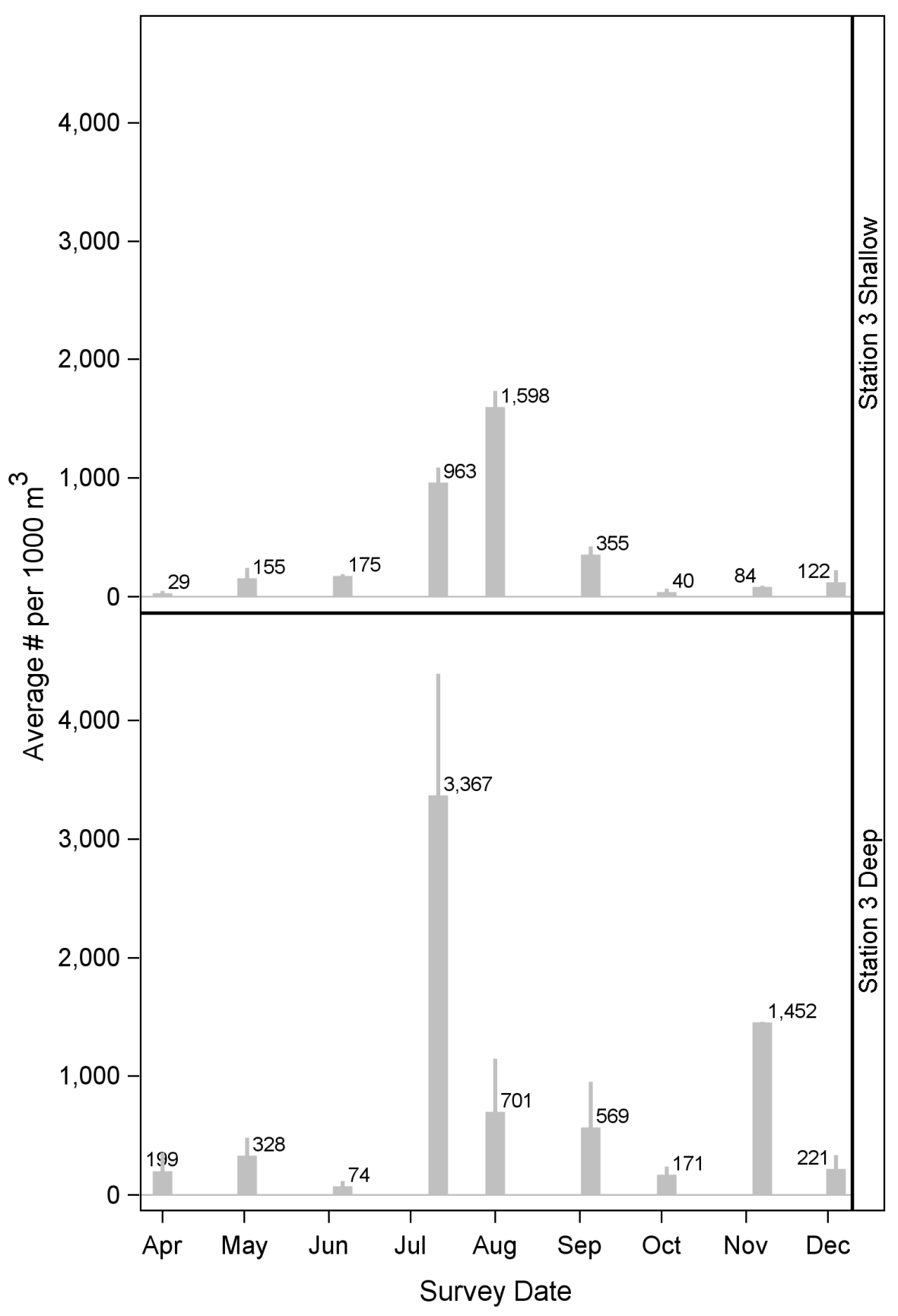

Figure 5-11. Average concentrations (plus one standard error) of Schindleria spp. larvae at two depth strata at Station 3 off Port Allen, Kauai from April-December 2012. Numbers at tops of bars are mean values. 


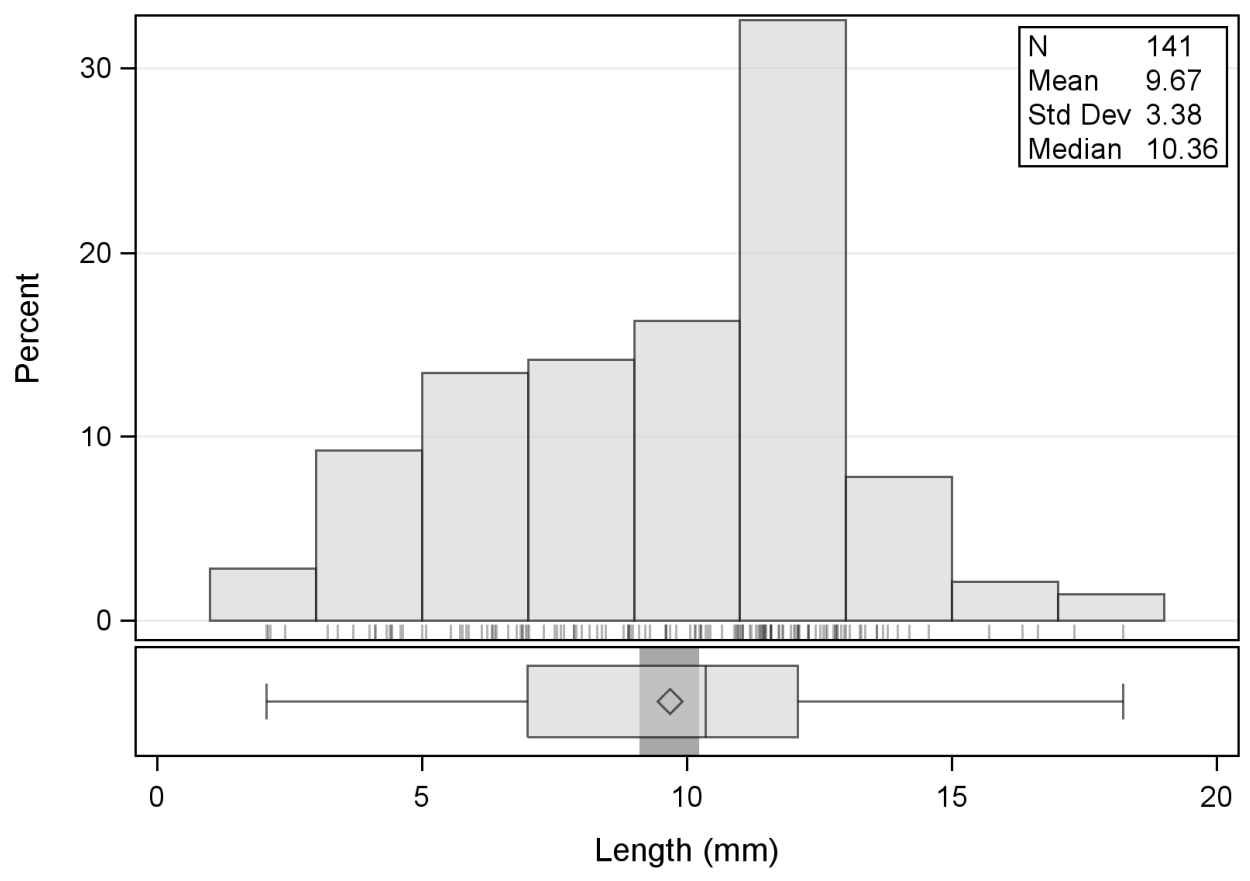

Figure 5-12. Length frequency of Schindleria spp. larvae measured from the samples.

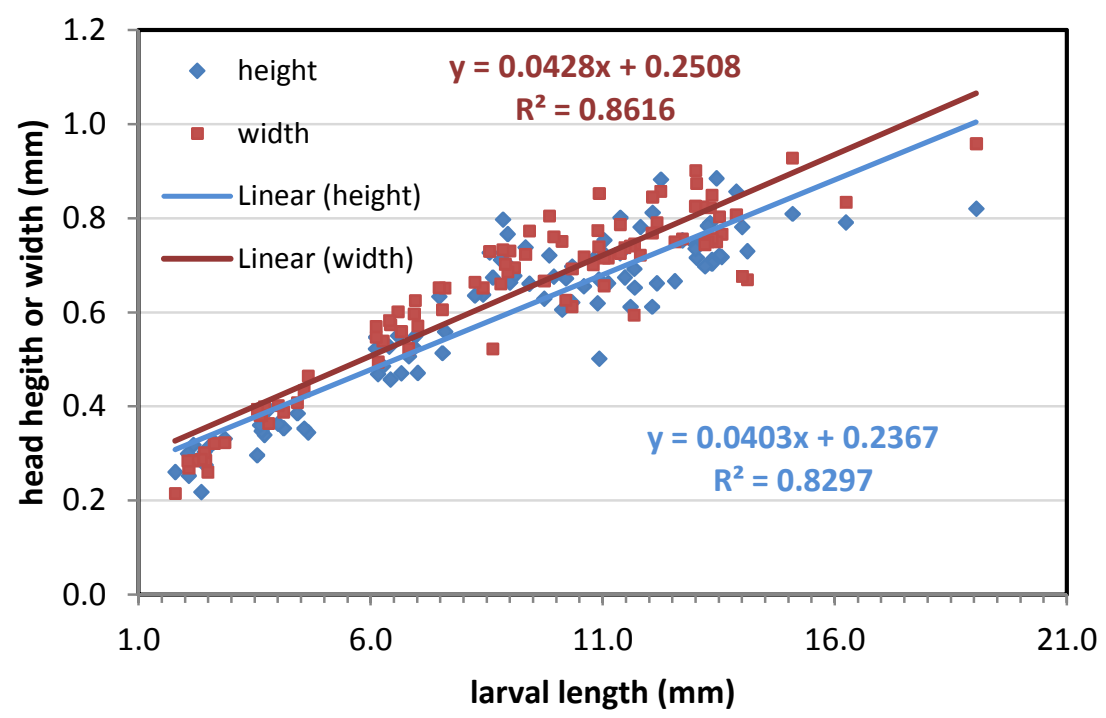

Figure 5-13. Larval length versus head capsule measurements of Schindleria spp. larvae. These measurements are for larvae measured during this study and others conducted in Hawaii. 


\subsubsection{Gobies (Gobiidae)}

Gobiidae (Figure 5-14) were the third most abundant taxon of larval fishes collected during this study $(11.5 \%$ of the total larvae collected) with an average concentration of 243 per $1,000 \mathrm{~m}^{3}$ (Table $5-2$ ). This taxon was most abundant at Station 2 with the lowest concentration being found at Station 1 (Table 5-3). Gobiidae larvae were most abundant during the August survey (Figure 5-15). Generally, more individuals were collected during the night sampling than during the day,

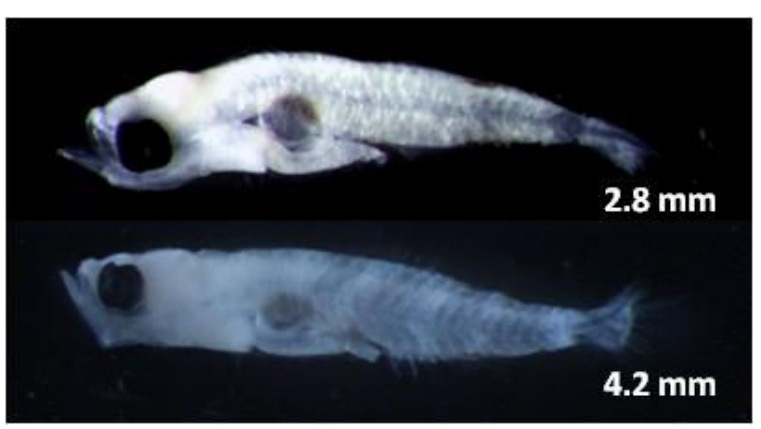

Figure 5-14. Gobiidae larvae collected during this study. but it was not consistent at all stations or during all surveys (Figure 5-16). An ANOVA for Gobiidae larvae, after transformation $(\log [\mathrm{x}+0.01])$, detected a significant interaction between the factors for station and sampling cycle $(\mathrm{p}<0.05)$ requiring that the individual comparisons among these treatment combinations be examined (Table 5-7). The comparisons among the individual treatment combinations detected significant differences between the day collection at Stations 1 and 2 and also between Stations 1 and 3 with Stations 2 and 3 abundances being higher in both instances. The comparisons also detected significant differences between the day and night sampling cycles at Station 1 with the night sampling cycle having higher abundance than the day sampling cycle.

The calculated values for the deeper depth strata at Station 3 did not show any consistent trend across surveys for higher concentrations in either the shallow or deep strata although average concentrations were generally higher at the deeper depths (Figure 5-17). The ANOVA analysis of the abundances at the two depths after log transformation $(\log [\mathrm{x}+0.1])$, did not detect a significant difference between depth strata for Gobiidae larvae $(\mathrm{p}=0.670)$.

The mean NL length of the goby larvae measured from the samples was about $2.5 \mathrm{~mm}$ with only a few individuals longer than $4 \mathrm{~mm}$ (Figure 5-18). The relationships between notochord length and head capsule measurements for Gobiidae larvae are presented in Figure 5-19. Head heights were slightly larger than head width at the same length. 


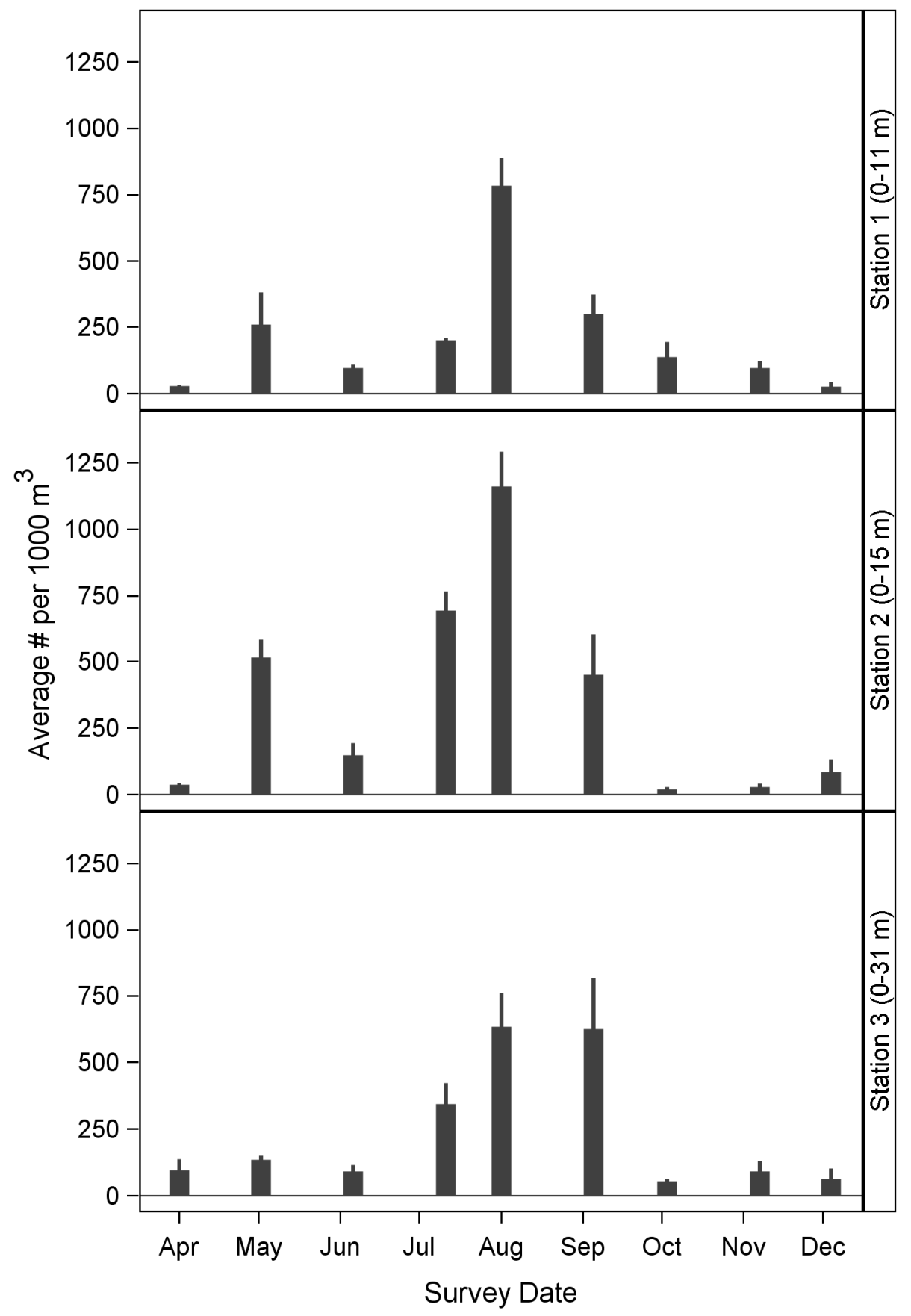

Figure 5-15. Average concentrations (plus one standard error) of Gobiidae larvae at the three sampling stations off Port Allen, Kauai from April-December 2012. 


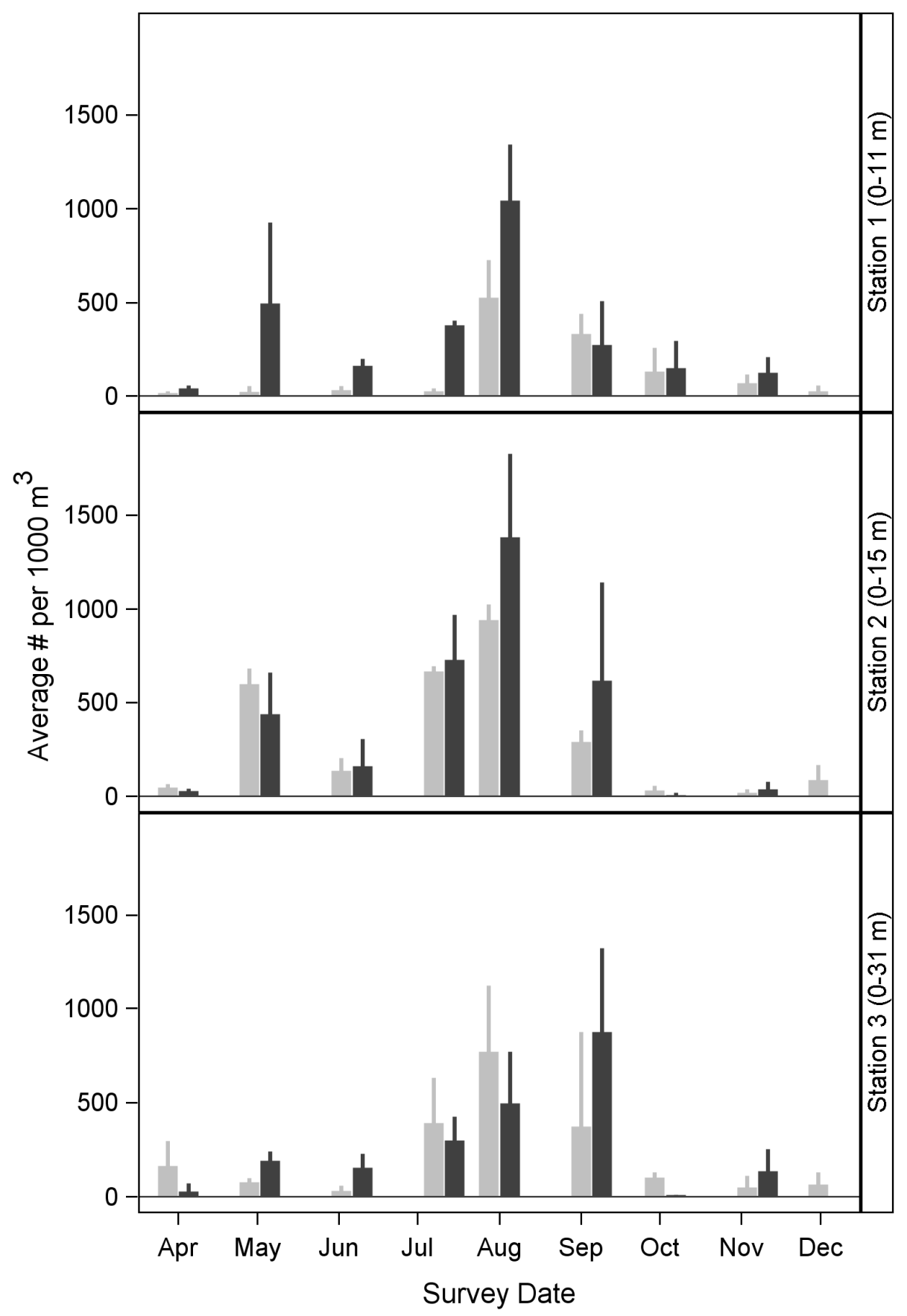

Figure 5-16. Average concentrations (plus one standard error) of Gobiidae larvae during day (gray bars) and night (black bars) sampling at the three stations off Port Allen, Kauai from April-December 2012. 
Table 5-7. Results of ANOVA of data on Gobiidae larvae from oblique tows of the entire water column at Stations 1, 2, and 3 during day and night sampling cycles across nine surveys off Port Allen, Kauai from April-December 2012. Tests significant at probability level of $95 \%$ are in bold.

\begin{tabular}{lcccc}
\hline Effect & $\begin{array}{c}\text { Numerator } \\
\text { degrees of } \\
\text { freedom }\end{array}$ & $\begin{array}{c}\text { Denominator } \\
\text { degrees of freedom }\end{array}$ & F-Value & Probability \\
\hline Station & 2 & 139 & 1.46 & 0.2358 \\
Sampling Cycle & 1 & 140 & 6.23 & $\mathbf{0 . 0 1 3 7}$ \\
Interaction - Cycle*Station & 2 & 139 & 5.38 & $\mathbf{0 . 0 0 5 6}$ \\
\hline & & & \\
Comparison of Treatment Levels for Interaction & & T-Value & Probability \\
\hline Station 1-D vs. Station 2-D & 139 & -3.41 & $\mathbf{0 . 0 0 0 9}$ \\
Station 1-D vs. Station 3-D & 139 & -2.3 & $\mathbf{0 . 0 2 3 2}$ \\
Station 2-D vs. Station 3-D & 139 & 1.11 & 0.2686 \\
Station 1-D vs. Station 1-N & 139 & -4.1 & $<.0001$ \\
Station 2-D vs. Station 2-N & 139 & 0.11 & 0.9133 \\
Station 3-D vs. Station 3-N & 139 & -0.4 & 0.6870 \\
Station 1-N vs. Station 2-N & 139 & 0.92 & 0.3593 \\
Station 1-N vs. Station 3-N & 139 & 1.46 & 0.1454 \\
Station 2-N vs. Station 3-N & 139 & 0.54 & 0.5870 \\
\hline
\end{tabular}




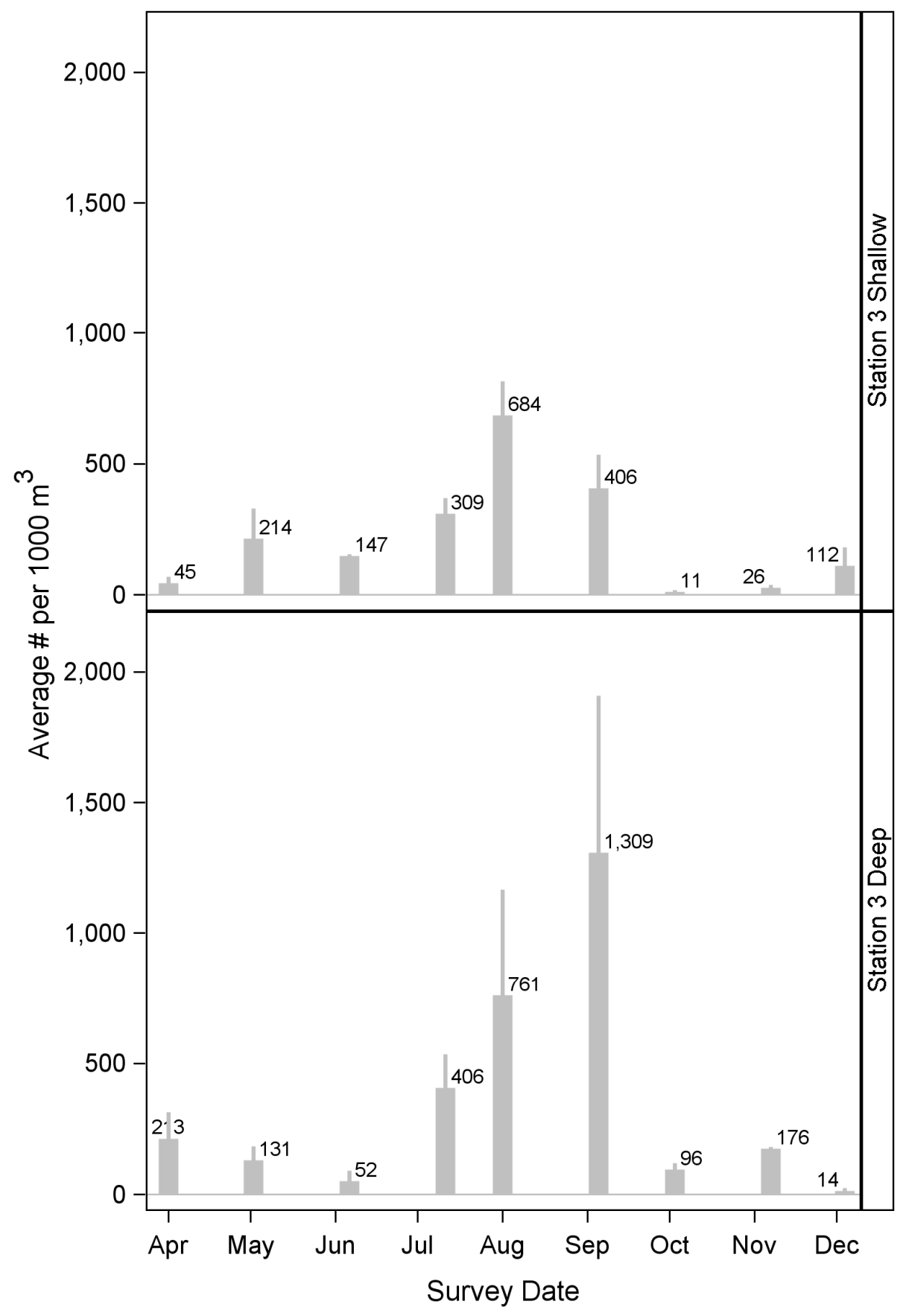

Figure 5-17. Average concentrations (plus one standard error) of Gobiidae larvae at two depth strata at Station 3 off Port Allen, Kauai from April-December 2012. Numbers at tops of bars are mean values. 


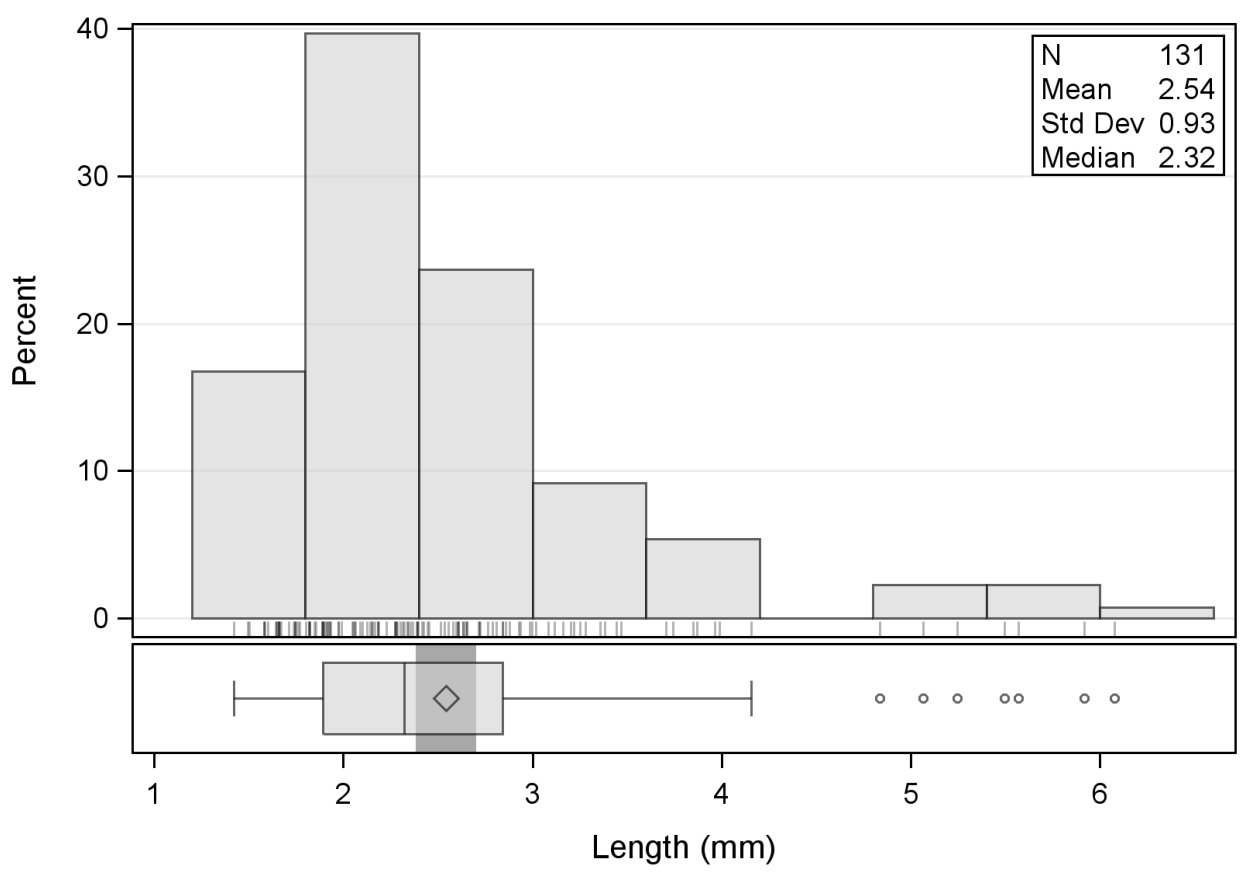

Figure 5-18. Length frequency of Gobiidae larvae measured from the samples.

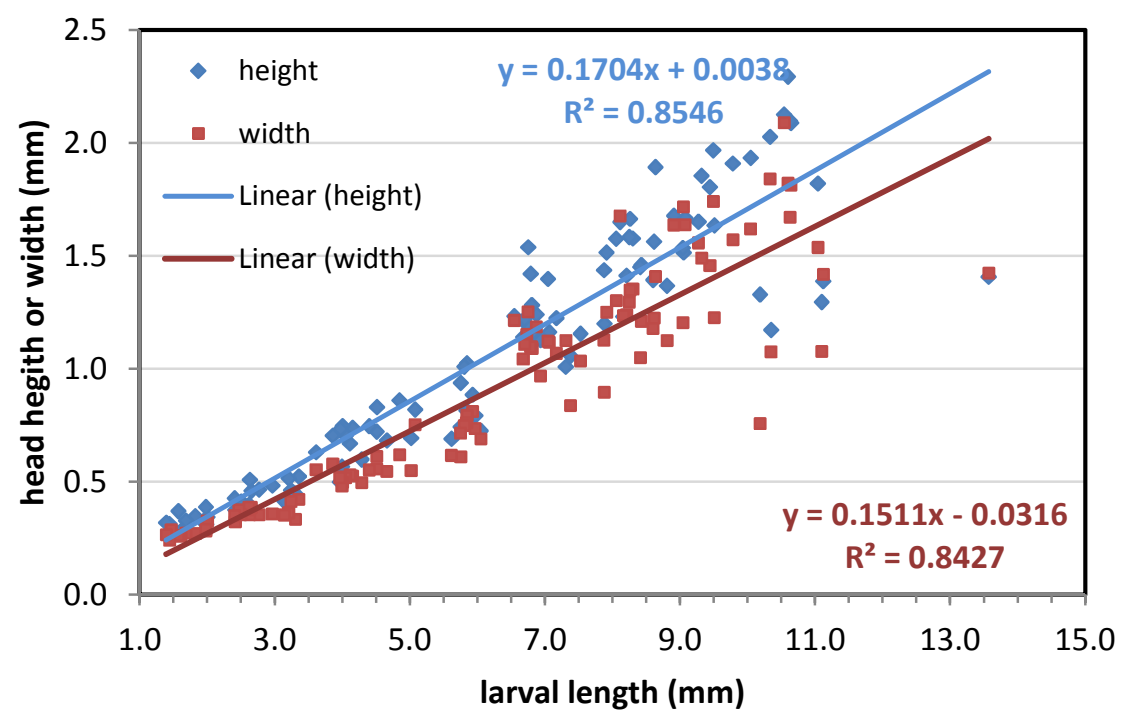

Figure 5-19. Larval length versus head capsule measurements of Gobiidae larvae. These measurements are for larvae measured during this study and others conducted in Hawaii. 


\subsubsection{Blennies and Hawaiian triplefin (Salariinae, Blenniinae and Enneapterygius atriceps)}

The Blennioidei suborder is a complex of six families with the Tripterygiidae (triplefins) and Blenniidae (blennies) being the only families represented in Hawaii. The Tripterygiids are small blennioid fishes, distinguished primarily by their three separate dorsal fins. They occur worldwide in tropical to temperate seas living on coral reefs or shallow rocky substrata, with highest concentrations in the Indo-Pacific. There are 30 genera and 125 species worldwide (Fricke 1994), but the Hawaiian triplefin (Enneapterygius atriceps) is the only species found in Hawaiian waters (Randall 2007).

Fishes in the family Blenniidae are small reef blennies up to $11 \mathrm{~cm}$. The group includes the fangblennies (Plagiotremus spp.), which are named for the large, recurved, canine teeth that is typical of the whole group. The fang is not used in feeding but is used for defense. Many in this group specialize in feeding upon mucous and scales of larger fish, using mimicry and stealth to achieve close proximity. Omobranchus obliquus may have been introduced to Hawaii with Tridacna clams brought in from the Samoa Islands.

Fishes in the subfamily Salariinae are small blennies, up to $19.3 \mathrm{~cm}$ long, found in tropical and subtropical marine waters, rarely in brackish and fresh water. They typically reside near shore and in bays shallower than $18 \mathrm{~m}$. They are benthic, usually living in holes, cracks, and tide pools. Nine species are present in Hawaiian waters, four of which are endemic to the Islands. Most are herbivorous, but at least one species, Exallias brevis, is known to feed on live coral polyps.

All blennies are small, elongate fishes with long dorsal and anal fins, blunt foreheads, and small paired pelvic fins. Many of the species have cirri on the orbital region of the head and are cryptic on reefs or shallow rocky substrates. This large family (53 genera and about 345 species worldwide [Randall 2007]) is divided into two subfamilies, both of which are represented in Hawaii. Fourteen species of blennies ( $p \bar{a} o^{\prime} o$ ) occur in Hawaii, eight of which are endemic. Common species include the zebra rockskipper (Istiblennius zebra), bullethead rockskipper (Blenniella gibifrons), scarface blenny (Cirripectes vanderbilti), marbled blenny (Entomacrodus marmoratus), shortbodied blenny (Exallias brevis), gargantuan blenny (Cirripectes obscurus), and fangblennies (Plagiotremus spp.).

\section{Life History and Ecology}

The primary habitats and depth distributions of some of the common blennies and triplefin that follow are from Randall (2007). The Hawaiian triplefin is common but rarely seen by the casual observer due to its small size and secretive habits and has been recorded from rocky or dead coral substrata in depths of 1-23 $\mathrm{m}$. The fangblenny is a reef-associated species that occurs from a few meters to depths of at least $55 \mathrm{~m}$. The zebra rockskipper is mainly an intertidal species found from the highest tidepools to the surfzone. The scarface 
blenny occurs on coral reefs and shallow rocky bottom substrates from less than one meter to $10 \mathrm{~m}$. Lastly, the gargantuan blenny is known to occur from 1-6 $\mathrm{m}$ deep on rocky shores exposed to wave action.

\section{Reproduction and Growth}

Blennies spawn small clusters of eggs that adhere to the substrate, often in crevices or tubes where they are attended by the male. However, some species, like the shortbodied blenny, spawn on the surface of live coral (often Porites) after clearing a small patch of polyps (Randall 2007).

Hawaiian triplefin can spawn throughout the year, but Longenecker and Langston (2005) found that they have a regular spawning season with a peak in early summer and decreased effort into late summer. Because of their short life span, estimated to be on the order of 4 months, triplefins only spawn over an approximately 2-month period. Batch fecundity is a cubic function of standard length, ranging from about 20-160 oocytes per batch. Rather than partitioning batches between multiple males and nesting sites, it is more likely that the females spawn an entire clutch of eggs in a single event (in a male-guarded nest). Actual egg development, incubation time and hatch length data are not available for this species, however, Enneapterygius etheostomus, another Indo-Pacific species of triplefin, deposits demersal, small (0.9-1.0-mm diameter), nearly spherical eggs. E. etheostomus hatches at 4.6-5.0 mm TL (Shiogaki and Dotsu 1973).

After hatching, Hawaiian triplefin larvae settle after about 30 days. Larval growth rates have not been measured but a size of $15 \mathrm{~mm}$ SL is attained at about 55 days for an average growth of $0.27 \mathrm{~mm} /$ day. Males reach maturity by $17 \mathrm{~mm}$ SL and females by $18 \mathrm{~mm}$ SL. Post larval growth rate was estimated at $0.34 \mathrm{~mm} /$ day (Longenecker and Langston 2005).

While batch fecundity and standard length relationships are best described by a cubic function, the data fits a linear model nearly as well, which makes the Hawaiian triplefin a good candidate for studies of environmental effects on recruitment success as the reproductive potential of a population can be modeled on adult abundance (Longenecker and Langston 2005). Diet consists mainly of harpacticoid copepods and amphipods, tanaids, and barnacle appendages (Longenecker and Langston 2005).

Another common species of blenny is the zebra rockskipper, a primarily intertidal species. For spawning, males prepare a clean patch of rock within their hole to serve as a nest, and then with a color display and behaviors, they attract females into the nest to lay eggs on the rock surface. The female leaves, but the male remains to tend and guard the eggs, which hatch in about a week. There is no information on larval duration for this species.

Most tropical blennies are herbivorous although one species feeds on coral polyps and 
some species (fangblennies) bite skin tissue and mucus and scales from other fish. Blennies are prey items for larger carnivorous fishes.

\section{Population Trends and Fishery}

No targeted fishery exists for blennies, although some species may be collected for the aquarium trade and some may be harvested for personal consumption.

\subsubsection{Sampling Results}

\subsection{Blennies (Salariinae)}

Salariinae (Figure 5-20) was the second most abundant larval taxon collected at the three stations during this study $(15.9 \%$ of the total larvae collected) with an average concentration from all the sampling of 335 larvae per 1,000 $\mathrm{m}^{3}$ (Table 5-2). The average concentrations from the oblique tows conducted through the entire water column at the three stations ranged from about 228 to 516 larvae per $1,000 \mathrm{~m}^{3}$ with the highest average concentration occurring at Station 1 (Table 5-3). The highest average concentrations of Salariinae were collected during the September survey at Station 1 and the August survey at Station 2 (Figure 5-21). The lowest average concentrations were

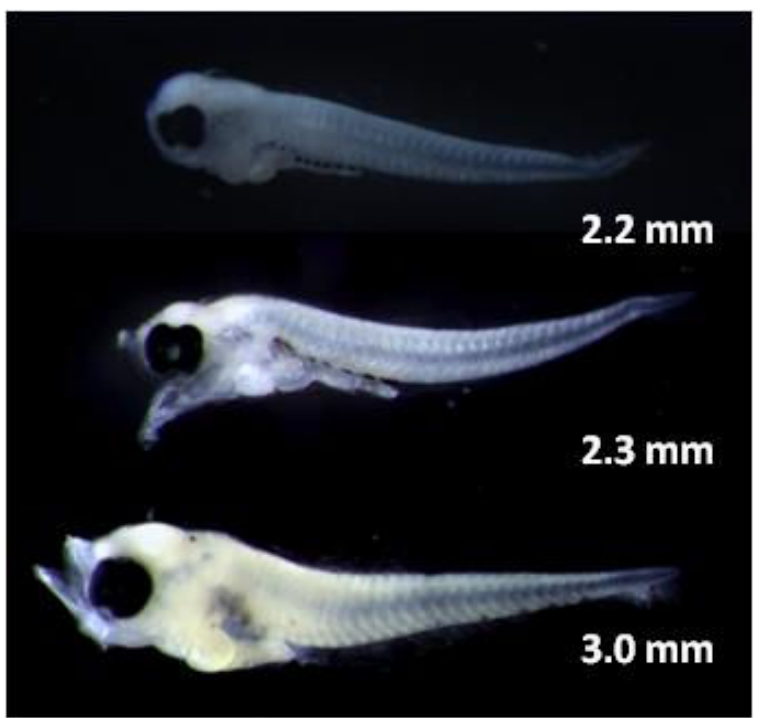

Figure 5-20. Salariinae larvae collected during this study. collected at Station 3. The average concentrations were generally higher during the night sampling cycle, especially at Station 1 (Figure 5-22). The ANOVA for Salariinae larvae, after transformation $(\log [\mathrm{x}+0.01])$, detected a significant interaction between the factors for station and sampling cycle $(\mathrm{p}<0.05)$ requiring that the individual comparisons among these treatment combinations be examined (Table 5-8). The comparisons among the individual treatment combinations detected significant differences between the day sampling cycle at Stations 1 and 2 and also between Stations 1 and 3 with Stations 2 and 3 abundances being higher in both instances for the day samples. The comparison of the night sampling cycles at these stations were also significantly different but the average concentrations during the night sampling cycle at Station 1 was higher than at Stations 2 or 3. The comparisons also detected significant differences between the day and night sampling cycles at Station 1 with the night having higher average concentrations than during the day sampling cycle. 
The calculated values for the deeper depth strata at Station 3 did not show any consistent trend across surveys for higher concentrations in either the shallow or deep zones although highest average concentrations were calculated for the deeper depth strata (Figure 5-23). The ANOVA of the abundances at the two depths, after log transformation $(\log [\mathrm{x}+0.01])$, did not detect a significant difference between depth strata for Salariinae larvae $(\mathrm{p}=0.156)$.

The mean NL length of Salariinae larvae measured from the samples was about $2.2 \mathrm{~mm}$ with only two larvae having lengths longer than $3 \mathrm{~mm}$ (Figure 5-24). The relationships between notochord length and head capsule measurements for Salariinae larvae are presented in Figure 5-25 and show that head heights were slightly larger than head widths at the same length. 


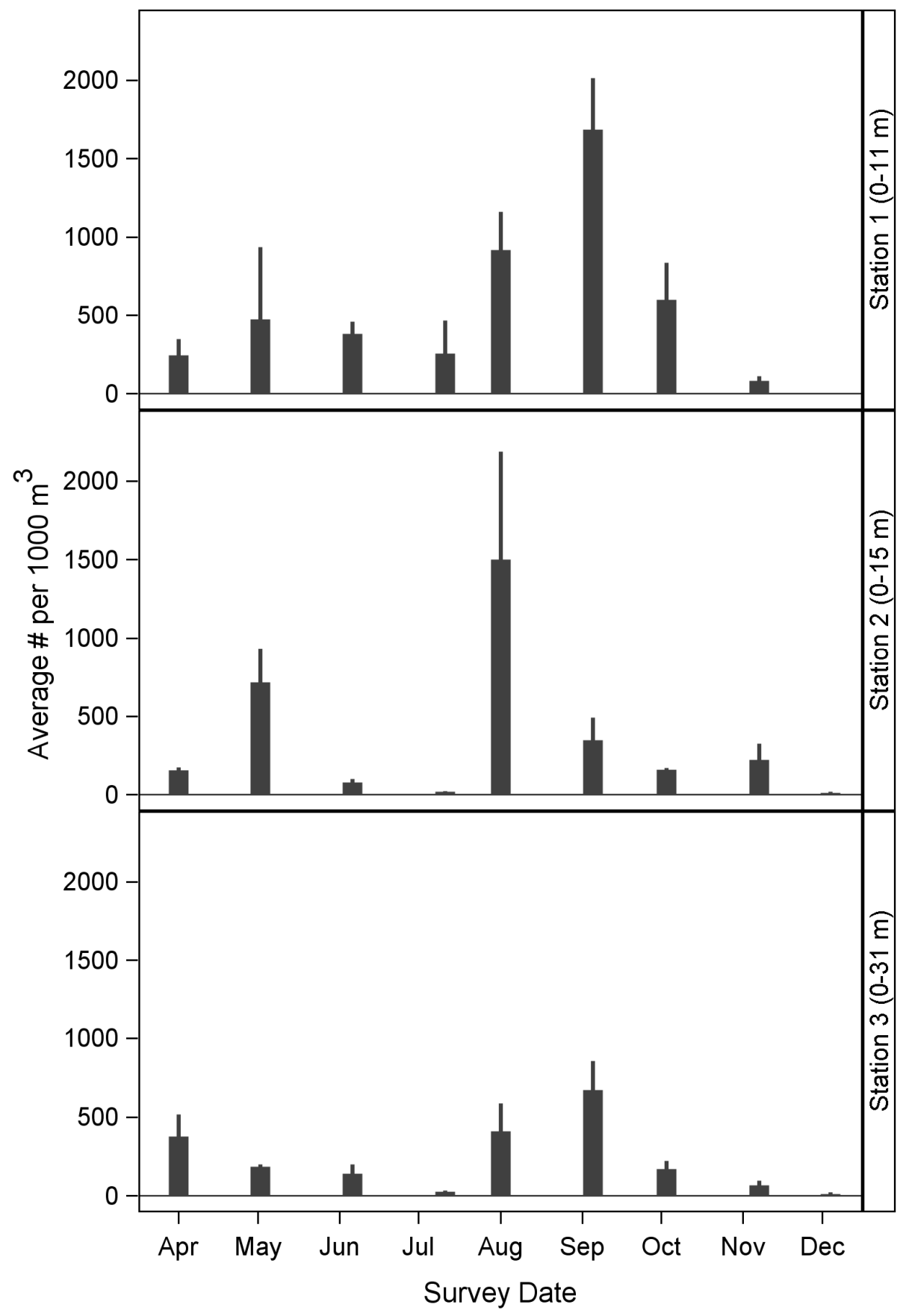

Figure 5-21. Average concentrations (plus one standard error) of Salariinae larvae at the three sampling stations off Port Allen, Kauai from April-December 2012. 


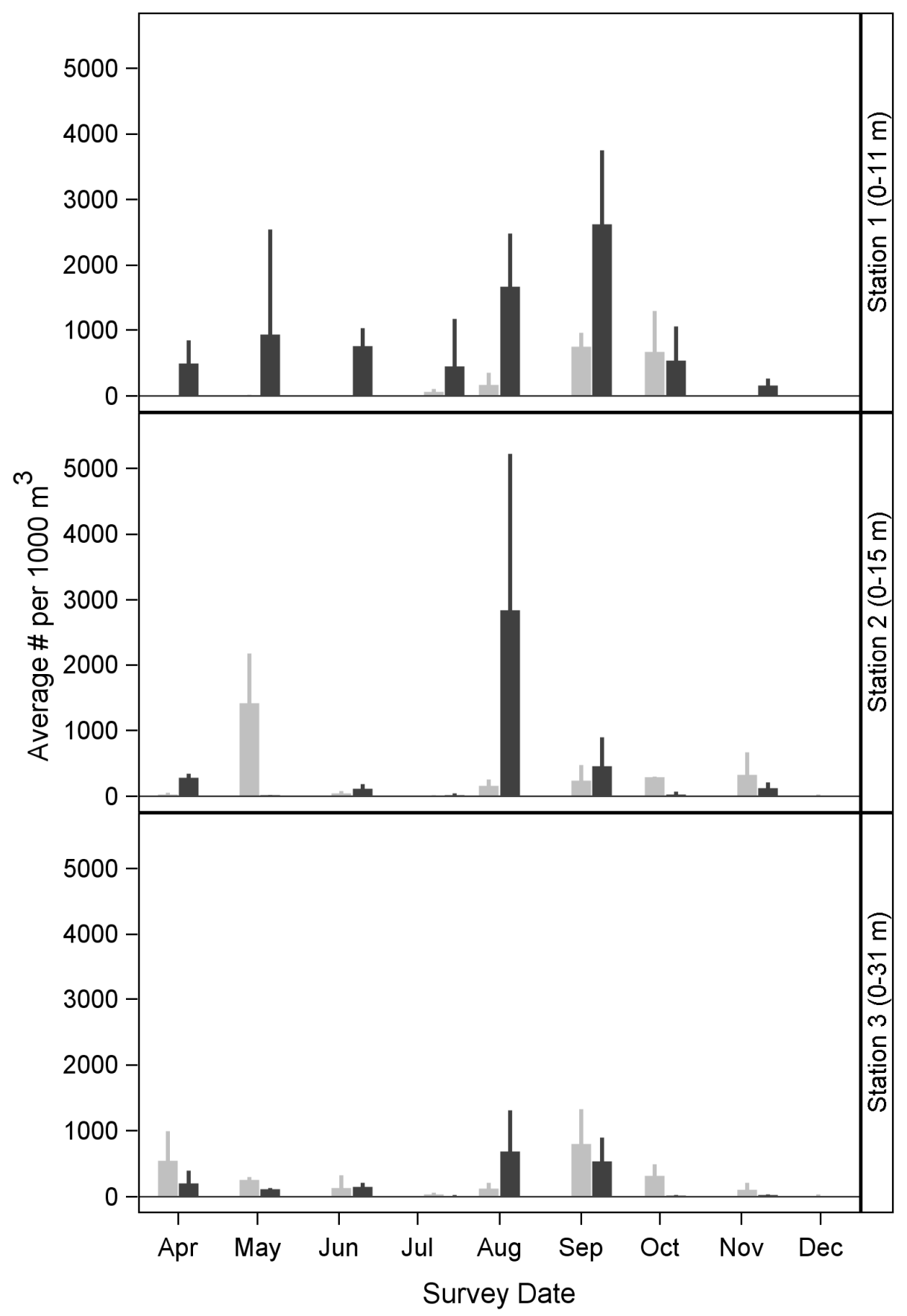

Figure 5-22. Average concentrations (plus one standard error) of Salariinae larvae during day (gray bars) and night (black bars) sampling at the three stations off Port Allen, Kauai from AprilDecember 2012. 
Table 5-8. Results of ANOVA of data on Salariinae larvae from oblique tows of the entire water column at Stations 1, 2, and 3 during day and night sampling cycles across nine surveys off Port Allen, Kauai from April-December 2012. Tests significant at probability level of $95 \%$ are in bold.

\begin{tabular}{lcccc}
\hline Effect & $\begin{array}{c}\text { Numerator } \\
\text { degrees of } \\
\text { freedom }\end{array}$ & $\begin{array}{c}\text { Denominator } \\
\text { degrees of } \\
\text { freedom }\end{array}$ & F-Value & Probability \\
\hline Station & 2 & 139 & 0.18 & 0.8327 \\
Sampling Cycle & 1 & 141 & 5.1 & $\mathbf{0 . 0 2 5 4}$ \\
Interaction - Cycle*Station & 2 & 139 & 13.35 & $<.0001$ \\
\hline & & & \\
Comparison of Treatment Levels for Interaction & & T-Value & Probability \\
\hline Station 1-D vs. Station 2-D & 139 & -2.49 & $\mathbf{0 . 0 1 3 9}$ \\
Station 1-D vs. Station 3-D & 139 & -3.20 & $\mathbf{0 . 0 0 1 7}$ \\
Station 2-D vs. Station 3-D & 139 & -0.71 & 0.4772 \\
Station 1-D vs. Station 1-N & 140 & -5.45 & $<.0001$ \\
Station 2-D vs. Station 2-N & 140 & 0.15 & 0.8784 \\
Station 3-D vs. Station 3-N & 140 & 1.33 & 0.1867 \\
Station 1-N vs. Station 2-N & 139 & 3.15 & $\mathbf{0 . 0 0 2 0}$ \\
Station 1-N vs. Station 3-N & 139 & 3.62 & $\mathbf{0 . 0 0 0 4}$ \\
Station 2-N vs. Station 3-N & 139 & 0.48 & 0.6334 \\
\hline
\end{tabular}




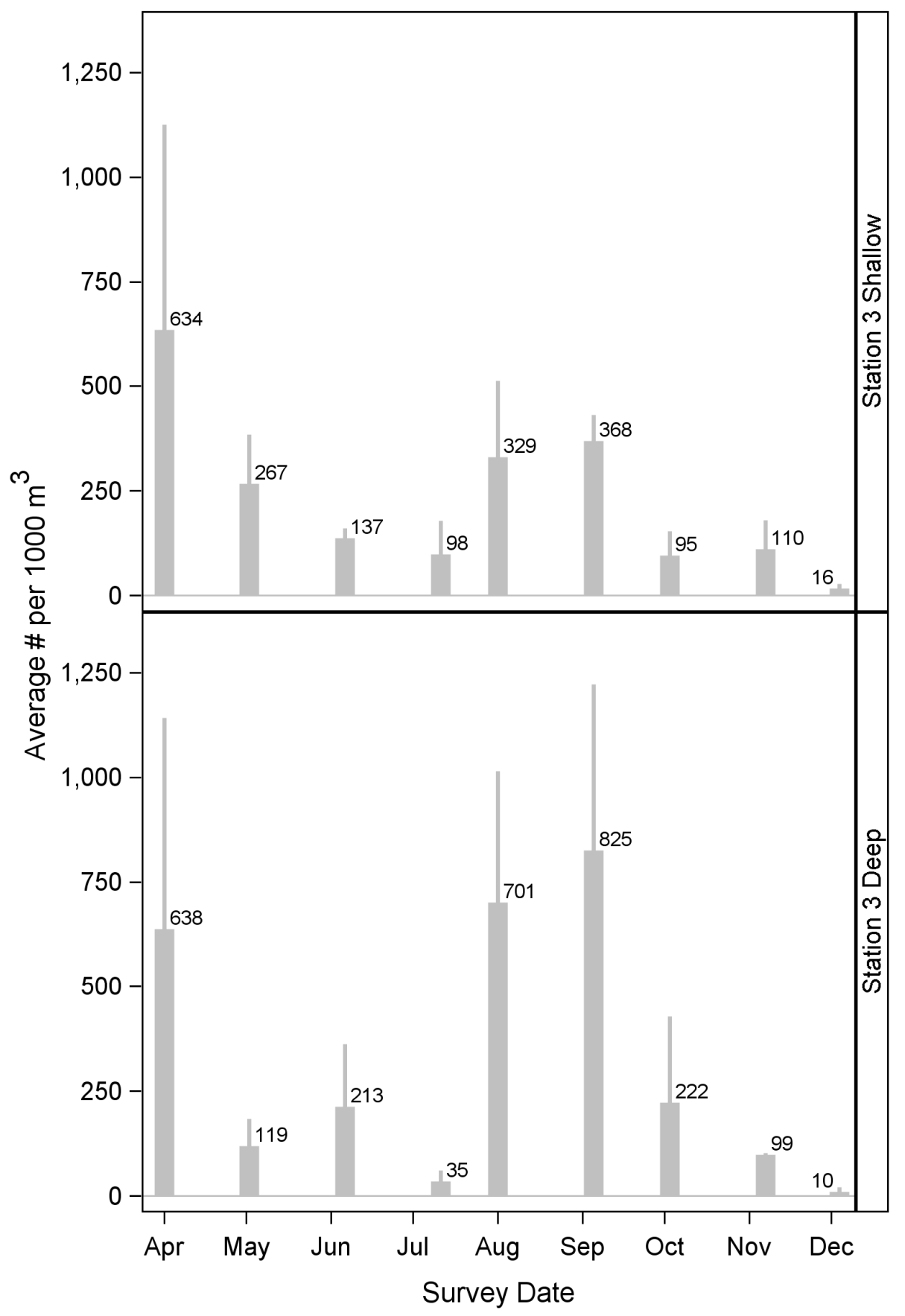

Figure 5-23. Average concentrations (plus one standard error) of Salariinae larvae at two depth strata at Station 3 off Port Allen, Kauai from April-December 2012. Numbers at tops of bars are mean values. 


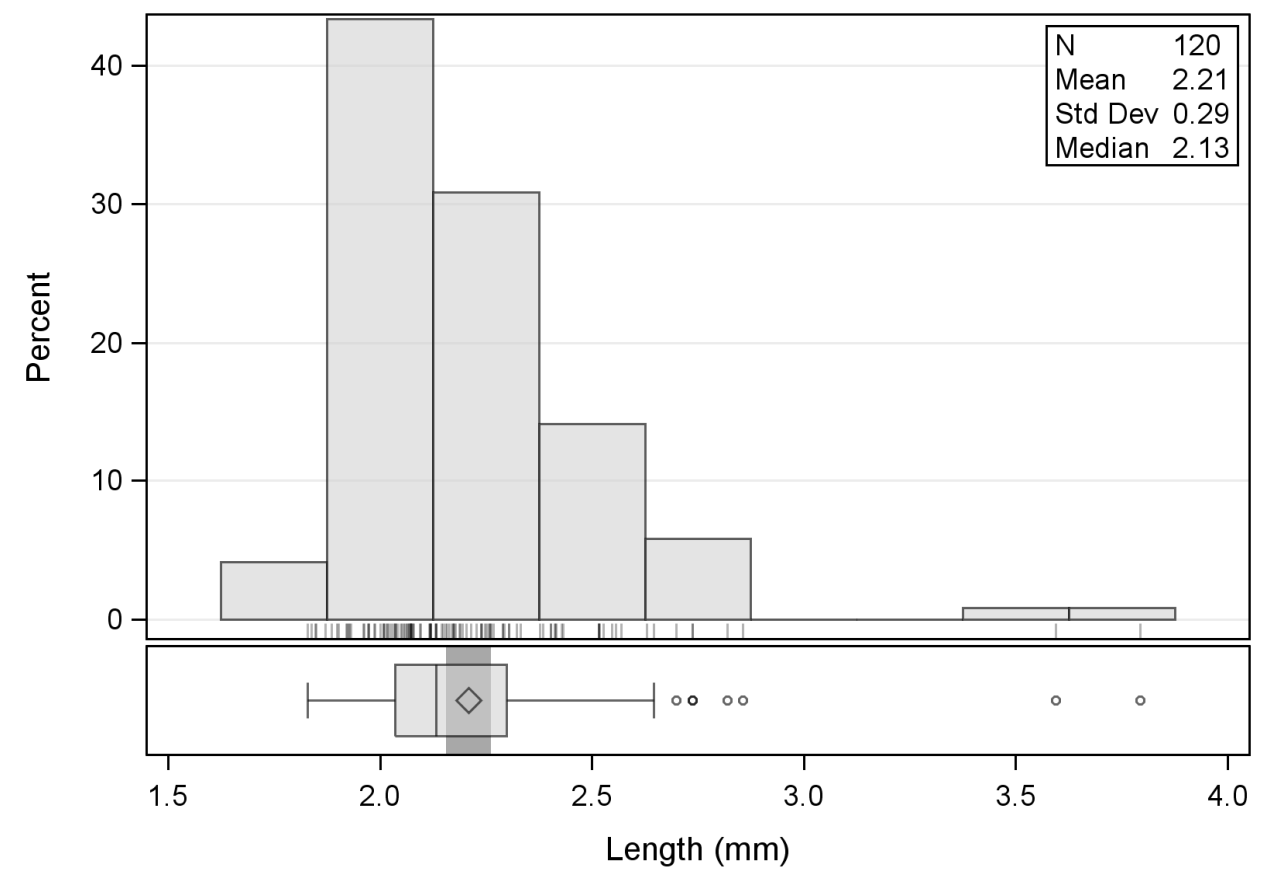

Figure 5-24. Length frequency of Salariinae larvae measured during this study.

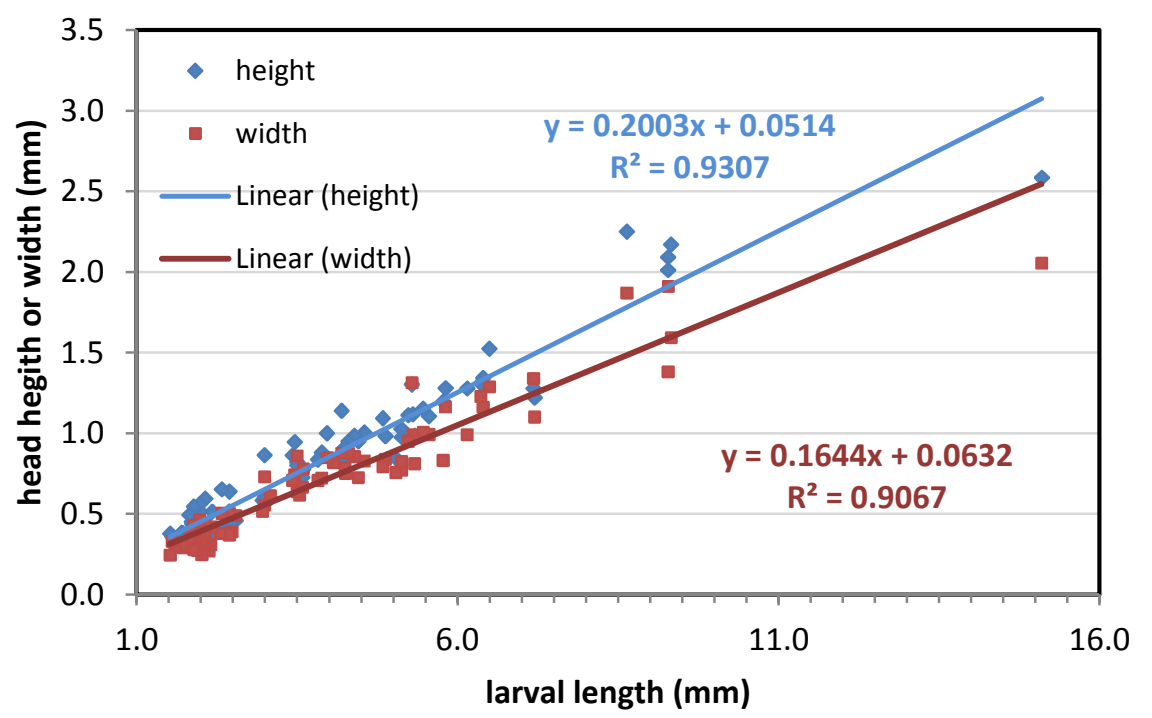

Figure 5-25. Larval length versus head capsule measurements of Salariinae and blenny larvae combined. These measurements are for larvae measured during this study and others conducted in Hawaii. 


\subsection{Hawaiian triplefin (Enneapterygius atriceps)}

The Hawaiian triplefin (Figure 5-26) was the fifth most abundant larval taxon collected ( $8.5 \%$ of the total larvae collected) with an average concentration from all the sampling of 180 larvae per $1,000 \mathrm{~m}^{3}$ (Table 5-2). They were collected in much higher concentrations at Station 1 than at either of the other two stations with their overall average concentration for all samples collected from the oblique tows at the three stations decreasing from 562 at Station 1, to only 77 at Station 2, and 52 at Station 3 (Table 5-3). The highest concentrations were collected during the July through September surveys (Figure

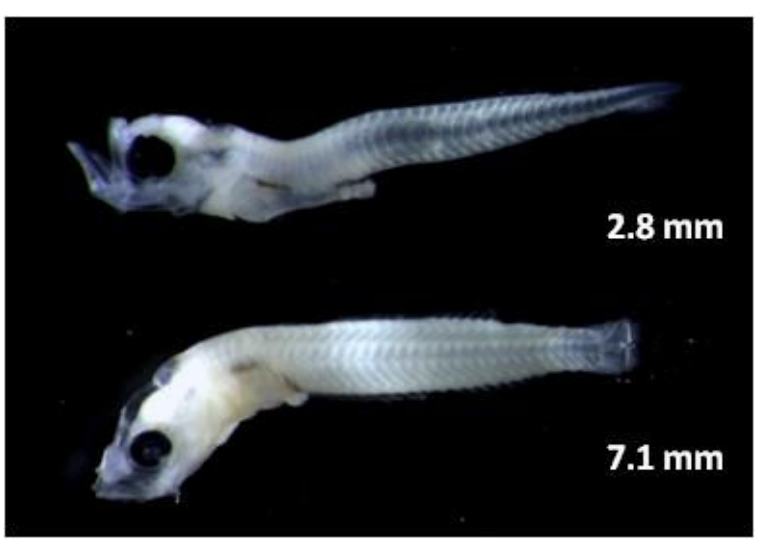

Figure 5-26. Hawaiian triplefin (Enneapterygius atriceps) larvae collected during this study. 5-27). There was no consistent trend in greater concentration of the triplefins during either the day or night sampling (Figure 5-28). An ANOVA of the data on Hawaiian triplefin concentrations after transformation $(\log [\mathrm{x}+0.01])$ detected a statistically significant difference among stations $(\mathrm{p}<0.05)$ (Table 5-9). The comparison of the individual stations showed that Station 1 had significantly higher average concentrations than Station 2 which had higher average concentrations than Station 3.

A comparison of the larval triplefin collections at the two depths at Station 3 showed that during the two surveys with the highest concentrations, they were estimated to be in higher abundance at the deeper strata (Figure 5-29). An ANOVA of the two depth strata was not conducted because the data did not meet the assumptions of the analysis due to the large numbers of samples with no individuals of this taxa.

As was seen with the Salariinae, the triplefins that were measured were generally small with a mean notochord length of $3.9 \mathrm{~mm}$ (Figure 5-30). Figure 5-31 shows that the head capsule height was generally greater than the width over the range of measured larvae. 
Table 5-9. Results of ANOVA of data on Enneapterygius atriceps larvae from oblique tows of the entire water column at Stations 1, 2, and 3 during day and night sampling cycles across nine surveys off Port Allen, Kauai from April-December 2012. Tests significant at probability level of $95 \%$ are in bold.

\begin{tabular}{lcccc}
\hline Effect & $\begin{array}{c}\text { Numerator } \\
\text { degrees of } \\
\text { freedom }\end{array}$ & $\begin{array}{c}\text { Denominator } \\
\text { degrees of } \\
\text { freedom }\end{array}$ & F-Value & Probability \\
\hline Station & 2 & 138 & 78.43 & $<.0001$ \\
Sampling Cycle & 1 & 144 & 0.84 & 0.3598 \\
Interaction - Cycle*Station & 2 & 138 & 0.92 & 0.4009 \\
\hline
\end{tabular}




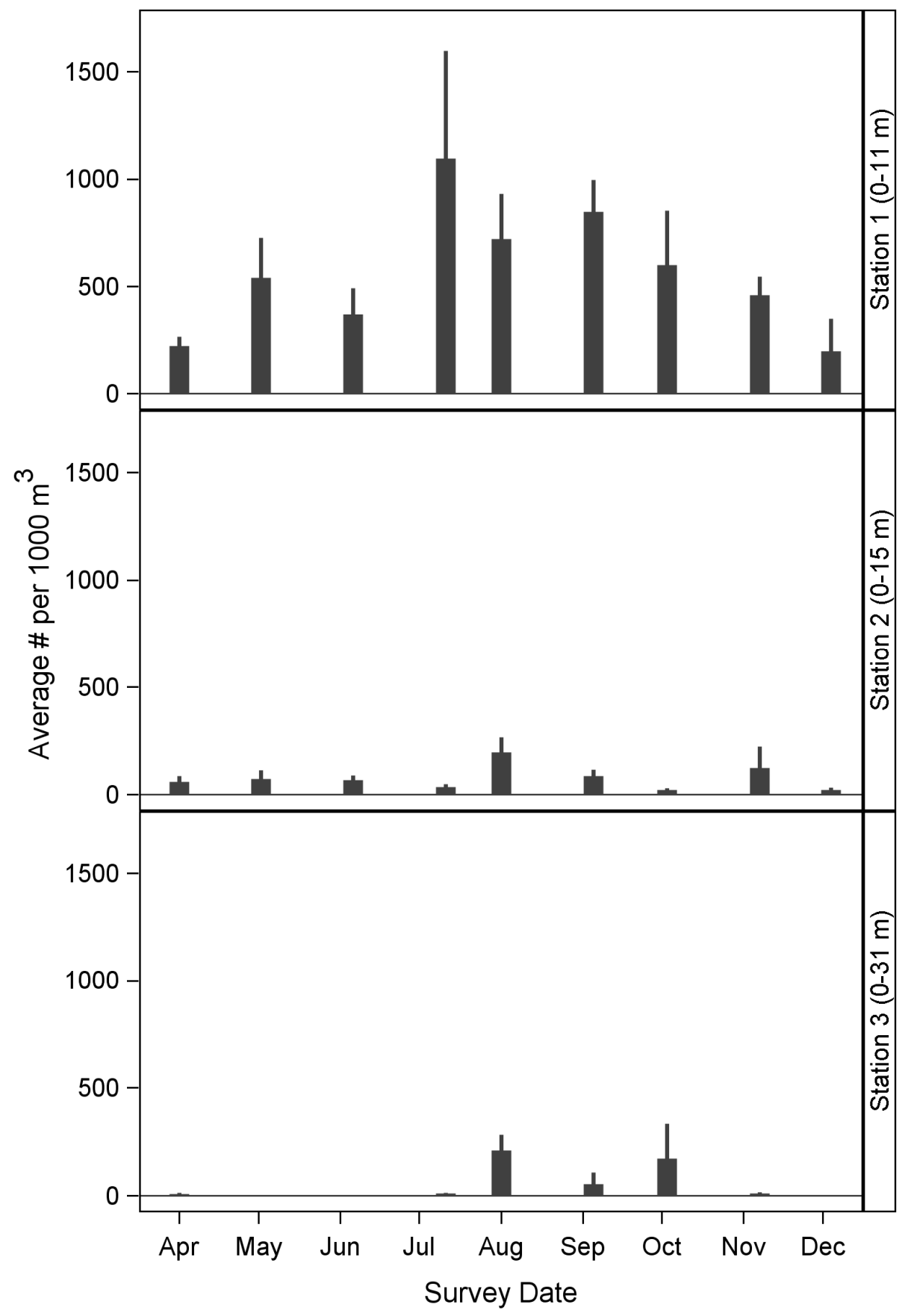

Figure 5-27. Average concentrations (plus one standard error) of Enneapterygius atriceps larvae at the three sampling stations off Port Allen, Kauai from April-December 2012. 


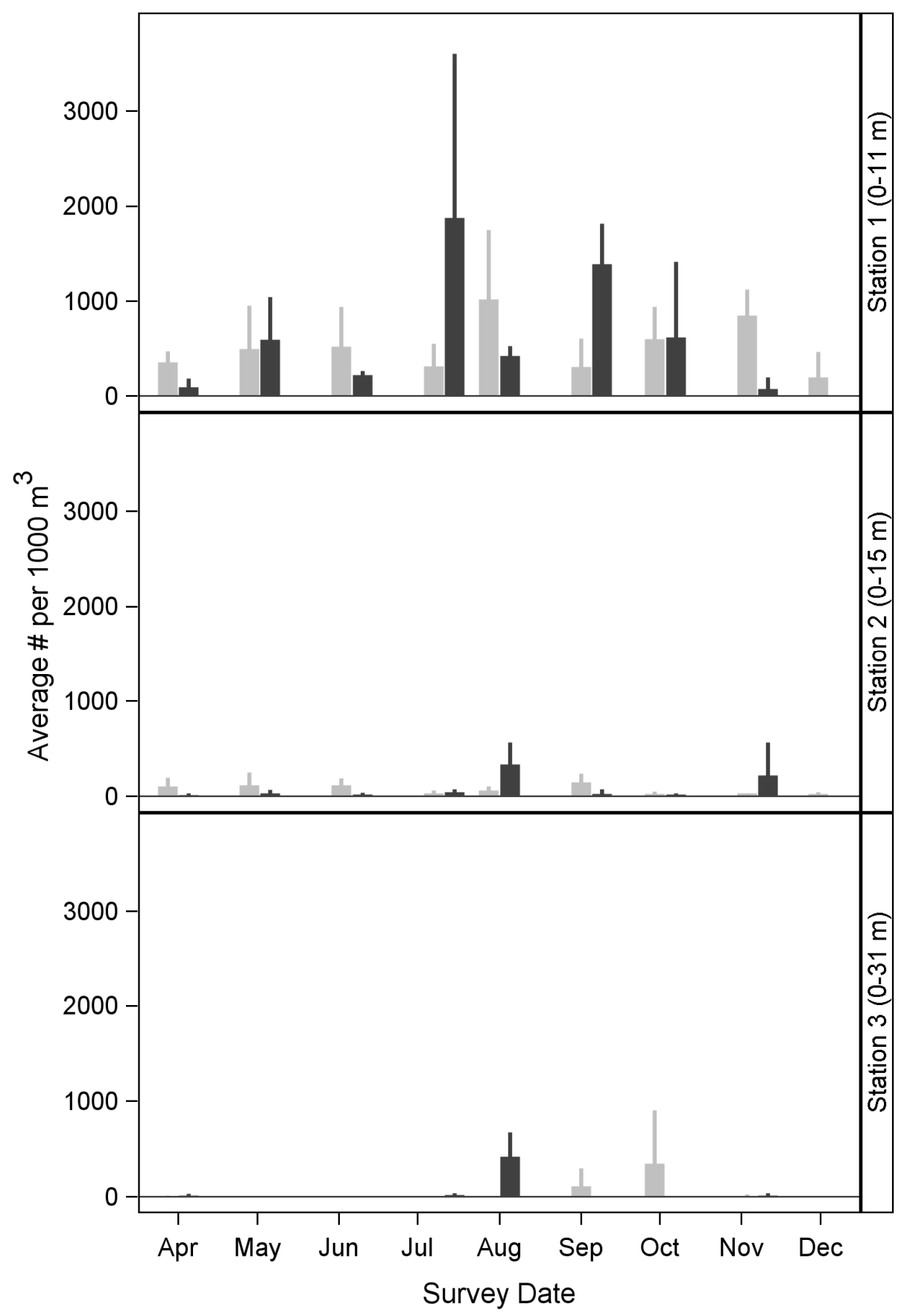

Figure 5-28. Average concentrations (plus one standard error) of Enneapterygius atriceps larvae during day (gray bars) and night (black bars) sampling at the three stations off Port Allen, Kauai from AprilDecember 2012. 


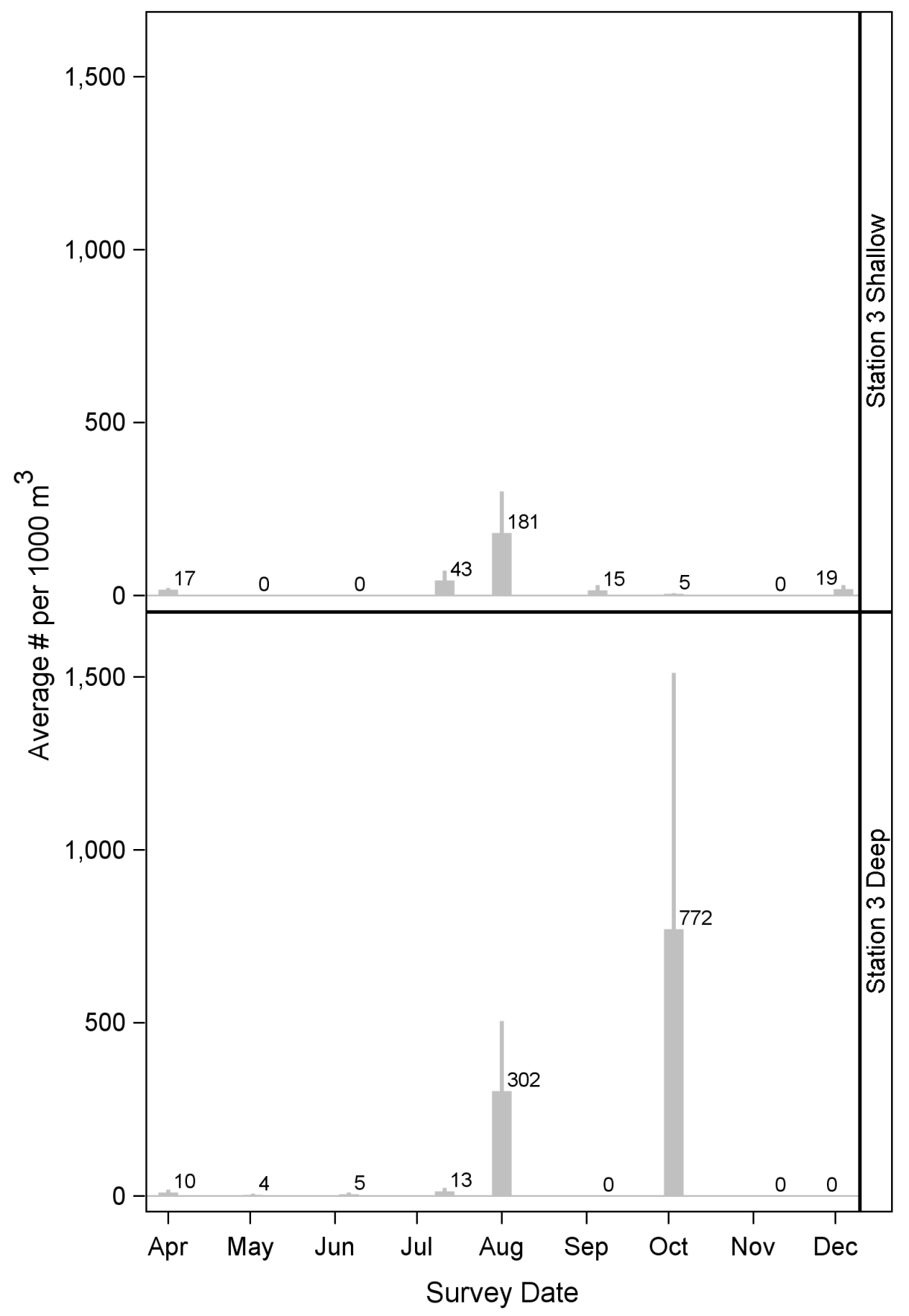

Figure 5-29. Average concentrations (plus one standard error) of Enneapterygius atriceps larvae at two depth strata at Station 3 off Port Allen, Kauai from April-December 2012. Numbers at tops of bars are mean values. 


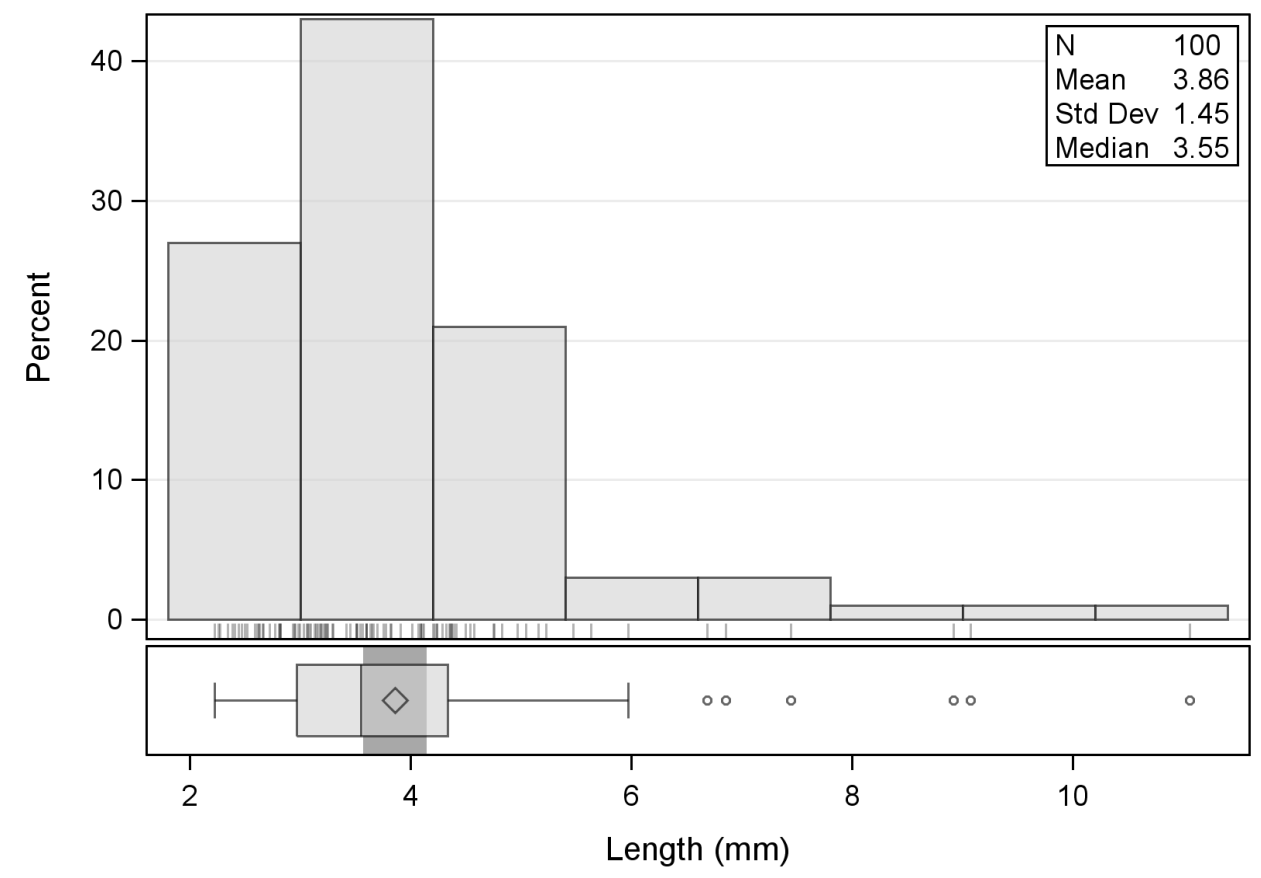

Figure 5-30. Length frequency of Enneapterygius atriceps larvae measured during this study.

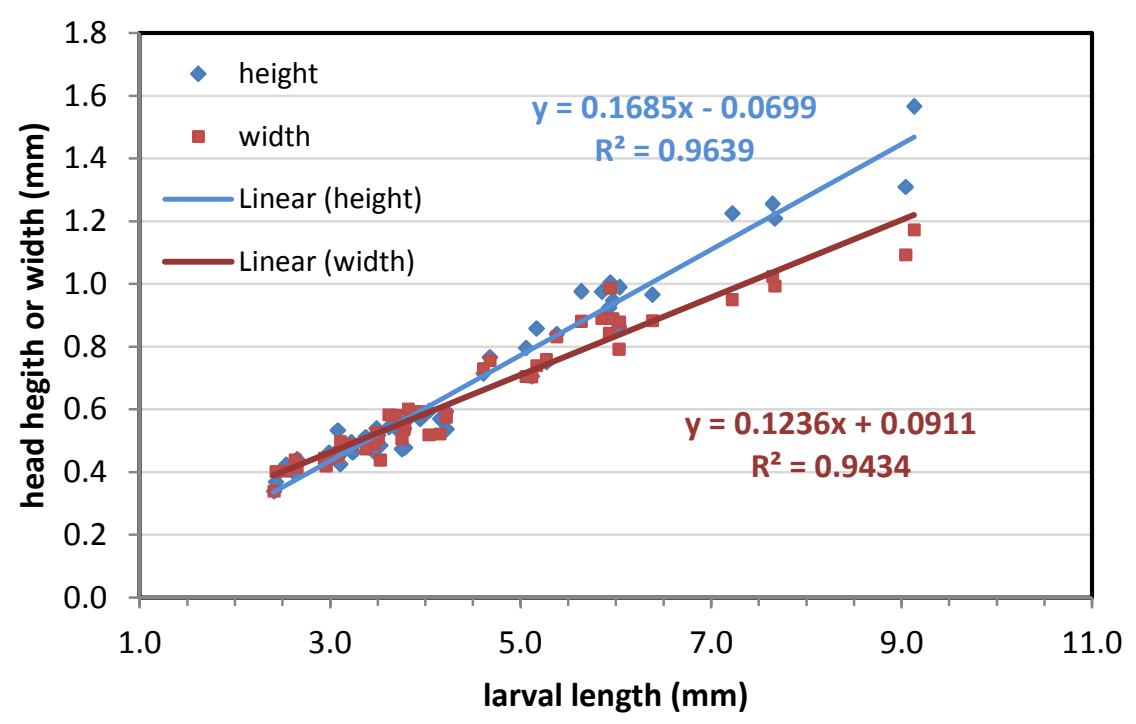

Figure 5-31. Larval length versus head capsule measurements of Enneapterygius atriceps larvae. These measurements are for larvae measured during this study and others conducted in Hawaii. 


\subsubsection{Damselfishes (Pomacentridae)}

There are 17 species of damselfishes from five genera that have been found in the waters around the Hawaiian Islands. These include eight species of Chromis, four species of Plectroglyphidodon, and three species of Abudefduf. Some of the more abundant damselfishes with larger adults include the Hawaiian sergeant (Abudefdufabdominalis), the Indo-Pacific sergeant (Abudefduf vaigiensis) and the Hawaiian dascyllus (Dascyllus albisella) (Figure 5-32). The

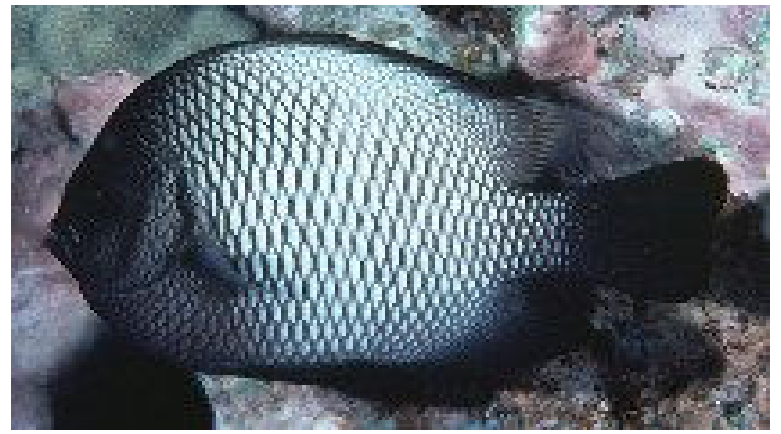

Figure 5-32. 'alo'ilo'i - Hawaiian dascyllus (Photo by J.E. Randall) Hawaiian sergeant is endemic to Johnston Atoll and the Hawaiian Islands, while the Hawaiian dascyllus is endemic to these two locations plus to the Kure Atoll (Mundy 2005, Randall 2007). The Indo-Pacific sergeant has a much broader range throughout the IndoPacific from South Africa and the Red Sea to Indonesia, Japan, Australia, Micronesia, the Hawaiian Islands, and the Marquesas Islands (Mundy 2005, Randall 2007). The IndoPacific sergeant was first recorded in the Hawaiian Islands in 1991, and may have been transported to the Islands in association with lost fishing nets (Mundy 2005).

\section{Life History and Ecology}

The Hawaiian sergeant (Figure 5-33) and Hawaiian dascyllus are known to spawn throughout the year with a peak for Hawaiian sergeant during spring and early summer (Helfrich 1959, Tyler 1995, Tyler and Stanton 1995). The Hawaiian dascyllus has two peaks in spawning in Kaneohe Bay on Oahu: June and September/October (Asoh and Yoshikawa 2002). Each male builds a nest and after a female deposits her adhesive eggs, the male guards them (Helfrich 1959, Tyler 1988, Danilowski 1995). Males also fan the eggs to increase the oxygen level near the eggs (Helfrich 1959). Each female generally only spawns with one male per nesting cycle but with different males during

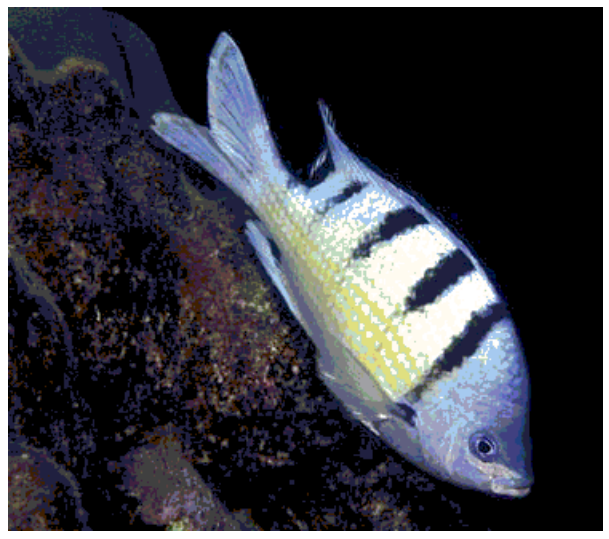

Figure 5-33. mamo - Hawaiian sergant (Photo by J.P. Hoover)

multiple nesting cycles (Asoh and Yoshikawa 2002). There is a higher rate of egg predation in nests that are either solitary or occur in low density than in areas where nest density is high (Tyler 1989, 1992). Spawning takes place throughout the daylight hours (Tyler 1995, Asoh and Yoshikawa 2002), often being synchronized within a nesting colony, possibly to decrease predation pressure (Tyler and Stanton 1995). The eggs are deposited in a single layer, with each nest containing eggs from one to five females (Helfrich 1959, Tyler 1988). 
The hatching of Hawaiian sergeant eggs generally begins five days after fertilization and continues to either day seven (Tyler 1995, Alshuth et al. 1998) or day nine (Asoh and Yoshikawa 2002). Hatching of Hawaiian dascyllus eggs takes place within 1-2 hours of sunset on the fourth day after fertilization at 26.2-29.1 ${ }^{\circ} \mathrm{C}$ (Asoh and Yoshikawa 2002).

Spawning of the Hawaiian dascyllus in Kaneohe Bay on Oahu occurred during 16 spawning cycles in 1997 and 10 cycles in 1998 (Asoh 2003). Spawning during each cycle lasted 2-3 days, with spawning taking place every 5-7 days. Females spawned in one to almost all of these cycles, with the average female spawning 10.7 times in 1997 and 5.67 times in 1998. Batch fecundity increased exponentially with body weight and ranged from 23,100 to 52,800 eggs. The average time required for a female to deposit her eggs was 122.7 minutes (range 20-286 minutes). Tyler (1992) found that by experimentally increasing the food supply for the Hawaiian sergeant, the number of clutches and the frequency of spawning also increased. Danilowicz (1995) and Stevenson (1963) found that a female spawns an average of 25,000 eggs with the number of ripe ovarian eggs increasing with body length (Table 5-10).

Table 5-10. Numbers of ripe ovarian eggs in relation to fish length for Hawaiian sergeant (Stevenson 1963).

\begin{tabular}{cc}
\hline \hline Fork Length (mm) & $\begin{array}{c}\text { Estimated \# eggs } \\
\text { (thousands) }\end{array}$ \\
\hline 104 & 12.7 \\
106 & 14.9 \\
110 & 15.8 \\
112 & 19.1 \\
117 & 25.2 \\
117 & 27.0 \\
120 & 29.1 \\
122 & 38.0 \\
125 & 43.7 \\
\hline
\end{tabular}

Radtke (1985) stated that the time from hatching until settlement of Hawaiian sergeant is 20-28 days, with an average length at settlement of about $11 \mathrm{~mm}$ TL; although, Danilowicz and Brown (1992) documented settlement in individuals as small as $8.5 \mathrm{~mm}$ TL. Based on Radtke's (1985) measurements, the pre-settlement growth rate was estimated to be $0.43 \pm$ $0.01 \mathrm{~mm} /$ day. He also stated that growth in length increased dramatically after settlement, but did not give a numerical estimate. Wellington and Victor (1989) presented a list of the number of days of larval duration for various Hawaiian damselfishes. The mean duration ranged from 17.5 to 32.7 days with a mean duration for the species presented being 26.0 days (Table 5-11).

Randall (2007) stated that the Hawaiian dascyllus is $2.4 \mathrm{~mm}$ long at hatching and settles at 
$15 \mathrm{~mm}$ TL. Based on a mean larval duration of 26.8 days (Table 5-11), the average larval growth rate would be about $0.47 \mathrm{~mm} /$ day. He also stated that juveniles of this species grow about $5 \mathrm{~mm} / \mathrm{month}(0.17 \mathrm{~mm} /$ day). Danilowicz and Brown (1992) measured the growth rate of the Hawaiian dascyllus in the lab from hatching until day 53 to be 0.41 $\mathrm{mm} /$ day. Stevenson (1963) calculated that recently settled juvenile Hawaiian dascyllus (13-20 mm TL) grew between $0.06-0.17 \mathrm{~mm} /$ day. He speculated that the range of rates was probably due to the amount of available food. Booth $(1992,1995)$ reported that this species reached maturity at about $70 \mathrm{~mm}$ TL, which was estimated to take 150-235 days. This yielded a growth rate estimate of $0.29-0.45 \mathrm{~mm} /$ day. Table 5-12 presents the growth rates for different sized Hawaiian dascyllus in 1987-1989 (Booth 1995). He found there was a higher growth rate in 1987 than in 1988, with the overall rate in 1987 being $0.30 \pm 0.1$ $\mathrm{mm} /$ day and $0.16 \pm 0.01 \mathrm{~mm} /$ day in 1988 .

Table 5-11. Damselfish larval durations (Wellington and Victor 1989).

\begin{tabular}{|c|c|c|c|}
\hline Species & Common Name & $\begin{array}{c}\text { Mean larval } \\
\text { duration (days) }\end{array}$ & $\begin{array}{l}\text { Range of larval } \\
\text { duration (days) }\end{array}$ \\
\hline Abudefdufabdominalis & Hawaiian sergeant & 17.5 & $17-18$ \\
\hline Abudefduf sordidus & Black spot sergeant & 26.1 & $23-31$ \\
\hline Chromis agilis & agile chromis & 32.7 & $30-35$ \\
\hline Chromis hanui & chocolate-dip chromis & 27.0 & 27 \\
\hline Chromis vanderbilti & blackfin chromis & 31.0 & $30-32$ \\
\hline Dascyllus albisella & Hawaiian dascyllus & 26.8 & $25-29$ \\
\hline Plectroglyphidodon imparipennis & brighteye damselfish & 17.5 & $28-33$ \\
\hline Plectroglyphidodon sindonis & rock damselfish & 30.0 & 30 \\
\hline \multirow[t]{2}{*}{ Stegastes fasciolatus } & Pacific gregory & 25.0 & $24-26$ \\
\hline & Average & 26.0 & \\
\hline
\end{tabular}

Table 5-12. Estimated growth rates of larval and juvenile Hawaiian dascyllus (from Booth 1995).

\begin{tabular}{lc}
\hline \hline Life Stage & $\begin{array}{c}\text { Growth rate range } \\
(\mathbf{m m} / \text { day })\end{array}$ \\
\hline Larvae & 0.26 \\
Juvenile; $<21 \mathrm{~mm} \mathrm{TL}$ & $0.19-0.3$ \\
Juvenile; $21-40 \mathrm{~mm} \mathrm{TL}$ & $0.14-0.28$ \\
Juvenile; $>40 \mathrm{~mm} \mathrm{TL}$ & $0.21-0.35$ \\
\hline
\end{tabular}

Medvick (1979) studied the growth rate of captive Hawaiian sergeants reared under different feeding regimes and temperatures and found that on an ad libitum diet their average growth rate ranged from $0.23 \mathrm{~mm} /$ day at $23.4^{\circ} \mathrm{C}$ to $0.47 \mathrm{~mm} /$ day at $32.4^{\circ} \mathrm{C}$.

Helfrich (1959) reported growth rates in this species ranging from 0.31 to $0.54 \mathrm{~mm} /$ day 
when they were fed natural food. Hawaiian sergeant juveniles were reported to grow at a rate of about $0.33 \mathrm{~mm} /$ day after transforming at a size of 13-15 mm TL (Randall 2007).

Danilowicz and Brown (1992) found that larval survival rates in the lab ranged from 0.1 to $41.2 \%$ from hatching to 10 weeks of age. When the larvae were raised at lower algal cell concentrations (lower food levels) there was $100 \%$ mortality. He stated that larval damselfishes may grow faster in the field than in the laboratory. Booth (1995) stated that the probability of a young Hawaiian dascyllus reaching maturity was $3.7 \pm 1.8 \%$ (mean \pm $95 \% \mathrm{CI}$ ) for a single recruit to $7.9 \pm 2.5 \%$ when in a group of 10 . Booth (1995) reported that only about $15 \%$ of Hawaiian dascyllus juveniles survive into their second month after settlement.

\section{Population Trends and Fishery}

Damselfishes have little commercial value, except for the aquarium trade (Leis and CarsonEwart 2004). However, they can become aggressive and territorial as they reach maturity, and thus may not be suitable for community aquariums.

\subsubsection{Sampling Results}

Pomacentridae larvae (Figure 5-34) were the fourth most abundant larvae collected during the study (10.5\% of total larvae collected) with an overall average concentration of 222 larvae per $1,000 \mathrm{~m}^{3}$ (Table 5-2). The highest average concentration was calculated from the samples at Station 2 (Table 5-3). The highest average monthly concentrations were observed during August and September at all three stations (Figure 5-35) with generally more larvae being collected at night than during the day, although this was not always consistent during all the surveys at all the stations (Figure 5-36). The ANOVA for Pomacentridae larvae, after transformation $(\log [\mathrm{x}+0.01])$, detected a significant difference between stations $(\mathrm{p}<0.05)$ (Table 5-13). The comparison of the individual stations showed that Station 2 had the highest average concentration and was significantly different from Station 1 but there were no significant differences detected between Station 3 and the other two stations.

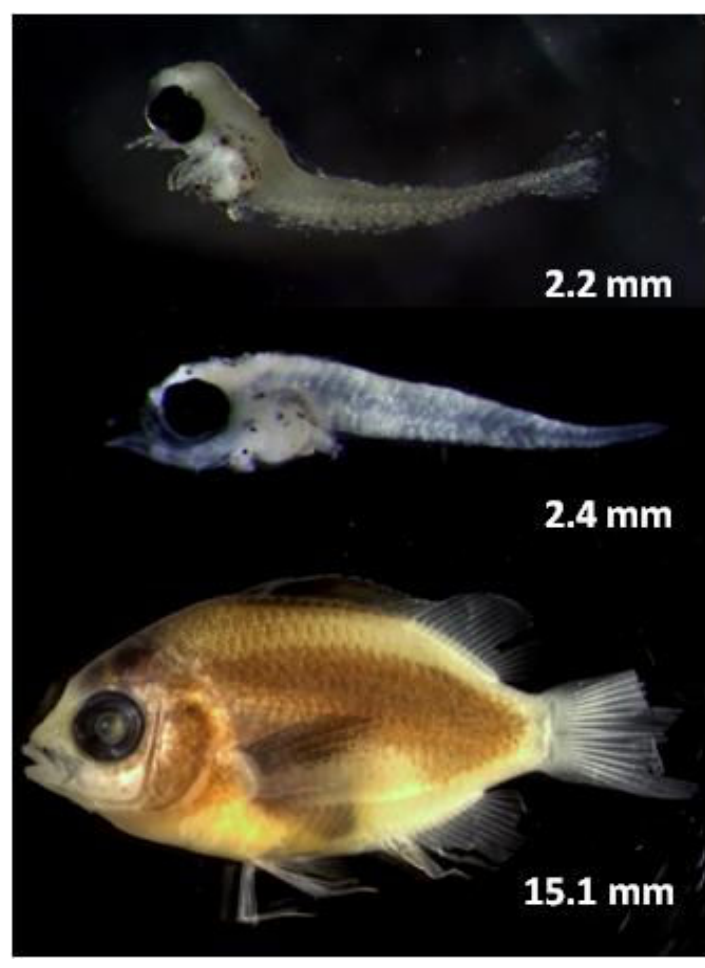

Figure 5-34. Pomacentridae larvae (top two images) and juvenile (bottom) collected during this study. 
The calculated values for the deeper depth strata at Station 3 did not show any consistent trend across surveys for higher concentrations in either the shallow or deep zones, although the highest average concentrations occurred at the deeper depth strata (Figure 5-37). The ANOVA of the abundances at the two depths, after log transformation $(\log [\mathrm{x}+0.1])$, detected a significant difference between depth strata with the higher average concentration occurring at the deeper depth strata.

The mean NL length of the Pomacentridae larvae that were measured was about $2.1 \mathrm{~mm}$ with only two individuals over $3 \mathrm{~mm}$ (Figure 5-38). The head of the Pomacentridae larvae was higher than it was wide at the measured lengths (Figure 5-34).

Table 5-13. Results of ANOVA of data on Pomacentridae larvae from oblique tows of the entire water column at Stations 1, 2, and 3 during day and night sampling cycles across nine surveys off Port Allen, Kauai from April-December 2012. Tests significant at probability level of $95 \%$ are in bold.

\begin{tabular}{lrrrr}
\hline Effect & $\begin{array}{c}\text { Numerator } \\
\text { degrees of } \\
\text { freedom }\end{array}$ & $\begin{array}{c}\text { Denominator } \\
\text { degrees of } \\
\text { freedom }\end{array}$ & F-Value & Probability \\
\hline Station & 2 & 139 & 3.12 & $\mathbf{0 . 0 4 7 5}$ \\
Sampling Cycle & 1 & 140 & 1.97 & 0.1623 \\
Interaction - Cycle*Station & 2 & 139 & 1.1 & 0.3345 \\
\hline
\end{tabular}




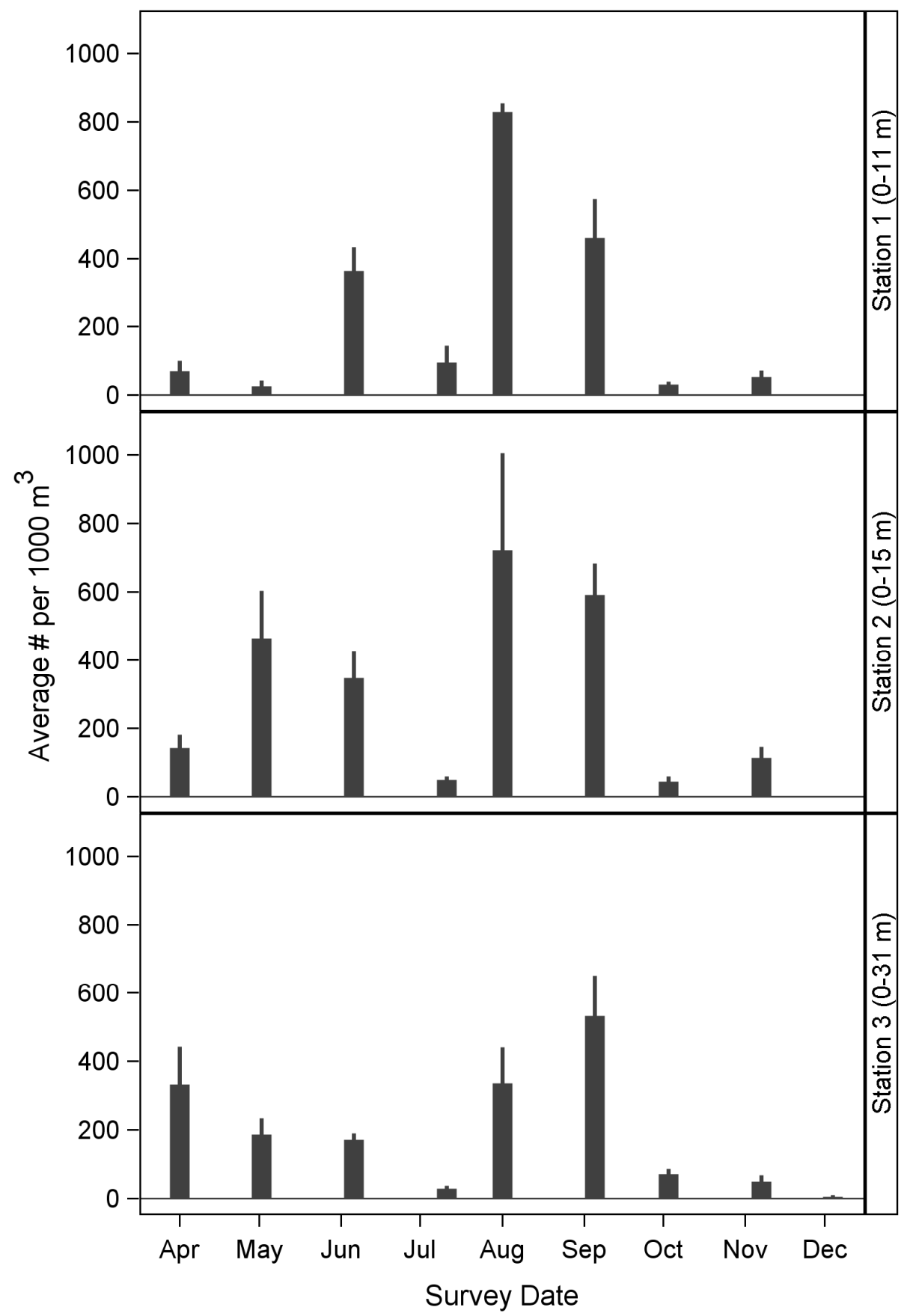

Figure 5-35. Average concentrations (plus one standard error) of Pomacentridae larvae at the three sampling stations off Port Allen, Kauai from April-December 2012. 


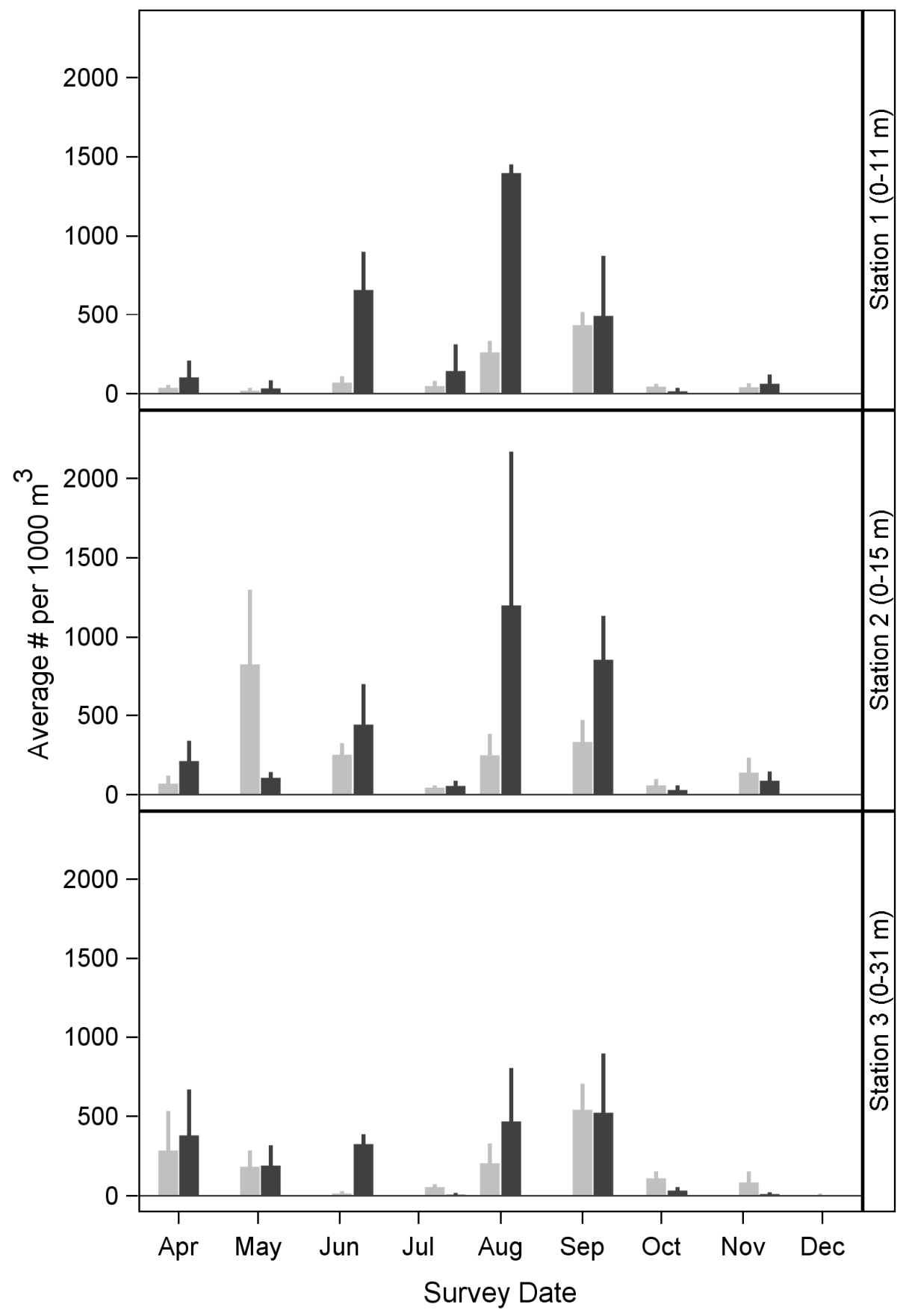

Figure 5-36. Average concentrations (plus one standard error) of Pomacentridae larvae during day (gray bars) and night (black bars) sampling at the three stations off Port Allen, Kauai from AprilDecember 2012. 


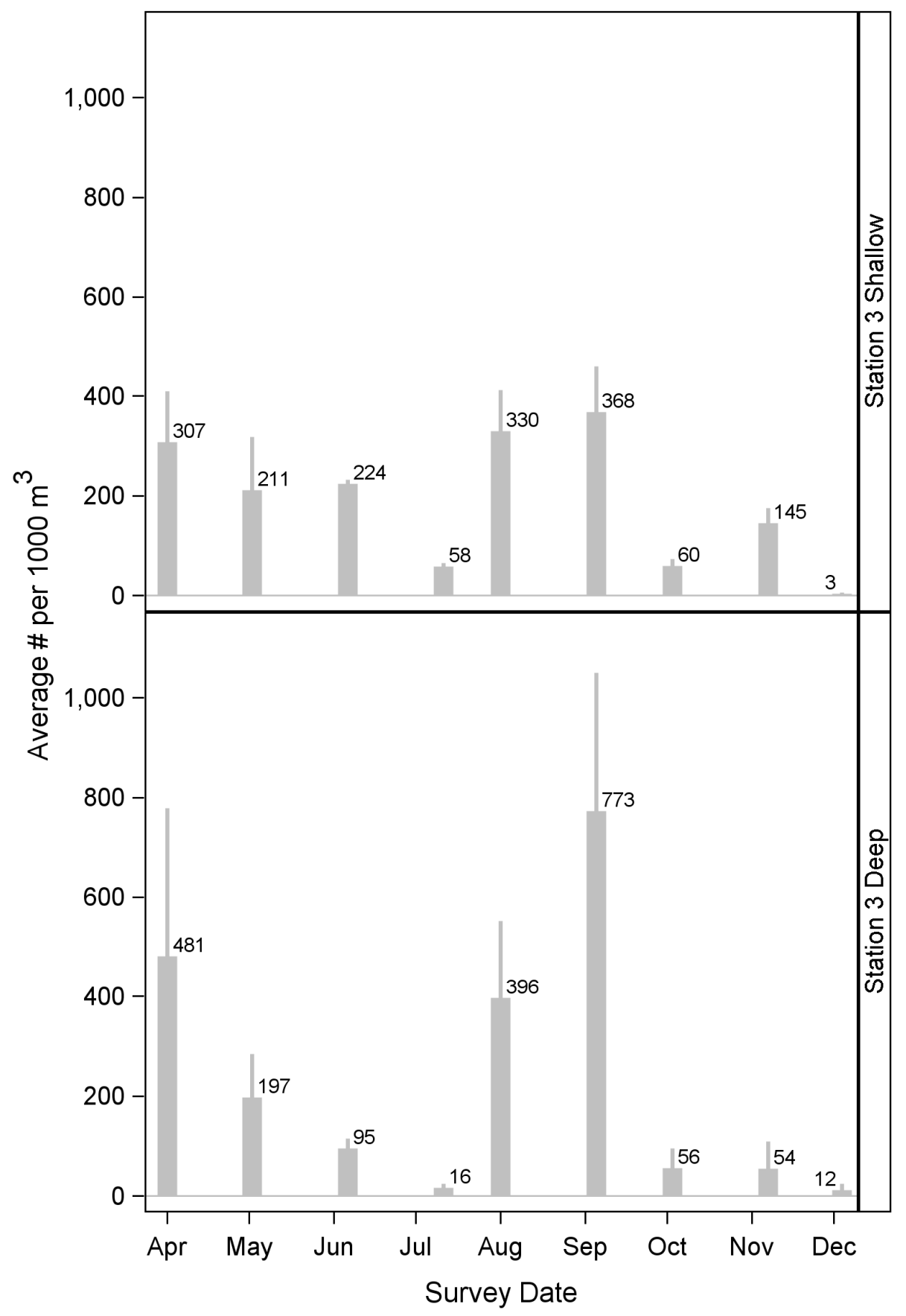

Figure 5-37. Average concentrations (plus one standard error) of Pomacentridae larvae at two depth strata at Station 3 off Port Allen, Kauai from April-December 2012. Numbers at tops of bars are mean values. 


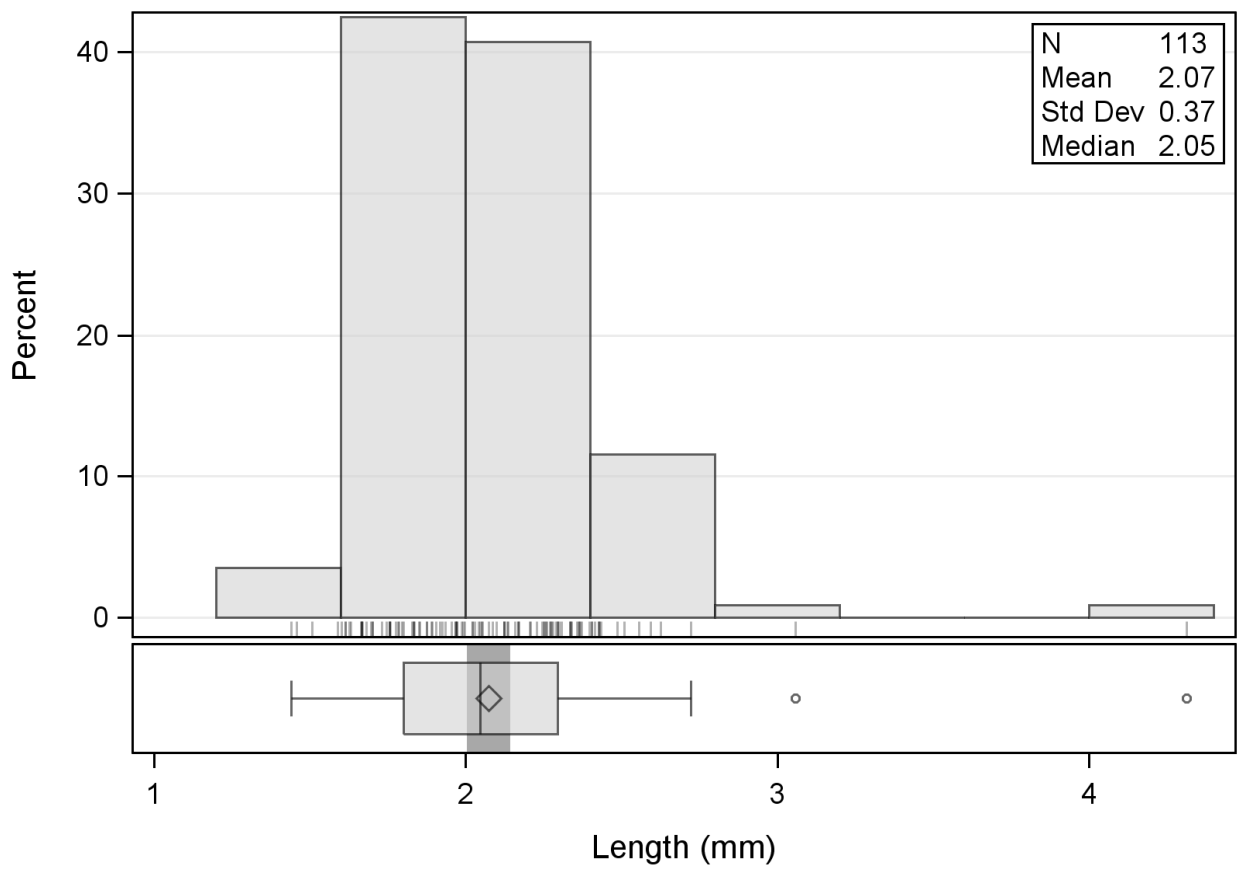

Figure 5-38. Length frequency of Pomacentridae larvae measured during this study.

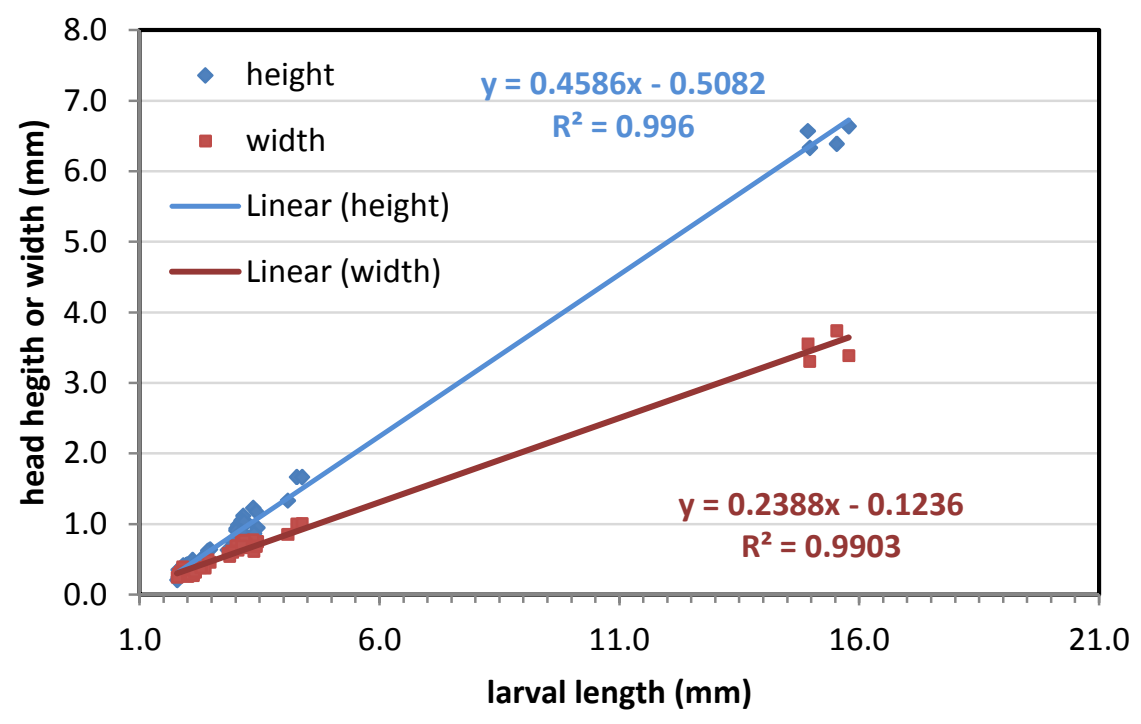

Figure 5-39. Larval length versus head capsule measurements of Pomacentridae larvae. These measurements are for larvae measured during this study and others conducted in Hawaii. 


\subsubsection{Hawaiian anchovy (Encrasicholina spp.)}

Anchovies (family Engraulidae) are small or moderate-sized clupeoid fishes. They are typically marine, coastal, and schooling fishes, occurring in all seas from about $60^{\circ} \mathrm{N}$ to $50^{\circ}$ $\mathrm{S}$, but some species enter brackish or freshwater to feed or spawn and some live there permanently (Whitehead et al. 1988). Anchovies and sardines are particularly numerous in coastal zones such as the eastern north Pacific where seasonal upwelling stimulates high levels of planktonic production. They feed on small planktonic animals, especially crustaceans, and all spawn relatively large numbers of eggs which hatch into planktonic larvae. In most species, the back is blue-green and the sides are silver, sometimes with a distinct silver stripe. There are 16 genera and some 139 species worldwide (Whitehead et al. 1988), of which two species, the Hawaiian anchovy or nehu (Encrasicholina purpurea) and the buccaneer anchovy (E. punctifer) are known from Hawaiian waters (Randall 2007). The nehu was classified in earlier literature as Stolephorus purpureus. While the buccaneer anchovy is wide-ranging and usually found offshore, the nehu, an endemic Hawaiian species, occurs inshore, often in brackish bays such as Hanapepe Bay at Port Allen. The following section summarizes information on the biology of the nehu.

\section{Life History and Ecology}

The Hawaiian anchovy is a schooling species that occurs predominantly in enclosed, semiestuarine areas such as Kaneohe Bay, Pearl Harbor, and Honolulu Harbor on Oahu (Tester 1955). Some evidence indicates that non-spawning adults may move into exposed coastal habitats (Clarke 1989a). The local populations are known to move daily between diurnal resting areas along turbid shorelines and nocturnal spawning and feeding areas in relatively clear channels (Somerton et al. 1993). It is a small (ca. $5.0-7.5 \mathrm{~cm} \mathrm{SL}$ ) and shortlived species, rarely exceeding one year in age and often living less than six months (Struhsaker and Uchiyama 1976).

Hawaiian anchovy may first spawn at a size of $35 \mathrm{~mm}$ SL (Yamashita 1951) and an age of 3-4 months post-hatch (Struhsaker and Uchiyama 1976). Most mature female Hawaiian anchovy spawn every other day continuously throughout the year (Clarke 1987, 1989b). Spawning is mainly concentrated in a one-hour period shortly after sunset (Clarke 1989b) and eggs are produced in densities of 100-1,000 per $\mathrm{m} 2$ of bottom area in water deeper than $5 \mathrm{~m}$ (Clarke 1987). Because Hawaiian anchovy eggs are ellipsoidal, they are easily distinguished from the spherical eggs of other species in plankton samples. Embryonic development time based on field observations showed a duration of 22-35 hours and was inversely related to water temperature (Clarke 1989b) with longest durations during the coldest (ca. $22^{\circ} \mathrm{C}$ ) months in spring and shortest durations during the warmer (ca. $27^{\circ} \mathrm{C}$ ) summer months. Laboratory experiments identified a similar relationship between temperature and egg development with $41 \mathrm{hrs}$ required at $19^{\circ} \mathrm{C}$ and $21 \mathrm{hrs}$ at $29^{\circ} \mathrm{C}$ (Yamashita 1951). 
Stratified depth sampling in Kaneohe Bay on Oahu indicated that eggs were spawned close to the bottom at depths that exceeded $10 \mathrm{~m}$ (Clarke 1992) and tended not to be transported into shallower depths. Egg abundance was highest between July and March (Clarke 1992).

There is a great deal of variability in the relationship between fecundity and length or weight in Hawaiian anchovy. Clarke (1987) measured the fecundity of 222 females ranging in length from 35 to $58 \mathrm{~mm}$ SL and found less than 100 eggs in the smallest fish to over 1,600 in the largest fish. Average fecundity was estimated from length-weight and weightfecundity equations (Clarke 1987) for females whose size range was 36-54 mm standard length with a median size of $45 \mathrm{~mm}$. Reproductive capacity varied seasonally with summer fish producing 570 eggs per gram wet body weight and winter fish producing 373 eggs per gram wet body weight. Leary et al. (1975) calculated that the fecundity of a hypothetical fish having a weight equal to the mean weight of the population was 566 eggs/g of fish weight. Rate of oocyte development is much faster in this tropical anchovy than in temperate species such as northern anchovy (Engraulis mordax) or Peruvian anchovy (E. ringens).

Newly hatched larvae are $2 \mathrm{~mm}$ in length and exhibit exponential growth to a length of about 15-17 mm. Body elongation begins to slow as the developing larvae increase in body depth and at about $20 \mathrm{~mm}$ they enter a linear growth phase to about $60 \mathrm{~mm}$ (Struhsaker and Uchiyama 1976). Early larvae feed almost exclusively on copepod larvae and then shift to a diet of adult copepods as they mature (Burdick 1969). By a size of approximately $30 \mathrm{~mm}$ the Hawaiian anchovy has completed its larval transformation and enters the juvenile stage, and the smallest mature individuals are first seen at approximately $35 \mathrm{~mm}$ SL (Yamashita 1951, Leary et al. 1975). There are no estimates of mortality rates in the literature for any life stages of Hawaiian anchovy.

\section{Population Trends and Fishery}

Hawaiian anchovy is collected commercially as bait for the Hawaiian hook-and-line fishery for skipjack tuna (Dalzell and Lewis 1989). Hawaiian anchovy populations can fluctuate considerably over time and therefore affect the quantity and the availability of the species for bait. It is considered a superior bait, especially for catching large skipjack (Shomura 1964). Stock assessments were developed to gauge the extent of the spawning population and biomass within the area of Pearl Harbor, Oahu (Somerton et al. 1993). Spawning biomass and commercial biomass (adults and juveniles) peaked in April with lows in October-November. Although there was a great deal of variation in the estimates, the greatest estimate was approximately 18 MT (metric tons) in April 1987 with an average throughout the year of approximately 2 MT. Spawning biomass was about one-fourth of the commercial biomass. Because of the relatively short generation times, population resilience is reported to be high with minimum population doubling time of less than 15 
months (K=1.7) (Fishbase 2007 and 2008).

Recent fisheries statistics for Hawaiian anchovy are not reported by the Hawaii Department of Land and Natural Resources, probably because the species is used mainly as bait and cannot be sold legally as dried or cured product. However, earlier reports list annual catches of Hawaiian anchovy at about 30,000 to 40,000 buckets (one bucket $\approx 5 \mathrm{~kg}$ ) from Pearl Harbor, Kaneohe Bay, and Keehi Lagoon on Oahu (Hida and Skillman 1983).

Other restrictions are a recreational catch limit of one gallon per day, and a requirement for commercial fishers to use nets less than $15 \mathrm{~m}$ in length when fishing. Available analyses of catch and effort data (Clarke 1989a) give no clear evidence that the fishery has seriously impacted the population, even though Hawaiian anchovy is in high demand as a baitfish. Based on estimates of Hawaiian anchovy consumption rates, standing crops, and fishery yields, it was concluded that Hawaiian anchovy probably have not been seriously impacted by human activity.

\subsubsection{Sampling Results}

The Hawaiian anchovy (nehu, Encrasicholina spp.) (Figure 5-40) was the seventh most abundant taxa collected during the study $(4.5 \%$ of the total larvae collected) with an overall average concentration of 96 larvae per $1,000 \mathrm{~m}^{3}$ (Table 5-2). Nehu were only collected in any substantial abundances during the November survey (Figure 5-41). Nehu concentration was highest at Station 3 (Table 5-3 and Figure 5-41),

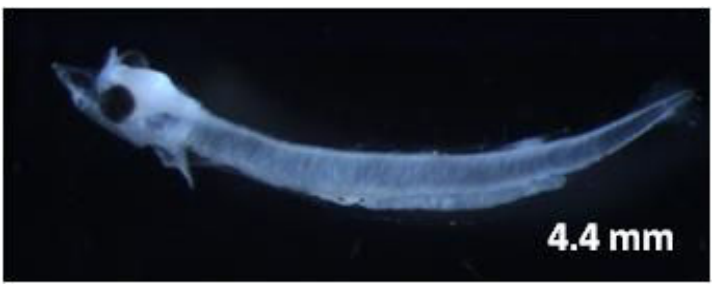

Figure 5-40. Hawaiian anchovy (Encrasicholina spp.) larva collected during this study. and it was generally more abundant during the day than during the night sampling cycles (Figure 5-42). The sampling at Station 3 showed that the highest concentrations of nehu were in the shallower collections (Figure 5-43). Due to nehu larvae only being collected during a single survey, analyses of the data at all three stations and between the different depths at Stations 3 was not conducted.

The majority of the Hawaiian anchovy larvae measured from the study were less than about $5 \mathrm{~mm}$ in notochord length with a mean size of $3.1 \mathrm{~mm}$ (Figure 5-44). Figure 5-45 shows that the head height and width was quite similar in size at all lengths measured. 


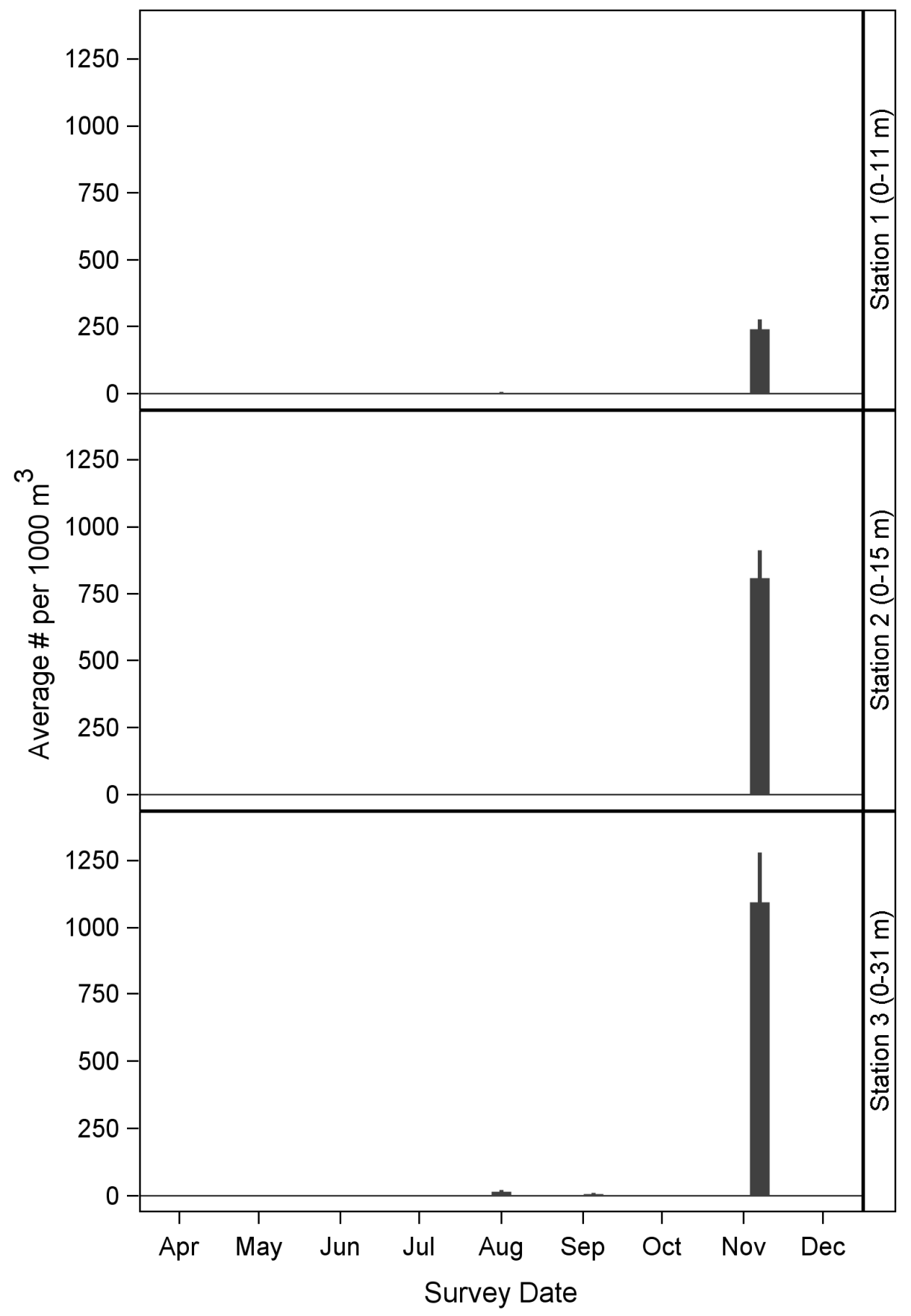

Figure 5-41. Average concentrations (plus one standard error) of Encrasicholina spp. larvae at the three sampling stations off Port Allen, Kauai from April-December 2012. 


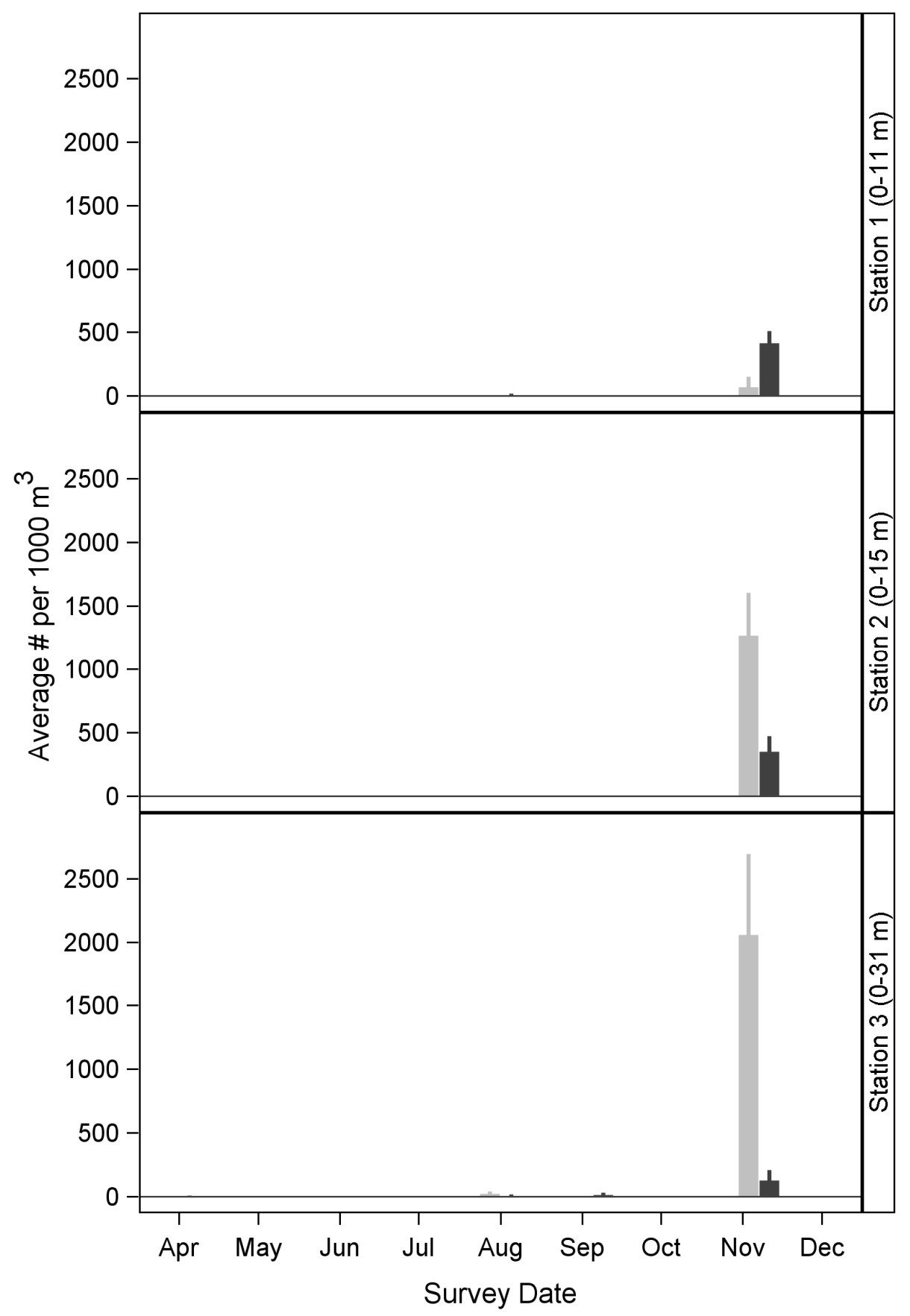

Figure 5-42. Average concentrations (plus one standard error) of Encrasicholina spp. larvae during day (gray bars) and night (black bars) sampling at the three stations off Port Allen, Kauai from AprilDecember 2012. 


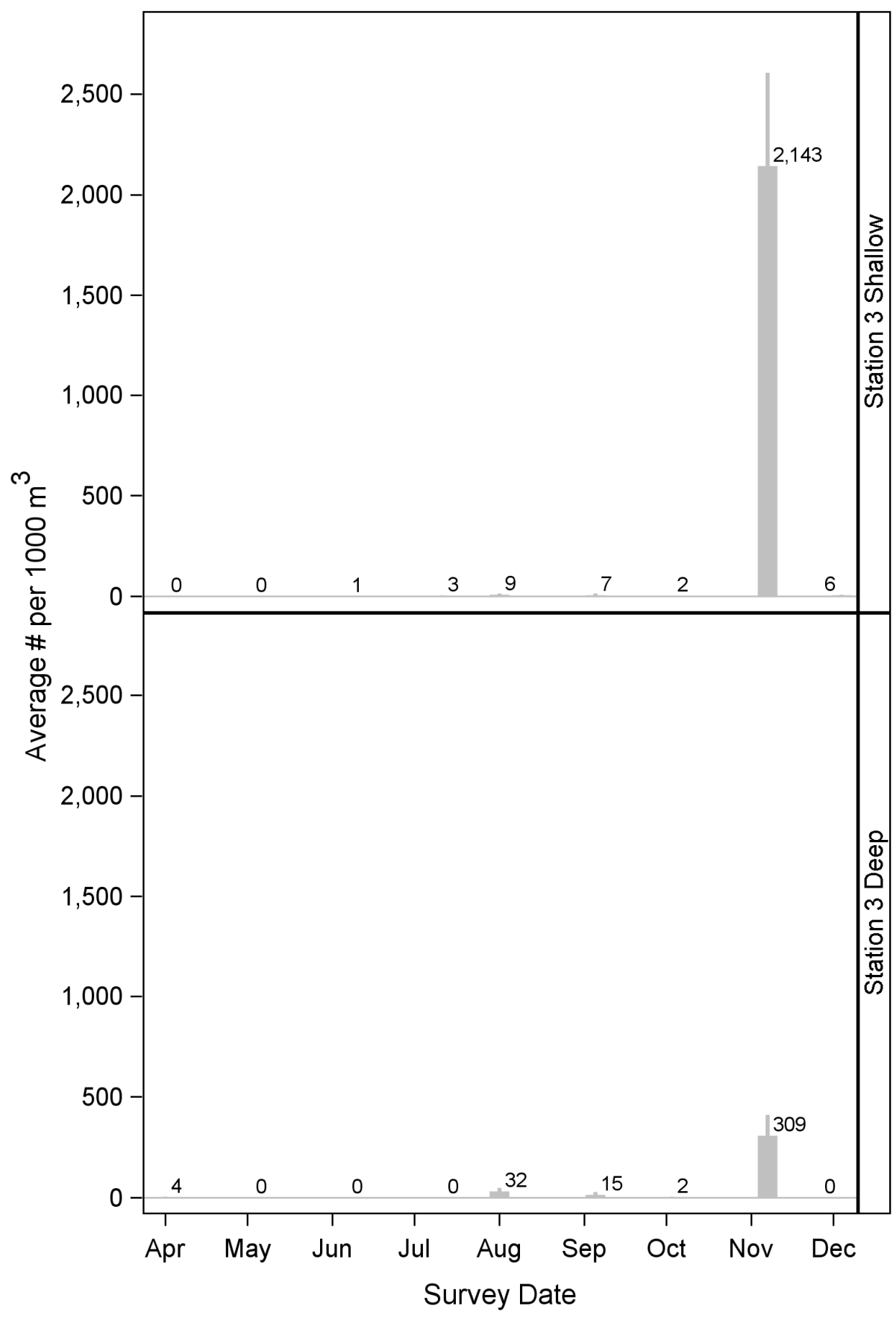

Figure 5-43. Average concentrations (plus one standard error) of Encrasicholina spp. larvae at two depth strata at Station 3 off Port Allen, Kauai from April-December 2012. Numbers at tops of bars are mean values. 


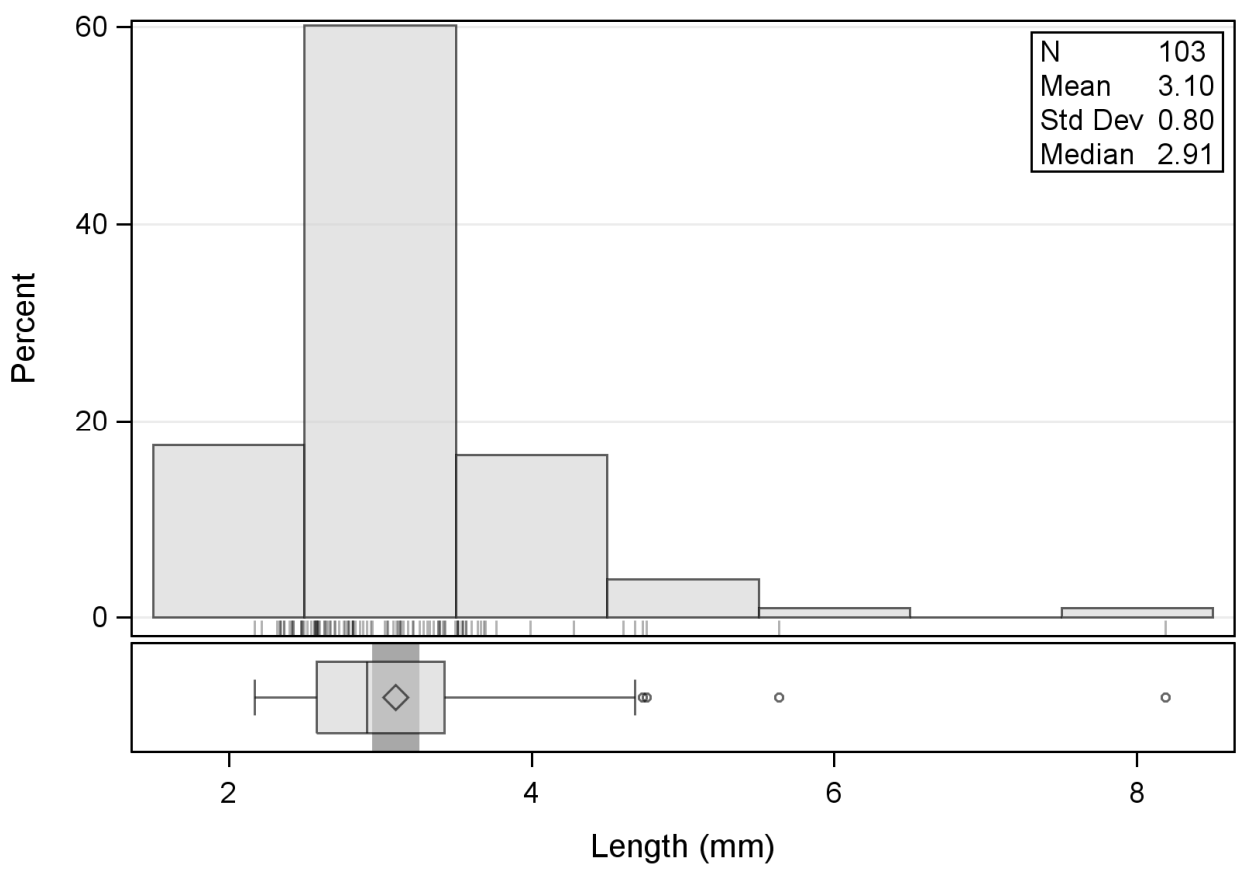

Figure 5-44. Length frequency of Encrasicholina spp. larvae measured during this study.

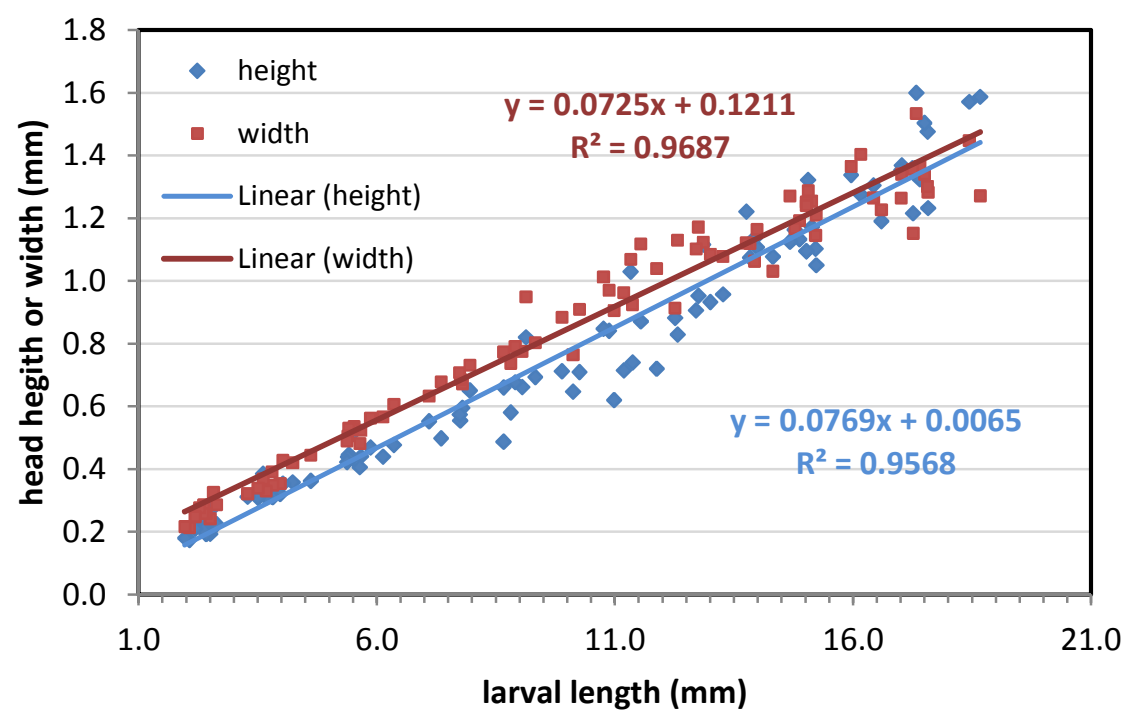

Figure 5-45. Larval length versus head capsule measurements of Encrasicholina spp. larvae. These measurements are for larvae measured during this study and others conducted in Hawaii. 


\subsubsection{Jacks (Carangidae)}

The family of Carangidae fishes (jacks, trevallys (Figure 5-46), and pompano) occurs worldwide in tropical and warm-temperate marine and estuarine waters. The family includes 32 genera and 140 species worldwide (Nelson 2006) with 23 species from 13 genera occurring in Hawaii (Randall 2007). Phylogenetic relationships among species have been described but are not clearly established (Smith-Vaniz 1984). Some of the morphological characteristics defining the jacks include a slender caudal peduncle with a deeply forked tail, separate dorsal fins,

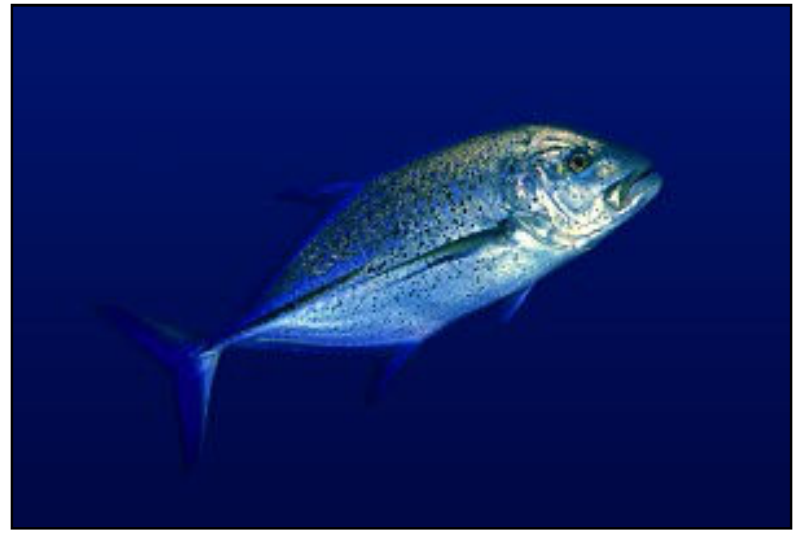

Figure 5-46. ' $\bar{o} m i l u$ - bluefin trevally (Photo by J.E. Randall). and spines detached from the anal fin, among others. The species can vary greatly in form from deep-bodied to fusiform, and sizes also vary widely from the small $(28 \mathrm{~cm})$ bigeye scad or akule (Selar crumenophthalmus) to the large $(165 \mathrm{~cm})$ giant trevally or ulua aukea (Caranx ignobilis). Many of the species are midwater to surface nektonic, fast-swimming, schooling predators and some of the smaller species routinely visit reefs to prey on smaller reef fishes. Because the larval stages of several species are very similar in appearance, especially in the earliest stages of development, and many are undescribed altogether, most of the carangid larvae collected in the present study were combined for analysis at the family level.

Growth equations for bluefin trevally and bigeye scad were developed by Sudekum et al. (1991) and Kawamoto (1973), respectively. Bigeye scad reach a length of approximately 21 $\mathrm{cm}$ after two years and can attain a maximum size of approximately $30 \mathrm{~cm}$. Bluefin trevally reach a length of nearly $35 \mathrm{~cm}$ SL after two years, and one specimen that was over $60 \mathrm{~cm}$ in length was aged at $6 \mathrm{yr}$. They are known to attain sizes exceeding $80 \mathrm{~cm}$ FL and $10.2 \mathrm{~kg}$, and based on their growth equation may grow even larger ( $\mathrm{L}$ inf $=90 \mathrm{~cm} \mathrm{SL}$ ). Bigeye scad have a relatively short estimated life span of 2.5 years (Ralston and Williams 1988), and tagging studies done in the wild estimated an annual mortality of $99.3 \%$ in Hawaiian waters (Kawamoto 1973).

A review of the ecology of Hawaiian jacks was compiled by Honebrink (2000), while additional information has been presented in Randall (2007). The African pompano (Alectis ciliaris) can grow quite large and feeds mainly on crustaceans but also occasionally on small fishes. The effects of carangid predation on reef resources were investigated by Sudekum et al. (1991). Bluefin trevally and giant trevally (Caranx ignobilis) were estimated to consume an average of $48 \mathrm{~kg}$ and $150 \mathrm{~kg}$ of food (mostly fishes) per year, respectively. At French Frigate Shoals where the study was conducted, this resulted in an estimated total 
consumption of 27.8 MT of prey per year for these two species alone, based on concurrent population estimates. Smaller jacks are known to be prey items for many species of larger piscivorous predators including barracuda, amberjacks, dolphinfish, and tunas.

\section{Reproduction}

Carangids (e.g., scad, Figure 5-47) spawn at varying levels throughout the year, but typically have a prolonged peak in spawning activity during the summer with spawning occurring repeatedly and periodically (Thresher 1984). They are broadcast spawners and have spherical, pelagic eggs that hatch 24-48 hrs after spawning at water temperatures from $18-30^{\circ} \mathrm{C}$ (Laroche et al. 1984). Carangid eggs are difficult to identify because of their similarity in size and structure to eggs produced by other families

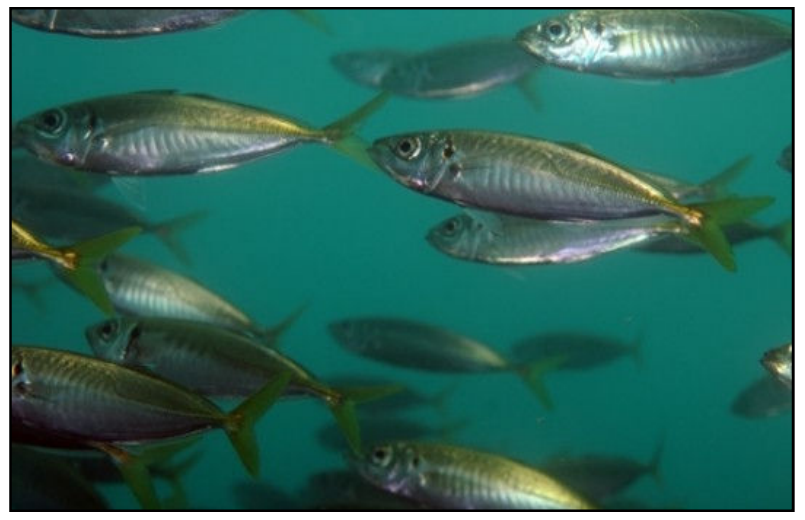

Figure 5-47. āmuka - yellowtail scad (Photo by J.P. Hoover) of percoid fishes, but eggs descriptions for some carangid species have been published (Watson and Leis 1974). Positive identification of some carangid eggs was also completed in the field by noting that certain species, in one case yellowtail scad, was the dominant carangid species occurring in the study area of Kaneohe Bay on Oahu (Clarke 1996).

Adult yellowtail scad spawn from March-September/October, with peaks near the beginning and end of the season, and a smaller peak in mid-summer (Miller and Sumida 1973, Watson and Leis 1973). There is, however, considerable interannual variation in the length of the spawning season, occasionally extending into December. Batch fecundity of females (188-232 mm SL) ranged from 63,000-161,000 eggs with a mean relative fecundity of 741 eggs per gram of body weight (Clarke 1996). The estimated batch fecundity for a female of average weight (155 g) is about 115,000 eggs. In Kaneohe Bay, eggs were only rarely collected in areas where the water depth was shallower than $10 \mathrm{~m}$ indicating a preference for deeper channels as spawning habitat (Clarke 1996).

Bigeye scad are multiple spawners that have a spawning period of April-October in Hawaiian waters (Clarke and Privitera 1995), but captive fishes have been reported to spawn during all months of the year (Iwai et al. 1996). The size at first maturity for captive males and females was $19 \mathrm{~cm}$ and $25 \mathrm{~cm}$ FL (fork length), respectively (Iwai et al. 1996). Small schools in captivity were found to spawn from 5-10 times per year and mean batch fecundity was estimated at 92,000 eggs (range 48,000-262,000 depending on size). They have been observed to form large schools in shallow waters during the spawning season, and have been described as Hawaii's most abundant carangid (Honebrink 2000). 
Bluefin trevally or 'ōmilu (Caranx melampygus) is one of the more common large, shallowwater, demersal Hawaiian jacks. Sudekum et al. (1991) characterized this species as highly fecund with a "profligate reproductive pattern" that is a characteristic of many pelagic marine fishes that are broadcast spawners. They are gravid from April-November with a peak spawning period from approximately May-August based on specimens collected in the northwestern Hawaiian Islands (Sudekum et al. 1991). Females reach sexual maturity at about $350 \mathrm{~mm}$ SL with the size at $50 \%$ maturity in the population at a length of about $400 \mathrm{~mm}$ SL. The number of mature ova in a reproductive female ranged from approximately 50,000 for a $328 \mathrm{~mm}$ SL (760 g) fish to over 4.2 million for a $640 \mathrm{~mm} \mathrm{SL}$ $(6,490 \mathrm{~g})$ fish.

\section{Population Trends and Fishery}

The bigeye scad is an important food fish and is a target of both sport and commercial fisheries in Hawaii. Because of its schooling behavior it can be encircled and caught using haul seines, or alternatively, it may be caught from skiffs using hand-lines (Kawamoto 1973). In 2005 over 227,000 kg of bigeye scad were landed in Hawaiian waters in addition to a substantial recreational fishery.

\subsubsection{Sampling Results}

The Carangidae larvae (Figure 5-48) collected during the study were composed of more than a single species based on their visual appearance; but, due to their small size, they could not be identified to the genus or species level. These larvae were the tenth most abundant taxon in the samples (1.6\% of the total larvae collected) with an overall average concentration of 34 larvae per 1,000 $\mathrm{m}^{3}$ (Table 5-2). Carangidae larvae were most abundant at Stations 2 and 3 (Table 5-3) during the September survey (Figure

5-49 ). Carangidae larvae appear to have been collected in higher abundance during the night sampling cycles than during the day cycle (Figure

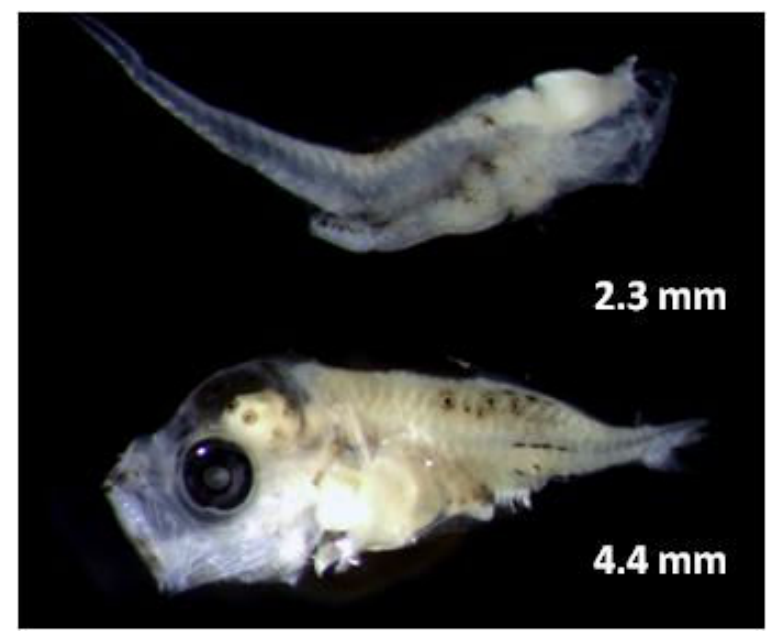

Figure 5-48. Carangidae larvae collected during this study. 5-50). The ANOVA for Carangidae larvae, after transformation $(\log [\mathrm{x}+0.01])$, detected a significant differences among effects for station and day and night sampling cycles ( $\mathrm{p}<$ 0.05) (Table 5-14). The comparison of the stations showed that the lower average concentration at Station 1 was significantly different from both Station 2 and 3, but no difference was detected between Stations 2 and 3. The higher average concentrations during the night sampling cycle were significantly different from the average 
concentrations during the day sampling.

The calculated values for the deeper depth strata at Station 3 did not show any consistent trend across surveys for higher concentrations in either the shallow or deep zones, although the highest average concentration occurred at the deeper depth strata during the September survey (Figure 5-51). No difference between depth strata was detected using ANOVA with data transformed as $\log [\mathrm{x}+0.01](\mathrm{p}=0.400)$.

As was seen with most of the other taxa, the Carangidae larvae were small with almost all the larvae that were measured less than $3 \mathrm{~mm}$ in notochord length (Figure 5-52). The mean length of was about $2.1 \mathrm{~mm}$. Figure 5-53 shows that the carangid head height is greater than its width.

Table 5-14. Results of ANOVA of data on Carangidae larvae from oblique tows of the entire water column at Stations 1, 2, and 3 during day and night sampling cycles across nine surveys off Port Allen, Kauai from April-December 2012. Tests significant at probability level of $95 \%$ are in bold.

\begin{tabular}{lccrc}
\hline Effect & $\begin{array}{c}\text { Numerator } \\
\text { degrees of } \\
\text { freedom }\end{array}$ & $\begin{array}{c}\text { Denominator } \\
\text { degrees of freedom }\end{array}$ & F-Value & Probability \\
\hline Station & 2 & 139 & 6.63 & $\mathbf{0 . 0 0 1 8}$ \\
Sampling Cycle & 1 & 142 & 13.41 & $\mathbf{0 . 0 0 0 4}$ \\
Interaction - Cycle*Station & 2 & 139 & 1.43 & 0.2427 \\
\hline
\end{tabular}




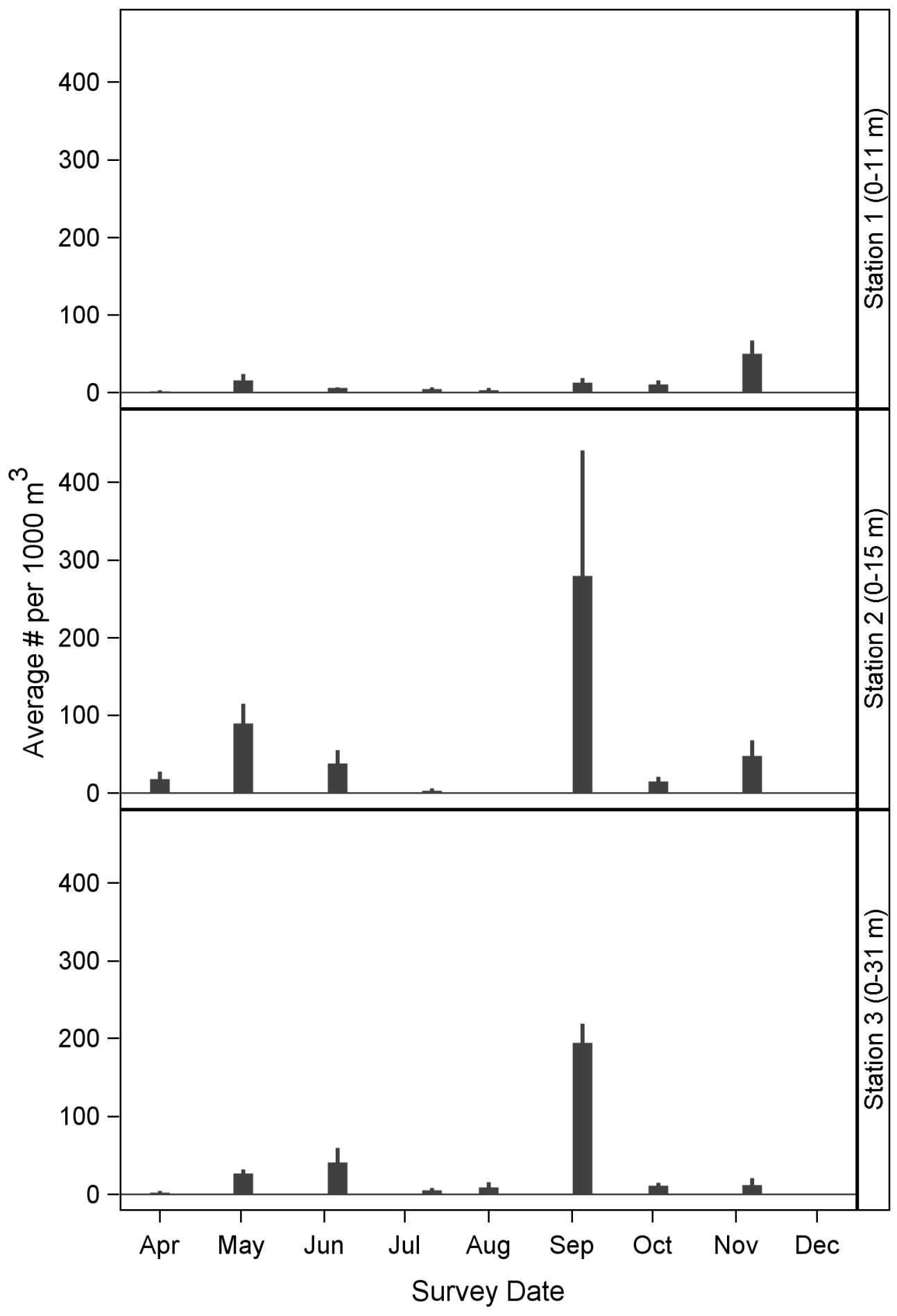

Figure 5-49. Average concentrations (plus one standard error) of Carangidae larvae at the three sampling stations off Port Allen, Kauai from April-December 2012. 


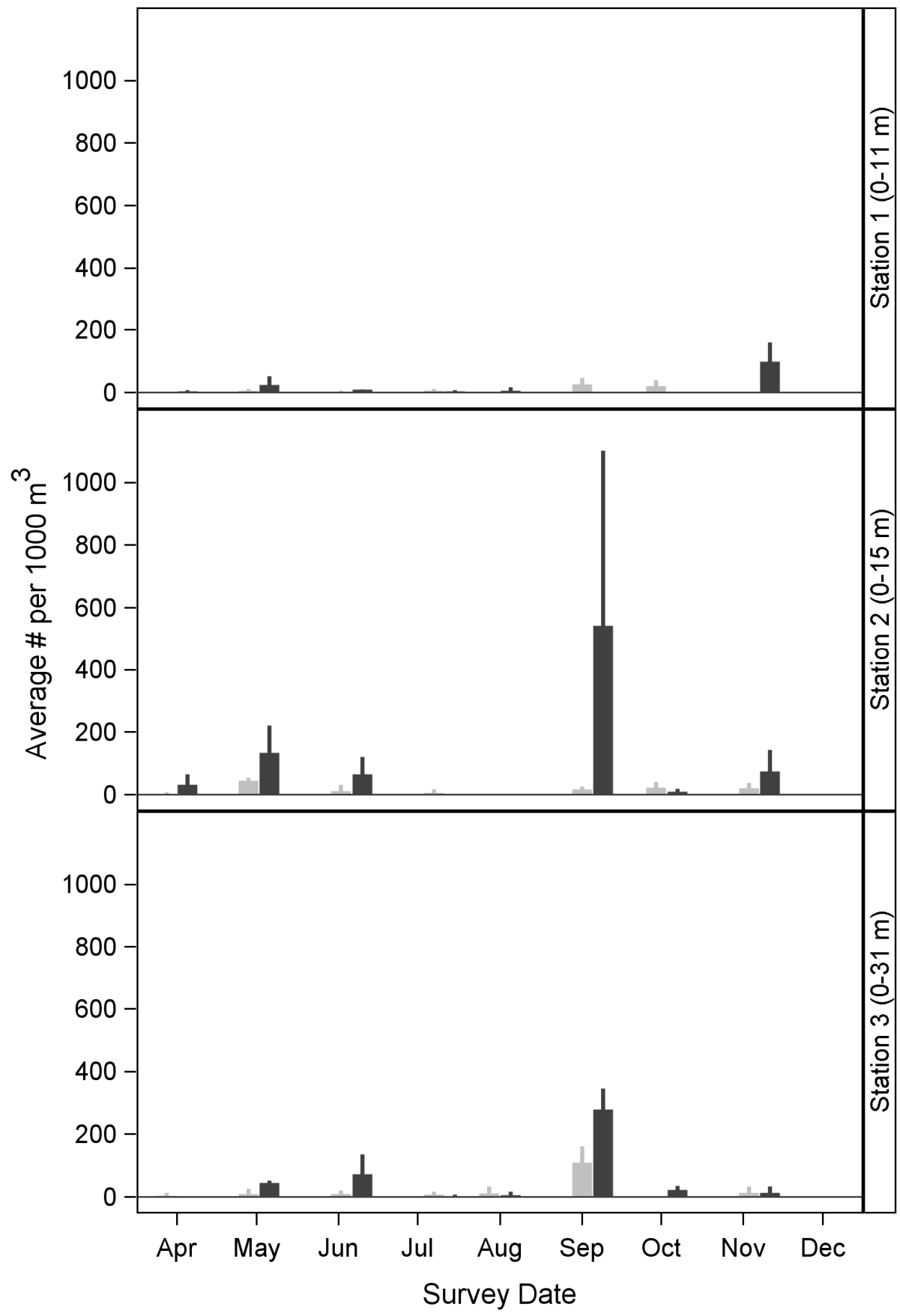

Figure 5-50. Average concentrations (plus one standard error) of Carangidae larvae during day (gray bars) and night (black bars) sampling at the three stations off Port Allen, Kauai from AprilDecember 2012. 


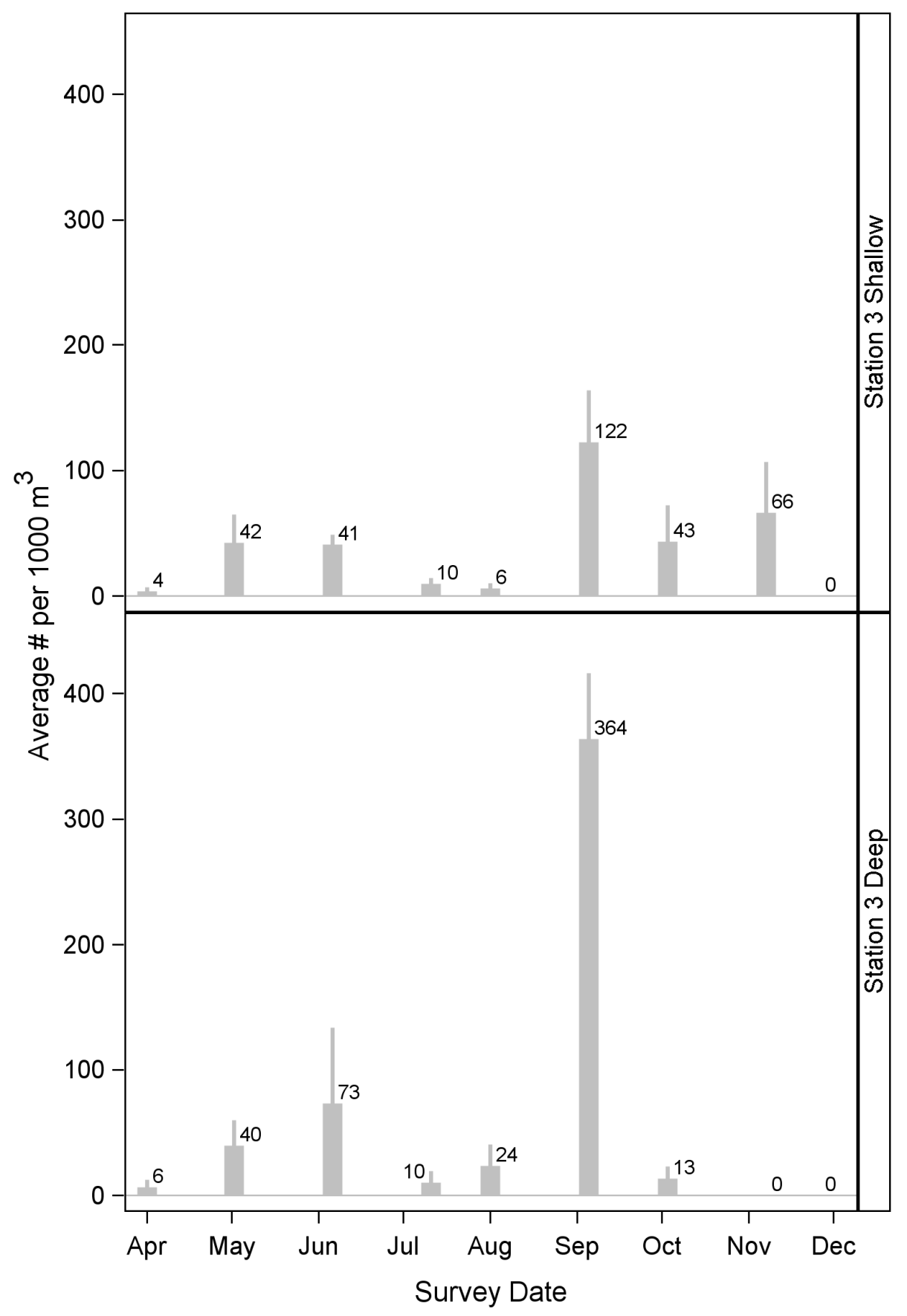

Figure 5-51. Average concentrations (plus one standard error) of Carangidae larvae at two depth strata at Station 3 off Port Allen, Kauai from April-December 2012. Numbers at tops of bars are mean values. 


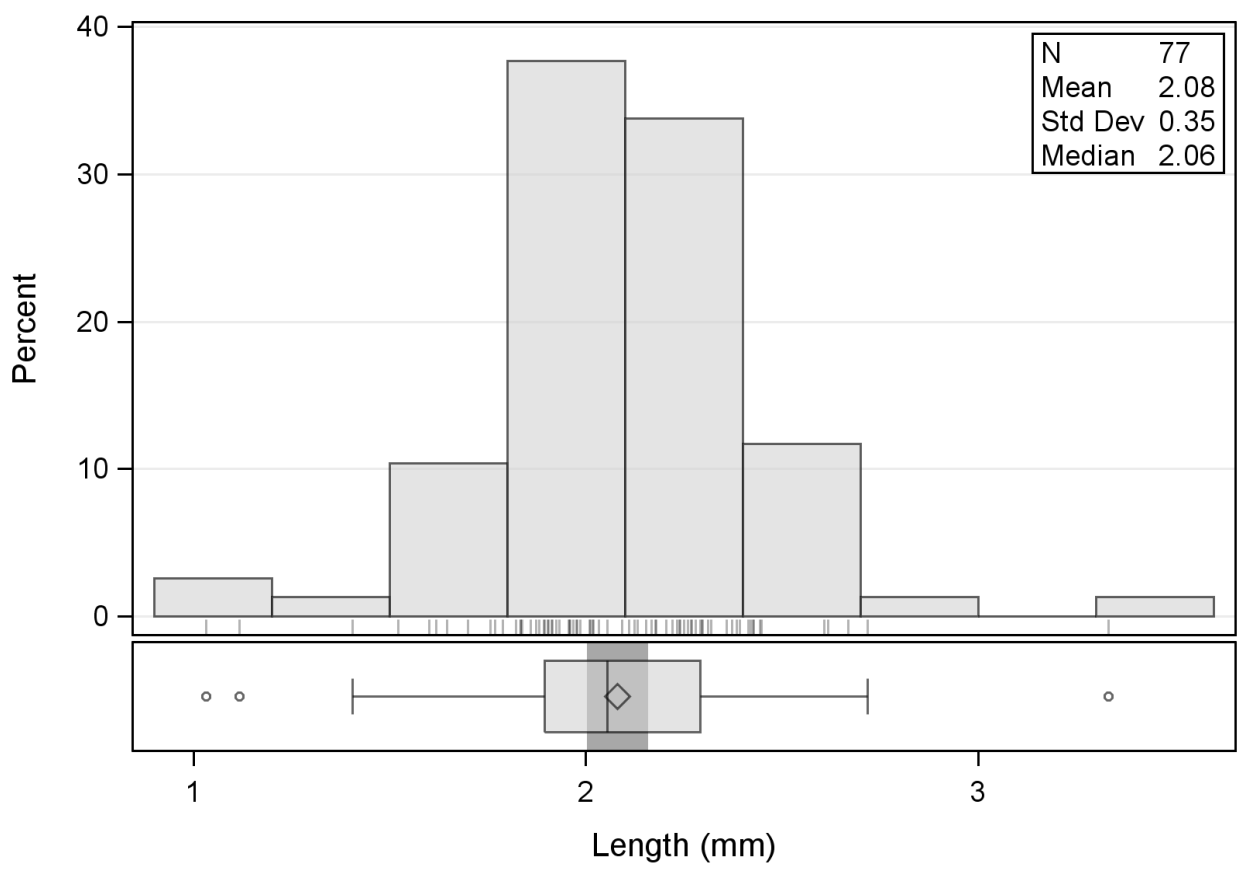

Figure 5-52. Length frequency of Carangidae larvae measured during this study.

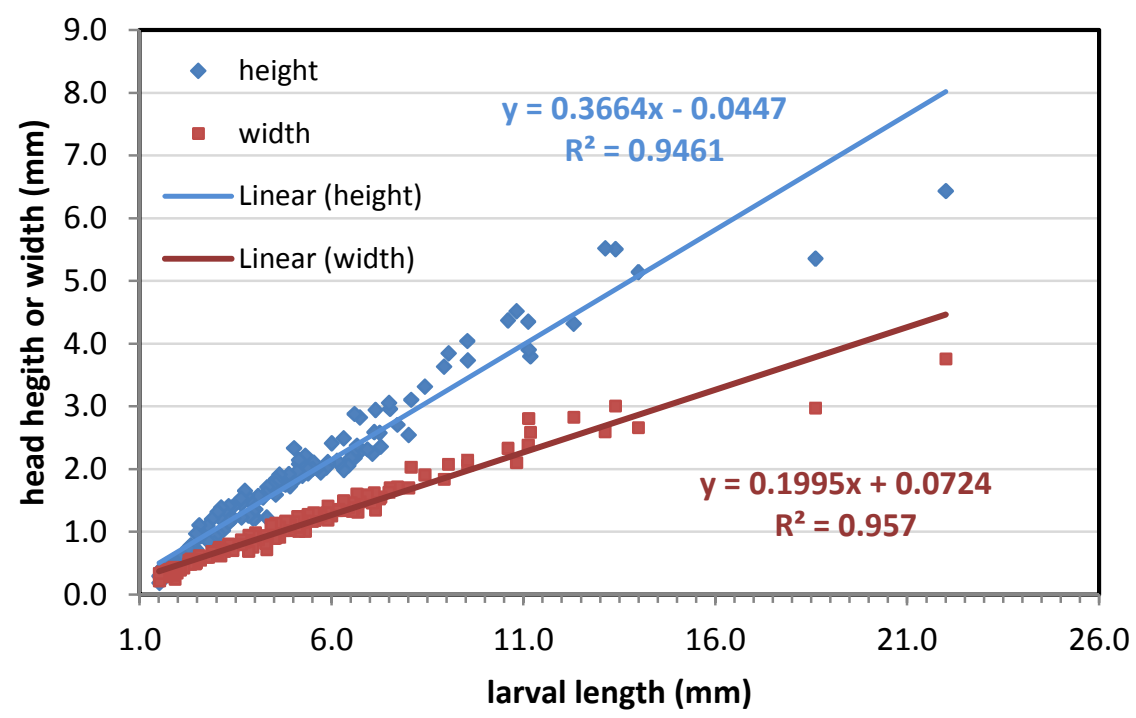

Figure 5-53. Larval length versus head capsule measurements of Carangidae larvae. These measurements are for larvae measured during this study and others conducted in Hawaii. 


\subsubsection{Cardinalfishes (Apogonidae)}

Cardinalfishes are a diverse group of small (only occasionally exceeding 9 or $10 \mathrm{~cm}$ (Thresher 1984), carnivorous, generally nocturnal fishes that live around coral reefs as well as various other habitats (Leis and Carson-Ewart 2004). Cardinalfishes are found mostly in shallow water throughout the tropics. There are a total of about 250 species of cardinalfishes worldwide with ten having been reported from the Hawaiian Islands (Mundy 2005, Randall 1998).

\section{Life History and Ecology}

The Hawaiian species of cardinalfishes are generally found in waters protected by fringing reefs, where they live in holes or caves or with other organisms (such as sea urchins, crown-of-thorns seastars, or anemones) during the day, and are in the open near these areas at night. The bay cardinalfish (Foa brachygramma) is a small species ( $44 \mathrm{~mm}$ mean adult SL) that is endemic to the Hawaiian Islands. In relation to the other cardinalfishes, the bay cardinalfish tends to seek shelter less during the day. They are usually found in calm, back-reef areas, bays, or estuaries (in salinities as low as 5\%o), and near undercut ledges and boulders. They are generally near the substrate but feed on plankton in the water column at night.

The most common species of cardinalfish in Hawaii is the iridescent cardinalfish (Pristiapogon kallopterus). It also occurs throughout the tropical Pacific and Indian Oceans. Around Oahu, they are found from 1-40 m depths in all substrates, most commonly in sand and limestone areas close to the substrate and less frequently in boulder areas. P. kallopterus has been occasionally seen in brackish waters (20\%) at night. They are mainly found around living coral heads and areas with light-colored sand.

The bandfin cardinalfish (Pristiapogon taeniopterus) has a disjunct distribution, part in the Indian Ocean and part in the Pacific (Mundy 2005). In the Pacific, it is geographically restricted to the Palmyra/Line Islands, Johnston Island, and from Hawaii to the French Frigate Shoals, in waters from 1-40 m deep. They are found more frequently in clear, open water, near structure such as large coral heads or substrates with high relief. The average adult is $118 \mathrm{~mm}$ in length (SL). At night, they are generally found within one meter of the bottom foraging on zooplankton and, at times, benthic prey.

Most, if not all, cardinalfishes are mouthbrooders, with the males the primary oral incubators (Thresher 1984). Spawning seasons appear to vary between the species. Temperate/cool water species spawn when water temperatures reach their annual maximum. Tropical species seem to have different seasonal spawning patterns. Based on settlement data, some species late spring-early summer peaks of settlement while other species from the same area have scattered year-round settlement (Russell et al. 1977, cited in Thresher 1981). Caribbean/Atlantic accounts suggest spring and fall peaks to year- 
round spawning (Thresher 1984).

Thresher (1984) stated that cardinalfishes apparently spawn at night or just before first light. A number of species form conspicuous spawning pairs (Thresher 1984) that brood, spawn, and court in the protection of holes, away from predators and disturbances (Chave 1978). In aquarium rearing observations, spawning occurred on roughly six-day intervals, at $27-28^{\circ} \mathrm{C}$ for several weeks. After courting, females extrude a ball of small $(0.24-0.7-\mathrm{mm}$ diameter [Thresher 1984]), usually spherical (some spindle-shaped) eggs, which the male quickly "inhales". Smith and Tyler (1972, cited in Thresher 1984) reported that females of western Atlantic species had a range of 610 - 3,722 ripe eggs. Several of those females possessed eggs in various stages of development, suggesting multiple spawnings in a season. Thresher (1984) stated that in the laboratory a female Apogon cyanosoma spawned at about six-day intervals for several weeks, but there was no indication of the number of eggs produced. In some species, males possibly carry eggs from several different spawnings (Thresher 1984).

Allen (1975, cited in Thresher 1984) reports eggs for the tropical species Sphaeramia orbicularis hatching in 8 days at $27-30^{\circ} \mathrm{C}$. Hatch length ranges from $2.3 \mathrm{~mm}$ (Phaeoptyx affinis; Smith et al. 1971, cited in Thresher 1984) to $3.3 \mathrm{~mm}$ (Sphaeramia orbicularis; Allen 1975, cited in Thresher 1984); but Leis and Carson-Ewart (2004) reported a hatch length range of 2.5-6.0 mm. Early preflexion to postflexion development varies from species to species. Notochord flexion occurs between 3.2-4.1 mm (Leis and Carson-Ewart 2004). Planktonic larval duration was estimated at about 58 days (range 56-61) for three species of Apogon and two species of Cheilodipterus at One Tree Island lagoon by noting the first sightings of males with eggs and subsequently settled juveniles (Thresher 1984). Using an average hatch length of $4.25 \mathrm{~mm}$, an average size of settlement of $17.5 \mathrm{~mm}$ (Thresher 1984) and 58 days to settlement, results in an estimated larval growth rate of $0.23 \mathrm{~mm} /$ day. Settlement size ranges from 10-25 mm. Allen (1975, cited in Thresher 1984) reports a juvenile growth rate of $6.4 \mathrm{~mm}$ per month for Sphaeramia orbicularis, resulting in an estimated juvenile growth rate of $0.21 \mathrm{~mm} /$ day (Thresher 1984). He also stated that the age at sexual maturity is unknown, but is probably a year or less due to their overall small size.

\section{Population Trends and Fishery}

Due to their small size and lack of records indicating the use of cardinalfishes as a baitfish, it is probably safe to assume that only a strictly ornamental fishery for the aquarium trade exists for cardinalfishes.

\subsubsection{Sampling Results}

The cardinalfishes collected during this study were identified into one of three taxa: 
Apogonidae, Apogon spp., and Pristiapogon spp. The following sections present the results for all Apogonidae combined and also for the two genera. The data on head capsule versus notochord length for these taxa were combined and presented as a single figure in the Apogonidae section.

\subsection{Cardinalfishes (Apogonidae)}

Apogonidae (Figure 5-54) was the twentieth most abundant taxon collected during this study $0.3 \%$ of the total larvae collected) with an overall average concentration of 7 larvae per $1,000 \mathrm{~m}^{3}$ (Figure 5-2). When the data for all cardinalfishes were combined, they had their highest

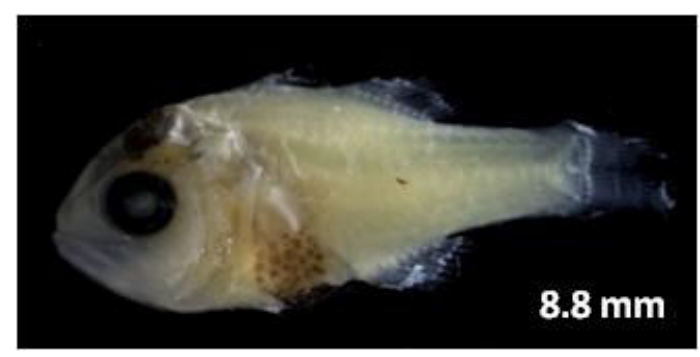

Figure 5-54. Apogonidae larvae collected during this study. concentrations during August and September at all three stations (Figure 5-55). A comparison of average concentrations between the day and night sampling cycles was not consistent across surveys (Figure 5-56). During August (month with highest concentrations) the larvae were more abundant during the night sampling cycle, but during September they were more abundant during the day at Stations 1 and 3 but similar at Station 2. The ANOVA for the Apogonidae larvae data, transformed as $\log (\mathrm{x}+0.01)$, did not detect a significant difference among the three stations $(\mathrm{p}=0.360)$ or between day-night sampling cycles $(\mathrm{p}=0.066)$ (Table 5-15).

The calculated values for the deeper depth strata at Station 3 showed that the concentration of Apogonidae generally appear to be higher in the deeper zone at Station 3 during all the surveys (Figure 5-57). No difference between depth strata was detected with the ANOVA of the data, transformed as $\log (x+0.01)(p=0.887)$, which was likely due to the large variation in larval Apogonidae concentrations between the samples collected at each depth and across surveys.

The notochord lengths of the larvae measured from the study showed that the vast majority were small (mean length of $3.1 \mathrm{~mm}$ and median length of $2.1 \mathrm{~mm}$ ) but a few larger individuals were also collected (Figure 5-58). A comparison of the head height and width to notochord length of the Apogonidae larvae showed that the height was larger than the width over the range of measured sizes (Figure 5-59). 
Table 5-15. Results of ANOVA of data on Apogonidae larvae from oblique tows of the entire water column at Stations 1, 2, and 3 during day and night sampling cycles across nine surveys off Port Allen, Kauai from April-December 2012. Tests significant at probability level of $95 \%$ are in bold.

\begin{tabular}{lcccc}
\hline Effect & $\begin{array}{c}\text { Numerator } \\
\text { degrees of } \\
\text { freedom }\end{array}$ & $\begin{array}{c}\text { Denominator } \\
\text { degrees of } \\
\text { freedom }\end{array}$ & F-Value & Probability \\
\hline Station & 2 & 139 & 1.03 & 0.3602 \\
Sampling Cycle & 1 & 141 & 3.43 & $\mathbf{0 . 0 6 6 2}$ \\
Interaction - Cycle*Station & 2 & 139 & 0.41 & 0.6652 \\
\hline
\end{tabular}




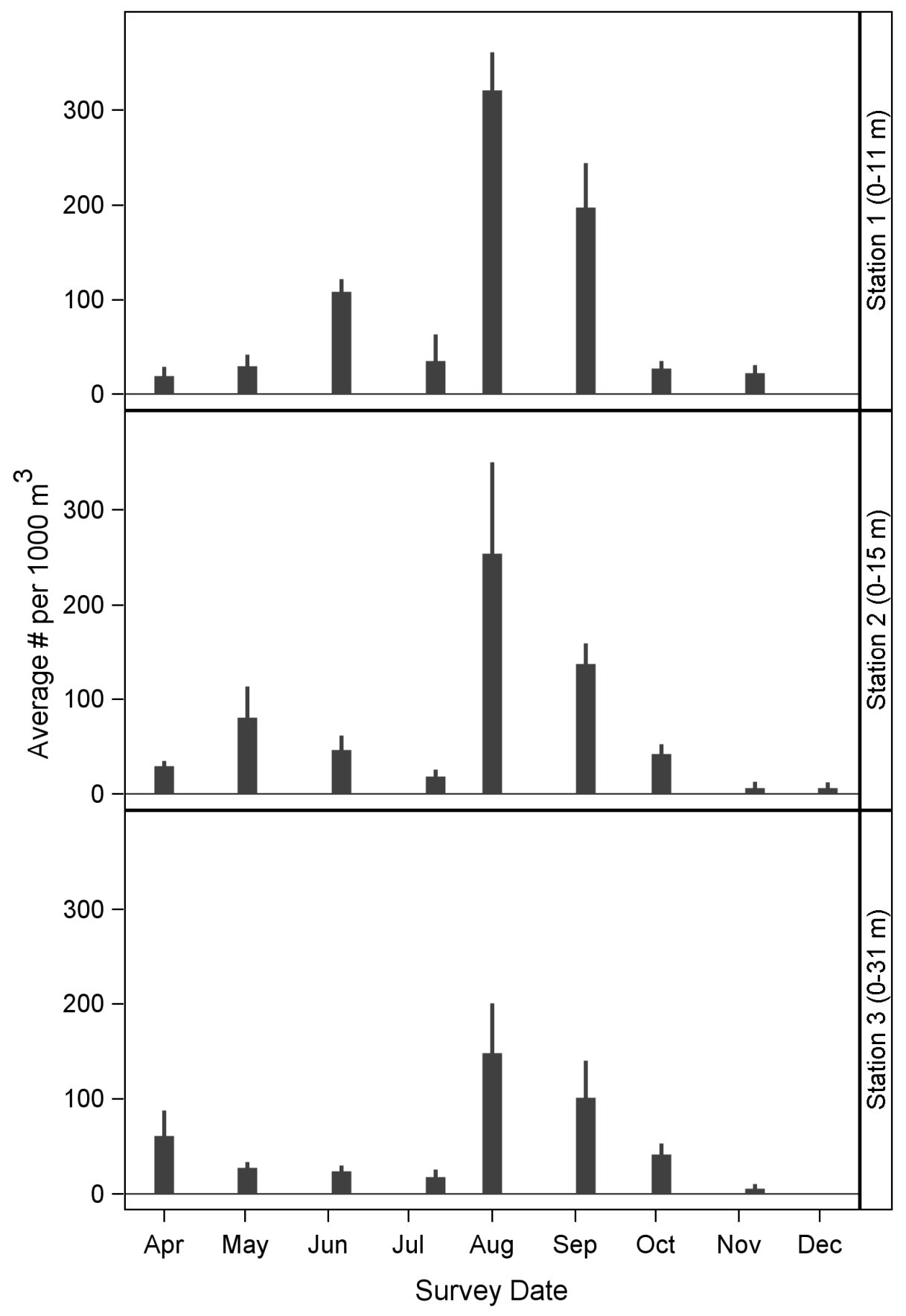

Figure 5-55. Average concentrations (plus one standard error) of all Apogonidae larvae combined at the three sampling stations off Port Allen, Kauai from April-December 2012. 


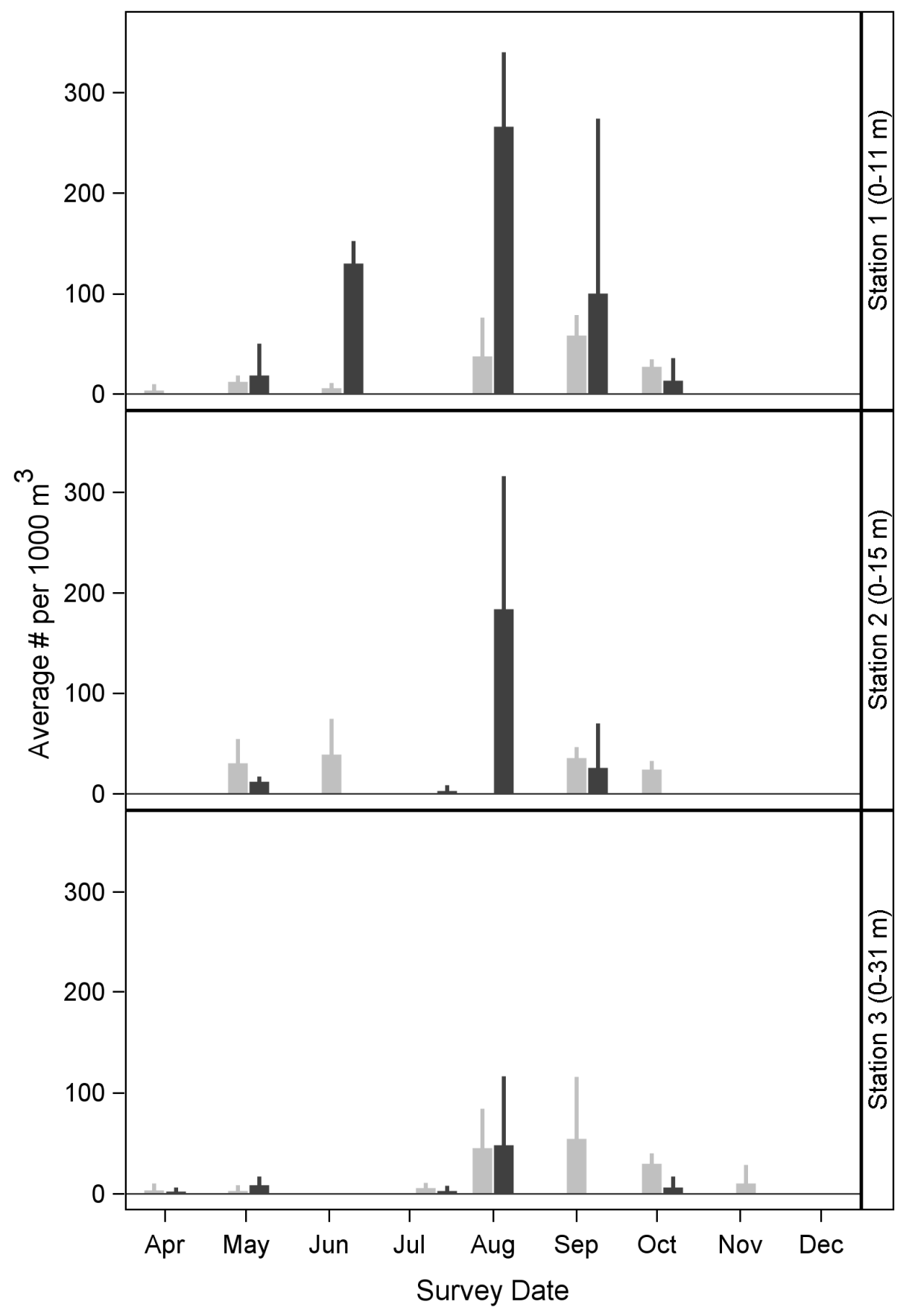

Figure 5-56. Average concentrations (plus one standard error) of all Apogonidae larvae combined during day (gray bars) and night (black bars) sampling at the three stations off Port Allen, Kauai from AprilDecember 2012. 


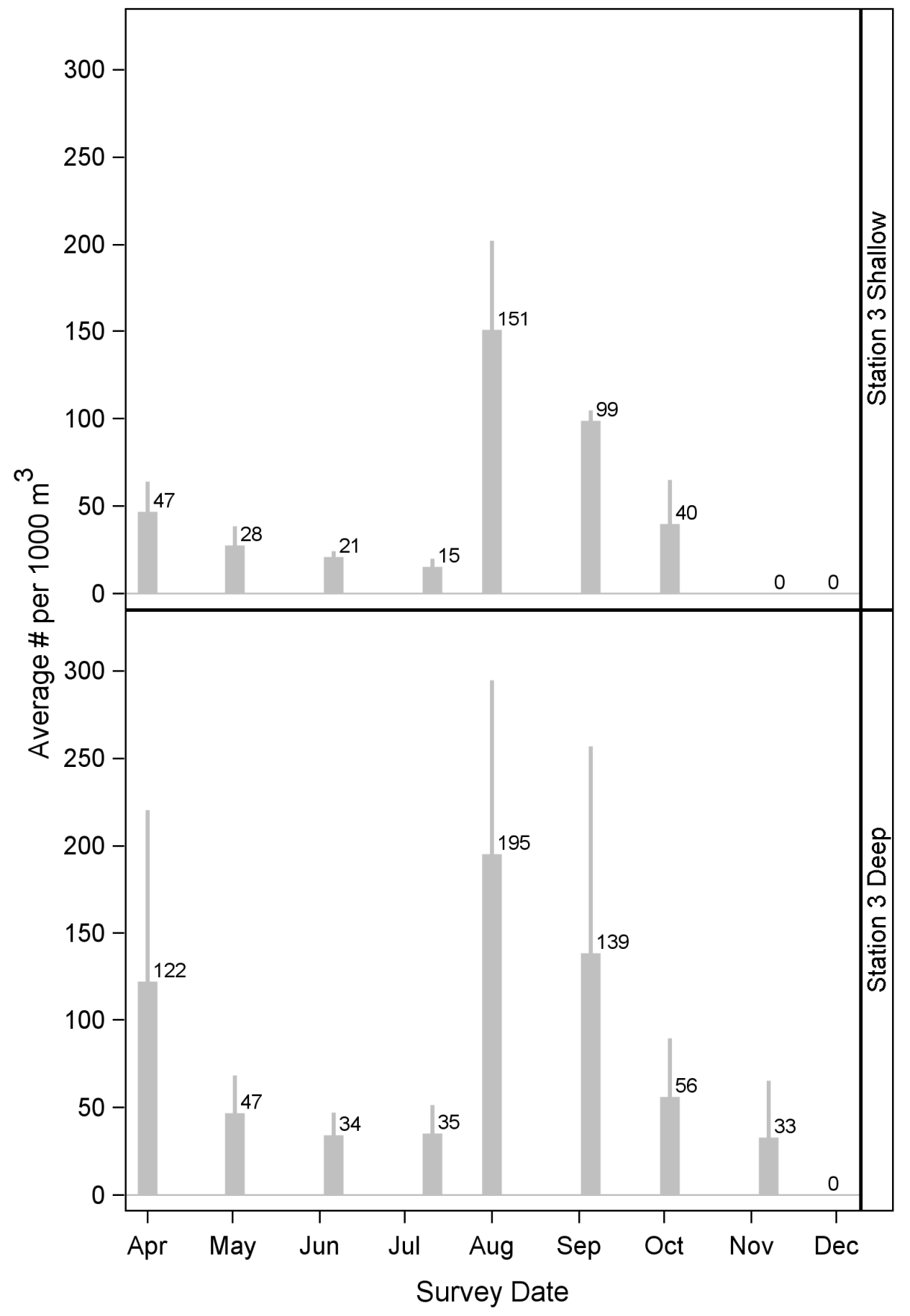

Figure 5-57. Average concentrations (plus one standard error) of Apogonidae larvae at two depth strata at Station 3 off Port Allen, Kauai from April-December 2012. Numbers at tops of bars are mean values. 


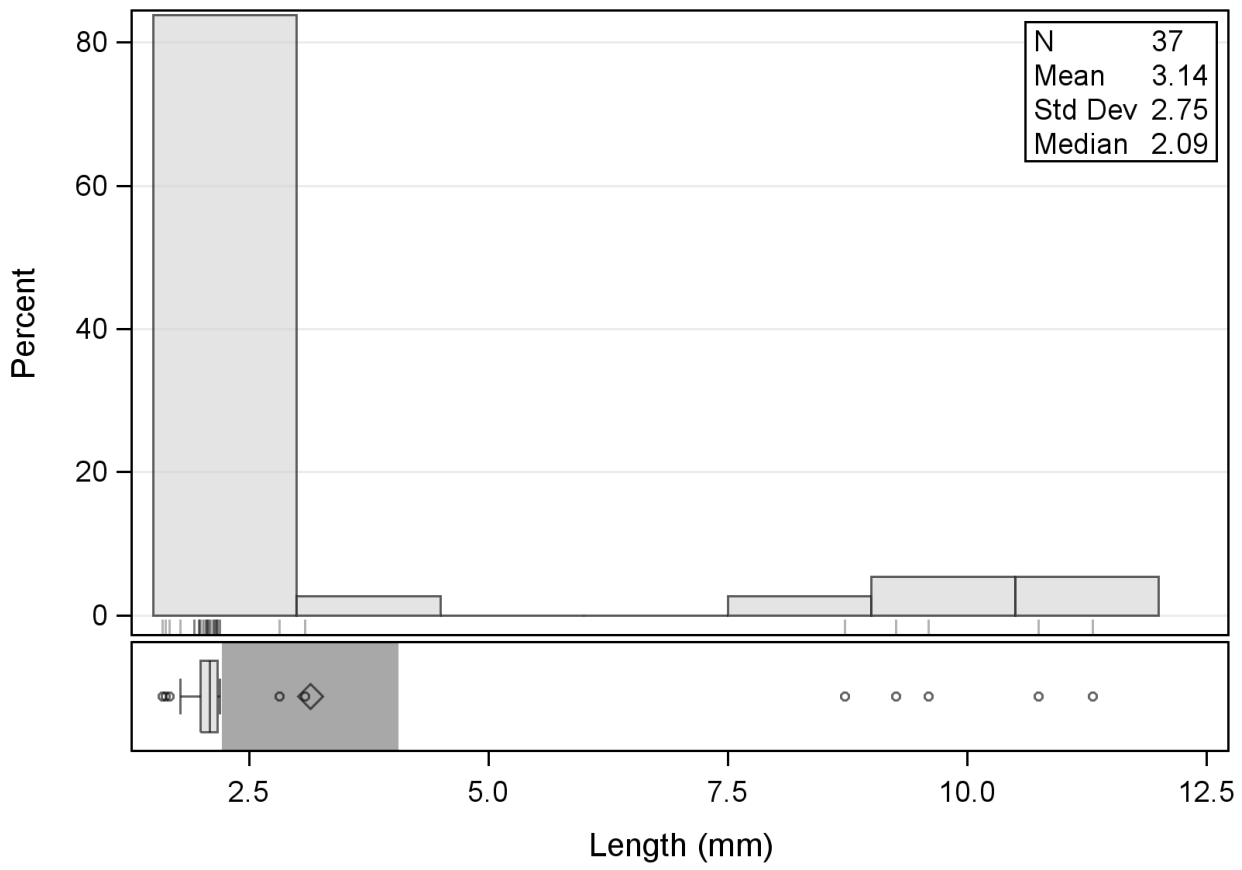

Figure 5-58. Length frequency of Apogonidae larvae measured during this study.

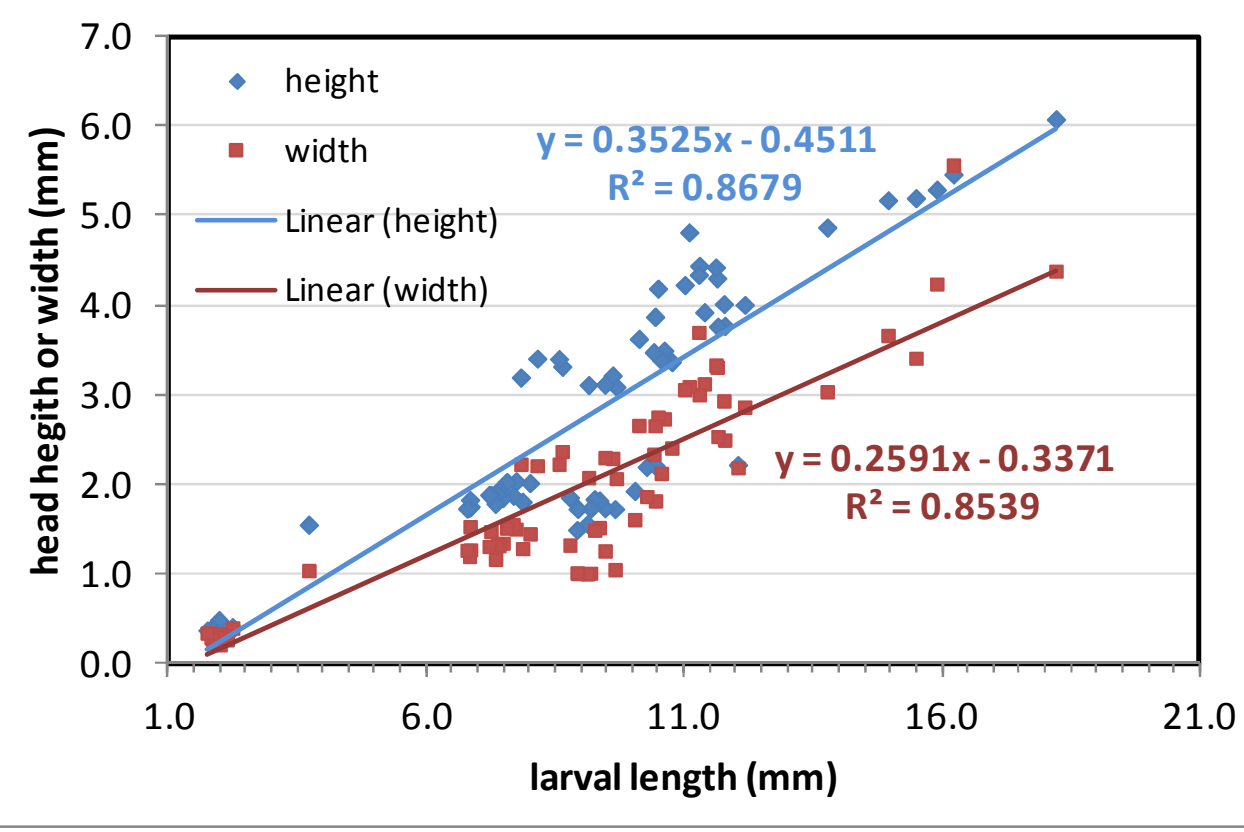

Figure 5-59. Larval length versus head capsule measurements of all Apogonidae larvae. This includes larvae identified as Apogonidae, Apogon spp., and Pristiapogon spp. These measurements are for larvae measured during this study and others conducted in Hawaii. 


\subsection{Cardinalfishes (Apogon spp.)}

Apogon spp. (Figure 5-60) were the twelfth most abundant larval fish taxon collected during this study $(0.9 \%$ of the total larvae collected) with an average concentration of 20 per $1,000 \mathrm{~m}^{3}$ (Table 5-2). Their average abundance was highest at the nearshore Station 1 and lowest at the offshore Station 3, (Table 5-3). They were collected in highest abundance during the August and September surveys (Figure 5-61).

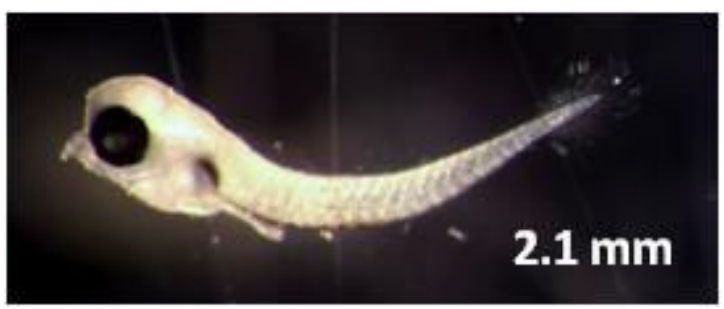

Figure 5-60. Apogon spp. larva collected during this study. The lowest abundances were collected in April, May, November and December. As was seen with Apogonidae, there was no clear trend in abundance differences between the day and night sampling periods (Figure 5-62). The ANOVA for Apogon spp. larval data, transformed as $\log (x+0.01)$, detected a significant difference in the abundances among stations $(\mathrm{p}=0.047)$, but no difference was detected between the day-night sampling periods $(\mathrm{p}=0.642)$ (Table 5-16). The comparison of the individual stations showed that Station 1 with the highest average concentration was significantly different from Station 3, but no other comparisons were statistically significant.

The depth comparison at Station 3 showed that Apogon spp. larvae were collected in higher concentrations in the deeper water than in the shallower depths (Figure 5-63), but there were too many samples from this station that had zero larvae to conduct an ANOVA.

The mean and median lengths of the Apogon spp. that were measured were almost identical $(1.8 \mathrm{~mm}$ ) with the largest individual being about $2.3 \mathrm{~mm}$ NL (Figure 5-64). The head capsule data for this taxon was combined with the other Apogonidae larvae in Figure 5-59.

Table 5-16. Results of ANOVA of data on Apogon spp. larvae from oblique tows of the entire water column at Stations 1, 2, and 3 during day and night sampling cycles across nine surveys off Port Allen, Kauai from April-December 2012. Tests significant at probability level of $95 \%$ are in bold.

\begin{tabular}{lcccc}
\hline Effect & $\begin{array}{c}\text { Numerator } \\
\text { degrees of } \\
\text { freedom }\end{array}$ & $\begin{array}{c}\text { Denominator } \\
\text { degrees of } \\
\text { freedom }\end{array}$ & F-Value & Probability \\
\hline Station & 2 & 139 & 3.11 & $\mathbf{0 . 0 4 7 5}$ \\
Sampling Cycle & 1 & 141 & 0.22 & 0.6423 \\
Interaction - Cycle*Station & 2 & 139 & 2.64 & 0.0751 \\
\hline
\end{tabular}




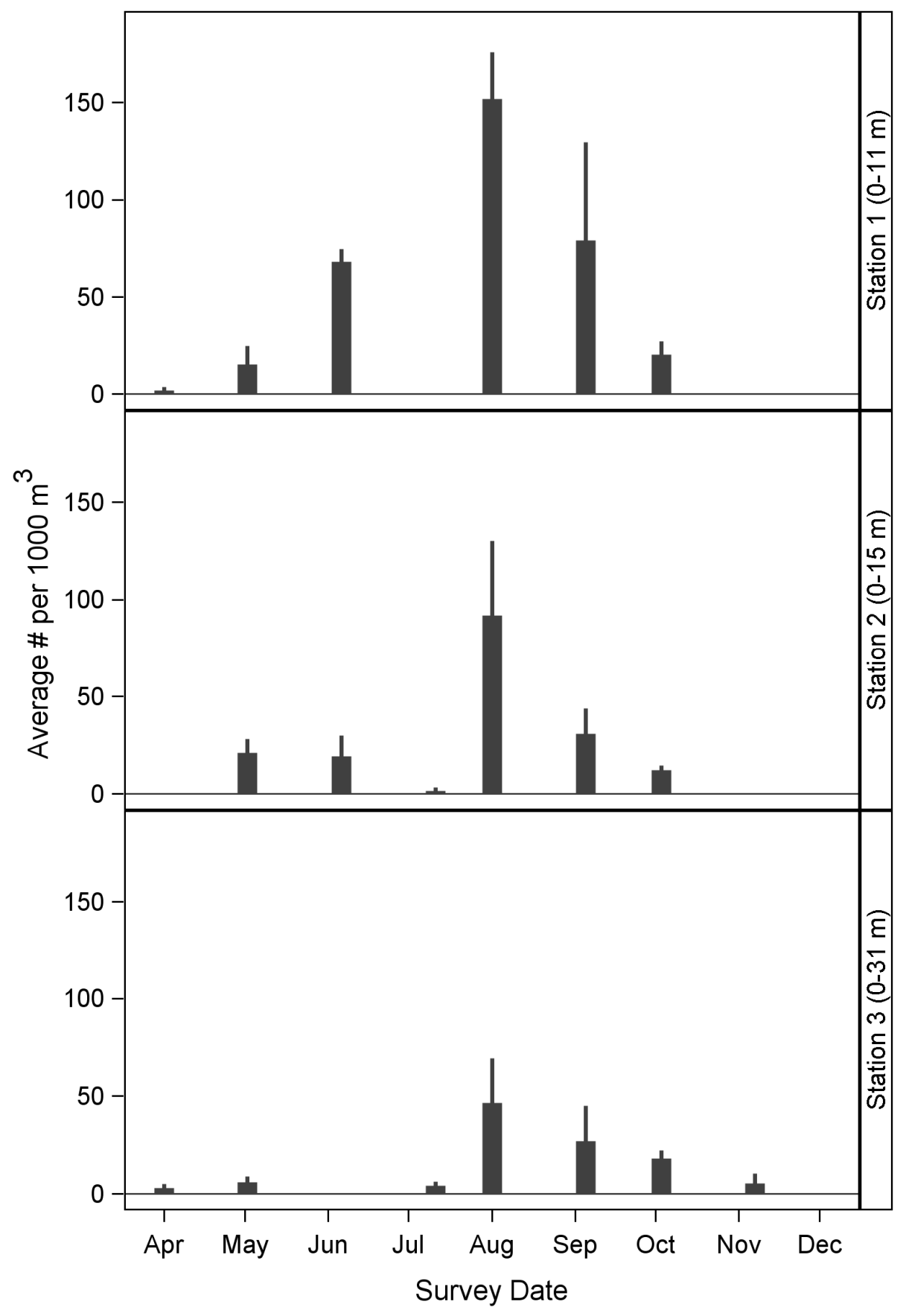

Figure 5-61. Average concentrations (plus one standard error) of Apogon spp. larvae at the three sampling stations off Port Allen, Kauai from April-December 2012. 


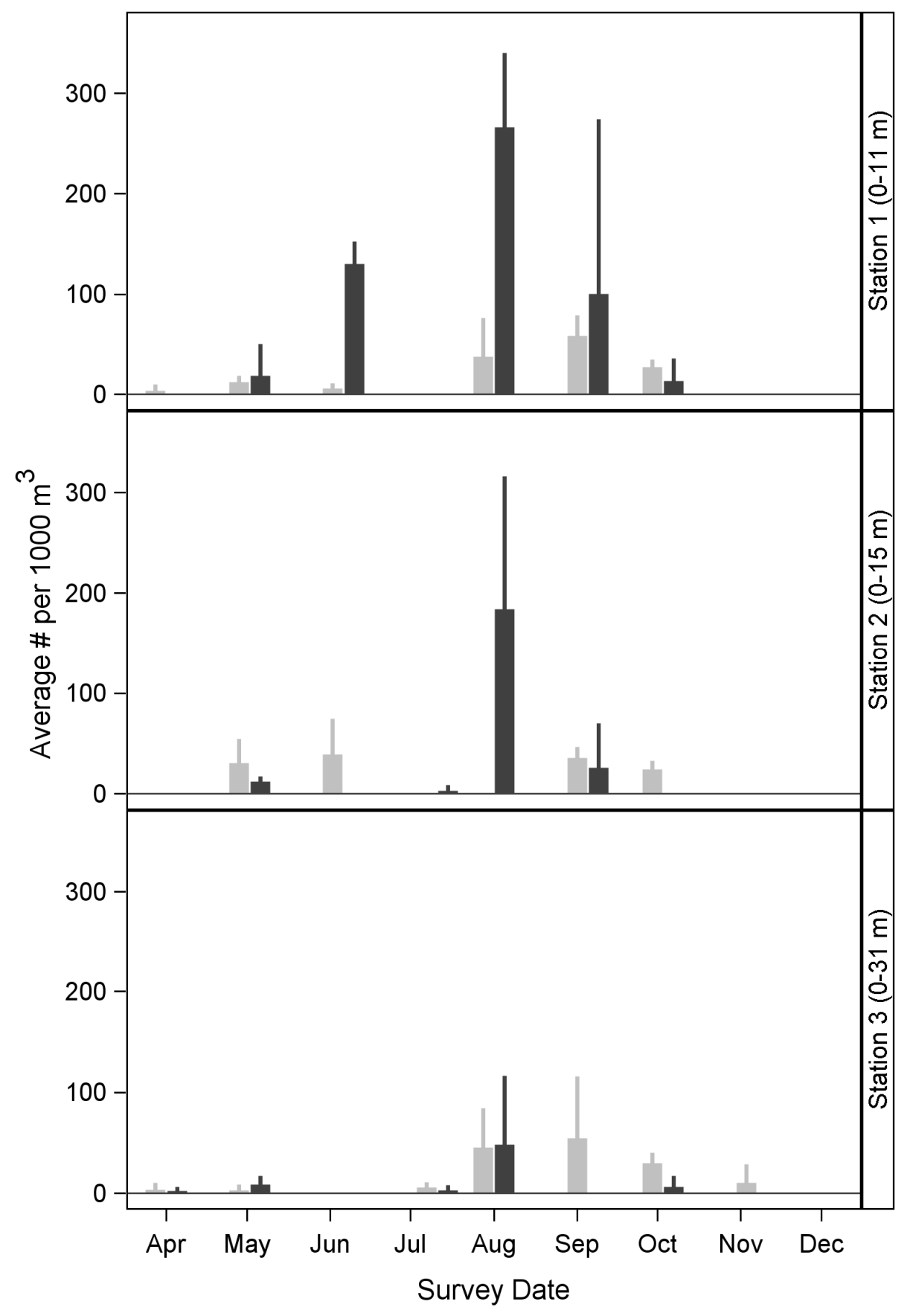

Figure 5-62. Average concentrations (plus one standard error) of Apogon spp. larvae during day (gray bars) and night (black bars) sampling at the three stations off Port Allen, Kauai from AprilDecember 2012. 


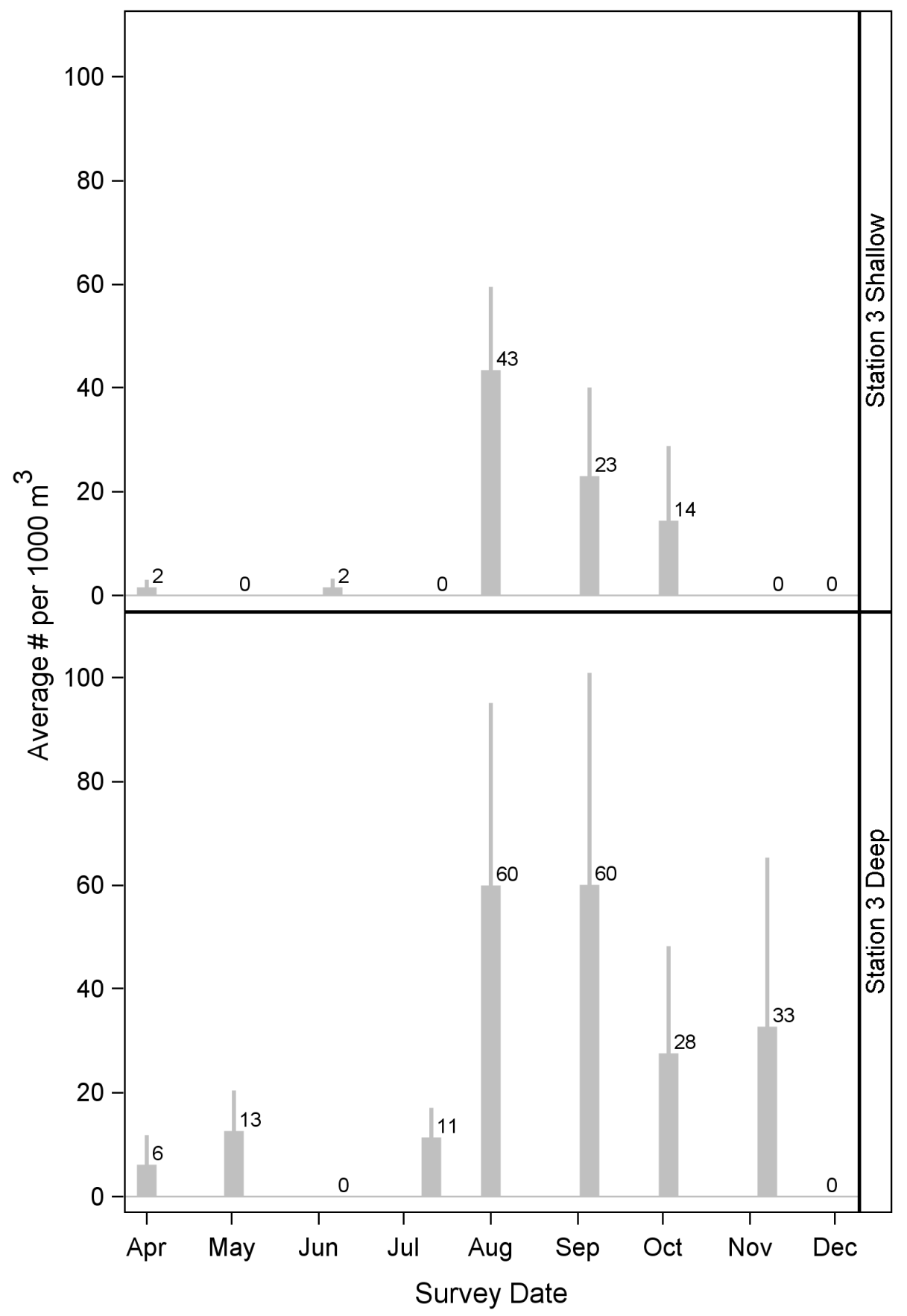

Figure 5-63. Average concentrations (plus one standard error) of Apogon spp. larvae at two depth strata at Station 3 off Port Allen, Kauai from April-December 2012. Numbers at tops of bars are mean values. 


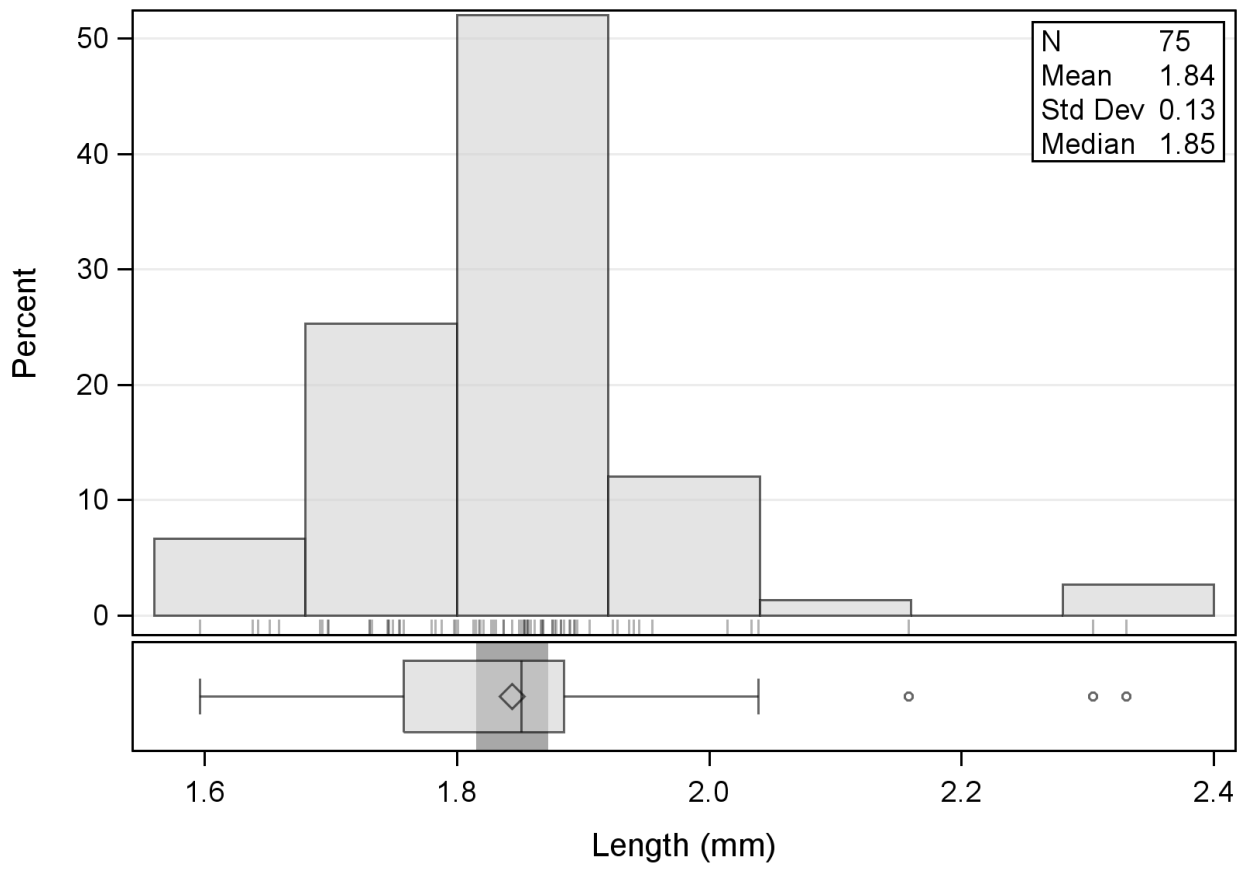

Figure 5-64. Length frequency of Apogon spp. larvae measured during this study. 


\subsection{Cardinalfishes (Pristiapogon spp.)}

Pristiapogon spp. larvae (Figure 5-65) were the eleventh most abundant taxon $(1.5 \%$ of the total larvae collected) with an average concentration of 31 per 1,000 $\mathrm{m}^{3}$ (Table 5-2). Pristiapogon spp. was more abundant at Stations 1 and 2 than at Station 3 (Table 5-3). Pristiapogon larvae were most abundant during the August survey and were in lowest abundance during the November and December surveys (Figure 5-66). The low abundance in December might be an artifact of fewer samples being collected during that survey. The concentrations of larvae were generally higher during the night sampling cycles (Figure

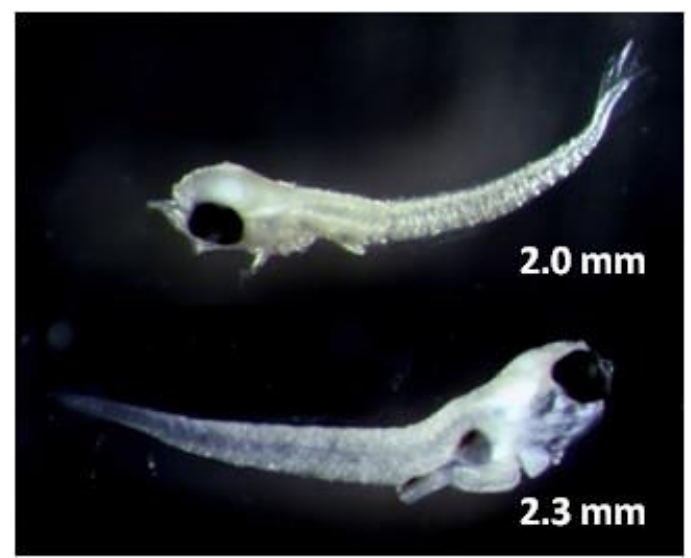

Figure 5-65. Pristiapogon spp. larvae collected during this study. 5-67). However, the ANOVA of the $\log (x+0.01)$ transformed data detected a significant difference between the day and night sampling periods ( $\mathrm{p}=0.008$ ) (night higher than day), but not among the three stations (Table 5-17).

At Station 3, this taxa was generally collected in higher concentrations in the deeper zone than in the shallower zone (Figure 5-68), but the ANOVA of the $\log (x+0.01)$ transformed data for Pristiapogon spp. larvae did not detect a significant difference between depth strata for these larvae $(\mathrm{p}=0.263)$.

As was observed in the other two Apogonidae taxa above, the Pristiapogon spp. larvae were small, with a mean size of only $2.0 \mathrm{~mm}$ NL (Figure 5-69). The largest individual measured was only about $2.4 \mathrm{~mm}$. The head capsule data for this taxon was combined with the other Apogonidae larvae in Figure 5-59. 


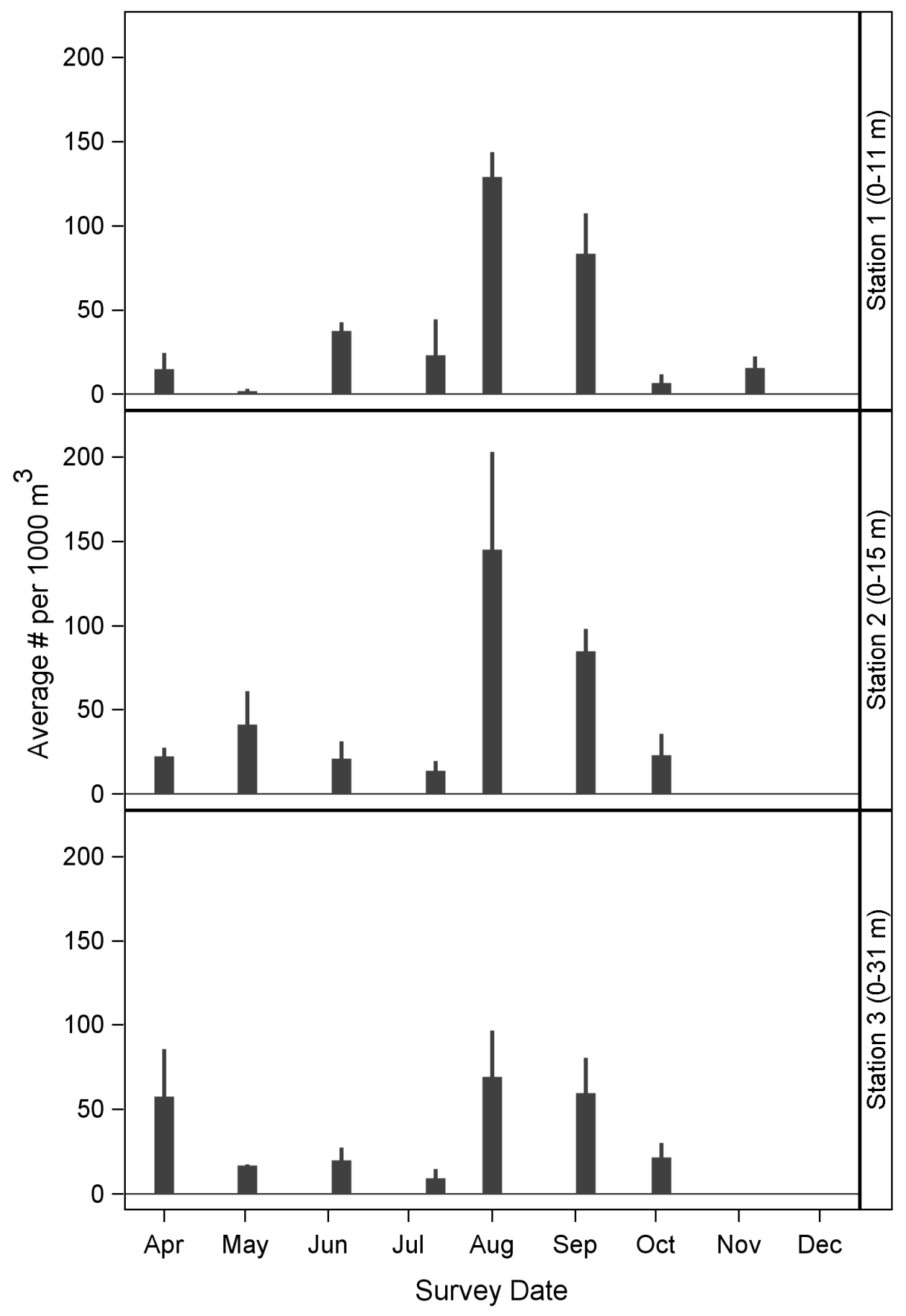

Figure 5-66. Average concentrations (plus one standard error) of Pristiapogon spp. larvae at the three sampling stations off Port Allen, Kauai from April-December 2012. 


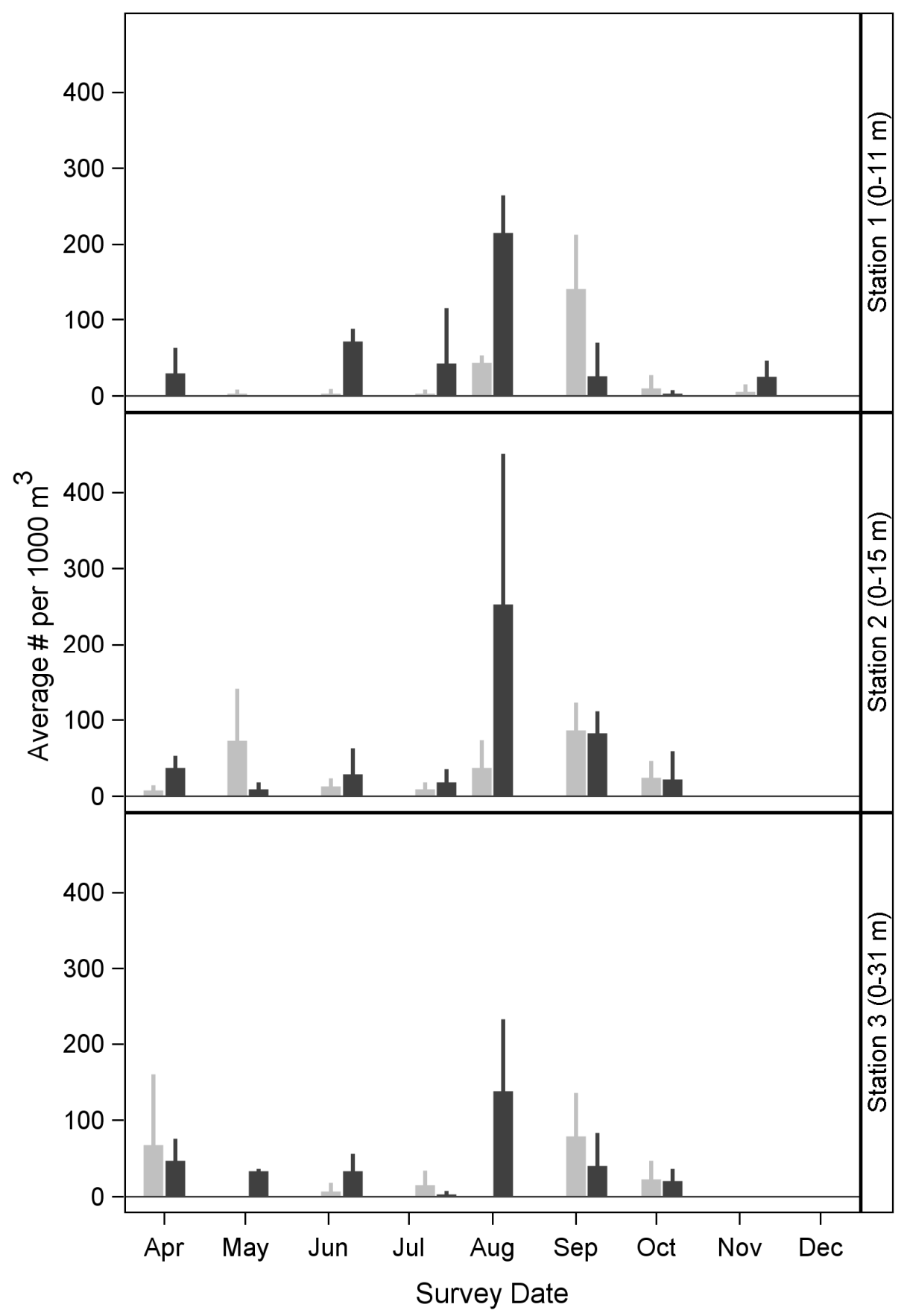

Figure 5-67. Average concentrations (plus one standard error) of Pristiapogon spp. larvae during day (gray bars) and night (black bars) sampling at the three stations off Port Allen, Kauai from AprilDecember 2012. 


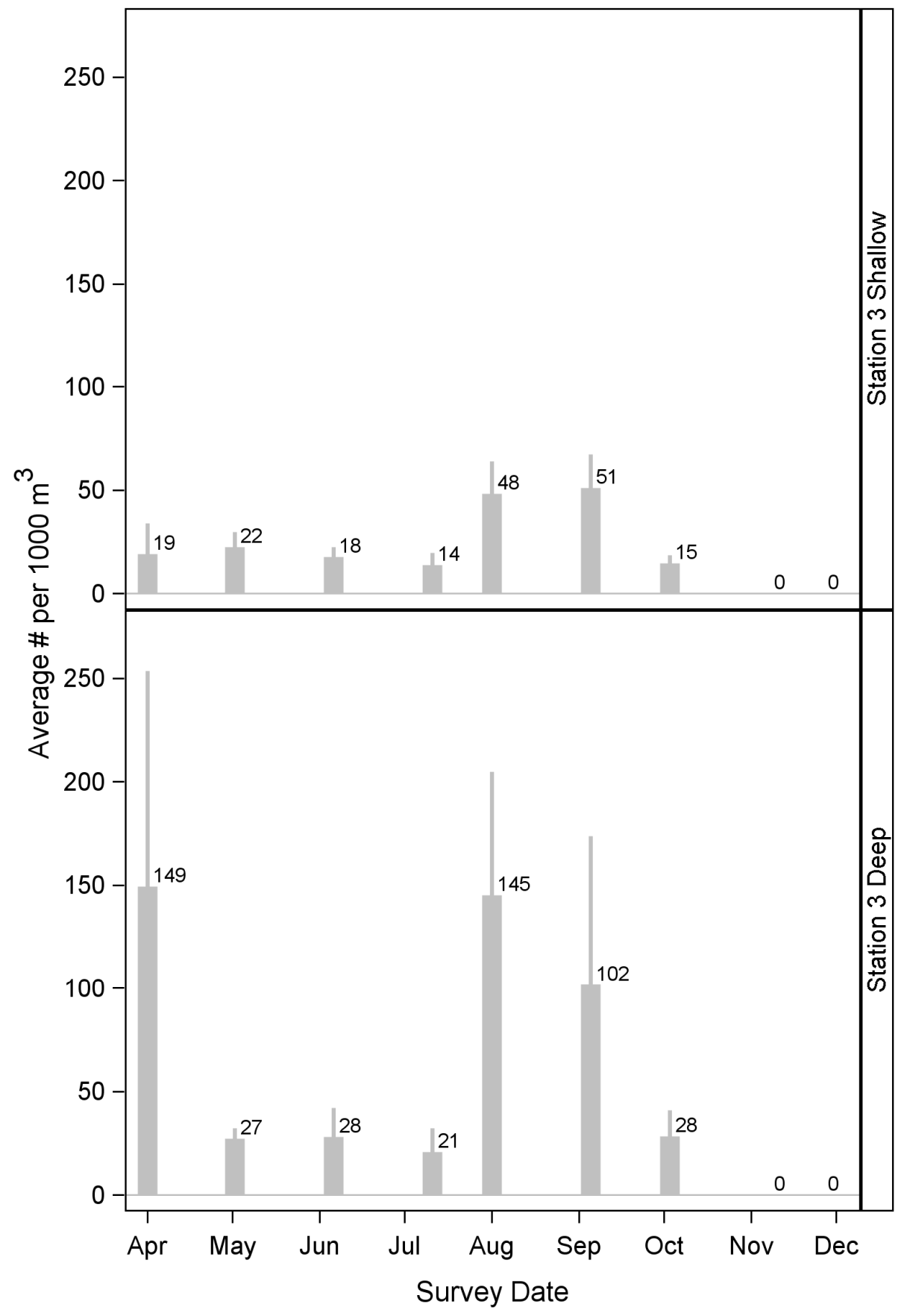

Figure 5-68. Average concentrations (plus one standard error) of Pristiapogon spp. larvae at two depth strata at Station 3 off Port Allen, Kauai from April-December 2012. Numbers at tops of bars are mean values. 
Table 5-17. Results of ANOVA of data on Pristiapogon spp. larvae from oblique tows of the entire water column at Stations 1, 2, and 3 during day and night sampling cycles across nine surveys off Port Allen, Kauai from April-December 2012. Tests significant at probability level of $95 \%$ are in bold.

\begin{tabular}{lcccc}
\hline Effect & $\begin{array}{c}\text { Numerator } \\
\text { degrees of } \\
\text { freedom }\end{array}$ & $\begin{array}{c}\text { Denominator } \\
\text { degrees of } \\
\text { freedom }\end{array}$ & F-Value & Probability \\
\hline Station & 2 & 139 & 0.68 & 0.5077 \\
Sampling Cycle & 1 & 141 & 7.26 & $\mathbf{0 . 0 0 7 9}$ \\
Interaction - Cycle*Station & 2 & 139 & 0.31 & 0.7344 \\
\hline
\end{tabular}

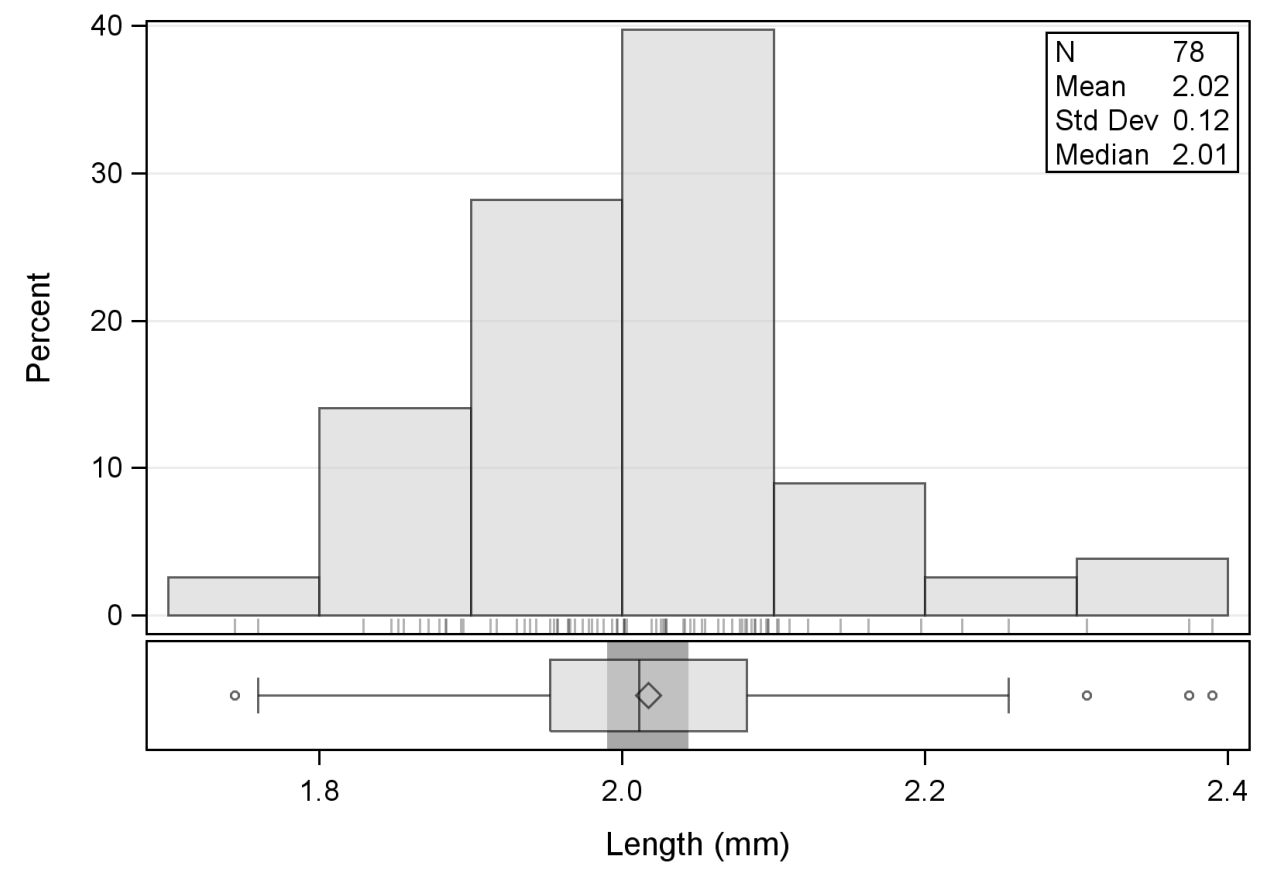

Figure 5-69. Length frequency of Pristiapogon spp. larvae measured during this study. 


\subsubsection{Tunas and Mackerels (Scombridae)}

The Scombridae family includes many recreationally- and commercially-valuable fishes worldwide with many species being highly sought as game fish (Randall, 2007). The tunas and mackerels are generally schooling, epipelagic, medium to very large predatory fishes. The family consists of 15 genera and 51 species (Randall 2007). Within Hawaiian waters, the Scombridae include seven genera and 13 species (Mundy, 2005).

The tunas and mackerels are characterized by their elongate, streamlined, fusiform bodies. These fishes are extremely fast swimmers which are continually in motion with wideranging migrations (Randall, 2007). Based on the myomere count of the scombrid larvae collected in this study, these individuals had to belong to one of four genera: Auxis, Katsuwonus, Euthynnus, and Thunnus.

\section{Life History}

The majority of scombrids are circumglobal or nearly circumglobal; however, the mackerel tuna, Euthynnus affinis, is found strictly in the Indo-Pacific, while the ahi, Thunnus orientalis, navigates the northern Pacific between 3-60 N. Bigeye tuna, Thunnus obseus, are the only tunas to range specifically within the Hawaiian archipelago (Mundy, 2005). The Scombridae are swift swimming fishes generally in surface waters and have wideranging migrations (Bond 1996).

Skipjack tuna, Katsuwonus pelamis, have an estimated growth rate ranging from 1.6 $\mathrm{mm} /$ day for fish up to $27 \mathrm{~cm}$ down to about $0.3 \mathrm{~mm} /$ day for fish from 71 to $80 \mathrm{~cm}$ in length. Pacific yellowfin tuna, Thunnus albacares, have an estimated growth rate of 1.4 $\mathrm{mm} /$ day for fish up to $64 \mathrm{~cm}$ in length and $0.9 \mathrm{~mm} /$ day for fish from 64 to $93 \mathrm{~cm}$ (Uchiyama and Struhsaker 1981).

Scombrids are oviparous, and spawn planktonic eggs, with newly hatched larvae being 2-4 mm NL. Spawning in yellowfin tuna (Thunnus albacares) can occur year round, with a peak possibly taking place during November-April. The smallest female found with mature ovaries in the eastern Pacific was $84 \mathrm{~cm}$ (Suzuki 1994 in Lehodey and Leroy 1999), and the estimated length at 50-percent maturity was $95 \mathrm{~cm}$. In the central equatorial Pacific, a few yellowfin tuna reach maturity at about $70-80 \mathrm{~cm}$, but data indicate that the majority do not mature until they reach 100-110 cm. (Lehodey and Leroy 1999).

Yellowfin tuna spawning appears to occur primarily at night with a peak between $10 \mathrm{pm}$ and 3 am at sea surface temperatures above 24-250 (Itano 2000). The mean batch fecundity estimates from the equatorial western Pacific and Hawaii region were 2.160 and 3.455 million oocytes or 54.7 and 63.5 oocytes per gram of body weight, respectively. Itano (2000) stated that they have a mean spawning interval of about 2 days. He also stated they show 50\% maturity in equatorial areas at about $104.6 \mathrm{~cm}$ (Itano 2000). Female skipjack 
tuna, Katsuwonus pelamis, from the South Pacific are known to spawn nearly every day (Hunter et al 1986).

\section{Population Trends and Fishery}

A total of over 13.6 million MT of various tuna were landed in Hawaii during 2009 (Division of Aquatic Resources 2010). The three tuna with the highest landings during 2009 were bigeye (Thunnus obesus) at over 9 million MT, yellowfin (Thunnus albacares) with about 2.6 million MT and skipjack Katsuwonus pelamis). By weight, more tunas are landed off Hawaii than any other group of fish, with the second most abundant taxon(based on weight landed) being billfishes at about 2.7 million kg during 2009. The landings of tuna from 2005 through 2009 has ranged from about 5.8 to 8.6 million $\mathrm{kg}$.

\subsubsection{Sampling Results}

The collected Scombridae larvae (Figure 5-70) were all combined in the following figures even though we were able to identify a number of individuals to the genus or species level. Scombridae larvae were the nineteenth most abundant taxon collected $(0.5 \%$ of total larvae collected) with an average concentration of 10 per $1,000 \mathrm{~m}^{3}$ (Table 5-2). They were more abundant at Station 2 and 3 than at Station 1 (Table 5-3). Their highest concentrations varied between the stations but generally occurred from June through November (Figure 5-71). No scombrid larvae were collected during the October or December surveys. As with most of the other taxa, this taxon was not consistently more abundant during either the day or night cycles (Figure 5-72). The ANOVA of the $\log (x+0.01)$ transformed data did not detect a significant difference between stations or day-night

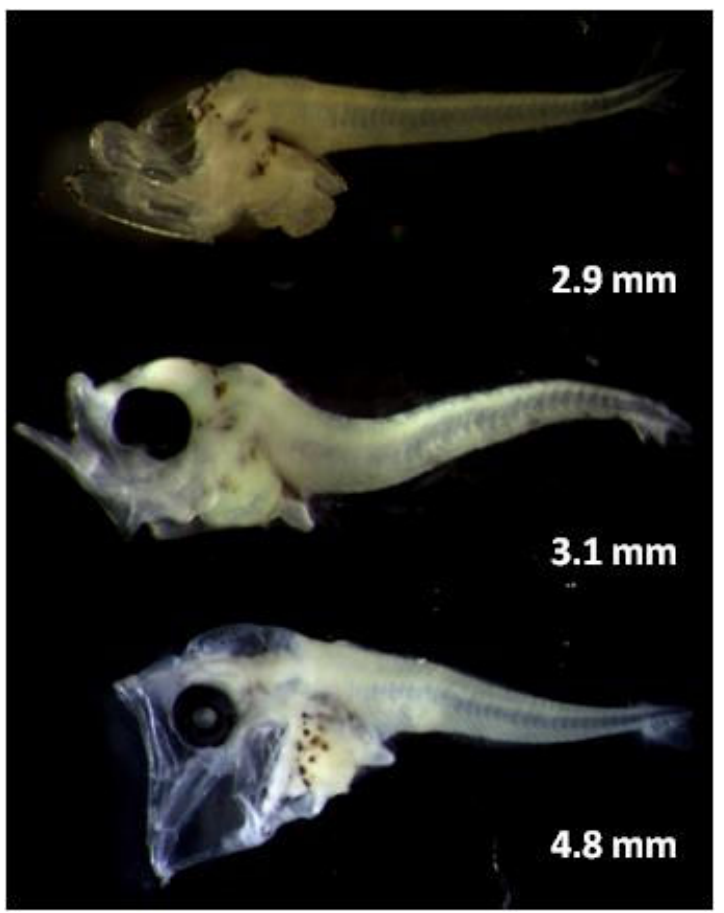

Figure 5-70. Scombridae larvae collected during this study. sampling cycles (Table 5-18).

The comparison between the calculated abundances at the deeper depth strata and the abundances from shallower depths at Station 3 did not reveal any clear pattern across all the surveys (Figure 5-73). The difference between the two depths could not be compared statistically using ANOVA due to the large number of samples with no scombrid larvae. 
Figure 5-74 shows that scombrid larvae that were measured had a mean notochord length of $2.7 \mathrm{~mm}$ with a maximum of less than $5 \mathrm{~mm}$. Due to the low number of scombrid larvae that were collected and their overall small size, no head capsule measurements were recorded.

Table 5-18. Results of ANOVA of data on Scombridae larvae from oblique tows of the entire water column at Stations 1, 2, and 3 during day and night sampling cycles across nine surveys off Port Allen, Kauai from April-December 2012. Tests significant at probability level of $95 \%$ are in bold.

\begin{tabular}{lcccc}
\hline Effect & $\begin{array}{c}\text { Numerator } \\
\text { degrees of } \\
\text { freedom }\end{array}$ & $\begin{array}{c}\text { Denominator } \\
\text { degrees of } \\
\text { freedom }\end{array}$ & F-Value & Probability \\
\hline Station & 2 & 138 & 2.27 & 0.1067 \\
Sampling Cycle & 1 & 143 & 3.72 & 0.0556 \\
Interaction - Cycle*Station & 2 & 138 & 0.41 & 0.6642 \\
\hline
\end{tabular}




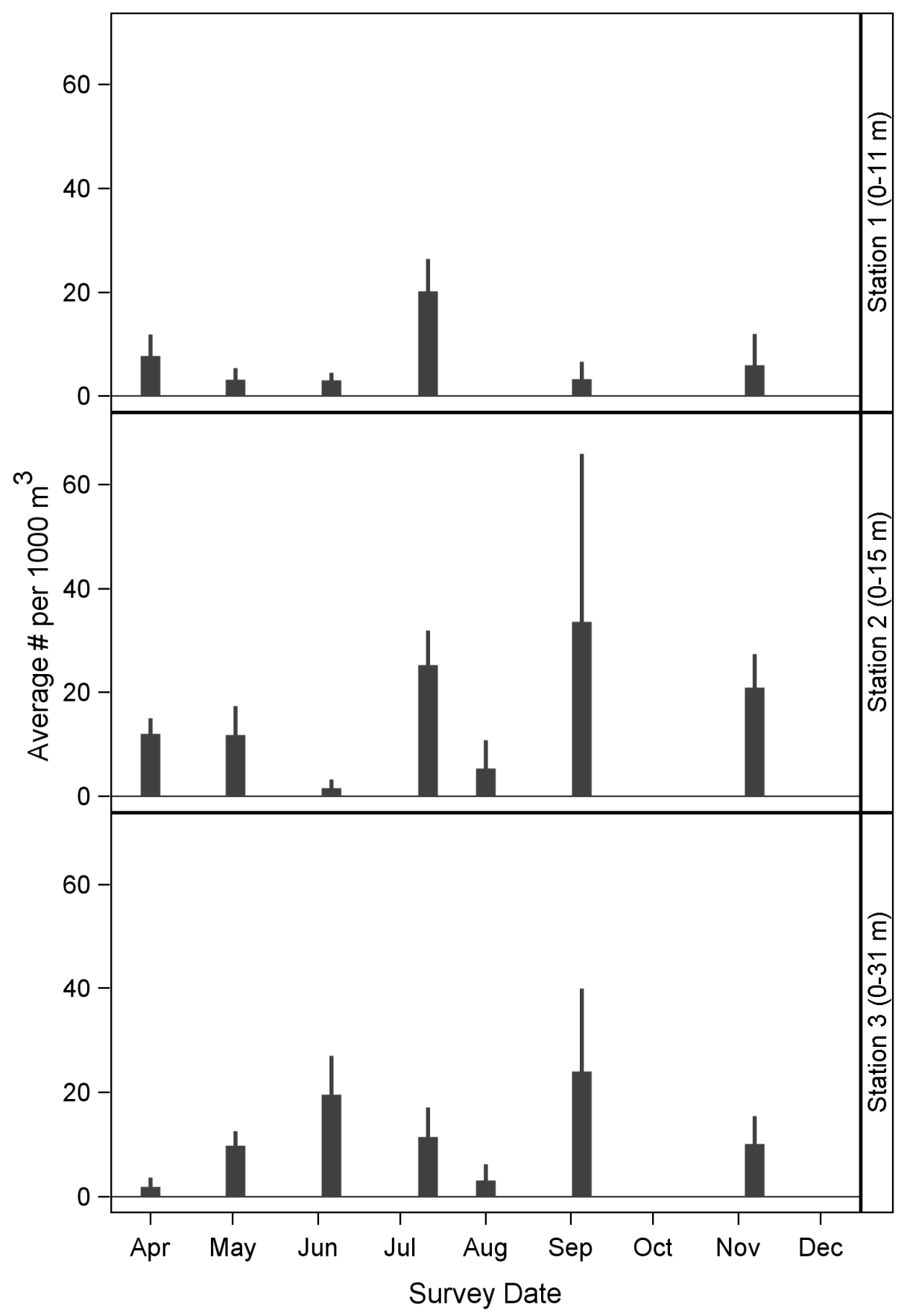

Figure 5-71. Average concentrations (plus one standard error) of Scombridae larvae at the three sampling stations off Port Allen, Kauai from April-December 2012. 


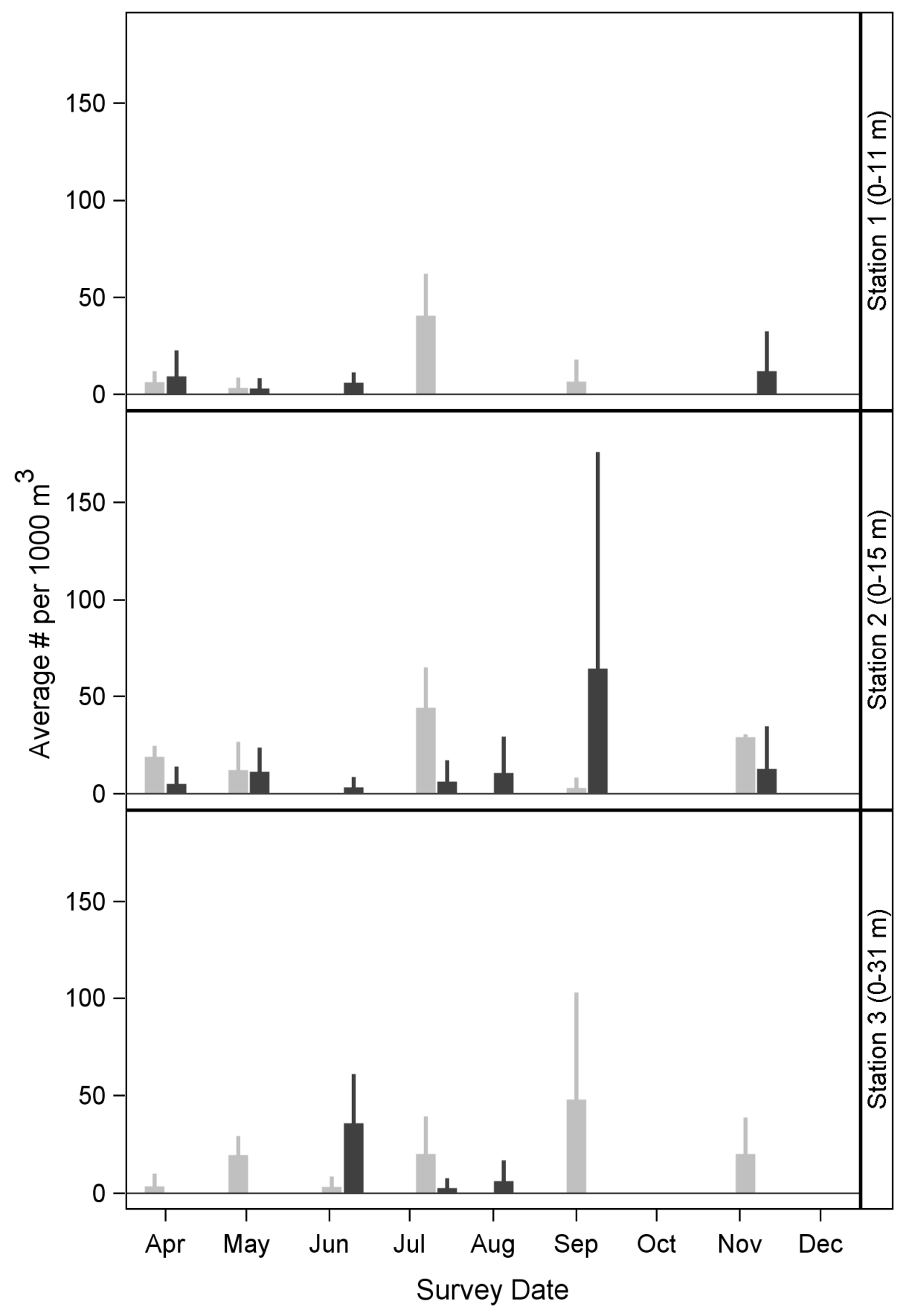

Figure 5-72. Average concentrations (plus one standard error) of Scombridae larvae during day (gray bars) and night (black bars) sampling at the three stations off Port Allen, Kauai from AprilDecember 2012. 


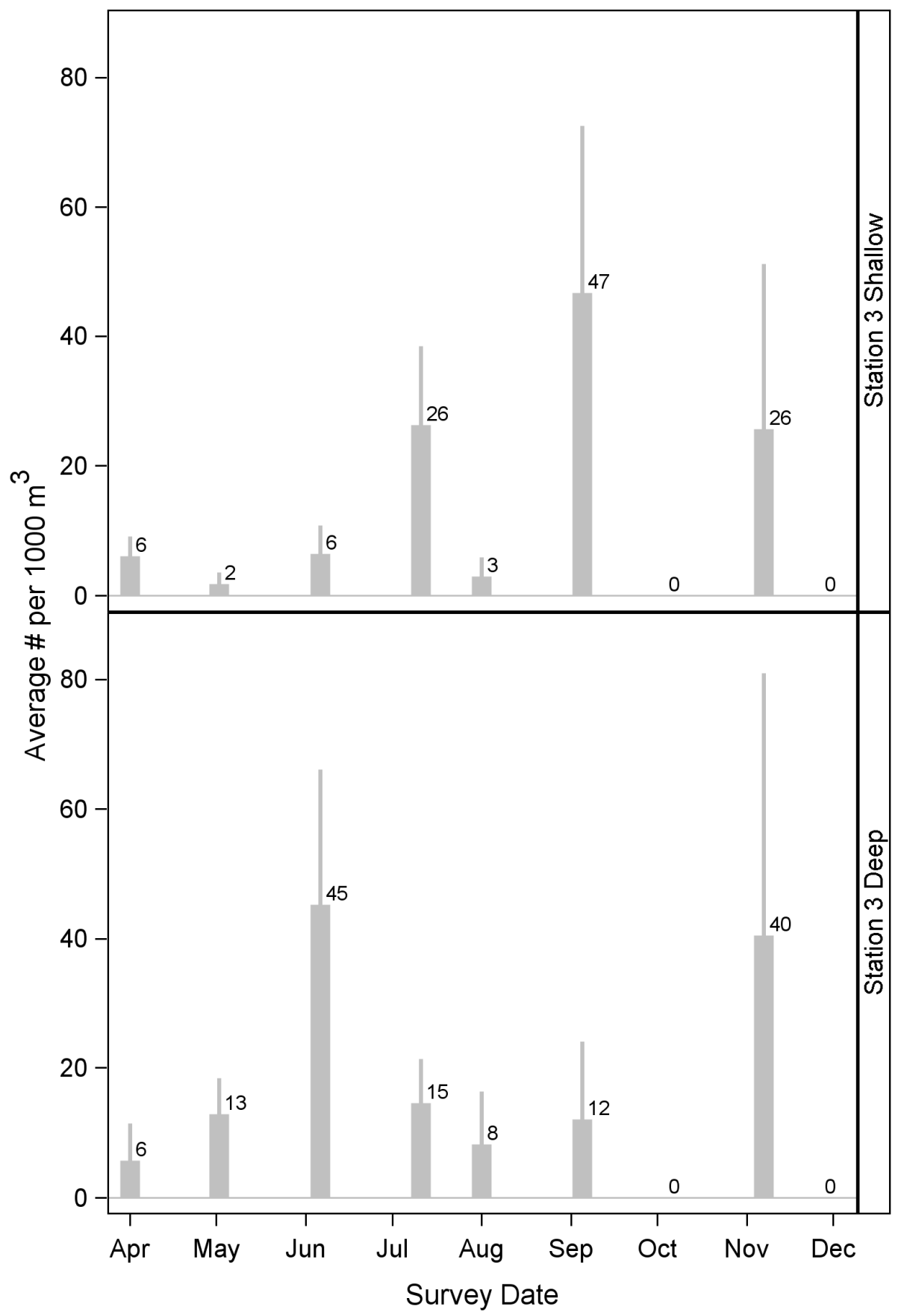

Figure 5-73. Average concentrations (plus one standard error) of Scombridae larvae at two depth strata at Station 3 off Port Allen, Kauai from April-December 2012. Numbers at tops of bars are mean values. 


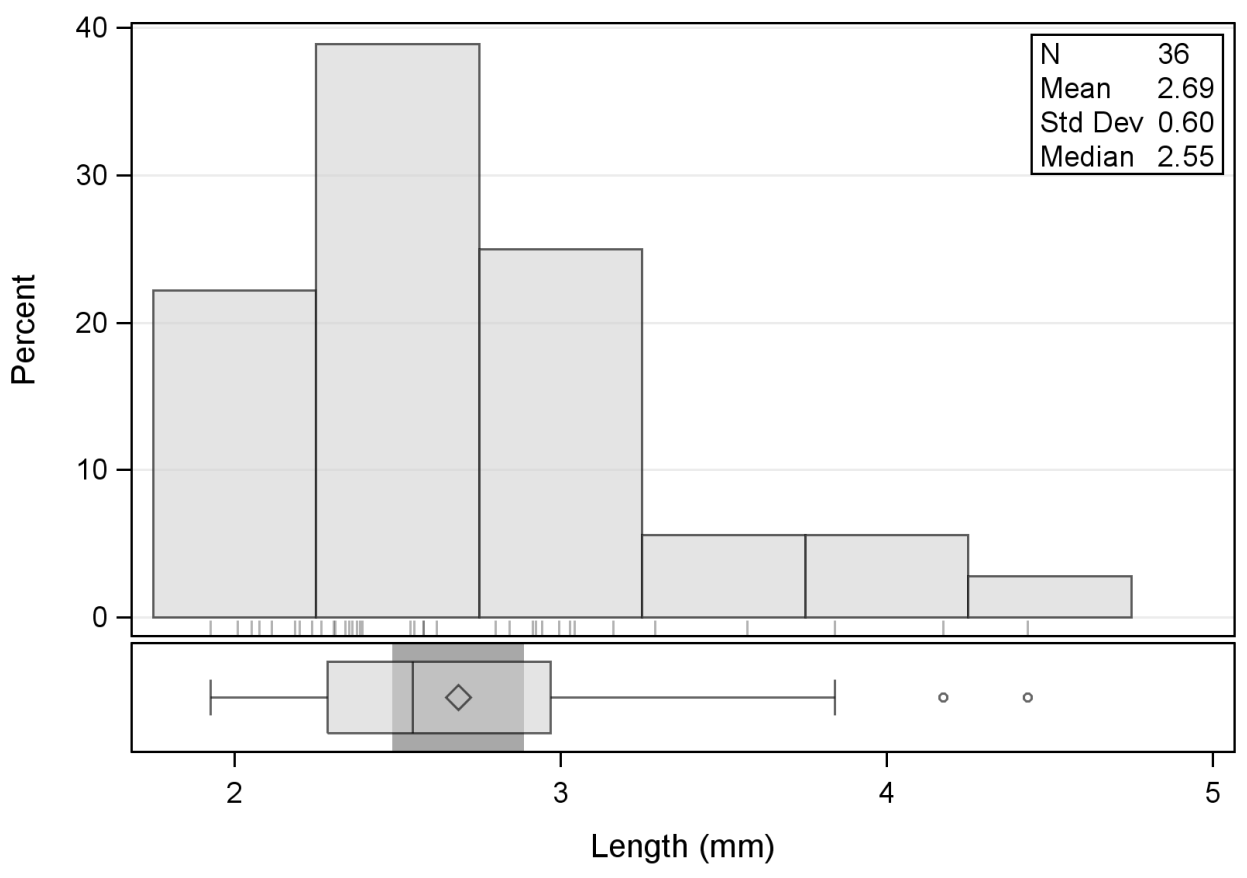

Figure 5-74. Length frequency of Scombridae larvae measured during this study. 


\subsection{Community Analysis}

The MDS analysis of 57 taxa at the three stations for the nine surveys shows that major source of variation among the samples is the differences among surveys (Figure 5-75). The distances among the stations during each survey were relatively small compared to the distances between surveys. While the data for Survey 9 are likely distinct from the other surveys because the average concentrations for that survey were only based on data from the daytime sampling cycle, other surveys such as Surveys 4, 5, 6, and 8 also show strong similarity among stations. The range of depths sampled at each of the stations and the small depth range between Station 1 closest to shore and Station 3 where sampling was down to depths of approximately $27 \mathrm{~m}(89 \mathrm{ft})$ probably accounts for the similarity among stations during the surveys relative to the differences among surveys.

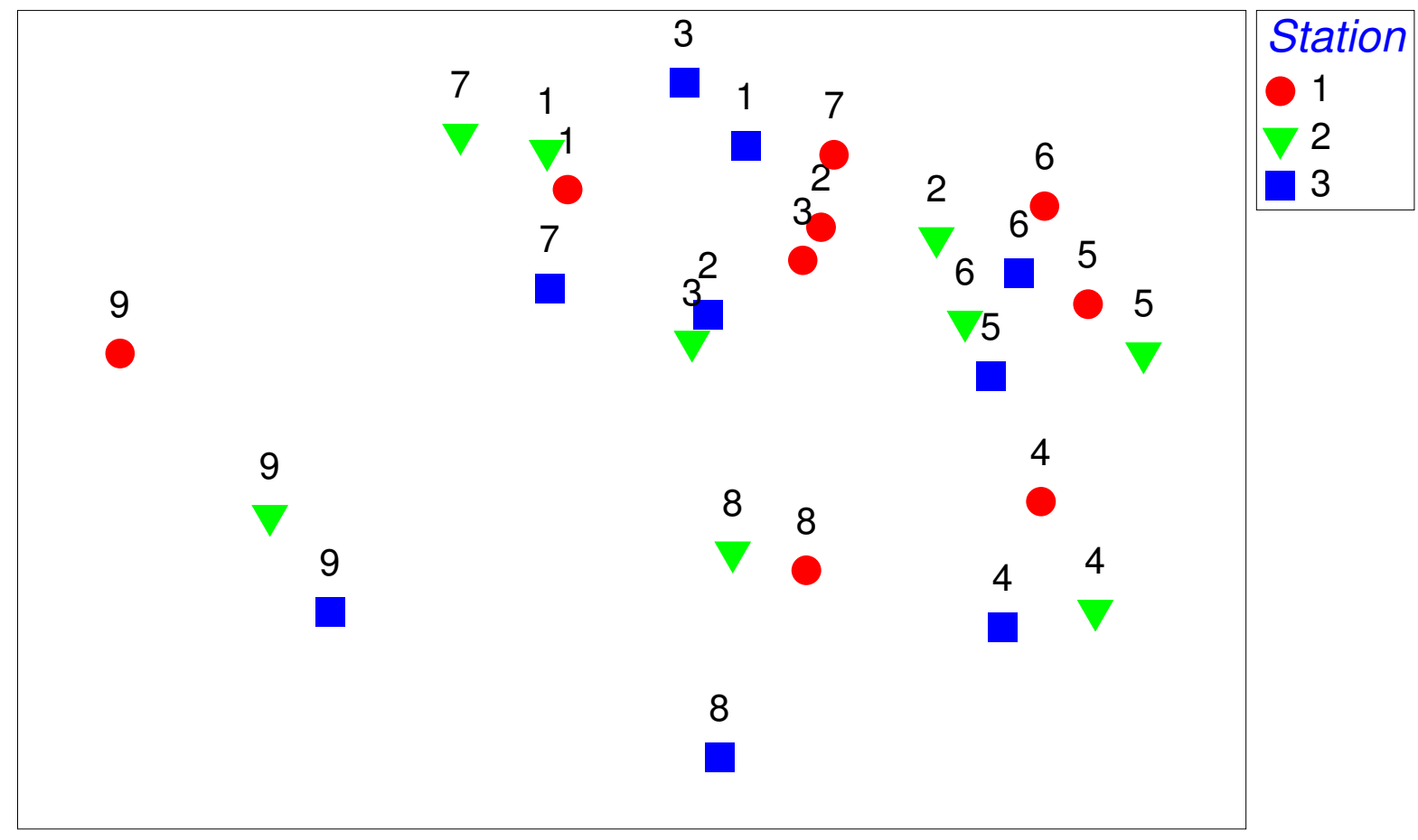

Figure 5-75. Multivariate analysis of average concentrations of larvae for each of the nine surveys (numbers above symbols) for the oblique tows through the water column at Stations 1 (red circle), 2 (green triangle), and 3 (blue square) using non-metric multidimensional scaling. 


\section{Discussion}

\subsection{General}

This study provides a baseline characterization of the species and abundances of ichthyoplankton present offshore of Port Allen, Kauai. The sampling was undertaken specifically to investigate the potential impacts of a proposed warm water intake for a shore-based OTEC facility located in Port Allen. In addition, the data generated in this study also represent the first comprehensive data set on nearshore ichthyoplankton off the south shore of Kauai. As noted by Myers et al. (1986), there is very little basic biological information on the early life stages of tropical marine species, making it difficult to estimate the potential impacts of OTEC. This study provides site-specific information on the taxa composition, distribution, and life stages of ichthyoplankton at the Port Allen site. This information will become a valuable contribution to the baseline data required to estimate the potential impact of a warm water intake in Port Allen.

This biological field study was the first step in assessing the environmental feasibility of OTEC in Port Allen, Kauai. The field study was designed to answer many of the requisite environmental questions for determining whether an OTEC facility and its warm water intake may pose a risk of ichthyoplankton entrainment, namely:

- Which species are present in the area where the warm water intake will be located?

- Are the species valued commercially, recreationally, ecologically, or culturally?

- Do the abundances of the organisms vary spatially or temporally?

- Can the baseline characterization of ichthyoplankton aid in the design of a warm water intake that minimizes the risk of entrainment?

Data collected during this study provide information on the taxonomic composition and abundances of the ichthyoplankton that occur in the area and their general distribution in the nearshore environment. As such, we can draw preliminary conclusions about the potential impact of a warm water intake on ichthyoplankton offshore of Port Allen.

The data indicate that there is a diverse group of species present offshore of Port Allen and that ichthyoplankton are present in relatively high concentrations. A peak in egg concentration was evident in April and May (Figure 5-1) and a peak in larval concentration was evident in July, August, and September (Figure 5-3) and. In general, the concentration of ichthyoplankton was higher than expected. Overall larval concentrations in the samples collected during this study were 2,111 larvae/1000 $\mathrm{m}^{3}$ (Table 5-2). Based on previous sampling conducted in the same approximate area (Hanapepe Harbor), Miller et al. (1979) documented concentrations of 133 and 63 larvae/1000 $\mathrm{m}^{3}$ in the offshore and nearshore stations, respectively during the summer and 32 and 15 larvae/1000 $\mathrm{m}^{3}$ during the winter. 
Though the sampling design of Miller et al. (1979) was quite different from ours, the results indicate that there has been no noticeable shift in the composition of taxa in the nearshore area of Port Allen. For example, in both studies, infantfishes dominated the summer collections (30.1\% of the total in Miller et al [1979]; $25.6 \%$ of the total in our study). Other frequently collected taxa in each study included blennies, gobies, cardinalfishes, and lanternfishes.

Previous entrainment monitoring studies were conducted by the Hawaiian Electric Company (HECO) on Oahu. At HECO's Honolulu and Kahe Generating Stations, the average concentrations of ichthyoplankton were 1,175 and 596 larvae/1000 $\mathrm{m}^{3}$, respectively (HECO 2011a, b).

In general, the fish larvae were small. The mean lengths of all of the frequently collected taxa were below $4.0 \mathrm{~mm}$, except for the most abundant taxon (Schindleria spp., $9.7 \mathrm{~mm} \mathrm{NL}$ ); which likely included adult Schindleria spp. which are neotenous (retain larval characteristics at maturity) and are very small even as adults. The associated head capsule dimensions were, therefore, also small for most of the abundant taxa except for the larger Schindleria spp. (Table 6-1).

Table 6-1. Mean notochord length and largest head capsule dimension of the dominant taxa collected.

\begin{tabular}{llrrr}
\hline Taxon & Common name & $\begin{array}{c}\text { \% of total } \\
\text { larvae } \\
\text { collected }\end{array}$ & $\begin{array}{c}\text { Mean } \\
\text { notochord } \\
\text { length } \\
\text { (mm) }\end{array}$ & $\begin{array}{c}\text { Largest head capsule } \\
\text { dimension }\end{array}$ \\
\hline Schindleria spp. & infantfishes & 25.6 & 9.7 & Height and width similar \\
Salariinae & blennies & 15.9 & 2.2 & Height slightly larger \\
Gobiidae & gobies & 11.5 & 2.5 & Height slightly larger \\
Pomacentridae & damselfishes & 10.5 & 2.1 & Height \\
Enneapterygius atriceps & Hawaiian triplefin & 8.5 & 3.9 & Height \\
Encrasicholina spp. & anchovies & 4.5 & 3.1 & Height and width similar \\
Carangidae & jacks & 1.6 & 2.1 & Height \\
Pristiapogon spp. & cardinalfishes & 1.5 & 2.0 & Height \\
Apogon spp. & cardinalfishes & 0.9 & 1.8 & Height \\
Scombridae & mackerels and tunas & 0.5 & 2.7 & ND ${ }^{1}$ \\
\hline
\end{tabular}

${ }^{1}$ No data recorded due to paucity in samples

The MDS analysis indicates that there was greater variation among the monthly sampling surveys (temporal variation) than among the sampling stations within each survey (spatial variation) (Figure 5-75). That the spatial variation was less a factor generally supports a 
conclusion that the distance from shore imparts relatively little influence on ichthyoplankton concentrations when compared to natural variation over time/seasons.

\subsection{Ichthyoplankton Taxa}

Few of the taxa collected are considered commercially- or recreationally-important; though some of the more abundantly-collected ones are important forage fishes for larger species that are. For example, infantfishes (Schindleria spp.), which dominated the collections (25.6\% of the total larvae collected) are considered the most abundant group of fishes in Hawaiian waters (Gosline and Brock 1960) and therefore would be expected in high numbers in the areas sampled during this study. Although infantfishes are not valued commercially or recreationally, their abundance in this study indicates that they are likely important to the ecology of the area sampled. Given that infantfishes have demersal eggs, there is a reduced risk of entraining eggs in an intake as they are not suspended in the water column; however, the abundance of infantfish larvae (likely adults as well as larvae) present in the samples collected indicates that this species is likely to be the one at the greatest risk of entrainment in an OTEC intake offshore of Port Allen.

Of all the taxa collected, those with established commercial and/or recreational value included Hawaiian anchovy (nehu or Encrasicholina spp.), jacks (Carangidae), mackerels and tunas (Scombridae), barracudas (Sphyraena spp.), and dolphinfish (Coryphaena spp.); together comprising less than $7 \%$ of the larvae collected. Potential impacts to Hawaiian anchovy and jacks may therefore come under scrutiny due to their economic value. However, the relatively low abundance of Hawaiian anchovy and jacks in the samples collected (4.5\% and 1.6\% of total larvae collected, respectively) indicates that at the Port Allen site, the potential for entraining large numbers should be minimal relative to other taxa. Somerton et al. (1993) indicated that Hawaiian anchovy are found exclusively within embayments. Given the proximity of the sampling stations to Hanapepe Bay, higher concentrations of Hawaiian anchovy were expected. Instead, Hawaiian anchovy were only collected in a single survey (November), indicating only a seasonal presence in the areas sampled. The location of the sampling stations outside of Hanapepe Harbor (i.e., beyond the breakwater and any influence of the freshwater inflow of the Hanapepe River) may have been sufficient to preclude collection of high concentrations of this taxon. Similarly, concentrations of Carangidae were very low in the areas sampled and should not represent a significant entrainment concern for an intake in this area.

The balance of the taxa collected during this study were characterized by larvae that grow into small adult fishes which are common in the nearshore environment. Species in these groups typically have no documented economic value, but may be important for other reasons (e.g., ecological). These include the blennies (Salariinae) and Hawaiian triplefins (Enneapterygius atriceps), gobies (Gobiidae, not including the infantfishes), damselfishes (Pomacentridae), and cardinalfishes (Apogonidae). These taxa comprised $49.1 \%$ of all 
larvae collected. The adults of these species are generally associated with structure such as coral, rock outcroppings and holes, and tidepools, though their larvae were present throughout the water column, as evidenced by their presence in the ichthyoplankton samples (Table 5-2). It is therefore likely that larvae of these taxa would be entrained by an intake in Port Allen.

Boehlert and Mundy (1996) collected ichthyoplankton in transects off the windward side (Kaoio Point) and leeward side (Kahe Point) of Oahu similar to how transects were laid out in the current study on Kauai. Many of the abundant taxa from our sampling on Kauai were also represented in their sampling on Oahu: Gobiidae (47\%), Myctophidae (21\%), Gonostomatidae (includes Cyclothone spp.) (8\%), Schindleriidae (4\%), Carangidae (2\%), Scombridae (1\%), and Blenniidae (1\%). Larval fish taxa collected in sufficient numbers for analysis by Leis (1982b) on the leeward side of Oahu in 1975 included many of the same taxa collected in our study: Triptergyion atriceps (earlier name for Enneapterygius atriceps) in the inshore zone; Schindleria spp. in the inshore-neritic zone; Gobiidae, Bleniidae, and Schindleria spp. in the neritic zone; and Myctophidae, Scombridae, and Gonostomatidae in the offshore-neritic zone. The composition of taxa collected by Watson and Leis (1974) in the Sampan Channel on the windward side of Oahu overlapped with ours on Kauai with Gobiidae and Schnidleriidae comprising the the top two larval taxa collected; though, Apogonidae (cardinalfishes) were more abundant than in our samples on Kauai.

\subsection{Spatial Variation}

\subsubsection{Distance from Shore}

Concentrations of eggs decreased slightly with increasing distance from shore; however, the differences were too small to detect any significant difference in egg concentrations among the three sampling stations (Table 5-3). Similarities in the egg concentrations among the three stations may reflect the fact that the seabed substrate and benthic habitat in the areas sampled were relatively homogeneous (pavement, pavement with sand channels, and patchy turf algae (Figure 3-5 and Figure 3-6). Higher resolution benthic habitat mapping would be useful for better characterizing the nearshore environment and quantities of the different habitats present. The absence of a strong trend in abundances of fish eggs with distance offshore may be due to the large number of nearshore taxa, such as gobies, infant fishes, and blennies, which have demersal eggs relative to the pelagic and deep water fishes such as jacks and tunas that have planktonic eggs.

The trend of decreasing concentrations with increasing distance from shore was much more prominent for fish larvae, with the greatest difference apparent when comparing Stations 1 and 2 to Station 3 offshore. Although the only significant difference among the stations was detected between Stations 1 and 3 during night cycles, the overall trend of decreasing concentrations offshore was generally expected (Table 4-5). This trend likely 
reflects the general assumption that biological productivity is greater nearshore than offshore. It is important to note, however, that despite lower concentrations offshore, the number of taxa collected was higher than in the sampling stations closer to shore (Table 5-2).

At Kahe Point on Oahu, Leis (1982b) documented that larval abundances generally decreased with distance from shore for most of the larval fishes collected. The offshore extent of the sampling in Port Allen was approximately $1 \mathrm{~km}(0.6 \mathrm{miles}) ;$ a distance covered in the first three of the four stations sampled by Leis (1982b). Comparison of the abundances of fish larvae between the two studies show similar trends for most of the species collected. For example, Hawaiian triplefin were collected in significantly higher concentrations from the sampling stations closest to shore and in the lowest concentrations at the sampling stations farthest from shore in both studies.

Infantfishes, the dominant taxon collected in the current study, displayed no significant difference in concentrations among the stations, though the lowest concentrations occurred at the station farthest offshore. Leis (1982b) documented varying distributions for different species and life stages of infantfishes. The concentration of adult Schindleria pietschmanni was 83 times higher at the station closest to shore than the station farthest from shore; while adult Schindleria praematurus and sub-adult Schindleria pietschmanni occurred in the highest concentrations in the two mid-distance sampling stations (neritic and offshore-neritic, respectively). The station furthest offshore in the sampling done by Leis was at a depth of 330-460 m which is much deeper than Station 3 and likely accounts for the differences in the results between the studies.

The trend in concentrations of blennies (Salariinae) in the current study also agrees with that of Leis (1982b), namely the highest concentrations occurred closest to shore with consistent decreases with distance offshore. Similarly, the current study and Leis (1982b) both documented highest concentrations of gobies and damselfishes near the midpoint of the offshore transect (i.e., neither in the nearest nor farthest sampling stations from shore). Lanternfish (Myctophidae) larvae in our study were found in the highest concentration in the station farthest from shore in contrast to Leis (198b2) who did not document any significant differences in concentrations among the stations sampled. However, Leis (1982b) grouped lanternfish larvae with other taxa characterized as having an offshoreneritic distribution which agrees well with our results and common knowledge regarding the adult habitat of this taxon (i.e., adults that occupy the oceanic-mesopelagic zone [Moyle and Cech 2004]).

Boehlert and Mundy (1993) reviewed existing information on the distribution of ichthyoplankton near seamounts and tropical oceanic islands. They concluded that four larval fish assemblages exist at tropical oceanic islands: an embayment assemblage (limited to bays and lagoons), a nearshore assemblage (within $0.5 \mathrm{~km}$ [0.3 miles] from shore), a 
neritic assemblage (between 0.5 and 3.0-5.0 km [0.3 and 1.9-3.1 miles] from shore), and an oceanic assemblage (between 3-5 $\mathrm{km}$ to $600 \mathrm{~km}$ [0.3-1.9-3.1 to 373 miles] offshore). These assemblages are generally synonymous to the distributional categories identified by Leis (1982b). The abundant taxa collected in our current study would be classified as nearshore and neritic assemblages, each characterized by structure-associated adults that lay demersal eggs. Sampling done by Leis (1982b) also concluded that larvae of fishes that spawn pelagic eggs were rarely collected in the nearshore zones. This is consistent with the taxa observed in our sampling on Kauai as the abundant larvae were characterized by species that either lay demersal eggs (Schindleria spp., Salariinae and Enneapterygius atriceps, Gobiidae, and Pomacentridae) or that orally brood the eggs (e.g., Apogonidae). Conversely, the predominant taxa collected in sampling conducted $13 \mathrm{~km}$ (8.1 miles) off the leeward coast of Oahu by Clarke (1991) were comprised of larvae from adults that spawn pelagic eggs presumably due to the fact that the sampling stations were a much greater distance from shore.

\subsubsection{Depth}

This study was designed to collect samples from two different offshore depth strata at Station 3 in an effort to determine whether any vertical stratification in ichthyoplankton existed. If ichthyoplankton is less dense in deeper zones, there is a potential benefit to locating an intake there instead of at or near the surface where larvae are more abundant. Contrary to expectations, the concentrations in the deeper stratum were generally higher for eggs and all larvae combined, though the differences were not significant. Forty-five pairs of samples were collected in the deepest stations in an effort to reveal the presence of any vertical stratification. In those 45 samples, the difference in depth between the shallow and deep strata ranged between 3.0 and $12.8 \mathrm{~m}$ (9.7 and $41.9 \mathrm{ft})$, and in most cases (87\%) the differences were greater than $10 \mathrm{~m}(32.8 \mathrm{ft})$. The variation in the differences between the depths of the sample pairs and the small differences between some of the sample pairs likely contributed to the inability to detect any significant differences between depth strata. Temperature differences between the two depth strata at Station 3 were essentially undetectable in our sampling, indicating that the thermocline was not crossed; therefore, it is unlikely that these samples captured any species or density differences that may be attributable to the thermocline (Ahlstrom 1959; Boehlert et al. 1992). Additional samples from locations that provide larger differences between the two depth strata could be useful for determining whether depth stratification exists for ichthyoplankton in the area.

Sampling conducted by Leis (1986) in another tropical marine system (Great Barrier Reef in Australia) indicated that the greatest number of taxa (rather than number or density of larvae) were collected in the deepest sampling stratum; however, the maximum depths sampled were relatively shallow 6 m (20 feet) compared to our study on Kauai (maximum of $27 \mathrm{~m}$ [88 feet]). Regardless, similar to Leis (1986) the largest number of taxa was collected at the deepest station furthest offshore in our study as well (Table 5-3). The 
number of taxa collected in the two depth strata at Station 3 could not be determined due to the sampling approach used, but the number of taxa collected at from the upper strata (74) was almost identical to the number collected at Station 1 which was closest to shore.

Some previous ichthyoplankton sampling conducted in the tropics presents results that conflict with conventional beliefs about the vertical stratification of larvae. For example, sampling conducted by Boehlert et al. (1992) at Johnston Atoll in the tropical Pacific yielded surprising results with peak abundances found in the 50 to $100-\mathrm{m}$ (164 to $328 \mathrm{ft}$ ) stratum, rather than in the stratum closest to the surface. However, the depths sampled $(0$ to $200 \mathrm{~m}$ [0 to $656 \mathrm{ft}$ ]) were far greater than those sampled in our current study (0 to $27 \mathrm{~m}$ [0 to $89 \mathrm{ft}$ ]), making the results difficult to compare with this studies. Boehlert et al. (1992) noted that when considered separately, many taxa did demonstrate a more typical variation with depth. Of the taxa common to both studies, Boehlert et al. (1992) noted the following regarding vertical distribution:

- Gobiidae and Eviota epiphanies were found in highest concentrations in the 50 to 100-m (164 to 328-ft) stratum, and

- Salariinae, Myctophidae, Cyclothone spp., Apogonidae, Coryphaena spp., Carangidae, and Scombridae were found in highest concentrations in the 0 to $50-\mathrm{m}$ ( 0 to $164-\mathrm{ft}$ ) stratum.

\subsection{Temporal Variation}

\subsubsection{Diel}

Various studies have documented diel differences in ichthyoplankton abundances, with most studies showing higher abundances during the nighttime (Ahlstrom 1959; Watson and Leis 1974; and Leis 1986). In the current study, there were significant $(\mathrm{p}<0.01)$ diel differences in both egg and larval concentrations. Egg concentrations were significantly higher at night at all three stations, while larval concentrations were significantly higher at night, but only at Station 1 for all larvae combined. However, the magnitude of this trend (nighttime concentrations roughly one-third greater than daytime) was small compared to Watson and Leis (1974) whose nighttime collections of larvae were 2 and 7 times greater than their daytime collections in Oahu's South Kaneohe Bay and Sampan Channel, respectively. Relative to the taxa collected in our study, Watson and Leis (1974) noted that despite the overall trend for all larvae together:

- Blennies were more abundant during daytime collections,

- Schindleria spp. were essentially absent during daytime collections,

- Carangidae increased from morning through evening, and

- Hawaiian anchovy peaked in the afternoon and evening 
Our sampling on Kauai revealed similar trends:

- One blenny taxon (Salariinae) was collected in significantly higher concentrations during the daytime, but the other blenny taxon (Enneapterygius atriceps) was not,

- Schindleria spp. were collected in significantly lower concentrations during the daytime, and

- Carangidae were collected in significantly higher concentrations during the nighttime

In contrast to Watson and Leis (1974), Hawaiian anchovy were generally collected in higher concentrations during the daytime, though, no statistical comparison could be made since this taxon was only collected during a single survey (November).

In the current study, concentrations were significantly higher at night for Schindleria spp. $(\mathrm{p}<0.01)$, Gobiidae $(\mathrm{p}<0.01)$, Salariinae $(\mathrm{p}<0.03)$, Carangidae $(\mathrm{p}<0.01)$, and Pristiapogon spp. $(\mathrm{p}<0.01)$. No significant difference in diel variations were detected for Enneapterygius atriceps, Pomacentridae, Apogonidae, Apogon spp., or Scombridae. Higher larval concentrations at night are typically associated with vertical nocturnal feeding migrations (Moyle and Cech 2004).

\subsubsection{Seasonal}

Sampling during this study was conducted over a nine-month duration rather than over a full annual cycle. Therefore, conclusions about ichthyoplankton seasonality are limited to periods during which samples were collected (April through December). In addition, the sampling conducted during this study represents only one year, and as such, does not document inter-annual variability in ichthyoplankton abundances.

Data indicated that there was a notable effect of season on ichthyoplankton density. The highest concentrations of fish eggs were collected during the April and May surveys with a smaller peak in abundance in September. These peaks agree well with previous observations by Watson and Leis (1974) who recorded highest egg abundances on the windward coast of Oahu in the early spring (March through May). Similarly, egg concentrations were low in June and December in both studies.

The peak in total larval density occurred in July, August, and September in this study, though it's important to note sampling was only conducted over a 9-month period, rather than a full annual period. Boehlert and Mundy (1996) also noted peaks in ichthyoplankton abundance during their June-July survey and their September survey off of Oahu, though sampling was not conducted year-round. Watson and Leis (1974) observed a bimodal peak in larval abundances on the windward coast of Oahu with the first peak occurring between 
February and mid-May (peak in April) and the second between late summer and early fall, which generally agrees with the peaks in our study.

Notably, Encrasicholina spp. were only present in November. Most mature female Hawaiian anchovy spawn every other day continuously throughout the year (Leary et al. 1975; Clarke 1987, 1989b), so the low abundance of this taxon in the samples was anamolous.

\subsection{Implications for OTEC Warm Water Intakes}

\subsubsection{General}

These site-specific data allow the developer to determine the following for the proposed Port Allen OTEC site:

- Whether commercially-, recreationally-, ecologically-, or culturally-valuable species may be impacted,

- Whether the location of the intake will provide a benefit to entrainable-sized organisms, and

- Whether the operation of the facility can be optimized to minimize entrainment of marine organisms

The OTEC facility proposed for Port Allen is designed to draw water from a depth of $10 \mathrm{~m}$ (33 ft). This depth is a balance between the depth which would provide the optimum water temperature for maximizing the thermodynamic cycle (and hence power output), minimize exposure to debris, and minimize potential impacts to navigation posed by a submerged intake structure. The first component of this project, therefore, was to evaluate various intake design concepts that satisfy the operational requirements of the proposed OTEC facility. The second component of this project included a comprehensive field sampling effort in the area where the intake may be located. This field sampling effort generated a baseline characterization of life stages that would be most vulnerable to intake entrainment. Combining the information from these two components of this project will be useful for identifying the best location and design for the warm water intake for this proposed shore-based OTEC facility.

The information from this study can be used to inform the development and siting of a warm water intake for an OTEC facility at Port Allen. The information of greatest value to assessing the intake designs considered includes:

- The composition of ichthyoplankton taxa present in the samples collected,

- The spatial variation (distance from shore, depth) in concentrations of ichthyoplankton, and

- The temporal variation (diel, seasonal) in concentrations of ichthyoplankton. 


\subsubsection{Ichthyoplankton Taxa Collected}

As noted above, only a small proportion (less than 7\%) of the larvae collected represent fishes with direct commercial or recreational financial value. Since impacts to commercially-and recreationally-important species often represent the highest profile issue for a seawater intake, this is encouraging. In addition, the absence of species listed under state or federal endangered species regulations (though lack of taxonomic knowledge of early life stages of these species is admittedly sparse) indicates that the risk to listed species would likely be low at a full-scale warm water OTEC intake constructed within the area sampled during this study.

However, it is also important to note that the balance of the larvae collected likely provide forage for fishes, including species that are economically-valued in Kauai. Understanding the ecological function of the taxa collected is also important for understanding the overall impacts of warm water withdrawal at Port Allen. The taxa that represent the top $75 \%$ of those collected are characterized by species that have a nearshore distribution as adults and typically live within the substrate (reef, rock, etc.). While all of the species in these taxa spawn demersal eggs (Leis 1982b; Boehlert and Mundy 1993), their larvae are planktonic and would therefore be at risk of entrainment in an OTEC warm water intake located in the area sampled. However, the duration of time that a larva is completely planktonic (freefloating without the ability to swim) is limited. The length of time that an individual larva is at risk of entrainment is a function of the species' growth rate and its location in the source waterbody in relation to the intake. Section 5 presents information, where available, on the growth rates of the taxa that were collected in greatest abundance. As larvae grow, their swimming ability increases and it is reasonable to expect that with improving swimming ability, the ability to avoid entrainment would improve as well. For example, Whittle (2003) notes that even late-stage infantfish larvae (Schindleria spp., the dominant taxa collected in this study) have sufficient swimming abilities to overcome the currents present in Kaneohe Bay, Oahu. It is therefore reasonable to assume that late-stage larvae of infantfish and other taxa would also possess some physical ability to avoid entrainment in a sufficiently low-velocity intake flow.

\subsubsection{Spatial Variation}

When considering section 316(b) of the CWA, a locational benefit may be accepted for an offshore intake location if data are available to demonstrate that the abundances of organisms there are consistently lower than onshore. General consensus is that spawning and nursery areas are usually found closer to shore in marine environments with abundances of early life stages decreasing with distance from shore. The EPA states the following (USEPA 2011): 
"In oceans, nearshore coastal waters are typically the most biologically productive areas. The euphotic zone (zone light available for photosynthesis) typically does not extend beyond the first 100 meters (328 feet) of depth. Therefore, inshore waters are generally more productive due to photosynthetic activity and due to the input from estuaries and runoff of nutrients from land."

The data collected indicate that the ichthyoplankton offshore of Port Allen do not vary substantially with distance from shore. Egg concentrations were very similar at the three stations. This may be an artifact of the sampling equipment which could only collect eggs that were planktonic/pelagic, and not eggs that are closer to the bottom. Those pelagic eggs are likely well dispersed throughout the limited sampling area covered in this study as a result of ocean/tidal currents, wave action, and wind. Intake impacts to eggs, therefore, are likely to be limited to the eggs of species that broadcast pelagic eggs (e.g., Encrasicholina spp. [Hawaiian anchovies], Cyclothone spp. [bristelmouths], Myctophidae [lanternfishes], and Scombridae [mackerels and tunas]). Since identification of eggs of tropical species is difficult, it would be difficult to determine with any certainty which species' eggs are likely to be impacted.

Absolute concentrations of larvae, however, did show a trend of higher concentrations close to shore and decreasing abundances with distance from shore. In most cases, this difference was not significant (only the difference between Stations 1 and 3 and only at night [Table 5-3]). Taken at face value, these data may indicate that an offshore intake location may be more environmentally-protective because concentrations are lower offshore; however, without data consistently demonstrating lower concentrations at the offshore station (Station 3) under all conditions (day and night), it is not clear that there is a substantial advantage to drawing warm water from an offshore location relative to an onshore location. Furthermore, many of the commercially- and recreationally-valuable species (e.g., Hawaiian anchovies, jacks, mackerels and tunas, barracudas, dolphinfishes, and bigeye scad) were found in greater concentrations at the offshore stations (though concentrations were still very low) (Table 5-3).

The potential for anthropogenic impacts must also be evaluated when considering construction of a large offshore intake structure, as offshore structures (anthropogenic or natural) have been shown to attract fish and other organisms. Helvey (1985) noted that offshore intake structures, such as those used at coastal power plants in southern California, accommodate a diverse group of fishes that are typically characterized as being reef/structure-associated. The engineered structure provides habitat which various species can utilize for cover and foraging. Species utilizing this space are also very likely to spawn their demersal eggs near the structure. As such, the larvae hatched from those eggs (when they move up into the water column) are likely to be at a greater risk of entrainment due simply to their proximity to the hydraulic influence of the intake. Since a large 
percentage $(>70 \%)$ of the taxa represented in the sampling at Port Allen are generally considered to be structure-associated fishes (infantfishes, blennies, gobies, damselfishes, and Hawaiian triplefins), it is likely that many of these fishes would recruit to an engineered offshore structure at Port Allen. Although the juvenile and adult fishes may be able to escape the hydraulic influence of the intake water flow, it also follows that many of the newly hatched larvae of these species would be at greater risk of entrainment due their proximity to the withdrawal point. Considering the large size of the offshore intake structure needed to provide the 1,473 MGD of warm water required, the potential for creating what would functionally become an engineered reef should be evaluated. The resource agencies (National Marine Fisheries Service and Hawaii Division of Aquatic Resources) would need to be engaged to determine the balance between an offshore intake structure that provides a locational benefit and one that creates an aggregating device that could exacerbate a potential entrainment issue by creating habitat.

In regards to variations in ichthyoplankton abundance with depth, the data are inconclusive, though they hint at higher concentrations in the deeper stratum at Station 3. However, no significant difference was detected between the two depth strata sampled at Station 3 during this study either for eggs or for all larvae combined. This may result in part from the study design and in part from the inherent patchiness of ichthyoplankton in the field. While the study provided adequate spatial variation in regards to distance from shore, the depths at which samples were collected may not have been deep enough to detect a difference. That said, sampling at greater depths was not necessarily warranted since constructing an intake at any greater depth (and therefore distance from shore) would not be feasible for a full-scale OTEC facility at Port Allen.

Additional studies would be useful for determining whether an offshore location would confer any biological benefit by reducing the potential for entrainment. As with the installation of a large engineered offshore intake structure, the presence of naturallyoccurring coral or other submerged structure may act as an aggregating device for larger fishes and/or as a recruitment structure for early life stages. A detailed habitat/coral survey would provide data on the location of any potential reef structures. Freidlander et al. (2005) and the National Ocean Service Biogeography Branch provide gross-scale information on the benthic habitats in the nearshore areas surrounding Kauai; however, the resolution provided is insufficient for identifying the detailed distribution of coral in the offshore area where an intake could be located. This data would also be helpful if an offshore intake is implemented as it will aid in identifying the best route for the piping if coral is present in the area.

\subsubsection{Temporal Variation}

Data on temporal variation can be useful for informing operation of some seawater intakes (e.g., conventional thermal power plants). For industries that do not require constant 
intake flow, it may be possible to coordinate withdrawal periods with periods of low ichthyoplankton abundance. Alternatively, the flow at some intakes can be reduced during peak ichthyoplankton periods. However, since OTEC relies on a consistent flow of warm water, reducing flow is not a viable option. Instead, the data on temporal variation will aid in generating estimates of potential entrainment impacts for the full-scale facility.

Temporal variation in ichthyoplankton density is important for estimating annual impacts of an operating seawater intake. As would be expected, entrainment would be greatest during the periods of highest ichthyoplankton abundance: April and May with a smaller peak in September for eggs; July, August, and September for larvae; and generally at night. Ideally, ichthyoplankton sampling should be conducted over a 12-month period (the current study was conducted over a nine-month period) to collect data over a complete annual cycle. Sampling over multiple years can be useful for accounting for inter-annual variability in ichthyoplankton populations and environmental conditions.

\subsubsection{Estimating Entrainment Impacts}

Annual entrainment estimates can be used to determine potential impacts on local fish populations through the application of various impact assessment models. Impact assessment models include both demographic models (Adult Equivalent Loss [AEL], Fecundity Hindcast [FH], and Production Foregone [PF]) and a conditional mortality model (Empirical Transport Model [ETM]). All of these models assume 100\% mortality of entrained larvae, which may not be the case for OTEC in which some entrainment survival is expected. Therefore, the entrainment estimates used in the models would need to be adjusted for the levels of entrainment survival determined for the intake.

AEL, FH, and PF are demographic models which are often used in cost-benefit analyses. Demographic models utilize life history information for a species to estimate the comparable number of adults resulting from the loss of the larvae. AEL uses entrainment data to convert larval entrainment losses into equivalent numbers of adult fish. For example, when taking into account natural mortality rates experienced by a particular species, the loss of 100,000 larvae may be equivalent to the loss of a single adult. Adults are easier to assign a value to, thus more valuable in an economic analysis designed to determine the value of the organisms lost to entrainment. FH uses entrainment data to calculate the number of fecund females that would be required to replace the number of eggs and larvae lost to entrainment. While AEL and FH estimate losses to adult population numbers, PF estimates losses to adult population biomass and is usually utilized for forage species.

ETM is a conditional mortality model. This model incorporates both biological and hydrodynamic data to determine the probability of a larva being entrained into the withdrawn water. In the ETM model, the risk of entrainment for a larva is dependent on 
the length of time it is susceptible to entrainment (based on larval length and growth rate), its geographic distribution (determined from ambient sampling of source waterbody), and the probability of entrainment into the withdrawn flow (based on ambient currents/hydrodynamics). Section 5 presents available data on the fecundity and growth rate of the dominant species in this study and this information could be used to complete an initial ETM assessment of the intake once further details on the intake design and volume are available. Another important component would be data on coastal currents in the area of Port Allen which would be used to determine the area and volume of the source water potentially affected by the intake.

Depending on the modeling approach used, the resulting impact assessments would then be used to estimate the potential effects on local populations. Although this is a direct outcome of the ETM approach, determining effects on local populations using one of the demographic approaches requires information on adult populations in the area. As a result, determining population-level impacts using demographic modeling is usually restricted to commercially or recreationally important fishes that have data collected by a fisheries resource agency. Regardless of the approach used, it is important that the impact assessments provide clear estimates of the extent of the impacts to stakeholders by converting unclear entrainment data into easily understood numbers or concepts.

\subsection{Conclusion}

Variation in ichthyoplankton abundances with distance from shore and depth are the two most important biological factors to consider during the preliminary intake selection process. The results from this environmental feasibility study indicate that the abundance of ichthyoplankton is lowest at the station furthest offshore (approximately 640 to $980 \mathrm{~m}$ $[2,100$ to $3,215 \mathrm{ft}$ ] offshore at depths between 15 to $30 \mathrm{~m}$ [49 to $98 \mathrm{ft}$ ]). An offshore intake located in the vicinity of this sampling station (Station 3) would be expected to expose fewer eggs and larvae to entrainment than an intake located closer to shore. However, the potential for a large engineered offshore structure to aggregate larger individuals of the dominant taxa collected in this study should be investigated further. If an offshore structure becomes habitat, the offspring of these individuals will subsequently be at increased risk of entrainment. Also, the number of fish taxa present at the offshore station was higher, indicating greater diversity there. Lastly, although it was not part of the scope of this study, consideration must be given to the impacts associated with the construction of an offshore intake on benthic habitat. Impacts will be specific to the method of construction with tunneling having relatively fewer impacts than the "trench and fill" approach described in Appendix B of this report. The lower-cost "trench and fill" approach to offshore pipeline installation would include the installation of rip rap on top of the backfilled pipe to provide armored protection. The rip rap would likely become habitat to which many taxa would be attracted and should be considered in evaluating intake options. 
Relative to variations in density with depth, no vertical stratification could be detected at the most offshore station, so little can be concluded about the biological benefit of withdrawing water from a deeper rather than shallower location. Furthermore, the data indicate that in aggregate, ichthyoplankton occurred in slightly higher concentrations in the deeper zone. At the depths sampled, there was no evidence of a thermocline and the ichthyoplankton appeared to be well-mixed in the water column in the turbulent coastal environment near Port Allen. Inasmuch as moving an intake withdrawal point offshore is done to take advantage of lower ichthyoplankton concentrations at depth, there does not appear, from these results, to be a clear benefit of a deeper intake location; however, given the lower concentrations of ichthyoplankton at the most offshore station, there may be a benefit associated with locating the intake withdrawal point offshore.

Regarding an onshore intake, similar consideration must be given to the potential for any requisite breakwater structure to aggregate fishes and create habitat to which fishes may recruit. However, the footprint of construction-related impacts associated with an onshore versus offshore intake would be limited to a smaller, more confined benthic area (see Appendix B of this report). Concentrations of larvae were greater at the most onshore stations (from the shore to approximately $640 \mathrm{~m}$ and to depths to $15 \mathrm{~m}$ ), though there was no detectable difference in egg concentrations. Also, as indicated by the MDS analysis (Figure 5-75), variation in ichthyoplankton concentrations was more affected by sampling month than by sampling station; i.e., the distance from shore had less to do with variability than the month in which samples were collected. Although an intake located onshore may be potentially exposed to slightly higher concentrations of fish larvae, this risk must be balanced by other avoided biological impacts (e.g., trenching for offshore pipes).

Measurements of the lengths of a subset of the collected larvae will be useful for evaluating the potential efficacy of various intake screening mesh sizes. As outlined in the OCEES and Alden (2011) Interim Report, relationships between fish lengths and head capsule dimensions can be used to estimate the probability of entrainment through various screen meshes. This information can also be used to select the optimal screen mesh size. In cases where early life stages are present in relatively high numbers, consideration must be given as to whether it is better environmental practice to impinge and return these small (often fragile) fishes using fine-mesh traveling water screens or if they stand a better chance at survival being entrained through the circulating water system. As indicated in OCEES and Alden (2011), the impingement and return process associated with a collection technology like traveling water screens may impart additional stress, injuries, scale loss, or mortality to the organisms. It is therefore important to consider the tradeoffs between impingement survival and entrainment survival when selecting the optimum screen mesh size.

Data collected during this study that are less important to the preliminary intake selection process are those on temporal variation (seasonal and diel). However, these data provide a 
basis for estimating the effects of various seawater withdrawal rates on annual entrainment estimates. With the collection of various oceanographic and intake operational data, these baseline data which document how the natural populations of ichthyoplankton vary temporally can be assimilated into a model to estimate annual impacts. 


\section{References}

Agard, J. B. R., J. Gobin, and R. M. Warwick. 1993. Analysis of marine macrobenthic community structure in relation to pollution, natural oil seepage and seasonal disturbance in a tropical environment (Trinidad, West Indies). Mar. Ecol. Prog. Ser. 92: 233-243.

Ahlstrom, E.H. 1959. Vertical distribution of pelagic fish eggs and larvae off California and Baja California. U.S. Fisheries Bulletin, 60: 107-146

Allen, G. R. 1975. The biology and taxonomy of the cardinalfish, Sphaeramia orbicularis (Pisces: Apogonidae). J. Royal Soc. West. Aust., 58: 86-92. Cited in Thresher, R. E. 1984. Reproduction in Reef Fishes. T. F. H. Publications Inc., Neptune City, NJ.

Alshuth, S. R., J. W. Tucker, Jr., and J. Hateley. 1998. Egg and larval development of laboratory-reared sergeant major, Abudefduf saxatilis (Pisces, Pomacentridae). Bull. Mar. Sci. 62(1): 121-133.

Asoh, K. 2003. Reproductive parameters of female Hawaiian damselfish, Dascyllus albisella, with comparison to other tropical and subtropical damselfishes. Mar. Biol. 143: 803-810.

Asoh, K. and T. Yoshikawa. 2002. The role of temperature and embryo development time in the diel timing of spawning in a coral-reef damselfish with high-frequency spawning synchrony. Env. Biol. Fishes 64: 379-392.

Boehlert, G.W., W. Watson, and L.C. Sun. 1992. Horizontal and vertical distributions of larval fishes around an isolated oceanic island in the tropical Pacific. Deep-Sea Research 39 (3/4): 439-466.

Boehlert, G.W. and B.C. Mundy. 1996. Ichthyoplankton Vertical Distributions near Oahu, Hawaii, 1985-1986: Data Report. NOAA Technical Memorandum MNFS, NOAA-TM-MNFSSWFSC-235.

Booth, D. J. 1992. Larval settlement patterns and preferences by domino damselfish Dascyllus albisella Gill. J. Exp. Mar. Biol. Ecol. 155: 85-104.

Booth, D. J. 1995. Juvenile groups in a coral-reef damselfish: Density-dependent effects on individual fitness and population demography. Ecology 76: 91-106.

Burdick, J. E. 1969. The feeding habits of nehu (Hawaiian anchovy) larvae. M. S. Thesis, Univ. Hawaii, Honolulu. 54 p.

Chave, E. H. 1978. General ecology of six species of Hawaiian cardinalfishes. Pac. Sci. 32(3): 245-270. 
Clarke, K. R and R. M. Warwick. 2001. Change in marine communities: an approach to statistical analysis and interpretation, 2nd edition. PRIMER-E: Plymouth, United Kingdom.

Clarke, K. R and R. N. Gorley. 2006. PRIMER v6: User Manual/Tutorial. PRIMER-E: Plymouth, United Kingdom.

Clarke, T. A. 1987. Fecundity and spawning frequency of the Hawaiian anchovy or nehu, Encrasicholina purpurea. Fish. Bull. 85(1): 127 -138.

Clarke, T. A. 1989a. Seasonal differences in spawning, egg size, and early development time of the Hawaiian anchovy or nehu, Encrasicholina purpurea. Fish. Bull. 85(1): 127 -138.

Clarke, T. A. 1989b. Species Profiles: Life Histories and Environmental Requirements of Coastal Vertebrates and Invertebrates Pacific Ocean Region. Report 4. The Hawaiian Anchovy or Nehu Encrasicholina purpurea (Engraulidae). NTIS Rep. ADA216653. 27 p.

Clarke, T.A. 1991. Larvae of Nearshore Fishes in Oceanic Waters near Oahu, Hawaii. NOAA Technical Report NMFS 101. US Department of Commerce. 19 pages.

Clarke, T. A. 1992. Egg abundance and spawning biomass of the Hawaiian anchovy or nehu, Encrasicholina purpurea, during 1984 -1988 in Kaneohe Bay, Hawaii. Pac. Sci. 46(3): 325 343.

Clarke, T. A. 1996. Reproductive biology and egg abundance of the yellowtail scad or omaka, Atule mate (Carangidae), in Kane'ohe Bay, Hawaii. Pac. Sci. 50(1): 93-107.

Clarke, T. A. and L. A. Privitera. 1995. Reproductive biology of two Hawaiian pelagic carangid fishes, the bigeye scad, Selar crumenophthalmus, and the round scad, Decapterus macarellus. Bull. Mar. Sci. 56(1): 33-47.

Dalzell, P. and A. D. Lewis. 1989. A review of the South Pacific tuna baitfisheries: small pelagic fisheries associated with coral reefs. Mar. Fish. Rev. 51: 1-10.

Danilowicz, B. S. 1995. Spatial patterns of spawning in the coral-reef damselfish Dascyllus albisella. Mar. Biol. 122: 145-155.

Danilowicz, B. S. and C. L. Brown. 1992. Rearing methods for two damselfish Dascyllus albisella and D. aruanus. Aquaculture 106: 141-149.

Firing, J and R.E. Brainard. 2006. Ten Years of Shipboard ADCP Measurements along the Northwestern Hawaiian Islands. Atoll Research Bulletin 543: 347-363.

Fishbase. 2007. Encrasicholina purpurea (Nehu). http://www.fishbase.org/Summary/SpeciesSummary.php?id=559. 
Fishbase. 2008. Encrasicholina punctifer (Nehu).

http://www.fishbase.org/Summary/SpeciesSummary.php?id=558.

Friedlander, A.M., G. Aeby, E. Brown, A. Clark, S. Coles, S. Dollar, C. Hunter, P. Jokiel, J. Smith, B. Walsh, I. Williams, and W. Wiltse. 2005. The State of Coral Reef Ecosystems of the Main Hawaiian Islands. pp. 222-269. In: J. Waddell (ed.), The State of Coral Reef Ecosystems of the United States and Pacific Freely Associated States: 2005. NOAA Technical Memorandum NOS NCCOS 11. NOAA/NCCOS Center for Coastal Monitoring and Assessment's Biogeography Team. Silver Spring, MD. 522 pp.

Fricke, R. 1994. Tripterygiid fishes of Australia, New Zealand and the southwest Pacific Ocean (Teleostei). Koeltz Scientific Books, Königstein, Germany. 585 p.

Gosline, W.A. and V. Brock, 1960. Handbook of Hawaiian Fishes. University of Hawaii Press. 273 pages. As cited in Whittle, A. 2003.

Gray, J.S., K.R. Clarke, R.M. Warwick and G. Hobbs. 1990. Detection of initial effects of pollution on marine benthos: an example from the Ekofisk and Eldfisk oilfields, North Sea. Mar. Ecol. Prog. Ser. 66: 285-299.

HECO (Hawaiian Electric Company). 2011a. Hawaiian Electric Company, Inc. Honolulu Generating Station CWA Section 316(b) Impingement Mortality and Entrainment Characterization Study: 2010-2011 Summary Report (Year 5). Prepared for Hawaiian Electric Company, Inc. Honolulu Generating Station.

HECO (Hawaiian Electric Company). 2011b. Hawaiian Electric Company, Inc. Kahe Generating Station CWA Section 316(b) Impingement Mortality and Entrainment Characterization Study: 2010-2011 Summary Report (Year 5). Prepared for Hawaiian Electric Company, Inc. Kahe Generating Station.

Helfrich, P. 1959. Observations on the reproductive behavior of the maomao, a Hawaiian damselfish. Proc. Hawaiian Acad. Sci. 34: 22.

Helvey, M. 1985. Behavioral factors influencing fish entrapment at offshore cooling-water intakes structures in Southern California. Marine Fisheries Review 47(1): 18-26.

Hida, T. S. and R. A. Skillman. 1983. A note on the commercial fisheries in Hawaii. Southwest Fisheries Center Administrative Report: H-82-20 (Revised). 11 p.

Honebrink, R. R. 2000. A review of the biology of the family Carangidae, with emphasis on species found in Hawaiian waters. Division of Aquatic Resources, Tech. Report 20-01, 37 p.

Hunter, J.R., B.J. Macewicz, and J.R. Sibert. 1986. The spawning frequency of skipjack tuna, 
Katsuwonus pelamis, from the South Pacific. Fishery Bulletin 84: 895-903.

Itano, D.G. 2000. The reproductive biology of yellowfin tuna (Thunnus albacares) in Hawaiian Waters and the Western Tropical Pacific Ocean: Project Summary. SOEST 00-01. JIMAR Contribution 00-328.

Iwai, T. Y., Jr., C. S. Tamaru, L. Yasukochi, S. Alexander, R. Yoshiumura, and M. Mitsuyasu. 1996. Natural spawning of captive bigeye scad Selar crumenophthalmus in Hawaii. J. World Aquaculture Soc. 27(3): 332-339.

Kawamoto, P. Y. 1973. Management investigation of the Akule or bigeye scad, Trachurops crumenopthalmus (Bloch). Hawaii Div. Fish and Game, Rep. No. H-4-r, Honolulu, HI.

Lang, L.L., C.B. Grimes, and R.F. Shaw. 1994. Variations in the age and growth of yellowfin tuna larvae, Thunnus albacares, collected about the Mississippi plume. Environmental Biology of Fishes 39: 259-270.

Laroche, W. A., W. F. Smith-Vaniz and S. L. Richardson. 1984. Carangidae: Development. In H. G. Moser, W. J. Richards, D. M. Cohen, M. P. Fahay, A. W. Kendall, Jr., and S. L. Richardson (Eds.), Ontogeny and Systematics of Fishes. Am. Soc. Ichthyologists Herpetologists, Spec. Publ. No. 1: 510-522.

Leary, D. F., G. I. Murphy, and M. Miller. 1975. Fecundity and length at first spawning of the Hawaiian anchovy, or nehu (Stolephorus purpureus Fowler) in Kaneohe Bay, Oahu. Pac. Sci. 29: 171-180.

Leis, J.M. 1982a. Hawaiian Creediid Fishes (Crytallodytes cookei and Limnichthys donaldsoni): Development of Eggs and larvae and Use of Pelagic Eggs to Trace Coastal Water Movement. Bulletin of Marine Science 32(1): 166-180.

Leis, J.M. 1982b. Nearshore Distributional Gradients of Larval Fish (15 taxa) and Planktonic Crustaceans (6 Taxa) in Hawaii. Mar Biol 72: 89-97.

Leis, J.M. 1986. Vertical and horizontal distribution of fish larvae near coral reefs at Lizard Island, Great Barrier Reef. Marine Biology 90: 505-516.

Leis, J. M. and B. M. Carson-Ewart. 2004. The larvae of Indo-Pacific coastal fishes. Brill: Boston-Leiden. 850 p.

Lehodey, P. and B. Leroy. 1999. Age and growth of yellowfin tuna (Thunnus albacares) from the western and central pacific Ocean as indicated by daily growth increments and tagging data. Working paper for Standing Committee on Tuna and Billfish. SCTB12. Tahiti. Oceanic Fisheries Programme, New Caledonia. 
Lobel P.S. and A.R. Robinson. 1988. Larval fishes and zooplankton in a cyclonic eddy in Hawaiian waters. J. Plankton Research 10: 1209-1223.

Longenecker, K. and R. Langston. 2005. Life history of the Hawaiian blackhead triplefin, Enneapterygius atriceps (Blennioidei, Tripterygiidae). Env. Biol. Fishes 73: 243-251.

Medvick, P. A. 1979. Growth rates of juvenile maomao, Abudefduf abdominalis at constant and cyclic temperatures. Trans. Amer. Fish. Soc. 108: 293-298.

Miller, J. M. and B. Y. Sumida. 1974. Development of eggs and larvae of Caranx mate (Carangidae). Fish. Bull. 72(2): 497-514.

Miller, J.M., W. Watson, and J.M. Leis. 1979. An Atlas of Common Nearshore Marine Fish Larvae of the Hawaiian Islands. Sea Grant Miscellaneous Report, UNIHI-SEAGRANT-MR-8002.

Milliken, G. A. and D. E. Johnson. 1984. Analysis of messy data. Van Nostrand Reinhold Co., New York.

Moser, H. G. (ed.). 1996. The early stages of fishes in the California Current Region. CalCOFI Atlas No. 33. Allen Press, Inc., Lawrence, KS. 1,505 p.

Moyle, P. B. and J.J. Cech, Jr.. 1988. Fishes: An introduction to ichthyology. Department of Wildlife and Fisheries Biology, U.C. Davis. Prentice Hall, Englewood Cliffs, NJ.

Mundy, B. 2005. Checklist of the fishes of the Hawaiian Archipelago. Bishop Museum Bulletin in Zoology 6. Bishop Museum Press. Honolulu. 704 pp.

Myers, E.P., Hoss, D.E., Matsumoto, W.M., Peters, D.S. Seki, M.P., Uchida, R.N., Ditmars, J.D., and R.A. Paddock. 1986. The Potential Impact of Ocean Thermal Energy Conversion (OTEC) on Fisheries. NOAA Technical Report NMFS 40.

Nelson, J. S. 2006. Fishes of the World, 4th Ed. John Wiley and Sons, Inc., New York. 624 p.

NOS (National Ocean Service). United States Coast Pilot 7. Pacific Coast: California, Oregon, Hawaii, and Pacific Coast. 2013 (45th) Edition.

OCEES (Ocean Engineering and Energy Systems) and Alden (Alden Research Laboratory, Inc.). 2011. The Potential Impacts of OTEC Intakes on Aquatic Organisms at an OTEC Site Under Development on Kauai, HI. Interim Report. July 2011.

Olsgard, F. and J. S. Gray. 1995. A comprehensive analysis of the effects of offshore oil and gas exploration and production on the benthic communities of the Norwegian continental shelf. Mar. Ecol. Prog. Ser. 122: 277-306. 
Schroeter, S.C., J.D. Dixon, J.K. Kastendiek, R.O. Smith, and J.R. Bence. 1993. Detecting the ecological effects of environmental impacts: a case study of kelp forest invertebrates. Ecol. Appl. 3: 331-350.

Somerton, D.A., D.R. Kobayashi, and K.C. Landgraf. Stock assessment of nehu, Encrasicholina purpurea, using the egg production method. Bulletin of Marine Science 53(2): 768-777.

Radtke, R. L. 1985. Life history characteristics of the Hawaiian damselfish, Abudefduf abdominalis, defined from otoliths. Proceedings of the Fifth International Coral Reef Congress, Tahiti. Vol. 5: 397-401.

Randall, J. E. 1998. Review of the cardinalfishes (Apogonidae) of the Hawaiian Islands, with descriptions of two new species. Aqua 3(1): 25 -38.

Randall, J. E. 2007. Reef and shore fishes of the Hawaiian Islands. Sea Grant College Program. Univ. Hawaii, Honolulu. 546 pp.

Russell, B. C., G. R. V. Anderson, and F. H. Talbot. 1977. Seasonality and recruitment of coral reef fishes. Aust. J. Mar. Fresh. Res. 28: 521 -528.

SAS Institute Inc.. 2008. SAS Software Version 9.2. Cary, NC.

Schroeter, S.C., J.D. Dixon, J.K. Kastendiek, R.O. Smith, and J.R. Bence. 1993. Detecting the ecological effects of environmental impacts: a case study of kelp forest invertebrates. Ecol. Appl. 3: 331-350.

Shiogaki, M. and Y. Dotsu. 1973. Egg development and larva rearing of the tripterygiid blenny, Enneapterygius etheostomus. Jap. J. Ichthyology 20: 42 -46. [in Japanese -English summary].

Shomura, R. S. 1964. Effectiveness of tilapia as live bait for skipjack tuna fishing. Trans. Am. Fish. Soc. 93: 291 -294.

Smith, C. L., E. H. Atz, and J. C. Tyler. 1971. Aspects of oral brooding in the cardinalfish Cheilodipterus affinis Poey (Apogonidae). Amer. Mus. novitates no. 2456:1-11. Cited in Thresher, R. E. 1984. Reproduction in reef fishes. T. F. H. Publications Inc., Neptune City, NJ.

Smith-Vaniz, W. F. 1984. Carangidae: relationships. In H. G. Moser et al. (eds.). Ontogeny and systematics of fishes. Spec. Publ. No. 1, Amer. Soc. Ichthyol. and Herp.: 522-530.

SOEST (School of Ocean and Earth Science and Technology) 2011. Main Hawaiian Islands Chart 200-002, Multibeam Bathymetry Data Synthesis. University of Hawaii at Manoa. 
Available at http://www.soest.hawaii.edu/hmrg/multibeam/products/mbs charts-200002.bty.b0.low.jpg

Somerton, D. A., D. R. Kobayashi and K. C. Landgraf. 1993. Stock assessment of nehu, Encrasicholina purpurea, using the egg production method. Bull. Mar. Sci. 53(2): 768 -777.

Stevenson, R. A., Jr. 1963. Life history and behavior of Dascyllus albisella Gill, a pomacentrid reef fish. Ph. D. Dissertation., Univ. Hawaii, Honolulu.

Struhsaker, P. and J. H. Uchiyama 1976. Age and growth of the nehu Stolephorus purpureus (Pisces: Engraulidae), from the Hawaiian Islands as indicated by daily growth increments of sagittae. Fish. Bull., U. S. 74: 9 -17.

Sudekum, A. E., J. D. Parrish, R. L. Radtke, and S. Ralston. 1991. Life history and ecology of large jacks in undisturbed, shallow, oceanic communities. Fish. Bull., U. S. 89: 493-513.

Tester, A. L. 1955. Variation in egg and larva production of the anchovy, Stolephorus purpureus Fowler, in Kaneohe Bay, Oahu, during 1950 -1952. Pac. Sci. 9: 31 -41.

Thacker, C. 1993. Interspecific distinctions and phylogeny of the progenetic Teleost genus Schindleria. Master Degree at university of Hawaii. 50 pages. As cited in Whittle, A. 2003.

Thresher, R. E. 1984. Reproduction in reef fishes. T.F.H. Publications. Neptune City, New Jersey.

Tyler, W. A., III, and F. G. Stanton. 1995. Potential influence of food abundance on spawning patterns in a damselfish, Abudefduf abdominalis. Bull. Mar. Sci. 57(3): 610-623.

Tyler, W. A., III. 1988. Spawning patterns in the Hawaiian sergeant, Abudefduf abdominalis (Family: Pomacentridae). Pac. Sci., 42(1-2), 136.

Tyler, W. A., III. 1989. Optimal colony size in the Hawaiian sergeant, Abudefduf abdominalis (Pisces: Pomacentridae). Pac. Sci., 43(2), 204.

Tyler, W. A., III. 1992. The spatial and temporal dynamics of colonial nesting in the maomao, Abudefduf abdominalis (Family: Pomacentridae). Ph.D. Dissertation. University of Hawaii. 215 pp.

Tyler, W. A., III. 1995. The adaptive significance of colonial nesting in a coral-reef fish. Anim. Behav. 49: 949-966.

Uchiyama, J.H. and P Struhsaker. 1981. Age and growth skipjack tuna, Katsuwonus pelamis, and Pacific yellowfin tuna, Thunnus albacares, as indicated by daily growth increments of sagittae. Fishery Bull 79: 151-162. 
USEPA (United States Environmental Protection Agency). 2011. Technical Development Document for the Proposed Section 316(b) Phase II Existing Facilities Rule. U.S. Environmental Protection Agency, Office of Water (4303T), Washington, D.C., March 28, 2011.

Watson, W. and J. M. Leis. 1974. Ichthyoplankton of Kaneohe Bay, Hawaii - A one-year study of fish eggs and larvae. University of Hawaii Sea Grant Technical Report. UNIHISEAGRANT-TR-75-01, Honolulu, 178 p.

Wellington, G. M. and B. C. Victor. 1989. Planktonic larval duration of one hundred species of Pacific and Atlantic damselfishes (Pomacentridae). Mar. Biol. 101: 557-567.

Whitehead, P. J. P., G. J. Nelson and T. Wongratana, 1988. FAO species catalogue. Vol. 7. Clupeoid fishes of the world (Suborder Clupeoidei). An annotated and illustrated catalogue of the herrings, sardines, pilchards, sprats, shads, anchovies and wolf-herrings. Part 2 Engraulididae. FAO Fish. Synop. 125(7/2): 305 -579.

Whittle, A. 2003. Ecology, Abundance, Diversity, and Distribution of larval fishes and Schindleriidae at two sites on Oahu, Hawaii. PhD dissertation, University of Hawaii. 100 pages.

Wilk, M.B. and R. Gnanadesikan. 1968. Probability plotting methods for the analysis of data. Biometrika 55: 1-17.

Yamashita, D. T. 1951. The embryological and larval development of the nehu, an engraulid baitfish of the Hawaiian Islands. M.S. Thesis, Univ. Hawaii, Honolulu. 64 p. 
Appendix A

DE-EE0002653

Appendix A. RAW ICHTHYOPLANKTON SAMPLING DATA, BY SURVEY 
Table A- 1. Baseline larval fish counts and average concentrations (\#/1000m $\left.{ }^{3}\right)$ for Survey 1, April 1 - $2,2012$.

\begin{tabular}{|c|c|c|c|c|c|c|c|c|c|c|}
\hline \multirow[b]{2}{*}{ Taxon } & \multirow[b]{2}{*}{ Common Name } & \multicolumn{2}{|c|}{ 1B } & \multicolumn{2}{|c|}{$2 B$} & \multicolumn{2}{|c|}{$3 B$} & \multicolumn{2}{|c|}{$3 \mathrm{M}$} & \multirow{2}{*}{$\begin{array}{r}\text { Average } \\
\text { Conc }\end{array}$} \\
\hline & & $\mathrm{Ct}$ & Conc & $\mathrm{Ct}$ & Conc & $\mathrm{Ct}$ & Conc & $\mathrm{Ct}$ & Conc & \\
\hline Salariinae & blennies & 263 & 244.67 & 106 & 154.67 & 239 & 375.13 & 369 & 633.90 & 352.09 \\
\hline Pomacentridae & damselfishes & 60 & 69.68 & 99 & 141.94 & 222 & 332.71 & 201 & 306.99 & 212.83 \\
\hline larvae, yolksac & yolksac larvae & 77 & 81.07 & 48 & 67.64 & 72 & 103.23 & 60 & 90.60 & 85.63 \\
\hline Enneapterygius atriceps & Hawaiian triplefin & 186 & 221.75 & 45 & 58.20 & 7 & 9.04 & 11 & 17.06 & 76.51 \\
\hline Cyclothone spp. & bristlemouths & 63 & 70.04 & 49 & 68.52 & 55 & 79.41 & 50 & 78.46 & 74.11 \\
\hline Myctophidae & lanternfishes & 74 & 99.45 & 33 & 45.95 & 77 & 97.97 & 20 & 30.99 & 68.59 \\
\hline Gobiidae & gobies & 29 & 25.54 & 25 & 34.72 & 70 & 90.53 & 28 & 43.62 & 48.60 \\
\hline Schindleria spp. & infantfishes & 27 & 22.38 & 15 & 20.74 & 70 & 83.23 & 19 & 29.18 & 38.88 \\
\hline Ceratoscopelus townsendi & dogtooth lampfish & 35 & 34.09 & 13 & 18.28 & 28 & 38.90 & 19 & 29.20 & 30.12 \\
\hline Pristiapogon spp. & cardinalfishes & 12 & 14.72 & 16 & 22.37 & 39 & 57.65 & 13 & 19.19 & 28.48 \\
\hline Hygophum proximum & lanternfish & 30 & 32.93 & 23 & 32.22 & 33 & 39.13 & 4 & 6.05 & 27.58 \\
\hline larval fish - damaged & damaged larval fishes & 10 & 11.13 & 16 & 23.47 & 24 & 33.03 & 16 & 24.75 & 23.09 \\
\hline Vinciguerria spp. & lightfishes & 34 & 38.20 & 6 & 8.26 & 13 & 15.89 & 8 & 12.49 & 18.71 \\
\hline Diaphus spp. & headlightfishes & 2 & 2.44 & 6 & 8.25 & 13 & 16.47 & 8 & 12.92 & 10.02 \\
\hline Symbolophorus spp. & lanternfishes & 13 & 16.69 & 1 & 1.20 & 13 & 15.52 & 2 & 3.30 & 9.17 \\
\hline Triphoturus nigrescens & highseas lampfish & 6 & 6.29 & 8 & 11.42 & 5 & 6.86 & 4 & 5.72 & 7.57 \\
\hline Apogonidae & cardinalfishes & 1 & 0.46 & 5 & 6.69 & - & - & 14 & 22.88 & 7.51 \\
\hline Lophiiformes/Tetraodontiformes & anglerfishes/puffers & 5 & 5.71 & 3 & 4.05 & 5 & 7.54 & 6 & 8.95 & 6.56 \\
\hline Perciformes & Perciformes fishes & 5 & 5.43 & 2 & 2.46 & 6 & 8.16 & 6 & 9.89 & 6.48 \\
\hline Carangidae & jacks & 2 & 1.83 & 12 & 17.56 & 2 & 2.33 & 2 & 3.56 & 6.32 \\
\hline Lampanyctus spp. & lanternfishes & 9 & 11.21 & - & - & 8 & 10.05 & 1 & 1.68 & 5.73 \\
\hline Scombridae & mackerels and tunas & 3 & 4.42 & 7 & 9.38 & 1 & 1.85 & 4 & 6.08 & 5.43 \\
\hline Bolinichthys spp. & lampfishes & 3 & 4.03 & 4 & 5.21 & 5 & 6.87 & 1 & 1.39 & 4.37 \\
\hline Lampadena spp. & lanternfishes & 2 & 2.73 & 7 & 10.27 & 2 & 2.76 & - & - & 3.94 \\
\hline larval/post-larval fish & larval fishes & 2 & 2.73 & 1 & 1.42 & 2 & 3.00 & 5 & 7.52 & 3.67 \\
\hline Nannobrachium spp. & lanternfishes & 6 & 6.43 & - & - & 7 & 8.16 & - & - & 3.65 \\
\hline Coryphaena hippurus & common dolphinfish & 1 & 1.09 & 3 & 4.12 & 4 & 5.39 & 2 & 3.01 & 3.40 \\
\hline Labridae/Scaridae & wrasses/parrotfishes & 3 & 3.26 & 4 & 5.55 & 1 & 1.85 & 2 & 2.90 & 3.39 \\
\hline Scorpaenidae & scorpion fishes & 4 & 6.12 & 1 & 1.42 & 3 & 3.70 & 1 & 1.52 & 3.19 \\
\hline Priolepis spp. & gobies & 2 & 2.93 & 2 & 2.85 & 4 & 5.39 & 1 & 1.52 & 3.17 \\
\hline Gempylus serpens & snake mackerel & - & - & 3 & 4.43 & 2 & 2.85 & 3 & 4.56 & 2.96 \\
\hline Gempylidae & snake mackerels & 4 & 3.24 & 1 & 1.42 & 2 & 2.33 & 2 & 3.34 & 2.58 \\
\hline Cirrhitidae & hawkfishes & 1 & 1.37 & - & - & 5 & 7.66 & - & 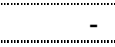 & 2.26 \\
\hline Bramidae & pomfrets & 1 & 1.22 & - & - & 3 & 4.23 & 2 & 2.94 & 2.10 \\
\hline
\end{tabular}


Table A- 1(continued). Baseline larval fish counts and average concentrations (\#/1000m³) for Survey 1, April 1 - $2,2012$.

\begin{tabular}{|c|c|c|c|c|c|c|c|c|c|c|}
\hline \multirow[b]{2}{*}{ Taxon } & \multirow[b]{2}{*}{ Common Name } & \multicolumn{2}{|c|}{ 1B } & \multicolumn{2}{|c|}{$2 B$} & \multicolumn{2}{|c|}{ 3B } & \multicolumn{2}{|c|}{$3 M$} & \multirow{2}{*}{$\begin{array}{r}\text { Average } \\
\text { Conc }\end{array}$} \\
\hline & & $\mathrm{Ct}$ & Conc & $\mathrm{Ct}$ & Conc & $\mathrm{Ct}$ & Conc & $\mathrm{Ct}$ & Conc & \\
\hline Callionymidae & dragonets & - & - & 1 & 1.20 & 2 & 2.55 & 2 & 3.34 & 1.77 \\
\hline Paralepididae & barracudinas & 3 & 4.42 & - & - & 2 & 2.33 & - & - & 1.69 \\
\hline "Howellidae" & pelagic basslets & 5 & 5.49 & - & - & 1 & 1.17 & - & "'"'"'- & 1.66 \\
\hline Apogon spp. & cardinalfishes & 1 & 1.84 & - & - & 2 & 3.01 & 1 & 1.52 & 1.59 \\
\hline Scombrolabrax heterolepis & black mackerel & - & - & 1 & 1.42 & 3 & 4.32 & - & - & 1.43 \\
\hline Labridae & wrasses & - & - & 3 & 3.80 & 1 & 1.47 & - & - & 1.32 \\
\hline Pseudamiops diaphanes & transparent cardinalfish & 2 & 2.19 & - & - & - & - & 2 & 3.03 & 1.30 \\
\hline Hygophum reinhardtii & slender lanternfish & 3 & 3.41 & - & - & 1 & 1.17 & - & - & 1.14 \\
\hline Gunnellichthys curiosus & curious wormfish & - & - & 2 & 2.67 & 1 & 1.16 & - & - & 0.96 \\
\hline Lampanyctus nobilis & lanternfish & 1 & 1.09 & - & - & 1 & 1.16 & 1 & 1.39 & 0.91 \\
\hline Notoscopelus spp. & lampfishes & 1 & 1.22 & - & - & (2) & 2.33 & - na & (3)- & 0.89 \\
\hline Melamphaes spp. & "'bigscales & - & - & - & - & 3 & 3.50 & - & "'"'-" & 0.87 \\
\hline Apogonidae/Gobiidae & cardinalfishes/gobies & - & - & - & - & 3 & 3.48 & - n - & (")"'-" & 0.87 \\
\hline Katsuwonus pelamis & skipjack tuna & 2 & 1.83 & 1 & 1.20 & - n & - & 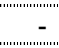 & - & 0.76 \\
\hline Myctophum spp. & lanternfishes & 6 & 2.79 & - & - & - & - & - & - n-" & 0.70 \\
\hline Cubiceps pauciradiatus & bigeye cigarfish & 2 & 2.79 & - & - & - & - & - & - & 0.70 \\
\hline Auxis spp. & frigate mackerels & 1 & 1.37 & 1 & 1.42 & - & - & - & - & 0.70 \\
\hline Stomiiformes & stomioids & - & - & 1 & 1.20 & "1 & 1.53 & - na & - & 0.68 \\
\hline Synodontidae & lizardfishes & - & - & - & - & 2 & 2.33 & - & - & 0.58 \\
\hline Nomeidae & driftfishes & 1 & 1.84 & - & - & - & - & - & "."- & 0.46 \\
\hline Phosichthyidae & lightfishes & 1 & 1.84 & - & - & - & - & - & - & 0.46 \\
\hline Epigonus spp. & scaleless dragonfishes & - & - & - & - & - & - & 1 & 1.78 & 0.44 \\
\hline Scomberoides lysan & double spotted queenfish & - & - & - & - & - & - & 1 & 1.78 & 0.44 \\
\hline Clupeidae & herrings & - & - & - & - & - & - & 1 & 1.68 & 0.42 \\
\hline Blenniidae & blennies & - & - & 1 & 1.58 & - & - & - & - & 0.40 \\
\hline Tetraodontiformes & puffers & - & - & 1 & 1.58 & - & - & - & - & 0.40 \\
\hline Astronesthes spp. & snaggletooths & - & (n) & - & - & 1 & 1.53 & (3) & - & 0.38 \\
\hline Taaningichthys spp. & lanternfishes & - & - & 1 & 1.52 & - n & - & - & - & 0.38 \\
\hline Plagiotremus spp. & fangblennies & - & - & - & - & 1 & 1.47 & - & - & 0.37 \\
\hline Sphyraena spp. & barracudas & - & - & 1 & 1.41 & - & - & - & - & 0.35 \\
\hline Encrasicholina spp. & anchovies & - & - & - & - & 1 & 1.38 & - & - & 0.35 \\
\hline Notosudidae & waryfishes & 1 & 1.37 & - & - & - & - & - na & - & 0.34 \\
\hline Elopomorpha & fishes & 1 & 1.22 & - & - & - & - & - & - & 0.30 \\
\hline Gonostoma atlanticum & Atlantic fangsaw & 1 & 1.22 & - & - & 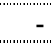 & - & - & - & 0.30 \\
\hline Ranzania laevis & slender mola & 1 & 1.22 & - & - & - & - & - & - & 0.30 \\
\hline Syngnathidae & pipefishes & - & - & 1 & 1.20 & - & - & - & - & 0.30 \\
\hline Lestidiops spp. & barracudina & - & - & - & - & 1 & 1.17 & - & - & 0.29 \\
\hline
\end{tabular}


Table A- 1(continued). Baseline larval fish counts and average concentrations $\left(\# / 1000 \mathrm{~m}^{3}\right)$ for Survey 1, April 1 - $2,2012$.

\begin{tabular}{|c|c|c|c|c|c|c|c|c|c|c|}
\hline \multirow[b]{2}{*}{ Taxon } & \multirow[b]{2}{*}{ Common Name } & \multicolumn{2}{|c|}{ 1B } & \multicolumn{2}{|c|}{$2 B$} & \multicolumn{2}{|c|}{ 3B } & \multicolumn{2}{|c|}{$3 M$} & \multirow{2}{*}{$\begin{array}{r}\text { Average } \\
\text { Conc }\end{array}$} \\
\hline & & $\mathrm{Ct}$ & Conc & $\mathrm{Ct}$ & Conc & $\mathrm{Ct}$ & Conc & $\mathrm{Ct}$ & Conc & \\
\hline Syngnathiformes & pipefishes and seahorses & - & & - & - & 1 & 1.16 & & - & 0.29 \\
\hline Hygophum spp. & lanternfishes & 1 & 1.09 & - & - & - & - & - & - & 0.27 \\
\hline Triglidae & searobins & 1 & 1.09 & - & - & - & $=$ & - & - & 0.27 \\
\hline Caristidae & manefishes & 1 & 0.95 & - & - & - & - & - & - & 0.24 \\
\hline Champsodon fimbriatus & toothfish & 1 & 0.95 & - & - & - & $=$ & "s. & - & 0.24 \\
\hline & Total Fishes: & 1,012 & & 579 & & 1,072 & & 893 & & \\
\hline
\end{tabular}


Table A- 2. Baseline larval fish counts and average concentrations (\#/1000m $\left.{ }^{3}\right)$ for Survey 2, May 2 - 3, 2012.

\begin{tabular}{|c|c|c|c|c|c|c|c|c|c|c|}
\hline \multirow[b]{2}{*}{ Taxon } & \multirow[b]{2}{*}{ Common Name } & \multicolumn{2}{|c|}{$1 \mathrm{~B}$} & \multicolumn{2}{|c|}{ 2B } & \multicolumn{2}{|c|}{$3 B$} & \multicolumn{2}{|c|}{$3 \mathrm{M}$} & \multirow{2}{*}{$\begin{array}{r}\text { Average } \\
\text { Conc }\end{array}$} \\
\hline & & $\mathrm{Ct}$ & Conc & $\mathrm{Ct}$ & Conc & $\mathrm{Ct}$ & Conc & $\mathrm{Ct}$ & Conc & \\
\hline Salariinae & blennies & 301 & 473.10 & 472 & 714.22 & 130 & 184.57 & 223 & 300.19 & 418.02 \\
\hline Gobiidae & gobies & 162 & 248.36 & 341 & 512.25 & 95 & 132.64 & 122 & 181.54 & 268.70 \\
\hline Pomacentridae & damselfishes & 17 & 26.35 & 309 & 465.37 & 134 & 186.81 & 231 & 310.85 & 247.35 \\
\hline Schindleria spp. & infantfishes & 84 & 128.70 & 176 & 263.50 & 138 & 189.09 & 86 & 129.37 & 177.67 \\
\hline Enneapterygius atriceps & Hawaiian triplefin & 343 & 540.65 & 48 & 73.27 & 1 & 1.49 & - & - & 153.85 \\
\hline larvae, yolksac & yolksac larvae & 28 & 42.45 & 82 & 121.45 & 106 & 145.99 & 67 & "' 93.76 & 100.91 \\
\hline Cyclothone spp. & bristlemouths & 5 & 7.70 & 65 & 96.83 & 62 & 85.76 & 77 & 111.84 & 75.53 \\
\hline Diaphus spp. & headlightfishes & 10 & 15.68 & 55 & 82.64 & (3) & 82.49 & 48 & - & 62.28 \\
\hline Myctophidae & lanternfishes & 41 & 63.12 & 47 & 70.20 & 40 & 58.10 & 40 & 57.44 & 62.21 \\
\hline Triphoturus nigrescens & highseas lampfish & 26 & 40.41 & 44 & 66.31 & 32 & 46.44 & 22 & 31.94 & 46.27 \\
\hline "Carangidae & jacks & 10 & 15.40 & 59 & 89.30 & 19 & 26.94 & 32 & "'45.30 & 44.23 \\
\hline Ceratoscopelus townsendi & dogtooth lampfish & 20 & 31.40 & 38 & 56.87 & 10 & 14.27 & 14 & 20.79 & 30.83 \\
\hline larval fish - damaged & damaged larval fishes & 4 & 6.29 & 12 & 17.69 & 25 & 35.14 & 20 & 27.68 & 21.70 \\
\hline Pristiapogon spp. & cardinalfishes & 1 & 1.60 & 27 & 41.16 & 12 & 16.83 & 19 & 26.21 & 21.45 \\
\hline Lampadena spp. & lanternfishes & - & - & 21 & 31.98 & 10 & 14.55 & 11 & 15.43 & 15.49 \\
\hline Lophiiformes/Tetraodontiformes & anglerfishes/puffers & 7 & 10.72 & 7 & 10.34 & 8 & 11.51 & 10 & 14.34 & 11.73 \\
\hline Apogon spp. & cardinalfishes & 10 & 15.25 & 14 & 21.15 & 4 & 5.92 & 2 & 2.54 & 11.22 \\
\hline Cubiceps spp. & cigarfishes & 1 & 1.52 & 12 & 17.68 & 3 & 4.60 & 9 & 12.02 & 8.96 \\
\hline Pseudamiops diaphanes & transparent cardinalfish & 7 & 10.87 & 11 & 16.84 & 2 & 2.88 & 1 & 1.48 & 8.02 \\
\hline Gempylus serpens & snake mackerel & - & - & 5 & 7.79 & 4 & 5.33 & 13 & 17.98 & 7.78 \\
\hline Perciformes & Perciformes fishes & 3 & 4.56 & 1 & 1.46 & 9 & 12.36 & 8 & 11.38 & 7.44 \\
\hline Bolinichthys spp. & lampfishes & 2 & 3.15 & 11 & 16.50 & 2 & 2.88 & 4 & 6.06 & 7.15 \\
\hline Scombridae & mackerels and tunas & 1 & 1.52 & 5 & 7.15 & 7 & 9.81 & 1 & 1.48 & 4.99 \\
\hline Priolepis spp. & gobies & 5 & 7.52 & 3 & 4.67 & 1 & 1.49 & 2 & 3.14 & 4.20 \\
\hline Apogonidae/Gobiidae & cardinalfishes/gobies & - & - & 8 & 11.99 & 3 & 3.93 & - & - & 3.98 \\
\hline Labridae & wrasses & - & - & 3 & 4.57 & 4 & 5.61 & 3 & 4.40 & 3.65 \\
\hline Diplophos spp. & lightfishes & - & - & 1 & 1.56 & 4 & 5.86 & 4 & 5.02 & 3.11 \\
\hline Lampanyctus spp. & lanternfishes & - & - & 2 & 2.93 & 3 & 4.06 & 4 & 5.38 & 3.09 \\
\hline larval/post-larval fish & larval fishes & 2 & 3.15 & 5 & 7.33 & - & $=$ & - & - n & 2.62 \\
\hline Sphyraena spp. & barracudas & - & - & - & - & 2 & 2.99 & 5 & 6.99 & 2.49 \\
\hline Apogonidae & cardinalfishes & - & - & 1 & 1.56 & 1 & 1.56 & 4 & 5.46 & 2.14 \\
\hline Exocoetidae & flyingfishes & - & - & - & - & 5 & 6.93 & 1 & 1.48 & 2.10 \\
\hline Katsuwonus pelamis & skipjack tuna & 1 & 1.60 & 3 & 4.67 & - & - & 1 & 1.27 & 1.89 \\
\hline Scorpaenidae & scorpion fishes & - & - & 2 & 3.03 & 2 & 2.56 & 1 & 1.29 & 1.72 \\
\hline Plagiotremus spp. & fangblennies & 1 & 1.61 & 2 & 3.12 & - & - & 1 & 1.27 & 1.50 \\
\hline Gunnellichthys curiosus & curious wormfish & - & - n & - & - & 3 & 4.37 & 1 & 1.48 & 1.46 \\
\hline Callionymidae & dragonets & - & - & 1 & 1.47 & - n & $=$ & 3 & 4.21 & 1.42 \\
\hline Coryphaena hippurus & common dolphinfish & 1 & 1.34 & 2 & 3.03 & 1 & 1.22 & - & "'-" & 1.39 \\
\hline
\end{tabular}


Table A- 2(continued). Baseline larval fish counts and average concentrations $\left(\# / 1000 \mathrm{~m}^{3}\right)$ for Survey 2 , May 2 - 3, 2012.

\begin{tabular}{|c|c|c|c|c|c|c|c|c|c|c|}
\hline \multirow[b]{2}{*}{ Taxon } & \multirow[b]{2}{*}{ Common Name } & \multicolumn{2}{|c|}{ 1B } & \multicolumn{2}{|c|}{ 2B } & \multicolumn{2}{|c|}{$3 B$} & \multicolumn{2}{|c|}{$3 \mathrm{M}$} & \multirow{2}{*}{$\begin{array}{r}\text { Average } \\
\text { Conc }\end{array}$} \\
\hline & & $\mathrm{Ct}$ & Conc & $\mathrm{Ct}$ & Conc & $\mathrm{Ct}$ & Conc & $\mathrm{Ct}$ & Conc & \\
\hline Syngnathidae & pipefishes & 3 & 4.66 & - & - & - & - & - & - & 1.17 \\
\hline Nannobrachium spp. & lanternfishes & 1 & 1.52 & 1 & 1.56 & 1 & 1.56 & (3) & 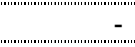 & 1.16 \\
\hline Asterropteryx semipunctata & halfspotted goby & 2 & 3.15 & - & - & - n - & - & 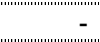 & 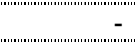 & 0.79 \\
\hline Ranzania laevis & slender mola & - & - & 2 & 3.11 & - n-" & - & - & - & 0.78 \\
\hline Lampanyctus nobilis & lanternfish & 1 & 1.60 & - & - & 1 & 1.50 & - n & 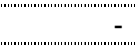 & 0.77 \\
\hline Hygophum proximum & lanternfish & - & - & 2 & 3.03 & 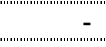 & - & (n) & 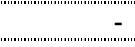 & 0.76 \\
\hline Synodontidae & lizardfishes & - & - & 2 & 3.03 & - & - & - & - n & 0.76 \\
\hline Cubiceps pauciradiatus & bigeye cigarfish & - & - & 1 & 1.56 & - & - & 1 & (1.29 & 0.71 \\
\hline Gempylidae & snake mackerels & - & - no & 1 & 1.56 & (3) & - & 1 & (') & 0.71 \\
\hline Iso hawaiiensis & Hawaiian surf sardine & 1 & 1.61 & - & - & - & - & - & - & 0.40 \\
\hline Foa brachygramma & bay cardinalfish & 1 & 1.60 & - & - & - & - & - & - & 0.40 \\
\hline Ahliesaurus brevis & waryfish & - & - & 1 & 1.56 & - & - & - & - & 0.39 \\
\hline Blenniidae & blennies & 1 & 1.54 & - & - & - & - & - & - & 0.38 \\
\hline Percoidei & Percoidei fishes & 1 & 1.52 & - & - & - n & - & - & - & 0.38 \\
\hline Vinciguerria spp. & lightfishes & 1 & 1.52 & - & - & - & - & (3) - & - & 0.38 \\
\hline Howellidae & pelagic basslets & - & $=$ & $=$ & - & 1 & 1.49 & - & - n & 0.37 \\
\hline Kyphosidae & sea chubs & - & - & 1 & 1.46 & "'?"'-" & - & - & 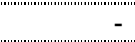 & 0.36 \\
\hline Lobianchia gemellarii & lampfish & - & - & 1 & 1.37 & - & - & - & - & 0.34 \\
\hline Stomiformes & stomioids & - & - n & 1 & 1.37 & 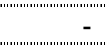 & - & - n & - n & 0.34 \\
\hline Cirrhitidae & hawkfishes & - & - & - & - & 1 & 1.22 & - & (3) & 0.30 \\
\hline Gigantura indica & telescope fish & - & - & - & - & 1 & 1.22 & - & - & 0.30 \\
\hline \multirow[t]{2}{*}{ Melamphaes spp. } & bigscales & - & - & - & - & 1 & 1.22 & - & - & 0.30 \\
\hline & Total Fishes: & 1,103 & & 1,905 & & 942 & & 1,092 & & \\
\hline fish eggs & fish eggs & 4,823 & $7,424.58$ & 19,190 & $27,933.02$ & 23,630 & $33,664.28$ & 28,900 & $38,778.54$ & $26,950.10$ \\
\hline
\end{tabular}


Table A- 3. Baseline larval fish counts and average concentrations $\left(\# / 1000 \mathrm{~m}^{3}\right)$ for Survey 3, June 6 - 7, 2012.

\begin{tabular}{|c|c|c|c|c|c|c|c|c|c|c|}
\hline \multirow[b]{2}{*}{ Taxon } & \multirow[b]{2}{*}{ Common Name } & \multicolumn{2}{|c|}{$1 \mathrm{~B}$} & \multicolumn{2}{|c|}{ 2B } & \multicolumn{2}{|c|}{$3 B$} & \multicolumn{2}{|c|}{$3 \mathrm{M}$} & \multirow{2}{*}{$\begin{array}{r}\text { Average } \\
\text { Conc }\end{array}$} \\
\hline & & $\mathrm{Ct}$ & Conc & $\mathrm{Ct}$ & Conc & $\mathrm{Ct}$ & Conc & $\mathrm{Ct}$ & Conc & \\
\hline Pomacentridae & damselfishes & 234 & 364.47 & 220 & 348.39 & 119 & 171.30 & 141 & 224.27 & 277.11 \\
\hline Myctophidae & 'lanternfishes & 70 & 107.23 & 23 & 36.63 & 260 & 375.20 & 261 & 412.51 & 232.89 \\
\hline Salariinae & blennies & 245 & 379.76 & 49 & 76.86 & 95 & 140.04 & 88 & 137.24 & 183.47 \\
\hline 'Schindleria spp. & infantfishes & 145 & 218.48 & 95 & 153.72 & 85 & 124.08 & 110 & 174.58 & 167.72 \\
\hline Gobiidae & gobies & 51 & 78.04 & 93 & 146.20 & 55 & 79.48 & 90 & 142.28 & 111.50 \\
\hline Enneapterygius atriceps & Hawaiian triplefin & 234 & 368.16 & 42 & 67.28 & 1 & 1.58 & - & - n & 109.25 \\
\hline Cyclothone spp. & bristlemouths & 19 & 30.45 & 37 & 59.15 & " 78 & 113.00 & 90 & 140.52 & 85.78 \\
\hline Lampadena spp. & lanternfishes & 17 & 26.53 & 17 & 26.48 & 30 & 43.39 & 43 & 68.29 & 41.17 \\
\hline Carangidae & jacks & 4 & 5.83 & 24 & 38.07 & 30 & 41.31 & 26 & 40.75 & 31.49 \\
\hline Pristiapogon spp. & cardinalfishes & 24 & 37.45 & 13 & 20.74 & 13 & 19.88 & 11 & 17.62 & 23.93 \\
\hline Apogon spp. & cardinalfishes & 44 & 68.07 & 12 & 19.41 & - n & $=$ & 1 & 1.59 & 22.27 \\
\hline Diaphus spp. & headlightfishes & 7 & 11.21 & 3 & 4.55 & 20 & 28.50 & 23 & 35.83 & 20.02 \\
\hline Triphoturus nigrescens & highseas lampfish & 4 & 5.81 & 4 & 6.30 & 27 & 38.14 & 15 & 23.07 & 18.33 \\
\hline Decapterus spp. & scad & 1 & 1.66 & - & - & 36 & 50.34 & 11 & 17.26 & 17.31 \\
\hline larval fish - damaged & damaged larval fishes & 6 & 9.14 & 7 & 11.36 & 13 & 18.66 & 14 & 21.78 & 15.23 \\
\hline Ceratoscopelus townsendi & dogtooth lampfish" & 13 & 20.10 & 13 & 20.38 & 6 & 8.83 & "'7"' 7 & 10.75 & 15.02 \\
\hline Decapterus macarellus & mackerel scad & - & - & 5 & 7.50 & 12 & 18.12 & 16 & 24.59 & 12.55 \\
\hline Perciformes & Perciformes fishes & 3 & 4.97 & 4 & 6.32 & 10 & 15.47 & 8 & 12.46 & 9.81 \\
\hline larvae, yolksac & yolksac larvae & - & - & 3 & 4.80 & 5 & 7.58 & 8 & 12.88 & 6.32 \\
\hline Chaetodontidae & butterflyfishes & 2 & 3.31 & - & - & 4 & 6.23 & 9 & 14.56 & 6.03 \\
\hline "Priolepis spp. & gobies & 11 & 17.53 & 1 & 1.60 & 2 & 2.54 & 1 & 1.64 & 5.83 \\
\hline Lophiiformes/Tetraodontiformes & anglerfishes/puffers & 5 & 7.33 & 2 & 3.35 & 4 & 5.46 & 4 & 6.42 & 5.64 \\
\hline Scombridae & mackerels and tunas & 2 & 2.99 & 1 & 1.60 & 7 & 9.90 & 3 & 4.91 & 4.85 \\
\hline Epigonus spp. & deepwater cardinalfishes & - & - & - & - & 8 & 11.94 & 4 & 6.27 & 4.55 \\
\hline Mullidae & goatfishes & - & - & - & - & 6 & 9.47 & 3 & 4.83 & 3.57 \\
\hline Blenniidae & blennies & - & - & 7 & 10.96 & 1 & 1.65 & 1 & 1.55 & 3.54 \\
\hline Exocoetidae & flyingfishes & - & - & - & - & 9 & 12.84 & - & - & 3.21 \\
\hline Holocentridae & squirrelfishes and soldierfishes & 1 & 1.66 & - & - & 1 & 1.43 & 6 & 9.55 & 3.16 \\
\hline Gempylus serpens & snake mackerel & - & - & - & - & 4 & 6.23 & 4 & 6.36 & 3.15 \\
\hline Scorpaenidae & scorpion fishes & 1 & 1.66 & 1 & 1.60 & 4 & 5.78 & 2 & 3.23 & 3.07 \\
\hline Labridae & wrasses & - & - & 2 & 3.20 & 5 & 6.98 & 1 & 1.55 & 2.93 \\
\hline Selar crumenophthalmus & bigeye scad & - & - & - & - & 7 & 10.06 & - & - & 2.51 \\
\hline Sphyraena spp. & barracudas & - & - & - & - & 3 & 4.73 & 3 & 4.80 & 2.38 \\
\hline larval/post-larval fish & larval fishes & 1 & 1.53 & - & - & 1 & 1.27 & 4 & 6.36 & 2.29 \\
\hline Apogonidae & cardinalfishes & - & - & 2 & 3.12 & 3 & 3.97 & 1 & 1.55 & 2.16 \\
\hline Stomiiformes & stomioids & - & - & - & - & 3 & 4.12 & 2 & 3.18 & 1.83 \\
\hline Eviota spp. & gobies & - & - & - & - & 5 & 7.14 & - & - & 1.78 \\
\hline Diplophos spp. & lightfishes & 1 & 1.66 & - & - & - & - & 3 & 4.67 & 1.58 \\
\hline
\end{tabular}


Table A- 3 (continued). Baseline larval fish counts and average concentrations (\#/1000m ${ }^{3}$ ) for Survey 3, June 6 - 7, 2012.

\begin{tabular}{|c|c|c|c|c|c|c|c|c|c|c|}
\hline \multirow[b]{2}{*}{ Taxon } & \multirow[b]{2}{*}{ Common Name } & \multicolumn{2}{|c|}{ 1B } & \multicolumn{2}{|c|}{ 2B } & \multicolumn{2}{|c|}{ 3B } & \multicolumn{2}{|c|}{$3 \mathrm{M}$} & \multirow{2}{*}{$\begin{array}{r}\text { Average } \\
\text { Conc }\end{array}$} \\
\hline & & $\mathrm{Ct}$ & Conc & $\mathrm{Ct}$ & Conc & $\mathrm{Ct}$ & Conc & $\mathrm{Ct}$ & Conc & \\
\hline Pseudamiops diaphanes & transparent cardinalfish & 2 & 3.19 & 2 & 3.06 & - & - & - & - & 1.56 \\
\hline Ipnopidae & tripod fishes & - & - & 2 & 3.12 & 2 & 2.94 & - & - & 1.52 \\
\hline Thunnus spp. & tunas & - & - & - & - & 3 & 3.81 & 1 & 1.55 & 1.34 \\
\hline Coryphaena hippurus & common dolphinfish & - & - & - & - & 2 & 3.31 & 1 & 1.64 & 1.24 \\
\hline Gempylidae & snake mackerels & 1 & 1.66 & - & - & 1 & 1.58 & 1 & 1.61 & 1.21 \\
\hline Plagiotremus spp. & fangblennies & - & - & - & - & 1 & 1.65 & 2 & 3.19 & 1.21 \\
\hline Vinciguerria spp. & lightfishes & - & - & - now & - & 2 & 3.08 & 1 & 1.55 & 1.16 \\
\hline Cirrhitidae & hawkfishes & $\ldots$ & - & - & - & 1 & 1.43 & 2 & 3.15 & 1.14 \\
\hline Apogonidae/Gobiidae & cardinalfishes/gobies & 1 & 1.53 & 1 & 1.60 & 1 & 1.43 & - & - & 1.14 \\
\hline Bolinichthys spp. & lampfishes & - & - & - & - & 2 & 2.94 & 1 & 1.59 & 1.13 \\
\hline Bathygobius spp. & frillfin gobies & - & - & - & - & 1 & 1.43 & 2 & 3.09 & 1.13 \\
\hline Katsuwonus pelamis & skipjack tuna & - & - & - & - & 3 & 4.43 & - & - & 1.11 \\
\hline Gunnellichthys curiosus & curious wormfish & - & - & - & - & 2 & 3.30 & - & - & 0.82 \\
\hline Syngnathidae & pipefishes & - & - & 2 & 3.06 & - & - & - & - & 0.76 \\
\hline Gonostomatidae & bristlemouths & - & - & - & - & 1 & 1.43 & 1 & 1.59 & 0.76 \\
\hline Cubiceps spp. & cigarfishes & - & - & - & -. & 2 & 2.94 & - & - & 0.74 \\
\hline Malacosteinae & loosejaws & -"- & - & - & - & 1 & 1.27 & 1 & 1.59 & 0.72 \\
\hline Atherinomorus insularum & Hawaiian silverside & - & - & - & - & 2 & 2.70 & - & - & 0.67 \\
\hline Anthiinae & sea basses & - & - & - ne & - & 2 & 2.54 & - & - n & 0.63 \\
\hline Synodontidae & lizardfishes & 1 & 1.66 & - & - & - & - & - & - & 0.41 \\
\hline Anguilliformes & eels & - & - & - & - & 1 & 1.65 & - & - & 0.41 \\
\hline Cubiceps pauciradiatus & bigeye cigarfish & - & - & - & - & 1 & 1.65 & - & - & 0.41 \\
\hline Creediidae & burrowers & 1 & 1.64 & - & - & - & - & - & - & 0.41 \\
\hline Ostraciidae & trunkfishes & - & - & - & - & - & - & 1 & 1.64 & 0.41 \\
\hline Bothidae & lefteye flounders & - & - & 1 & 1.60 & - & - & - & - & 0.40 \\
\hline Scombroidei & albacores, mackerels, and tunas & - & - & - & - & - & - & 1 & 1.59 & 0.40 \\
\hline Asterropteryx semipunctata & halfspotted goby & - & - & - & - & 1 & 1.58 & - & - & 0.39 \\
\hline Melanostomiinae & scaleless black dragonfishes & - & - & - & - & - & - n & 1 & 1.55 & 0.39 \\
\hline Auxis spp. & frigate mackerels & - & - & - & - & 1 & 1.43 & - & - & 0.36 \\
\hline Clupeidae & herrings & - & - & - & - & 1 & 1.43 & - & (3) & 0.36 \\
\hline Encrasicholina spp. & anchovies & - & - & - & - & - & - & 1 & 1.42 & 0.36 \\
\hline Callionymidae & dragonets & - & - & - & - & 1 & 1.27 & - & - & 0.32 \\
\hline Lampanyctus nobilis & lanternfish & 1 & 1.18 & - & - & - & - n & - & - & 0.29 \\
\hline & Total Fishes: & 1,152 & & 688 & & 1,007 & & 1,031 & & \\
\hline fish eggs & fish eggs & 3,689 & $5,705.77$ & 3,685 & $5,775.85$ & 3,812 & $5,552.73$ & 6,352 & $9,588.64$ & $6,655.75$ \\
\hline
\end{tabular}


Table A- 4. Baseline larval fish counts and average concentrations (\#/1000m ${ }^{3}$ ) for Survey 4, July 11 - $12,2012$.

\begin{tabular}{|c|c|c|c|c|c|c|c|c|c|c|}
\hline Taxon & Common Name & $\mathrm{Ct}$ & Conc & $\mathrm{Ct}$ & Conc & $\mathrm{Ct}$ & Conc & $\mathrm{Ct}$ & Conc & Conc \\
\hline Schindleria spp. & infantfishes & 1,926 & $3,038.42$ & 1,898 & $2,953.59$ & 1,239 & $1,787.48$ & 618 & 962.94 & $2,185.61$ \\
\hline Gobiidae & gobies & 125 & 191.15 & 440 & 683.44 & 231 & 331.67 & 202 & 307.43 & 378.42 \\
\hline Enneapterygius atriceps & Hawaiian triplefin & 700 & $1,095.42$ & 23 & 35.99 & 7 & 9.88 & 28 & 42.96 & 296.06 \\
\hline Salariinae & blennies & 167 & 254.65 & 11 & 16.86 & 17 & 24.33 & 61 & 98.22 & 98.51 \\
\hline Myctophidae & lanternfishes & 65 & 99.06 & 61 & 95.18 & 53 & 79.45 & 67 & 104.70 & 94.60 \\
\hline Pomacentridae & damselfishes & 62 & 94.75 & 32 & 49.51 & 22 & 29.68 & 37 & 57.57 & 57.88 \\
\hline Cyclothone spp. & bristlemouths & 28 & 42.68 & 37 & 58.00 & 40 & 57.10 & 34 & 54.20 & 52.99 \\
\hline Scombridae & mackerels and tunas & 12 & 18.73 & 13 & 20.62 & 7 & 10.05 & 18 & 26.29 & 18.92 \\
\hline larvae, yolksac & yolksac larvae & 4 & 6.17 & 16 & 24.81 & 10 & 14.31 & 13 & 20.42 & 16.43 \\
\hline Vinciguerria spp. & lightfishes & 6 & 9.07 & 6 & 9.33 & 13 & 18.83 & 17 & 27.17 & 16.10 \\
\hline Pristiapogon spp. & cardinalfishes & 15 & 22.86 & 9 & 13.71 & 7 & 9.17 & 9 & 13.67 & 14.85 \\
\hline Triphoturus nigrescens & highseas lampfish & 6 & 9.27 & 6 & 9.38 & 9 & 12.60 & 15 & 23.24 & 13.62 \\
\hline larval fish - damaged & damaged larval fishes & 4 & 5.89 & 11 & 16.68 & 6 & 8.95 & 14 & 21.39 & 13.22 \\
\hline Cubiceps spp. & cigarfishes & 6 & 9.05 & 7 & 11.12 & 8 & 11.03 & 5 & 7.99 & 9.80 \\
\hline Diaphus spp. & headlightfishes & 4 & 5.89 & 11 & 16.96 & 4 & 6.01 & 4 & 5.97 & 8.71 \\
\hline Decapterus macarellus & mackerel scad & 11 & 16.70 & 1 & 1.61 & 4 & 5.54 & 5 & 7.59 & 7.86 \\
\hline Priolepis spp. & gobies & 5 & 7.57 & 6 & 9.46 & 4 & 5.87 & 1 & 1.64 & 6.13 \\
\hline Carangidae & jacks & 3 & 4.56 & 2 & 3.15 & 4 & 5.31 & 6 & 9.60 & 5.66 \\
\hline Apogonidae/Gobiidae & cardinalfishes/gobies & - & - & 2 & 3.14 & 2 & 3.04 & 9 & 14.10 & 5.07 \\
\hline Lampadena spp. & lanternfishes & 2 & 3.06 & 4 & 6.32 & 2 & 2.82 & 1 & 1.64 & 3.46 \\
\hline Pseudamiops diaphanes & transparent cardinalfish & 7 & 10.57 & 1 & 1.57 & 1 & 1.23 & - & - & 3.34 \\
\hline Cubiceps pauciradiatus & bigeye cigarfish & - & - & $=$ & - & - & - & 7 & 11.00 & 2.75 \\
\hline larval/post-larval fish & larval fishes & - & - & 5 & 7.90 & 2 & 3.08 & - & - & 2.75 \\
\hline Apogonidae & cardinalfishes & 1 & 1.46 & 1 & 1.61 & 2 & 3.08 & 1 & 1.64 & 1.95 \\
\hline Katsuwonus pelamis & skipjack tuna & 1 & 1.50 & 3 & 4.62 & 1 & 1.39 & - & - & 1.88 \\
\hline Iso hawaiiensis & Hawaiian surf sardine & - & - & 2 & 2.96 & - & - & 2 & 3.11 & 1.52 \\
\hline Eviota spp. & gobies & - & - & 1 & 1.57 & 3 & 4.48 & - & - & 1.51 \\
\hline Apogon spp. & cardinalfishes & - & - & 1 & 1.57 & 3 & 4.27 & - & - & 1.46 \\
\hline Hygophum proximum & lanternfish & - & - & 2 & 3.18 & - & - & 1 & 1.64 & 1.20 \\
\hline Labridae/Scaridae & wrasses/parrotfishes & 3 & 4.66 & - & - & - & - & - & - & 1.17 \\
\hline Bathygobius spp. & frillfin gobies & 1 & 1.46 & - & - & 2 & 3.08 & - & - & 1.14 \\
\hline Percoidei & Percoidei fishes & - & - & 2 & 3.22 & - & - & - & - & 0.81 \\
\hline Stomiiformes & stomioids & - & - & 1 & 1.57 & - & - & 1 & 1.64 & 0.80 \\
\hline Howellidae & pelagic basslets & - & - & - & - & - & - & 2 & 3.19 & 0.80 \\
\hline Lampanyctus nobilis & lanternfish & - & - & 1 & 1.57 & 1 & 1.59 & - & - & 0.79 \\
\hline Blenniidae & blennies & - & - & 1 & 1.61 & - & - & 1 & 1.54 & 0.79 \\
\hline Bothidae & lefteye flounders & - & - & 2 & 3.14 & - & - & - & - & 0.79 \\
\hline Symbolophorus spp. & lanternfishes & - & - & - & - & $=$ & - & 2 & 3.11 & 0.78 \\
\hline
\end{tabular}


Table A- 4 (continued). Baseline larval fish counts and average concentrations (\#/1000m $\left.{ }^{3}\right)$ for Survey 4, July 11 - $12,2012$.

\begin{tabular}{|c|c|c|c|c|c|c|c|c|c|c|}
\hline \multirow[b]{2}{*}{ Taxon } & \multirow[b]{2}{*}{ Common Name } & \multicolumn{2}{|c|}{ 1B } & \multicolumn{2}{|c|}{ 2B } & \multicolumn{2}{|c|}{ 3B } & \multicolumn{2}{|c|}{$3 \mathrm{M}$} & \multirow{2}{*}{$\begin{array}{r}\text { Average } \\
\text { Conc }\end{array}$} \\
\hline & & $\mathrm{Ct}$ & Conc & $\mathrm{Ct}$ & Conc & $\mathrm{Ct}$ & Conc & $\mathrm{Ct}$ & Conc & \\
\hline Scorpaenidae & scorpion fishes & - & - & - & - & 2 & 3.08 & - & - & 0.77 \\
\hline Melanostomiinae & scaleless black dragonfishes & 1 & 1.50 & 1 & 1.57 & - & - & - & - & 0.77 \\
\hline 'Callionymidae & dragonets & - & - n & - & - & 1 & 1.39 & 1 & 1.64 & 0.76 \\
\hline Gonostomatidae & bristlemouths & - & - & 2 & 2.96 & - & - & - & - & 0.74 \\
\hline Encrasicholina spp. & anchovies & - & - n & - & - & 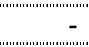 & - & 2 & 2.78 & 0.69 \\
\hline Evermannellidae & sabertooth fishes & - & 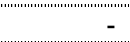 & - & - & - & - & 1 & 1.64 & 0.41 \\
\hline Syngnathidae & pipefishes & - & 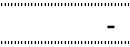 & - & - & 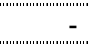 & - & 1 & 1.64 & 0.41 \\
\hline Lestidiops spp. & barracudina & - & - & 1 & 1.57 & "'"'"' - - & - & - & 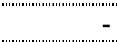 & 0.39 \\
\hline Phosichthyidae & lightfishes & - & - & 1 & 1.57 & - & - & - & - & 0.39 \\
\hline Decapterus spp. & scad & - & - & 1 & 1.57 & - & - & - & - n & 0.39 \\
\hline Perciformes & Perciformes fishes & - & - & 1 & 1.57 & - & - & - & - & 0.39 \\
\hline Asterropteryx semipunctata & halfspotted goby & - & - & 1 & 1.53 & - & - & - & 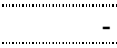 & 0.38 \\
\hline Gunnellichthys curiosus & curious wormfish & - & - & 1 & 1.53 & - & - & - & - & 0.38 \\
\hline Stemonosudis spp. & barracudinas & - & - & 1 & 1.53 & - & - & - & - & 0.38 \\
\hline Hygophum reinhardtii & slender lanternfish & 1 & 1.52 & - & - & - & - & - & - n & 0.38 \\
\hline Synodontidae & lizardfishes & 1 & 1.46 & - & - & - & - & - & - & 0.37 \\
\hline Atherinomorus insularum & "'Hawaiian silverside & - & - & - & - & "'1"'t' & 1.39 & - & - & 0.35 \\
\hline & Total Fishes: & 3,167 & & 2,629 & & 1,708 & & 1,186 & & \\
\hline fish eggs & fish eggs & 4,246 & $6,486.36$ & 7,430 & $11,573.76$ & 3,886 & $5,722.08$ & 5,103 & $8,033.11$ & $7,953.83$ \\
\hline
\end{tabular}


Table A- 5. Baseline larval fish counts and average concentrations (\#/1000m³) for Survey 5, August 1 - $2,2012$.

\begin{tabular}{|c|c|c|c|c|c|c|c|c|c|c|}
\hline \multirow[b]{2}{*}{ Taxon } & \multirow[b]{2}{*}{ Common Name } & \multicolumn{2}{|c|}{ 1B } & \multicolumn{2}{|c|}{ 2B } & \multicolumn{2}{|c|}{$3 B$} & \multicolumn{2}{|c|}{$3 \mathrm{M}$} & \multirow{2}{*}{$\begin{array}{r}\text { Average } \\
\text { Conc }\end{array}$} \\
\hline & & $\mathrm{Ct}$ & Conc & $\mathrm{Ct}$ & Conc & $\mathrm{Ct}$ & Conc & $\mathrm{Ct}$ & Conc & \\
\hline Schindleria spp. & infantfishes & 458 & 697.56 & 1,220 & $1,761.20$ & 884 & $1,278.65$ & 1,060 & $1,598.30$ & $1,333.93$ \\
\hline Salariinae & blennies & 590 & 920.54 & 1,036 & $1,500.42$ & 272 & 407.88 & 215 & 329.49 & 789.58 \\
\hline Gobiidae & gobies & 476 & 732.26 & 768 & $1,127.10$ & 432 & 600.90 & 449 & 662.87 & 780.78 \\
\hline Pomacentridae & damselfishes & 536 & 828.90 & 496 & 722.92 & 228 & 336.70 & 217 & 329.97 & 554.63 \\
\hline Enneapterygius atriceps & Hawaiian triplefin & 466 & 721.10 & 136 & 197.73 & 140 & 209.18 & 116 & 181.09 & 327.28 \\
\hline 'Pristiapogon spp. & cardinalfishes & 84 & 129.25 & 100 & 145.06 & 46 & 69.13 & 32 & 48.18 & 97.91 \\
\hline Apogon spp. & cardinalfishes & 98 & 151.76 & 64 & 92.03 & 32 & 46.67 & 29 & 43.43 & 83.47 \\
\hline Myctophidae & lanternfishes & 32 & 48.86 & 48 & 69.21 & 28 & 41.79 & 35 & 54.17 & 53.51 \\
\hline Perciformes & Perciformes fishes & 16 & 24.61 & 32 & 49.32 & 36 & 50.85 & 29 & 43.44 & 42.06 \\
\hline Cyclothone spp. & bristlemouths & 24 & 36.77 & 12 & 16.90 & 28 & 42.25 & 43 & 64.38 & 40.07 \\
\hline larval fish - damaged & damaged larval fishes & 28 & 43.40 & 40 & 60.42 & 4 & 5.48 & 24 & 35.77 & 36.27 \\
\hline 'Diaphus spp. & headlightfishes & 22 & 33.16 & 16 & 24.18 & 26 & 36.20 & 30 & 43.68 & 34.30 \\
\hline Apogonidae & cardinalfishes & 14 & 21.33 & 4 & 5.38 & 18 & 25.89 & 39 & 56.16 & 27.19 \\
\hline Priolepis spp. & gobies & 28 & 42.94 & 24 & 34.74 & 10 & 15.11 & 5 & 7.91 & 25.18 \\
\hline larvae, yolksac & yolksac larvae & 10 & 15.30 & 16 & 23.61 & 12 & 17.87 & 10 & 14.53 & 17.83 \\
\hline larval/post-larval fish & larval fishes & 14 & 21.05 & 8 & 11.52 & 6 & 8.10 & 18 & 26.66 & 16.83 \\
\hline Cirrhitidae & hawkfishes & 8 & 12.60 & 4 & 6.26 & 4 & 6.21 & 20 & 29.50 & 13.64 \\
\hline Lampadena spp. & lanternfishes & - & - & - & - & 20 & 29.00 & 15 & 23.37 & 13.09 \\
\hline Triphoturus nigrescens & highseas lampfish & 2 & 3.00 & 8 & 11.54 & 10 & 15.03 & 11 & 16.26 & 11.46 \\
\hline Vinciguerria spp. & lightfishes & 4 & 6.02 & 16 & 23.98 & 2 & 3.10 & 8 & 11.67 & 11.19 \\
\hline Pseudamiops diaphanes & transparent cardinalfish & 12 & 18.76 & 8 & 11.56 & 4 & 6.10 & 2 & 2.94 & 9.84 \\
\hline Decapterus macarellus & mackerel scad & 4 & 6.01 & - & - & - n & - & 22 & 32.49 & 9.62 \\
\hline Bathygobius spp." & frillfin gobies & 6 & 9.38 & - & - & 12 & 16.93 & 8 & 11.77 & 9.52 \\
\hline Scorpaenidae & scorpion fishes & 8 & 12.42 & 8 & 12.30 & 8 & 11.45 & - ne- & 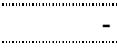 & 9.04 \\
\hline Synodontidae & lizardfishes & 4 & 6.23 & 12 & 18.68 & 4 & 5.48 & 4 & 5.59 & 9.00 \\
\hline Encrasicholina spp. & anchovies & 2 & 3.00 & - & - & 10 & 14.39 & 6 & 9.07 & 6.62 \\
\hline Balistidae & triggerfishes & 2 & 3.04 & 4 & 5.83 & 4 & 4.99 & 8 & 11.88 & 6.44 \\
\hline Lophiiformes/Tetraodontiformes & anglerfishes/puffers & 2 & 3.04 & 8 & 12.42 & 4 & 5.97 & 1 & 1.59 & 5.75 \\
\hline Callionymidae & dragonets & - & - & 8 & 10.75 & 4 & 5.80 & 4 & 5.59 & 5.54 \\
\hline Syngnathidae & pipefishes & 6 & 9.28 & 4 & 5.83 & - & - & 2 & 3.00 & 4.53 \\
\hline Carangidae & jacks & 2 & 3.04 & - & - & 6 & 8.96 & 4 & 5.94 & 4.49 \\
\hline Cubiceps pauciradiatus & bigeye cigarfish & 2 & 3.00 & - & - & 8 & 11.28 & 2 & 3.13 & 4.35 \\
\hline Iso hawaiiensis & Hawaiian surf sardine & - & - & 12 & 16.13 & - & - & - & (n) & 4.03 \\
\hline Gunnellichthys curiosus & curious wormfish & - & - & 4 & 6.16 & 4 & 5.97 & 1 & 1.59 & 3.43 \\
\hline Ammodytidae & sand lances & 4 & 6.01 & - & - & - & - & 4 & 6.13 & 3.03 \\
\hline Apogonidae/Gobiidae & cardinalfishes/gobies & - & - n & 4 & 5.83 & 4 & 6.21 & - & - & 3.01 \\
\hline Clupeidae & herrings & - & - & 4 & 5.38 & 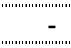 & - & 4 & 6.13 & 2.88 \\
\hline Creediidae & burrowers & - & "'-"'- & 4 & 6.16 & "'"'-"' & - & 2 & 3.00 & 2.29 \\
\hline
\end{tabular}


Table A- 5(continued). Baseline larval fish counts and average concentrations (\#/1000m³) for Survey 5, August 1 - $2,2012$.

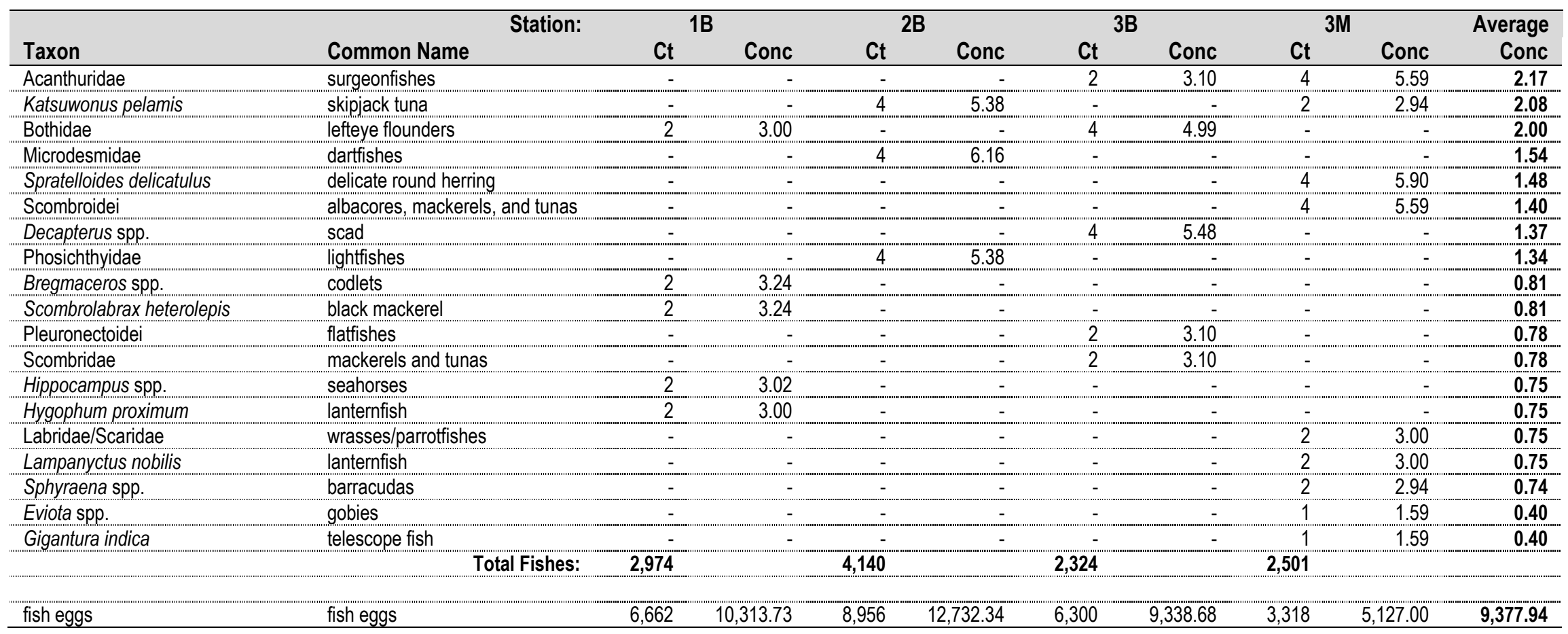


Table A- 6. Baseline larval fish counts and average concentrations $\left(\# / 1000 \mathrm{~m}^{3}\right)$ for Survey 6, September 5 - 6, 2012.

\begin{tabular}{|c|c|c|c|c|c|c|c|c|c|c|}
\hline \multirow[b]{2}{*}{ Taxon } & \multirow[b]{2}{*}{ Common Name } & \multicolumn{2}{|c|}{ 1B } & \multicolumn{2}{|c|}{$2 B$} & \multicolumn{2}{|c|}{ 3B } & \multicolumn{2}{|c|}{$3 \mathrm{M}$} & \multirow{2}{*}{$\begin{array}{r}\text { Average } \\
\text { Conc }\end{array}$} \\
\hline & & $\mathrm{Ct}$ & Conc & $\mathrm{Ct}$ & Conc & $\mathrm{Ct}$ & Conc & $\mathrm{Ct}$ & Conc & \\
\hline Salariinae & blennies & 1,043 & $1,684.88$ & 232 & 346.48 & 445 & 669.97 & 331 & 505.74 & 801.77 \\
\hline Pomacentridae & damselfishes & 286 & 461.10 & 395 & 592.53 & 353 & 533.33 & 321 & 487.63 & 518.65 \\
\hline Gobiidae & gobies & 175 & 277.82 & 290 & 431.39 & 383 & 570.13 & 228 & 364.13 & 410.87 \\
\hline Schindleria spp. & infantfishes & 234 & 373.77 & 306 & 458.55 & 255 & 380.39 & 191 & 307.35 & 380.01 \\
\hline Enneapterygius atriceps & Hawaiian triplefin & 522 & 848.63 & 60 & 86.88 & 36 & 54.03 & 10 & 15.71 & 251.31 \\
\hline Carangidae & jacks & 8 & 12.59 & 185 & 279.82 & 131 & 193.96 & 86 & 131.46 & 154.46 \\
\hline Myctophidae & lanternfishes & 32 & 50.82 & 77 & 114.58 & 145 & 218.45 & 79 & 120.30 & 126.04 \\
\hline larvae, yolksac & yolksac larvae & 30 & 47.35 & 71 & 107.02 & 47 & 72.59 & 80 & 118.03 & 86.25 \\
\hline Pristiapogon spp... & cardinalfishes & 52 & 83.57 & 57 & 84.72 & 40 & 59.75 & 44 & ( & 73.54 \\
\hline Spratelloides delicatulus & delicate round herring & 68 & 107.61 & 37 & 53.82 & 12 & 17.99 & 8 & 12.32 & 47.93 \\
\hline larval fish - damaged & damaged larval fishes & 20 & 32.14 & 42 & 64.01 & 37 & 55.27 & 20 & 29.85 & 45.32 \\
\hline Apogon spp. & cardinalfishes & 50 & 79.11 & 21 & 30.79 & 18 & 27.14 & 20 & 30.99 & 42.01 \\
\hline Cyclothone spp. & bristlemouths & 26 & 41.24 & 20 & 29.84 & 25 & 37.50 & 24 & 36.20 & 36.19 \\
\hline Balistidae & triggerfishes & 2 & 3.27 & 10 & 14.24 & 35 & 52.77 & 42 & 61.44 & 32.93 \\
\hline Labridae & wrasses & 6 & 9.54 & 22 & 33.10 & 44 & 67.77 & 10 & 15.28 & 31.42 \\
\hline Triphoturus nigrescens & highseas lampfish & 6 & 9.54 & 23 & 34.09 & 25 & 37.07 & 24 & 36.30 & 29.25 \\
\hline Lampadena spp. & lanternfishes & 2 & 3.27 & 15 & 22.81 & 40 & 60.07 & 10 & 15.18 & 25.33 \\
\hline Scombridae & mackerels and tunas & 2 & 3.27 & 16 & 23.00 & 16 & 24.00 & 33 & 50.86 & 25.28 \\
\hline Diaphus spp. & headlightfishes & 2 & 3.04 & 26 & 39.62 & 22 & 33.47 & 12 & 18.68 & 23.70 \\
\hline Perciformes & Perciformes fishes & 4 & 6.54 & 14 & 20.87 & 33 & 46.71 & 12 & 17.74 & 22.97 \\
\hline larval/post-larval fish & larval fishes & 6 & 9.79 & 15 & 22.81 & 17 & 25.21 & 12 & 17.93 & 18.93 \\
\hline Cirrhitidae & hawkfishes & 2 & 3.25 & 7 & 11.40 & 17 & 25.49 & 19 & 29.94 & 17.52 \\
\hline Apogonidae & cardinalfishes & 14 & 21.72 & 3 & 4.42 & 7 & 10.97 & 17 & 26.67 & 15.95 \\
\hline Bathygobius spp. & frillfin gobies & - & - & 7 & 10.73 & 21 & 31.65 & 6 & 9.14 & 12.88 \\
\hline Eviota spp. & gobies & - & - & 4 & 6.43 & 13 & 17.74 & 8 & 12.70 & 9.22 \\
\hline Decapterus macarellus & mackerel scad & - & - & 22 & 33.54 & - & - & - & - & 8.38 \\
\hline Priolepis spp. & gobies & 14 & 22.11 & 2 & 2.92 & 3 & 4.98 & 2 & 2.97 & 8.24 \\
\hline Pseudamiops diaphanes & transparent cardinalfish & 8 & 12.75 & 11 & 16.89 & 2 & 2.99 & - & - & 8.16 \\
\hline Plagiotremus spp. & fangblennies & - & - & 7 & 11.40 & 2 & 2.99 & 8 & 12.11 & 6.63 \\
\hline Sphyraena spp. & barracudas & - & - & - & - & 17 & 25.30 & - & - & 6.33 \\
\hline Labridae/Scaridae & wrasses/parrotfishes & - & - & - & - & 16 & 23.94 & (3) - & 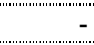 & 5.99 \\
\hline Cubiceps spp. & cigarfishes & 10 & 15.42 & - & - & 3 & 4.98 & - & - & 5.10 \\
\hline Callionymidae & dragonets & - & - & 12 & 17.16 & (n) & - & - & (3) - & 4.29 \\
\hline Diplophos spp. & lightfishes & - & 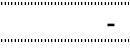 & 7 & 11.40 & 3 & 4.98 & (n) & (n) & 4.09 \\
\hline Clupeidae & herrings & 8 & 12.55 & - & - & 2 & 3.00 & - no & 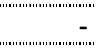 & 3.89 \\
\hline Lophiiformes/Tetraodontiformes & anglerfishes/puffers & 2 & 3.04 & - & - & 6 & 8.99 & 2 & 2.97 & 3.75 \\
\hline Blenniidae & blennies & - & ........ & - & - & 9 & 14.32 & - & 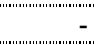 & 3.58 \\
\hline Scaridae & parrotfishes & - & 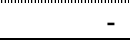 & - & - & 9 & 14.32 & - & '"' & 3.58 \\
\hline
\end{tabular}


Table A- 6(continued). Baseline larval fish counts and average concentrations $\left(\# / 1000 \mathrm{~m}^{3}\right)$ for Survey 6, September 5 - 6, 2012.

\begin{tabular}{|c|c|c|c|c|c|c|c|c|c|c|}
\hline \multirow[b]{2}{*}{ Taxon } & \multirow[b]{2}{*}{ Common Name } & \multicolumn{2}{|c|}{ 1B } & \multicolumn{2}{|c|}{ 2B } & \multicolumn{2}{|c|}{ 3B } & \multicolumn{2}{|c|}{$3 \mathrm{M}$} & \multirow{2}{*}{$\begin{array}{r}\text { Average } \\
\text { Conc }\end{array}$} \\
\hline & & $\mathrm{Ct}$ & Conc & $\mathrm{Ct}$ & Conc & $\mathrm{Ct}$ & Conc & $\mathrm{Ct}$ & Conc & \\
\hline Gunnellichthys curiosus & curious wormfish & - & - & 4 & 6.43 & 2 & 2.99 & 2 & 2.97 & 3.10 \\
\hline Scorpaenidae & scorpion fishes & - & - & - & - & 4 & 5.99 & 4 & 6.16 & 3.04 \\
\hline Selar crumenophthalmus & bigeye scad & - & - n & 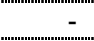 & - & 9 & 11.83 & 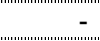 & - n & 2.96 \\
\hline Encrasicholina spp. & anchovies & - & - & - & - & 4 & 5.91 & 4 & (3.64 & 2.89 \\
\hline Epigonus spp. & deepwater cardinalfishes & - & - & 7 & 10.73 & - & - & - & - n & 2.68 \\
\hline Priacanthidae & bigeyes & - & - & 7 & 10.73 & 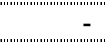 & - & (3) & - na & 2.68 \\
\hline Thunnus spp. & tunas & - & - & 7 & 10.73 & - n & - & - n & 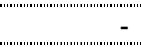 & 2.68 \\
\hline Stomiformes & stomioids & - & - & - & - & 6 & 9.95 & - & (') & 2.49 \\
\hline Vinciguerria spp. & lightfishes & - & - & - & - & 4 & 6.18 & - & - n & 1.55 \\
\hline Decapterus spp. & scad & - & - & - & - & 4 & 5.91 & - & - & 1.48 \\
\hline Exocoetidae & flyingfishes & - & - & - & - & 4 & 5.91 & - & - & 1.48 \\
\hline Elopomorpha & fishes & - & - & - & - & 3 & 4.98 & - & (3) & 1.24 \\
\hline Cubiceps pauciradiatus & bigeye cigarfish & - & - & 1 & 1.54 & $=$ & - & 2 & 2.97 & 1.13 \\
\hline Apogonidae/Gobiidae & cardinalfishes/gobies & - & - & 1 & 1.38 & 2 & 2.99 & - n & - n & 1.09 \\
\hline Syngnathidae & pipefishes & - & - & - & - & 2 & 3.00 & - & (') & 0.75 \\
\hline Ammodytidae & sand lances & - & - & - & - & 2 & 2.99 & - & 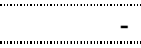 & 0.75 \\
\hline Coryphaena hippurus & common dolphinfish & - & - & - & - & - & - & 2 & 2.97 & 0.74 \\
\hline \multirow[t]{2}{*}{ Atherinomorus insularum } & Hawaiian silverside & - & - & 1 & 1.54 & - & - & - & - n & 0.39 \\
\hline & Total Fishes: & 2,632 & & 2,044 & & 2,336 & & 1,670 & & \\
\hline fish eggs & fish eggs & 10,800 & $17,388.70$ & 9,190 & $13,740.24$ & 13,580 & $20,336.25$ & 12,404 & $19,684.83$ & $17,787.50$ \\
\hline
\end{tabular}


Table A- 7. Baseline larval fish counts and average concentrations $\left(\# / 1000 \mathrm{~m}^{3}\right)$ for Survey 7 , October 3 - 4, 2012.

\begin{tabular}{|c|c|c|c|c|c|c|c|c|c|c|}
\hline \multirow[b]{2}{*}{ Taxon } & \multirow[b]{2}{*}{ Common Name } & \multicolumn{2}{|c|}{$1 \mathrm{~B}$} & \multicolumn{2}{|c|}{ 2B } & \multicolumn{2}{|c|}{$3 B$} & \multicolumn{2}{|c|}{$3 \mathrm{M}$} & \multirow{2}{*}{$\begin{array}{r}\text { Average } \\
\text { Conc }\end{array}$} \\
\hline & & $\mathrm{Ct}$ & Conc & $\mathrm{Ct}$ & Conc & $\mathrm{Ct}$ & Conc & $\mathrm{Ct}$ & Conc & \\
\hline Salariinae & blennies & 384 & 600.95 & 116 & 158.34 & 122 & 169.84 & 55 & 87.05 & 254.04 \\
\hline Enneapterygius atriceps & Hawaiian triplefin & 378 & 601.94 & 17 & 22.26 & 115 & 173.76 & 4 & 6.08 & 201.01 \\
\hline Schindleria spp. & infantfishes & 71 & 112.05 & 44 & 55.52 & 69 & 99.85 & 22 & 36.12 & 75.88 \\
\hline Cyclothone spp. & bristlemouths & 34 & 53.99 & 30 & 42.55 & 21 & 28.77 & 73 & 112.13 & 59.36 \\
\hline Myctophidae & lanternfishes & 49 & 77.86 & 27 & 37.27 & 20 & 24.55 & 63 & 97.65 & 59.33 \\
\hline Gobiidae & gobies & 81 & 128.71 & 13 & 17.05 & 36 & 51.05 & 9 & 13.63 & 52.61 \\
\hline Pomacentridae & damselfishes & 19 & 30.28 & 32 & 43.75 & 51 & 71.79 & 35 & 54.34 & 50.04 \\
\hline larvae, yolksac & yolksac larvae & 17 & 27.84 & 31 & 43.00 & 20 & 26.79 & 52 & - & 44.75 \\
\hline Spratelloides delicatulus & delicate round herring & 50 & 79.01 & 8 & 9.97 & 8 & 11.50 & 7 & 10.69 & 27.79 \\
\hline Carangidae & jacks & 7 & 10.39 & 11 & 15.15 & 8 & 11.07 & 23 & 36.01 & 18.16 \\
\hline Apogon spp. & cardinalfishes & 13 & 20.16 & 9 & 12.18 & 13 & 17.97 & 9 & 15.08 & 16.35 \\
\hline Pristiapogon spp. & cardinalfishes & 4 & 6.41 & 16 & 23.12 & 15 & 21.61 & 8 & 12.13 & 15.82 \\
\hline Perciformes & Perciformes fishes & 26 & 41.16 & 2 & 2.90 & 3 & 3.97 & 1 & (n) & 12.40 \\
\hline 'Diaphus spp. & headlightfishes & 14 & 22.40 & 1 & 1.34 & 1 & 1.57 & 9 & 13.92 & 9.81 \\
\hline larval fish - damaged & damaged larval fishes & 7 & 10.76 & 3 & 4.09 & 1 & 1.42 & 7 & 10.54 & 6.70 \\
\hline Lophiiformes/Tetraodontiformes & anglerfishes/puffers & - & - & 3 & 4.19 & 10 & 14.41 & 3 & 4.47 & 5.77 \\
\hline Vinciguerria spp. & lightfishes & 3 & 5.44 & - & - & 5 & 6.79 & 7 & 10.61 & 5.71 \\
\hline Priolepis spp. & gobies & 6 & 9.43 & 2 & 2.70 & 1 & 1.42 & 1 & 1.47 & 3.76 \\
\hline Iso hawaiiensis & Hawaiian surf sardine & - & - & 11 & 13.78 & - & - & - & - & 3.45 \\
\hline Lampadena spp. & lanternfishes & - & 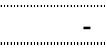 & 4 & 5.39 & - n l- & - & 5 & 7.62 & 3.25 \\
\hline Clupeidae & herrings & 6 & 10.21 & - & - & - & - & - & - & 2.55 \\
\hline Apogonidae & cardinalfishes & - & - & 4 & 5.32 & 1 & 1.57 & 2 & 2.95 & 2.46 \\
\hline Hygophum proximum & lanternfish & 3 & 5.44 & 3 & 4.06 & - & - & - & - & 2.37 \\
\hline Diplophos spp. & lightfishes & - & - & 1 & 1.56 & 4 & 5.40 & 1 & 1.47 & 2.11 \\
\hline Lampanyctus nobilis & lanternfish & - & - & - & - & 3 & 3.83 & 3 & 4.47 & 2.08 \\
\hline Coryphaena hippurus & common dolphinfish & - & - & - & - & "'+"1 & 1.57 & 4 & 6.31 & 1.97 \\
\hline Pseudamiops diaphanes & transparent cardinalfish & - & - & 1 & 1.18 & - & - & 4 & 6.00 & 1.80 \\
\hline Gonostomatidae & bristlemouths & - & 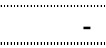 & 3 & 3.66 & 2 & 1.95 & 1 & 1.54 & 1.79 \\
\hline Plagiotremus spp. & fangblennies & 2 & 3.21 & - & $=$ & 3 & 3.83 & - & - & 1.76 \\
\hline Labridae & wrasses & - & - & 2 & 2.58 & 1 & 0.97 & 2 & 3.01 & 1.64 \\
\hline Triphoturus nigrescens & highseas lampfish & 2 & 2.38 & - & - & 1 & 0.97 & 2 & 3.01 & 1.59 \\
\hline Callionymidae & dragonets & - & - & 1 & 1.56 & - & - & 3 & 4.48 & 1.51 \\
\hline Apogonidae/Gobiidae & cardinalfishes/gobies & - & - & - & - & 4 & 5.58 & - & - & 1.39 \\
\hline Gunnellichthys curiosus & curious wormfish & 2 & 2.38 & - & - & - & - & 2 & 3.08 & 1.37 \\
\hline Lestidiops spp. & barracudina & - & - & - & - & - & - & 3 & 4.58 & 1.14 \\
\hline Encrasicholina spp. & anchovies & - & - & - & - & 1 & 0.97 & 2 & 3.12 & 1.02 \\
\hline larval/post-larval fish & larval fishes & - & - & - & - & 1 & 1.75 & 1 & 1.58 & 0.83 \\
\hline Notosudidae & "waryfishes & - & "'-"'- & - & - & "'"'-"' & - & 2 & 3.08 & 0.77 \\
\hline
\end{tabular}


Table A- 7 (continued). Baseline larval fish counts and average concentrations $\left(\# / 1000 \mathrm{~m}^{3}\right)$ for Survey 7 , October 3 - 4, 2012.

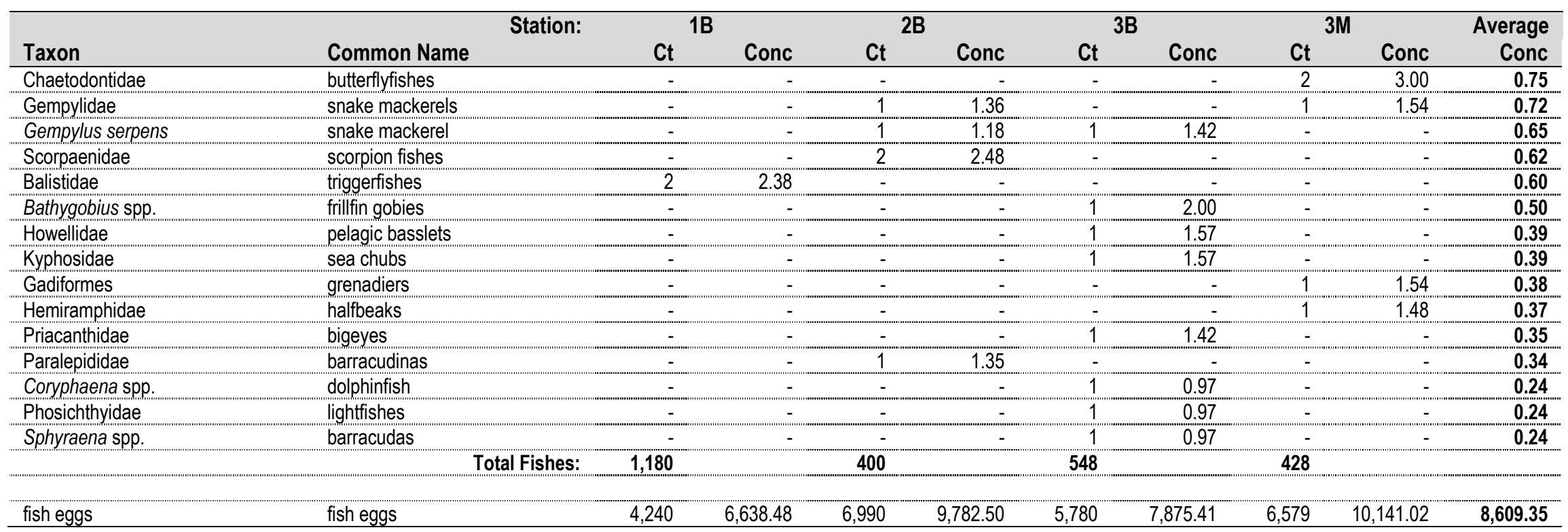


Table A- 8. Baseline larval fish counts and average concentrations $\left(\# / 1000 \mathrm{~m}^{3}\right)$ for Survey 8, November 7 - 8, 2012.

\begin{tabular}{|c|c|c|c|c|c|c|c|c|c|c|}
\hline \multirow[b]{2}{*}{ Taxon } & \multirow[b]{2}{*}{ Common Name } & \multicolumn{2}{|c|}{ 1B } & \multicolumn{2}{|c|}{ 2B } & \multicolumn{2}{|c|}{$3 B$} & \multicolumn{2}{|c|}{$3 \mathrm{M}$} & \multirow{2}{*}{$\begin{array}{r}\text { Average } \\
\text { Conc }\end{array}$} \\
\hline & & $\mathrm{Ct}$ & Conc & $\mathrm{Ct}$ & Conc & $\mathrm{Ct}$ & Conc & $\mathrm{Ct}$ & Conc & \\
\hline Encrasicholina spp. & anchovies & 158 & 239.15 & 521 & 809.35 & 742 & $1,094.31$ & 795 & $1,249.11$ & 847.98 \\
\hline Schindleria spp. & infantfishes & 402 & 599.84 & 308 & 463.62 & 280 & 428.51 & 94 & 149.51 & 410.37 \\
\hline Enneapterygius atriceps & Hawaiian triplefin & 302 & 460.90 & 85 & 124.37 & 7 & 10.17 & 2 & 3.23 & 149.67 \\
\hline Salariinae & blennies & 52 & 81.11 & 141 & 223.22 & 43 & 65.17 & 43 & 66.09 & 108.90 \\
\hline Pomacentridae & damselfishes & 34 & 52.10 & 72 & 113.38 & 32 & 48.62 & 52 & 80.98 & 73.77 \\
\hline Gobiidae & gobies & 58 & 90.14 & 18 & 28.73 & 62 & 92.60 & 24 & 38.06 & 62.38 \\
\hline Myctophidae & lanternfishes & 18 & 28.63 & 42 & 64.33 & 44 & 65.06 & 32 & 50.10 & 52.03 \\
\hline Carangidae & jacks & 32 & 49.67 & 30 & 47.52 & 8 & 12.23 & 28 & (4) & 38.36 \\
\hline larvae, yolksac & yolksac larvae & 32 & 48.96 & 20 & 30.92 & - & 22.40 & 27 & 42.09 & 36.09 \\
\hline Spratelloides delicatulus & delicate round herring & 6 & 9.16 & 4 & 6.36 & 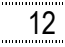 & 18.50 & 16 & 25.51 & 14.88 \\
\hline Scombridae & mackerels and tunas & 4 & 5.93 & 13 & 20.93 & ( & 10.09 & 10 & 15.43 & 13.10 \\
\hline Pomacanthidae & angelfishes & 4 & 6.56 & - & - & (n) & 18.39 & 17 & 26.71 & 12.92 \\
\hline larval fish - damaged & damaged larval fishes & - & - & 8 & 12.71 & 8 & 12.29 & 12 & 19.13 & 11.03 \\
\hline Labridae & wrasses & 10 & 16.35 & - & - & 4 & 6.10 & 6 & 10.15 & 8.15 \\
\hline Lophifformes/Tetraodontiformes & anglerfishes/puffers & 2 & 2.82 & 8 & 12.10 & 5 & 7.06 & 6 & 9.52 & 7.87 \\
\hline Hygophum proximum & lanternfish & - & - n & - & - & 4 & 6.10 & 12 & 19.15 & 6.31 \\
\hline Scorpaenidae & scorpion fishes & 2 & 2.82 & - & - & 6 & 9.19 & 8 & 12.74 & 6.19 \\
\hline Blenniidae & blennies & 8 & 13.12 & - & - & 6 & 9.36 & - & - & 5.62 \\
\hline Cyclothone spp. & bristlemouths & - & - & 10 & 15.84 & 2 & 3.15 & - & - & 4.75 \\
\hline Synodontidae & lizardfishes & 4 & 6.56 & - & - & - & - & 6 & 10.15 & 4.18 \\
\hline Diaphus spp. & headlightfishes & 4 & 5.93 & - & - & - & - & 6 & 10.15 & 4.02 \\
\hline Perciformes & Perciformes fishes & 6 & 9.59 & - & - & - & - & 4 & 6.41 & 4.00 \\
\hline Gunnellichthys curiosus & curious wormfish & 6 & 9.50 & - & - & 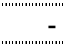 & - & 4 & 6.31 & 3.95 \\
\hline Pristiapogon spp. & cardinalfishes & 10 & 15.30 & - & - & - & - & - & - & 3.83 \\
\hline Symbolophorus spp. & lanternfishes & - & - & - & - & 3 & 3.96 & 6 & 10.15 & 3.53 \\
\hline Pseudamiops diaphanes & transparent cardinalfish & 4 & 6.47 & 4 & 6.35 & - & - & - & - & 3.20 \\
\hline Lampadena spp. & lanternfishes & - & - & - & - & - & - & 6 & 10.15 & 2.54 \\
\hline Vinciguerria spp. & lightfishes & - & - & 3 & 4.91 & 3 & 5.23 & - & - n & 2.53 \\
\hline larval/post-larval fish & larval fishes & - & - & 3 & 4.58 & 3 & 5.23 & - & - & 2.45 \\
\hline Bathygobius spp. & frillfin gobies & 4 & 6.06 & - & - & - & - & 2 & 3.15 & 2.30 \\
\hline Clupeidae & herrings & - & - & 4 & 5.75 & - & - & 2 & 3.23 & 2.25 \\
\hline Plagiotremus spp. & fangblennies & - & - & 4 & 5.75 & - & - & 2 & 3.23 & 2.25 \\
\hline Gempylidae & snake mackerels & 4 & 6.56 & - & - & - & 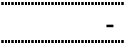 & 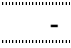 & 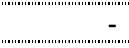 & 1.64 \\
\hline Nomeidae & drifffishes & 4 & 6.56 & - & - & 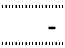 & - & - & 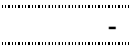 & 1.64 \\
\hline Epigonus spp. & deepwater cardinalfishes & - & (3) & - & - & - n & - & 4 & 6.41 & 1.60 \\
\hline Priolepis spp. & gobies & - & - n & - & - & - n & - & 4 & 6.41 & 1.60 \\
\hline Callionymidae & dragonets & - & - & - & - & - n & - & 4 & 6.37 & 1.59 \\
\hline Selar crumenophthalmus & bigeye scad & - & - & - & - & 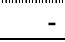 & - & 4 & 6.37 & 1.59 \\
\hline
\end{tabular}

Selar crumenophthalmus

bigeye scad

6.37

1.59 
Table A- 8 (continued). Baseline larval fish counts and average concentrations $\left(\# / 1000 \mathrm{~m}^{3}\right)$ for Survey 8 , November 7 - 8, 2012.

\begin{tabular}{|c|c|c|c|c|c|c|c|c|c|c|}
\hline \multirow[b]{2}{*}{ Taxon } & \multirow[b]{2}{*}{ Common Name } & \multicolumn{2}{|c|}{ 1B } & \multicolumn{2}{|c|}{ 2B } & \multicolumn{2}{|c|}{ 3B } & \multicolumn{2}{|c|}{$3 M$} & \multirow{2}{*}{$\begin{array}{r}\text { Average } \\
\text { Conc }\end{array}$} \\
\hline & & $\mathrm{Ct}$ & Conc & $\mathrm{Ct}$ & Conc & $\mathrm{Ct}$ & Conc & $\mathrm{Ct}$ & Conc & \\
\hline Mullidae & goatfishes & 4 & 5.84 & - & - & - & - & - & - & 1.46 \\
\hline Stomiformes & stomioids & 4 & 5.84 & - & - & (") & - & (3)'- & - n & 1.46 \\
\hline Atherinomorus insularum & Hawaiian silverside & - & - n & 4 & 5.75 & - n & - & (n) & - n & 1.44 \\
\hline Apogon spp. & cardinalfishes & - & - nan & - & - & 3 & 5.23 & - & 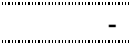 & 1.31 \\
\hline Melamphaes spp. & bigscales & - & - no & - & - & 3 & 5.23 & - ne & - n & 1.31 \\
\hline Scombroidei & albacores, mackerels, and tunas & - & - non & - & - & 3 & 5.23 & - no & - no & 1.31 \\
\hline Priacanthidae & bigeyes & - & - n lo & 3 & 5.09 & 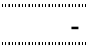 & - & - n & 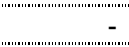 & 1.27 \\
\hline Lampanyctus nobilis & lanternfish & - & - & 3 & 4.91 & - n & - & - & (3) & 1.23 \\
\hline Balistidae & triggerfishes & - & - non & 3 & 4.58 & 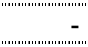 & - & - no & 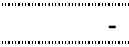 & 1.15 \\
\hline Exocoetidae & flyingfishes & - & - & - & - & 2 & 3.15 & - & (3) - & 0.79 \\
\hline Sphyraena spp. & barracudas & - & - n & - & - & 2 & 3.15 & - & - & 0.79 \\
\hline Diplophos spp. & lightfishes & - & - & - & - & 2 & 3.10 & - & - & 0.78 \\
\hline Syngnathidae & pipefishes & - & - & - & - & 2 & 3.10 & - & - & 0.78 \\
\hline & Total Fishes: & 1,178 & & 1,312 & & 1,331 & & 1,238 & & \\
\hline fish eggs & fish eggs & 2,734 & $4,269.14$ & 2,666 & $4,181.79$ & 4,816 & $7,363.10$ & 4,685 & $7,431.08$ & $5,811.28$ \\
\hline
\end{tabular}


Table A- 9. Baseline larval fish counts and average concentrations (\#/1000m $\left.{ }^{3}\right)$ for Survey 9, December 4, 2012.

\begin{tabular}{|c|c|c|c|c|c|c|c|c|c|c|}
\hline \multirow[b]{2}{*}{ Taxon } & \multirow[b]{2}{*}{ Common Name } & \multicolumn{2}{|c|}{ 1B } & \multicolumn{2}{|c|}{ 2B } & \multicolumn{2}{|c|}{$3 B$} & \multicolumn{2}{|c|}{$3 \mathrm{M}$} & \multirow{2}{*}{$\begin{array}{r}\text { Average } \\
\text { Conc }\end{array}$} \\
\hline & & $\mathrm{Ct}$ & Conc & $\mathrm{Ct}$ & Conc & $\mathrm{Ct}$ & Conc & $\mathrm{Ct}$ & Conc & \\
\hline Schindleria spp. & infantfishes & - & - & 24 & 73.09 & 62 & 151.75 & 38 & 121.97 & 86.70 \\
\hline Gobiidae & gobies & 8 & 25.95 & 28 & 85.19 & 24 & 64.30 & 35 & - & 71.75 \\
\hline Myctophidae & lanternfishes & 23 & 64.56 & 24 & 73.63 & 20 & 52.98 & 24 & ( & 67.07 \\
\hline 'Vinciguerria spp.' & lightfishes & 16 & 45.42 & 18 & 55.11 & 12 & 32.53 & 35 & 112.46 & 61.38 \\
\hline Enneapterygius atriceps & Hawaiian triplefin & 63 & 195.94 & 7 & 22.17 & - & - & 6 & - 18.54 & 59.16 \\
\hline Salariinae & blennies & - & - n & 4 & 12.65 & 4 & 11.64 & 5 & 15.96 & 10.06 \\
\hline Scorpaenidae & scorpion fishes & - & - & 1 & 3.13 & - & - & 8 & 25.52 & 7.16 \\
\hline Symbolophorus spp. & lanternfishes & - & - & 1 & 3.13 & 2 & 5.82 & 6 & 19.35 & 7.07 \\
\hline larvae, yolksac & yolksac larvae & 3 & 9.70 & 4 & 11.98 & 2 & 5.82 & - & 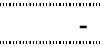 & 6.88 \\
\hline Diaphus spp. & headlightfishes & - & - & - & - & - & - & 6 & 19.35 & 4.84 \\
\hline Melamphaes spp. & bigscales & 2 & 6.55 & 2 & 6.25 & 2 & 5.82 & - & - & 4.66 \\
\hline larval/post-larval fish & larval fishes & - & - & 4 & 12.50 & 2 & 5.82 & - & 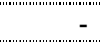 & 4.58 \\
\hline Paralepididae & barracudinas & 3 & 8.40 & 1 & 3.13 & 2 & 5.50 & - & - & 4.26 \\
\hline Hygophum proximum & lanternfish & 2 & 5.25 & - & - & 2 & 5.50 & - & - n & 2.69 \\
\hline Hygophum reinhardtii & slender lanternfish & - & - & - & - & 2 & 4.08 & 2 & 6.45 & 2.63 \\
\hline Pomacentridae & damselfishes & - & - & - & - & 2 & 5.50 & 1 & 3.10 & 2.15 \\
\hline Stomiiformes & stomioids & - & - & - & - & - & - & 2 & - 6.45 & 1.61 \\
\hline Ammodytidae & sand lances & - & - & 2 & 6.39 & - & - & - & - n & 1.60 \\
\hline Encrasicholina spp. & anchovies & - & - n la & - & - & 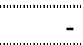 & - & 2 & - 6.17 & 1.54 \\
\hline Pseudamiops diaphanes & transparent cardinalfish & - & "."- & 2 & 5.99 & - & - & - & - & 1.50 \\
\hline Sudis atrox & fierce pike smelt & - & - & - & - & 2 & 5.82 & - & - & 1.45 \\
\hline Gunnellichthys curiosus & curious wormfish & - & - & - & - & 2 & 5.50 & - & - & 1.37 \\
\hline Lophiiformes/Tetraodontiformes & anglerfishes/puffers & 1 & 3.15 & - & - & - & - & - & - & 0.79 \\
\hline \multirow[t]{2}{*}{ Plagiotremus spp. } & fangblennies & 1 & 3.15 & - & - & - & - & 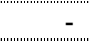 & - & 0.79 \\
\hline & Total Fishes: & 4,156 & & 4,195 & & 6,400 & & 6,264 & & \\
\hline fish eggs & fish eggs & 101 & 312.26 & 57 & 176.44 & 184 & 485.77 & 169 & 525.22 & 374.92 \\
\hline
\end{tabular}


Appendix B

DE-EE0002653

Appendix B. ALTERNATIVE WARM WATER INTAKE DESIGNS AND COSTS

B-1 


\section{ALTERNATIVE WARM WATER INTAKE DESIGNS AND COSTS FOR AN OTEC SITE UNDER DEVELOPMENT ON KAUAI, HI}

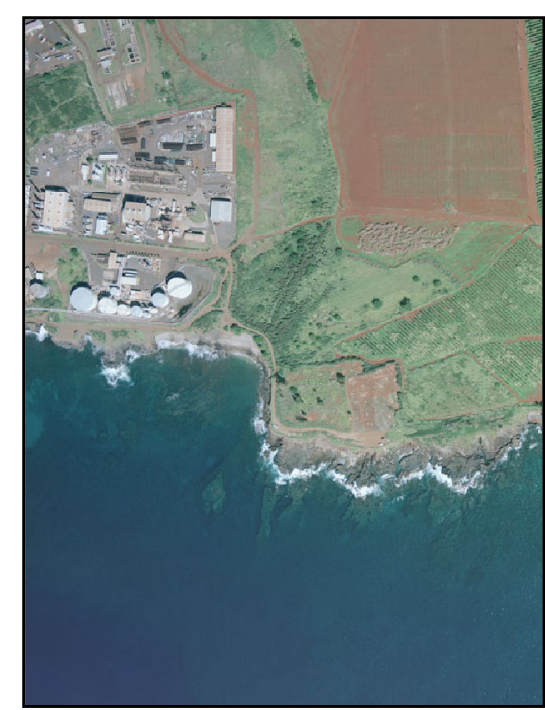

Submitted to:

U.S. Department of Energy

Golden Field Office

Award Number: DE-EE0002653

Submitted by:
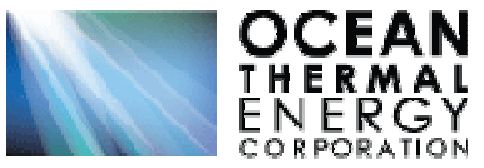

10432 Balls Ford Road

Suite 300/Office 322

Manassas, VA 20109
ALDEN Research Laboratory, Inc.

30 Shrewsbury Street Holden, MA 01520

May 2013 


\section{TABLE OF CONTENTS}

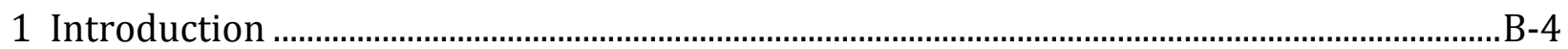

2 Offshore Velocity Cap Intake with Coarse-Mesh (9.5-mm) Modified Traveling Water Screens ...................................................................................................................................

3 Coarse-mesh (9.5-mm) Modified Traveling Water Screens with Onshore Intake..............B-9

4 Wide-slot (9.5-mm) Cylindrical Wedgewire Screens............................................................ B-13

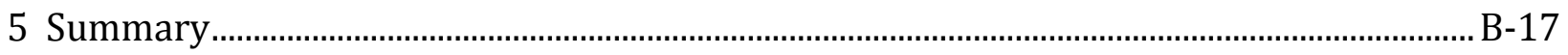

6 References................................................................................................................ B-18

\section{Table of Figures}

Figure B-1. Coarse-mesh Modified Traveling Water Screens with Offshore Velocity Cap (Plan). B-6

Figure B-2. Coarse-mesh Modified Traveling Water Screens with Offshore Velocity Cap (Sections). B-7

Figure B-3. Coarse-mesh Modified Traveling Water Screens with Onshore Intake (Plan).....B-10 Figure B-4. Coarse-mesh Modified Traveling Water Screens with Onshore Intake (Section).... B11

Figure B-5. Narrow-Slow Wedgewire Screen Intake (Plan)....................................................... B-14

Figure B-6. Wide-slot Wedgewire Screen Intake (Sections).................................................... B-15

\section{Table of Tables}

Table B-1. Summary Costs for Coarse-mesh Modified Traveling Water Screens with Offshore Velocity Cap. B-8

Table B-2. Summary Costs for Coarse-mesh Modified Traveling Water Screens with Onshore Intake. B-12

Table B-3. Summary Costs for Wide-slot Cylindrical Wedgewire Intake. B-16

Table B-4. Total Estimated Capital Costs of Intake Alternatives. B-17 


\section{Introduction}

There are currently no explicit regulations regarding organism screening for warm water intakes at OTEC facilities. The proposed regulations under Section 316(b) of the Clean Water Act (316(b)) provide a good estimate of what will be required since indications are that OTEC projects will also have to abide by 316(b). The uncertainty in OTEC intake regulation is whether future NOAA regulations would be more stringent than those established by 316(b). Section 316(b) requires fish protection on a site-specific basis and protection ranges from a reduction in impingement mortality only to a reduction in both impingement mortality and entrainment. The level of protection required at OTEC facilities is currently unknown until NOAA issues regulations; however, NOAA has recently released an OTEC Needs Assessment with the University of New Hampshire (CRRC 2012) which provides insight into anticipated requirements.

In the Interim Report (OCEES and Alden 2011, Appendix C), a conservative approach was used when preparing the three conceptual designs for the warm water intake. These designs were based on the most stringent 316(b) requirements to reduce both impingement and entrainment and incorporate features such as low intake velocities, small screening mesh size, and potential tunneling under coral in the nearshore environment. These features, while minimizing the environmental impact resulted in high costs for the warm water intake.

The focus of this addendum is to provide less conservative alternative intake designs that can be installed at a lower cost. The three new warm water intake designs presented in this addendum incorporate fish-friendly features that are consistent with the proposed 316 (b) regulations to reduce only impingement mortality, such as 3/8-inch (9.5-mm) mesh openings, no standard intake velocities, and fish-friendly screens. With a larger mesh size, these designs will not reduce the entrainment of smaller organisms through the facility.

Development of the costs for the three new designs used a similar methodology as the three designs presented in the Interim Report (OCEES and Alden 2011, Appendix C). These costs are based on preliminary designs and best available information. Site-specific investigations of the subsurface geology, ocean currents, and weather patterns are needed to better refine these estimates.

\section{Offshore Velocity Cap Intake with Coarse-Mesh (9.5-mm) Modified Traveling Water Screens}

The offshore velocity cap intake with coarse-mesh modified traveling water screen is designed to draw ocean water from approximately 1,000 ft offshore of the plant location in about $35 \mathrm{ft}$ of water. The offshore velocity cap acts as a fish protection measure by inducing a horizontal inflow vector that can be sensed and avoided by later life stages of fish (i.e., juveniles and adults). This behavioral barrier would reduce entrapment of fish and other organisms within the intake system but would not eliminate entrapment because 
there is no physical barrier to exclude fish from entering the velocity cap. After passing through the velocity cap, the seawater would flow down through the intake tunnels to the plant forebay, located on-shore. Once within the forebay, intake water would pass through a trash rack and modified traveling water screens before being drawn into the pumping system.

The design presented in this section varies from the design presented in the Interim Report (OCEES and Alden 2011, Appendix C). In this design a single velocity cap with a $10 \mathrm{ft}$ high by $55 \mathrm{ft}$ wide opening is proposed. This opening size results in a $2 \mathrm{ft} / \mathrm{sec}$ velocity at the mouth of the velocity cap. The shape of the velocity cap differs from a standard velocity cap because the intake pipes proposed with this option are connected directly to the cap and do not require a vertical header pipe. To prevent sand from entering the warm water intake the invert of the velocity cap was placed $5 \mathrm{ft}$ above the sea floor. The velocity cap can be seen in Figure B-1.

As with the previous design, two 14-ft inside diameter (ID) intake pipes will be used to convey flow from the velocity cap to the plant. Unlike the previous design, the intake pipes would be placed in a shallow trench on the ocean bottom instead of tunneled under the sea floor. This method was selected over tunneling to reduce the cost and level of effort required to install the pipes. Placing the pipes on the sea floor would impact reefs (if present) or other benthic habitat along the path of the pipe. The intake pipes would be installed by floating sections of pipe into their placement location and sinking them in place. Once the pipes are placed, the trench will be backfilled and covered in rip-rap to anchor and protect the pipes. This installation method is faster than tunneling but is more prone to delays caused by adverse ocean conditions. The proposed layout of the intake pipes is shown in Figure B-2.

The two intake pipes would terminate at a shared onshore forebay as shown in Figure B-2 The forebay provides a transition area for the flow before it passes through the trash rack and modified traveling water screens. Laying the intake pipes on the sea floor allows the pipes to be sloped up to the bottom of the forebay, because the invert of the forebay is assumed to be at El. $-30.0 \mathrm{ft}$, verses El. $-162.3 \mathrm{ft}$ in the previous design. This design includes headgates and stoplogs to control water flow and allow maintenance within the forebay. After approximately $50 \mathrm{ft}$, the forebay will transition into four screen bays. Across the face of each screen bay would be a trash rack to prevent passage of large debris. A single motorized trash rake would remove debris collected on the trash racks. Traveling water screens with fish protection features would be located behind the trash racks. The four modified traveling water screens would be $14 \mathrm{ft}$ wide and $51 \mathrm{ft}$ high. These screens would be equipped with $9.5-\mathrm{mm}$ mesh. Fine-mesh $(\leq 2.0-\mathrm{mm})$ was not used in this design because these screens are not intended to collect smaller, entrainable organisms. Including the head loss through the intake pipes, the velocity approaching the traveling screens would be $1.5 \mathrm{ft} / \mathrm{sec}$ at the mean low water level which is three times the approach velocity used in the Interim Report (OCEES and Alden 2011, Appendix C). 


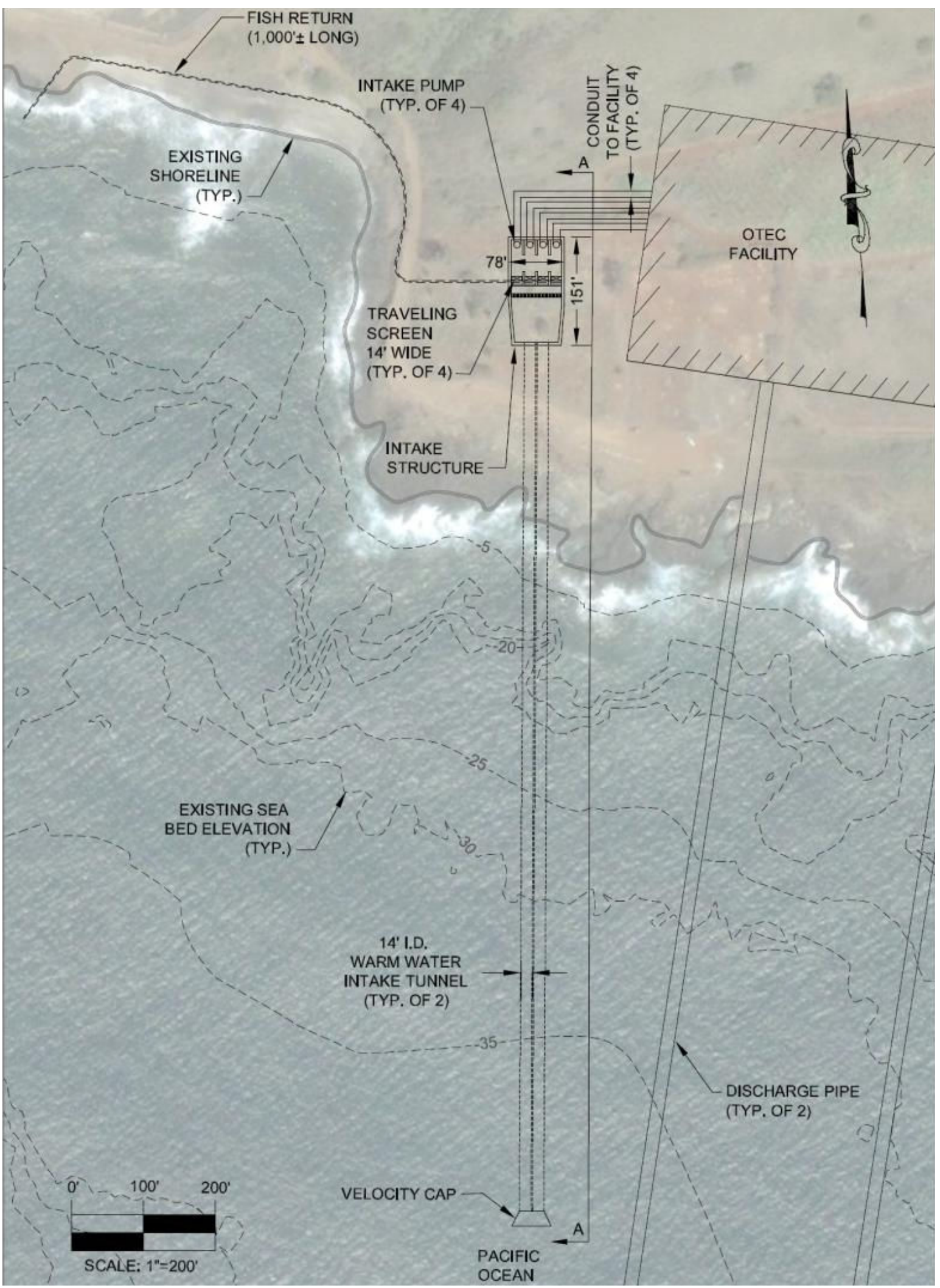

Figure B-1. Coarse-mesh Modified Traveling Water Screens with Offshore Velocity Cap (Plan). 


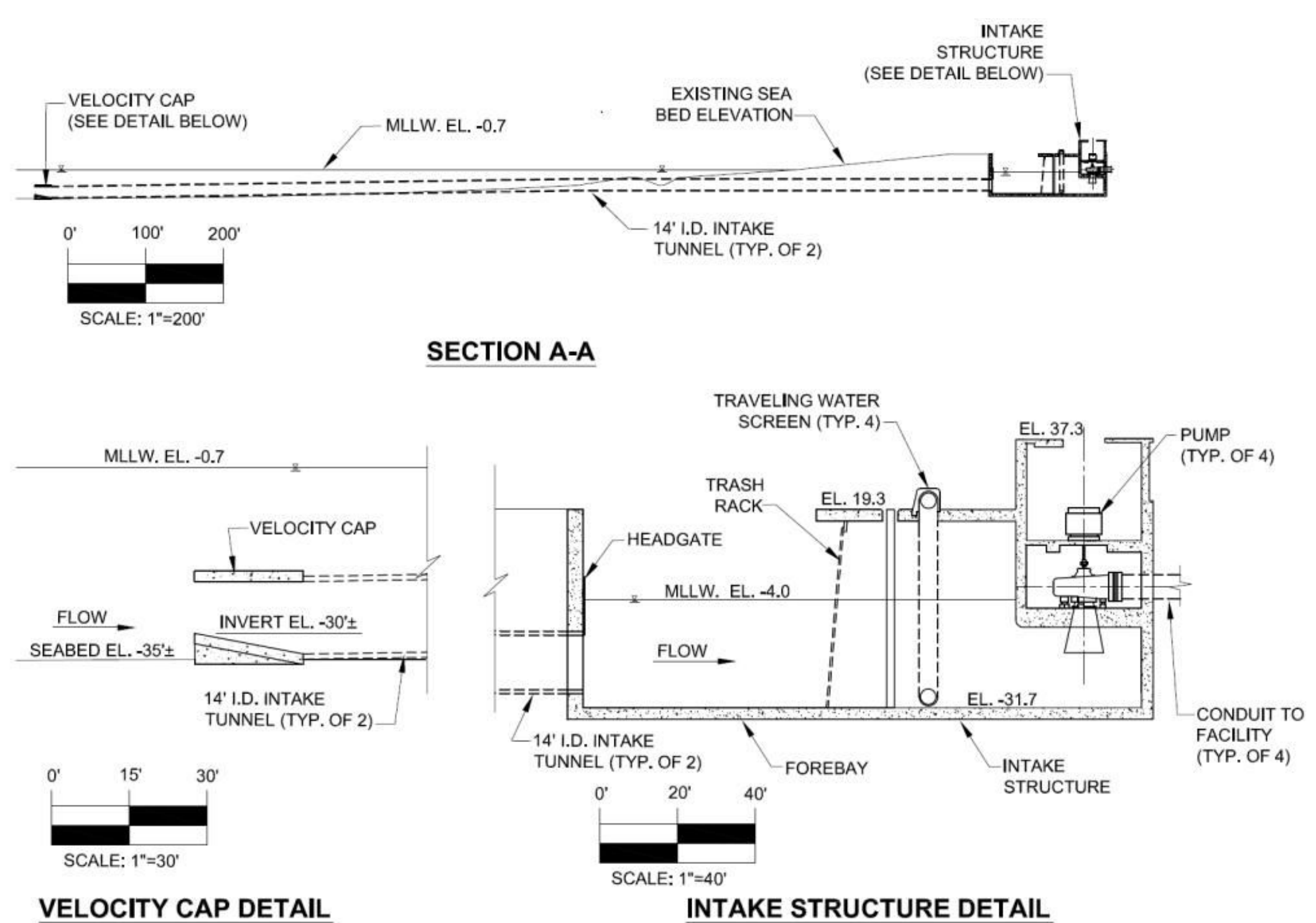

Figure B-2. Coarse-mesh Modified Traveling Water Screens with Offshore Velocity Cap (Sections). 
The major cost components of this intake alternative are itemized in Table B-1. Mobilization and demobilization are assumed to be $10 \%$ of the remaining direct costs. Major costs include: the construction and installation of the primary distribution pipes; construction of the forebay; as well as the traveling water screens themselves.

Table B-1. Summary Costs for Coarse-mesh Modified Traveling Water Screens with Offshore Velocity Cap.

\begin{tabular}{|lc|}
\hline Item & Estimated Cost \\
\hline Direct Costs & \\
Mobilization and Demobilization & $\$ 3,508,000$ \\
Tunnel Entrance & $\$ 2,136,000$ \\
Cofferdam \& Shoring & $\$ 236,000$ \\
Excavate Sea Floor & $\$ 960,000$ \\
Intake Pipe & $\$ 17,448,000$ \\
Forebay & $\$ 2,532,000$ \\
New Intake Structures including Access Roads & $\$ 2,744,000$ \\
Trash Rack & $\$ 650,000$ \\
Spraywash System & $\$ 192,000$ \\
Ristroph Coarse-Mesh Traveling Water Screens & $\$ 3,880,000$ \\
Fish and Debris Return System & $\$ 994,000$ \\
Velocity Cap & $\$ 281,000$ \\
Warm Water Pumps & $\$ 3,031,000$ \\
\hline Direct Costs (2013 \$) & $\$ 35,561,000$ \\
Indirect Costs, Taxes and Overhead and Profit & $\$ 8,535,000$ \\
Subtotal & $\$ 44,096,000$ \\
Allowance for Indeterminates/Contingencies & $\$ 11,024,000$ \\
\hline Total Estimated Project Costs (2013 \$) & $\$ \mathbf{5 5 , 1 2 0 , 0 0 0}$ \\
\hline
\end{tabular}




\section{$3 \quad$ Coarse-mesh (9.5-mm) Modified Traveling Water Screens with Onshore Intake}

As an alternative to the fine-mesh modified traveling water screens with an onshore intake in the Interim Report (OCEES and Alden 2011, Appendix C), an onshore intake with coarsemesh modified traveling water screens was evaluated. Coarse-mesh screens will only reduce impingement mortality, not entrainment of early life stages. In addition to using coarse-mesh screens, other changes in the design to reduce the cost include a $1.5 \mathrm{ft} / \mathrm{sec}$ approach velocity versus $0.5 \mathrm{ft} / \mathrm{sec}$ in the fine-mesh design, reduced excavation, and a smaller breakwater.

The proposed onshore intake is shown in Figure B-3. At this location, the intake is protected from the prevailing currents, generally from northwest to southeast (Firing and Brainard 2006), by the peninsula that creates the western shore of Hanapepe Bay. A protective breakwater located south of the proposed intake location was included in the design to further protect the intake from storm damage. This breakwater is smaller than the breakwater included in the fine-mesh intake design in the Interim Report (OCEES and Alden 2011, Appendix C).

The onshore intake will include trash racks, stoplogs, and modified traveling water screens. The modified traveling water screens are designed for a $1.5 \mathrm{ft} / \mathrm{sec}$ approach velocity under mean low water conditions which is three times the approach velocity used in the Interim Report (OCEES and Alden 2011, Appendix C). The onshore intake is designed for four 14-ft wide and 47-ft deep modified traveling water screens with 9.5-mm mesh, six fewer screens than the fine-mesh screen alternative proposed in the Interim Report (OCEES and Alden 2011, Appendix C). A sectional view of the proposed intake is shown in Figure B-4. Fish and debris removed from the screens would be returned to the bay west of the intake structure. An excavated intake channel would extend from the face of the intake out to the El.-30 ft contour to help convey water to the onshore intake. 


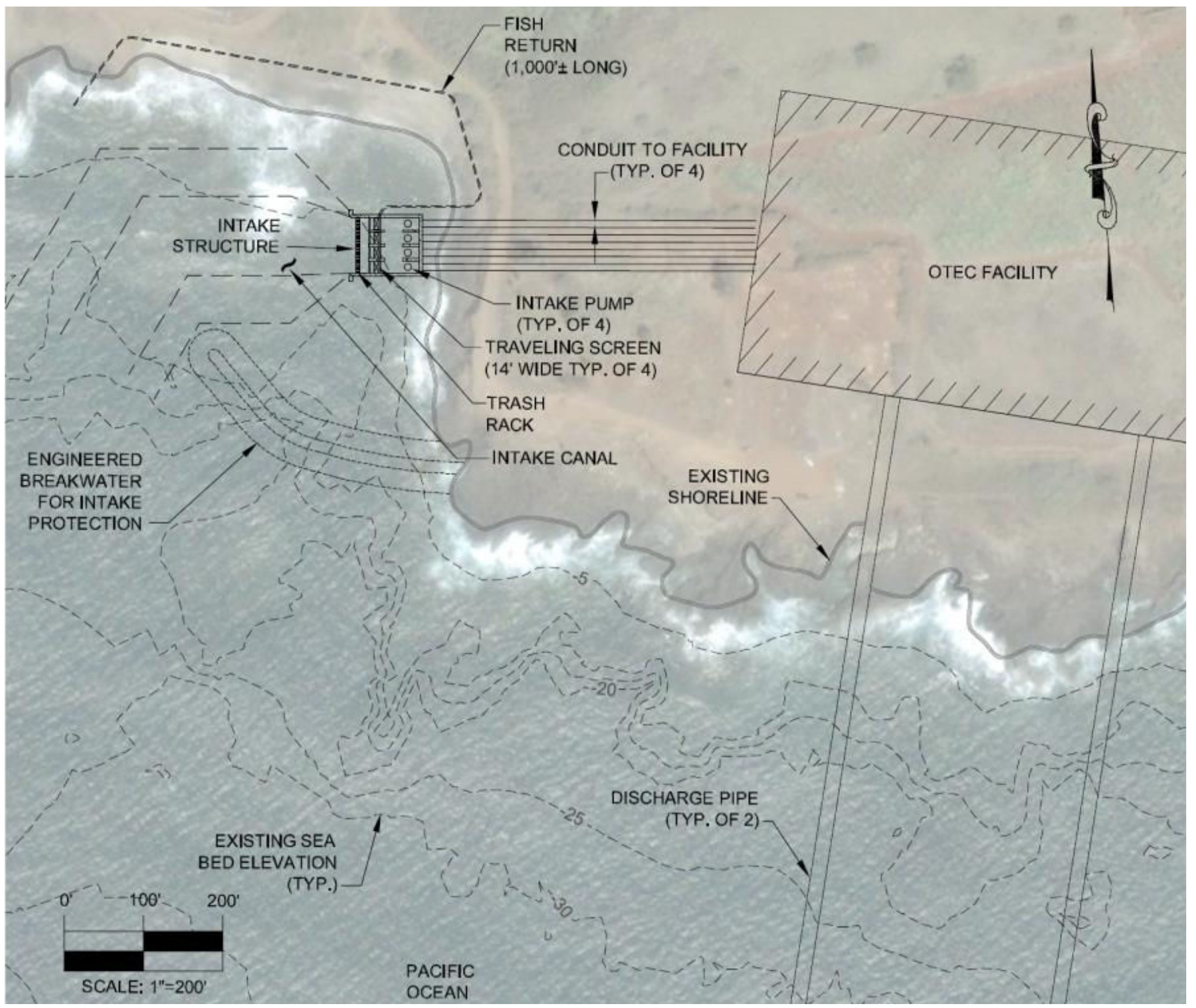

Figure B-3. Coarse-mesh Modified Traveling Water Screens with Onshore Intake (Plan). 


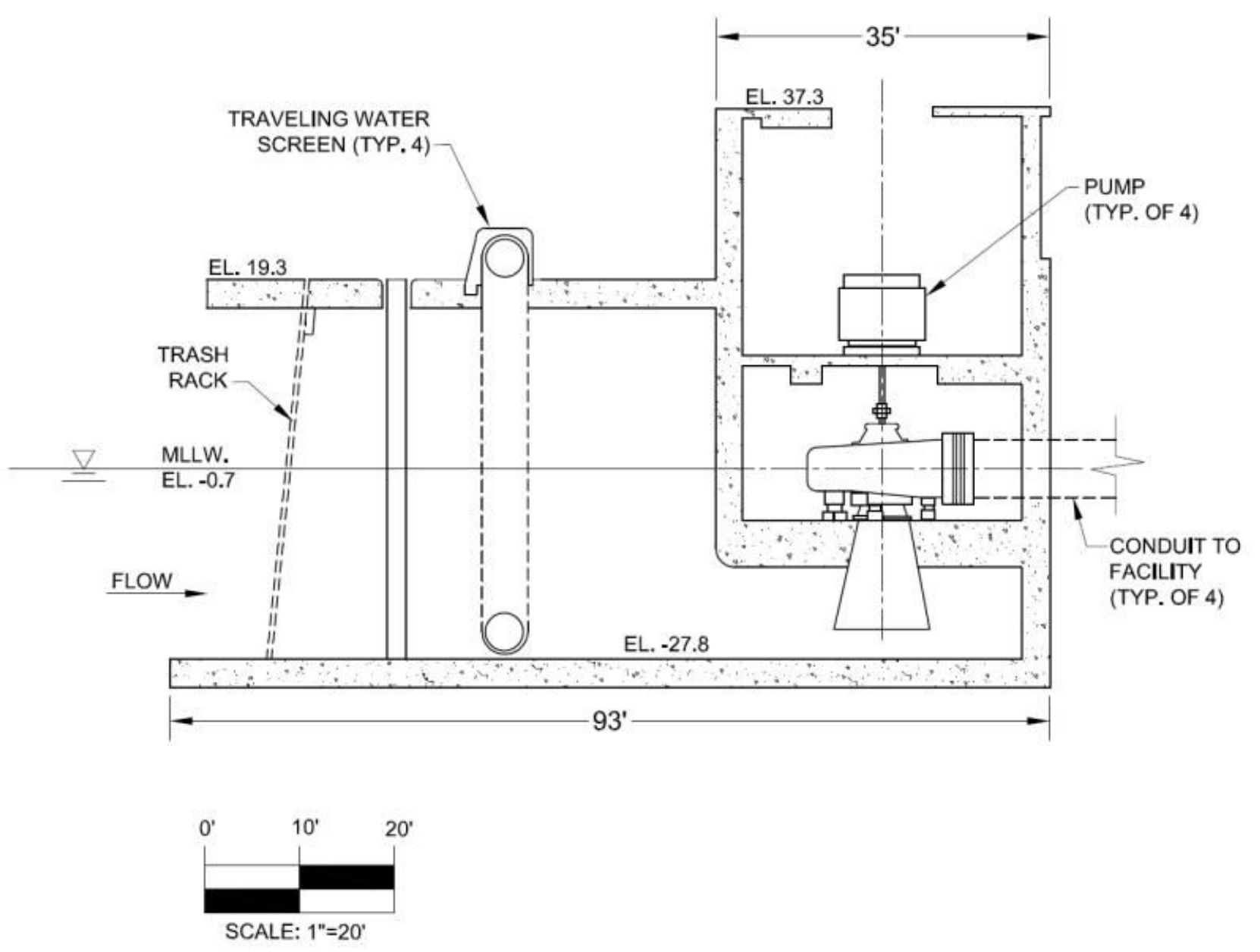

Figure B-4. Coarse-mesh Modified Traveling Water Screens with Onshore Intake (Section). 
Major cost components of the onshore traveling water screen intake alternative have been itemized in Table B-2. Mobilization and demobilization are assumed to be $10 \%$ of the remaining direct costs. Major costs associated with the construction of the 9.5-mm onshore intake traveling water screen include excavation of the intake area and channel, cofferdams and shoring, and the traveling water screens themselves.

Table B-2. Summary Costs for Coarse-mesh Modified Traveling Water Screens with Onshore Intake.

\begin{tabular}{|lc|}
\hline Item & Estimated Cost \\
\hline Direct Costs & \\
Mobilization and Demobilization & $\$ 2,920,000$ \\
Cofferdam \& Shoring & $\$ 3,674,000$ \\
Excavate Intake Channel (Intake to Breakwater) & $\$ 12,555,000$ \\
New Intake Structures & $\$ 2,174,000$ \\
Breakwater & $\$ 2,349,000$ \\
Trash Rack & $\$ 650,000$ \\
Spray Wash System & $\$ 192,000$ \\
Ristroph Coarse-Mesh Traveling Water Screens & $\$ 3,580,000$ \\
Fish and Debris Return System & $\$ 994,000$ \\
Warm Water Pumps & $\$ 3,031,000$ \\
\hline Direct Costs (2013 \$) & $\$ 32,119,000$ \\
Indirect Costs, Taxes and Overhead and Profit & $\$ 7,709,000$ \\
Subtotal & $\$ 39,828,000$ \\
Allowance for Indeterminates/Contingencies & $\$ 9,957,000$ \\
\hline Total Estimated Project Costs (2013 \$) & $\$ \mathbf{4 9 , 7 8 5 , 0 0 0}$ \\
\hline
\end{tabular}




\section{$4 \quad$ Wide-slot (9.5-mm) Cylindrical Wedgewire Screens}

This cylindrical wedgewire alternative uses wide slot $(9.5-\mathrm{mm})$ wedgewire screens along with laid pipe to provide a lower cost wedgewire option than presented in the Interim Report (OCEES and Alden 2011, Appendix C). Increasing the slot size of the openings on wedgewire screens reduces the number of screens needed because the increased open area allows more flow to pass through the screen while maintaining a $0.5 \mathrm{ft} / \mathrm{sec}$ through-slot velocity. The larger slot size screens would not physically exclude the smaller organisms that the narrow-slot $(2.0-\mathrm{mm})$ alternative proposed in the Interim Report (OCEES and Alden 2011, Appendix C) would. Note that the through-slot velocity would remain at 0.5 $\mathrm{ft} / \mathrm{sec}$ as this is a design requirement to prevent any issues with impingement.

Twelve 10-ft diameter, tee-shaped, wide-slot cylindrical wedgewire screens are used in this design to screen the total warm water withdrawal, as shown in Figure B-5 These screens would be made out of a copper-nickel alloy to reduce biofouling of the screens. After passing through the cylindrical wedgewire screens, the seawater would flow through two intake pipes. These pipes would be 14-ft ID and placed in a shallow trench similar to the pipes used for the velocity cap alternative. Intake tunnels, used in the wedgewire options presented in the Interim Report (OCEES and Alden 2011, Appendix C), were not used in order to reduce construction costs. The intake pipes would convey flow to the facility forebay located on-shore. The layout of the screens and plant forebay is provided in Figure B-6. Because all of the flow passes through wedgewire screens before reaching the forebay, no additional screening is needed on-shore. 


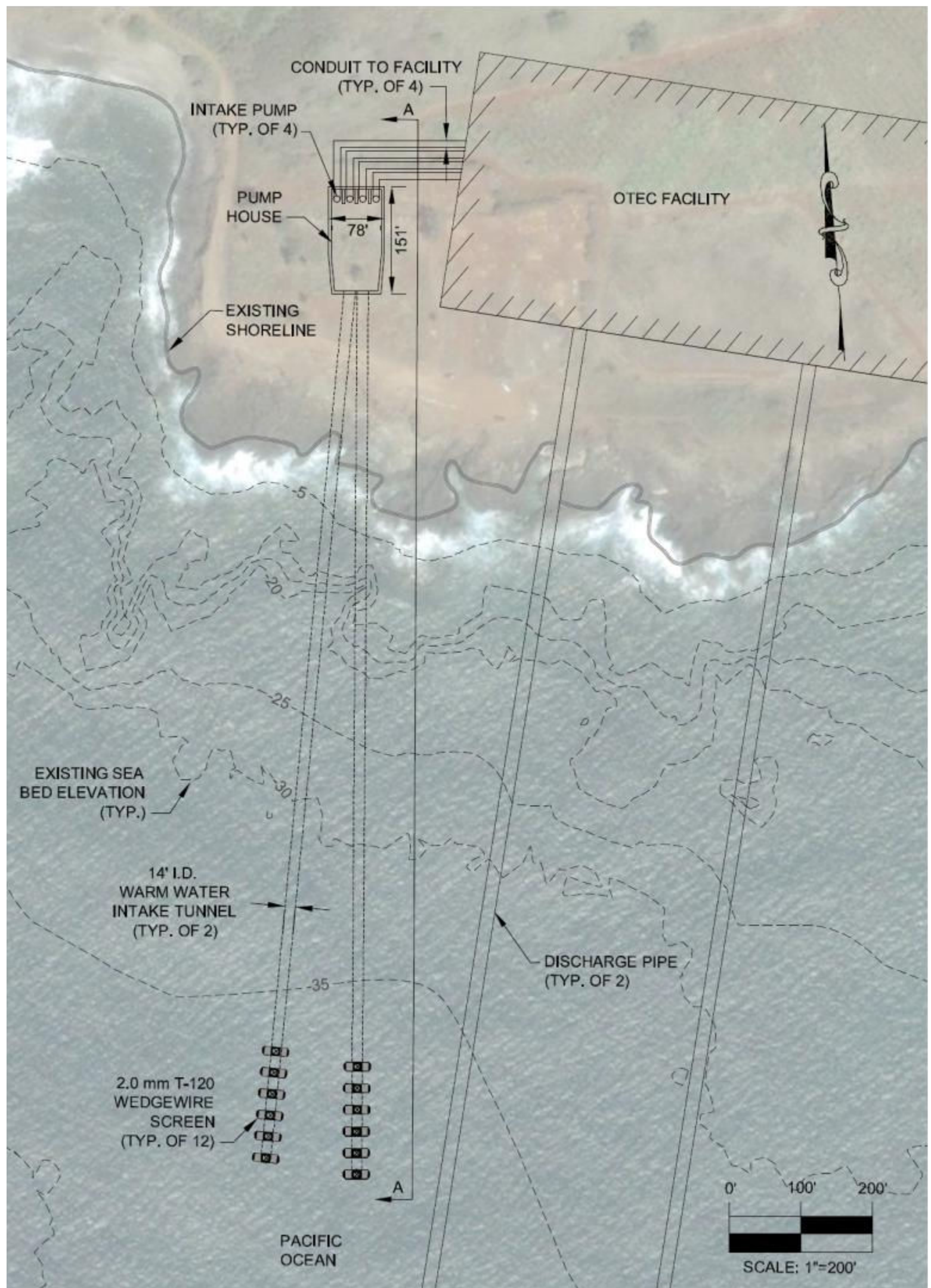

Figure B-5. Narrow-Slow Wedgewire Screen Intake (Plan). 


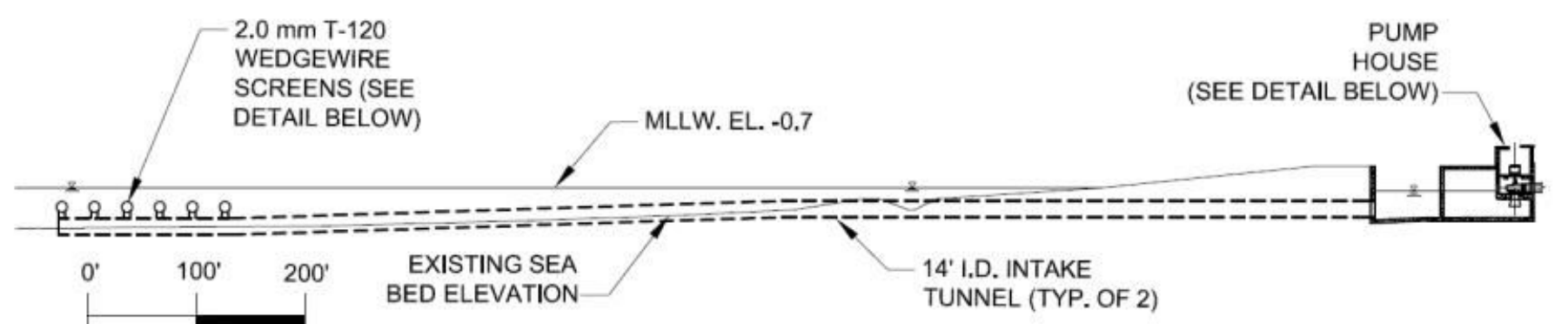

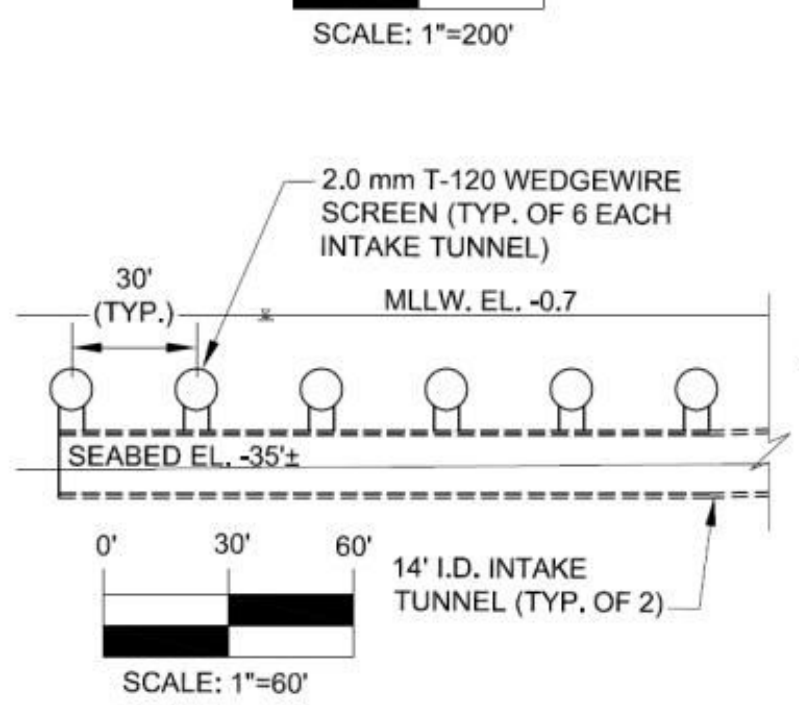

WEDGEWIRE SCREEN DETAIL

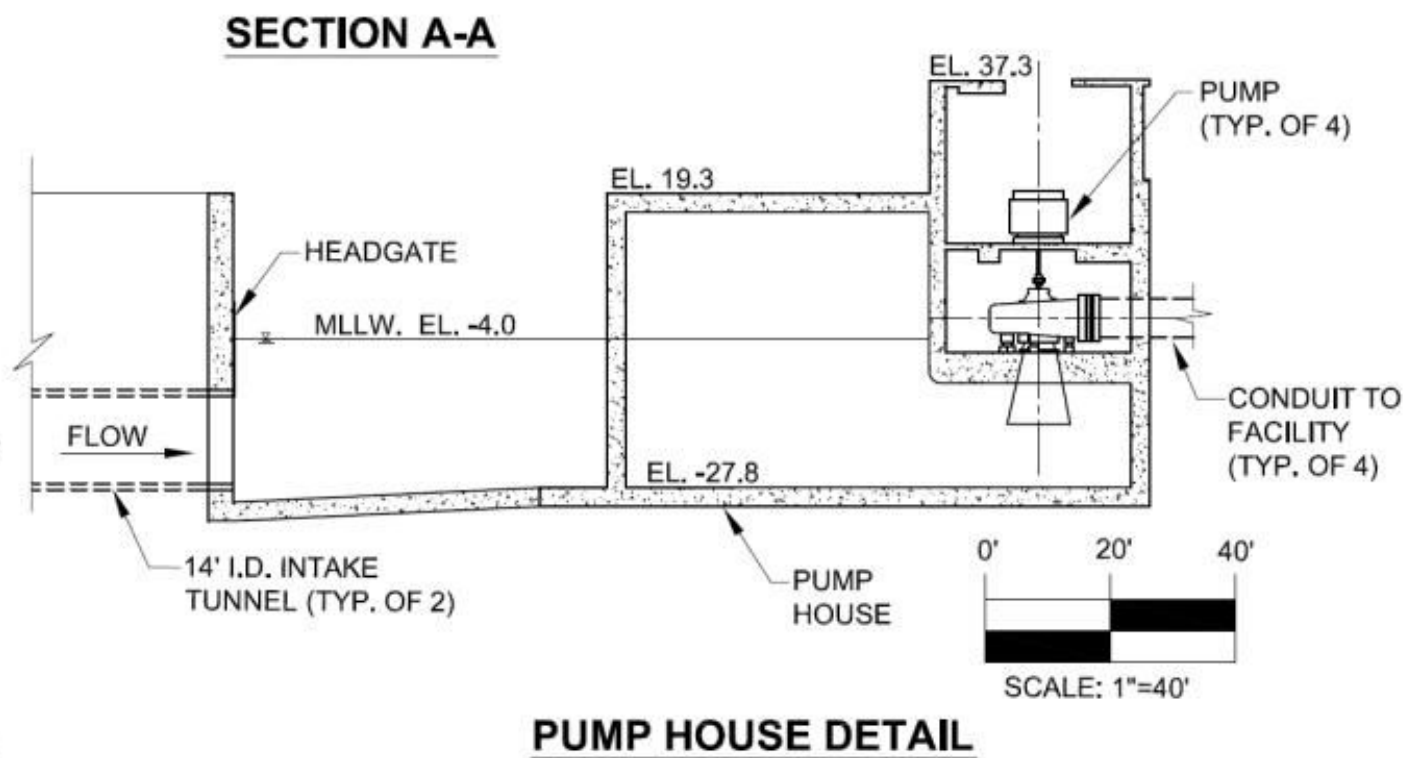

Figure B-6. Wide-slot Wedgewire Screen Intake (Sections). 
The major cost components of the wide-slot cylindrical wedgewire screen intake have been itemized in Table B-3. Mobilization and demobilization are assumed to be $10 \%$ of the remaining direct costs. Major costs include: the construction of the intake pipes and installation of the screens.

Table B-3. Summary Costs for Wide-slot Cylindrical Wedgewire Intake.

\begin{tabular}{|lc|}
\hline Item & Estimated Cost \\
\hline Direct Costs & \\
Mobilization and Demobilization & $\$ 3,223,000$ \\
Tunnel Entrance & $\$ 2,136,000$ \\
Cofferdam \& Shoring & $\$ 236,000$ \\
Excavate Sea Floor & $\$ 960,000$ \\
Intake Pipe & $\$ 17,448,000$ \\
Forebay & $\$ 2,532,000$ \\
New Intake Structures & $\$ 2,494,000$ \\
Screen Supports & $\$ 816,000$ \\
T-120 Screens & $\$ 3,578,000$ \\
Warm Water Pumps & $\$ 2,031,000$ \\
\hline Direct Costs (2013 \$) & $\$ 35,454,000$ \\
Indirect Costs & $\$ 8,509,000$ \\
Subtotal & $\$ 43,963,000$ \\
Allowance for Indeterminates/Contingencies & $\$ 10,991,000$ \\
\hline Total Estimated Project Costs (2013 \$) & $\$ \mathbf{5 4 , 9 5 4 , 0 0 0}$ \\
\hline
\end{tabular}




\section{Summary}

The costs for the three intake alternatives presented in this appendix are intended to provide a lower end range of costs that can be expected for the proposed Port Allen OTEC facility's warm water intake. These alternatives are very similar to the three presented in the Interim Report (OCEES and Alden 2011, Appendix C) except they are designed to reduce only impingement mortality and include design features intended to lower their construction and installation cost. Some of the design changes include:

- Increased screen approach velocity $(0.5 \mathrm{ft} / \mathrm{sec}$ to $1.5 \mathrm{ft} / \mathrm{sec})$

- Increased screen mesh sizes (2.0-mm to $9.5-\mathrm{mm})$

- Different pipe laying techniques (tunneling to shallow trenching)

- Reduced excavation and dredging (dredged embayment to dredged channel)

A summary of the costs for the three alternatives in this appendix and the three from the Interim Report (OCEES and Alden 2011, Appendix C) are presented in Table B-4. The table is arranged to show the impact of the cost saving measures for similar alternatives. The costs for the alternatives from the Interim Report (OCEES and Alden 2011, Appendix C) have been updated from 2011 dollars to 2013 dollars by applying a multiplier of 1.03 to account for inflation.

Table B-4. Total Estimated Capital Costs of Intake Alternatives.

\begin{tabular}{|l|c|c|}
\hline \multicolumn{1}{|c|}{ Intake Alternative } & $\begin{array}{c}\text { Alternatives with } \\
\text { Fine-mesh } \\
\text { (Interim Report, } \\
\text { OCEES and Alden } \\
\text { 2011, Appendix C) }\end{array}$ & $\begin{array}{c}\text { Alternatives with } \\
\text { Coarse-mesh } \\
\text { (Appendix B) }\end{array}$ \\
\hline $\begin{array}{l}\text { Modified Traveling Water Screens } \\
\text { with Offshore Velocity Cap Intake }\end{array}$ & $\$ 204,399,000$ & $\$ 55,120,000$ \\
\hline $\begin{array}{l}\text { Modified Traveling Water Screens } \\
\text { with Onshore Intake }\end{array}$ & $\$ 126,729,000$ & $\$ 49,785,000$ \\
\hline $\begin{array}{l}\text { Cylindrical Wedgewire Screens with } \\
\text { Offshore Intake }\end{array}$ & $\$ 216,514,000$ & $\$ 54,954,000$ \\
\hline
\end{tabular}




\section{References}

Firing, J and R.E. Brainard. 2006. Ten Years of Shipboard ADCP Measurements along the Northwestern Hawaiian Islands. Atoll Research Bulletin 543: 347-363.

CRRC (Coastal Response Research Center). 2012. Ocean Thermal Energy Conversion: Information Needs Assessment. University of New Hampshire, Durham, NH, 25 pp and appendices. 
Appendix C

DE-EE0002653

Appendix C. THE POTENTIAL IMPACTS OF OTEC INTAKES ON AQUATIC

ORGANISMS AT AN OTEC SITE UNDER DEVELOPMENT ON KAUAI, HI: INTERIM REPORT

C-1 


\section{THE POTENTIAL IMPACTS OF OTEC INTAKES ON AQUATIC ORGANISMS AT AN OTEC SITE UNDER DEVELOPMENT ON KAUAI, HI \\ INTERIM REPORT}

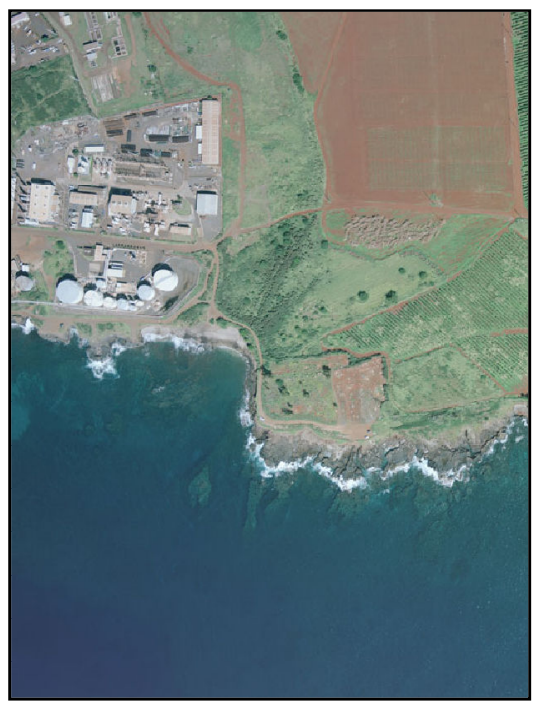

Submitted to:

U.S. Department of Energy

Golden Field Office

Award Number: DE-EE0002653

Submitted by:

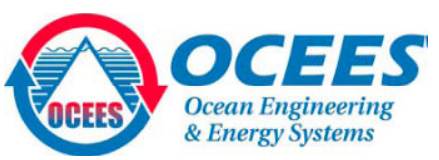

Seven Waterfront Plaza

500 Ala Moana Blvd., Suite 400

Honolulu, HI 96813
ALDEN Research Laboratory, Inc.

30 Shrewsbury Street Holden, MA 01520

July, 2011 


\section{TABLE OF CONTENTS}

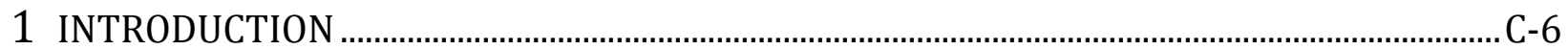

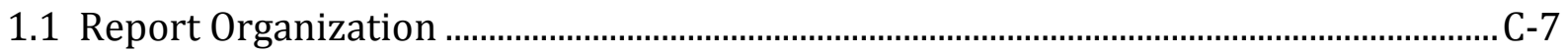

2 REGULATIONS RELATIVE TO OTEC INTAKE DESIGN …………………………………….....

2.1 Clean Water Act Section 316(b) ………………........................................................

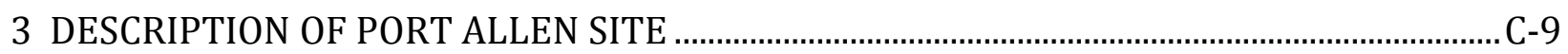

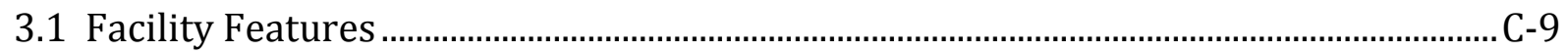

3.2 Existing Hydraulic Conditions ………………............................................................... -12

4 EVALUATION OF WARM WATER INTAKE ALTERNATIVES .................................................. C-14

4.1 Evaluation and Preliminary Screening of Intake Alternatives ..................................... C-14

4.2 Method for Preliminary Screening of Intake Alternatives............................................. C-14

4.3 Biological Considerations …………………………............................................... C-15

4.4 Results of the Preliminary Screening ……………....................................................... -16

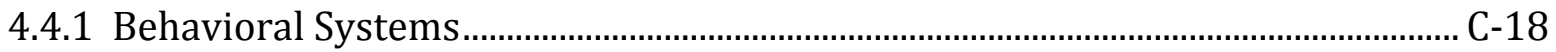

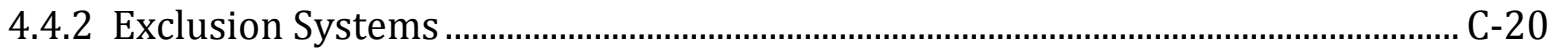

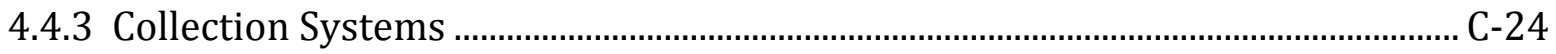

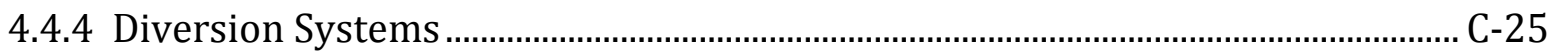

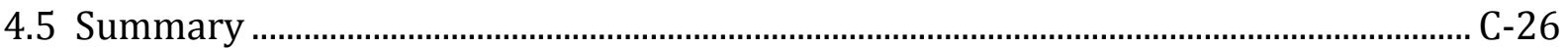

5 DETAILED DESCRITPION OF SELECTED INTAKE TECHNOLOGIES.................................... C-28

5.1 Modified Traveling Water Screens $(0.5,2.0$, and $9.5 \mathrm{~mm})$........................................... C-28

5.1.1 Modified Traveling Water Screens - Offshore Intake Location............................... C-32

5.1.2 Modified Traveling Water Screens - Onshore Intake Location.............................. C-35

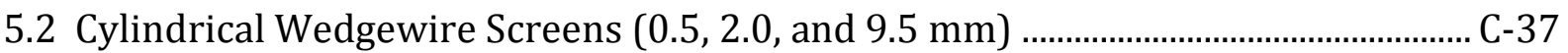

5.3 Modular Inclined Screens (MIS) ………………..................................................... C-42

6 INTAKE TECHNOLOGIES SELECTED FOR CONCEPTUAL DESIGN AND PRELIMINARY

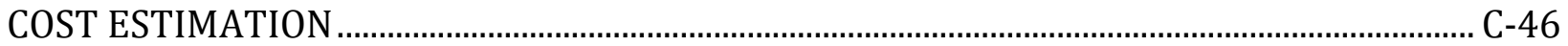

6.1 Fine-Mesh (2-mm) Modified Traveling Water Screens with Offshore Velocity Cap Intake C-48

6.2 Fine-mesh (2-mm) Modified Traveling Water Screens with Onshore Intake.......... C-54

6.3 Narrow-slot (2-mm) Cylindrical Wedgewire Screens ................................................ C-58

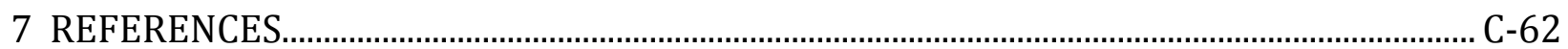




\section{TABLE OF FIGURES}

Figure C-1. Location of proposed Port Allen OTEC facility.

Figure C-2. Proposed OTEC facility location (with approximate locations of appurtenant structures).

Figure C-3. Longterm mean ocean currents near Port Allen (image from Firing and Brainard 2006).

Figure C-4. Behavioral barriers that have been shown to be biologically effective for particular species. From left to right: strobe lights, sound transducers, and air bubble curtains.

Figure C-5. Velocity caps. From left to right: schematic of a typical velocity cap and the velocity cap used at San Onofre Nuclear Generating Station in California.

Figure C-6. Aquatic filter barrier (AFB). From left to right: schematic of support structure for an AFB and close-up of AFB material with perforations.

Figure C-7. Barrier net. From left to right: barrier net installation and close-up of barrier net mesh.

Figure C-8. Conventional (unmodified) traveling water screen. From left to right: schematic from EPRI (1986) and image of an actual screen face.

Figure C-9. Cylindrical wedgewire screens.

Figure C-10. Modified traveling water screens. From left to right: modified traveling water screen with fish lifting buckets and fish impinged on a modified traveling water screen during a laboratory evaluation.

C-25

Figure C-11. Modular inclined screen. From left to right: schematic of an MIS retrofit at and existing intake and an individual MIS unit.

Figure C-12. Plans and sections of a typical rotary-disc screen (left) and typical dual-flow screen (right).

Figure C-13. Fish collected in a lifting bucket of a modified traveling water screen during a laboratory evaluation.

Figure C-14. Conceptual design of proposed offshore intake with velocity cap and onshore modified traveling water screenhouse.

Figure C-15. Plan and section of velocity cap for offshore intake for proposed Port Allen site.

Figure C-16. Conceptual design of proposed onshore intake with modified traveling water screens. C-36

Figure C-17. Plan of a typical T-120 cylindrical wedgewire screen for proposed Port Allen site. 
Figure C-18. Conceptual design of proposed $0.5-\mathrm{mm}$ cylindrical wedgewire intake......... C-39

Figure C-19. Conceptual design of proposed 2.0-mm cylindrical wedgewire intake......... C-40

Figure C-20. Conceptual design of proposed 9.5-mm cylindrical wedgewire intake.......... - 41

Figure C-21. Plan and Section of a modular inclined screen (MIS) for the proposed Port Allen site. C-44

Figure C-22. Conceptual design of proposed 2-mm modular inclined screen (MIS) intake. C45

Figure C-23. Fine-mesh modified traveling water screens with offshore velocity cap (plan). C-51

Figure C-24. Fine-mesh modified traveling water screens with offshore velocity cap (sections) C-52

Figure C-25. Fine-mesh modified traveling water screens with onshore intake (plan)...C-55

Figure C-26. Fine-mesh modified traveling water screens with onshore intake (section)... C56

Figure C-27. Fine-mesh wedgewire screen intake (plan). C-59

Figure C-28. Fine-mesh wedgewire screen intake (sections). C-60

\section{TABLE OF TABLES}

Table C- 1. Pertinent project data - Proposed Port Allen OTEC facility. C-13

Table C- 2. Preliminary screening of intake alternatives for the proposed OTEC facility.

Technologies selected for further evaluation appear in bold. $\mathrm{C}-17$

Table C- 3. Number of T-120 wedgewire screens required for each slot size considered.... C37

Table C- 4. Total estimated capital costs of intake alternatives C-48

Table C- 5. Summary costs for fine-mesh modified traveling water screens with offshore velocity cap. C-53

Table C- 6. Summary costs for fine-mesh modified traveling water screen with onshore intake. C-57

Table C- 7. Summary costs for narrow-slot cylindrical wedgewire intake. C-61 


\section{INTRODUCTION}

In the fledgling marine and hydrokinetic (MHK) renewable energy industry, the U.S. Department of Energy (DOE) has taken a leadership role by providing funding to support projects that advance both specific project deployment efforts and the advancement of the MHK industry as a whole. Ocean thermal energy conversion (OTEC) is an MHK technology with the potential to provide baseload power to tropical island communities and remote U.S. military installations. As with other renewable energy technologies, however, there are potential challenges to its commercialization: technological, financial, social, and environmental. Given the large volumes of seawater required to drive the electricityproducing cycle, there is potential for the intakes to negatively impact the marine resources of the source waterbody.

Implicit in the responsible development of the OTEC industry, is the careful evaluation of the intake technologies available for the withdrawal of the warm and cold water required to drive the electricity-producing cycle. Of the two intakes, the warm water intake has the greater potential to impact aquatic life since it will be drawing water from a more biologically productive area of the ocean. Given this potential, it is critical that the warm water intake technology selected is designed to minimize the environmental risk. By comprehensively assessing the feasibility of all of the intake technologies available, OTEC developers can appropriately select the one with the greatest potential for a given site. Furthermore, it is important to make initial assessments of the potential impact to aquatic life that a warm water OTEC intake may have at a particular site under consideration. The DOE project described in this report was designed to meet both of these objectives by:

- Completing a site-specific assessment of available and feasible warm water intake technologies to determine the best intake designs for minimizing impacts to aquatic organisms

- Completing a field sampling program at the Port Allen, Kauai OTEC site to collect biological data that will help determine the potential efficacy of a selected intake technology to minimize impacts to aquatic organisms

In addition to the potential environmental impacts of any potential warm water OTEC intakes, consideration has to be given to the economic and engineering feasibility of each intake alternative. Promotion of the MHK industry dictates that the intake solutions selected must also be economically viable for the industry to grow. If the capital or operational expenditure for a selected intake alternative is too great, the industry may not be able to bear the cost. To that end, an additional objective of this DOE project was to develop preliminary costs for the warm water intake technologies with the greatest potential for application at the site under consideration in Kauai. 


\subsection{Report Organization}

This report is organized sequentially to illustrate the intake selection and preliminary design process. It progresses from a broad to a more detailed evaluation of the intake alternatives. As the evaluation narrows the feasible alternatives down to the three presented in the Section 6, more conceptual level engineering detail is derived to support the design process. For this reason, modifications/refinements are made in Section 6 to the conceptual designs developed in Section 5.

While a typical engineering design process does not typically present earlier designs that have been improved upon, the OCEES Team felt that illustrating all the steps in the intake selection/design process would be valuable to the marine renewable energy industry and would be valuable for promoting the development of OTEC as a viable marine renewable energy technology (stated goals of the Funding Opportunity Announcement under which this work is being conducted).

The final technical report that will be prepared for this project at the completion of the second year of study will likely focus only on refined designs of the three intake alternatives described in Section 6. The balance of this Interim Report can be included as an appendix to the final report for readers that would like more detail on how the three intake alternatives were selected.

\section{REGULATIONS RELATIVE TO OTEC INTAKE DESIGN}

The National Oceanic and Atmospheric Administration (NOAA) was identified in 1980 as the sole federal level licensing authority for all OTEC facilities. The OTEC ACT of 1980 "established a licensing and permitting system for the development of OTEC as a commercial energy technology. Without a legal framework, including the site security and predictability it provides, financing and insuring commercial OTEC operations may have been impossible. The OTEC Act applies to facilities located in U.S. territorial waters or connected to the United States by pipeline or cable. The law also applies to all OTEC plantships owned or operated by U.S. citizens and all OTEC facilities or plantships documented under U.S. law. The OTEC Act requires that a person obtain a license from NOAA in order to own, construct, or operate such a facility or plantship. The OTEC Act and the implementing regulations provide the framework for the development of a commercial OTEC industry." (NOAA 1996).

In 1996, the regulations implementing the ACT were removed since "No applications for licenses of commercial OTEC facilities or plantships have yet been received by NOAA, and there has been a low level of NOAA activity under the OTEC Act." (NOAA 1996). Although the regulations were removed, the OTEC Act itself still remains in force and is ready to be applied in the event that a permit application is filed. Detailed guidelines and standards 
would not be provided by specific regulations, instead, "They would be introduced if deemed necessary on a site-specific, case-by-case basis to prevent significant adverse effects on the environment or to prevent other results contrary to law." Furthermore, the OTEC Act would require that an application for an OTEC facility license be accompanied by details on "the proposed site, descriptions of the operating features of the plan, and assessments of the potential impacts of construction and operation." Therefore, there are very few published details on the intake design criteria to which OTEC facilities will be held.

In a NOAA Technical Report, Myers et al. (1986) estimated the operating conditions for initial U.S. OTEC deployments. This report considered OTEC development sites on the west coast of Oahu and on the southeast coast of Puerto Rico. In order to minimize the potential for impingement and entrainment of aquatic organisms, it was estimated that intake velocities measured outside the intake structure would be required to be between 0.25 and $0.30 \mathrm{~m} / \mathrm{s}(0.82$ and $0.98 \mathrm{ft} / \mathrm{sec})$. It is unclear if this refers to approach velocities measured some distance from the intake screen or if this refers to through-mesh velocities.

Additionally, there are no details provided on screen mesh sizes. Typically, mesh sizes are chosen to prevent the entrainment of debris that will plug the heat exchanger elements; however NOAA or other regulatory agencies may require finer meshes to provide greater protection to fish and other aquatic organisms. Finer mesh screens create greater head loss through the circulating water systems than coarser meshes and will negatively impact power generation efficiency.

Aside from the information provided in Myers et al. (1986), there have been no indications as to the potential intake design requirements for warm water OTEC intakes. Keeping in mind the fact that NOAA does not typically function in a regulatory capacity, it is reasonable to expect NOAA to lean heavily on regulations developed under section 316(b) of the Clean Water Act. These 316(b) regulations were developed to regulate cooling water intakes at conventional power plants in the U.S.

\subsection{Clean Water Act Section 316(b)}

The Clean Water Act set national performance standards to minimize adverse environmental impacts caused by water withdrawals. As described on the EPA's website, Section 316(b) of the Clean Water Act "requires that the location, design, construction and capacity of cooling water intake structures reflect the best technology available for minimizing adverse environmental impact. More than 1,500 industrial facilities use large volumes of cooling water from lakes, rivers, estuaries or oceans to cool their plants, including steam electric power plants, pulp and paper makers, chemical manufacturers, petroleum refiners, and manufacturers of primary metals like iron and steel and aluminum." 
“Cooling water intake structures cause adverse environmental impact by pulling large numbers of fish and shellfish or their eggs into a power plant's or factory's cooling system. There, the organisms may be killed or injured by heat, physical stress, or by chemicals used to clean the cooling system. Larger organisms may be killed or injured when they are trapped against screens at the front of an intake structure." (EPA 2010). These impacts are commonly referred to as impingement mortality and entrainment (IM\&E).

A more detailed description of 316(b) regulations that are pertinent to warm water OTEC intake design is provided in Attachment A.

\section{DESCRIPTION OF PORT ALLEN SITE}

\subsection{Facility Features}

The proposed Port Allen Ocean Thermal Energy Conversion (OTEC) Facility is to be situated near Port Allen, on the southern tip of the island of Kauai, in Hawaii (Figure C-1). The facility intake and discharge are to be located in the Pacific Ocean just southeast of Hanapepe Bay. The facility is to consist of one or more warm water intake structures, one or more cold water intake structures and one or more discharge structures (Figure C-2).

The facility is to have a nominal rated capacity of 20 megawatts (MW) using a patented process to exploit the difference in surface temperature and deep sea temperature in the Pacific Ocean to produce electricity. The full-scale warm water intake volume would be approximately 1,473 million gallons per day (MGD) [64.5 cubic meters per second ( $\left.\mathrm{m}^{3} / \mathrm{s}\right)$ ]. The full-scale cold water intake volume would be approximately 1,008 MGD $\left(44.2 \mathrm{~m}^{3} / \mathrm{s}\right)$. These intake flow rates are comparable to some large fossil-fueled thermal power plants. A summary of pertinent plant design data is provided in Table C- 1 . 


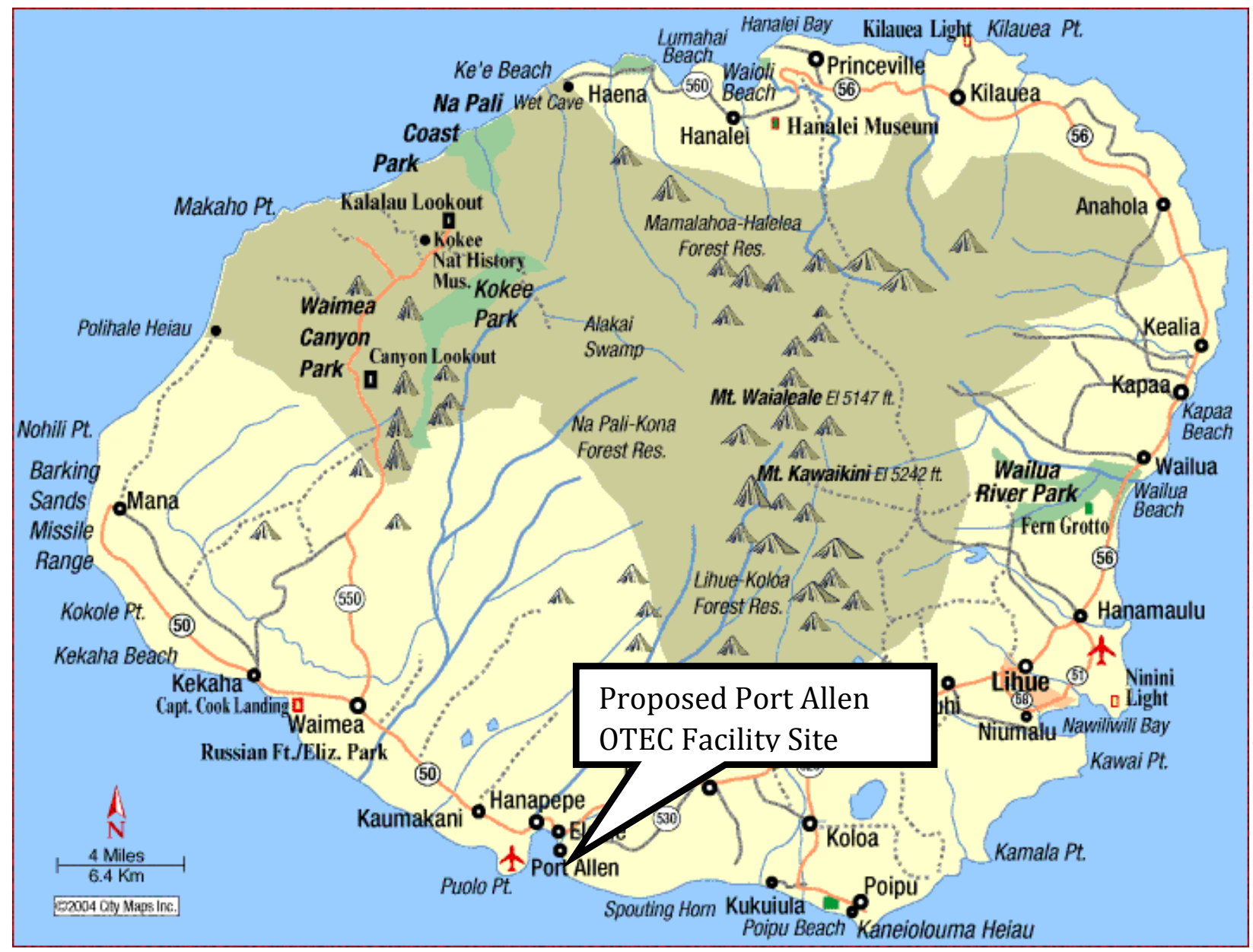

Figure C-1. Location of proposed Port Allen OTEC facility. 


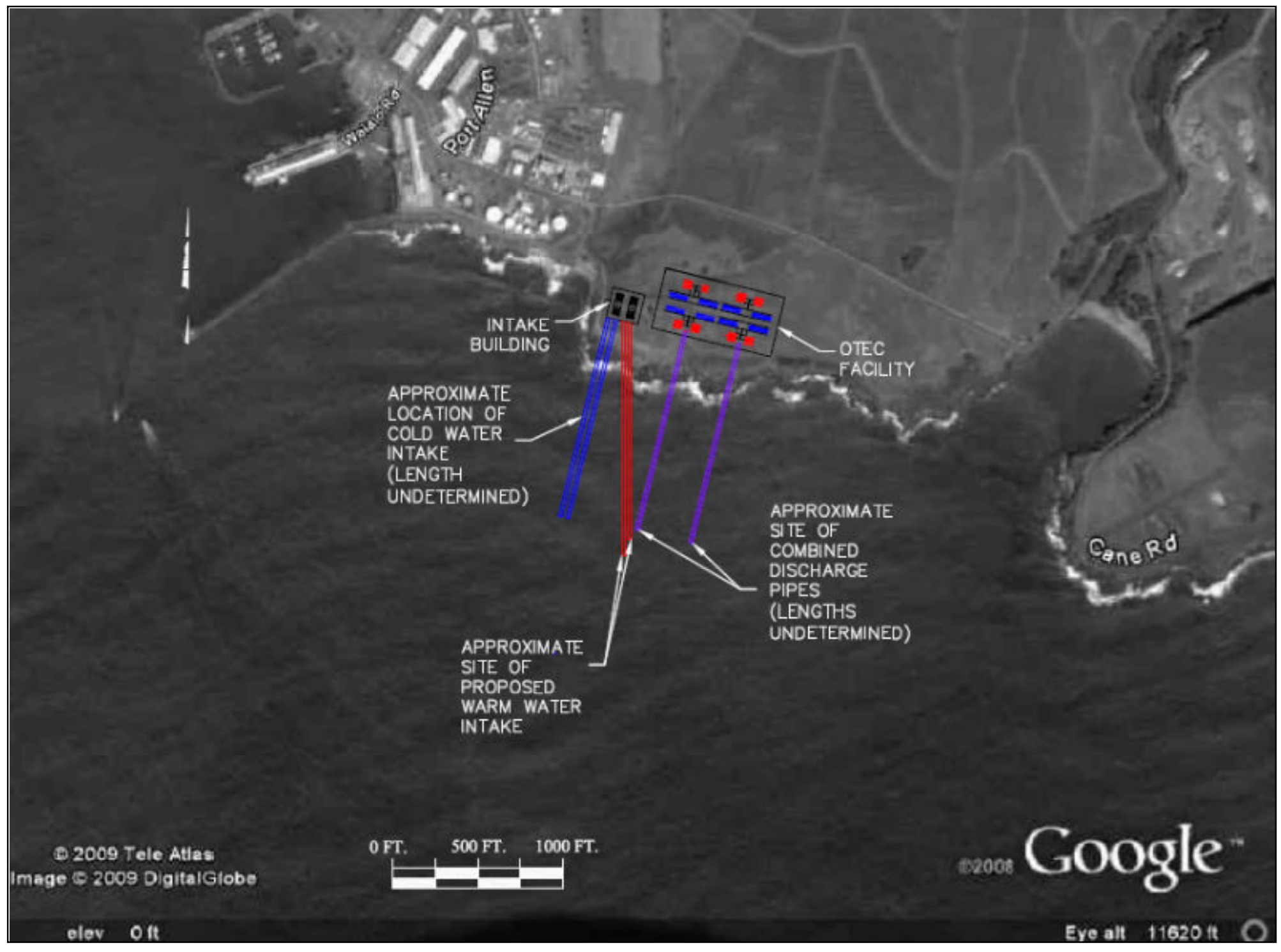

Figure C-2. Proposed OTEC facility location (with approximate locations of appurtenant structures). 


\subsection{Existing Hydraulic Conditions}

According to NOAA Station 1611347 in Port Allen, water levels fluctuate from a low of El. $1.35 \mathrm{ft}$ during low tide to El. $1.81 \mathrm{ft}$ during high tide. These water levels are relative to mean sea level (MSL) and they are predicted using a harmonic pattern with an average tidal cycle (high tide to high tide) of 13 hours and 5 minutes.

The predominant ocean currents parallel the Port Allen coastline from the northwest to the southeast (Firing and Brainard 2006, Figure C-3).

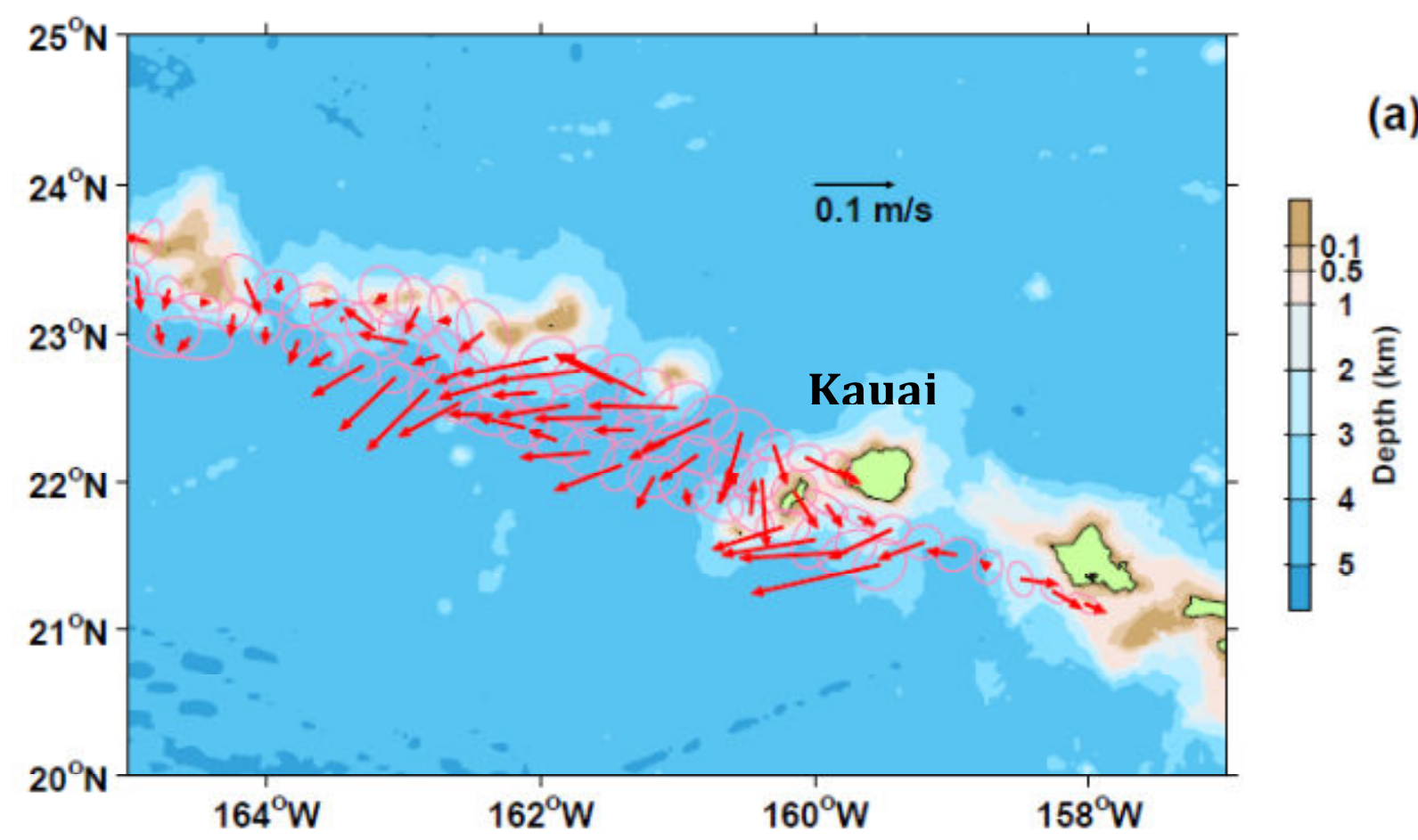

Figure C-3. Longterm mean ocean currents near Port Allen (image from Firing and Brainard 2006).

Table C- 1 provides additional pertinent project data for the proposed Port Allen OTEC facility. 
Table C- 1. Pertinent project data - Proposed Port Allen OTEC facility.

Location

Port Allen, Hawaii

Latitude: N 53 53' 50"

Longitude: W 159'35’00"

Waterbody: Pacific Ocean

Estimated Project Intake Flow

Warm Water: 1,473 MGD $\left(64.5 \mathrm{~m}^{3} / \mathrm{s}\right)$

Cold Water: 1,008 MGD (44.2 $\left.\mathrm{m}^{3} / \mathrm{s}\right)$

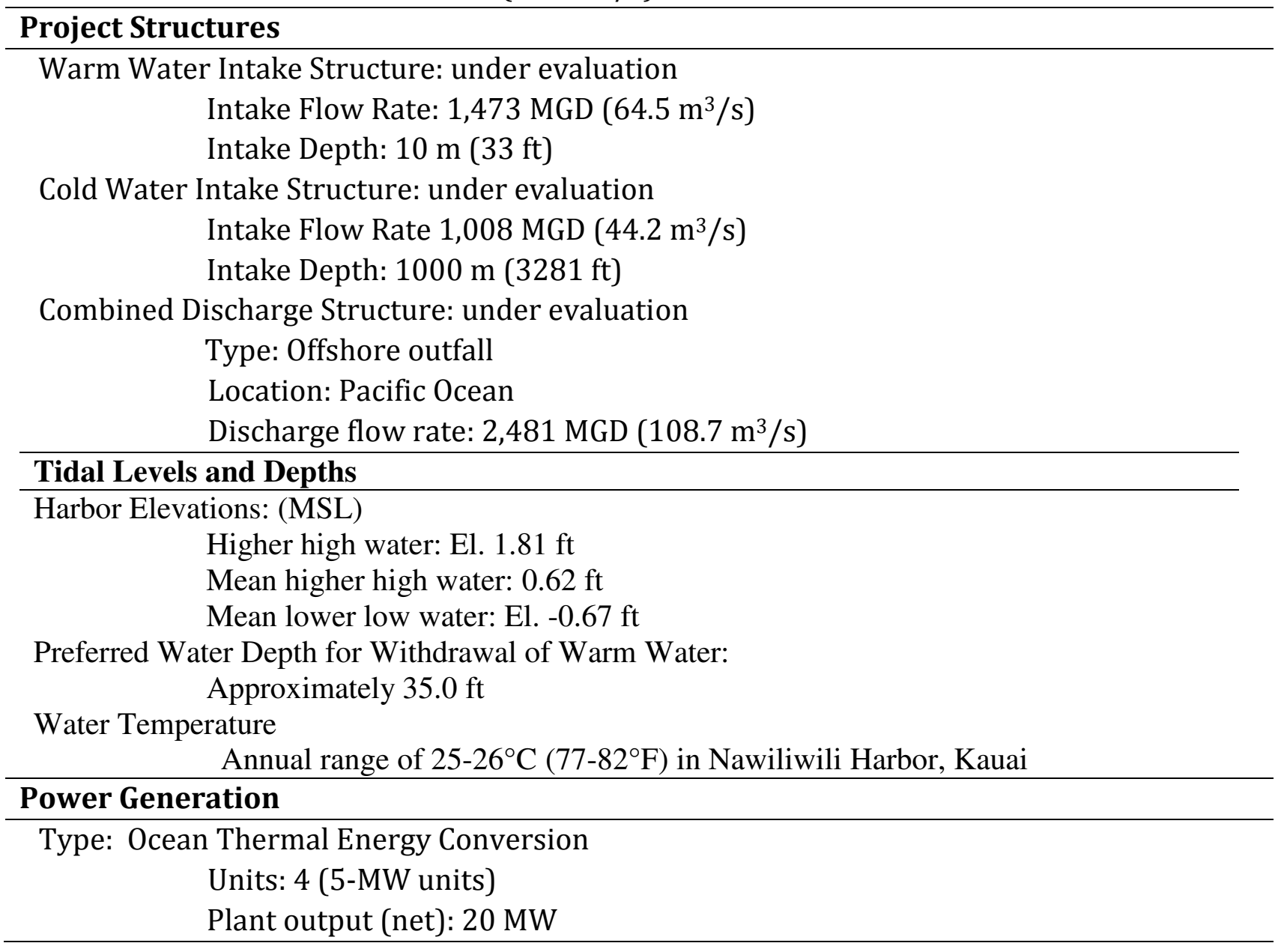




\section{EVALUATION OF WARM WATER INTAKE ALTERNATIVES}

\subsection{Evaluation and Preliminary Screening of Intake Alternatives}

Criteria used to evaluate warm water intake alternatives that may be appropriate for application at the proposed Port Allen OTEC facility are defined in this section. The screening process used for selecting alternatives for intake technologies for preliminary evaluation is presented in Section 4.2.

To determine the alternatives that have the greatest potential to effectively protect fish and that are the most viable within the physical constraints, numerous criteria were used to evaluate the relative advantages and disadvantages of each alternative and to select those technologies for more detailed development. The criteria represent key aspects of any potentially successful protection strategy and are not listed in order of priority. The following general considerations were used to evaluate alternative warm water intake technologies and do not necessarily address potential regulatory concerns as regulations have yet to be written by NOAA:

- Alternatives should be designed to reduce impingement mortality (IM) of large organisms.

- Alternatives should be designed to reduce entrainment (E) of smaller organisms.

- Alternatives should provide effective protection throughout the entire water column such that they are effective with all species potentially susceptible to IM\&E.

- Alternatives should function under expected debris loading and hydraulic conditions in the Pacific Ocean near Port Allen.

- Alternatives should meet worker and public safety requirements.

- Alternatives should not adversely impact navigation.

- Alternatives should not adversely impact the subsea vegetation or geology (i.e., coral reefs).

- Alternatives should be compatible with recreational uses of the region.

\subsection{Method for Preliminary Screening of Intake Alternatives}

The available warm water intake alternatives that met the evaluation criteria above were subjected to a screening process to determine which technologies offer the greatest potential for practical application at the proposed Port Allen OTEC facility. The results of the preliminary screening are summarized below in Table C- 2 . A technology was considered to have potential for application at this site if: 
- The technology has proven biological effectiveness to minimize IM\&E impacts.

- The technology is available and does not require extensive engineering development.

- The technology has engineering and/or biological advantages over the other technologies evaluated.

The preliminary screening process was as objective as possible. However, in assessing the potential for each intake alternative under physical, hydraulic, and environmental conditions in which they may never before have been applied, Alden had to use best professional judgment based on experience.

A technology was deemed to have proven biological effectiveness if empirical test data (preferably from full-scale application) were available that documented its biological effectiveness. If engineering data exist in sufficient detail to develop a conceptual design and/or if the technology has been constructed at another site, it was judged to be an available technology. Each technology was qualitatively assessed to identify whether it had biological and/or engineering advantages over the other alternatives. For example, an intake technology that has been proven effective at reducing losses for many species and under a variety of intake conditions has a biological advantage over one that has been proven effective with only a few species or under limited intake conditions. From an engineering perspective, one technology may hold an advantage over another if the civil/structural requirements for its installation are substantially less.

\subsection{Biological Considerations}

A number of biological data are critical to estimating the potential performance of any intake technology. Basic life history data can indicate which species and lifestages may be present at a proposed intake location. In addition, basic life history information can aid in determining, for each species and lifestage, the potential susceptibility to entrainment or impingement. For instance, the duration of each early life history stage (i.e., egg, yolk-sac larva, post yolk-sac larva, juvenile) will relate to the organism's swimming ability and, therefore, its ability to avoid the hydraulic influence of an intake. At the earliest stages (egg and young larva), there is little to no swimming ability, thus making these organisms much more susceptible to impingement and entrainment. However, as the larva grows and swimming ability increases, the susceptibility to impingement and entrainment decreases. The potential for entrainment relies heavily upon the organism's location in the water body, its swimming ability, and the extent of the hydraulic zone of influence of the intake.

Unfortunately, there is a paucity of basic life history data relative to tropical species. In addition, Myers et al. (1986) stated that there is relatively little information available on the spatial or temporal distribution of early lifestages of tropical fishes. A more detailed 
description of the biological considerations associated with this intake evaluation is provided in Attachment B.

\subsection{Results of the Preliminary Screening}

Three intake technologies (in various combinations of screen mesh sizes and layouts) are considered viable for the Port Allen OTEC facility warm water intake. The selected intake technologies are:

- Modified traveling water screens

O Offshore modified traveling water screen intake with velocity cap (with screen meshes of $0.5,2.0$, or $9.5 \mathrm{~mm}$ )

- Onshore modified traveling water screen intake (with screen meshes of 0.5 , 2.0 , or $9.5 \mathrm{~mm}$ )

- Cylindrical wedgewire screens (with screen slot sizes of $0.5,2.0$, or $9.5 \mathrm{~mm}$ )

- Modular inclined screens $(2.0 \mathrm{~mm})$

These technologies have proven biological effectiveness and have advantages over other concepts (Table C- 2). All of these concepts have been previously developed to a level such that a conceptual design could be prepared for this proposed OTEC facility.

A summary of the evaluation for each selected technology is provided below in this section (Section 4). A detailed description of the potential application of the selected technologies at the Port Allen site is included below in Section 5. 
Table C- 2. Preliminary screening of intake alternatives for the proposed OTEC facility. Technologies selected for further evaluation appear in bold.

\begin{tabular}{|c|c|c|c|c|}
\hline Concept & $\begin{array}{l}\text { Biological } \\
\text { Effectivenes } \\
\text { s Proven }\end{array}$ & $\begin{array}{l}\text { Engineering } \\
\text { Data Exist } \\
\text { to Develop a } \\
\text { Conceptual } \\
\text { Design }\end{array}$ & $\begin{array}{l}\text { Advantages } \\
\text { Over Other } \\
\text { Concepts } \\
\text { (e.g. cost, } \\
\text { footprint) }\end{array}$ & $\begin{array}{l}\text { Potential } \\
\text { for } \\
\text { Application } \\
\text { at the } \\
\text { Proposed } \\
\text { OTEC }\end{array}$ \\
\hline \multicolumn{5}{|l|}{ Behavioral Systems } \\
\hline Sound & Yes & Yes & No & No \\
\hline Infrasound & No & Yes & Yes & No \\
\hline Strobe Lights & Yes & Yes & No & No \\
\hline Mercury Lights & No & Yes & Yes & No \\
\hline Chemicals & No & No & No & No \\
\hline Electric Screens & No & Yes & No & No \\
\hline Air Bubble Curtain & Yes & Yes & No & No \\
\hline Water Jet Curtain & No & Yes & No & No \\
\hline Hanging Chains & No & Yes & No & No \\
\hline Visual Keys & No & Yes & No & No \\
\hline $\begin{array}{l}\text { Hybrid Barriers (e.g., strobe } \\
\text { light/air bubble curtain) }\end{array}$ & No & No & No & No \\
\hline $\begin{array}{l}\text { Velocity Cap (in } \\
\text { conjunction with modified } \\
\text { traveling water screens) }\end{array}$ & Yes & Yes & Yes & Yes \\
\hline \multicolumn{5}{|l|}{ Exclusion Systems } \\
\hline Fixed-screens & Yes & Yes & No & No \\
\hline $\begin{array}{l}\text { Conventional Traveling } \\
\text { Water Screens }\end{array}$ & Yes & Yes & No & No \\
\hline Rotary Drum Screens & Yes & Yes & No & No \\
\hline Barrier Net & Yes & Yes & Yes & No \\
\hline Bar Rack Barrier & No & Yes & Yes & No \\
\hline Infiltration Intakes & Yes & Yes & No & No \\
\hline Porous Dike & Yes & Yes & No & No \\
\hline Aquatic Filter Barrier & Yes & No & Yes & No \\
\hline $\begin{array}{l}\text { Cylindrical Wedgewire } \\
\text { Screen }\end{array}$ & Yes & Yes & Yes & Yes \\
\hline
\end{tabular}




\begin{tabular}{|c|c|c|c|c|}
\hline Concept & $\begin{array}{l}\text { Biological } \\
\text { Effectivenes } \\
\text { s Proven }\end{array}$ & $\begin{array}{l}\text { Engineering } \\
\text { Alternative } \\
\text { Available }\end{array}$ & $\begin{array}{l}\text { Advantages } \\
\text { Over Other } \\
\text { Concepts }\end{array}$ & $\begin{array}{l}\text { Potential } \\
\text { for } \\
\text { Application } \\
\text { at the } \\
\text { Proposed } \\
\text { nare }\end{array}$ \\
\hline \multicolumn{5}{|l|}{ Collection Systems } \\
\hline $\begin{array}{l}\text { Modified Traveling Screens } \\
\text { with Fish Protection }\end{array}$ & Yes & Yes & Yes & Yes \\
\hline Fish Pumps & Yes & Yes & No & No \\
\hline \multicolumn{5}{|l|}{ Diversion Systems } \\
\hline Louvers/Angled Bar Racks & Yes & Yes & No & No \\
\hline $\begin{array}{l}\text { Angled Screens (Fixed or } \\
\text { Traveling) }\end{array}$ & Yes & Yes & No & No \\
\hline Angled Rotary Drum Screens & Yes & Yes & No & No \\
\hline Inclined Plane Screens & No & Yes & No & No \\
\hline Eicher Screen & Yes & Yes & No & No \\
\hline Modular Inclined Screens & Yes & Yes & Yes & Yes \\
\hline $\begin{array}{l}\text { Submerged Traveling Water } \\
\text { Screens }\end{array}$ & No & Yes & No & No \\
\hline Modified Pump Operation & Yes & Yes & No & No \\
\hline
\end{tabular}

The following subsections describe, in more detail, the screening that was conducted for the available intake technologies. These subsections are organized into the four main groups into which the intake technologies can be categorized. Depending on their mode of action, intake systems fall into one of four categories: behavioral systems, which alter or take advantage of natural behavior patterns to attract or repel fish; exclusion systems, which physically block fish passage; collection systems, which actively collect fish for their return to a safe release location; and diversion systems, which divert fish to bypasses for return to a safe release location. Each subsection presents a discussion of the potential benefits and limitations of technologies in each group and the potential applicability of the technologies for the Port Allen site.

\subsubsection{Behavioral Systems}

Behavioral systems function on the premise that some fish species can be repelled or attracted by various stimuli. Behavioral barriers that have received research focus over the years include sound, light, turbulence, air bubbles, electricity, chemicals, and flow velocity. 
In particular, sound, strobe lights, and air bubble curtains (Figure C-4) have been shown to effectively repel particular species of fish. Critical in the effectiveness of such behavioral barriers is the target organism's ability to mount a directional response to the stimulus. As such, these technologies are only effective with later life stages of fish (i.e., juveniles and adults) since early life stages (i.e., eggs and some larvae) may have little to no ability to overcome the hydraulic influence of the withdrawn flow despite whether they can sense the behavioral stimulus or not. Therefore, behavioral barriers alone (or in conjunction with other behavioral barriers) cannot be considered as alternatives that will effectively address entrainment of early life stages of fishes at the proposed OTEC facility and have been eliminated from further evaluation for the Port Allen site.

In addition to the limited biological efficacy, there are practical engineering constraints associated with many behavioral barriers. For example, strobe lights function optimally in water with low turbidity; as turbidity increases, the effective range of the light emitted decreases. Air bubble curtains can be compromised by water velocities and may require special design considerations at tidal sites where flow direction and magnitudes change daily. For this reason, it would be very difficult to design an effective air bubble curtain in an open ocean environment. There are also challenges with evenly distributing compressed air to large air bubble curtain installations. Uneven air distribution can reduce the ability to create a uniform, continuous barrier without gaps. Lastly, behavioral technologies could pose a potential harassment risk to protected marine mammals.
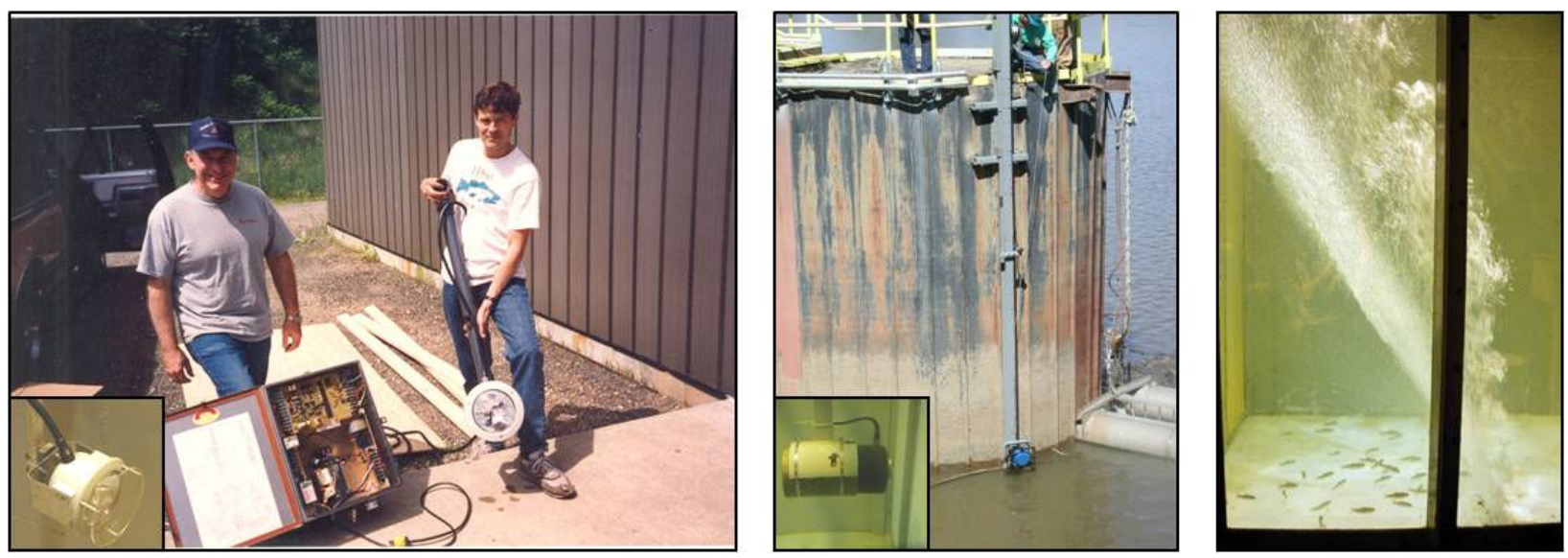

Figure C-4. Behavioral barriers that have been shown to be biologically effective for particular species. From left to right: strobe lights, sound transducers, and air bubble curtains.

Velocity caps, however, are behavioral barriers that can be used in conjunction with other intake technologies (e.g., modified traveling water screens with fish protection features) to reliably minimize the impacts of intakes on aquatic life. A velocity cap (Figure C-5) is a behavioral barrier that changes what would otherwise be vertical flow vectors at an 
uncapped intake riser to horizontal flow vectors. It has been shown that horizontal flow vectors are more easily sensed and avoided by fishes (Beck et al. 2007; Lifton and Storr 1978; Weight 1958).
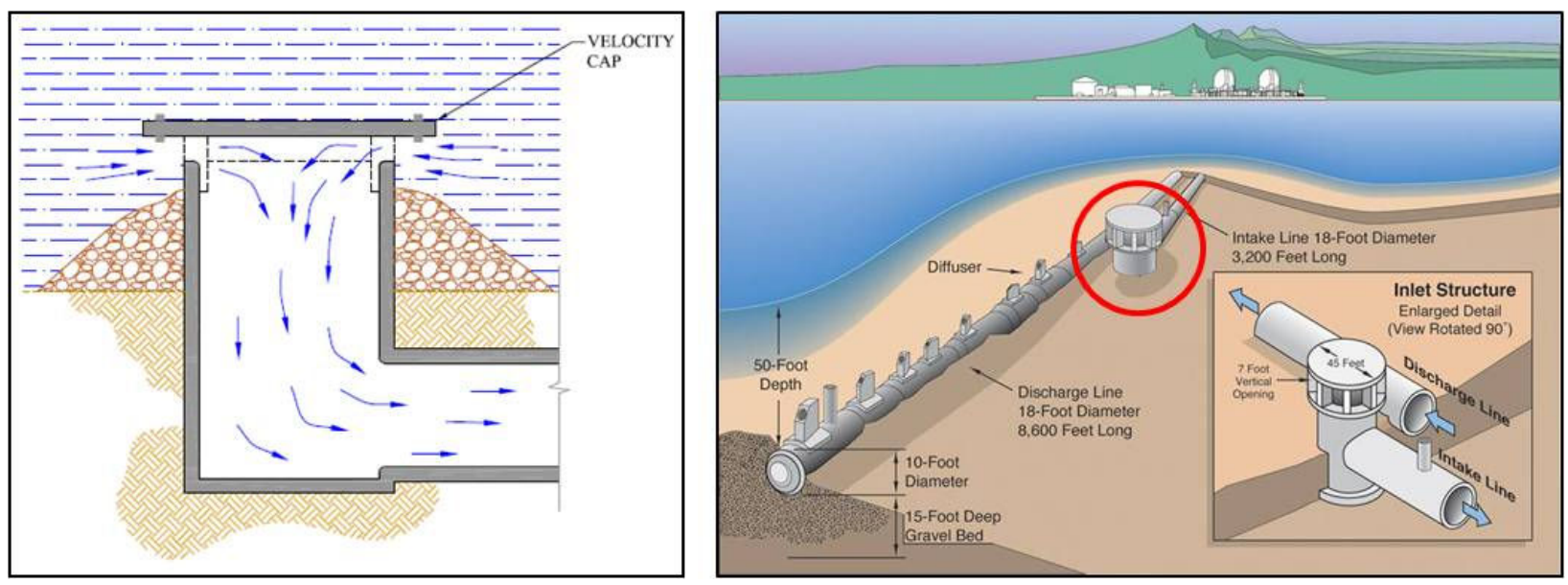

Figure C-5. Velocity caps. From left to right: schematic of a typical velocity cap and the velocity cap used at San Onofre Nuclear Generating Station in California.

A velocity cap, therefore, can be an integral component of a complete intake system. Such an intake system could be designed to include a velocity cap at an offshore intake point that draws water through an intake pipeline or tunnel to an onshore screening facility. The onshore screening facility could be housed in a sump that comprises the onshore portion of the intake system. This onshore screening facility would be fitted with modified traveling water screens, which, depending on the mesh size used, could minimize both impingement mortality and entrainment. The offshore velocity cap would operate as a behavioral barrier to minimize the entrapment of later life stages of fish (i.e., juveniles and adults) within the intake system. A detailed description of the application of a velocity cap as an intake system component at the Port Allen site is provided below in Section 5.

\subsubsection{Exclusion Systems}

Exclusion systems include technologies that passively prevent the passage of organisms based on their size. Their potential effectiveness can be determined based on the size distribution of the organisms that may come in contact with it. Simply put, exclusion technologies function on the premise that a screen will physically exclude organisms equal to or greater than its mesh size. Some specific exclusion technologies have good potential for minimizing IM\&E at the Port Allen site, while others do not.

An aquatic filter barrier (AFB) is an exclusion technology comprised of two layers of geotextile material with an air purge system installed between the layers to permit automatic cleaning of accumulated silt and debris (Figure C-6). This cleaning system can 
also gently free impinged fish eggs and larvae and other organisms with low motility. The flow approaching an AFB is currently limited to approximately $10 \mathrm{gpm} / \mathrm{ft}^{2}$. Based on this criterion, the proposed OTEC facility for Port Allen would require about 209,000 $\mathrm{ft}^{2}$ of AFB to achieve this velocity and would be approximately 8,000 ft long, assuming a 26 - $\mathrm{ft}$ average

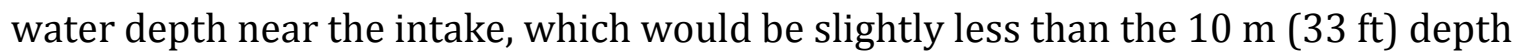
required. This length of filter barrier has the potential to negatively impact navigation and recreation activities in the ocean. In addition, although AFB has proven effective in reducing the impingement mortality and entrainment of early life stages of fish at some open freshwater intakes, there are significant engineering challenges associated with its use. Deployment and maintenance of AFB has been shown to be difficult. Application of this intake technology has been limited to two freshwater installations on the Hudson River in New York. At these sites, the AFB has undergone significant failures due to ambient hydraulic and hydrodynamic forces, excessive debris loading, and ineffective backwashing (LMS 1996, 1997). Furthermore, there are no instances in which AFB has been used in a marine environment and it is expected that tidal and wind-driven currents in the ocean pose potentially insurmountable design obstacles. As a result of the site constraints and lack of data available on the performance of the AFB in an open ocean environment, it has been eliminated from further evaluation for the Port Allen site.
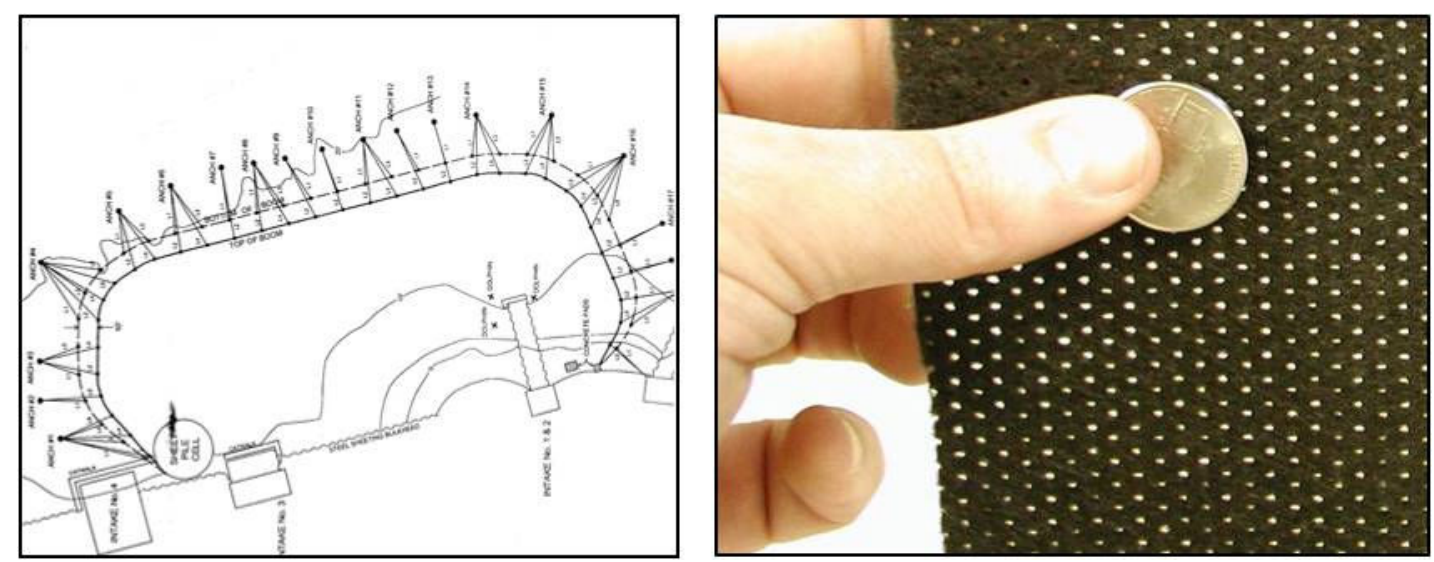

Figure C-6. Aquatic filter barrier (AFB). From left to right: schematic of support structure for an AFB and close-up of AFB material with perforations.

A barrier net is an exclusion technology that functions in a similar manner to AFB (Figure C-7). Barrier nets typically have larger mesh sizes than AFB, and as such, may be effective for minimizing impingement mortality, but finer-mesh barrier nets are still considered experimental and therefore cannot be considered for reductions in entrainment. Similar to AFB, they are easily fouled by silt and algae and would require labor-intensive cleaning. As with $\mathrm{AFB}$, there are engineering challenges associated with the design and maintenance of a barrier net support structure in an open ocean environment. For these reasons, barrier nets have been eliminated from further evaluation for the Port Allen site. 

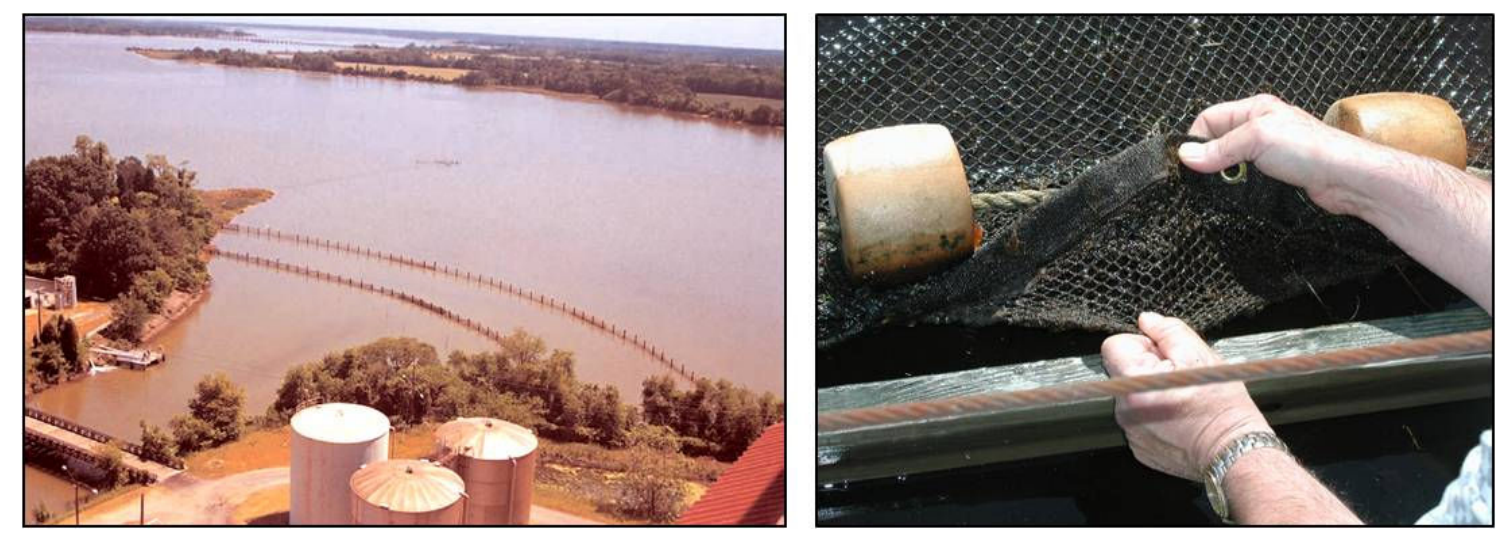

Figure C-7. Barrier net. From left to right: barrier net installation and close-up of barrier net mesh.

Conventional traveling water screens (i.e., those without any fish protection features) are standard features at most large industrial water intakes (Figure C-8). The ability of traveling screens to act as a physical barrier to fish, while not resulting in impingement, is dependent on many site-specific factors such as the size of the fish, the flow velocity, the location of screens, and the presence of escape routes. As exclusion devices, traveling water screens cannot be considered for protection of early life stages or for aquatic organisms that have little or no motility. However, under the proper hydraulic conditions, these screens can prevent the entrainment of juvenile and adult fish with the ability to avoid impingement on the screen mesh.

Biologically speaking, traveling water screens generally result in high mortality to all but the hardiest species that become impinged on them. For this reason, and because recent regulatory trends indicate an emphasis on the protection of early lifestages, traveling water screens have been eliminated from further evaluation for the Port Allen site. 

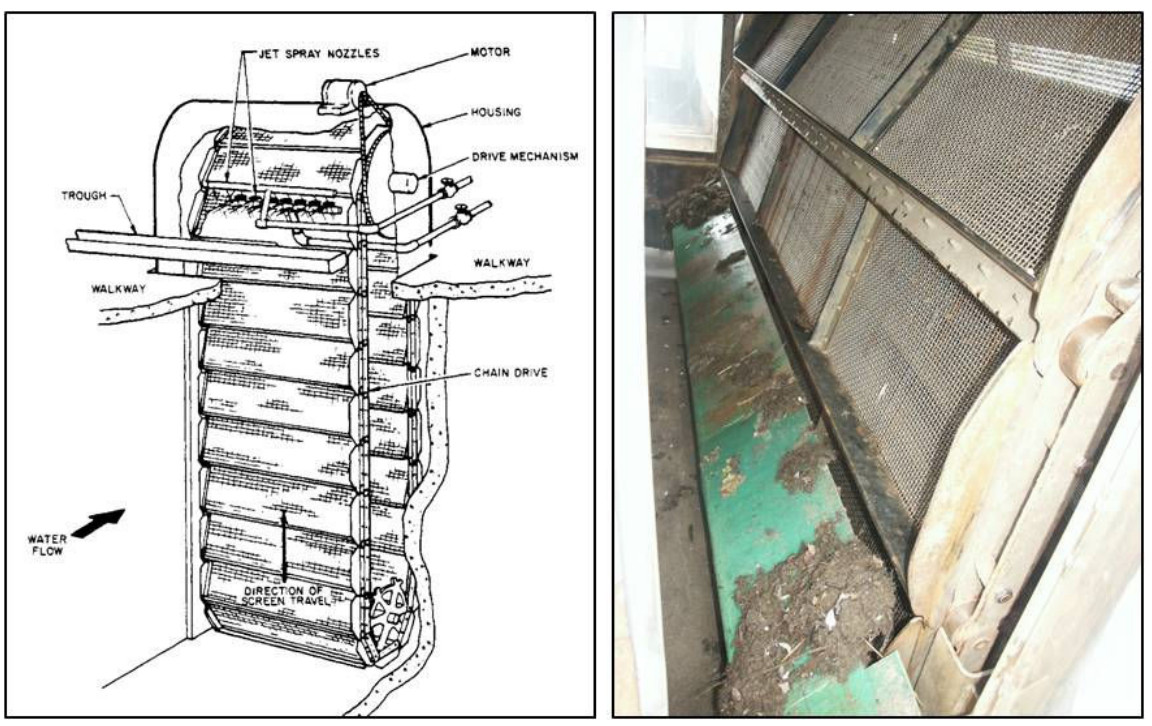

Figure C-8. Conventional (unmodified) traveling water screen. From left to right: schematic from EPRI (1986) and image of an actual screen face.

Cylindrical wedgewire screens have good potential to minimize IM\&E at the Port Allen site. Cylindrical wedgewire screens utilize wire that is V- or wedge-shaped in cross-section. The wire is welded to a framing system to form a slotted screening element (Figure C-9). In order to effectively reduce impingement and entrainment, these screens are typically designed with the following biological considerations in mind:

- Screen slot size must be sufficiently small to physically block passage of the smallest life stage to be protected

- Through-slot velocity should be low

- Relatively high velocity ambient sweeping currents are preferred (to carry organisms and debris around and away from the screen)

These screens have been biologically effective in preventing entrainment and impingement of fish and have not caused unusual maintenance problems. However, the potential for clogging and biofouling is a major concern, so careful consideration needs to be given to the cleaning mechanism/process. Given the proper hydraulic conditions, cylindrical wedgewire screens are more easily cleaned than other exclusion technologies such as fixed-screens and barrier nets. Therefore, cylindrical wedgwire screens have a cleaning advantage over other exclusion technologies. Similarly, cylindrical wedgewire screens have a biological advantage in that they can exclude more lifestages from entrainment than conventional screens and bar racks. For these reasons, narrow- and wide-slot wedgewire screens have been selected for further evaluation at the proposed OTEC facility. A detailed description of the application of cylindrical wedgewire screens at the Port Allen site is provided below in Section 5. 

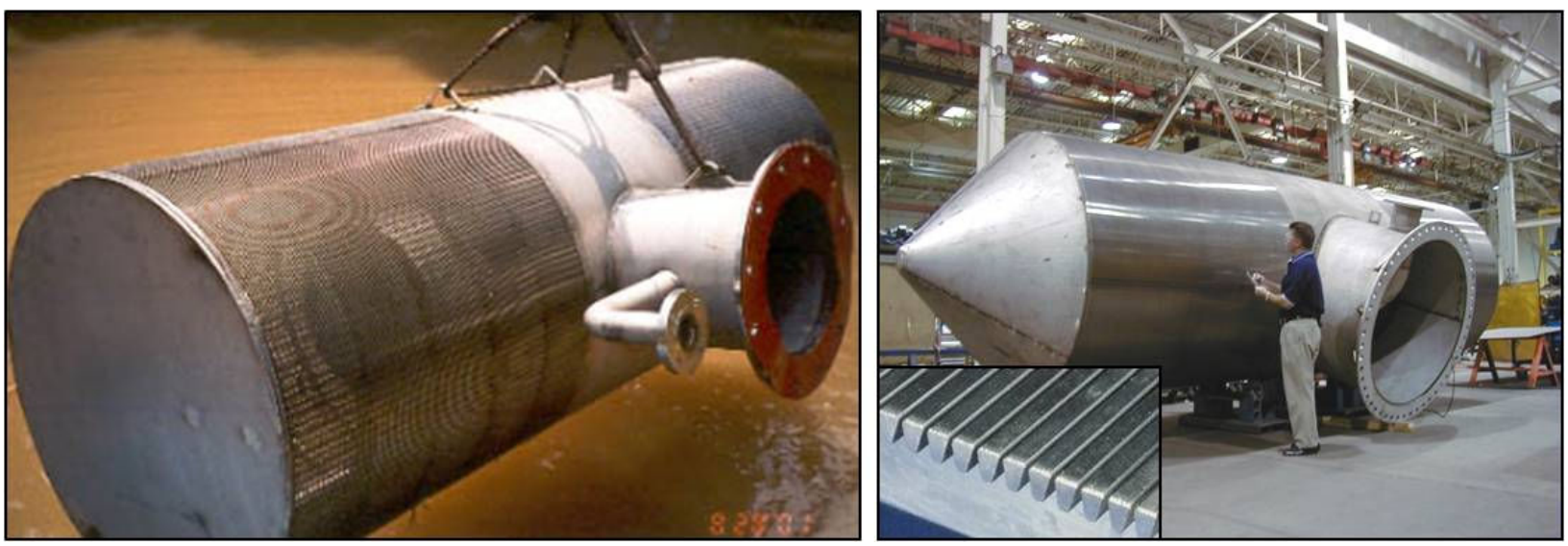

Figure C-9. Cylindrical wedgewire screens.

\subsubsection{Collection Systems}

Collection systems are designed to either actively or passively collect organisms and direct them to a bypass. Their potential effectiveness can be determined in much the same way as discussed above for exclusion systems; however, since the organisms are being collected, it is necessary to know how well they survive the collection and return process. Therefore, while the potential efficacy of exclusion systems can be determined based on the size of the organisms in relation to the size of the mesh, the potential efficacy of collection systems also has to take into account injury and mortality that may be imparted by the collection and return systems. Additional information is provided in Attachment B on estimating impingement survival.

The modified traveling water screen is one of the most popular collection technologies used at cooling water intake structures in the power industry (Figure C-10). These screens represent an improvement over conventional traveling water screens in that they have been modified to include fish lifting buckets. Furthermore, over the years, the design of the fish lifting bucket has been optimized to produce internal hydraulics that are conducive to transporting fish gently. These screens have biological and engineering advantages over other intake technologies.

Four alternatives currently exist for traveling screens with fish protection features. Ristroph traveling water screens (Ristroph), Geiger MultiDisc ${ }^{\text {TM }}$ Screening System (Geiger), Beaudrey Water Intake Protection screens (WIP), and Hydrolox ${ }^{\mathrm{TM}}$ screens (Hydrolox) are all engineered to reduce IM\&E. Ristroph traveling screens currently have the most biological data available. Limited biological data exists for the Geiger, WIP, and Hydrolox screens; however, these designs should provide comparable biological efficacy. 
If modified traveling water screens are to be used, they could be installed at the shoreward end of an offshore intake pipeline in a sump that comprises the onshore portion of the intake system. Modified traveling water screens with fish protection features could be used at the sump to collect fish after the larger organisms (e.g., marine mammals and turtles) and debris have been excluded at the offshore intake point by coarse-mesh screening.
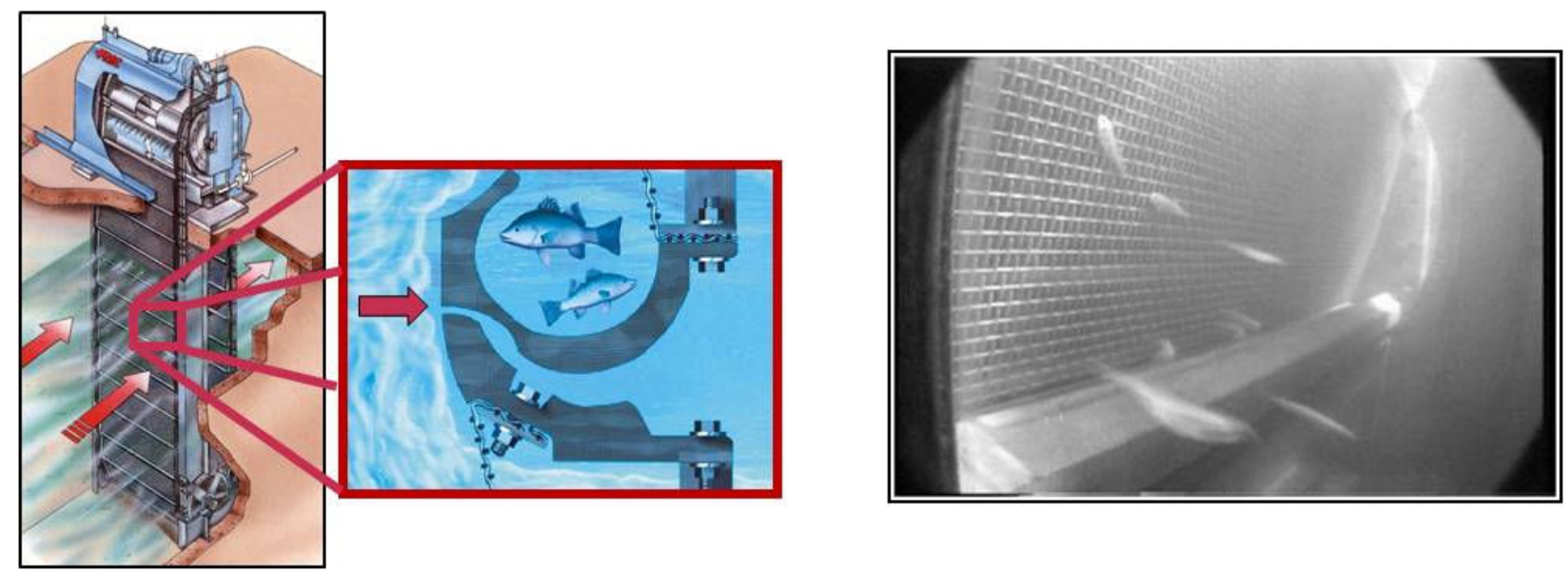

Figure C-10. Modified traveling water screens. From left to right: modified traveling water screen with fish lifting buckets and fish impinged on a modified traveling water screen during a laboratory evaluation.

\subsubsection{Diversion Systems}

Diversion systems are designed to divert fish to bypasses for return to a safe release location. The potential effectiveness of diversion systems can be estimated similar to collection systems. That is, the effectiveness is based on the diversion efficiency as well as the survival of organisms through the return system. Therefore, as with collection systems, diversion systems must take into account injury and mortality that may be imparted by the return system.

The modular inclined screen (MIS, Figure C-11) is a diversion technology that diverts organisms to a bypass where they are then pumped, through fish-friendly pumps, to a return system which leads back to the source waterbody. The MIS has biological and engineering advantages over other types of collection technologies including louvers, angled bar racks, and angled screens in the prevention of impingement. MIS offers the potential to effectively divert many species at high velocities. The ability of the MIS to operate at high velocity helps reduce the need for large intake structures. This type of screen is designed to operate at velocities up to $10 \mathrm{ft} / \mathrm{sec}$. Similar screen types, such as Eicher screens, are designed for installation in hydroelectric project penstocks and would not be applicable at the proposed Port Allen OTEC facility. However, the MIS with a 2.0- 
$\mathrm{mm}$ mesh screen may be effective at reducing impingement mortality and entrainment of some species and lifestages if used in the sump at the OTEC facility.

The combined results of laboratory and field evaluations of the MIS (Taft et al. 1997; EPRI 1994 and 1996) have demonstrated that the MIS is an effective fish diversion device that has the potential for protecting fish at water intakes. Studies to date have only evaluated possible application at hydroelectric projects. Further, no full-scale MIS facility has been constructed and evaluated. That said, the MIS is considered a technically feasible intake alternative for the warm water intake of the Port Allen OTEC facility; however, due to the lack of any full-scale applications, a larger-scale evaluation would be recommended to evaluate its potential with the target species at Port Allen.
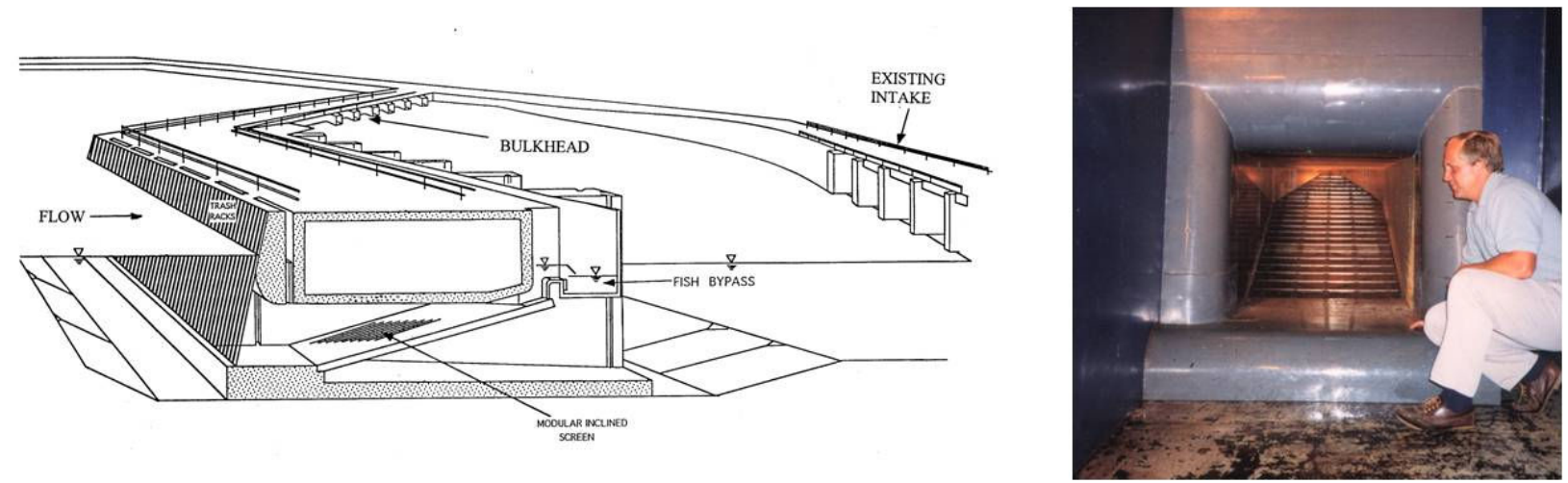

Figure C-11. Modular inclined screen. From left to right: schematic of an MIS retrofit at and existing intake and an individual MIS unit.

\subsection{Summary}

The preliminary screening of intake technologies available for the Port Allen facility (Table C- 2) indicates that three intake technologies (in various combinations of screen mesh sizes and layouts) have potential for application to minimize IM\&E at the warm water intake:

- Modified traveling water screens

- Offshore modified traveling water screen intake with velocity cap (with screen meshes of $0.5,2.0$, or $9.5 \mathrm{~mm}$ )

- Onshore modified traveling water screen intake (with screen meshes of 0.5 , 2.0 , or $9.5 \mathrm{~mm}$ )

- Cylindrical wedgewire screens (with screen slot sizes of $0.5,2.0$, or $9.5 \mathrm{~mm}$ )

- Modular inclined screens $(2.0 \mathrm{~mm})$

It is in OCEES' best interest to consider technologies designed to minimize both impingement mortality and entrainment (i.e., those with $0.5-$ and $2.0-\mathrm{mm}$ mesh/slot sizes) 
for the proposed OTEC facility, as rules requiring a reduction in IM\&E over a calculated baseline are likely to be promulgated. Information on technologies which would only reduce impingement mortality (i.e., those with $9.5-\mathrm{mm}$ mesh/slot sizes) is included in the event that this facility is able to attain entrainment reduction through other compliance alternatives (i.e., reduced operation during seasons of high ichthyoplankton abundance) or OCEES is able to demonstrate that there is some through-plant survival of organisms entrained through the warm water intake system. Attachment B provides more detail on the biological considerations associated with the warm water intake alternatives. 


\section{DETAILED DESCRITPION OF SELECTED INTAKE TECHNOLOGIES}

This section provides detailed descriptions of the intake technologies that were selected in Section 4 for further evaluation. The additional detail provided in this section takes into consideration the following factors:

- site-specific factors that may influence the design;

- technical considerations associated with the design, installation, operation, and maintenance, and

- potential biological effectiveness.

The following sections present, for each intake technology, the factors that may influence the design and the technical considerations associated with the design, installation, operation, and maintenance. Preliminary conceptual designs were developed for each of the selected intake technologies to illustrate potential intake configurations for each alternative. Preliminary drawings are provided for each intake alternative to further inform the selection process.

\subsection{Modified Traveling Water Screens $(0.5,2.0$, and $9.5 \mathrm{~mm})$}

Modified traveling water screens with fish protection features (e.g., Ristroph screens) are the most common technology used at cooling water intake structures (CWIS) for fish protection. This technology uses a "collection / transfer" concept. Although the system is designed to minimize stress to aquatic organisms, the process of collection and transfer will impart a stress to the organisms that would not be experienced if they were not impinged. Some species and lifestages of fish may suffer greater injury or mortality than others (i.e., injury and mortality are species- and lifestage-specific). Generally, as a fish increases in size, survival increases.

Modified traveling water screens could be used to reduce both impingement mortality and entrainment at the proposed Port Allen OTEC facility. Fine-mesh (0.5- and 2.0-mm) screens would reduce both impingement mortality and entrainment, while coarse-mesh (9.5-mm) screens would reduce impingement mortality only. Modified traveling water screens with fish protection features are very similar to conventional traveling water screens with the exception that they have fish buckets, high- and low-pressure spraywashes, fish return systems, and are rotated continuously. Currently, there are several variations of modified traveling water screens available. Each of these technologies has comparable impingement survival while offering unique operational benefits. Modified traveling water screens (i.e., screens with fish protection features) have been successfully used at a number of facilities for many years. Rotary-disc screens are another screening technology that would provide the additional benefit of eliminating debris carryover into the heat exchanger passage tubes (Figure C-12). Dual-flow and center-flow screens with 
fish protection features are also proven technologies and offer the additional benefit of eliminating debris carry-over and reducing headloss across the screens (Figure C-12). For this evaluation, Alden has assumed that typical through-flow modified traveling water screens would be installed; however, all of the screens types listed above are applicable for Port Allen.

Fish protection features included on modified traveling water screens include a screen panel equipped with a water-filled lifting bucket to hold collected organisms as they are carried up with the rotation of the screen (Figure C-13). The screens can be operated periodically or continuously to reduce impingement time. As each bucket passes over the top of the screen, fish are rinsed into a collection trough by a low-pressure (e.g., 5-20 psi) spraywash system after which a high-pressure (e.g., 60-100 psi) spraywash system removes impinged debris. The rinsed fish are collected in a water-filled trough on the downstream side of the screen. Once collected, the fish are transported, in water, through a fish return system back to a safe release location in the source waterbody.

The screens for the proposed Port Allen facility would have a mesh size of 0.5, 2.0, or 9.5 $\mathrm{mm}$. However, the ultimate mesh size (mesh size can be customized) selected will be determined by the fish species and lifestages found in the vicinity of the intake structure and the facility's operational constraints as well through consultation with the resource agencies involved. The 0.5 - and $2.0-\mathrm{mm}$ mesh panels would be more prone to debris loading than the conventional 9.5- $\mathrm{mm}$ mesh panels due to greater retention of finer debris; but, the smooth nature of fine-mesh materials tends to increase the cleaning efficiency of the spraywash system by reducing the potential for stapling of long, filamentous debris. For example, during a pilot study of a 0.5-mm fine-mesh screen at Tampa Electric's Big Bend Station, the prototype fine-mesh screen operated successfully during periods of heavy jellyfish and detritus concentrations (Mussalli et al. 1978). Since completion of the pilot study, fine-mesh screens have been installed and operated successfully at Big Bend. Continuous or frequent rotation of the screens at the proposed Port Allen facility would limit the period of debris accumulation, mitigating any increase in headloss as a result of debris retention.

The modified traveling water screens for the proposed Port Allen facility would be designed for an approach velocity of $0.5 \mathrm{ft} / \mathrm{sec}$. As stated in the 316(b) Rule for new (Phase I) facilities, "The approach velocity is the velocity measured just in front of the screen face or at the opening of the cooling water intake structure in the surface water source, and is biologically the most important velocity"(EPA 2001). However, it is also important to note that EPA indicated that despite the appropriateness of approach velocity, through-screen velocity would be used to measure compliance for new facilities. This decision was made since EPA felt that through-screen velocity would be easier to calculate, monitor, and measure. Approach velocity is used for the design of the proposed OTEC facility's modified 
traveling water screens since it is a biologically meaningful velocity measurement.

To achieve low intake velocities for a large intake flows, it is common to use the widest screens available. For the purposes of this intake evaluation, 14 - $\mathrm{ft}$ wide screens were selected to minimize the number required. A screen height of approximately $52 \mathrm{ft}$ is required in order to ensure a 10-ft clearance above the high water level (approx. El $5.0 \mathrm{ft}$ ). The effective screen height, or the height of the screen between the screen invert (approx. El. $-37 \mathrm{ft}$ ) and low water level (approx. El $-1.75 \mathrm{ft}$ ), is approximately at El. $35.25 \mathrm{ft}$ in order to maintain a maximum $0.5 \mathrm{ft} / \mathrm{sec}$ approach velocity. The requisite screenhouse would have to be $177 \mathrm{ft}$ wide in order to accommodate the ten 14 - $\mathrm{ft}$ wide screens and concrete screenbay walls that would be required. 

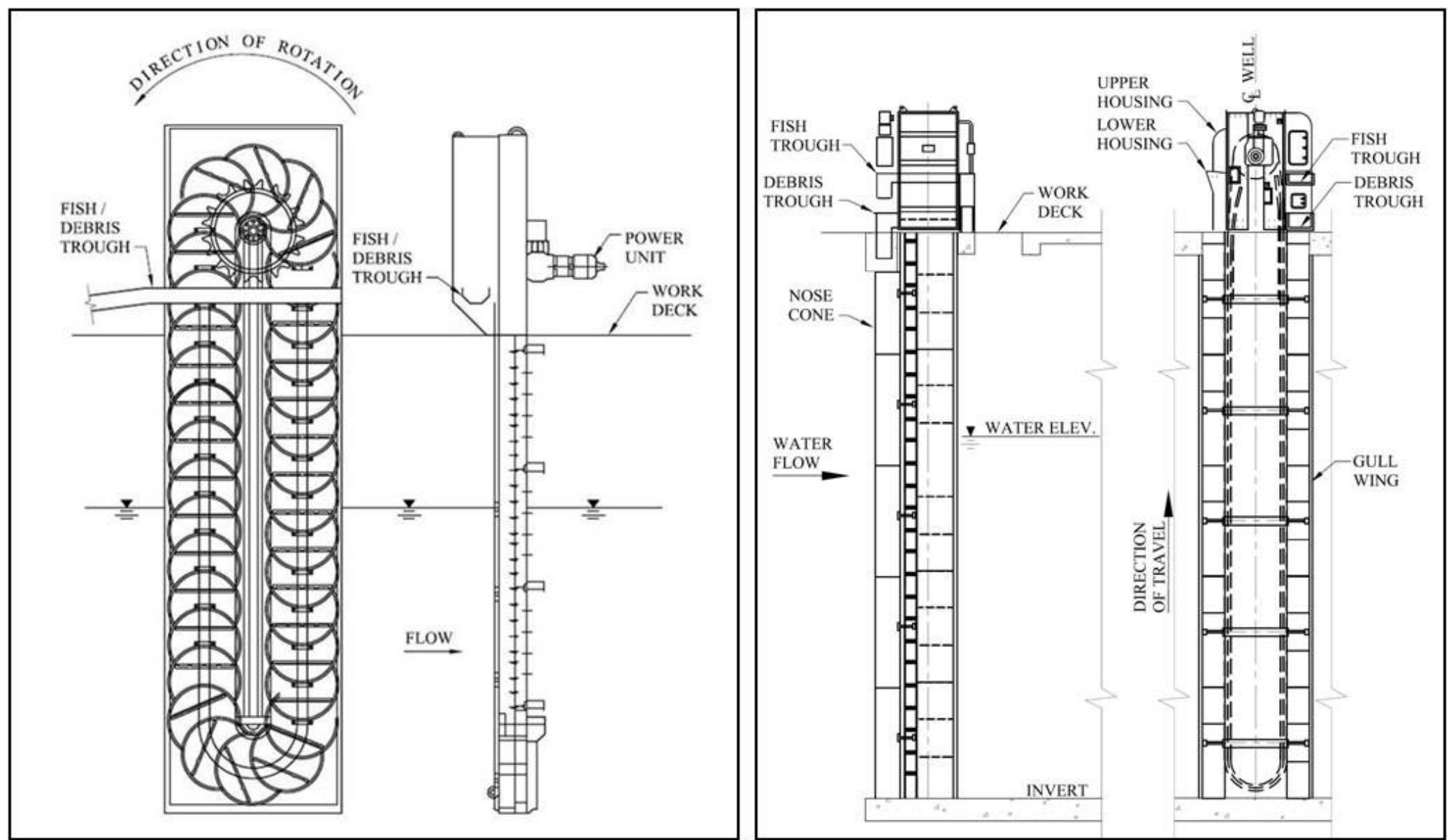

Figure C-12. Plans and sections of a typical rotary-disc screen (left) and typical dual-flow screen (right). 


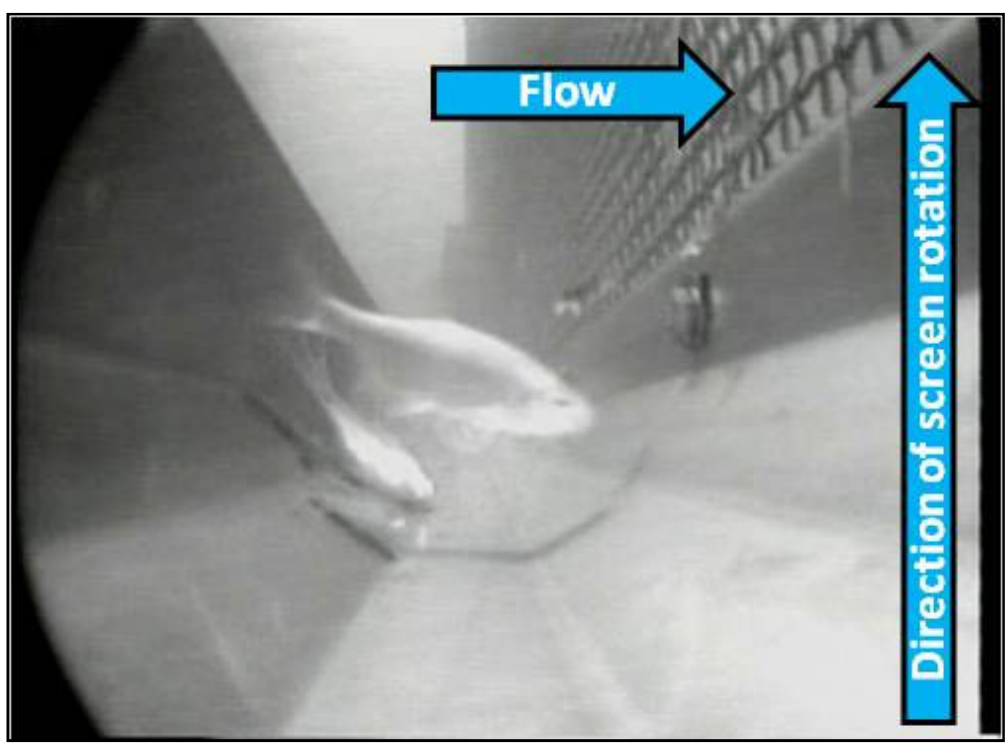

Figure C-13. Fish collected in a lifting bucket of a modified traveling water screen during a laboratory evaluation.

Modified traveling water screens could be used in two different general intake configurations at the proposed Port Allen facility. Water could be withdrawn from an offshore location and delivered to an onshore screenhouse or water could be withdrawn from a shoreline location through an onshore screenhouse. These two options are described in more detail below.

\subsubsection{Modified Traveling Water Screens - Offshore Intake Location}

An offshore intake (Figure C-14) would be comprised of an intake tunnel or pipe with a velocity cap at the offshore terminus. The velocity cap would be designed with coarselyspaced bar racks to prevent large debris and organisms from entering the intake (Figure C15). The velocity cap would be located at distance of $1,000 \mathrm{ft}$ or more from the shoreline (approximately 1,300-ft total length) at a depth that provides the required submergence for the intake and for navigation in the area. Flow entering the velocity cap would be piped to an onshore screenhouse located adjacent to the proposed OTEC facility onshore. This onshore screenhouse would require a fish return system to transfer collected organisms back to the source waterbody. Figure C-14 presents the conceptual design of a modified traveling water screen intake system with an offshore velocity cap intake. 


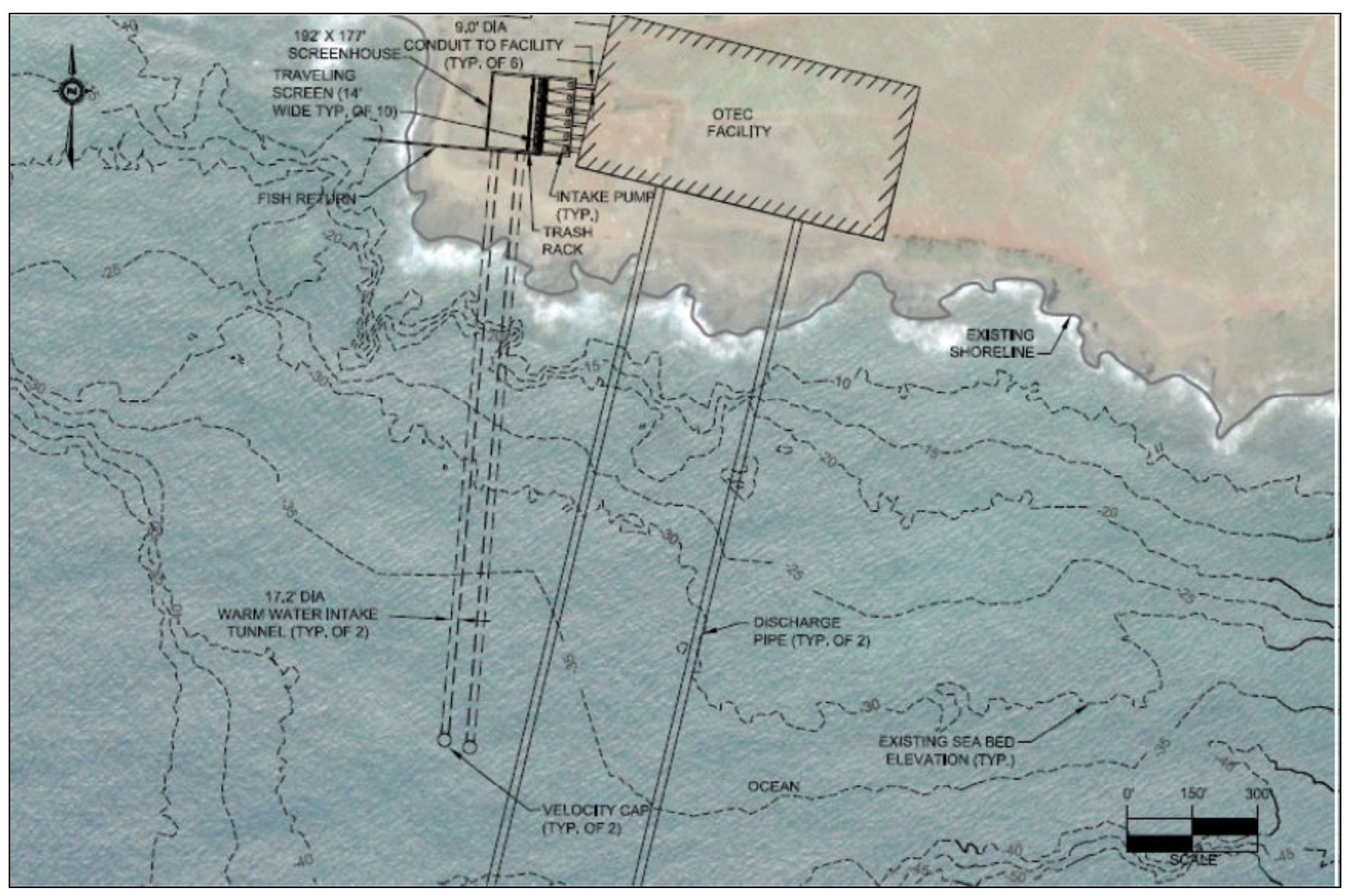

Figure C-14. Conceptual design of proposed offshore intake with velocity cap and onshore modified traveling water screenhouse. 


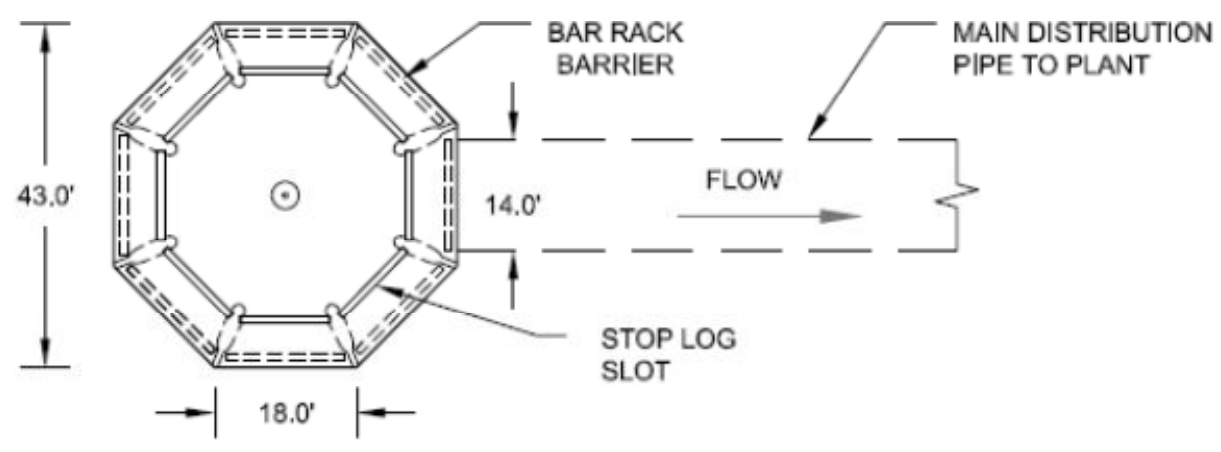

\section{VELOCITY CAP - PLAN}
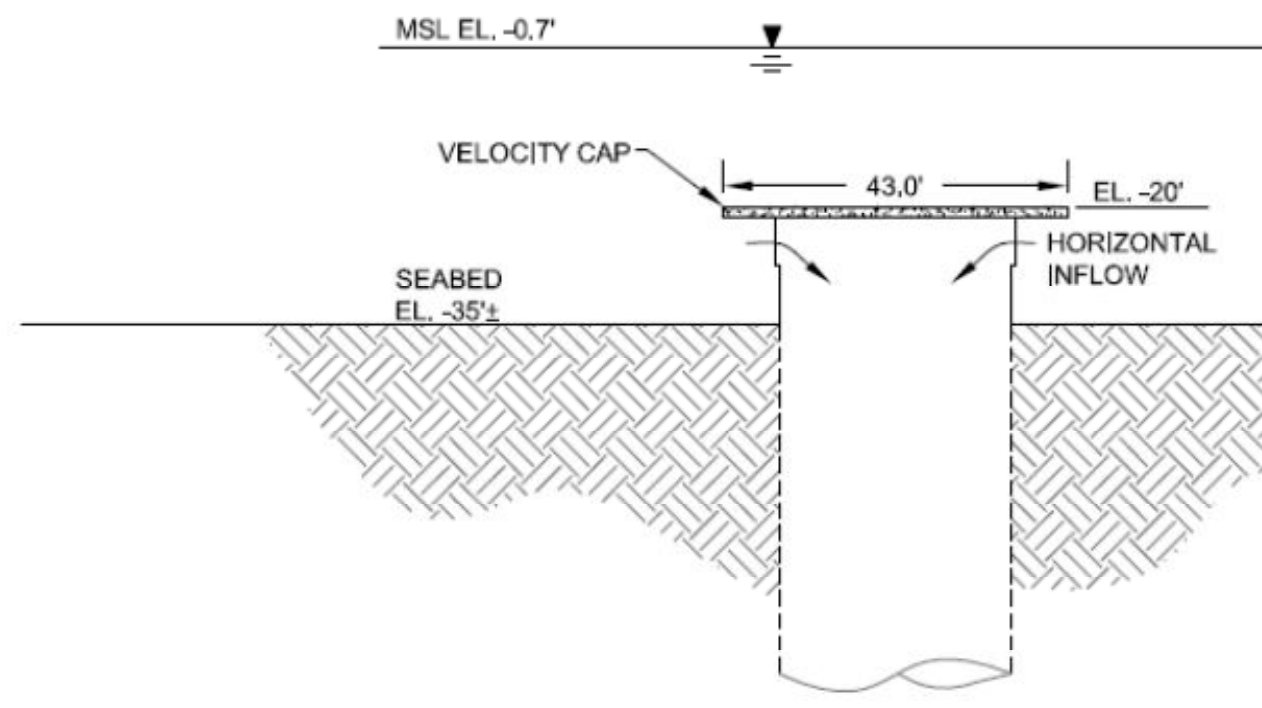

VELOCITY CAP - SECTION

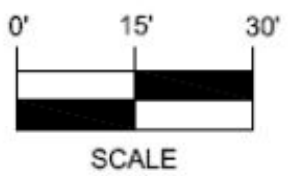

Figure C-15. Plan and section of velocity cap for offshore intake for proposed Port Allen site. 


\subsubsection{Modified Traveling Water Screens - Onshore Intake Location}

An onshore intake (Figure C-16) would also require a bar rack structure to exclude large debris and organisms. A breakwater also would be required in order to protect the screenhouse from large ocean swells. Additional consideration would have to be given to the presence/location of coral reefs and navigation channels and how this may impact the breakwater design. Biological activity would also be expected to be greater in this nearshore environment than further offshore. As with the offshore intake described above, this onshore screenhouse would require a fish return system to transfer collected organisms back to the source waterbody. Figure C-16 presents the conceptual design of an onshore modified traveling water screen intake system.

An onshore intake would be less expensive to construct than an offshore intake. However, it is expected that biological productivity (e.g., presence of coral and high density of marine life) will be considerably greater in the vicinity of the onshore location than in the offshore location. Therefore, a shoreline intake may be less attractive for environmental and permitting reasons. 


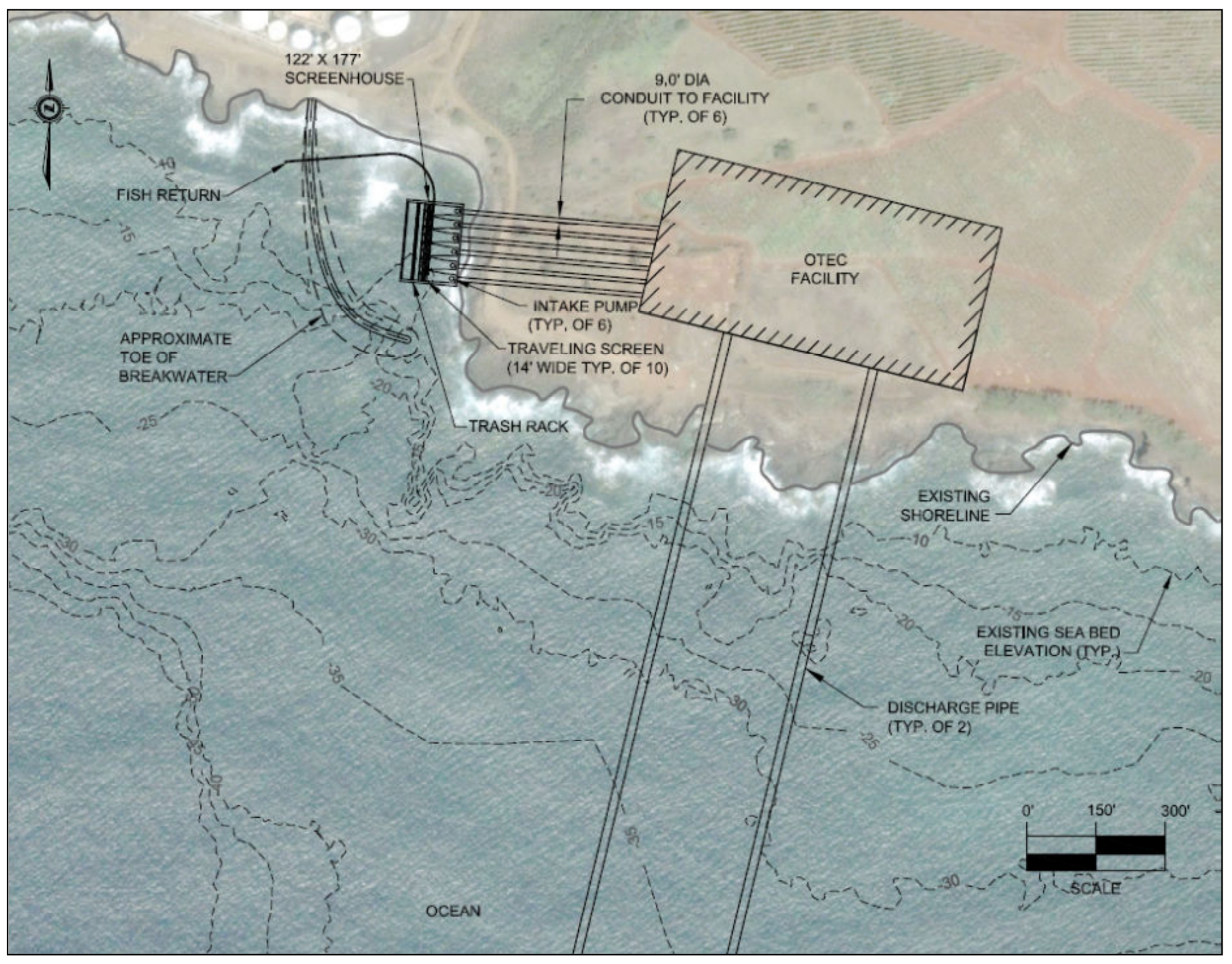

Figure C-16. Conceptual design of proposed onshore intake with modified traveling water screens. 


\subsection{Cylindrical Wedgewire Screens $(0.5,2.0$, and $9.5 \mathrm{~mm})$}

Cylindrical wedgewire screens are an exclusion technology that could be installed at the proposed OTEC facility to reduce IM\&E. The percent exclusion is based on the screen slot width and the size of the organisms. Based on previous research, cylindrical wedgewire screens designed with a $0.5 \mathrm{ft} / \mathrm{sec}$ through-slot velocity will virtually eliminate impingement and wedgewire screens with narrow slots $(0.5-$ and $2.0-\mathrm{mm})$ should also minimize entrainment of many species and lifestages.

Similar to the modified traveling water screen alternative above, the slot widths evaluated include $0.5,2.0$, and $9.5 \mathrm{~mm}$. These screens range from 1 to $10 \mathrm{ft}$ in diameter and have two screen sections, mounted to a center " $\mathrm{T}$ " section. A plan of a typical T-120 (120-in. diameter) cylindrical wedgewire screen is shown in Figure C-17. The selected design includes the use of T-120 cylindrical wedgewire screens. Each screen's total length would be $32.5 \mathrm{ft}$. Assuming a $0.5 \mathrm{ft} / \mathrm{sec}$ target through-slot velocity, the number of screens required for a warm water flow of 1,472 MGD would be approximately 41, 18, and 9 for screens with $0.5-\mathrm{mm}, 2.0-\mathrm{mm}$ and $9.5-\mathrm{mm}$ slot sizes, respectively (Table C- 3 ).

Table C- 3. Number of T-120 wedgewire screens required for each slot size considered. Through-slot

\begin{tabular}{ccc}
$\begin{array}{c}\text { Slot size } \\
\text { (mm) }\end{array}$ & $\begin{array}{c}\text { velocity } \\
\text { (ft/sec) }\end{array}$ & $\begin{array}{c}\text { Number of T- } \\
\mathbf{1 2 0} \text { screens }\end{array}$ \\
\hline 0.5 & 0.5 & 41 \\
2.0 & 0.5 & 18 \\
9.5 & 0.5 & 9 \\
\hline
\end{tabular}

Unlike the previous alternative, wedgewire screens are not considered for shoreline deployment since the large number of screens required would result in a shoreline intake that is not feasible for construction. Rather, the screens would be mounted offshore at the end of two intake tunnels, approximately $17.2 \mathrm{ft}$ in diameter. These tunnels would extend approximately 1,559, 1,329, and 1,329 ft offshore from the pumphouse, for the 0.5-, 2.0-, and $9.5-\mathrm{mm}$ screens, respectively. These are the distances required to ensure that a clearance of at least $20 \mathrm{ft}$ above the top of the screens is provided for navigational purposes. The 0.5-, 2.0-, and 9.5-mm screens would be mounted on manifolds running perpendicular to the intake tunnels in order to provide optimal flow conditions through the screens. Conceptual designs for the 0.5-, 2.0-, and 9.5-mm screen slot sizes are provided below in Figure C-18, Figure C-19, and Figure C-20, respectively.

Biofouling of wedgewire screens in the marine environment of the Pacific Ocean is a potential concern. Therefore the screens would be constructed of a corrosion-resistant 70- 
30 copper-nickel alloy (Z-alloy). Past studies have indicated that copper alloys can significantly reduce biofouling (Wiersema et al. 1979; Weisberg et al. 1986). An air backwash is typically used to periodically clean the face of a cylindrical wedgewire screen of accumulated debris and biofouling. The release of air on the inside of the screen creates a scouring action on the screen as it rises and passes through the narrow slots. The air compressor and requisite controls are typically located onshore with compressed air being piped to each wedgewire screen. However, due to the distance of the wedgewire array from the shore, the delivery of compressed air is not considered to be a feasible cleaning option. The location of the screen arrays offshore should expose them to ambient sweeping currents that may contribute to keeping the screens clean. To remove debris that may have accumulated on the screens, Alden has assumed that each screen would periodically need to be cleaned manually by divers. Due to site-specificity, the frequency of cleaning would have to be determined either through pilot testing or once the screens are installed and data are available on the rate of biofouling.
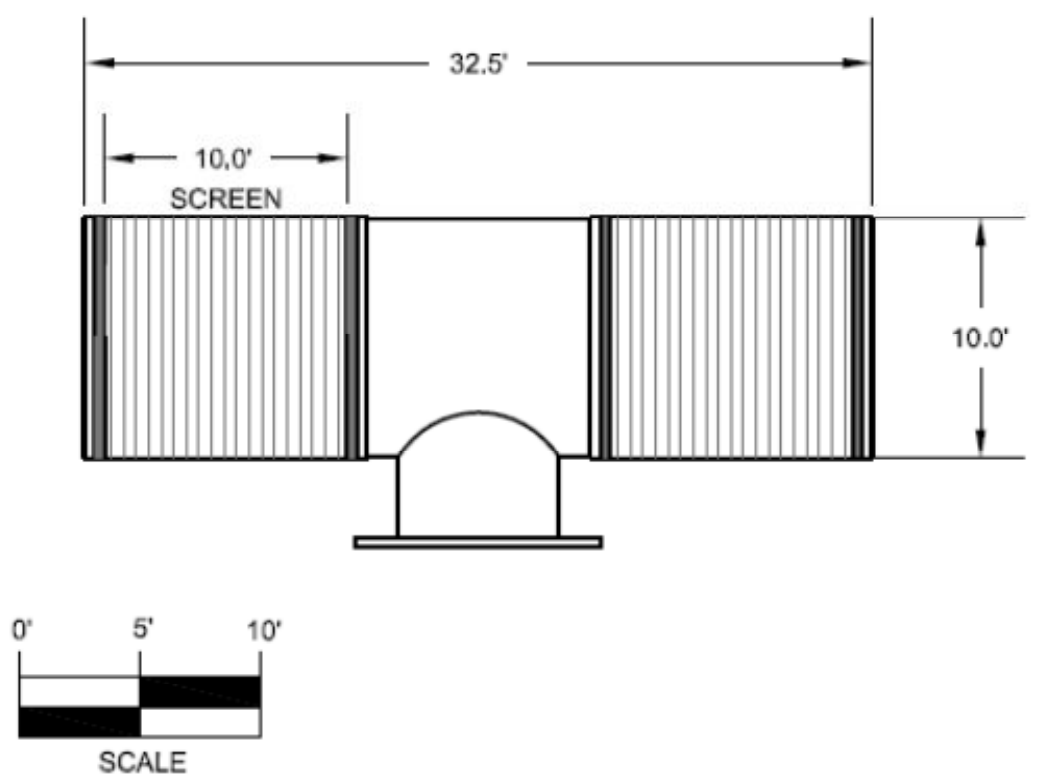

Figure C-17. Plan of a typical T-120 cylindrical wedgewire screen for proposed Port Allen site. 


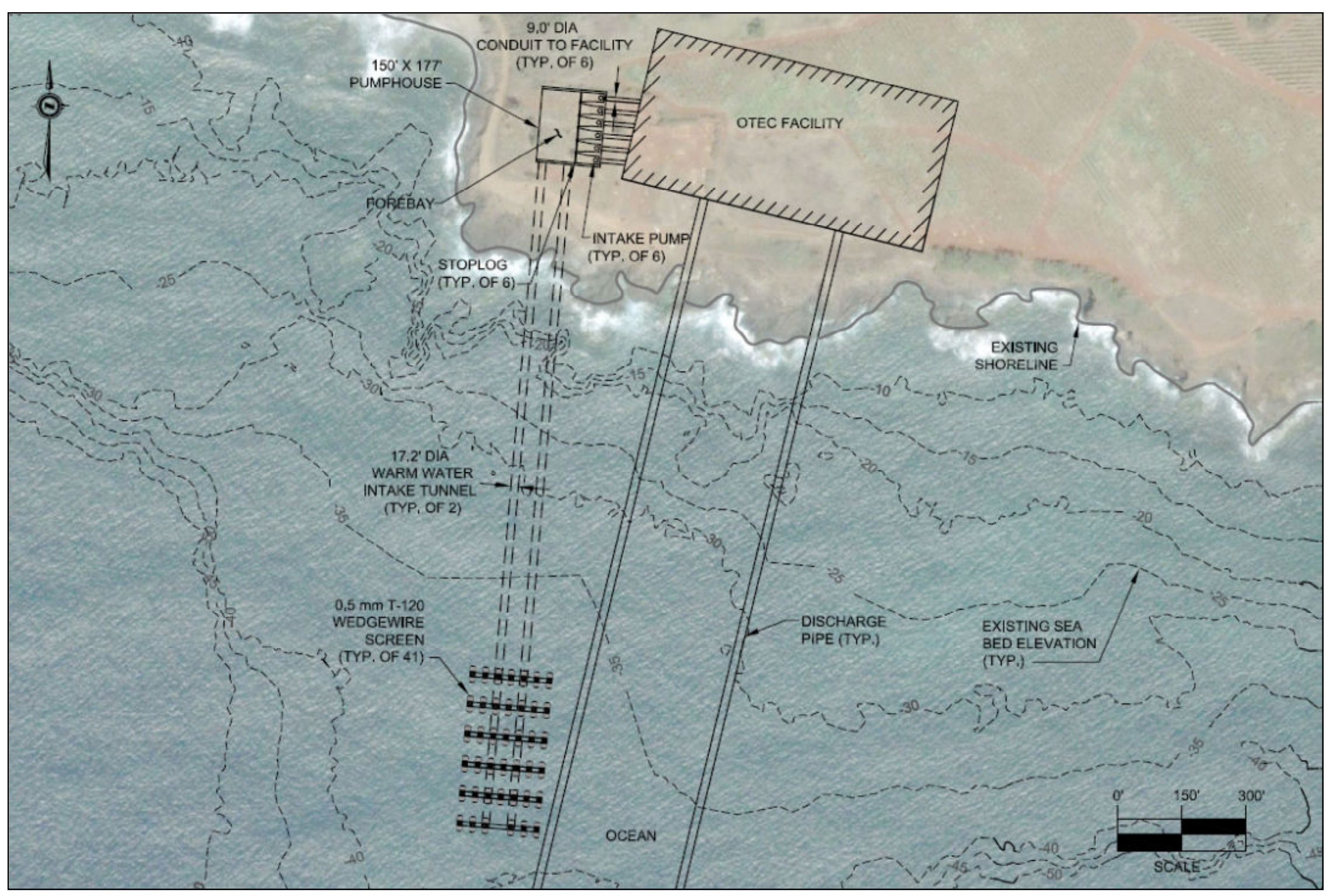

Figure C-18. Conceptual design of proposed 0.5-mm cylindrical wedgewire intake. 


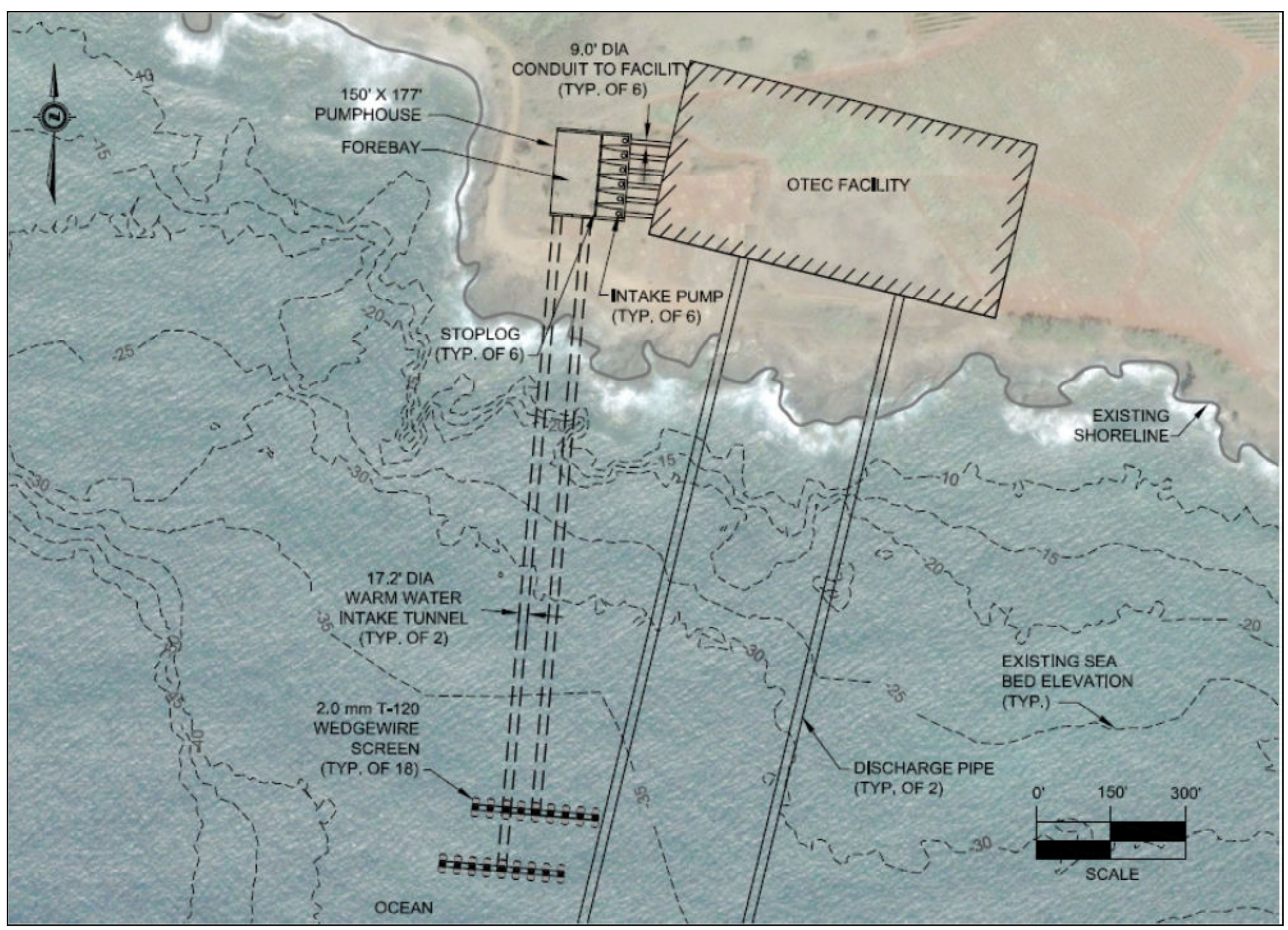

Figure C-19. Conceptual design of proposed 2.0-mm cylindrical wedgewire intake. 


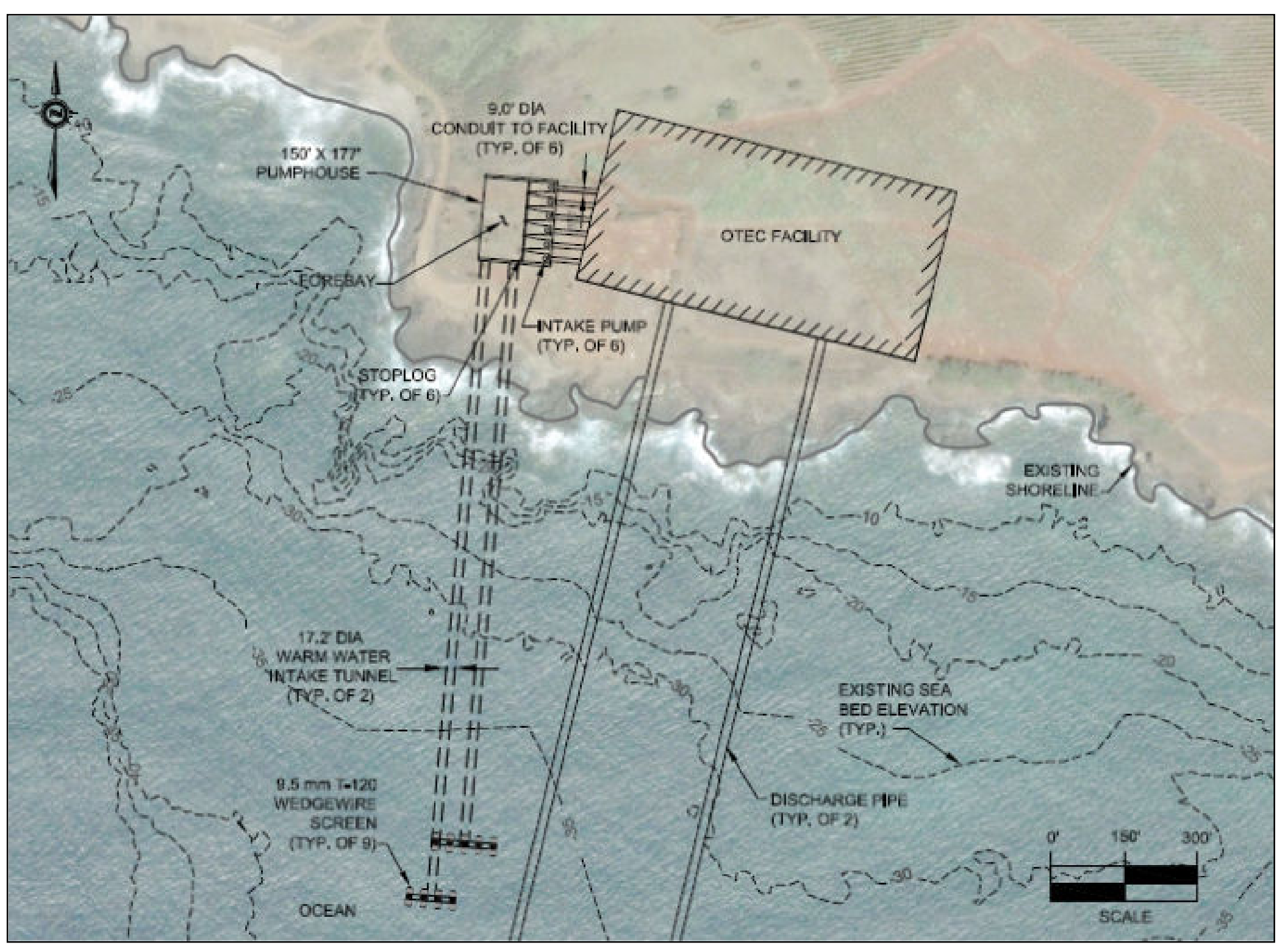

Figure C-20. Conceptual design of proposed 9.5-mm cylindrical wedgewire intake. 


\subsection{Modular Inclined Screens (MIS)}

The modular inclined screen (MIS) is a relatively new diversion technology that is designed to divert, collect, and transport fish back to the source waterbody. An MIS module consists of a square entrance, upstream and downstream stoplogs (for de-watering), an inclined screen set at a shallow angle ( 10 to 20 degrees) to the flow, and a bypass for directing diverted fish to a transport pipe (Figure C-21). Each module is completely enclosed and is designed to operate at relatively high water velocities ranging from 2 to $10 \mathrm{ft} / \mathrm{sec}$, depending on the species and lifestages to be protected.

Research indicates that the MIS is effective in safely bypassing a number of species and life stages (EPRI 1994; EPRI 1996; Taft et al. 1997). With a screen mesh slot size of $2.0 \mathrm{~mm}$, the MIS would have potential to minimize impingement mortality and possibly entrainment. However no data are available relative to the passage efficiency or survival of Hawaiian species through an MIS.

At the proposed Port Allen OTEC facility, six MIS modules could be installed at the onshore terminus of the intake tunnels. The coarsely screened water would travel through the offshore velocity caps, through the intake tunnels to a plenum, from which each module would draw the intake flow. The individual modules would have a 14 -ft square approach area. Based on the total flow requirements, the average approach velocity to each MIS would be $2.5 \mathrm{ft} / \mathrm{sec}$. The headloss through the screen would be approximately $1 \mathrm{ft}$ in a clean condition. A conceptual design of the MIS intake is shown in Figure C-22.

Cleaning of the screens would be necessary to minimize adverse impacts on facility operation resulting from debris accumulation (i.e., additional head losses) and to maintain the fish diversion efficiency of the inclined screens. The screens are cleaned by pivoting them to backwash the debris from the screen face (see Figure C-21). Because the screens would be operated continuously year round in a tropical environment, approximately one hour per day should be devoted to the operation and maintenance of these screens. In doing so, each screen would have to be offline for that hour. However, screen downtime can be staggered such that no less than four screens are operating at any one time. The conceptual design (Figure C-22) includes an additional MIS module so that during cleaning, full-plant flow remains uninterrupted.

The fish bypass flow from each module would travel in a 3-ft diameter pipe (ensuring a velocity of less than $4 \mathrm{ft} / \mathrm{sec}$ ) to a sump. Three fish-friendly pumps would transport the fish from the sump to a fish return pipe $6 \mathrm{ft}$ in diameter. To minimize the potential for recirculation of returned organisms, the fish return pipe would discharge to a location approximately $100 \mathrm{ft}$ from the shore where existing currents could aid in preventing recirculation.

All the ancillary issues associated with fine-mesh modified traveling screens, such as return to a safe location in the source waterbody, apply to the MIS. Biofouling of the screen mesh 
also may be an issue; however, the high approach velocity in conjunction with use of Zalloy screens should reduce the effects of biofouling. 

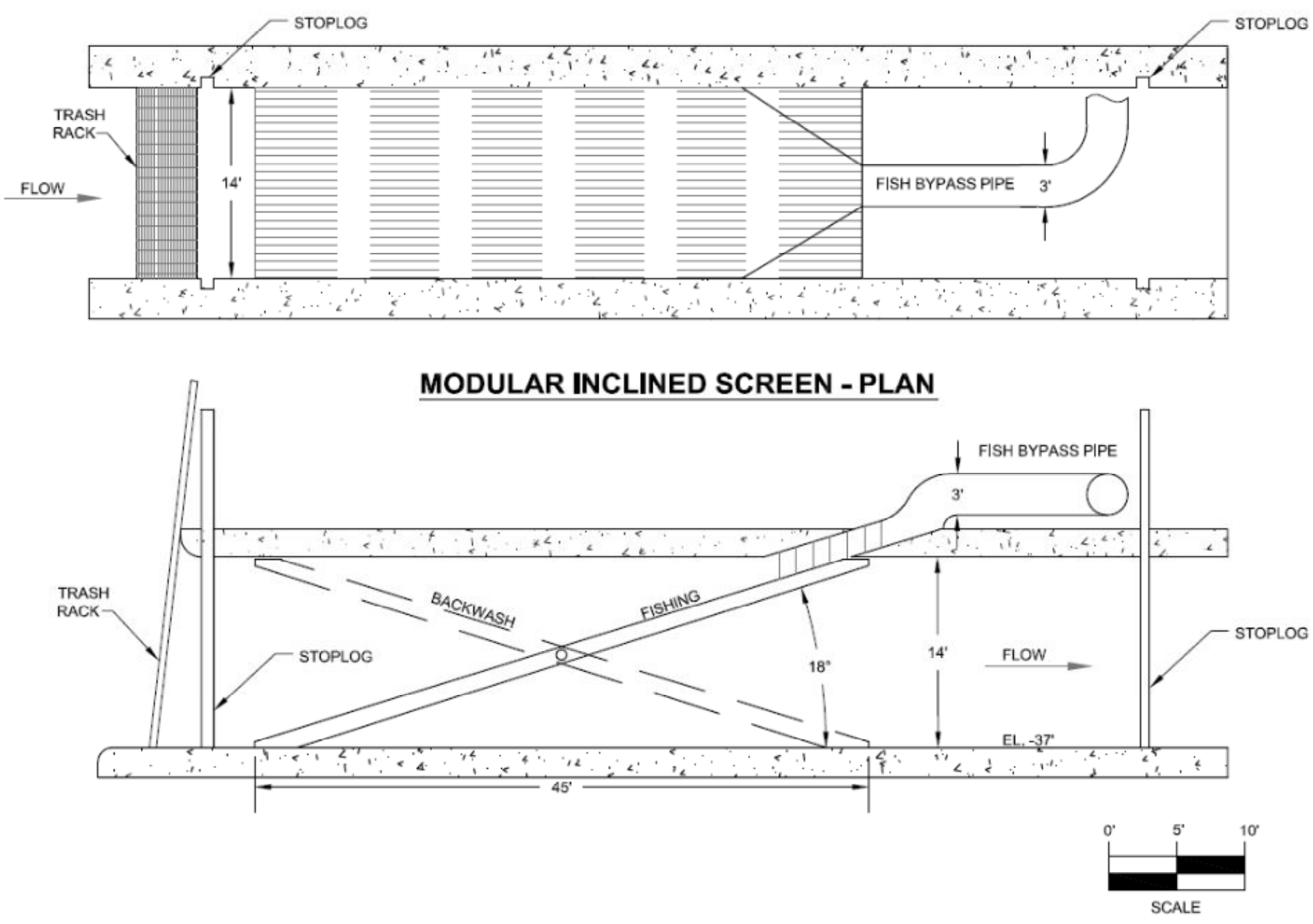

MODULAR INCLINED SCREEN - SECTION

Figure C-21. Plan and Section of a modular inclined screen (MIS) for the proposed Port Allen site. 


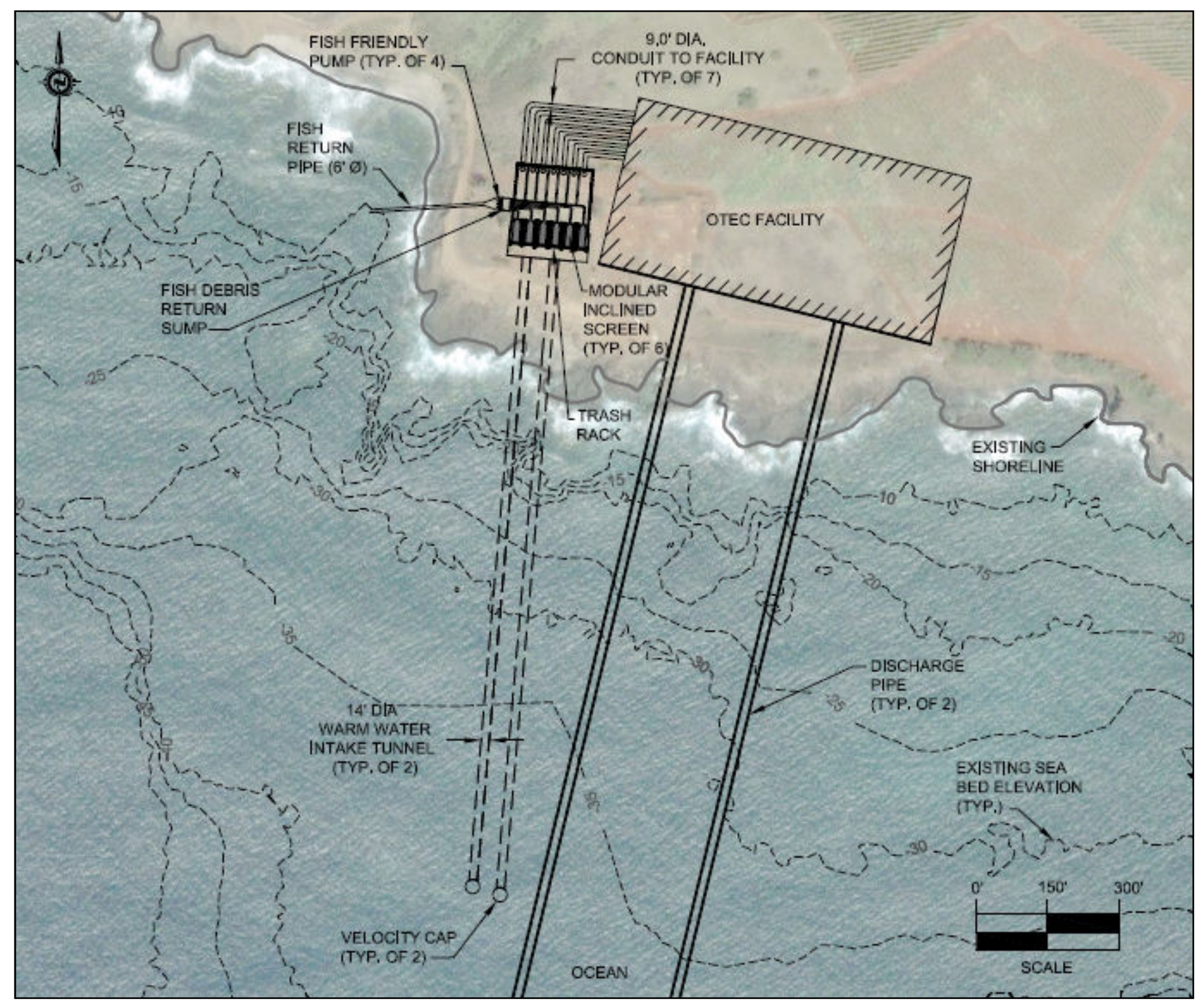

Figure C-22. Conceptual design of proposed 2-mm modular inclined screen (MIS) intake. 


\section{INTAKE TECHNOLOGIES SELECTED FOR CONCEPTUAL DESIGN AND PRELIMINARY COST ESTIMATION}

Due to the large volume of water required, the warm water intake structure will be large and will likely require substantial civil works. Furthermore, potentially strict intake criteria imposed by regulatory agencies to protect aquatic organisms from impingement and entrainment (i.e., small screen mesh size and low intake velocities) have the potential to significantly impact the size, type, and cost of intake required. Therefore, the cost of implementing the technologies selected for application at the proposed Port Allen OTEC facility's warm water intake is another practical consideration that will impact the feasibility of constructing a plant at this site.

Based on the conceptual designs discussed in Section 5, the following intakes were selected for further conceptual development and for preliminary cost estimation:

- Fine-mesh (2-mm) modified traveling water screens with offshore velocity cap intake;

- Fine-mesh (2-mm) modified traveling water screens with onshore intake; and

- Narrow-slot (2-mm) cylindrical wedgewire screens.

A single screen mesh/slot size $(2 \mathrm{~mm})$ was chosen for each alternative to allow better comparison among the options. In addition, $2-\mathrm{mm}$ is a compromise between the 0.5 - and 9.5-mm meshes/slot sizes evaluated in the earlier sections of this report. While $9.5 \mathrm{~mm}$ is not likely to be acceptable to resource agencies for protection of marine life, $0.5 \mathrm{~mm}$ is not likely to be acceptable for the Port Allen OTEC facility due to cost and operational reasons. Note that the MIS alternative (Section 5.3) is not included in this section since its costs are not as well defined due to the fact that it has yet to be built at a full scale.

Preliminary design calculations required to complete the preliminary cost estimate assume an approach velocity of $0.5 \mathrm{ft} / \mathrm{sec}$ for the traveling water screen alternatives and a throughscreen velocity of $0.5 \mathrm{ft} / \mathrm{sec}$ for the wedgewire screen alternative.

The conceptual designs presented in Section 5 of this report were used as the basis for design refinement and development of initial costs based on quantity take-offs of materials, equipment and labor. In addition, data from similar projects were used as well as best professional judgment based on intake design experience. Where necessary, the conceptual designs presented in Section 5 have been refined in Section 6 to provide better resolution on costs. The costs and designs generated are preliminary in nature and are intended only for order-of-magnitude comparisons between the options selected.

The cost estimates presented assume the following:

- Present-day prices and fully contracted labor rates as of 2011; 
- Forty-hour work-week with single-shift operation for construction activities;

- Direct costs for material and labor required for construction of all project features. The direct costs also include distributable costs for site non-manual supervision, temporary facilities, equipment rental, and support services incurred during construction. These costs have been taken as $85 \%$ of the total cost for each alternative;

- Indirect costs for labor and related expenses for engineering services to prepare drawings, specifications and design documents. The indirect costs have been taken as $10 \%$ of the direct costs for each alternative;

- Allowance for indeterminates to cover uncertainties in design and construction at this preliminary stage of study. An allowance for indeterminates is a judgment factor that is added to estimate figures to complete the final cost estimate, while still allowing for other uncertainties in the data used in developing these estimates. The allowance for indeterminates has been taken as $10 \%$ of the direct, distributable, and indirect costs of each alternative; and

- Contingency factor to account for possible additional costs that may develop but cannot be predetermined (e.g., labor difficulties, delivery delays, weather). The contingency factor has been taken as $15 \%$ of the direct, distributable, indirect, and allowance for indeterminate costs of each concept.

Certain costs have not been included in this analysis since they are typically part of later design stages for a project of this size and will depend heavily upon the final site selected for the intake. At this time, the project costs do not include the following items that should be included later to obtain total capital cost estimates:

- Costs to perform additional engineering, laboratory or field studies that may be required, such as hydraulic model studies, biological evaluations of prototype fish protection systems, soil sampling, geotechnical borings, hydrography, geophysical surveys and wetlands delineation and mitigation;

- Costs to dispose of any hazardous or non-hazardous materials that may be encountered during excavation and dredging activities;

- Costs for administration of project contracts and for engineering and construction management;

- Price escalation;

- Permitting costs;

- Energy costs;

- Financing cost; and

- Cost of delays.

A discussion of estimated project costs for the selected fish protection options is presented in Sections 6.1 through 6.3. Table C- 4provides a summary of estimated total capital costs 
for each alternative selected.

Table C- 4. Total estimated capital costs of intake alternatives

\begin{tabular}{|l|c|}
\hline Intake Alternative & $\begin{array}{c}\text { Estimated Total Capital Cost } \\
\text { (\$) }\end{array}$ \\
\hline $\begin{array}{l}\text { Fine-mesh (2-mm) Modified Traveling Water } \\
\text { Screens with Offshore Velocity Cap Intake }\end{array}$ & $\$ 198,446,000$ \\
\hline $\begin{array}{l}\text { Fine-mesh (2-mm) Modified Traveling Water } \\
\text { Screens with Onshore Intake }\end{array}$ & $\$ 123,038,000$ \\
\hline $\begin{array}{l}\text { Narrow-slot (2-mm) Cylindrical Wedgewire } \\
\text { Screens with Offshore Intake }\end{array}$ & $\$ 210,208,000$ \\
\hline
\end{tabular}

The conceptual designs discussed in Section 5 were refined as part of developing the preliminary cost estimates. A discussion of these refinements is provided in Sections 6.1 through 6.3. Note that not all design features are discussed, only those which have been updated and those which significantly influence project cost.

Table C- 4 indicates that estimated costs for a warm water OTEC intake at Port Allen will be between approximately $\$ 120,000,000$ and $\$ 210,000,000$. The highest-cost alternative is estimated to be the fine-mesh cylindrical wedgewire screens located offshore. The principal cost drivers for the cylindrical wedgewire screen intake include the costly efforts to tunnel and construct the primary conveyance pipes as well as the installation of a series of header pipes and T-Screen modules. Additionally, there are anticipated challenges in the construction and installation of the offshore system, which will likely be completed without dewatering, that add to the total cost. Although the offshore velocity cap alternative has similar construction requirements, it is substantially less complex than the wedgewire screen installation since it does not require multiple headers pipes. The major components contributing to the total cost of the alternative that would use onshore traveling water screens with an offshore velocity cap are the cost of the tunneling and offshore conveyance pipes as well as the series of onshore forebay components such as the traveling water screens, stoplogs, and training wall structures which are required. The major components contributing to the total cost of the alternative that would use onshore traveling water screens within an onshore intake structure are the cost of forebay components (traveling water screens, stoplogs, and training wall structures) as well as the dredging of the intake lagoon and construction of protective breakwater structures.

\subsection{Fine-Mesh (2-mm) Modified Traveling Water Screens with Offshore Velocity Cap Intake}


The fine-mesh modified traveling water screen with an offshore velocity cap intake structure is designed to draw ocean water from approximately 1,330 ft offshore of the plant location at a maximum screen approach velocity of $0.5 \mathrm{ft} / \mathrm{sec}$. The use of a velocity cap as a protection measure at the offshore intake point provides a behavioral barrier by inducing a horizontal inflow vector versus a vertical inflow vector that would result from a vertical pipe riser without a cap. This behavioral barrier would minimize the entrapment of later life stages of fish (i.e., juveniles and adults) within the intake system. After passing through the velocity cap, the seawater would flow down through the pipe riser and then horizontally through the intake tunnels to the plant forebay, located on-shore. Once within the forebay, flow would pass through a trashrack, stoplog bays, and finally the modified traveling water screens before being draw into the pumping system. Several design refinements were made to the conceptual design presented in Section 5. The calculations indicated that rather than a total of two caps each with a flow opening of $3 \mathrm{ft}$ high and a diameter of $260 \mathrm{ft}$, a total of four caps each with a flow opening of $10 \mathrm{ft}$ high and a diameter of $40 \mathrm{ft}$ would be preferable for constructability reasons. The change in the number of total velocity caps required a change in the flow conveyances from the velocity caps to the primary distribution pipes. This resulted in two adjacent velocity caps directly connected to each of the two primary distribution pipes as shown in Figure C-23.

Previous estimates of the inside diameter (ID) of the primary conveyance pipe was $17.2 \mathrm{ft}$; however, further calculations indicated that an ID of approximately $14 \mathrm{ft}$ is preferable for several reasons. The vertical elevations and depth of water required over the velocity cap indicated that the cap location could be shifted closer to shore effectively reducing the total pipe length. The reduction in length reduced the head loss estimates allowing the potential for reduction in ID. Preliminary calculations estimate the total head loss through the pipe to be less than $1 \mathrm{ft}$ and the pipe velocity to be 7 to $8 \mathrm{ft} / \mathrm{sec}$. Head losses reduce pumping efficiency and should be minimized where possible

As shown in Figure C-24 (Section A-A, B-B), it is anticipated that the primary conveyance pipes will be constructed via tunneling through the existing bedrock. Tunneling was judged to be a preferable method of constructing flow conveyance structures as it provides for a low impact means of construction and long term operations. Tunneling provides an opportunity to convey flow from offshore while avoiding potential impacts to sensitive reef habitat (if it is determined that the design cannot be modified to avoid the reef) and other benthic habitat as well as reducing potential impact on navigation. However, the result is that the downstream invert elevation of the primary conveyance pipes is approximately $175 \mathrm{ft}$ below the estimated existing typical ground surface elevation in the proposed forebay area. As such, it can be seen in Figure C-24 (Section C-C) that the result is a vertical shaft in the southwest corner of the forebay which allows flow from the pipe invert elevation to rise and flow into the primary forebay area. Based upon existing elevation contours, as well as factors such as navigation, it has been assumed that the pipes will be tunneled through existing bedrock utilizing a tunnel boring machine (TBM). The updated 
design includes a set of headgates located within the forebay structure to allow for water control and maintenance requirements within the forebay. Finally, based on the updated design, the overall footprint of the forebay structure has been reduced from approximately $192 \mathrm{ft}$ by $178 \mathrm{ft}$ to $132 \mathrm{ft}$ by $178 \mathrm{ft}$. 


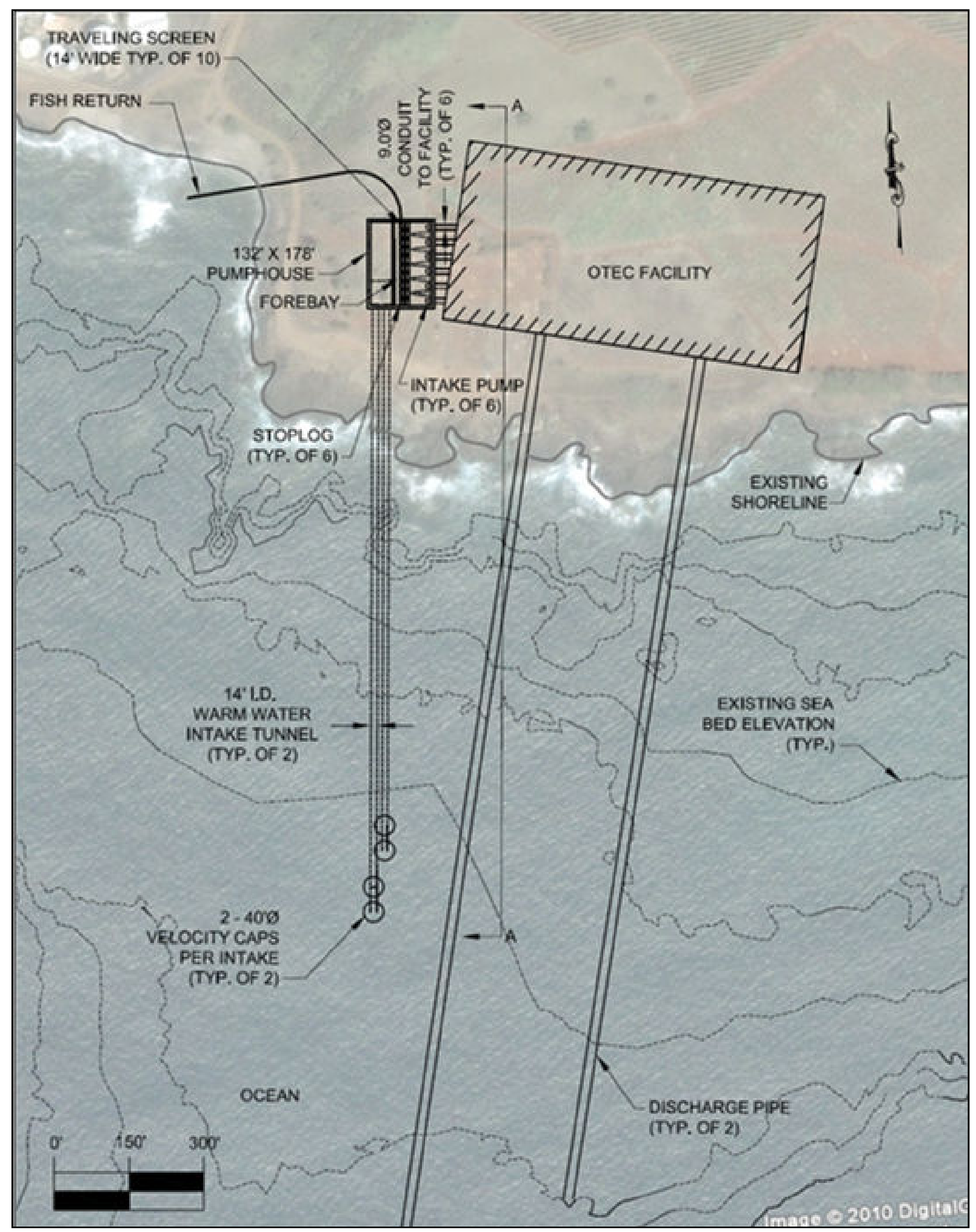

Figure C-23. Fine-mesh modified traveling water screens with offshore velocity cap (plan). 


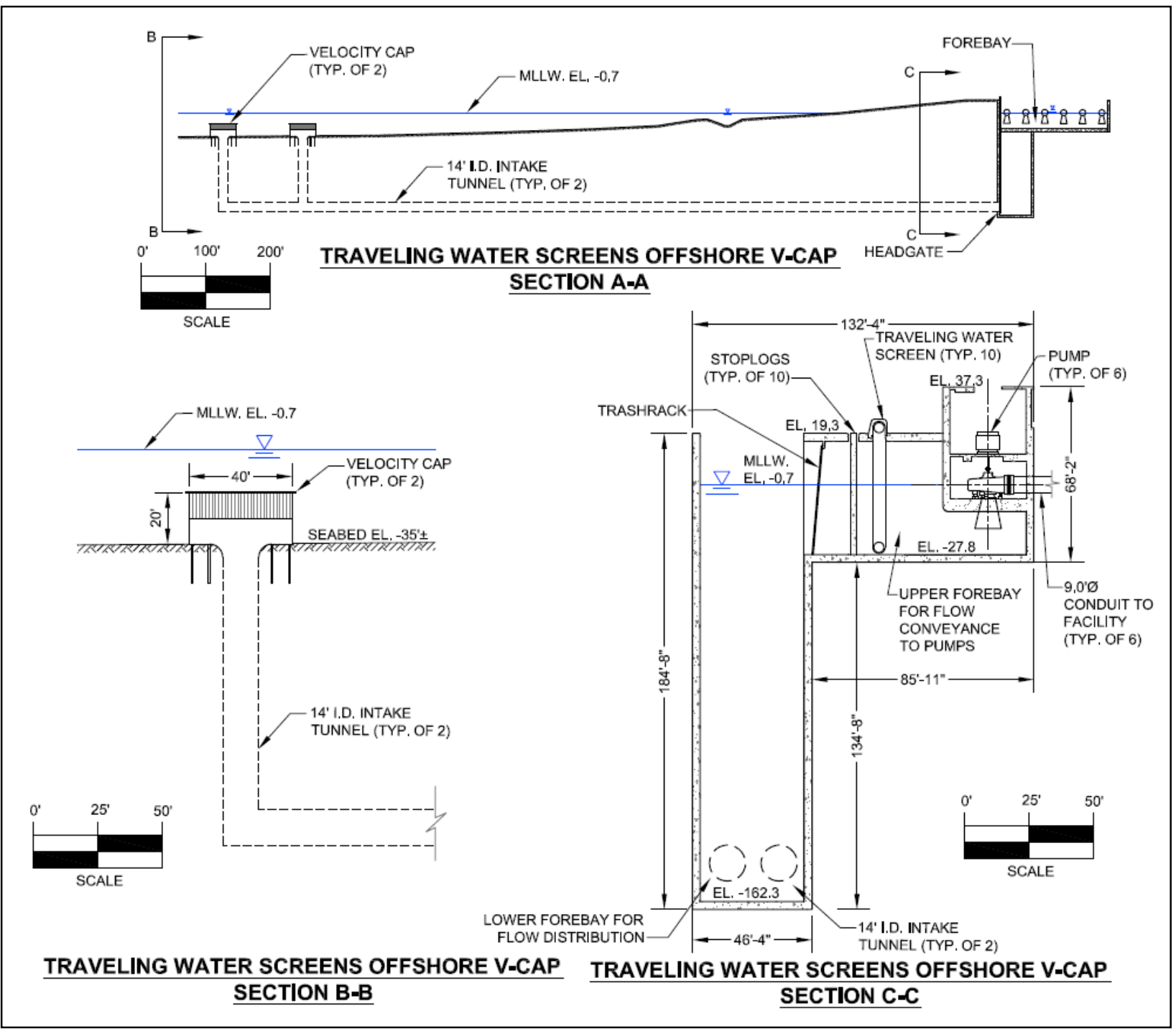

Figure C-24. Fine-mesh modified traveling water screens with offshore velocity cap (sections).

The major cost components of the modified traveling water screen with offshore velocity cap intake alternative have been itemized in Table C- 5. Mobilization and demobilization are assumed as $10 \%$ of the remaining direct costs. Major costs include: the construction of the primary distribution pipes (tunneling); installation (cranes, barges, and installation); as well as the traveling water screens themselves.

Due to the preliminary level of design, some costs were very conceptually estimated. The cost of tunneling is dependent upon a variety of factors including the subsurface conditions (material type, angle material, etc.), specific characteristics of the TBM utilized (power, cutting blade, rpm, etc.) and construction sequencing. As these factors cannot be determined without more detailed design, geotechnical borings, and consultation with 
tunneling consultants (among others), best estimates were made based upon available information. Research indicated that on a linear foot basis, the total cost of tunneling would be approximately $\$ 8,000,000$, while the total cost of an individual machine was on the order of $\$ 25,000,000$. At this time, it has been assumed that a single TBM would be purchased for the project at a cost of $\$ 25,000,000$.

Table C- 5. Summary costs for fine-mesh modified traveling water screens with offshore velocity cap.

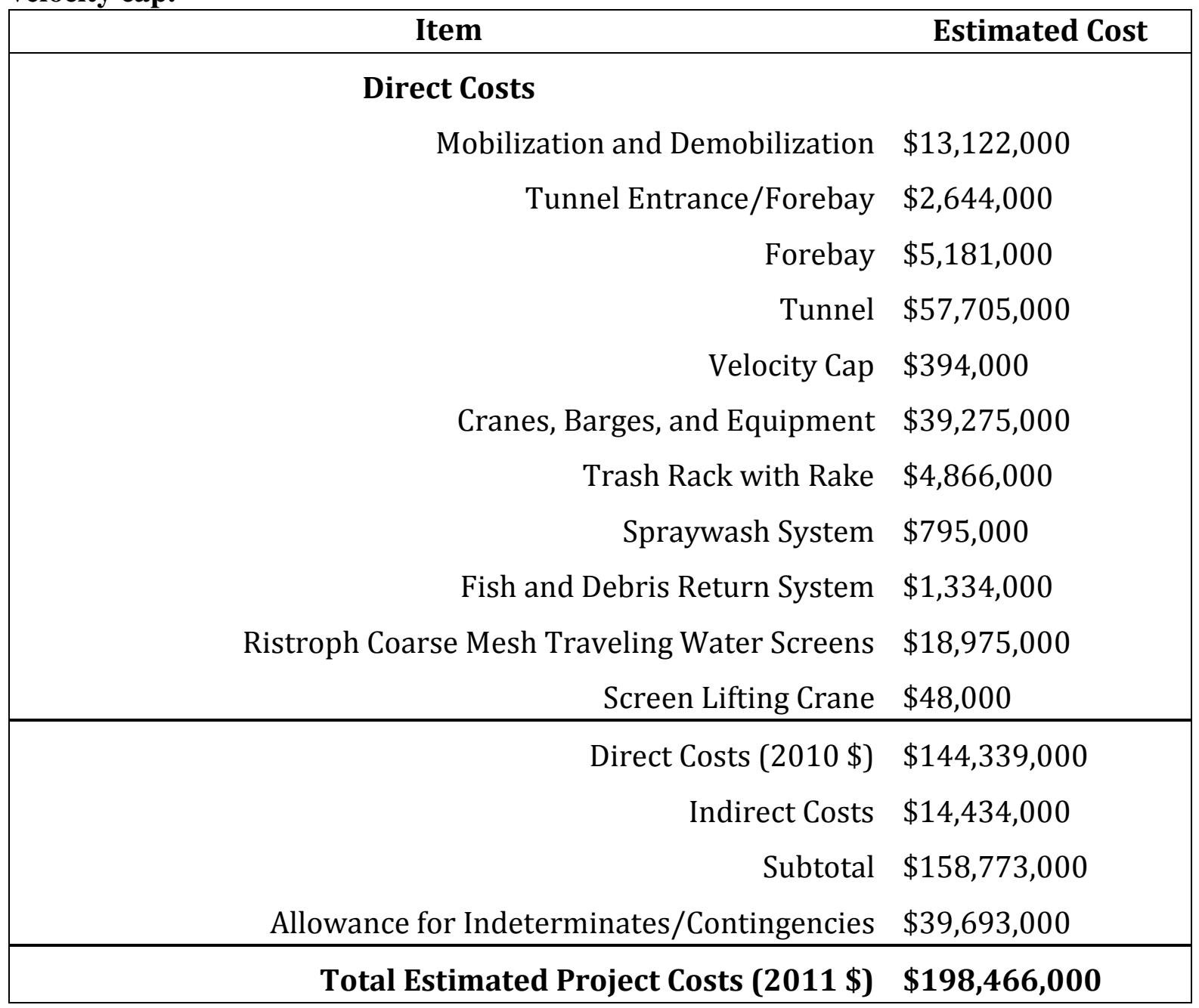




\subsection{Fine-mesh (2-mm) Modified Traveling Water Screens with Onshore Intake}

The installation of fine-mesh modified traveling water screens with an onshore intake is fundamentally similar to a typical cooling water intake structure at conventional thermal power plants. A forebay structure would be constructed onshore and flow would be conveyed directly from the adjacent ocean to the intake structure. Although this would eliminate the need for tunneling and pipes to convey seawater from an offshore location, some additional infrastructure will be required. Available oceanic current data indicates that prevailing currents travel parallel to the shoreline, generally from northwest to southeast (Figure C-3). To prevent erosion and damage to the intake structure from oceanic current and storm surges, a protective offshore breakwater and intake lagoon has been included in the cost estimate. This breakwater was initially presented in Section 5; however, the configuration has been slightly modified for enhanced flow conveyance. Additionally, a review of the existing elevations in the intake lagoon as well as the required forebay depth indicates that significant dredging will be required. This dredging will be limited to the intake lagoon.

As cooling water will flow directly into the forebay structure, a trashrack, stoplogs and modified traveling water screens will be required within the forebay structure. Based upon the peak design flow and velocity requirements, it has been estimated that 10 modified traveling water screens approximately $14 \mathrm{ft}$ wide and $47 \mathrm{ft}$ deep are required. 


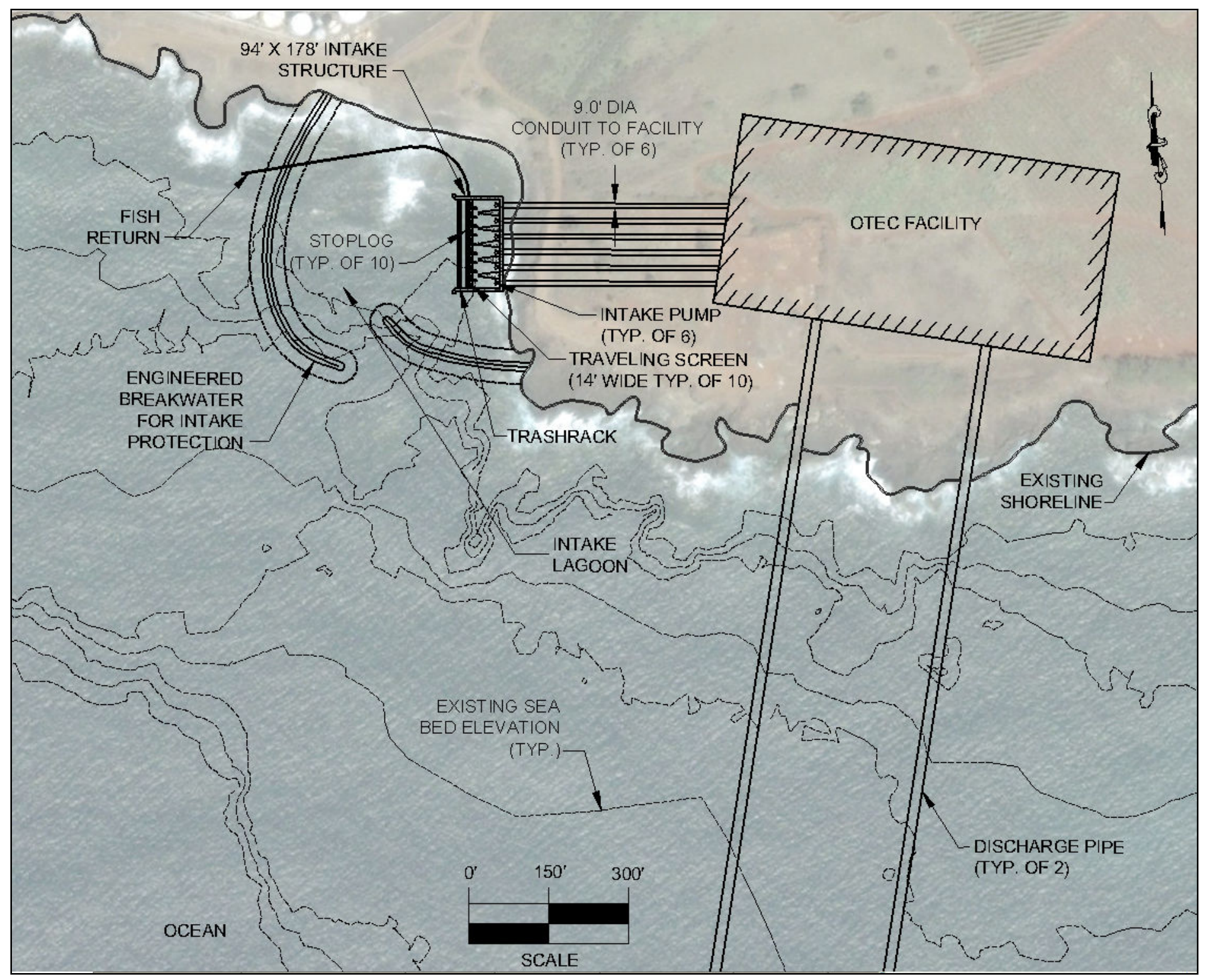

Figure C-25. Fine-mesh modified traveling water screens with onshore intake (plan). 


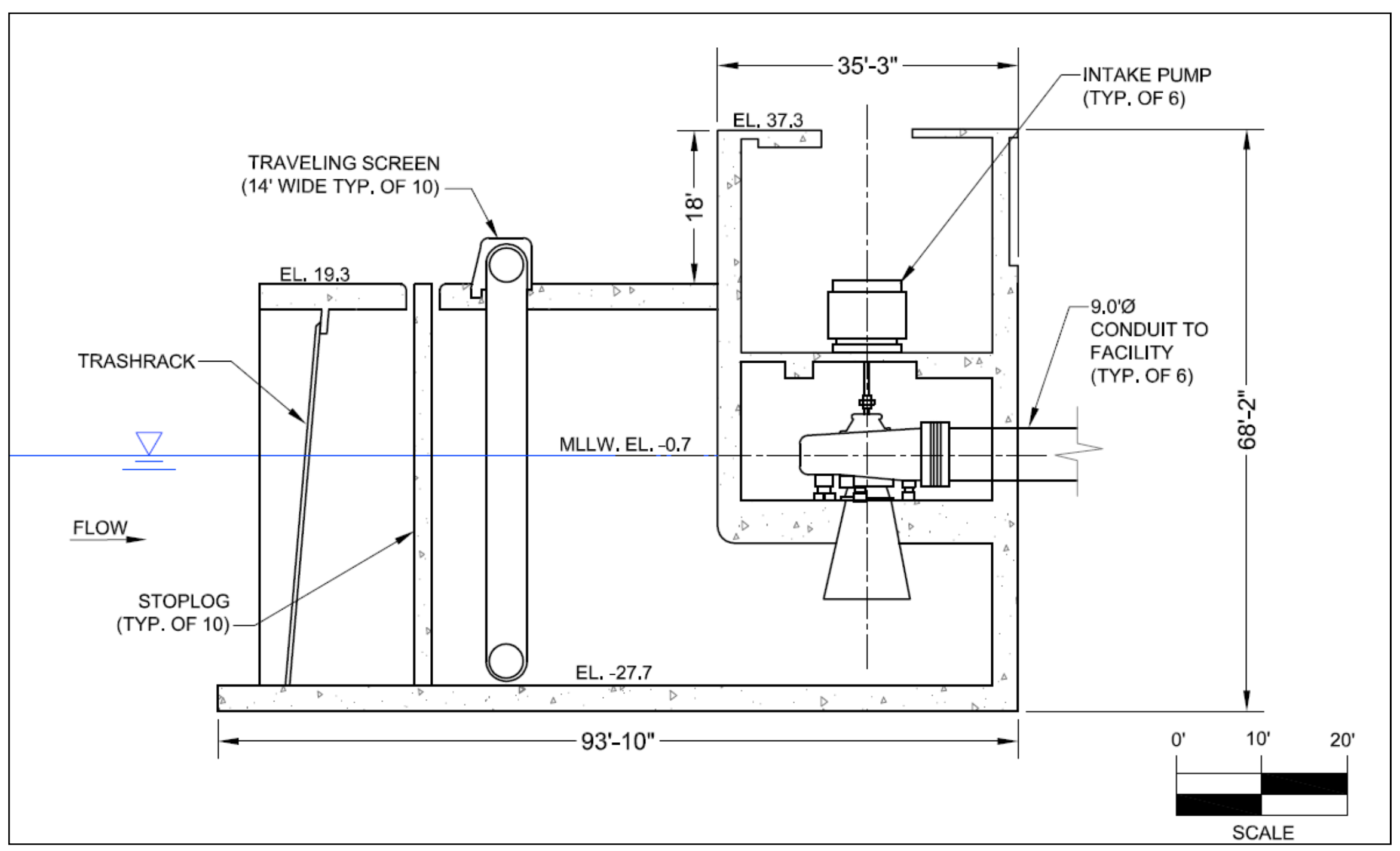

Figure C-26. Fine-mesh modified traveling water screens with onshore intake (section). 
Major cost components of the onshore traveling water screen intake alternative have been itemized in Table C- 6 . Mobilization and demobilization are assumed as $10 \%$ of the remaining direct costs. Major costs associated with the construction of the 2-mm onshore intake traveling water screen include the construction of the intake structure (excavation and concrete placement) as well as the traveling water screens themselves. Other alternatives have not required cofferdams and shoring due to water depth and configuration; however, this alternative did require additional water control structures.

Table C- 6. Summary costs for fine-mesh modified traveling water screen with onshore intake.

\begin{tabular}{|c|c|}
\hline Item & Estimated Cost \\
\hline \multicolumn{2}{|l|}{ Direct Costs } \\
\hline Mobilization and Demobilization & $\$ 8,135,000$ \\
\hline Cofferdam \& Shoring & $\$ 1,590,000$ \\
\hline Intake Structures & $\$ 40,842,000$ \\
\hline Trash Rack with Rake & $\$ 2,613,000$ \\
\hline Spraywash System & $\$ 5,228,000$ \\
\hline Fish and Debris Return System & $\$ 1,575,000$ \\
\hline Ristroph Coarse Mesh Traveling Water Screens & $\$ 19,709,000$ \\
\hline Screen Lifting Crane & $\$ 40,000$ \\
\hline Barges, Divers and Equipment & $\$ 9,750,000$ \\
\hline Direct Costs (2010\$) & $\$ 89,482,000$ \\
\hline Indirect Costs & $\$ 8,948,200$ \\
\hline Subtotal & $\$ 98,430,000$ \\
\hline Allowance for Indeterminates/Contingencies & $\$ 24,608,000$ \\
\hline Total Estimated Project Costs (2011 \$) & $\$ 123,038,000$ \\
\hline
\end{tabular}




\subsection{Narrow-slot (2-mm) Cylindrical Wedgewire Screens}

Cylindrical wedgewire screens are an exclusion technology that could be installed the proposed OTEC facility to reduce IM\&E. After passing through the fine-mesh cylindrical wedgewire screens, the seawater would flow down to a header pipe which concentrates and conveys it to one of the two primary distribution pipes. The primary distribution pipes would convey flow to the plant forebay located on-shore. Once flow has equilibrated within the forebay, it is directly utilized by the pumping structure. The means of conveying flows to the forebay is conceptually similar to that which is proposed from the offshore velocity cap; however, once within the forebay, no additional screening (such as trashrack or traveling water screens) is required as flow will have been adequately pre-screened by the 2-mm wedgewiare screens.

Changes to the conceptual design discussed in Section 5 have been made based upon a more detailed (but still preliminary) design. Primary flow conveyance from the offshore intake structure to the forebay structure would be via two 14- $\mathrm{ft}$ ID pipes. Previous pipe diameter estimates assumed an ID of approximately $17.2 \mathrm{ft}$. Similar to the discussion presented in Section 6.1 for the intake system utilizing a velocity cap, for several reasons, the proposed ID has been decreased to $14 \mathrm{ft}$. Further, after a review of the existing topography and elevation data, it was determined that the total pipe length could be reduced by shifting the previous design closer to shore. Additionally, the allowable headlosses have been altered as it was determined that up to a $1 \mathrm{ft}$ head loss through the system is acceptable by the facility developer. Based upon existing elevation contours as well as factors such as navigation, it has been assumed that the pipes will be tunneled through existing bedrock utilizing a tunneling boring machine (TBM). The updated design includes a set of headgates located within the forebay structure to allow for water control within the forebay.

The general orientation of the T-Screens has been modified (rotated by 90 degrees) such that the predominant ocean currents (Figure C-3) will be parallel to the axis of the Tscreens, thereby reducing the potential to impinge debris on the screens. Due to the reorientation of the screens, it was found that minor modification to the orientation of the primary conveyance pipes was also required to prevent hydraulic interaction without increasing the footprint of the forebay (i.e. the primary conveyance pipes are no longer parallel). As shown in Figure C-27, the westerly pipe has been rotated from its connection at the forebay to provide clearance offshore where the T-screens are located. 


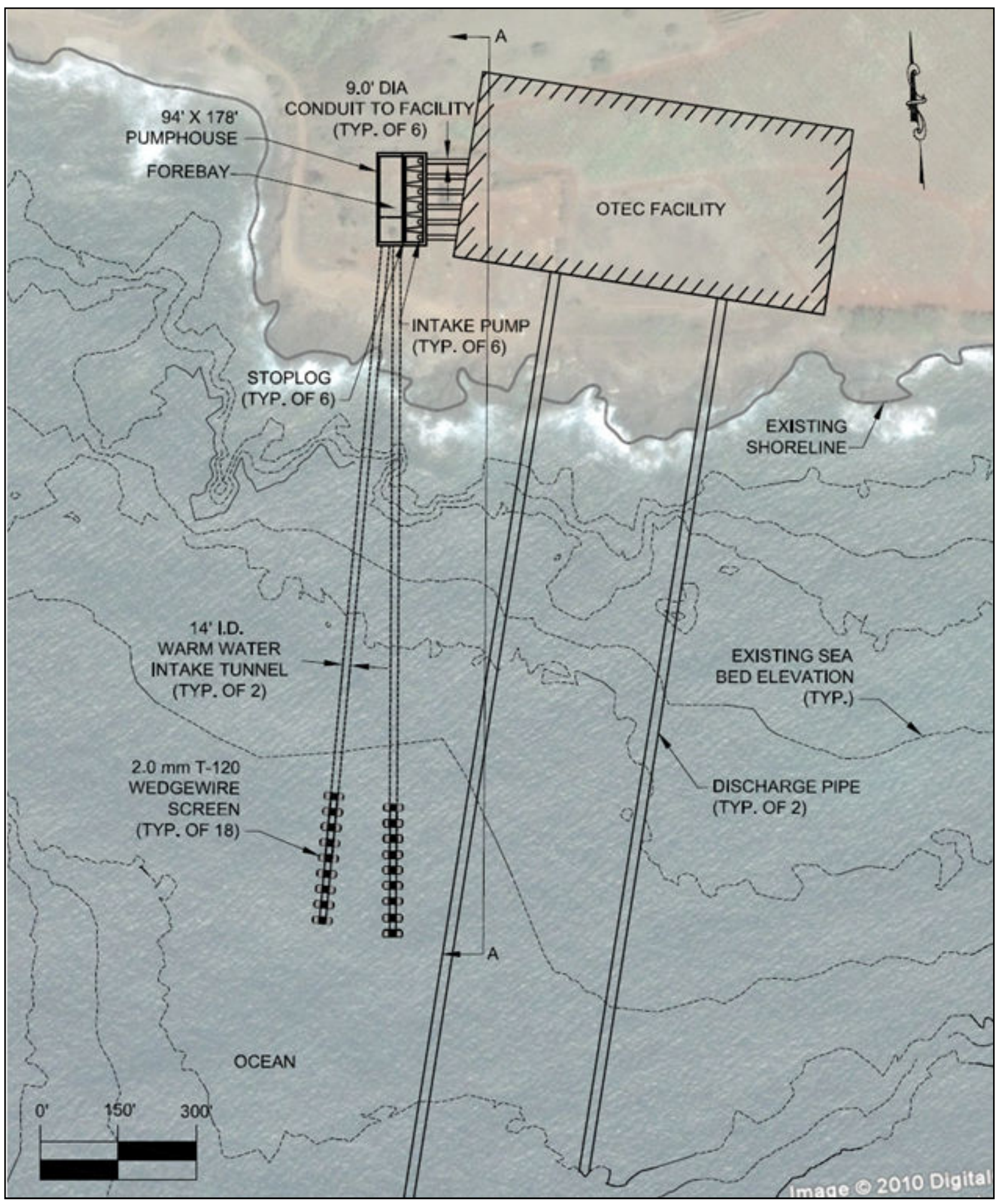

Figure C-27. Fine-mesh wedgewire screen intake (plan). 


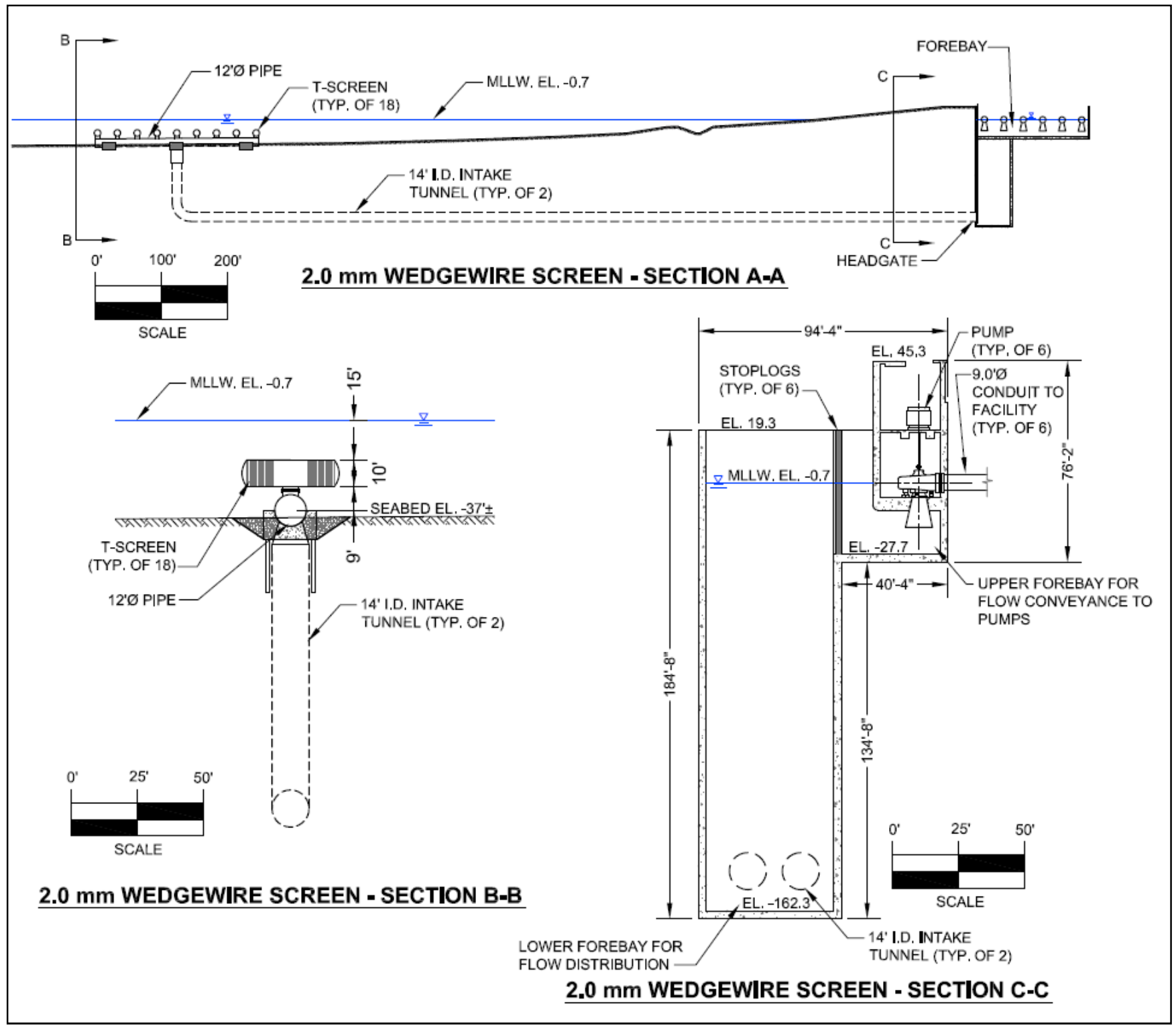

Figure C-28. Fine-mesh wedgewire screen intake (sections). 
The major cost components of the fine-mesh cylindrical wedgewire screen intake have been itemized in Table C- 7 . Mobilization and demobilization are assumed as $10 \%$ of the remaining direct costs. Major costs include: the construction of the primary distribution pipes (tunneling); and installation (cranes, barges, and installation).

Table C- 7. Summary costs for narrow-slot cylindrical wedgewire intake.

\begin{tabular}{|rl|}
\hline \multicolumn{1}{|c|}{ Item } & Estimated Cost \\
\hline Direct Costs & \\
Mobilization and Demobilization & $\$ 13,898,000$ \\
Tunnel Entrance/Forebay & $\$ 2,710,000$ \\
Forebay & $\$ 5,261,000$ \\
Tunnel & $\$ 56,606,000$ \\
Offshore connection & $\$ 22,935,000$ \\
Header pipes & $\$ 2,557,000$ \\
Wedge Wire Screens & $\$ 9,145,000$ \\
Cranes, Barges and Equipment & $\$ 39,766,000$ \\
Direct Costs (2010 \$) & $\$ 152,878,000$ \\
Indirect Costs & $\$ 15,288,000$ \\
Subtotal & $\$ 168,166,000$ \\
\hline Allowance for Indeterminates/Contingencies & $\$ 42,042,000$ \\
\hline Total Estimated Project Costs (2011 \$) & $\$ \mathbf{2 1 0 , 2 0 8 , 0 0 0}$ \\
\hline
\end{tabular}




\section{REFERENCES}

Beck, S., E. Miller, D. Bailey, and J. Steinbeck. 2007. Quantification of Effectiveness of Velocity Caps. Presented at: American Fisheries Society's 137th Annual Meeting, San Francisco, CA. September 2-6, 2007.

Bracket Green USA, Inc. (Bracket Green). 2007. Advanced Water Screening Technology Product Catalog. http://www.bgusa.com/DualFlowBrochure.htm.

Environmental Protection Agency (EPA_. 2001. National Pollutant Discharge Elimination System: Regulations Addressing Cooling Water Intake Structures for New Facilities; Final Rule. December 18, 2001, Federal Register: Vol. 66, No. 243, Pg 65256-65345.

EPA. 2010. http://www.epa.gov/waterscience/316b/basic.htm Accessed 12/30/2010.

Electric Power Research Institute (EPRI). 1986. Assessment of Downstream Migrant Fish Protection Technologies for Hydroelectric Application. EPRI AP-4711.

EPRI. 1994. Biological Evaluation of a Modular Inclined Screen for Protecting Fish at Water Intakes. TR-104121.

EPRI. 1996. Evaluation of the Modular Inclined Screen (MIS) at the Green Island Hydroelectric Project: 1995 Test Results. TR-106498.

Firing, J and R.E. Brainard. 2006. Ten Years of Shipboard ADCP Measurements along the Northwestern Hawaiian Islands. Atoll Research Bulletin 543: 347-363.

Passavant-Geiger (Geiger). 2005. Multi-disk MDs 500-10000. Drawing Number 065295-10 .

Lawler, Matusky \& Skelly Engineers LLP (LMS). 1996. Lovett Generating Station Gunderboom Evaluation Program 1995. Prepared for Orange and Rockland Utilities, Inc.

Lawler, Matusky \& Skelly Engineers LLP (LMS). 1997. Lovett Generating Station Gunderboom Evaluation Program 1996. Prepared for Orange and Rockland Utilities, Inc.

Lifton, W. S. and J. F. Storr. 1978. The Effect of Environmental Variables on Fish Impingement. In L. D. Jensen (ed.), Proceedings of the Fourth National Workshop on Entrainment and Impingement. EA Communications. ISBN: 0-931842-01-8.

Mussalli Y.G., E.P, Taft and P. Hofmann. 1978. Biological and Engineering Considerations in the Fine Screening of Small Organisms. Proceedings of the Workshop on Larval Exclusion Systems for Power Plant Cooling Water Intakes, San Diego, CA, February 7-8, 1998.

Myers, E.P., Hoss, D.E., Matsumoto, W.M., Peters, D.S. Seki, M.P., Uchida, R.N., Ditmars, J.D., and R.A. Paddock. 1986. The Potential Impact of Ocean Thermal Energy Conversion (OTEC) on Fisheries. NOAA Technical Report NMFS 40.

National Oceanic and Atmospheric Administration (NOAA). 1996. Ocean Thermal Energy Conversion Licensing Program - Proposed Rules. January 30, 1996. Federal Register: Vol. 61, No. 20, pg. 2969-2971.

Taft, E. P., A. W. Plizga, E. M. Paolini, and C. W. Sullivan. 1997. Protecting Fish with the New Modular Inclined Screen. The Environmental Professional 19(1):185-191. 
Weight, R.H. 1958. Ocean Cooling Water System for 800 MW Power Station. Journal of the Power Division of the American Society of Civil Engineers. Paper 1888.

Weisberg, Stephen B., C. Foster Stroup, A.F. Holland. 1986. Tests of Biofouling Control Technologies for Use with Fine-mesh Screens in an Estuarine Environment. MTS Journal. 2 (No 3):37-34.

Wiersema, James, M., D. Hogg, and L. J. Eck. 1979. Biofouling Studies in Galveston BayBiological Aspects. In: Passive Intake Screen Workshop. December 4-5, 1979. Chicago, IL. 


\section{ATTACHMENT A}

\section{OVERVIEW OF CLEAN WATER ACT SECTION 316(b)}




\section{TABLE OF CONTENTS}

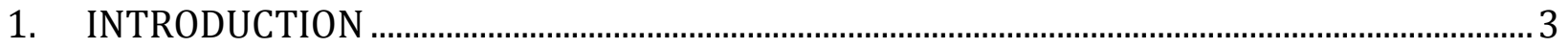

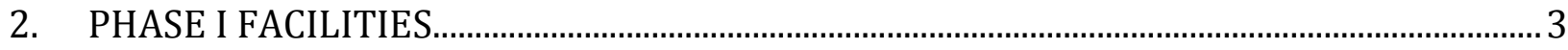

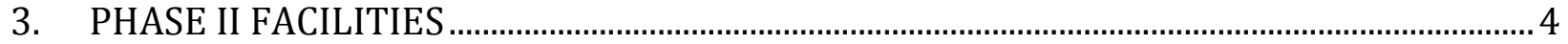

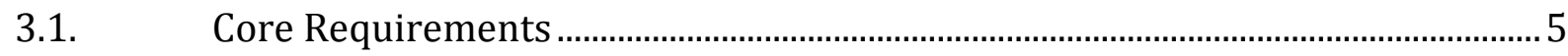

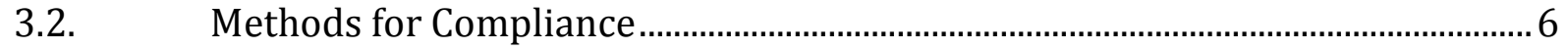

3.2.1. Flow Commensurate with Closed-Cycle Cooling or $0.5 \mathrm{ft} / \mathrm{sec}$ Through-Screen

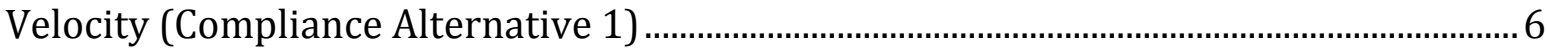

3.2.2. Existing Intake Meets the Standards (Compliance Alternative 2)....................... 6

3.2.3. Proposed Technology, Operation, and/or Restoration to Meet the Standard (Compliance Alternative 3).................................................................................................. 6

3.2.4. EPA-Approved Technology (Compliance Alternative 4)....................................... 7

3.2.5. Site-Specific BTA (Compliance Alternative 5) ........................................................ 7

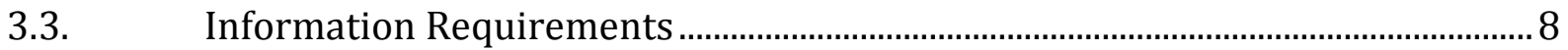

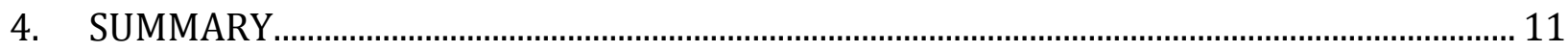

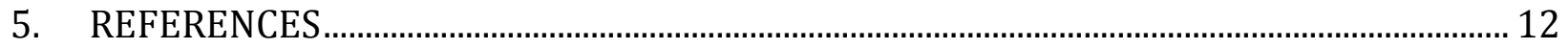




\section{INTRODUCTION}

Guidance originally promulgated by the U.S. Environmental Agency (EPA) for the implementation of Section 316(b) of the Clean Water Act set national performance standards to minimize adverse environmental impacts caused by water withdrawals. Section 316(b) requires that the location, design, construction and capacity of cooling water intake structures reflect the best technology available for minimizing adverse environmental impact. Rules to implement Section 316(b) were developed in three phases:

- $\quad$ Phase I covers new facilities

- Phase II covers large existing conventional power plants

- Phase III covers some existing facilities and oil and gas facilities

This attachment provides a summary of the pertinent portions of Section 316(b) that may apply to the regulation of warm water OTEC intakes.

\section{PHASE I FACILITIES}

New OTEC facilities would be considered Phase I facilities under Section 316(b). Facilities in this group are those that withdraw over 2 million gallons per day (MGD) and use at least $25 \%$ of that water for cooling purposes. Although, OTEC is using the warm water for evaporative (versus cooling) purposes in a closed cycle system, it is likely that it would be classified in this same category.

The requirements listed in the Final Rule for Phase I New Facilities are as follows in this excerpt from the Federal Register (USEPA 2001):

Today's final rule establishes a two-track approach for regulating cooling water intake structures at new facilities. Track I establishes uniform requirements based on facility cooling water intake capacity. Track II provides dischargers with the opportunity to establish that alternative requirements will achieve comparable performance. The regulated entity has the opportunity to choose which track it will follow. The Track I and Track II requirements are summarized below.

Under Track I, new facilities with a design intake flow equal to or greater than 10 MGD, must meet the following requirements:

1) Cooling water intake flow must be at a level commensurate with that achievable with a closed-cycle, recirculating cooling system; (40 CFR 125.84(b)(1))

2) Through-screen intake velocity must be less than or equal to 0.5 feet per second; (40 CFR 125.84(b)(2)) 
3) Location- and capacity-based limits on proportional intake flow must be met (for fresh water rivers or streams, intake flow must be less than or equal to 5 percent of the mean annual flow; for lakes or reservoirs, intake flow may not disrupt natural thermal stratification or turnover pattern (where present) of the source water except in cases where the disruption is determined to be beneficial to the management of fisheries for fish and shellfish by any fishery management agency(ies); for estuaries or tidal rivers, intake flow must be less than or equal to 1 percent of the tidal excursion volume; for oceans, there are no proportional flow requirements); (40 CFR 125.84(b)(3)), and

4) Design and construction technologies for minimizing impingement mortality and entrainment must be selected and implemented if certain conditions exist where the cooling water intake structure is located. (40 CFR 125.84(b)(4) and (5)).

Under Track II, new facilities must meet the following requirements:

1) Employ technologies that will reduce the level of adverse environmental impact to a comparable level to that which would be achieved under the Track I requirements (as demonstrated in a Comprehensive Demonstration Study); (40 CFR 125.84(d)(1)) and

2) The same proportional intake flow limitations as in Track I, based on the intake source water, must be met; (40 CFR 125.84(d)(2)).

Section IV.B and V. of this preamble provides a more detailed discussion of the requirements included under this two-track approach. The two-track approach provides new facilities with a well-defined set of requirements that constitute best technology available (BTA) for minimizing adverse environmental impact and can be implemented relatively quickly. This approach also provides flexibility to operators who believe alternative or emerging technologies would be just as effective at reducing impingement and entrainment.

\section{PHASE II FACILITIES}

In addition to 316(b) requirements for Phase I New Facilities, there are portions of the Phase II Existing Facilities Rule that may influence future warm water intake regulations in the OTEC industry. There has also been much research and development conducted on cooling water intakes at Phase II Existing Facilities (i.e., large existing power plants). For these reasons, some details are provided below relative to the implementation of 316(b) regulations at Phase II Existing Facilities. It is important to note, however, that the Rule implementing Section 316(b) for Phase II facilities was remanded in 2007 due to a lawsuit brought by the non-profit group Riverkeeper. In the absence of a federal level Rule, implementation of 316(b) was left to the individual states' Best Professional Judgment (BPJ). The EPA has issued a draft Phase II Rule on March 28, 2011 which remains open for public comment until July 19, 2011. 
The details described below were for the original Phase II 316(b) Rule.

\subsection{Core Requirements}

EPA's preferred alternative for Phase II facilities involved the use of national performance standards (i.e., a reduction in impingement mortality (IM) of all life stages of fish and shellfish of $80-95 \%$ from the "calculation baseline" and at some facilities, a reduction in entrainment of all life stages of fish and shellfish by $60-90 \%$ from the "calculation baseline" (USEPA $2004 \S 125.94[\mathrm{~b}]$ ). Facilities that EPA required to meet the entrainment reduction standard were those facilities that had a capacity utilization rate (the ratio between the average annual net generation of power by the facility (in $\mathrm{MWh}$ ) and the total net capability of the facility to generate power (in MW) multiplied by the number of hours during a year) of $15 \%$ or greater and withdrew water from a tidal river, estuary, ocean, or Great Lake. Both the IM and entrainment standards applied to facilities that were located on a freshwater river and had a design intake flow greater than $5 \%$ of the mean annual river flow. A summary of which performance standards applied to each waterbody appears in Table 1.

The "calculation baseline" is an estimate of IM\&E that would occur at a facility if it were designed and operated in the following ways:

- The cooling water system is designed as a once-through system.

- The opening of the cooling water intake structure is located at the shoreline near the surface of the source waterbody and the face of the standard 3/8-inch mesh traveling screen is oriented parallel to it.

- The baseline practices, procedures, and structural configuration are those that a facility would maintain in the absence of any structural or operational controls that would reduce IM\&E, including flow or velocity reductions, implemented in whole or in part for the purposes of reducing IM\&E.

EPA allowed for some flexibility in the "calculation baseline" at the facility level. EPA allowed a facility to use the current level of IM\&E as the "calculation baseline." This could potentially streamline the permit application since the facility could determine the baseline using data collected during the IM\&E Study (a requirement of the Comprehensive Demonstration Study [CDS], described below in Table 2). A facility was also allowed to request that an alternative intake location be used (e.g., at a depth other than at or near the surface or at a location other than the shoreline) if the utility can demonstrate to the Director that the alternate location would correspond to a higher baseline level of IM and/or entrainment.

A facility was allowed to estimate the "calculation baseline" using: 1) historical IM\&E data from a facility; 2) IM\&E data from another facility with comparable design, operational, and 
environmental conditions; 3) current biological data collected in the waterbody near the CWIS; or 4) current IM\&E data collected at a facility.

\subsection{Methods for Compliance}

There were five compliance alternatives that EPA indicated a facility may use to comply with $\S 316($ b) of the Clean Water Act. All five compliance options, as stated by EPA, would reduce impingement mortality by $80-95 \%$ and entrainment (where applicable) by 60-90\% (or equivalent environmental benefit) for all Phase II Existing Facilities. The five compliance alternatives are described in more detail in the following sections.

\subsubsection{Flow Commensurate with Closed-Cycle Cooling or $0.5 \mathrm{ft} / \mathrm{sec}$ Through- Screen Velocity (Compliance Alternative 1)}

Two methods existed for complying with Compliance Alternative 1. The first method was to demonstrate that a facility had or would reduce intake flow commensurate with a closed-cycle system. Using closed-cycle cooling reduces intake flow by 70-98\% compared to a once-through system, depending on the cycles of concentration of the cooling system. EPA assumed that impingement mortality and entrainment would be reduced by the same amount. EPA deemed such a reduction in flow as satisfying the applicable IM\&E performance standard for all waterbodies. EPA would not require a facility that had installed or would install a closed-cycle system to submit a CDS. A second method for complying using Compliance Alternative 1 allowed a facility to meet the IM standard by having or reducing design intake velocity ${ }^{1}$ to $0.5 \mathrm{ft} / \mathrm{sec}$ or less. A facility that reduced the design intake velocity would not have to submit CDS information pertaining to IM. However, if the facility had to comply with both the IM and entrainment standards, EPA would require all the CDS information pertaining to entrainment.

\subsubsection{Existing Intake Meets the Standards (Compliance Alternative 2)}

Under the second Compliance Alternative, a facility could meet the performance standards by demonstrating that existing design and construction (D\&C) technologies and/or restoration measures met the applicable performance standards.

\subsubsection{Proposed Technology, Operation, and/or Restoration to Meet the Standard (Compliance Alternative 3)}

The third Compliance Alternative allowed a utility to comply by demonstrating that the facility in question would meet the applicable performance standards by implementing D\&C technologies and/or restoration measures. EPA defined technologies as physical

\footnotetext{
${ }^{1}$ EPA defines design intake velocity as the value assigned (during the design of a CWIS) to the average speed at which intake water passes through the open area of the intake screen (or other device) against which organisms might be impinged or through which they might be entrained. Alden believes that this synonymous with through-screen velocity.
} 
modifications to the intake (e.g., fine mesh screens, wedge wire screens, fish handling and return systems, aquatic filter barrier systems, etc.). Examples of operational measures include seasonal flow reductions, a reduction in velocity, installation of variable speed pumps, and adjustment of maintenance shutdowns, etc. Finally, a facility could use restoration that produces a level of organisms in the waterbody that is "substantially similar" to that which would result from meeting the applicable performance standards. A facility could use all three of these methods alone or in conjunction with each other to meet the performance standards.

\subsubsection{EPA-Approved Technology (Compliance Alternative 4)}

The Rule stated that a facility could demonstrate to the Director that it had installed and was properly operating and maintaining a Rule-specified and approved D\&C technology in accordance with $§ 125.99(\mathrm{a})$.

EPA had one pre-approved technology for compliance: submerged cylindrical wedge wire screens in freshwater rivers or streams. The Director could approve additional technologies if it was demonstrated that the technology in question could "consistently meet" the performance standards.

A facility could use submerged cylindrical wedge wire screens when its CWIS was located in a freshwater river or stream, where there was sufficient ambient current to properly clean the screens, where the maximum through-slot velocity was $0.5 \mathrm{ft} / \mathrm{sec}$, where the slot size was protective of all the species and life stages that required protection, and where all the condenser cooling water flowed through the wedge wire screens. A facility could use this alternative to meet both the IM and entrainment standards. If a facility need only meet the IM standard, then wedge wire screens would meet the requirements of Compliance Alternative 1 ( $0.5 \mathrm{ft} / \mathrm{sec}$ through-screen velocity). Facilities where both the IM\&E standards applied would need to conduct verification monitoring of entrainable organisms.

In addition, under this Compliance Alternative, a facility or other interested persons could submit a request to the Director for approval of a different technology. If the Director approved the technology, all facilities with similar site conditions under his or her jurisdiction could use it, if the State's administrative procedures allowed it. Requests for approval of a technology submitted to the Director had to include a detailed description of the technology, a list of design criteria for the technology and site characteristics, and conditions that each facility must possess in order to ensure that the technology can consistently meet the performance standards at any facility with applicable design criteria, site characteristics, and conditions. Prior to approving a technology, the Director had to allow public notice and opportunity for comments on the approval of the technology.

\subsubsection{Site-Specific BTA (Compliance Alternative 5)}

The Rule included two methods for a facility to obtain a site-specific BTA determination: 
the Cost-Cost and Cost-Benefit tests. Both tests are fundamentally similar in that they compare the site-specific costs necessary to meet the applicable national performance standards to either the costs that EPA estimated for a like facility in calculating the national costs or the benefits that a facility would achieve by complying with the performance standards. If the site-specific costs were "significantly greater than" EPA's costs or the benefits that a facility would attain, then the Director could make a site-specific BTA determination.

If a facility chose to use the Cost-Cost test, EPA would require it to submit two additional studies with the CDS. These studies were the Comprehensive Cost Evaluation Study and the Site-Specific Technology Plan. For a facility choosing to use the Cost-Benefit test, a third study would need to be included: the Benefits Valuation Study.

\subsection{Information Requirements}

The Rule required substantial engineering and biological information to establish a baseline; to determine which of the performance standards was applicable; to justify the selection of BTA; and, subsequently, to monitor the performance of the selected operational, technological, and/or restoration measure the facility used to meet the performance standards. A utility needed to develop and present considerable data and studies during the permit renewal process and had to maintain extensive ongoing management of selected alternatives. In whole, the studies required comprised the Comprehensive Demonstration Study (CDS).

Table 1. Applicable National Performance Standards Based on Waterbody Type, Capacity Utilization Rate, and Design Intake Flow (Exhibit V-1 - USEPA 2004).

\begin{tabular}{|c|c|c|c|}
\hline Waterbody Type & $\begin{array}{l}\text { Capacity Utilization } \\
\text { Rate }\end{array}$ & Design Intake Flow & $\begin{array}{l}\text { Applicable Performance } \\
\text { Standard }\end{array}$ \\
\hline \multirow[t]{2}{*}{$\begin{array}{l}\text { Freshwater river or } \\
\text { stream }\end{array}$} & Less than $15 \%$ & $\mathrm{~N} / \mathrm{A}^{1}$ & $\begin{array}{l}\text { Impingement mortality } \\
\text { only }\end{array}$ \\
\hline & $\begin{array}{l}\text { Equal to or greater } \\
\text { than } 15 \%\end{array}$ & $\begin{array}{l}5 \% \text { or less of mean } \\
\text { annual flow } \\
\text { Greater than } 5 \% \text { of } \\
\text { mean annual flow }\end{array}$ & $\begin{array}{l}\text { Impingement mortality } \\
\text { only } \\
\text { Impingement mortality and } \\
\text { entrainment }\end{array}$ \\
\hline \multirow[t]{2}{*}{$\begin{array}{l}\text { Tidal river, estuary, } \\
\text { or ocean }\end{array}$} & Less than $15 \%$ & $\mathrm{~N} / \mathrm{A}^{1}$ & $\begin{array}{l}\text { Impingement mortality } \\
\text { only }\end{array}$ \\
\hline & $\begin{array}{l}\text { Equal to or greater } \\
\text { than } 15 \%\end{array}$ & $\mathrm{~N} / \mathrm{A}$ & $\begin{array}{l}\text { Impingement mortality and } \\
\text { entrainment }\end{array}$ \\
\hline \multirow[t]{2}{*}{ Great Lakes } & Less than $15 \%$ & $\mathrm{~N} / \mathrm{A}$ & $\begin{array}{l}\text { Impingement mortality } \\
\text { only }\end{array}$ \\
\hline & $\begin{array}{l}\text { Equal to or greater } \\
\text { than } 15 \%\end{array}$ & $\mathrm{~N} / \mathrm{A}$ & $\begin{array}{l}\text { Impingement mortality and } \\
\text { entrainment }\end{array}$ \\
\hline
\end{tabular}




\begin{tabular}{|c|c|c|c|}
\hline Lakes or reservoirs & $\mathrm{N} / \mathrm{A}$ & $\begin{array}{l}\text { Increase in design } \\
\text { intake flow must not } \\
\text { disrupt thermal } \\
\text { stratification except } \\
\text { where it does not } \\
\text { adversely affect the } \\
\text { management of } \\
\text { fisheries }\end{array}$ & $\begin{array}{l}\text { Impingement mortality } \\
\text { only }\end{array}$ \\
\hline
\end{tabular}

1. DETERMINATION OF APPROPRIATE COMPLIANCE REDUCTIONS IN NOT APPLICABLE 
Table 2. Comprehensive Demonstration Study (CDS) Requirements for Each Compliance Alternative (Exhibit V-2 - USEPA 2004).

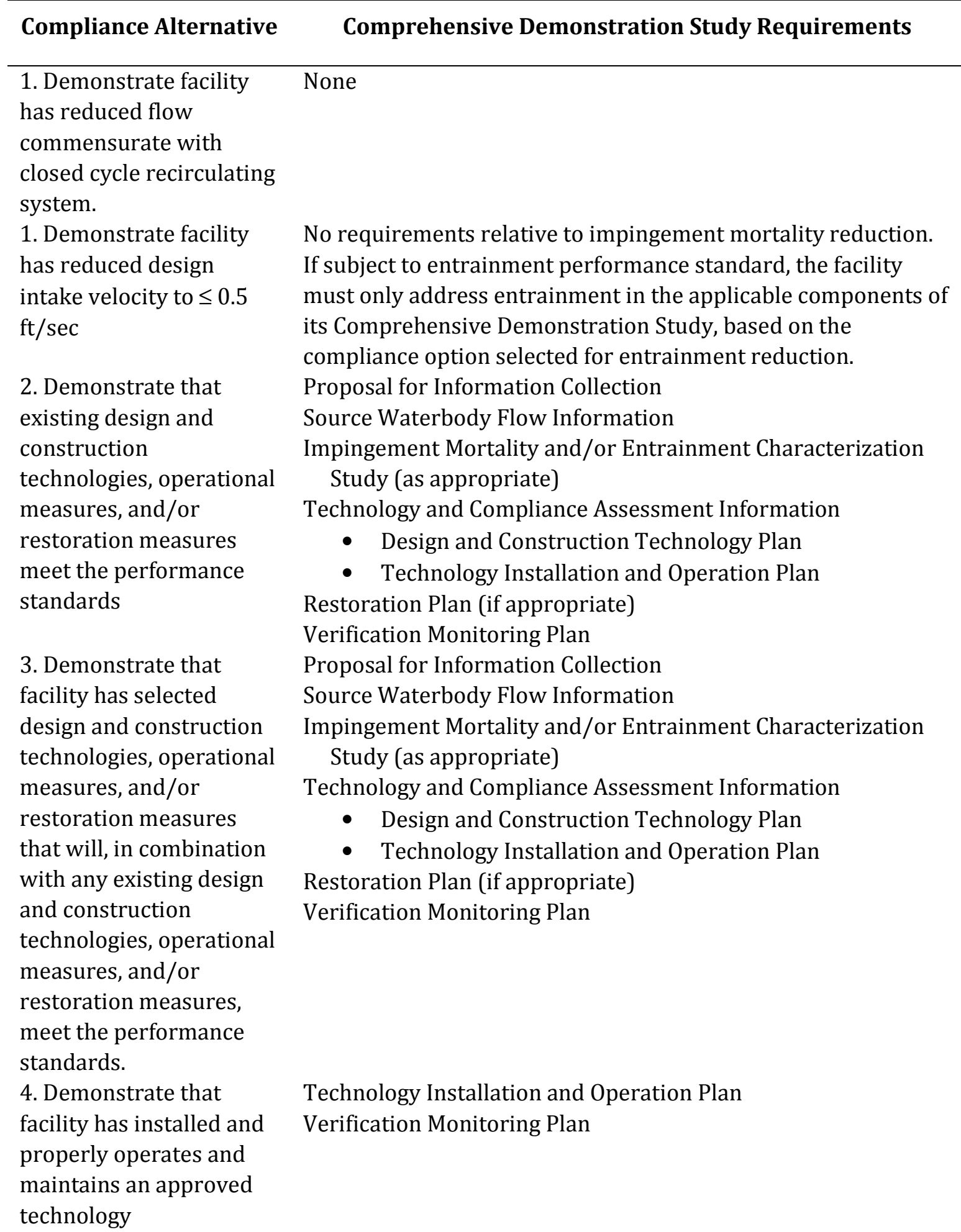


Table 2. Continued

\begin{tabular}{|c|c|}
\hline $\begin{array}{l}\text { 5. demonstrate that a } \\
\text { site-specific } \\
\text { determination of BTA } \\
\text { appropriate }\end{array}$ & $\begin{array}{l}\text { Proposal for Information Collection } \\
\text { Source Waterbody Flow Information } \\
\text { Impingement Mortality and/or Entrainment Characterization } \\
\text { Study (as appropriate) } \\
\text { Technology Installation and Operation Plan } \\
\text { Restoration Plan (if appropriate) } \\
\text { Information to Support Site Specific Determination of BTA } \\
\text { including: } \\
\text { - Comprehensive Cost Evaluation Study (Cost-Cost test } \\
\text { and Cost-Benefit test); } \\
\text { - Valuation of Monetized Benefits of Reducing IM\&E } \\
\text { (Cost-Benefit test only); } \\
\text { Site-Specific Technology Plan (Cost-Cost test and Cost- } \\
\text { Benefit test); } \\
\text { Verification Monitoring Plan }\end{array}$ \\
\hline
\end{tabular}

\section{SUMMARY}

The description of Section 316(b) above is provided to illustrate the various components that may be required to demonstrate compliance with a regulatory intake standard. Section 316(b) of the CWA is specific to power plant cooling water intakes; however, the OTEC industry expects that the National Oceanic and Atmospheric Administration (NOAA) will rely heavily on the expertise of the EPA in defining the intake performance standards and methods for compliance for the OTEC industry. Furthermore, NOAA has given no indication of their intentions or potential regulatory standards relative to OTEC warm water intakes. It is therefore prudent to develop OTEC projects with an eye towards future regulations. At this point, in the absence of guidance or participation from NOAA, it is difficult to predict design criteria for the warm water intake at Port Allen. The OCEES Team has used its Best Professional Judgment (BPJ) to select warm water intake options based on its experience with 316(b) in the power generation industry, as these regulations are currently the most useful in the preliminary design process. 


\section{REFERENCES}

United States Environmental Protection Agency (EPA). 2001. National Pollutant Discharge Elimination System - Regulations Addressing Cooling Water Intake Structures for New Facilities; Final Rule. December 18, 2001 Federal Register: Vol. 66, No. 243 Pg 6525665345 .

United States Environmental Protection Agency (EPA). 2004. National Pollutant Discharge Elimination System - Final Regulations to Establish Requirements for Cooling Water Intake Structures at Phase II Existing Facilities. July 9, 2004 Federal Register: Vol. 69, No. 131 Pg 41576-41693. 


\section{ATTACHMENT B}

\section{BIOLOGICAL EFFICACY ESTIMATES}




\section{TABLE OF CONTENTS}

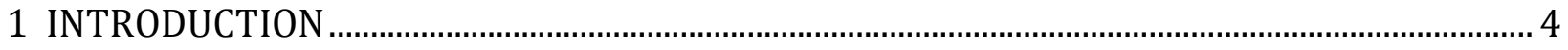

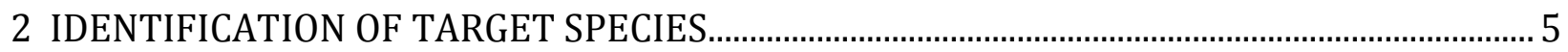

2.1 Target Species for Port Allen................................................................................................. 6

3 METHOD FOR ESTIMATING BIOLOGICAL EFFICACY OF INTAKE TECHNOLOGIES ............10

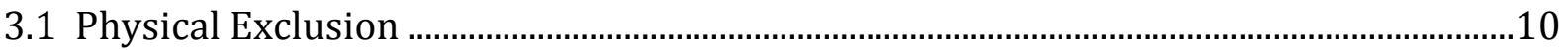

3.2 Impingement Survival..............................................................................................11

3.3 Entrainment Survival ...............................................................................................12

4 ESTIMATED BIOLOGICAL PERFORMANCE OF SELECTED INTAKE TECHNOLOGIES..........15

4.1 Fine-mesh (0.5- and 2.0-mm) Modified Traveling Water Screens .................................15

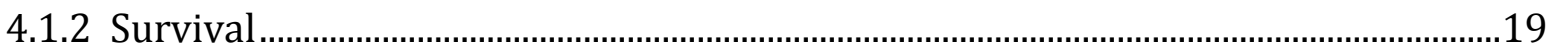

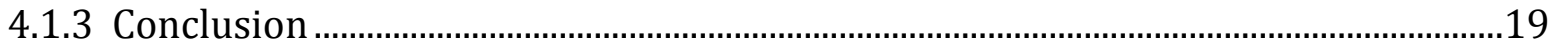

4.2 Narrow-slot (0.5- and 2.0-mm) Cylindrical Wedgewire Screens....................................21

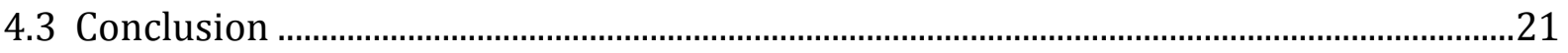

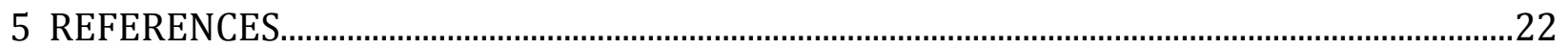




\section{TABLE OF FIGURES}

Figure 1. Kahe Generating Station shoreline intake and discharge structures.

Figure 2. Sampling locations in Kaneohe Bay during the study conducted by Watson and Leis (1974).

Figure 3. Sampling locations off of Kahe Point during the study conducted by Leis (1982). Drawing taken from Leis (1982).

Figure 4. Head capsule depth (HCD) measurement used to estimate physical exclusion of larvae.

Figure 5. Example illustrating the relationship between fish length and probability of entrainment through a $2.0-\mathrm{mm}$ mesh.

Figure 6. General temperature exposure history for an entrained organism through a separate warm water discharge and a mixed warm and cold water discharge. Graph assumes the temperature exposure durations presented in Lamadrid-Rose and Boehlert (1988) and a receiving waterbody temperature of $23^{\circ} \mathrm{C}$.

Figure 7. Linear regressions of head capsule depth (HCD) to length for target species. ......16

Figure 8. Probability of entrainment through 0.5- and 2.0-mm mesh. Estimates are based on HCD calculations for the target species at Port Allen. Surrogate species used to generate HCD regressions are noted in Table 3.

\section{TABLE OF TABLES}

Table 1. List of potential target species at Port Allen, Kauai.

Table 2. Top ten species in Kauai as reported by the commercial fishing industry (data provided by the Hawaii Division of Aquatic Resources, 01/21/2011).

Table 3. Estimates of physical exclusion for the Port Allen target species. Presented as the length at which $100 \%$ of the organisms would be physically excluded by $0.5-$ and $2.0-\mathrm{mm}$ mesh. Mesh of 9.5- $\mathrm{mm}$ is not presented since fish large enough to be excluded are also likely to possess swimming capabilities sufficient to avoid interaction with the screen. .....18 


\section{INTRODUCTION}

A number of biological data are critical to estimating the potential performance of any intake technology. Basic biological sampling data can indicate which species and lifestages may be present at a proposed intake location. In addition, basic life history information can aid in determining, for each species and lifestage, the potential susceptibility to entrainment or impingement. This susceptibility is based on a number of biological details, including the preferred habitats of each species, their uses of the habitats (foraging, spawning, etc.), the duration of each species' lifestages, the swimming abilities of each species and lifestage, and the survival rate of organisms exposed to intake screens.

For instance, basic ichthyological sampling data can determine whether a particular species or lifestage is present in the intake area. Furthermore, the duration of each early life history stage (i.e., egg, yolk-sac larva, post yolk-sac larva, juvenile) will add to the resolution of the length of time that species are susceptible to intake impacts since size relates to the organism's swimming ability and, therefore, its ability to avoid the hydraulic influence of an intake. At the earliest stages (egg and young larva), there is little to no swimming ability, thus making these organisms much more susceptible to impingement and entrainment. However, as the larva grows and swimming ability increases, the susceptibility to impingement and entrainment decreases. The potential for entrainment relies heavily upon the organism's location in the water body, its swimming ability, and the extent of the hydraulic zone of influence of the intake.

While there is ample biological data available for temperate species that are typically of concern at large industrial water intakes in the continental U.S.; unfortunately, there is a paucity of basic biological data relative to tropical species. Myers et al. (1986) stated that there is relatively little information available on the spatial or temporal distribution of early lifestages of tropical fishes. Therefore, for tropical fish species, it can be more difficult to generate accurate estimates of an intake's performance.

The steps taken to estimate the biological efficacy of each warm water intake technology considered for Port Allen are outlined in this Attachment. In general, it begins by identifying the species that are most likely to be targeted for protection. It then describes the methods used to determine the potential for each technology to protect the target organisms. In the main Interim Report, the warm water intake alternatives were initially narrowed down to modified traveling water screens (meshes of $0.5,2.0$, and $9.5 \mathrm{~mm}$ ), cylindrical wedgewire screens (slot sizes of $0.5,2.0$, and $9.5 \mathrm{~mm}$ ), and modular inclined screens (mesh of $2.0 \mathrm{~mm}$ ). The technologies and screen mesh sizes considered in this Attachment are those that are biologically proven in both pilot-scale and full-scale applications at industrial water intakes. Furthermore, the mesh sizes considered in this Attachment (and in Section 6.0 of the Interim Report) are those that would minimize both impingement and entrainment (i.e., 0.5 - and 2.0-mm mesh) and no further consideration is 
given to those that would minimize only impingement (i.e., 9.5-mm mesh). Note that the 2.0-mm MIS alternative (Section 5.3 of Interim Report) is not included in this section since it has yet to be evaluated at a full scale. However, the predictions of physical exclusion for its $2-\mathrm{mm}$ mesh should be similar to the exclusion with the 2-mm meshes of the other technologies.

\section{IDENTIFICATION OF TARGET SPECIES}

The first critical step in determining the biological efficacy of an intake technology is to identify the species and lifestages that will potentially be affected by its operation. Without an accurate definition of the target species at the intake location, an OTEC project developer may be left at a disadvantage in designing the most environmentally benign warm water intake possible. In addition to protecting aquatic resources, intakes must also be cost-effective in order to produce energy at competitive rates. Project developers have a difficult task balancing these often competing obligations. For this reason, progress in the OTEC industry can be easily impeded.

A number of sources can be relied upon for defining the target species for protection; however, these sources may not always agree. Target species can be identified using biological sampling data, commercial landings data, ecological functionality, social and cultural perception, and economic value. In most cases, the group of target species that necessitates protection from intake operations results from a combination of the sources listed above. It is important for OTEC developers to be able to efficiently navigate these criteria of resource valuation in order to reach a consensus on the target species group for protection. Without a clear definition of the target species group, the selection and location of the proper intake technology cannot be completed effectively.

There is a wide national and international range in both intake regulation and the approaches taken to defining the target species. For example, one country may put more of a priority on protecting species that are commercially important, while another may emphasize protection of a species considered rare, endangered, or culturally important. Overall, though, there is typically little structured guidance from resource authorities on the methods for defining the group of species to be protected. Such is the case with the OTEC industry as the regulator (the National Oceanic and Atmospheric Administration) has provided limited guidance on the biological performance criteria to which the intakes may be held. Rather, the onus is on the developer to identify the target species and allow the resource agencies to review the list and provide comments or concurrence.

Section 316(b) of the Clean Water Act required that, "the location, design, construction, and capacity of cooling water intake structures reflect the best technology available (BTA) for minimizing adverse environmental impact" and "adverse environmental impact" referred to the direct impacts of impingement and entrainment of aquatic organisms. Original 
guidance language offered with this regulation indicated that adverse impacts were those that "may interfere with the maintenance or establishment of optimum yields to sport or commercial fish or shellfish, decrease populations of endangered organisms, and seriously disrupt sensitive ecosystems."(USEPA 1976). As suggested by this language, the first step in defining potential adverse environmental impacts requires that the target species for protection be identified. The USEPA offered a definition for what it termed "critical aquatic organisms". These were described as:

"those species which would be involved with the intake structure and are: (1) Representative, in terms of their biological requirements, of a balanced, indigenous community of fish, shellfish, and wildlife; (2) commercially or recreationally valuable (e.g. among the top ten species landed - by dollar value); (3) threatened or endangered; (4) critical to the structure and function of the ecological system (e.g. habitat formers); (5) potentially capable of becoming localized nuisance species; (6) necessary, in the food chain, for the well-being of species determined in 1-4; (7) one of 1-6 and have high potential susceptibility to entrapment-impingement and/or entrainment; and (8) critical aquatic organisms based on 1-7, are suggested by the applicant, and are approved by the appropriate regulatory agencies." (USEPA 1977).

The CWA, therefore, describes a wide range of approaches to identifying important species for protection. The eight criteria listed above indicate that aquatic organisms have economic value, intrinsic value, scientific value, and an ecosystem function value. The origin of these values is presumably derived from empirical data that have been collected from economic analyses, biological sampling, and ecological research.

In an early publication on the potential environmental impacts of power plant intakes, Sonnichsen et al. (1973) described the preferred means for identifying target species for protection at cooling water intakes. As the first step, the authors suggest conducting biological sampling to identify the species present, their relative composition, and their seasonality. Often, in the power generation industry, these data are available from previous sampling programs conducted at nearby or similar locations. When these data are available, an educated decision can be made about which species are the most susceptible to impingement and entrainment due to abundance, proximity to the intake location, or particular biological characteristics. At other sites, however, defining target species may be more difficult due to the paucity of existing data. Such is the case in the Port Allen. In these cases, a sampling study must be designed and conducted to generate original empirical data. This project includes a future sampling study to generate these data for Port Allen.

\subsection{Target Species for Port Allen}

The list of target species for Port Allen (Table 1) has been developed based on available ichthyoplankton data for the Hawaiian Islands. The list should be considered conservative 
since it is unlikely that all species will be found in the vicinity of the warm water intake for the Port Allen OTEC facility. The target species list was synthesized from various sources since there are relatively few data available on the distribution and abundance of many Hawaiian fish species (particularly for early lifestages). Greater resolution on the actual target species for this site will be gained during future field sampling efforts.

Table 1. List of potential target species at Port Allen, Kauai.

\begin{tabular}{|c|c|c|}
\hline Common Name & Family & Scientific Name \\
\hline Bigeye scad & Carangidae & Selar crumenophthalmus \\
\hline Blennies & Bleniidae & $\begin{array}{l}\text { Enchelyurus brunneolus } \\
\text { Istiblennius zebra }\end{array}$ \\
\hline Cardinalfishes & Apogonidae & Foa brachygramma \\
\hline Damselfishes & Pomacentridae & Abudefduf abdominalis \\
\hline Gobies & Gobiidae & Psilogobius mainlandii \\
\hline Hawaiian & & \\
\hline anchovy & Engraulidae & Encrasicholina purpurea \\
\hline Infantfishes & Schindleriidae & Schindleria pietschmanni \\
\hline Jacks & Carangidae & Caranx (Atule) mate \\
\hline Lanternfishes & Myctophidae & $\begin{array}{l}\text { Ceratoscopelus warmingi } \\
\text { Diaphus spp } \\
\text { Lampedina luminosa } \\
\text { Hygophum proximum }\end{array}$ \\
\hline Mahi mahi & Corpaenidae & Coryphaena hippurus \\
\hline Skipjack tuna & Scombridae & $\begin{array}{l}\text { Katsuwonus pelamis } \\
\text { Tripterygion atriceps (Enneapterygius }\end{array}$ \\
\hline Triplefins & Tripterygiidae & atriceps) \\
\hline Wahoo & Scombridae & Acanthocybium solandri \\
\hline Yellowfin tuna & Scombridae & Thunnus albacares \\
\hline
\end{tabular}

The following section provides a brief description of the sources used in developing the list of target species for this proposed OTEC facility:

\section{a. Hawaiian Electric Company's Kahe Generating Station - Impingement mortality and entrainment characterization studies (Tenera and AECOS 2008)}

The Kahe Generating Station is a fossil-fueled thermal power plant located on the west side of Oahu. It utilizes a conventional shoreline intake (Figure 1) which is also a potential intake alternative for the warm water intake at the Port Allen OTEC site. Therefore, due to their relative proximity and given that they will likely begin drawing seawater from similar depths and locations, ichthyoplankton data from Kahe were used in developing the list of 
potential target species at Port Allen. These data were originally collected to fulfill 316(b) requirements and are valuable in determining the species that may be susceptible to impingement or entrainment at Port Allen.

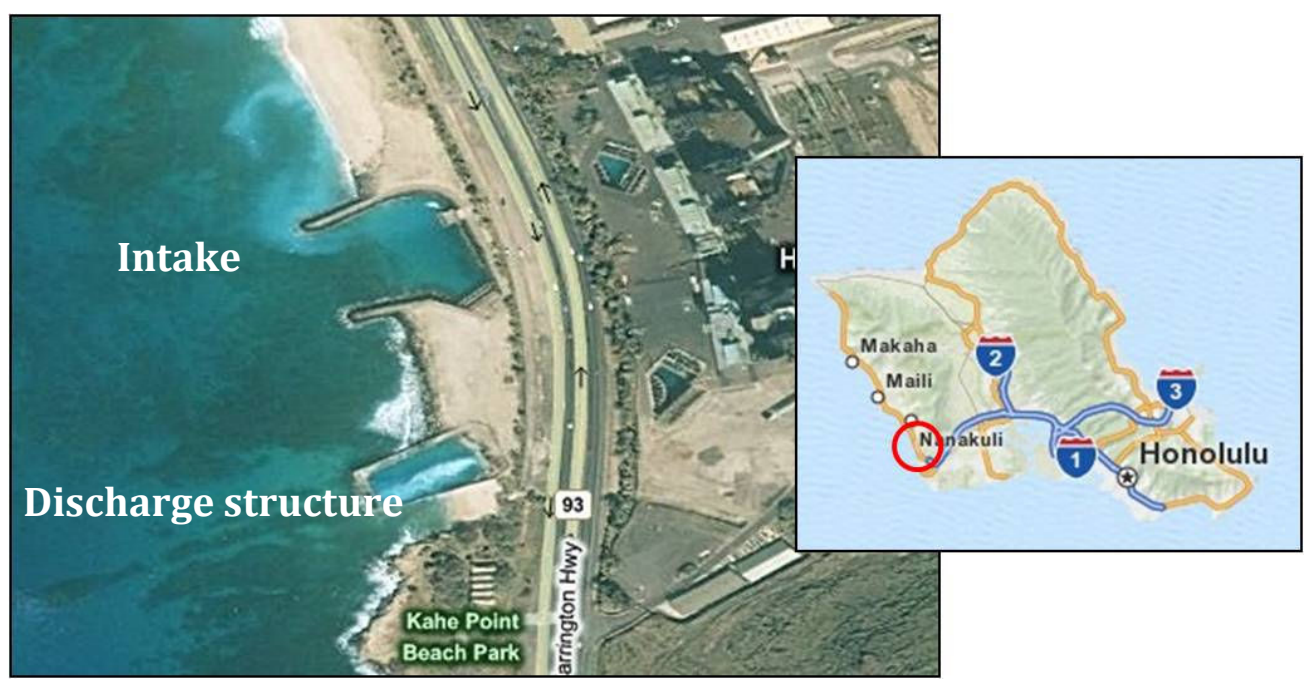

Figure 1. Kahe Generating Station shoreline intake and discharge structures.

\section{b. Kaneohe Bay, Oahu - Year-long ichthyoplankton survey (Watson and Leis 1974)}

This was a year-long study designed to assess the fish egg resources of Kaneohe Bay to inform aquaculture efforts at the Hawaii Institute of Marine Biology. The locations from which samples were collected are representative of the locations where warm water is likely to be withdrawn by an OTEC facility in Port Allen (Figure 2).

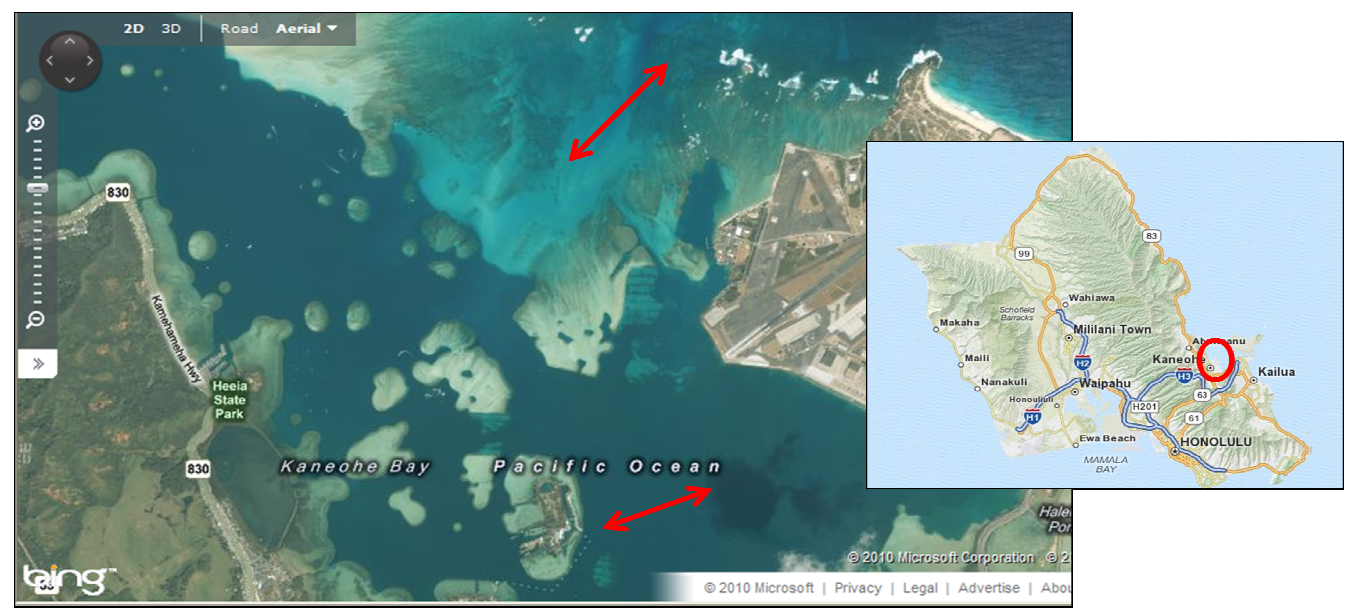

Figure 2. Sampling locations in Kaneohe Bay during the study conducted by Watson and Leis (1974). 


\section{c. Nearshore ichthyoplankton sampling at Kahe Point, Oahu (Leis 1982)}

As with the sampling conducted at the Kahe Generating Station, the samples in this study were collected from locations (Figure 3) that are representative of the locations from which warm water would be withdrawn by an OTEC facility in Port Allen. In addition, the study was designed to yield information about the density gradients of larval organisms as distance from shore increases - data that may aid in the effective siting of an intake terminus.

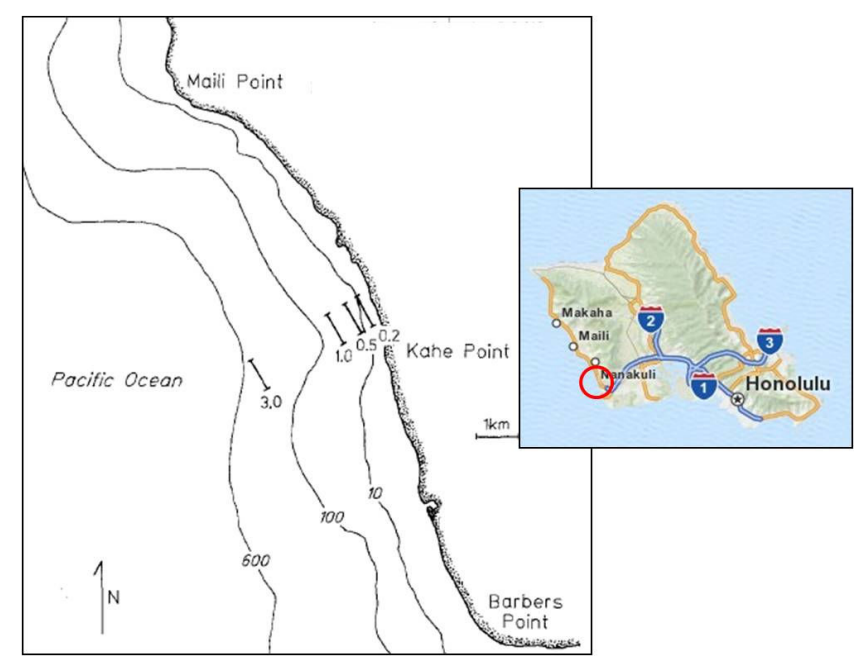

Figure 3. Sampling locations off of Kahe Point during the study conducted by Leis (1982). Drawing taken from Leis (1982).

\section{d. Commercial landing record for Kauai}

Commercial landing records were supplied by the Hawaii Division of Aquatic Resources for the island of Kauai for the 2008 calendar year (Table 2). These data are important in determining the island-specific value of each species to the commercial fishing industry.

Table 2. Top ten species in Kauai as reported by the commercial fishing industry (data provided by the Hawaii Division of Aquatic Resources, 01/21/2011).

\begin{tabular}{|c|c|c|c|c|c|}
\hline \multicolumn{3}{|c|}{ Kauai landings by area fished } & \multicolumn{3}{|c|}{ Kauai port landings } \\
\hline Species & $\begin{array}{r}\text { No. } \\
\text { caught }\end{array}$ & $\begin{array}{r}\text { Lbs. } \\
\text { caught }\end{array}$ & Species & $\begin{array}{r}\text { No. } \\
\text { caught }\end{array}$ & $\begin{array}{l}\text { Lbs. } \\
\text { caught }\end{array}$ \\
\hline Yellowfin tuna & 7,025 & 225,377 & Yellowfin tuna & 7,038 & 223,349 \\
\hline Akule & 493,693 & 166,786 & Ono & 3,563 & 87,027 \\
\hline Ono & 3,225 & 78,165 & Mahimahi & 2,968 & 50,267 \\
\hline Mahimahi & 2,899 & 49,392 & Aku & 6,926 & 48,803 \\
\hline Aku & 6,939 & 49,093 & Blue marlin & 251 & 41,127 \\
\hline Blue marlin & 250 & 41,120 & Uku & 3,147 & 33,679 \\
\hline Hahalalu & 98,663 & 24,651 & $\overline{\text { Akule }}$ & 52,693 & 27,440 \\
\hline Uku & 2,196 & 21,291 & Bigeye tuna & 1,067 & 13,714 \\
\hline Bigeye tuna & 1,062 & 13,662 & Menpachi & 11,030 & 7,144 \\
\hline Menpachi & 11,030 & 7,144 & Onaga & 685 & 5,294 \\
\hline
\end{tabular}

\begin{tabular}{|l|r|r|r|}
\hline \multicolumn{3}{|c|}{ Top ten species reported by fish dealers } \\
\hline Species & $\begin{array}{r}\text { No. } \\
\text { bought }\end{array}$ & $\begin{array}{r}\text { Lbs. } \\
\text { bought }\end{array}$ & Value \\
\hline Yellowfin tuna & 2,236 & 129,284 & $\$ 418,376$ \\
\hline Ono & 2,561 & 61,766 & $\$ 230,118$ \\
\hline Uku & 2,614 & 27,224 & $\$ 104,521$ \\
\hline Mahimahi & 1,626 & 27,023 & $\$ 92,116$ \\
\hline Akule & 2 & 13,181 & $\$ 37,842$ \\
\hline Blue marlin & 171 & 24,706 & $\$ 33,645$ \\
\hline Onaga & 177 & 1,419 & $\$ 8,766$ \\
\hline Menpachi & 106 & 2,161 & $\$ 7,425$ \\
\hline Aku & 282 & 3,892 & $\$ 7,311$ \\
\hline Bigeye tuna & 61 & 1,893 & $\$ 6,904$ \\
\hline
\end{tabular}




\section{METHOD FOR ESTIMATING BIOLOGICAL EFFICACY OF INTAKE TECHNOLOGIES}

The methods used to estimate an intake technology's biological efficacy depend upon its mode of action (e.g., exclusion [passive mode] versus collection [active mode]). In addition, the site-specific intake design and operating characteristics, and the morphological, physiological, and behavioral characteristics of the organisms involved at the intake will impact the efficacy of a screening technology. Typically, determining the potential efficacy of various intake screening technologies takes into account two principal components for which empirical data are available: physical exclusion and impingement survival. The following sections describe these components in more detail.

\subsection{Physical Exclusion}

For exclusion technologies (e.g., narrow-slot wedgewire screens), the key factor is organism size in relation to the mesh size or slot width. Exclusion of fish larvae can be estimated using the head capsule depth (HCD), the widest non-compressible portion of the larval body (Figure 4). When head capsules are larger than the nominal opening size of the screening material, a larva will not be entrained. With larvae, the orientation of the organism at the time of contact with the screen will also influence its likelihood of being entrained. In addition, the ratio of ambient velocity to through-mesh velocity and the swimming ability of the larvae will also impact the probability of entrainment. In the case of juvenile and adult fish, exclusion can be estimated using the limiting body depth of the organisms.

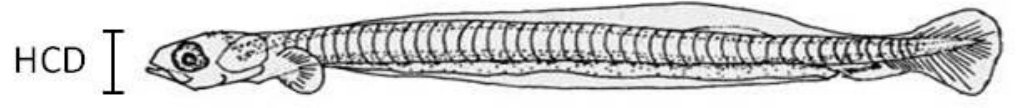

Figure 4. Head capsule depth (HCD) measurement used to estimate physical exclusion of larvae.

As fish length (or egg diameter) increases, the probability of the larva being entrained through the screen mesh decreases (Figure 5). As shown in the example Figure 5 below, at a fish length of approximately $12 \mathrm{~mm}$, the probability of entrainment is $0 \%$ (i.e. all fish of this length or greater would be retained by the mesh). At intermediate points along the curve, the probability of entrainment can be predicted. For example, in the example Figure 5 , just over $40 \%$ of fish measuring approximately $8 \mathrm{~mm}$ in length would be expected to be entrained. It is important to note that there are other important factors that affect exclusion (e.g., organism behavior, orientation of organisms, ambient hydraulics); 
therefore, the physical exclusion component should be considered a conservative estimate Section 4 below provides more detail on how the estimated biological performance has been determined for each of the three warm water intakes technologies that were selected.

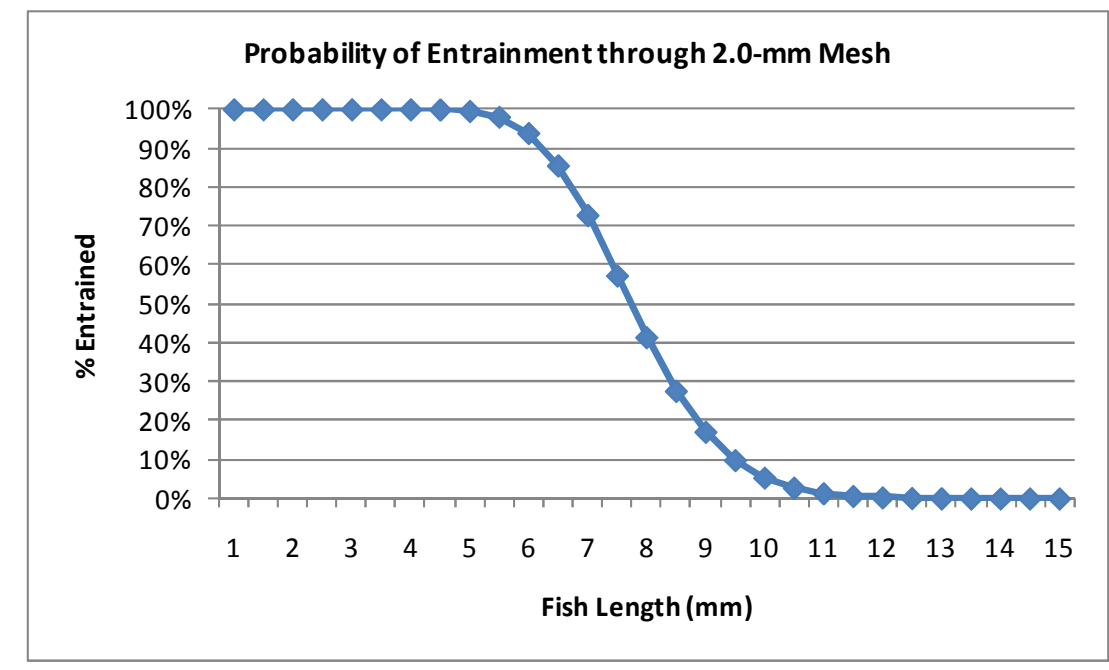

Figure 5. Example illustrating the relationship between fish length and probability of entrainment through a 2.0-mm mesh.

\subsection{Impingement Survival}

For collection technologies (e.g., modified traveling water screens), biological effectiveness is measured in two ways: retention and survival. In addition to the physical exclusion (also known as retention) of the organisms, collection technologies handle the organisms during the transfer process back to the source waterbody. This handling may impart additional stress, injuries, scale loss, or mortality to the organisms. Therefore, the second component of biological effectiveness with such collection technologies is the survival of the organisms that are impinged on and subsequently handled by the technology. The survival of these impinged organisms is dependent upon their biology (lifestage, relative hardiness, etc.) and the screen operating characteristics (rotation speed, spraywash pressure, etc.).

While impingement survival data are readily available for many species that are typically of concern at conventional thermal power plants in the continental U.S., there are no impingement survival data available for the target species at Port Allen. In addition, since there are no survival data available for similar species that could be reliably considered surrogates of the target species at Port Allen, it is not possible to estimate survival for Port Allen target species. 


\subsection{Entrainment Survival}

This evaluation of the potential biological efficacy of the selected intake screens does not take into account any potential through-plant survival. Entrainment survival (also known as through-plant survival) refers to the potential for species entrained into the water circulation system to survive the process upon discharge back to the source waterbody. There are a number of factors affecting the survival of entrained organisms. The Electric Power Research Institute (EPRI 2000) identified the following principal factors which influence entrainment survival at conventional thermal power plants:

- Species

- Lifestage/size of organisms

- Biocide presence

- Mechanical stresses

- Temperature of effluent

Entrainment survival has been well documented at conventional steam electric power plants where thermal thresholds are relatively well-defined for species that are typically of concern (Mayhew et al. 2000). EPRI (2000) published a comprehensive report reviewing entrainment survival data for a number of conventional thermal power plants in the U.S. in temperate waters. In addition to field-documented entrainment survival, there has been a considerable amount of laboratory research on the thermal tolerances of important species occurring near power plant intakes (e.g., EA 1978). This thermal tolerance data is very useful in predicting the potential for entrainment survival on a species-specific basis. In Port Allen, however, there is considerable uncertainty regarding the amount of entrainment survival that can be expected simply because there is very little known about the biology of the species here (e.g., thermal tolerances). As Myers et al. (1986) indicated, the generation of basic information on tropical species (particularly early lifestages) is a major research goal.

While most of the factors affecting entrainment survival are shared between conventional thermal power plants and an OTEC facility, the major difference is in the direction of the temperature change in the effluent. Conventional steam electric power plants draw seawater for cooling purposes, thus creating an increase in temperature at the discharge point. However, in a closed-cycle OTEC facility, as is proposed for Port Allen, the warm water will be used to evaporate the working fluid, thus creating a decrease in temperature at the discharge point.

Relative to seawater used to cool steam in a conventional fossil-fueled power plant, the absolute temperature change $(\Delta \mathrm{T})$ across the Port Allen OTEC heat exchanger (evaporator) will be comparable (approximately $7^{\circ} \mathrm{C}$ ). Entrainment survival associated with comparable temperature changes in power plants has been shown to be greater than zero (ranging between 0 and 98\%); though, survival has been shown to be very site- and species-specific 
(USEPA 2006, Mayhew et al. 2000, and EPRI 2000). Reported $\triangle$ Ts for power plants exceeded $14^{\circ} \mathrm{C}$ in some cases (USEPA 2006). While the absolute $\triangle \mathrm{T}$ across the OTEC system evaporator is comparable to (and in some cases lower than) the absolute $\Delta \mathrm{T}$ reported at conventional thermal power plants, it is not currently possible to estimate the potential for entrainment survival of organisms through the warm water circulation system without basic data on:

- the species present,

- the lifestages (eggs, larvae, or both) that would be susceptible to entrainment,

- the duration of exposure to the stresses,

- their tolerances to the thermal (drop in temperature), mechanical, and chemical stresses associated with passage through a warm water OTEC system.

Two additional variables that will affect entrainment survival include 1) the discharge approach (i.e., separate or mixed discharges for the cold and warm water) and 2) the ambient water temperature at the discharge point in the receiving water body. Figure 6 presents the generalized temperature exposure history under the two discharge approaches. The $\Delta \mathrm{T}$ for an organism entrained through the warm water intake of a facility that has a separate warm water discharge line would be $-7^{\circ} \mathrm{C}$. The $\Delta \mathrm{T}$ for an organism entrained through the warm water intake of a facility that has a mixed warm-cold discharge line would be $-8^{\circ} \mathrm{C}$. Therefore, separate discharge lines for the warm and cold water would create a $\Delta \mathrm{T}$ for an organism entrained through the warm water intake that is $1^{\circ} \mathrm{C}$ less than a single mixed discharge line. The slight thermal benefit provided by using two separate discharge lines for the proposed Port Allen OTEC facility would likely be outweighed by the cost. 


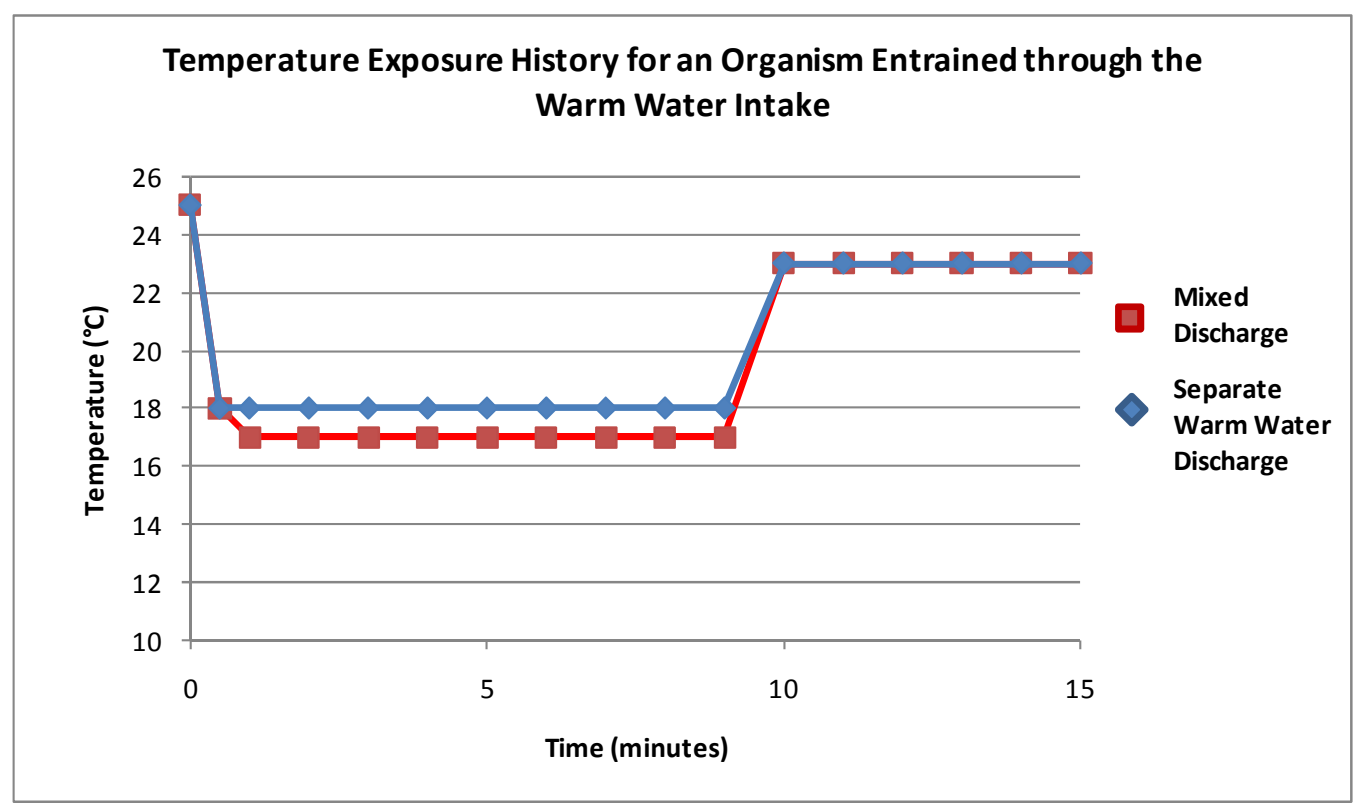

Figure 6. General temperature exposure history for an entrained organism through a separate warm water discharge and a mixed warm and cold water discharge. Graph assumes the temperature exposure durations presented in Lamadrid-Rose and Boehlert (1988) and a receiving waterbody temperature of $23^{\circ} \mathrm{C}$.

Though there are few data available on the impacts of cold shock, there are some data available from the National Marine Fisheries Service (NMFS). NMFS undertook a laboratory study in 1988 to evaluate the effects of cold-shock on early lifestages of select tropical fishes (Lamadrid-Rose and Boehlert 1988). The fishes were cultured in the lab and exposed to changes in temperature that were expected at a proposed OTEC plant for Kahe Point, Honolulu. Tests were conducted with mahimahi (Coryphaena hippurus) eggs and larvae, manini (Acanthurus triostegus) eggs and larvae, and striped mullet (Mugil cephalus) juveniles. Each species and lifestage was exposed to a $\Delta \mathrm{T}$ of 5,10 , and $15^{\circ} \mathrm{C}$ for different durations $(8,16$, and 24 minutes). In general, the earlier stage eggs were the most susceptible to cold-shock. As eggs matured, mortality decreased. Exposure time did not significantly affect survival of eggs. Trials with larvae resulted in high mortality for both control and treatment fish, making it difficult to tease out thermal effects on survival. Although the $\Delta \mathrm{T}$ range tested likely exceeded the $\Delta \mathrm{T}$ that is expected at proposed OTEC facilities, the authors concluded that thermal stress, with the other entrainment survival stresses (e.g., mechanical stress, biocides), could result in lethal or sublethal effects on early lifestages of fish.

It is clear that additional research is required in order to draw any conclusions about the potential for entrainment survival at OTEC facilites. It is very site-specific, process-specific, and species-specific. The study described above is of limited value since it was designed to expose test organisms to a temperature profile for a co-located OTEC facility that would 
have made use of the heated effluent from the Kahe Point Generating Station as its warm water intake feedwater. In addition, the temperature ranges tested were higher than what would be expected at a typical OTEC facility.

\section{ESTIMATED BIOLOGICAL PERFORMANCE OF SELECTED INTAKE TECHNOLOGIES}

The following sections describe the estimated biological performance of the various intake alternatives. The intake alternatives can be broadly categorized into the collection technologies (both of the fine-mesh traveling water screen intakes) and the exclusion technology (narrow-slot wedgewire screen intake)

\subsection{Fine-mesh (0.5- and 2.0-mm) Modified Traveling Water Screens}

\subsubsection{Exclusion}

Fine-mesh (0.5- and 2.0-mm) modified traveling water screens would provide a high level of protection to organisms at Port Allen. However, there have been few installations of fine-mesh screens in a marine environment. Furthermore, retention is rarely measured. As such, there are limited empirical data upon which to estimate retention. In the absence of empirical data, organism retention for early lifestages can be estimated using the morphometric dimensions of the species in question. In more specific terms, the predicted retention that is achievable with a given screen mesh-size can be estimated using the head capsule depth of the organism (Black and Tuttle 2008). Smith et al. (1968) found that the maximum cross-sectional diameter of an organism must be greater than the mesh diagonal length if it is to be fully retained. Therefore, for a given cross-sectional diameter and associated standard deviation, the percentage retained is calculated by integration under a normal curve. Retention is a species-specific measure, as there is substantial variation in the morphometric characteristics among species. Thus, species-specific estimates of head capsule depth were deemed the best approach to describe an organism's potential to be retained.

Larval fish are soft-bodied and can be compressed; consequently, the deepest noncompressible portion of the body (head capsule) was used to predict exclusion in this analysis. Regressions of body length to head capsule depth (HCD) were developed based on morphometric measurements gleaned from scale-drawings of species that are likely to be of concern at Port Allen. These regressions allowed species-specific HCDs to be predicted for larvae of any given length. The HCD regressions for each of the target species groups are shown in Figure 7. 


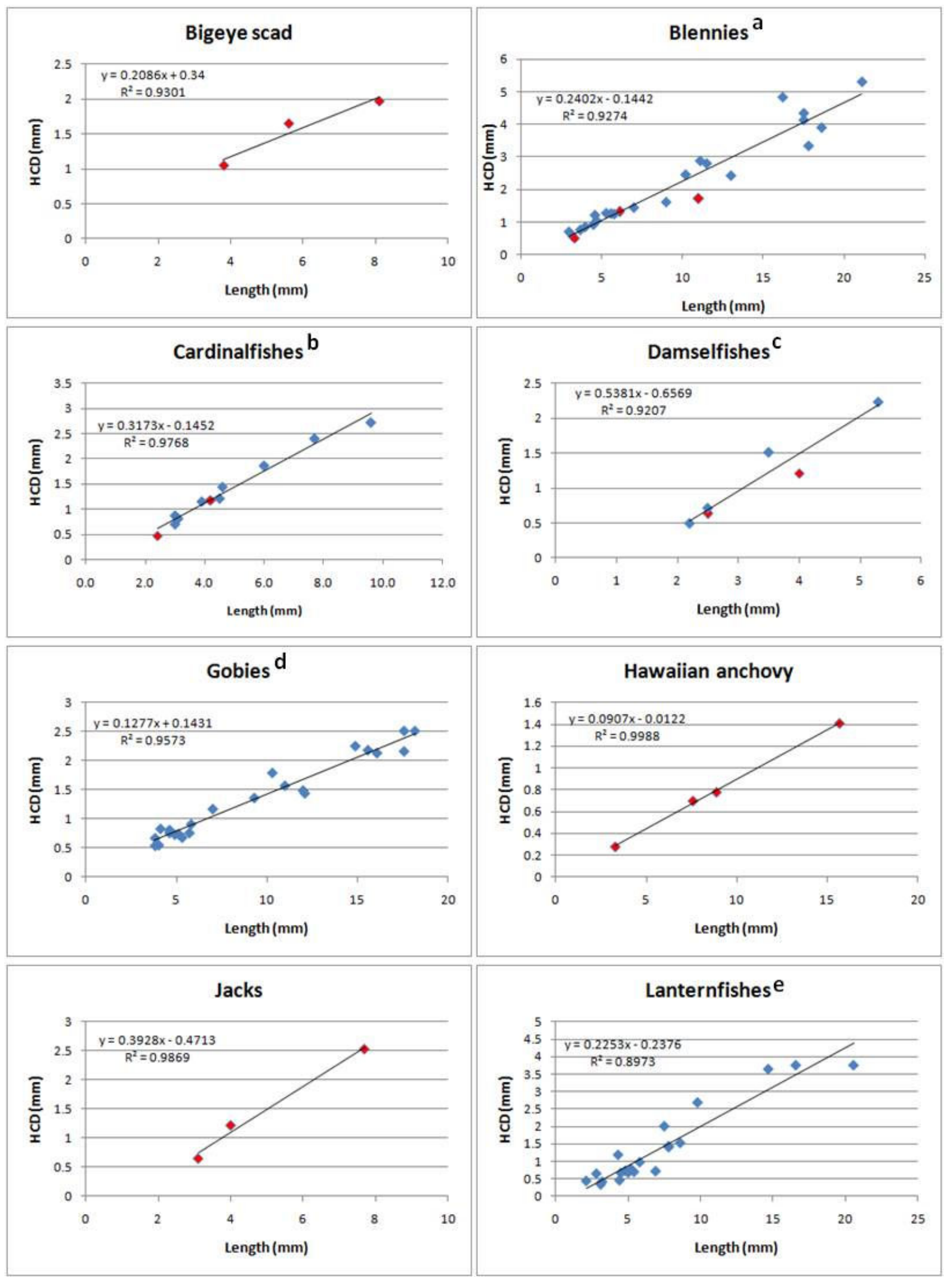

Figure 7. Linear regressions of head capsule depth (HCD) to length for target species. 


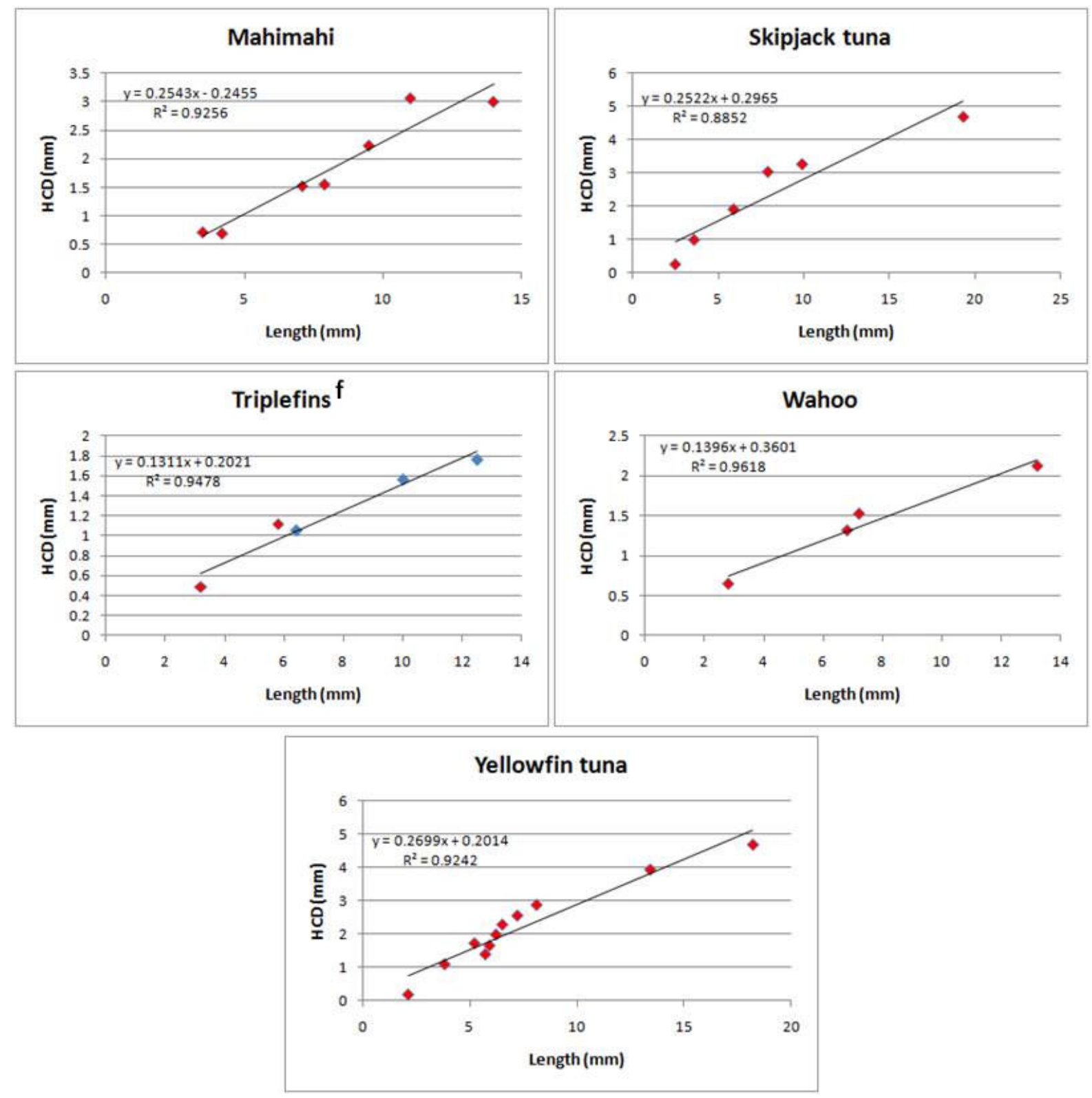

Figure 7 (cont). Linear regressions of head capsule depth (HCD) to length for target species. Red datapoints indicate data for the target species; blue datapoints indicate data for surrogate species. Surrogate species used to generate HCD regressions are noted in Table 3. 
The predicted HCDs allowed an estimation of the probability of entrainment and, conversely, the probability of impingement (100\% minus probability of entrainment). Since no length frequency distributions were available for the species likely to be of interest in Port Allen, for the purposes of this analysis, larval lengths were assumed to be evenly distributed over the range of larval lengths reported in the literature. The resulting estimates of physical exclusion based on the regressions are presented below in Table 3.

Table 3. Estimates of physical exclusion for the Port Allen target species. Presented as the length at which $100 \%$ of the organisms would be physically excluded by 0.5 and 2.0-mm mesh. Mesh of 9.5- $\mathrm{mm}$ is not presented since fish large enough to be excluded are also likely to possess swimming capabilities sufficient to avoid interaction with the screen.

\begin{tabular}{|c|c|c|c|c|}
\hline \multirow[b]{2}{*}{ Common Name } & \multirow[b]{2}{*}{ Family } & \multirow[b]{2}{*}{ Scientific Name } & \multicolumn{2}{|c|}{$\begin{array}{c}\text { Length (mm) at which } \\
100 \% \text { are physically } \\
\text { excluded }\end{array}$} \\
\hline & & & $\begin{array}{c}\text { 0.5-mm } \\
\text { mesh }\end{array}$ & $\begin{array}{c}\text { 2.0-mm } \\
\text { mesh }\end{array}$ \\
\hline Bigeye scad & Carangidae & Selar crumenophthalmus & 2.0 & 12.5 \\
\hline Blennies & Bleniidae $^{a}$ & $\begin{array}{l}\text { Enchelyurus brunneolus } \\
\text { Istiblennius zebra }\end{array}$ & 2.5 & 12.0 \\
\hline Cardinalfishes & Apogonidae & Foa brachygramma & 3.0 & 10.0 \\
\hline Damselfishes & Pomacentridae $^{c}$ & Abudefduf abdominalis & 3.0 & 7.0 \\
\hline Gobies & Gobiidaed $^{\mathrm{d}}$ & Psilogobius mainlandii & 5.0 & 22.0 \\
\hline Hawaiian anchovy & Engraulidae & Encrasicholina purpurea & 8.0 & 32.5 \\
\hline Infantfishes & Schindleriidae & Schindleria pietschmanni & \multicolumn{2}{|c|}{ Insufficient data } \\
\hline Jacks & Carangidae & Caranx (Atule) mate & 3.5 & 9.0 \\
\hline Lanternfishes & Myctophidae & $\begin{array}{l}\text { Ceratoscopelus warmingi } \\
\text { Diaphus spp } \\
\text { Lampedina luminosa } \\
\text { Hygophum proximum }\end{array}$ & 4.5 & 14.5 \\
\hline Mahimahi & Corpaenidae & Coryphaena hippurus & 2.0 & 11.0 \\
\hline Skipjack tuna & Scombridae & Katsuwonus pelamis & 2.0 & 10.5 \\
\hline Triplefins & Tripterygiidae $^{f}$ & Tripterygion atriceps & 4.5 & 21.0 \\
\hline Wahoo & Scombridae & Acanthocybium solandri & 3.0 & 18.5 \\
\hline Yellowfin tuna & Scombridae & Thunnus albacares & 3.5 & 12.0 \\
\hline \multicolumn{5}{|c|}{$\begin{array}{l}\text { In addition to the target species, the following surrogates were used to develop regression } \\
{ }^{a} \text { Blenniidae: Hypsoblennius brevipinnis, H. gentilis, H. jenkinsi, H. gilberti, and H. proteus } \\
{ }^{b} \text { Apogonidae: Apogon atricaudus, A. guadalupensis, and A. retrosella } \\
{ }^{c} \text { Pomacentridae: Abudefduf troschelii } \\
{ }^{d} \text { Gobiidae: Clevelandia ios, Ilypnus gilberti, Gillichthys mirabilis, Quietula y-cauda, Acanthogobius flavimanus } \\
{ }^{e} \text { Myctophidae: Lampedina luminosa, Hygophum proximum } \\
\text { fTripterygiidae: Axoclinus carminalis }\end{array}$} \\
\hline
\end{tabular}


These data are also presented graphically in Figure 8. As can be seen in this figure, the curve's x-axis intercept represents the length at which $100 \%$ of each species can be expected to be excluded.

\subsubsection{Survival}

There are no impingement survival data available for the target species at Port Allen. In addition, since there are no survival data available for similar species that could be considered surrogates of the target species at Port Allen, it is not possible to estimate survival for Port Allen target species at this time.

\subsubsection{Conclusion}

Fine-mesh (0.5- and 2.0-mm) modified traveling water screens would likely minimize impingement and entrainment at Port Allen, but post-collection survival for early lifestages would likely be low for the more sensitive larvae. For the following reasons, there is considerable uncertainty surrounding the biological efficacy of fine-mesh traveling screens:

- there are limited data available from fine-mesh screen installations,

- the data that are available are for temperate species, and

- the data are very species- and site-specific.

Pilot-scale studies would be required to establish baseline data on the survival of organisms impinged on the mesh to determine if acceptable levels of post-collection survival of eggs and larvae can be achieved.

For operational and cost reasons, $0.5-\mathrm{mm}$ modified traveling water screens were eliminated from this evaluation. Modified traveling water screens with 2-mm mesh would provide a good level of protection to marine life in the area of the proposed warm water intake. 

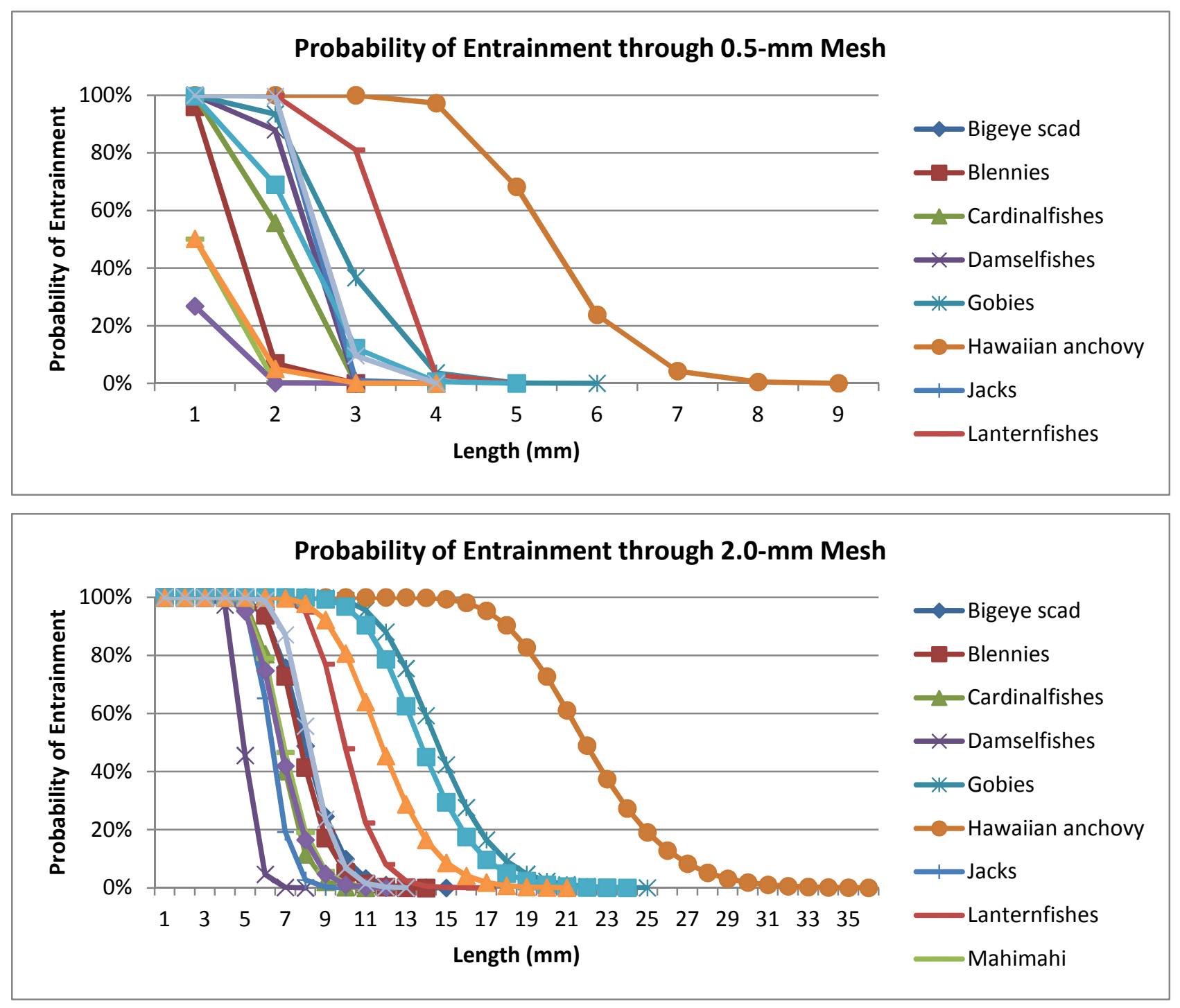

Figure 8. Probability of entrainment through 0.5- and 2.0-mm mesh. Estimates are based on HCD calculations for the target species at Port Allen. Surrogate species used to generate HCD regressions are noted in Table 3. 


\subsection{Narrow-slot (0.5- and 2.0-mm) Cylindrical Wedgewire Screens}

Narrow-slot cylindrical wedgewire screens are exclusion devices that act as passive barriers to reduce the entrainment of aquatic organisms into water intakes. The efficacy of wedgewire screens is dictated primarily by the slot (opening) size and the sizes of the organisms present near the screens. In addition, local flow conditions that include the though-slot velocity and ambient currents can affect screen performance. Entrainment has been positively correlated to through-slot velocity and inversely related to ambient velocity (Hanson et al. 1978; Heuer and Tomljanovich 1978). Furthermore, the interaction between these two velocity parameters is important, with available data suggesting that the ratio of ambient velocity to slot velocity should be maximized for effective exclusion of aquatic organisms (Hanson et al. 1978). This interaction was confirmed by laboratory studies (EPRI 2003) that demonstrated an inverse relationship between the ratio of ambient velocity to slot velocity and both entrainment and impingement rates. Wedgewire screen designs developed in this assessment use a maximum through-slot velocity of $0.5 \mathrm{ft} / \mathrm{sec}$.

The methods used to estimate the exclusion rates of larval fish with narrow-slot wedgewire screens are identical to those described above for fine-mesh modified traveling water screens (Section 4.1). However, physical exclusion is just one piece of the overall efficacy of the screens. The low through-slot velocity coupled with the swimming ability of larval fish as they develop increases the efficacy. In the case of juvenile and adult fish, the 0.5 - $\mathrm{ft} / \mathrm{sec}$ through-slot velocity should allow healthy individuals to avoid contact with the screens and virtually eliminate impingement (Gulvas \& Zeitoun 1979, Zeitoun et al. 1981). Furthermore, depending on which slot size is used (0.5- or 2.0-mm), the narrow slots should physically exclude all/most impingeable-sized fish.

\subsection{Conclusion}

Narrow-slot (0.5- and 2.0-mm) cylindrical wedgewire screens would likely minimize entrainment and impingement at Port Allen. Since wedgewire is an exclusion device, the survival of impinged organisms does not have to be considered in estimating the biological efficacy.

For operational and cost reasons, $0.5-\mathrm{mm}$ cylindrical wedgewire screens were eliminated from this evaluation. Cylindrical wedgewire screens with 2-mm slots would provide a good level of protection to marine life in the area of the proposed warm water intake. 


\section{REFERENCES}

Black, J.L. and L.R. Tuttle. 2008. Using Fish Morphometry to Predict Entrainment Reduction of Wedgewire Screens. Presented at the 64th Annual Northeast Fish and Wildlife Conference, April 2008, Galloway, New Jersey.

Electric Power Research Institute (EPRI). 2000. Review of Entrainment Survival Studies: 19702000. EPRI, Palo Alto, CA: 2000. 1000757.

Electric Power Research Institute (EPRI). 2003. Laboratory Evaluation of Wedge Wire Screens for Protecting Early Lifestages of Fish at Cooling Water Intakes. EPRI, Palo Alto, CA: 2003. 1005339.

Ecological Analysts, Inc. (EA). 1978. Thermal Effects Literature Review for the Hudson River Representative Important Species. Prepared for Central Hudson Gas and Electric Corporation, March 1978.

Gulvas, J.A. and I.H. Zeitoun. 1979. Cylindrical Wedge-wire Screen Investigations in Offshore Lake Michigan for the J.H. Campbell Plant, 1979. In: Passive Intake Screen Workshop, Chicago, IL., December 4-5, 1979. Prepared by Consumers Power Company, Jackson, Michigan.

Hanson, B. N., W. H. Bason, B. E. Beitz, and K. E. Charles. 1978. Studies of Profile-Wire Screens as Surface Water Intakes. Special Report for Delmarva Power and Light Company.

Heuer, J. H. and D. A. Tomljanovich. 1978. A Study on the Protection of Fish Larvae at Water Intakes Using Wedge-Wire Screening. TVA Technical Note B26.

Lamadrid-Rose, Y. and G.W. Boehlert. 1988. Effects of Cold Shock on Egg, Larval, and Juvenile Stages of Tropical Fishes: Potential Impacts of Ocean Thermal Energy Conversion. Marine Environmentl Research 25: 175-193.

Leis, W. 1982. Nearshore Distributional Gradients of Larval Fish (15 Taxa) and Planktonic Crustaceans (6 Taxa) in Hawaii. Marine Biology 72: 89-97.

Mayhew, D.A., L.D. Jensen, D.F. Hanson, and P.H. Muessig. 2000. A Comparative Review of Entrainment Survival Studies at Power Plants in Estuarine Environments. Environmental Science and Policy 3: S295-S301.

Myers, E.P., D.E. Hoss, W.M. Matsumoto, D.S. Peters, M.P. Seki, R.N. Uchida, J.D. Ditmars, and R.A. Paddock. 1986. The Potential Impact of Ocean Thermal Energy Conversion (OTEC) on Fisheries. NOAA Technical Report NMFS 40.

Smith, P.E., R.C. Counts, and R.I. Clutter. 1968. Changes in Filtering Efficiency of Plankton Nets Due to Clogging Under Tow. ICES Journal of Marine Science 32: 232-248. 
Sonnichsen, J., Bentley, B., Bailey, G., and R. Nakatani. 1973. A Review of Thermal Power Plant Intake Structure Designs and Related Environmental Considerations. Prepared by Hanford Engineering Development Laboratory. Prepared for the U.S. Atomic Energy Commission.

Tenera Environmental and AECOS, Inc. 2008. CWA Section 316(b) Impingment Mortalit and Entrainment Characterization Study: Summary Report - Year Two. Submitted to Hawaiian Electric Company, Inc.

United States Environmental Protection Agency (USEPA). 1976. Development Document for Best Technology Available for the Location, Design, Construction, and Capacity of Cooling Water Intake Structures for Minimizing Adverse Environmental Impact. EPA 440/1-76/015a. Washington D.C.

United States Environmental Protection Agency (USEPA). 1977. Guidance for Evaluating the Adverse Impact of Cooling Water Intake Structures on the Aquatic Environment: Section 316(b) [Draft]. Office of Water, Washington, D.C.

United States Environmental Protection Agency (USEPA). 2006. Regional Benefits Analysis for the Final Section 316(b) Phase III Existing Facilities Rule. EPA-821-R-04-007.

Watson, W. and J.M. Leis. 1974. Ichthyoplankton of Kaneohe Bay, Hawaii - A One-year Study of Fish Eggs and Larvae. UNHI SeaGrant-TR-75-01.

Zeitoun, I.H, J.A. Gulvas and D.B. Roarabaugh. 1981. Effectiveness of Fine-Mesh Cylindrical Wedge-wire Screens in Reducing Entrainment of Lake Michigan Ichthyoplankton. Can. J. Fish. Aquat. Sci. 38: 120-125. 